\title{
THE HERPETOLOGY OF HISPANIOLA
}

\author{
By Doris M. Cochran
}

\section{INTRODUCTION}

This study of the herpetology of Hispaniola has been undertaken for the purpose of advancing the survey of the amphibian and reptile fauna of the Greater Antilles. Of these islands Hispaniola has remained the least known faunistically until the past two decades, during which time thorough collecting in certain regions has multiplied the number of species known to science. Although undoubtedly a great many more species, and perhaps even some genera, remain to be discovered in areas in which little collecting has so far been done, it is hoped that the following keys, descriptions, and figures of the species already known from Hispaniola may prove to be a stimulus to further discoveries.

Hispaniola, with the adjoining islets, now divided between the Republic of Haiti and the Dominican Republic, has been referred to by earlier writers as San Domingo, St. Domingue, Santo Domingo, Hayti, and Haiti. When such names are used without any specific river or town or other geographic feature that might serve to locate them definitely, it is often impossible to say whether it was the intention of the author to refer to the entire island or to either one of its political subdivisions, properly spoken of as the Republic of Haiti and the Dominican Republic. The old name of Hispaniola is now taken to refer to the island as a whole and the adjoining islets Gonave, Tortue, Sept Frères, Saona, Alta Vela, Beata, Ile à Vache, and the Cayemites. In the locality lists the abbreviation "D. R." refers to the Dominican Republic, and "Haiti" to the Republic of Haiti alone. Equivocal records are given in quotation marks. While the island of Navassa is not included in this survey, figures of the types of the two Navassan reptiles, Typhlops sulcatus and Celestus badius, will be found in the discussion of their apparent allies in Hispaniola.

For the loan of specimens my thanks are due to Dr. Thomas Barbour, of the Museum of Comparative Zoology; to Mrs. Helen T. Gaige, of the Museum of Zoology at Ann Arbor; and to K. P. Schmidt, of the Field Museum. I am indebted to Dr. G. K. Noble, of the American Museum of Natural History, for the loan of several paratypes, and to Dr. E. R. Dunn for specimens in the Academy of Natural Sciences of Philadelphia. I have borrowed some Leiocephali 
from the British Museum, which Boulenger had listed, and H. W. Parker kindly furnished me with lists of other specimens in that museum, while I was later allowed to examine these specimens and those in several other European collections during a visit in 1938. My sincere thanks are due to Dr. Leonhard Stejneger, of the United States National Museum, whose unfailing interest, encouragement, and assistance in the many problems involved have made the completion of the work possible.

Most of the figures for this Herpetology of Hispaniola were made by me from photographs. In a few instances, where the specimens were mutilated or otherwise unsuited to photography, the drawings are freehand. When figures have been copied from earlier publications, credit is given in the legends.

\section{PHYSIOGRAPHY}

An excellent summary of the geographical features of Hispaniola appeared in "The Birds of Haiti and the Dominican Republic," by Dr. Alexander Wetmore and Bradshaw H. Swales. ${ }^{1}$ There is little to add to their discussion, except to remark that the extremely rugged character of the island's surface has proved to be a very effective means of isolation to certain genera of amphibians and reptiles, so that a truly astonishing number of entirely localized forms is often found within a relatively restricted area.

The Massif de la Selle Mountains, whose tops were islands when the Cul-de-Sac Plain was below sea level, supplies a good example of this condition, for within the past few years two new genera of lizards and a new genus of snakes have been found on Peak La Selle.

Another interesting evidence of specialization carried out to subspecies is found in the genus Leiocephalus. No less than 11 distinct subspecies of the personatus group are now known from Hispaniola as a whole-seven from the mainland and one each from four of the adjoining islets.

The snakes of the genus Leimadophis have the tendency to local specialization to nearly the same degree, as seven subspecies of the parvifrons stock can be recognized, three rather poorly separated forms from the present main body of the island and four rather distinct forms from outlying islets. An example of the effect of the removal of a natural barrier is evident here. Almost within the memory of the oldest inhabitant, Samaná Peninsula was an island separated from the main body of Hispaniola by a rapidly filling strait, in which pirate vessels were said to have lain in wait for richly laden merchantmen sailing for Europe. On this island a black form of Leimadophis developed. The melanistic color is found in a good many of the protenus specimens from the northeastern part of the Dominican Republic, and, as a matter of fact, it is at present very

1 U. S. Nat. Mus. Bull. 155, pp. 2-7, 1931. 
difficult to find a satisfactory basis for the separation of niger and protenus as subspecies, since so many intergrading specimens now exist in the lowlands lying between the areas once separated by stretches of sea.

\section{DISTRIBUTION OF GREATER ANTILLEAN GENERA}

In table 1 are listed the genera occurring on the neighboring islands of the Greater Antilles. Hispaniola has 19 genera in common with Cuba. Cuba has 10 genera that Hispaniola lacks, but, on the other hand, Hispaniola has 13 genera not found in Cuba.

TABLE 1.-Distribution of Greater Antillean genera of amphibians and reptiles ${ }^{1}$

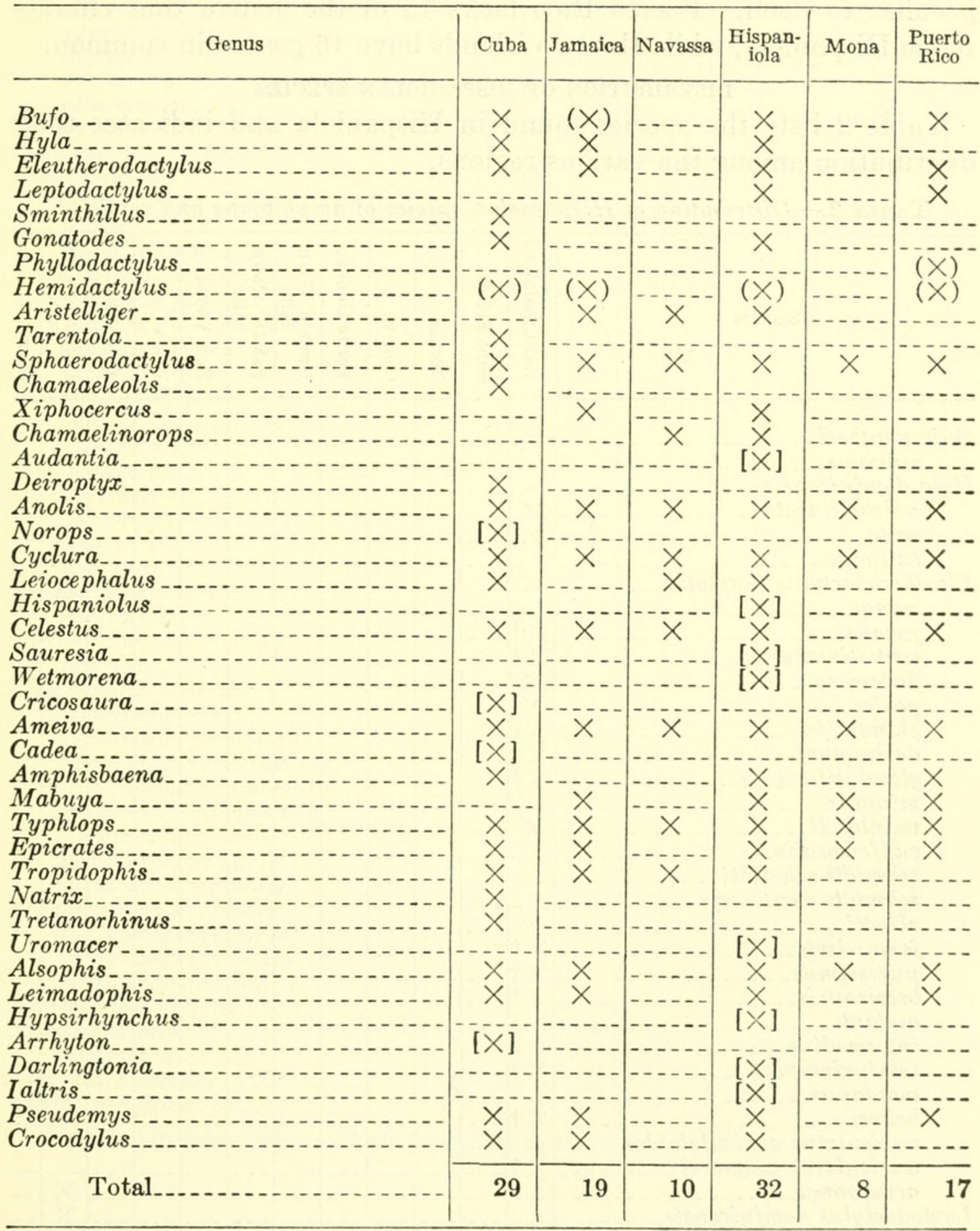

${ }^{1}(\mathrm{X})$ Introduced; $[\mathrm{X}]$ endemic. 
Hispaniola and Jamaica have 19 genera in common. Jamaica has no genus that is not also found in Hispaniola, while Hispaniola has 13 that do not occur in Jamaica-a condition perhaps to be expected as Hispaniola is so much the larger of the two islands.

The tiny isolated rock called Navassa supports 10 genera, all of which are represented in Hispaniola, including the highly specialized iguanid genus Chamaelinorops, which is not known from any other localities except Navassa and western Haiti.

Surveying the islands east of Hispaniola, we find that Puerto Rico has only one (nonendemic!) genus-Phyllodactylus-which is not represented on Hispaniola, while Mona does not have a single genus peculiar to itself. Puerto Rico lacks 15 of the genera that characterize Hispaniola, while the two islands have 16 genera in common.

DISTRIBUTION OF HISPANIOLAN SPECIES

Table 2 lists the species found in Hispaniola and indicates their distribution among the various regions.

TABLE 2.-Distribution of Hispaniolan species of amphibians and reptiles ${ }^{1}$

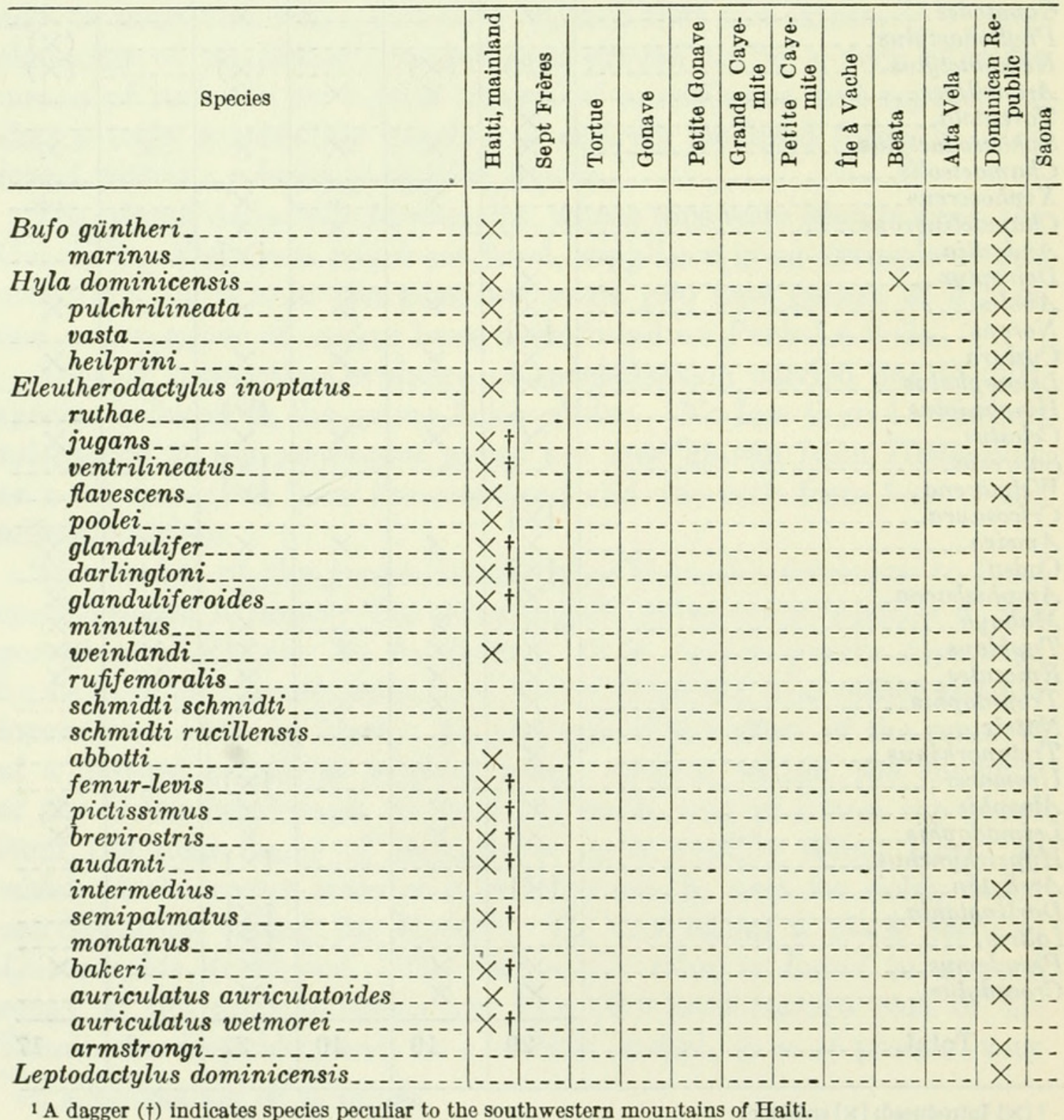


TABLE 2.-Distribution of Hispaniolan species of amphibians and reptiles ${ }^{1-}$ Con.

\begin{tabular}{|c|c|c|c|c|c|c|c|c|c|c|c|c|}
\hline Species & 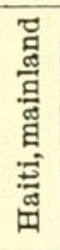 & 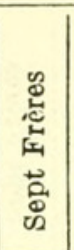 & \begin{tabular}{l}
0 \\
\multirow{2}{*}{} \\
H
\end{tabular} & 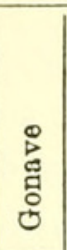 & 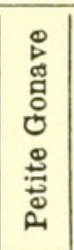 & 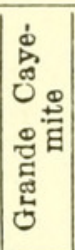 & 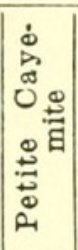 & 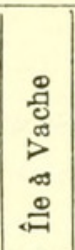 & 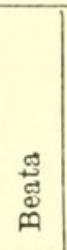 & $\begin{array}{l}\frac{a}{0} \\
\frac{0}{0} \\
\frac{\pi}{4}\end{array}$ & 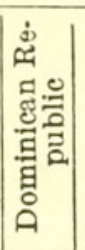 & \\
\hline-- & $x$ & $\cdots$ & -- & X &.- & & & & & & & \\
\hline$k i i_{--}$ & $\begin{array}{l}x \\
x\end{array}$ & -- & --- & -- & & & $\begin{array}{ll}-- \\
--\end{array}$ & -- & & -- & $\times$ & . \\
\hline Aristelliger & $x$ & -- & --- & $x$ & $\ldots$ & & 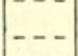 & - & & $\times ?$ & & \\
\hline 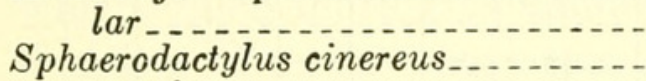 & $\begin{array}{l}x \\
x\end{array}$ & $\mid--$ & -- & X & - & & & $-\ldots$ & & $\cdots$ & $x$ & 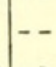 \\
\hline $\begin{array}{l}\text { copei } \\
\text { steineaeri }\end{array}$ & $\hat{x}$ & $\cdots$ & - & $\cdots$ & $\begin{array}{ll}--- \\
---\end{array}$ & X & - & 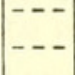 & & $\begin{array}{ll}\cdots \\
\cdots\end{array}$ & $|--\cdot|$ & - \\
\hline$\cdots$ & X & 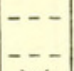 & -- & $\cdots$ & -- & -- & & & & $-\overline{1}$ & $-\bar{x}$ & \\
\hline$\cdots$ & X & x & $\cdots$ & -- & -- & $\ldots$ & - & - & - & $\cdots$ & $x$ & \\
\hline & & -- & -- & -- & --- & & & -- & & $\bar{x}$ & $x$ & \\
\hline Xiphe & $\times \dagger$ & $\ldots$ & -- & $\ldots$ & & & & & & ה & & \\
\hline & $x \dot{t}$ & $\ldots$ & $\ldots$ & $\ldots$ & $\ldots$ & & & & & $\ldots$ & & \\
\hline . & &.- & $\cdots$ & $\cdots$ & $\ldots$ & & & & & $\ldots$ & $x$ & \\
\hline & & -- & -- & & $-\cdots$ & & & & & -- & $\underset{x}{x}$ & \\
\hline & & $\cdots$ & -- & x & & & & & & & $\begin{array}{l}x \\
x\end{array}$ & \\
\hline ......... & $\times$ & $\ldots$ & $x$ & $\ldots$ & -- & $x$ & $x$ & & & $\ldots$ & $x$ & \\
\hline & & -- & $\cdots$ & $\cdots$ & $-\cdots$ & -- & $-\cdots$ & X & & $\bar{x}$ & $\cdots$ & \\
\hline & & $\ldots$ & $\ldots$ & & & -.. & & $\ldots$ & $x$ & $\ldots$ & & \\
\hline & X &.- & & $x$ & $x$ & & & & & & & \\
\hline & x & $\ldots$ & X & -- & $-\cdots$ & $\times$ & - & $x$ & & -- & $x$ & \\
\hline & & -- & $\cdots$ & Y & & - & & $-\cdots$ & X & & $-\cdots$ & \\
\hline & & -- & $-\cdots$ & $x$ & X & -- & & & & & -- & \\
\hline & & & & & -- & & & & & & 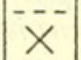 & \\
\hline & x & -. & $x$ & $x$ & $\ldots$ & & & & & & & \\
\hline & $x$ & -- & $-\cdots$ & $x$ & $-\cdots$ & $x$ & --- & $x$ & & & & \\
\hline $\begin{array}{r}\text { he } \\
\text { Audan }\end{array}$ & & -- & - & $\cdots$ & $\cdots$ & $\cdots$ & - & & & & & \\
\hline & & -1 & & & & 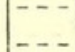 & $\begin{array}{ll}- & -\end{array}$ & $\cdots$ & & & & \\
\hline Cyclure & $x$ & -- & $x$ & $x$ & $x$ & $x$ & - - & & & $-\ldots$ & $\hat{x}$ & \\
\hline eiocep & & & & -- & $\cdots$ & $\cdots$ & & & & & $x$ & \\
\hline $\begin{array}{r}\text { rocep } \\
m\end{array}$ & X & $x$ & X & $\cdots$ & -- & $\ldots$ & & & & -- & $X$ & \\
\hline & 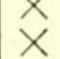 & - & $\cdots$ & - & & $\cdots$ & $-\cdots$ & X & & & x & \\
\hline & $x$ & -- & & 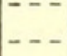 & -- & & &.- & & & - & \\
\hline & & & & &.- & & & & & & $x$ & \\
\hline & & & & & & & & & & $x$ & & \\
\hline & $x$ &.- & - & - & -. & & & & & -- & & \\
\hline & $x$ & & & & & & & -- & & & X & \\
\hline & & & & & & & & & & & $\frac{x}{x}$ & \\
\hline & & & & . & & & & & & & $x$ & \\
\hline $\begin{array}{l}p \\
p\end{array}$ & & & {$[-$} & $x$ & -- & & & & & & -- & \\
\hline & & & & & -- & & & & & & & \\
\hline & & & & & & & & & & & & \\
\hline & & & & X & - & & & & & -- & $\stackrel{x}{x}$ & \\
\hline & & & & $x$ & & & & & & & $\hat{x}$ & \\
\hline
\end{tabular}

${ }^{1}$ A dagger ( $\dagger$ ) indicates species peculiar to the southwestern mountains of Haiti. 
TABLE 2.-Distribution of Hispaniolan species of amphibians and reptiles ${ }^{1}-$ Con.

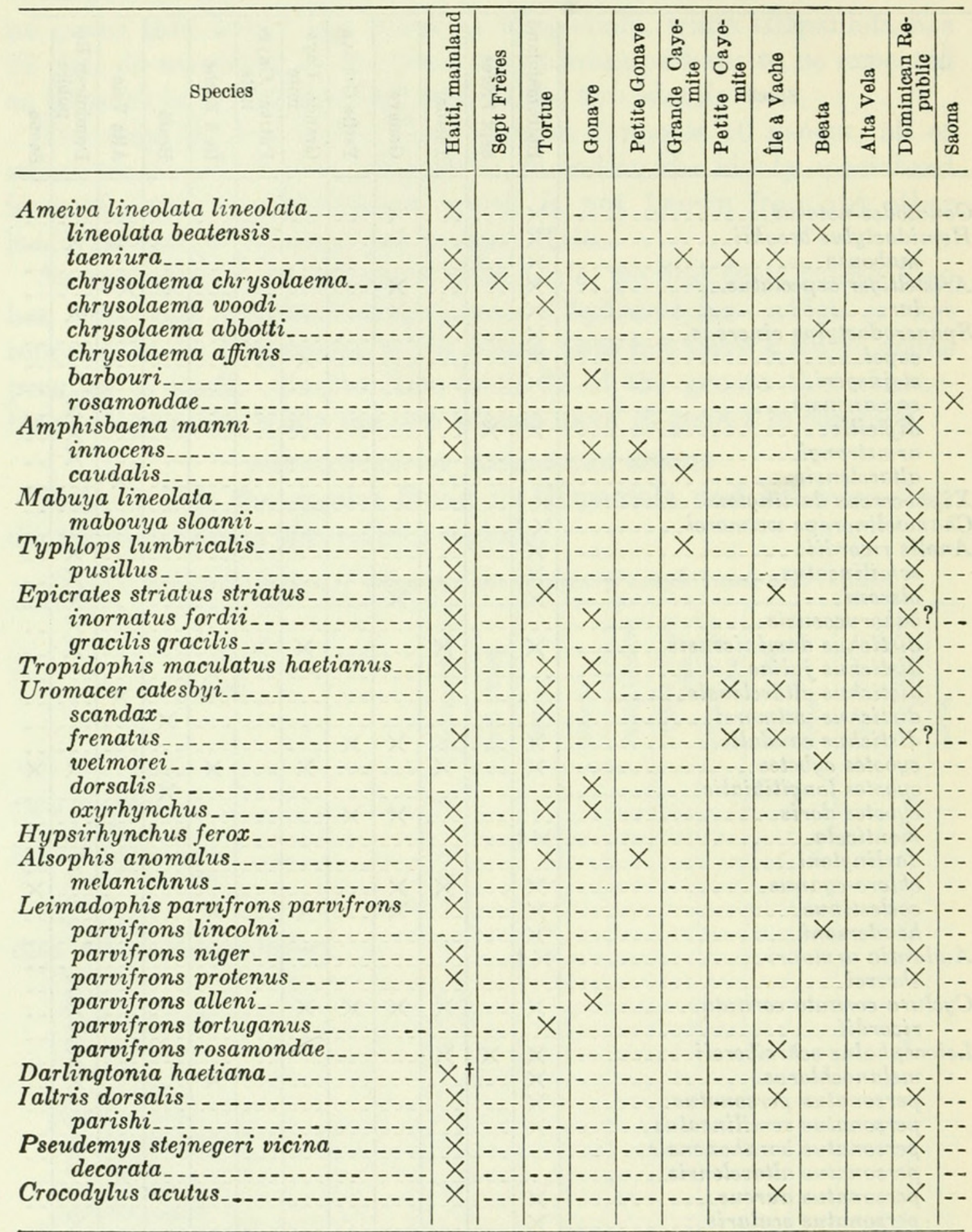

1 A dagger ( $\dagger$ ) indicates species peculiar to the southwestern mountains of Haiti.

\section{THE NONINDIGENOUS SPECIES}

Out of 128 species and subspecies now known to inhabit Hispaniola, only 6 or 7 are not indigenous. Of the 32 known genera, 7 are found nowhere else.

Among the nonendemic forms now recorded from Hispaniola, Bufo marinus, which was very recently introduced, seems to be gaining a real foothold in Monte Cristi. Hemidactylus brookii, originally intro- 
duced from Africa with the traffic in slaves, has now become established in tropical America.

The same is true of Hemidactylus mabouia. Another gecko, Sphaerodactylus cinereus, is one of the commonest species in Cuba, whence it was probably transported to southern Florida, Navassa, and Haiti. The slipperyback, Mabuya mabouya sloanii, represented very rarely in Hispaniola, is considered by Dr. Dunn (1936, p. 546) to be the same as the form occurring in the southern Bahamas, Jamaica, the Virgin Islands, Mona, and Puerto Rico. Typhlops lumbricalis is a species of which much more Hispaniolan material is needed before an ultimate decision as to its status can be made. Crocodylus acutus is found in Cuba, Hispaniola, Jamaica, Florida, and Central America.

\section{SPECIES ERRONEOUSLY RECORDED FROM HISPANIOLA}

The type of Spelerpes infuscatus Peters, now in the Berlin Museum (No. 6556), supposedly from "Hayti," has been positively identified by Dr. E. R. Dunn as Oedipus lineolus Cope and hence must have come from Mexico (Dunn, 1926). The intensive collecting done during the past few years leaves little expectation of finding any endemic tailed amphibian in the West Indies.

Hispaniolan records of Eleutherodactylus auriculatus Cope are undoubtedly based on misidentifications of the several small frogs that bear quite a close resemblance to the rather variable true auriculatus of Cuba.

Boulenger's record of a Dendrobates trivittatus (1882, p. 145) from "S. Domingo" is probably based on an incorrect locality record, as no true Dendrobates is to be expected so far out of its range.

\section{Class AMPHIBIA}

\section{Order SALIENTIA}

\section{KEY TO THE GENERA OF HISPANIOLAN FROGS AND TOADS}

$a^{1}$. No teeth (family Bufonidae) Bufo (p. 8)

$a^{2}$. Teeth on upper jaw and roof of mouth.

$b^{1}$. Diapophyses of sacral vertebrae dilated (family Hylidae) _._Hyla (p. 13)

$b^{2}$. Diapophyses of sacral vertebrae cylindrical or slightly dilated (family Leptodactylidae)

$c^{1}$. Sternum without a bony style Eleutherodactylus (p. 24) $c^{2}$. Sternum with a bony style_............... Leptodactylus (p. 84)

One genus, Leptodactylus, is represented by a single species on Hispaniola. Four species of Hyba are known, while Eleutherodactylus has 24 well-marked species at present and the probability of others yet to be discovered. Bufo now has two species, B. marinus having recently been introduced in the Dominican Republic. 


\section{Family BUFONIDAE}

\section{Genus BUFO Laurenti}

1768. Bufo Laurenti, Synopsis reptilium, p. 25 (type, B. vulgaris).

The "common" toad of Hispaniola, so long known as Bufo gutturosus, is far less rare than the Puerto Rican form, which has occasioned so much active search. The validity of the application of the name had apparently not been questioned, in spite of the accessibility to specimens in Europe and in this country.

\section{BUFO GÜNTHERI, new species}

Figures 1, 2

1829. Bufo strumosus Gravenhorst, Deliciae musei zoologici Vratislaviensis, p. 59 , pl. 9, fig. 3 (not of Daudin, 1802).-Dumeril and Bibron, Erpétologie générale, vol. 8, p. 716, 1841 (part, specimens from "Saint Domingue" collected by A. Ricord).

1858. Bufo gutturosus GüNther, Catalogue of the Batrachia Salientia in the collection of the British Museum, p. 67, pl. 5, fig. B (St. Domingo, Hayti) (not of Latreille, 1801).-Boulenger, ibid., ed. 2, p. 324, 1882.-Garman, Bull. Essex Inst., vol. 19, p. 16, 1887 (Port au Prince, Hayti).-Fischer, Jahrb. Hamburg Wiss. Inst., vol. 5, p. 24, 1888 (Cape Haytien, Hayti).Müller, Verh. Naturf. Ges. Basel, vol. 10, pt. 1, p. 200, 1892 (Cape Hayti).Barbour, Mem. Mus. Comp. Zool., vol. 44, No. 2, p. 241, 1914; Zoologica, vol. 11, No. 4, p. 75, 1930; vol. 19, No. 3, p. 91, 1933; Bull. Mus. Comp. Zool., vol. 82, No. 2, p. 97, 1937.-Sснміdт, Bull. Amer. Mus. Nat. Hist., vol. 44, art. 2, p. 7, 1921; Scientific Survey of Porto Rico and the Virgin Islands, New York Acad. Sci., vol. 10, pt. 1, p. 29, 1928.-Nieden, Das Tierreich, Anura I, p. 187, 1923.-Mertens, Senckenbergiana, vol. 20 , No. 5, p. 332, 1938; Publ. Inst. Cient. Domínico-Alemán, vol. 1, p. 82, 1939.-Böкеr, Publ. Inst. Cient. Domínico-Alemán, vol. 1, p. 16, 1939.

1863. Phrynoidis gutturosus Cope, Proc. Acad. Nat. Sci. Philadelphia, 1862, p. 358.

Diagnosis.-Head with bony ridges; a tympanum; upper eyelid normal; supraorbital and postorbital ridges forming together a more or less regular curve; edge of jaws not dilated horizontally; snout prominent, relatively wide and thick; subnasal and labial crests very weak; a tarsal fold; pustulose warts confined to anterior part of back.

Type.-U.S.N.M. No. 59081, an adult female from Port-au-Prince, Haiti, collected by Celestino Bencomo in 1916.

Description of the type.-Top of head bony, with very large crests enclosing a deep hollow between the orbits, the height of the supraorbital crest being about $4 \mathrm{~mm}$. above the interorbital space and $2 \mathrm{~mm}$. above the eyelid; a heavy orbital crest completely encircling the eye, nearly parallel with its fellow above the eye, most prominent behind the eye, but becoming less pronounced below, with a prominent supratympanic crest projecting from it posteriorly and ending in a rounded knob above and behind the ear; canthus rostralis with a comparatively weak, low crest, which joins the orbital crest; a slight, poorly developed 
supralabial crest and an equally faint subnasal ridge; no true parietal crest present, although there is a bony prominence with elongate ridges on that region; snout prominent; lores concave; eyes sunk deep in large squarish sockets; upper lip slightly extended horizontally; tympanum elliptically erect, its horizontal diameter about one-half the width of the eye; parotoid gland large, descending behind the ear and ending below the level of the jaw, but not of very distinct outline posteriorly where it merges with the skin of the back, which is similarly covered with scattered pustulose conical warts on its anterior

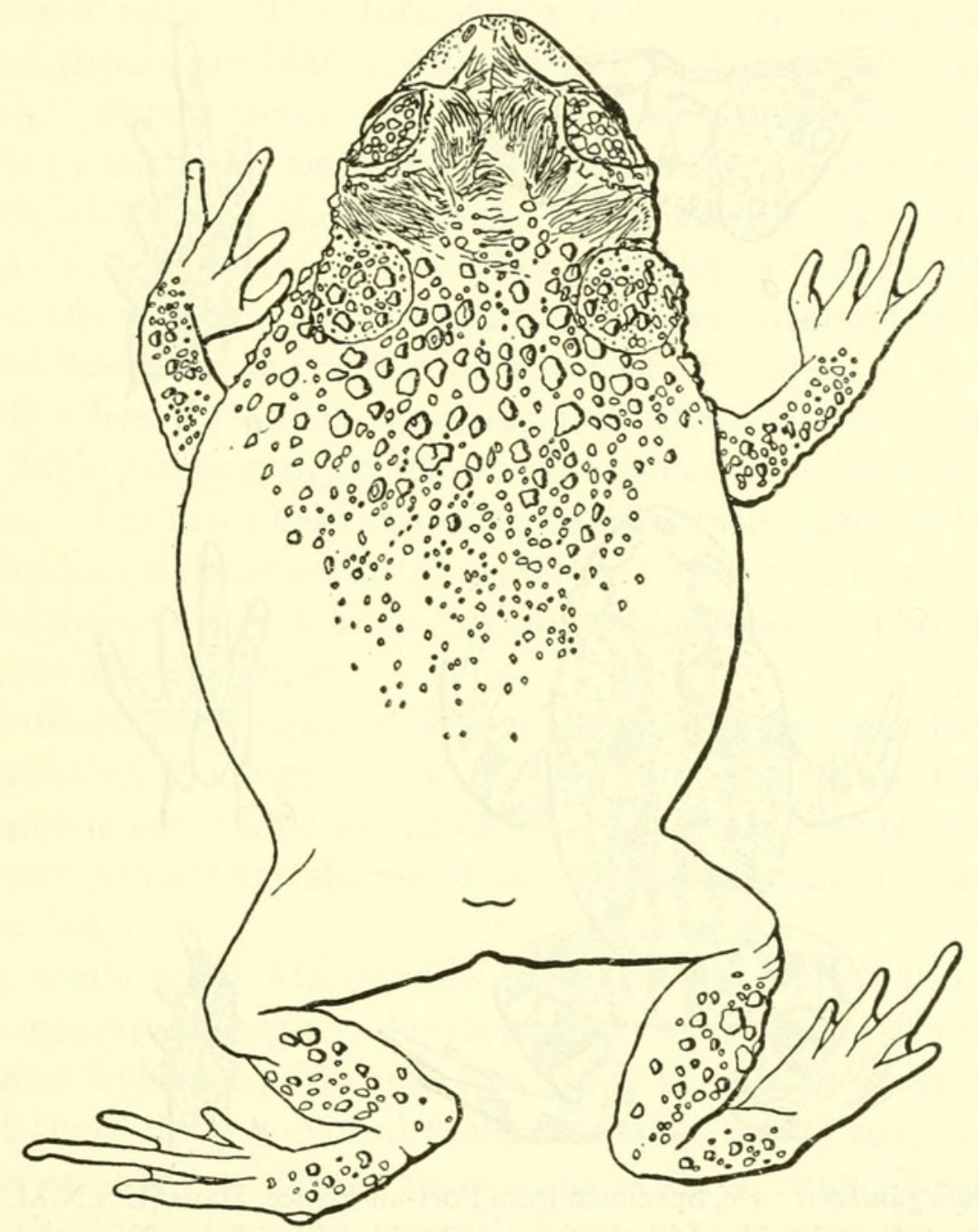

Figure 1.-Bufo güntheri: Dorsal view. Type, U.S.N.M. No. 59081, from Port-au-Prince, Haiti. Natural size.

portion, the largest of these occurring in a group on each side of the midline, well behind the parotoids; first finger slightly shorter than second; toes about one-half webbed; subarticular tubercles conical, single; one large metacarpal and two well-developed metatarsal tubercles; a strong fold on tarsus, ending distally in an elongate tarsal ridge; no single large tibial gland in evidence, although many conical pustulose warts are present; posterior portion of back and upper parts of limbs glandular but not tubercular, presenting a sharp contrast to the skin of the forepart of the back and the tibia and the forearm, 
which is covered with conspicuous conical pustulose tubercles, which are markedly spinose only in the region behind the ear; skin of belly areolate, becoming finely tuberculate on the throat and rather heavily tuberculate beneath the thighs; skin beneath tibia and forearm smooth; upper surfaces of hands and feet nearly smooth.

Dimensions: Tip of snout to vent, $84 \mathrm{~mm}$; t tip of snout to posterior border of ear, $24 \mathrm{~mm}$.; greatest width of head, $28 \mathrm{~mm}$.; foreleg, $43 \mathrm{~mm}$.; hindleg from groin, $79 \mathrm{~mm}$.

Color (in alcohol): Head clay color; back irregularly mottled with
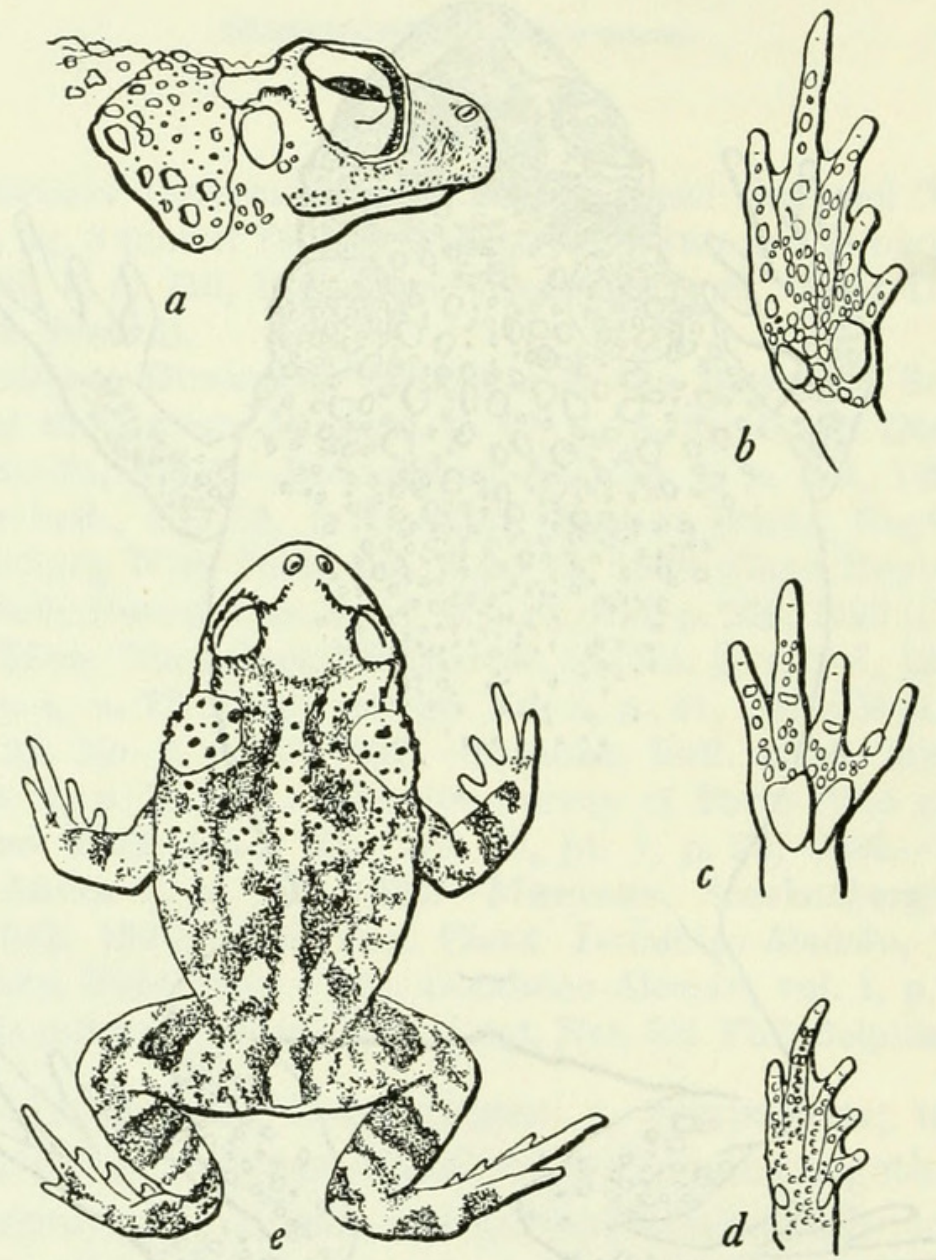

Figure 2.-Bufo güntheri: a-c, Specimen from Port-au-Prince, Haiti (U.S.N.M.No. 59081): $a$, Side of head; $b$, underside of hindfoot; $c$, underside of forefoot. Natural size. $d$, Foot of specimen from Diquini, Haiti (M.C.Z. No. 3098). Two-thirds natural size. e, Diagram of color pattern of young.

chocolate-brown and burnt umber, darker posteriorly, less heavy anteriorly where it appears to be confined mostly to the pustulose warts; traces of clay color between the warts; fore limbs burnt umber, hind limbs seal brown above; hands and feet clay color; lower parts clay color to ochraceous, immaculate.

Variations $s^{\text {in }}$ the paratypes.-A second specimen (U.S.N.M. No. 59082 ) from the same place, measuring $53 \mathrm{~mm}$. in length, is very similar to the described specimen in proportions and in webbing of toes; its"skin is slightly rougher on the belly and on the posterior part 
of the back. A faint black suffusion on the throat indicates that this individual is a male, and the inner surface of the thumb is brown, although not yet enlarged.

Another male (U.S.N.M. No. 75993) from Cap-Haïtien measuring $50 \mathrm{~mm}$. in length is much more interesting. While its head and body proportions are quite similar to those of the two already mentioned, its toes are much more fully webbed - in fact, the web reaches the base of the terminal disk in the fourth and fifth toes. In addition, the tarsal fold in this toad is produced in a true tarsal "shovel" with a narrow sharp edge. The forearm is immensely enlarged, and the thumb and throat are blackened, showing that breeding was about to take place. This specimen, being in better preservation than the others, shows the color pattern more distinctly. The head crests are edged with black, and the pustulate tubercles also have an increased pigmentation. A coarsely reticulate pattern of dark on light is evident on the upper surface behind the brown interocular bar, which crosses the head at the posterior level of the eyes. On the upper parts of the legs the dark reticulations often enlarge to form very irregular dark patches, of which one on top of each tibia is especially prominent. The arms bear some less definite reticulations, but there is a corresponding dark spot in the middle of each forearm. The tarsal and carpal regions are faintly barred with brown. The metacarpal tubercles are also darkened.

In the collection of eight adult or nearly adult toads at the Museum of Comparative Zoology there is another toad from Cap-Haïtien collected at the same time as our 75993. The two are identical in most respects, except that the shovel of the M.C.Z. specimen is not one-half so pronounced.

In two toads from Manneville (M.C.Z. Nos. 3101 and 3102) the webs are nearly as highly developed as in the Cap-Haïtien toads. Three toads from Diquini and two from Momance have prominent webs, but these do not extend along the sides of the toes in so wide a fringe, nor are they so deeply incised, as in those from Cap-Haïtien.

One of the toads from Manneville has a rather irregular, wide, light dorsal stripe and an equally irregular lateral stripe from the parotoids to the thighs. One of the Momance toads shows the lateral stripes plainly, with just a suggestion of the dorsal stripe. The black bar on the forearm is a distinctive feature in all the toads. In the adults, the tips of the toes and fingers, as well as all the palmar and plantar tubercles, are dark brown.

The Field Museum specimen (F.M.N.H. No. 5559) is now bleached so that no trace of a pattern shows, except on the back of the hindleg, where brown mottling appears. The head crests are extremely pronounced. The webs are very apparent on the hind feet, while the tarsal "shovel" is quite prominent. From the tip of the snout to the 
anus it measures $83 \mathrm{~mm}$.; tip of snout to posterior border of tympanum, $26 \mathrm{~mm}$. ; greatest width of head, $31 \mathrm{~mm}$.; foreleg, $50 \mathrm{~mm}$.; hindleg from groin, $88 \mathrm{~mm}$. Compared with U.S.N.M. No. 59081, which is practically identical in head and body length, the foot of F.M.N.H. No. 5559 is relatively very long, the third toe being particularly noticeable for its length when compared to that of 59081. The tibia of 5559 also appears to be somewhat longer compared to the National Museum specimen.

Remarks.-A manuscript note by Dr. Stejneger reads as follows: "There can be no doubt that Latreille and Daudin described as Bufo gutturosus (and the latter also as B. strumosus) a toad totally different from the one occurring in Santo Domingo or any of the Antilles. Short and unsatisfactory as are their descriptions, the statement that 'all the digits are a little separated, without membranes and short' is sufficient to preclude the adoption of the name to the present species. The habitat of the type specimen was unknown, and the specimen itself appears to be lost, so that it may never be known to what species the name really belongs."

Although this species is from the same stock as are the other similarly crested West Indian toads, it is well differentiated from the others. Bufo lemur from Puerto Rico has a much narrower and thinner snout, so that the head in profile looks quite different from the Hispaniolan species. The presence of a strong subnasal and a very pronounced labial crest in the Puerto Rican toad, and their nearly complete absence in the Hispaniolan species, constitute another point of distinct difference. The pustulose warts of the back are more or less confined to the anterior portion in güntheri, while they are uniformly scattered on anterior and posterior surfaces in lemur.

Specimens examined.-As listed in table 3.

TABLE 3.-Specimens of Bufo güntheri examined

\begin{tabular}{|c|c|c|c|}
\hline Museum No. & Locality & Date & Collector \\
\hline U.S.N.M. & & \multirow{4}{*}{$\begin{array}{l}1916 \ldots . \\
1916 . . \\
1913 .\end{array}$} & \multirow{4}{*}{$\begin{array}{l}\text { C. Bencomo. } \\
\text { Do. } \\
\text { W. M. Mann. }\end{array}$} \\
\hline 59081 (type) .. & Port-au-Prince, Haiti. & & \\
\hline $59082 \ldots \ldots$ & do & & \\
\hline $75993 \ldots \ldots$ & Cap-HaItien, Haiti.... & & \\
\hline M.C.Z. & & & \multirow{6}{*}{$\begin{array}{l}\text { W. Wilson. } \\
\text { W. M. Mann. } \\
\text { Do. } \\
\text { Do. } \\
\text { Do. } \\
\text { Do. }\end{array}$} \\
\hline $3097-3099$ & Diquini, Haiti......... & 1913 & \\
\hline 3101,3102 & Manneville, Haiti & $1913 \ldots \ldots \ldots \ldots$ & \\
\hline $3103,3104 \ldots \ldots$ & Momance, Haiti...... & $1913 \ldots \ldots \ldots$ & \\
\hline 3124 (12 juv.) & Grand Rivière, Haiti.. & 1913 & \\
\hline $3125-3127 \ldots \ldots$. & Cap-Haitien, Haiti.... & $1913 \ldots$ & \\
\hline F.M.N.H. & \multirow{2}{*}{ Monte Cristi, D. R. } & \multirow{2}{*}{ June 1916_... } & \multirow{2}{*}{ K. P. Schmidt. } \\
\hline & & & \\
\hline
\end{tabular}




\section{BUFO MARINUS (Linnaeus)?}

1758. Rana marina Linnaeus, Systema naturae, ed. 10, vol. 1, p. 211.

1938. Bufo marinus marinus Mertens, Senckenbergiana, vol. 20, p. 332; Publ.

Inst. Cient. Domínico-Alemán, vol. 1, p. 82, 1939.-Böker, Publ. Inst. Cient. Domínico-Alemán, vol. 1, p. 16, 1939.

The report by Dr. Mertens of the finding of young individuals at Río Jaina seems to be proof that this introduced form has established itself definitely in the Dominican Republic. A second locality, Monte Cristi, is likewise recorded in the same publication. The Museum of Comparative Zoology has a fine specimen, No. 22486, from the latter place, while another, No. 22485, was collected in Santa Barbara do Samaná by W. J. Clench.

\section{Family HYLIDAE}

\section{Genus HYLA Laurenti}

1768. Hyla Laurenti, Synopsis reptilium, p. 32 (type, H. viridis).

Of the four species of tree toads occurring in Hispaniola, the commonest by far is the bony-headed Hyla dominicensis, which is found about dwellings and on verandas in almost every town on the island. Hence it appears in great numbers in every collection of natural-history specimens brought back from there. Somewhat less common generally, but abundant in certain localities, is Hyla pulchrilineata, probably the most beautifully marked of the four. Hyla heilprini, with its dagger-shaped prepollex, is as yet known only from Pacificador Province in the Dominican Republic. The giant Hyla vasta, largest of all the hylas, is commoner than its former rarity in museum collections would indicate.

\section{KEY TO HYLA OF HISPANIOLA}

$a^{1}$. Derm of head involved in the rugose cranial ossification .- dominicensis (p. 13)

$a^{2}$. Derm of head not involved in the cranial ossification.

$b^{1}$. Outer fingers perfectly free pulchrilineata (p. 17)

$b^{2}$. Outer fingers nearly entirely webbed.

$c^{1}$. A dermal fringe on outer borders of limbs vasta (p. 19)

$c^{2}$. No dermal fringe on limbs heilprini (p. 22)

\section{HYLA DOMINICENSIS (Tschudi)}

FiguRE 3

1838. Hypsiboas dominicensis Tschudi, Mém. Soc. Sci. Nat. Neuchâtel, vol. 2, p. 30 .

1838. Hyla dominicensis "Mus. Paris" in Tschudi, Mém. Soc. Sci. Nat. Neuchâtel, vol. 2, p. 72 (in synonymy).-Boulenger, Catalogue of the Batrachia Salientia in the collection of the British Museum, ed. 2, p. 370, 1882 (part).Barbour, Mem. Mus. Comp. Zool., vol. 44, No. 2, p. 239, 1914; Zoologica, vol. 11, No. 4, p. 73, 1930; vol. 19, No. 3, p. 89, 1935.-Хснміdт, Bull.

\footnotetext{
Complete synonymy not given.
} 
Amer. Mus. Nat. Hist., vol. 44, art. 2, p. 8, 1921.-Cochran, Proc. U. S. Nat. Mus., vol. 66, art. 6, p. 3, 1924; Occ. Pap. Boston Soc. Nat. Hist., vol. 8, p. $164,1934$.

1841. Trachycephalus dominicensis DumeriL and Bibron, Erpétologie générale, p. 540.-GÜNTher, Catalogue of the Batrachia Salientia in the collection of the British Museum, p. 118, 1858 (part).

1863. Trachycephalus ovatus Cope, Proc. Acad. Nat. Sci. Philadelphia, 1862, p. 44.

1882. Hyla ovata Boulenger, Catalogue of the Batrachia Salientia in the col-

lection of the British Museum, ed. 2, p. 369 (part).

1892. H. (T.) ovata Müllen, Verh. Naturf. Ges. Basel, vol. 10, pt. 1, p. 200.-

Meerwarth, Mitt. Nat. Mus. Hamburg, vol. 18, p. 40, 1901.-Barbodr and Loveridge, Bull. Mus. Comp. Zool., vol. 69, No. 10, p. 351, 1929.

1882. Hyla septentrionalis Boulenger, Catalogue of the Batrachia Salientia in the collection of the British Museum, ed. 2, p. 369 (part).

1937. Hyla septentrionalis dominicensis BARBour, Bull. Mus. Comp. Zool., vol. 82 , No. 2 , p. 94 .

1938. Hyla dominicensis dominicensis Mertens, Senckenbergiana, vol. 20, No. 5,

p. 332 ; Publ. Inst. Cient. Domínico-Alemán, vol. 1, p. 84, 1939.-Böker,

Publ. Inst. Cient. Domínico-Alemán, vol. 1, p. 16, 1939.

Description.-U.S.N.M. No. 66670 , an adult female from Laguna, Samaná Peninsula, Dominican Republic, collected on December 11, 1923, by Dr. W. L. Abbott. Tongue broader than long, slightly emarginate behind; vomerine teeth in two short, heavy, almost contiguous series between the choanae; head slightly broader than long; nostrils near the tip of the snout, their distance from each other two-thirds as great as their distance from the eye; snout rounded in profile and when viewed from above; interorbital width three times the diameter of the upper eyelid; derm of head completely ossified (in the adult); canthus rostralis sharp and projecting, the loreal region deeply concave; upper lip slightly projecting; tympanum separated from the eye by one-third its own diameter, very distinct below, its upper border hidden by a heavy glandular fold, which emanates from the posterior corner of the eyelid and fades out shortly behind the level of the armpits; the hindlimb being adpressed, the tibiotarsal articulation reaches the end of the snout; digits with large disks, those of the fingers larger than the tympanum, those of the toes equaling it; fingers one-fourth webbed, toes three-fourths webbed. Skin fairly smooth above, with small glandules here and there on the back and sides; lower surfaces very coarsely granular; no tarsal fold.

Color (in alcohol): Upper parts drab to fawn color, with a very irregular coarsely reticulated pattern of chocolate on the back centering about a poorly defined ) (-shaped marking extending from the posterior eyelids to behind the shoulders, with other large irregular blotches following it; limbs with traces of dark cross bars and many irregular dark blotches; posterior borders of upper and lower lips with several dark spots; under parts immaculate olive-buff, the throat faintly suffused with fawn color. 
Dimensions: Tip of snout to vent, $88 \mathrm{~mm}$.; tip of snout to posterior border of ear, $28 \mathrm{~mm}$.; greatest width of head, $30 \mathrm{~mm}$.; hindleg from vent, $140 \mathrm{~mm}$.; foreleg, $51 \mathrm{~mm}$.; tibia, $47 \mathrm{~mm}$.

Variations.-In life the color pattern changes to a great extent in this species, not only in groups of individuals but in the same in-

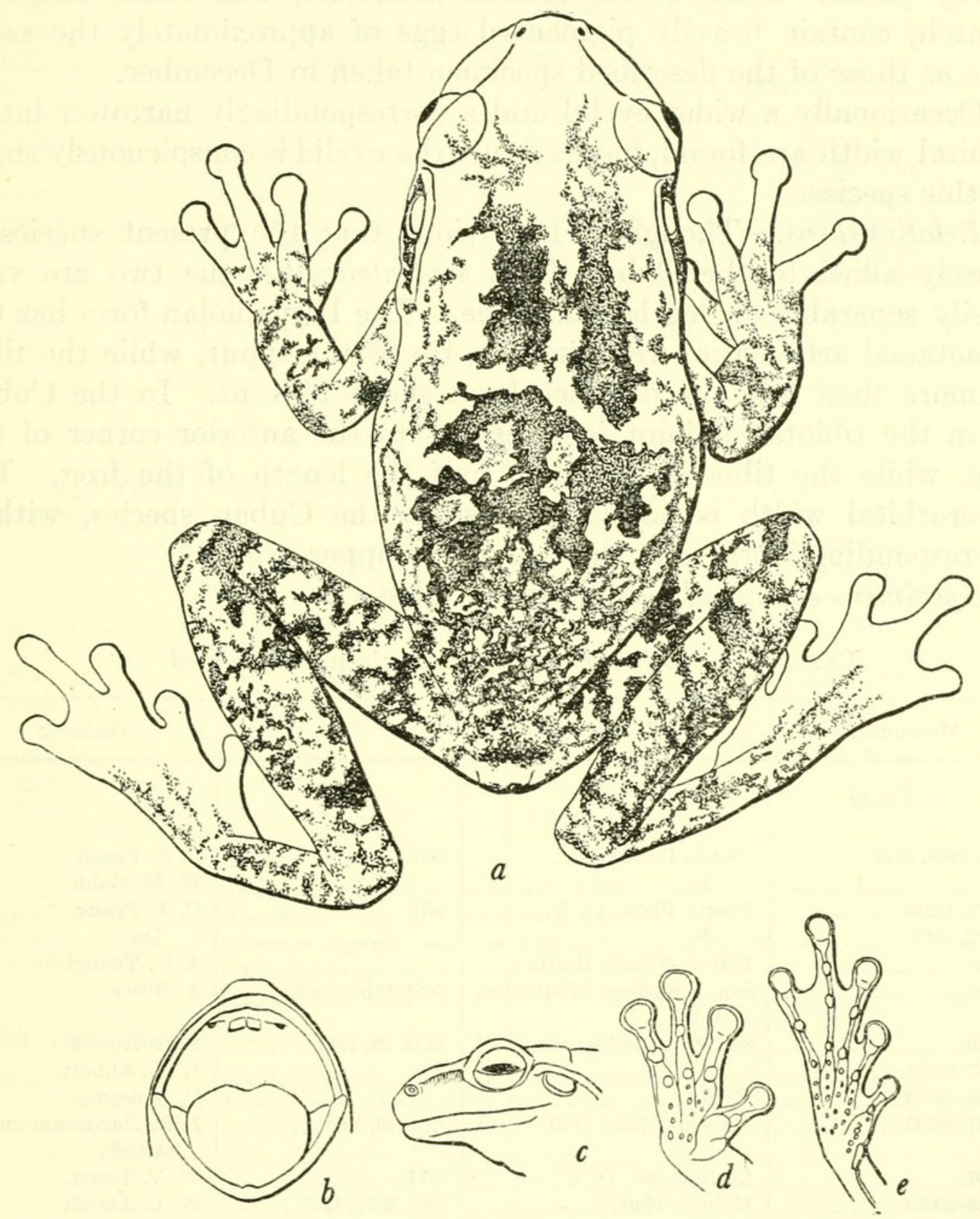

Figure 3.-Hyla dominicensis: $a$, Dorsal view; $b$, inside of mouth; $c$, side of head; $d$, underside of forefoot; $e$, underside of hindfoot. U.S.N.M. No. 66670, from Laguna, Dominican Republic. Natural size.

dividual at different times. In alcoholic specimens, the coarse reticulation on the back may usually be made out, although some frogs are of a lichen-gray color with very little evidence of pattern. The leg bands are often much more definite and regular than in the figured specimen, while occasionally the under parts of the legs have numerous round dark spots. 
A male (U.S.N.M. No. 74545) from Río San Juan measures $61 \mathrm{~mm}$. from snout to vent, and this seems to be about the maximum size for males, the females averaging over one-fourth longer. The males have very prominent external vocal pouches on each side of the throat, while the inner surface of the thumb is an enlarged, black, horny patch. Some of the females from Río San Juan, taken in March, contain heavily pigmented eggs of approximately the same size as those of the described specimen taken in December.

Occasionally a wider eyelid and a correspondingly narrower interorbital width are found, but as a rule the eyelid is conspicuously small in this species.

Relationships.-Though it is obvious that the present species is closely allied to the Cuban Hyla septentrionalis, the two are very easily separable on leg length alone. The Hispaniolan form has the tibiotarsal articulation reaching the tip of the snout, while the tibia is more than half the distance from snout to vent. In the Cuban form the tibiotarsal joint just reaches to the anterior corner of the eye, while the tibia is less than half the length of the frog. The interorbital width is noticeably less in the Cuban species, with a corresponding increase in the size of the upper eyelid.

Specimens examined.-As listed in table 4.

TABLE 4.-Specimens of Hyla dominicensis examined

\begin{tabular}{|c|c|c|c|}
\hline Museum No. & Locality & Date & Collector \\
\hline \multicolumn{4}{|l|}{ U.S.N.M. } \\
\hline 9806-9808, 9813. . & "Santo Domingo"........ & 1877. & C. A. Fraser. \\
\hline 9845 & do & $\ldots$ & W. M. Gabb. \\
\hline $10272,10274 \ldots \ldots$ & Puerto Plata, D. R........... & 1878 & C. A. Fraser. \\
\hline $12102,12103 \ldots \ldots$ & do................... & (2) & Do. \\
\hline 12148 & Port-au-Prince, Haiti. ......... & - & A. C. Younglove. \\
\hline $35992 \ldots \ldots$ & $\begin{array}{l}\text { San Francisco Mountains, } \\
\text { D. R. }\end{array}$ & September 1905 & A. Busck. \\
\hline 49940 & San Pedro de Macoris, D. R. & Mar. 28, 1913.. & P. G. Russell. \\
\hline $55087-55092 \ldots$ & - & $1916 \ldots \ldots \ldots$ & W. L. Abbott. \\
\hline $59083,59084 \ldots \ldots \ldots$ & Haiti. & - & C. Bencomo. \\
\hline $59257-59262 \ldots \ldots \ldots \ldots$ & Port-au-Prince, Haiti.......... & Apr. 10, 1917 ............ & $\begin{array}{l}\text { J. B. Henderson and } \mathbf{P} \text {. } \\
\text { Bartsch. }\end{array}$ \\
\hline $60497 \ldots \ldots$. & La Romana, D. R & 1913 & W. V. Tower. \\
\hline $60636-60639 \ldots$ & 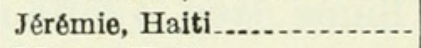 & Dec. $2-10,1917 \ldots$ & W. L. Abbott. \\
\hline $60610-60649 \ldots$ & Moron, Haiti & Dec. $20-22,1917 \ldots$ & Do. \\
\hline 61930 & Laguna, D. R & Mar. 10,1919 & Do. \\
\hline 64909 & Petit Trou, D. R & Feb. 16, 1922 . . . . . & Do. \\
\hline $65028-65053 \ldots \ldots$ & Laguna, D. R & May 1922 & Do. \\
\hline 65091 & Lo Bracita, D. R & Apr. $12,1922 \ldots$ & Do. \\
\hline 65120 & Laguna, D. R & May $11,1922 \ldots$ & Do. \\
\hline 65725 & Las Cañitas, D. R & Feb. $25,1923 \ldots \ldots$ & Do. \\
\hline $65726,65727 \ldots \ldots \ldots$ & Liali, D. R & Feb. 9, 1923 $\ldots . . . .$. & Do. \\
\hline $65728,65729 \ldots$ & Samaná and Laguna, D. R. & March 1923 & Do. \\
\hline $66670-66672 \ldots$ & Laguna, D. R & Dec. $11,1923 \ldots \ldots$ & Do. \\
\hline $66673,66674 \ldots \ldots \ldots$ & $\longrightarrow, \mathrm{D}, \mathrm{R}$ & 1923 & Do. \\
\hline 66766 & Samaná Peninsula, D. R .... & | $1923 \ldots \ldots \ldots \ldots$ & Do. \\
\hline
\end{tabular}


TABLE 4.-Specimens of Hyla dominicensis examined-Continued

\begin{tabular}{|c|c|c|c|}
\hline Museum No. & Locality & Date & Collector \\
\hline \multicolumn{4}{|l|}{ U.S.N.M.-Con. } \\
\hline $69199 \ldots \ldots$ & Port-au-Prince, Haiti_.... & Apr. 11, 1925 . . . & \multirow{15}{*}{$\begin{array}{l}\text { G. S. Miller, Jr. } \\
\text { Do. } \\
\text { Do. } \\
\text { Do. } \\
\text { W. A. Hoffmann. } \\
\text { Do. } \\
\text { Do. } \\
\text { E. C. Leonard. } \\
\text { A. Wetmore. } \\
\text { G. S. Miller, Jr. } \\
\text { J. S. C. Boswell. } \\
\text { A. J. Poole and W. Per- } \\
\text { rygo. } \\
\text { L. H. Parish and W. Per- } \\
\text { rygo. } \\
\text { Johnson-Smithsonian } \\
\text { Exped. }\end{array}$} \\
\hline $69200,69201 \ldots$ & San Michel, Haiti....... & Mar. 23-Apr. 1, 1925 & \\
\hline $69202-69209 \ldots$ & Mon Repos, Haiti........... & Mar. $4,1925 \ldots$ & \\
\hline 69210 & Mariani, Haiti ............. & Mar. $9,1925 \ldots . . . .$. & \\
\hline 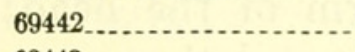 & Crois des Missions, Haiti.... & May $7,1925 \ldots \ldots$ & \\
\hline 69443 & Camp Perrin, Haiti........ & July $30,1925 \ldots . .$. & \\
\hline $69446,69447 \ldots .$. & Mariani, Haiti & Jan. $16,1925 \ldots$ & \\
\hline 70638 & Source of Mariani, Haiti. ... & Nov. 1925-Mar. 1926_. & \\
\hline $72615,72616 \ldots \ldots \ldots \ldots$ & Fonds-des-Nègres, Haiti .... & Apr. $5,1927 \ldots \ldots$ & \\
\hline $74518-74548$ & Río San Juan, D. R........... & March 1928 & \\
\hline $75877-75880 \ldots \ldots \ldots \ldots$ & Frère, Haiti................. & Aug. 26, 1928 ......... & \\
\hline 76658 & Dondon, Haiti........... & Jan. $18-20,1929 \ldots \ldots$ & \\
\hline $80831-80836 \ldots$ & Île à Vache, Haiti... & Apr. $30,1930 \ldots$ & \\
\hline $30346 \ldots . . . .$. & Santa Barbara, D. R........ & February 1933. & \\
\hline \multicolumn{3}{|l|}{ M.C.Z. } & \\
\hline $\begin{array}{l}1518 \text { (type of Trachy- } \\
\text { cephalus ovatus). }\end{array}$ & Jérémie, Haiti....... & Apr. $20,1865 \ldots$ & D. F. Weinland. \\
\hline 1523 & Haiti............ & & D. F. Weinland? \\
\hline 2048 & Samaná, D. R....... & $1882 \ldots \ldots$ & \multirow{4}{*}{$\begin{array}{l}\text { M. A. Frazar. } \\
\text { Do. } \\
\text { S. Garman. }\end{array}$} \\
\hline 2049 & Puerto Plata, D. R & $1881 \ldots$ & \\
\hline $2173 \ldots \ldots$ & Île à Vache, Haiti....... & - & \\
\hline 2246 & Haiti................ & - & \\
\hline 3089-3096 & Diquini, Haiti. & 1913 & \multirow{6}{*}{$\begin{array}{l}\text { W. M. Mann. } \\
\text { Do. } \\
\text { E. Lieder. } \\
\text { Utowana Exped. } \\
\text { P. J. Darlington. } \\
\text { Do. }\end{array}$} \\
\hline $3105-3114$ & Cap-Haitien, Haiti..... & $1913 \ldots \ldots$ & \\
\hline 8633 & La Romana, D. R & $1922 \ldots \ldots \ldots$ & \\
\hline $19701-19703$ & Cap-Haitien, Haiti.............. & March $1934 \ldots . .$. & \\
\hline $22479-22481 \ldots \ldots \ldots \ldots$ & Sosúa, D. R. & 1938 & \\
\hline $23543-23544$ & Puerto Plata, D. R & June $10,1938 \ldots \ldots$ & \\
\hline F.M.N.H. & & & \multirow{5}{*}{$\begin{array}{l}\text { E. Kaempfer. } \\
\text { Do. } \\
\text { Do. }\end{array}$} \\
\hline $5911 \ldots$ & 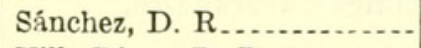 & Feb. 4, 1924.. & \\
\hline $5908-5910$ & Villa Rivas, D. R & $1924 \ldots \ldots \ldots$ & \\
\hline 5927 (6 spec.) & $\begin{array}{l}\text { Hills near Samaná Bay, D. } \\
\text { R. }\end{array}$ & 1924 & \\
\hline $13268 \ldots$ & Trou CaIman, Haiti .......... & & \\
\hline \multicolumn{4}{|l|}{ Unio. Puerto Rico } \\
\hline & Kenskoff, Haiti... & June $20,1938 \ldots$ & José A. Ramos. \\
\hline
\end{tabular}

\section{hyla PUlChrilineata Cope}

\section{FIGURE 4}

1869. Hyla pulchrilineata Cope, Proc. Amer. Philos. Soc., vol. 11, p. 163.Bodlenger, Catalogue of the Batrachia Salientia in the collection of the British Museum, ed. 2, vol. 1, p. 378, 1882.-Barbour, Mem. Mus. Comp. Zool., vol. 44, No. 2, pp. 227, 239, 1914; Zoologica, vol. 11, No. 4, p. 73, 1930; vol. 19, No. 3, p. 89, 1935; Bull. Mus. Comp. Zool., vol. 82, No. 2, p. 95, 1937.-Sснмлдт, Bull. Amer. Mus. Nat. Hist., vol. 44, art. 2, p. 8, fig. 1, 1921.-Noble, Nat. Hist., vol. 23, p. 115, photograph, 1923.-Nieden, Das Tierreich, Anura I, p. 312, 1923.-Cochran, Proc. U. S. Nat. Mus., vol. 66, art. 6, p. 3, 1924.-DunN, Proc. Boston Soc. Nat. Hist., vol. 38, No. 4, p. $123,1926$. 
Description.-U.S.N.M. No. 65733, an adult male from Samaná and Laguna, D. R., taken by Dr. W. L. Abbott in March 1923. Tongue broader than long, slightly emarginate behind; vomerine teeth in two straight heavy groups on a line with the posterior borders of the choanae; head broader than long; nostrils near the tip of the snout, their distance from each other equal to their distance from the eye; snout rounded; interorbital width equal to the greatest diameter of the eye; no indication of ossification in the derm of the head; canthus rostralis rounded, the loreal region concave, and the upper lip projecting conspicuously; tympanum distinct, its width slightly more than half that of the eye; the hind limb being adpressed, the

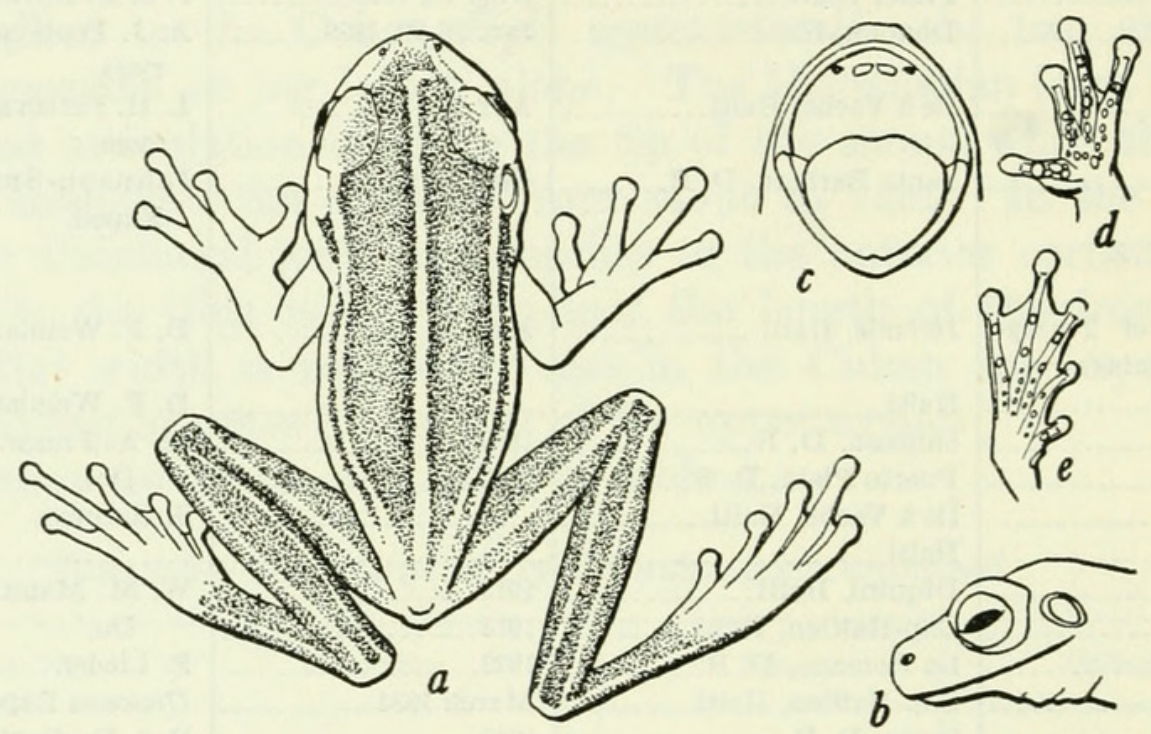

Figure 4.-Hyla pulchrilineata: $a$, Dorsal view; $b$, side of head; $c$, inside of mouth; $d$, underside of forefoot; $e$, underside of hindfoot. U.S.N.M. No. 65733, from Samaná and Laguna, Dominican Republic. One and one-half times natural size.

tibiotarsal articulation reaches beyond the tip of the snout; digits with large disks, those of the fingers about equal to the tympanum, those of the toes about two-thirds the size of the tympanum; fingers with the merest trace of a web, toes one-half webbed; skin minutely glandular above, practically smooth; throat, chest, abdomen, and thighs coarsely granular; a supratympanic fold continuing backward behind the ear and ending just above the insertion of the shoulder; a very slight dorsolateral fold; a pair of external vocal sacs. Male in the breeding season with a large black horny patch on the inner portion of the first finger and with a very prominent fold of skin across the throat.

Color (in alcohol): Upper parts deep fawn color, lightening toward the extremities; a narrow light median dorsal line (golden-yellow in life); a light line beginning above the nostril, continuing back along the canthus rostralis, through the eye, above the tympanum and along the sides, curving inward toward the vent; a brighter but more 
irregular line beginning on the upper lip, continuing below the tympanum and forking at the shoulders to send one branch partway down the side of the body, and the other to the wrist; a similar light line on the thigh and two on the tibia; lower parts pale buff, immaculate.

Dimensions: Tip of snout to vent, $29 \mathrm{~mm}$.; tip of snout to posterior border of ear, $10 \mathrm{~mm}$.; greatest width of head, $10.5 \mathrm{~mm}$.; hindleg, $47 \mathrm{~mm}$.; foreleg, $17 \mathrm{~mm}$.; tibia, $16 \mathrm{~mm}$.

Variations.-Many variations in color pattern are met with in a large series of males. In many the lines are more brilliant and obvious than in the described specimen; in others they are scarcely visible. The upper lip sometimes has a curved line running upward behind the nostrils and downward before the eye, with another sinuous curve in the region between eye and ear. The females show very indistinct traces of the original pattern. They are larger than the males, reaching about $38 \mathrm{~mm}$. in length, while males do not exceed $32 \mathrm{~mm}$. The tibiotarsal articulation does not reach beyond the tip of the snout in some cases.

Specimens examined.-As listed in table 5.

TABLE 5.-Specimens of Hyla pulchrilineata examined

\begin{tabular}{|c|c|c|c|}
\hline U.S.N.M. No. & Locality & Date & Collector \\
\hline $10273 \ldots \ldots$ & Puerto Plata, D. R & $1878 \ldots \ldots$ & C. A. Fraser. \\
\hline $65058-65088$ & Laguna, D. R & May 11,1922 & W. L. Abbott. \\
\hline $65730-65751 \ldots$. & Samaná and Laguna, D. R & Mar. 1923 . . . . . . & Do. \\
\hline $69211,69212 \ldots .$. & Mariani, Haiti. . & Mar. 6, 1925 ....... & G. S. Miller, Jr. \\
\hline $69448-69450 \ldots \ldots$ & Tord, Haiti. . . . & Mar. 12, 1925_...... & W. A. Hoffman. \\
\hline $74551-74596 \ldots \ldots \ldots$ & Río San Juan, D. R & Mar. 1928.......... & G. S. Miller, Jr. \\
\hline
\end{tabular}

\section{HYLA VASTA Cope}

\section{Figure 5}

1871. Hyla vasta Cope, Proc. Acad. Nat. Sci. Philadelphia, 1871, p. 219.Boulenger, Catalogue of the Batrachia Salientia in the collection of the British Museum, ed. 2, p. 351, 1882.-Barbour, Mem. Mus. Comp. Zool., vol. 44, No. 2, p. 238, 1914; Zoologica, vol. 11, No. 4, p. 73, 1930; vol. 19, No. 3, p. 89, 1935; Bull. Mus. Comp. Zool., vol. 82, No. 2, p. 94, 1937.Noble, Nat. Hist., vol. 23, No. 2, pp. 104-117, 1923; Amer. Mus. Nov., No. 165 , pp. 10-11, 1925; Ann. New York Acad. Sci., vol. 30, pp. 95-100, fig. 23b, pl. 9, fig. B (tadpole), 1927.-Nieden, Das Tierreich, Anura I, p. 312, 1923.-Cochran, Proc. U. S. Nat. Mus., vol. 66, art. 6, p. 3, 1924.Mertens, Senckenbergiana, vol. 20, No. 5, p. 333, 1938; Publ. Inst. Cient. Domínico-Alemán, vol. 1, p. 84, 1939.-Böker, Publ. Inst. Cient. DomínicoAlemán, vol. 1, p. 16, 1939.

Description.-U.S.N.M. No. 65757, an adult male from Liali, Dominican Republic, collected on February 9, 1923, by Dr. W. L. Abbott. Tongue broader than long, slightly emarginate behind; 
vomerine teeth in two heavy, wide series on a line with the posterior border of the choanae and not separated from each other by any appreciable distance; head broader than long; nostrils near the tip of the snout, their distance from each other equal to their distance from the eye; snout somewhat truncate in profile, rounded when viewed from above; interorbital width slightly exceeding the diameter of the eye opening; no indication of ossification in the derm of the

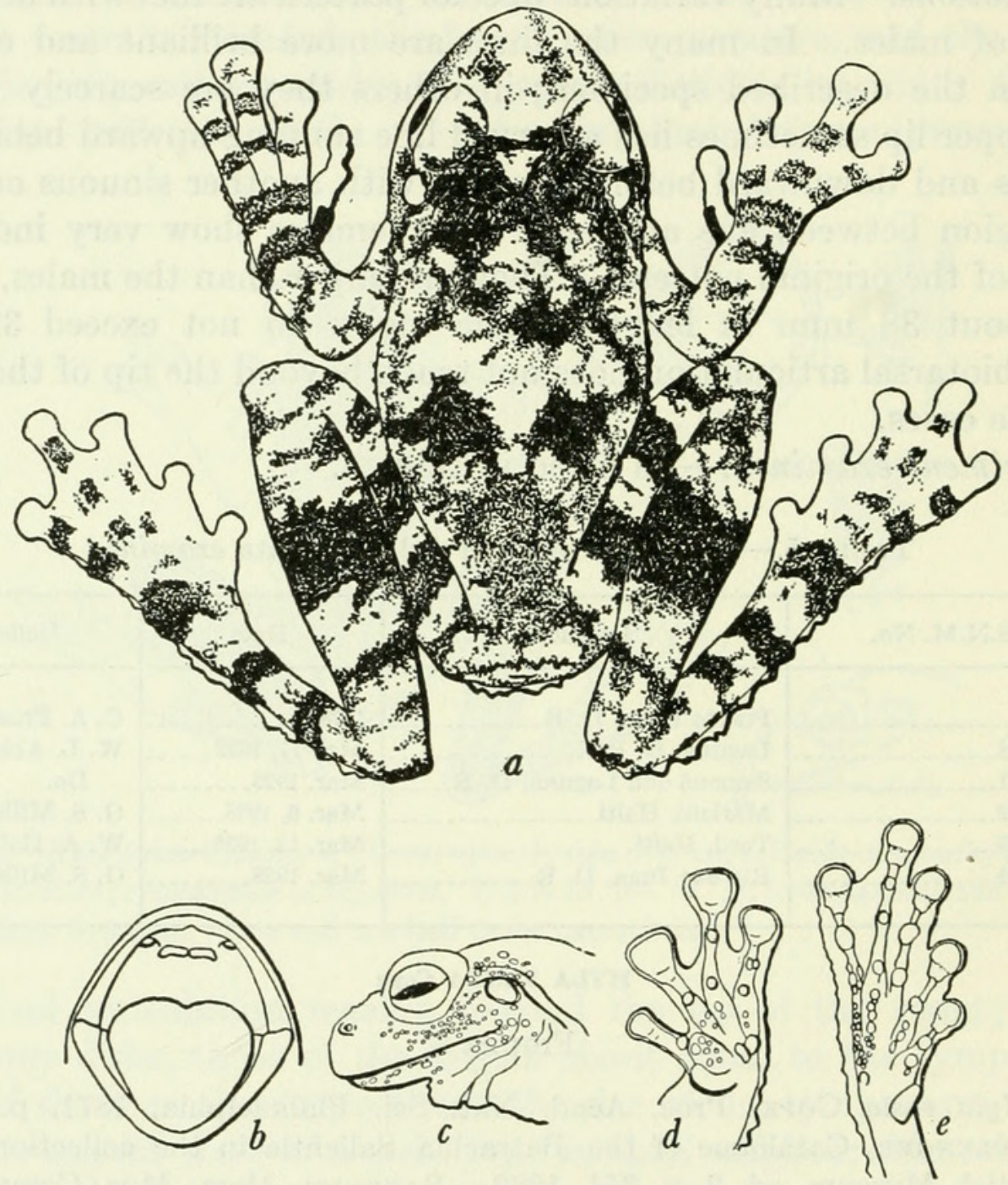

Figure 5.-Hyla vasta: $a$, Dorsal view; $b$, inside of mouth; $c$, side of head; $d$, underside of forefoot; $e$, underside of hindfoot. U.S.N.M. No. 65757, from Liali, Dominican Republic. Three-fourths natural size.

head; canthus rostralis rounded, the loreal region concave; upper lip not projecting conspicuously; tympanum distinct, its width slightly more than half that of the eye opening, separated from the eye by a little less than its width. The hindlimb being adpressed, the tibiotarsal articulation reaches beyond the tip of the snout; digits with very large disks, those of the fingers about one and one-fourth times the diameter of the tympanum, those of the toes slightly larger than 
the tympanum; fingers half webbed, toes two-thirds webbed. Skin excessively glandular above with numerous tubercular prominences especially evident around the tympanum and lower jaw, on the loreal region, and on the sides of the body; lower surfaces of body and limbs very coarsely granular; a well-developed supratympanic fold; a heavy, serrate fold of skin along the outer border of the arm and leg, continuing to the extremity of the outer digit; a patch of elongate glandular prominences on each leg below the anus. Male with a large brown patch on the very much enlarged inner portion of the first finger, without external vocal sacs.

Color (in alcohol): Above drab-gray, with large, slate-colored irregular mottlings in a broad area across the occiput and involving the posterior half of the upper eyelids, and several pairs of similar large irregular spots on the back; limbs heavily cross-banded with slate; lower parts pale drab-gray, the chin and throat sprinkled with small slate-colored spots.

Dimensions: Tip of snout to vent, $87 \mathrm{~mm}$.; tip of snout to posterior border of ear, $27 \mathrm{~mm}$.; greatest width of head, $30 \mathrm{~mm}$.; hindleg, $132 \mathrm{~mm}$.; foreleg, $48 \mathrm{~mm}$.; tibia, $47 \mathrm{~mm}$.

Variations.-There is little variation in the bodily proportions between individuals of this species. The color pattern varies to some extent, as one would expect, notably in the coarseness of the spots on the back and in the width of the bars crossing the upper surface of the legs. The largest examples of both sexes come from San Juan River, the female (U.S.N.M. No. 74514) measuring $142 \mathrm{~mm}$. from snout to vent, and the male (U.S.N.M. No. 74516) $112 \mathrm{~mm}$. The females from the Samaná Peninsula, taken in February 1924, contained great numbers of immature eggs. A very young frog only $26 \mathrm{~mm}$. in length from Camp Perrin is pale drab above, with a dark butterflyshaped marking across the posterior half of the head and a dark chevron across the middle of the back. The limbs are cross-barred. The area below the eye to the lip margin is distinctly white.

Habits.-Dr. Noble (1927, pp. 95-96) has recorded the breeding habits of this species: "Hyla vasta laid its eggs in little basins in the gravel and stones on the edge of the pools in the mountain torrent (one observation). Six days after hatching the larvae made their way out of one of the basins over wet stones into the torrent pool. As they grew older they developed better stream lines than the tadpoles of $H$. dominicensis. They were equipped with more rows of teeth. The mouth was larger and better adapted to holding on to rocks in the stream. Its tail was thicker and more muscular than that of the stagnant-pool tadpole." The eggs of vasta are pigmented and the recently hatched larva is dark. The external gills are not large, and the larva does not rise to the surface in the early stages. 
After they have reached the mountain pool, they grow into thicktailed, large-mouthed tadpoles having no back fin. The mature larva in its adhesive mouth and slim body form is well adapted to life in a mountain stream.

Relationships.-Although one might be inclined to believe at first glance that the closest relative of Hyla vasta is the equally large Hyla lichenata of the neighboring island of Jamaica, examinations of the life history of the two species lead to different conclusions. All the Jamaican frogs lay their eggs in bromeliads, while all the Hispaniolan ones go through the normal procedure of depositing eggs in streams, as Dr. Dunn points out. Dr. Noble believes that Hyla vasta is related to some basin-breeding species on the mainland of South America, possibly to Hyla rosenbergi.

Specimens examined.-As listed in table 6.

TABLE 6.-Specimens of Hyla vasta examined

\begin{tabular}{|c|c|c|c|}
\hline U.S.N.M. No. & Locality & Date & Collector \\
\hline $55301 \ldots$ & El Rín, D. R........ & Oct. $8,1916 \ldots$ & W. L. Abbott. \\
\hline 65090 & Lo Bracita, D. R & Apr. $15,1922 \ldots .$. & Do. \\
\hline $65752-65759$ & Liali, D. R & Feb. 9-10, 1923 .... & Do. \\
\hline $66983-66989$ & Samaná Peninsula, D. R... & Feb. 1924 & J. King. \\
\hline 69444 & Camp Perrin, Haiti & Aug. 2, 1925 & W. A. Hoffmann. \\
\hline 69445 & La Vallee, Haiti. & June $23,1925 \ldots . .$. & Do. \\
\hline $74514-74517,74550$ & Río San Juan, D. R & March 1928......... & G. S. Miller, Jr. \\
\hline
\end{tabular}

\section{HYLA HEILPRINI Noble}

Figure 6

1923. Hyla heilprini Noble, Amer. Mus. Nov., No. 61, p. 1 (type locality, Lo Bracita, Prov. Pacificador, Dominican Republic).-Barbour and LoveRIDGe, Bull. Mus. Comp. Zool., vol. 69, No. 10, p. 279, 1929.-Barbour, Zoologica, vol. 11, No. 4, p. 74, 1930; vol. 19, No. 3, p. 90, 1935; Bull. Mus. Comp. Zool., vol. 82, No. 2, p. 95, 1937.-Mertens, Senckenbergiana, vol. 20, No. 5, p. 333, 1938; Publ. Inst. Cient. Domínico-Alemán, vol. 1, p. 84, 1939.-Böker, Publ. Inst. Cient. Domínico-Alemán, vol. 1, p. 16, 1939.

Original description.--"Diagnosis.-A medium-sized Hyla differing remarkably from any other Greater Antillean species in possessing a dagger-shaped prepollex visible in both sexes but enormously developed and with exposed point in the male; fingers two-thirds, toes completely webbed; vomerine teeth in two straight series on a level with the posterior border of the choanæ. Coloration in preserved material largely dependent on fixation; a series of transverse bars of a dark color and a scattering of white specks usually present on 
the dorsal surface and readily distinguishing the species from other Dominican forms.

"TYPe.-A.M.N.H. No. 11401; adult, ơ; among stones in ravine of mountain torrent, Lo Bracita, Prov. Pacificador [Dominican Republic]; August 20, 1922; G. K. Noble.

"Description of Type.-Tongue broader than long, emarginate behind; vomerine teeth in two groups in contact and forming almost a continuous series between the choanæ on a level with their posterior

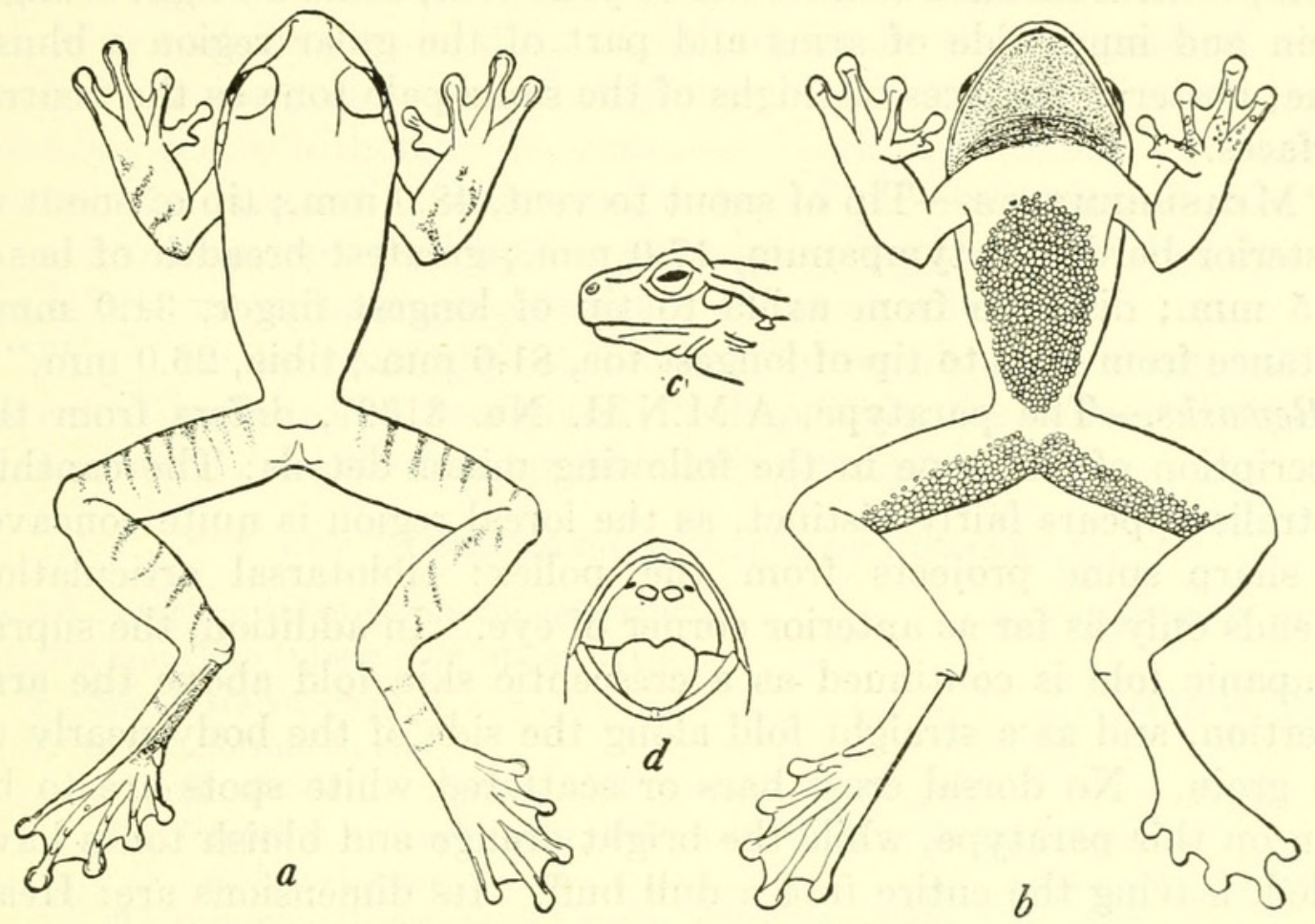

Figure 6.-Hyla heilprini: $a$, Dorsum; $b$, venter; $c$, profile of head; $d$, inside of mouth. A.M.N.H. No. 31307, paratype, from Lo Bracita, Dominican Republic. Three-fourths natural size.

margin; head much broader than long; nostrils near the end of the snout, the distance from the extreme tip (midpoint) of snout to nostril contained more than two times in the distance between nostril and eye; snout rounded; interorbital width greater than the greatest diameter of the eye; no indication of ossification in the derm of head; canthus rostralis rounded, the loreal region sloping gradually; tympanum distinct, slightly more than half the greatest diameter of the eye. Hind limb being adpressed, the tibio-tarsal articulation reaches nearly to the nostril; digits with large discs, of the same diameter as the tympanum; fingers two-thirds webbed, toes completely webbed (but the web does not reach the disc of the fourth toe); a large, 
recurved prepollex with an exposed spine directed inward. Skin finely glandular above, almost smooth; skin of abdomen and ventral surfaces of the thighs coarsely granular; a supra-tympanic fold but no dorso-lateral one; a subgular vocal sac present.

"Ground tone (of preserved specimen) pale grayish blue above, suffused with a darker tone; some indication of nine transverse bars of a dark brown on the back; a more distinct series of five or six bars on the thighs; upper surface sprinkled with about thirty small white spots; ventral surfaces straw-color to yellowish; axilla a bright orange; groin and inner side of arms and part of the gular region a bluish tone; posterior surfaces of thighs of the same pale tone as the ventral surfaces.

"Measurements.-Tip of snout to vent, $48.0 \mathrm{~mm}$.; tip of snout to posterior border of tympanum, $17.0 \mathrm{~mm}$; greatest breadth of head, $18.5 \mathrm{~mm}$.; distance from axilla to tip of longest finger, $31.0 \mathrm{~mm}$.; distance from vent to tip of longest toe, $81.0 \mathrm{~mm}$.; tibia, $26.0 \mathrm{~mm}$."

Remarks.-The paratype, A.M.N.H. No. 31307, differs from the description of the type in the following minor details: The canthus rostralis appears fairly distinct, as the loreal region is quite concave; no sharp spine projects from the pollex; tibiotarsal articulation extends only as far as anterior corner of eye. In addition, the supratympanic fold is continued as a crescentic skin fold above the arm insertion, and as a straight fold along the side of the body nearly to the groin. No dorsal cross bars or scattered white spots are to be seen on this paratype, while the bright orange and bluish tones have faded, leaving the entire frog a dull buff. Its dimensions are: Head and body, $38 \mathrm{~mm}$.; head length, $17 \mathrm{~mm}$.; head width, $18 \mathrm{~mm}$.; eye diameter, $5 \mathrm{~mm}$.; foreleg, $16 \mathrm{~mm}$; hindleg, $80 \mathrm{~mm}$.; tibia, $25 \mathrm{~mm}$.; femur, $26 \mathrm{~mm}$. from anus, $23 \mathrm{~mm}$. from groin.

The only other example of this species examined by me is M.C.Z. No. 23539 , taken in 1938 at Los Limones, Dominican Republic, by P. J. Darlington.

\section{Family LEPTODACTYLIDAE}

\section{Genus ELEUTHERODACTYLUS Duméril and Bibron}

1841. Eleutherodactylus Duméril and Bibron, Erpétologie générale, vol. 8, p. 620 (type, E. martinicensis).

Some of the 26 known forms of Eleutherodactylus in Hispaniola seem to belong in natural groups, while other species apparently 
have no close allies now existing on this island. Those that can be readily grouped together are glandulifer, darlingtoni, and glanduliferoides, all possessing a heavy gland in the groin, with other glands on posterior femur and elsewhere. Such glands are not known in any other West Indian members of the genus. The only two forms with notched toes, flavescens and poolei, also obviously belong together, while jugans and ventrilineatus, from mountaintops at the opposite ends of the same range, may almost rank as subspecies because of their very close resemblance, in spite of the reduction of vomerine teeth in ventrilineatus and its slightly different ventral pattern. The largest species on the island, inoptatus, does not seem to have a close relative there, although its vomerine teeth are similar to those of ruthae and schmidti. These and some of the remaining species can be arbitrarily separated into one group having the belly skin smooth, while the others have granular skin at least posteriorly.

There are undoubtedly still other forms of this varied and interesting genus to be discovered on Hispaniola, the biological exploration of which is still very far from being complete.

\section{KEY TO ELEUTHERODACTYLUS OF HISPANIOLA}

$a^{1}$. A spinelike tubercle on upper eyelid. inoptatus (p. 27)

$a^{2}$. No spinelike tubercle on upper eyelid.

$b^{1}$. Snout shovel-shaped ruthae (p. 31)

$b^{2}$. Snout normal in shape.

$c^{1}$. Digits swollen at tips but not distinctly enlarged.

$d^{1}$. Vomerine teeth strongly developed; belly with large light and dark spots........... jugans (p. 33)

$d^{2}$. Vomerine teeth weak; belly with fine light and dark spots. ventrilineatus (p. 35)

$c^{2}$. Tips of digits enlarged into definite disks.

$d^{1}$. Toes and fingers conspicuously notched.

$e^{1}$. Vomerine teeth heavy; tympanum two-thirds eye diameter................................ flavescens (p. 37)

$e^{2}$. Vomerine teeth weak; tympanum one-half eye diameter. poolei (p. 39)

$d^{2}$. Toes and fingers rounded at tips.

$e^{1}$. Heavy glands in groin, on posterior femur, and near forearm in adult.

$f^{1}$. Adpressed heel reaching tip of snout glandulifer (p. 42)

$f^{2}$. Adpressed heel not reaching beyond eye.

$g^{1}$. Disk of third finger covering more than half tympanum....... darlingtoni (p. 43)

$g^{2}$. Disk of third finger covering less than half tympanum. glanduliferoides (p.45) 
$e^{2}$. No heavy glands on body or limbs. $f^{1}$. Belly smooth (sometimes slightly granular in
abbotti).

$g^{1}$. Adpressed heel reaching to tympanum or posterior

border of eye

$g^{2}$. Adpressed heel reaching at least to center of eye.

$h^{1}$. No light interorbital band

weinlandi (p. 49)

$h^{2}$. A light interorbital band.

$i^{1}$. Heels touching without overlapping- rufifemoralis (p. 52)

$i^{2}$. Heels overlapping greatly.

$j^{1}$. Adpressed heel reaching beyond anterior corner of eye.

$k^{1}$. Upper eyelid equal to interorbital width.

$l^{1}$. Heel reaching nearly to nostril

schmidti schmidti (p. 54)

$l^{2}$. Heel reaching considerably beyond tip of snout........ schmidti rucillensis (p. 56)

$k^{2}$. Upper eyelid less than interorbital width.

$l^{1}$. Size small, $21 \mathrm{~mm}$; adpressed heel reaching beyond eye............. abbotti (p. 58)

$l^{2}$. Size large, $42 \mathrm{~mm}$; adpressed heel reaching beyond tip of snout__ femur-levis (p. 61)

$j^{2}$. Adpressed heel not reaching beyond anterior corner of eye.

$k^{1}$. A dark lateral stripe on side of head and shoulders_._._.

$k^{2}$. No dark lateral stripe

$f^{2}$. Belly granular.

$g^{1}$. Heel not reaching beyond posterior corner of tympanum; size small.

$h^{1}$. Vomerine teeth relatively weak; snout longer;

back more tubercular................ audanti (p.65)

$h^{2}$. Vomerine teeth strongly developed; snout shorter;

back faintly granular or smooth _... intermedius (p. 70)

$g^{2}$. Heel reaching to posterior corner of eye.

$h^{1}$. Disk of third finger considerably larger than tympanum .......... semipalmatus (p. 72)

$h^{2}$. Disk of third finger equal to tympanum, or smaller.

$i^{1}$. Toes with a vestigial web.

$j^{1}$. Finger disks equal to tympanum_-..- montanus (p. 73)

$j^{2}$. Finger disks equal only three-quarters tympanic area_._._. . _. auriculatus wetmorei (p. 74)

$i^{2}$. Toes free.

$j^{1}$. Eye large, equal to snout in length.

$k^{1}$. Vomerine teeth between outer rims of choanae...... auriculatus auriculatoides (p. 77)

$k^{2}$. Vomerine teeth extending lateral to outer rims of choanae....... armstrongi (p. 79)

$j^{2}$. Eye small, its diameter two-thirds its distance from end of snout bakeri (p. 82) 


\section{ELEUTHERODACTYLUS INOPTATUS (Barbour)}

\section{FigURE 7}

1914. Leptodactylus inoptatus Barbour, Mem. Mus. Comp. Zool., vol. 44, No. 2, p. 252 (type locality, Diquini, Haiti; collector, W. M. Mann; type in Mus. Comp. Zool., No. 3087).-Nieden, Das Tierreich, Anura I, p. 475, 1923.Barbour and Loveridge, Bull. Mus. Comp. Zool., vol. 69, No. 10, p. 293, 1929.

1921. Eleutherodactylus inoptatus Schмidt, Bull. Amer. Mus. Nat. Hist., vol. 44, art. 2, p. 9.-Cochran, Proc. U. S. Nat. Mus., vol. 66, art. 6, p. 2, 1924; Proc. Biol. Soc. Washington, vol. 41, p. 54, 1928.-BArbour, Reptiles and amphibians, p. 96, 1926; Zoologica, vol. 11, No. 4, p. 76, 1930; vol. 19, No. 3, p. 93, 1935; Bull. Mus. Comp. Zool., vol. 82, No. 2, p. 100, 1937.-Noble, Nat. Hist., vol. 30, pp. 89, 90, fig. 19 (larva), 1927.

Description.-U.S.N.M.No. 65024, an adult from Laguna, Samaná Peninsula, Dominican Republic, collected by Dr. W. L. Abbott in May 1922. Tongue broad, faintly emarginate behind; vomerine teeth in two very oblique groups some distance behind the choanae, the outer portion of each group short and not extending beyond the outer borders of the choanae, the inner portion rather long and distinctly though narrowly separated from its fellow; head relatively large; nostril much nearer to the tip of snout than to the eye, separated from the eye by a distance a little greater than the diameter of the eye; upper eyelid equal to the interorbital width; a short but heavy spine near the posterior border of the upper eyelid; tympanum about twothirds the diameter of the eye, separated from it by a little more than half its own diameter; disks of fingers moderately large, first finger very slightly longer than second; disks of toes smaller, first toe short, reaching subarticular tubercle of second; fifth toe longer than third; subarticular tubercles well developed; two metatarsal tubercles, the outer faintly discernible and small, the inner very large and prominent; a few weak palmar and plantar tubercles; no tarsal fold; a distinct tubercle on the heel; the bent limbs being pressed along the sides, knee and elbow overlap; the hind limbs being adpressed, the heel reaches far beyond the snout; the hind limbs being placed vertically to the axis of the body, the heels greatly overlap. Skin of head, back, and throat very finely pustular, more coarsely so on the sides around the anus and on the femur; a well-developed dorsolateral glandular fold; a heavy fold leaving the posterior corner of the eye, going above the tympanum and passing diagonally downward behind the arm, where it branches, one of the branches shortly becoming lost in the axillar region, the other branch paralleling the dorsolateral fold nearly to the groin; a number of short, narrow, glandular ridges on the anterior half of the back, running diagonally even onto the eyelids, and similar but longer ones on arms, legs, and feet; a small tuberclelike projection in the center of the interorbital region caused by the junction of several of these small ridges; small glandular tubercles on the loreal region and in front of the ear; skin of belly and lower surfaces of 
thighs coarsely granular; skin of chest and of lower surfaces of arms and of tibia quite smooth; numerous throatfolds on the throat, indicating the presence of a large external vocal sac.

Dimensions: Tip of snout to vent, $64 \mathrm{~mm}$.; width of head, $27 \mathrm{~mm}$.; diameter of eye, $8 \mathrm{~mm}$; diameter of tympanum, $5 \mathrm{~mm}$.; foreleg from axilla, $39 \mathrm{~mm}$; hindleg from vent, $118 \mathrm{~mm}$.; vent to heel, $70 \mathrm{~mm}$.

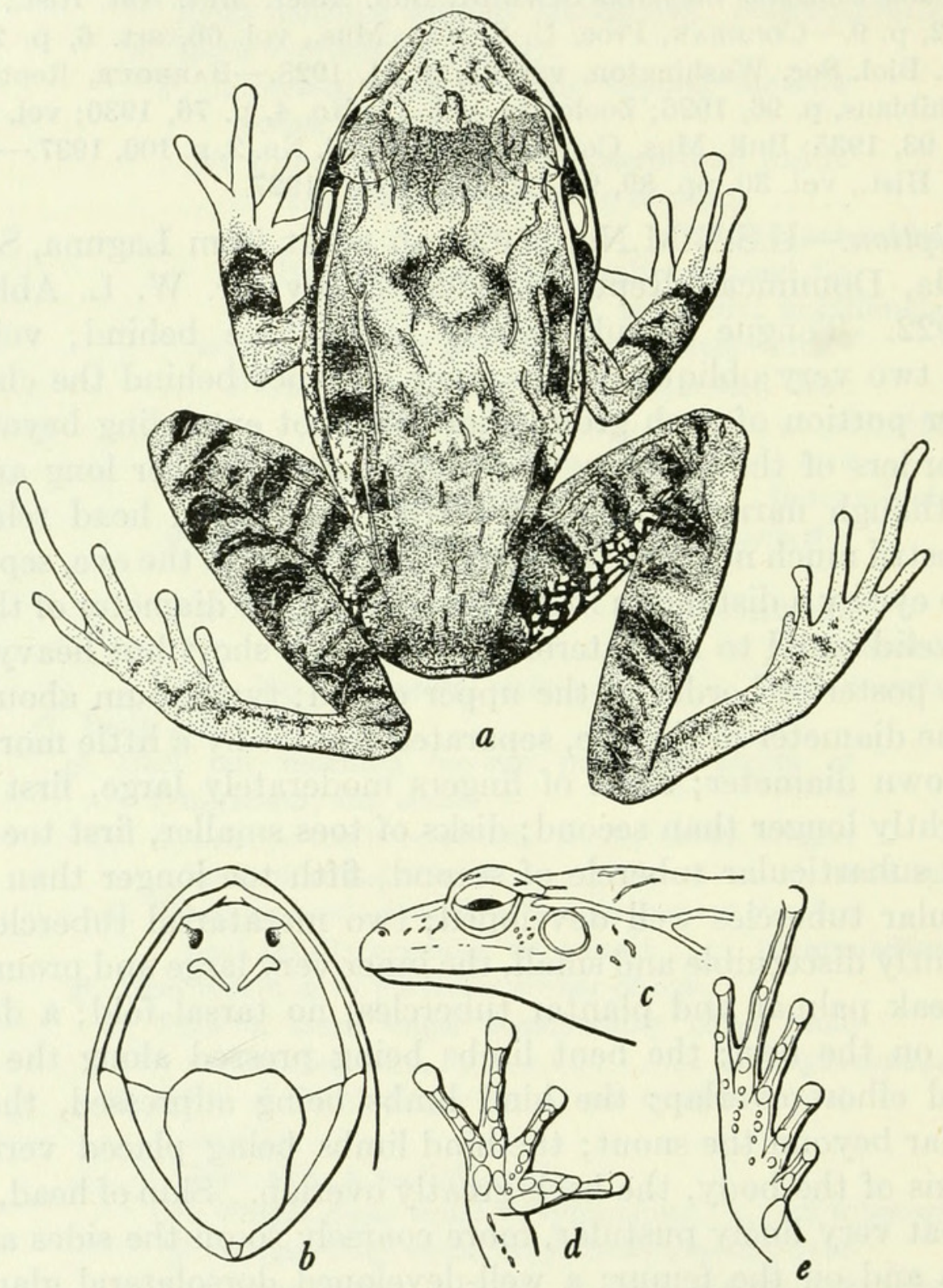

Figure 7.-Eleutherodactylus inoptatus: $a$, Dorsal view; $b$, inside of mouth; $c$, side of head; $d$, underside of forefoot; $e$, underside of hindfoot. U.S.N.M. No. 65024, from Laguna, Dominican Republic. Natural size.

Color (in alcohol): Upper surfaces mouse gray; canthal region slate color; a black line starting behind the eye, continuing through the upper part of the tympanum and dropping to meet a conspicuous white line that leaves the posterior corner of the mouth, both lines disappearing above the shoulder; a series of vertical slate-colored bars along the sides below the dorsolateral fold, and slate-colored cross 
bars on the legs; lips edged with an irregular dark line, followed by a metallic light stripe; lower surfaces olive-buff, except the throat and lower parts of extremities, which are suffused with slate color; where the colors of the upper and lower surfaces meet, on the legs and on the sides, there is an area where the slate color makes a coarse reticulated pattern enclosing prominent small spots of light olive-buff; above this on the femur there is a wide irregular light bar.

Variations.- -Some differences in the length of the snout are apparent in a series of these frogs. Among six from Laguna, the snout length is one and one-third to one and two-thirds the diameter of the eye. The toes are as usual somewhat different in the size of the disks. In a series of 24 individuals of all ages from the San Juan River, the skin is found to be intensely roughened and glandular in the young, while in big females the skin is practically smooth on the entire upper surface.

A surprisingly great variation in color occurs at all ages. Some of the young are much more strikingly patterned than others, and their colors are darker. In U.S.N.M. No. 74619, for instance, the bars on the hindlegs stand out with great distinctness, the entire dorsal region is slate color, and the pale interorbital bar is conspicuous, while the heavy glands on the back are pale in color. No. 74622, another young one from the same collection, is a pasty light olivegray, on which the interorbital bar is almost lost; the limb bars are distinct but much lighter than in the preceding specimen, while the back has the same light tone as the glandular ridges. The adult frogs show nearly as much variation in hue, although the glandular ridges are very much reduced and scarcely differentiated by color. Often the throat, chest, and lower surfaces of arms and legs are suffused with slate color.

The largest of the frogs at hand, measuring $88 \mathrm{~mm}$. in length, is U.S.N.M. No. 74600 from Río San Juan. The tibia is 63.6 percent of the length of head and body in this specimen. The tibial length is surprisingly constant in 24 individuals (exceeding $40 \mathrm{~mm}$. in length) ranging from 58.5 to 63.9 percent, with an average of 61.7 percent of the length of head and body.

The specimen described, as well as 20 other adults from the northeastern part of the Dominican Republic, differs substantially from the description of the unique type of inoptatus, which came from Diquini, Haiti. In the first place, the interorbital diameter is said to be over twice the width of the upper eyelid in the type, while in my series it is never over one and one-half times the width of the upper eyelid, and in one case is equal, in one slightly less. The tarsometatarsal articulation of the adpressed foot in the type reaches the nostril; in the present series it extends far beyond the tip of the snout con- 
stantly. Two metatarsal tubercles were present in the type; in the frogs from the Dominican Republic the outer tubercle is absent or so weak that it can scarcely be distinguished in all but two specimens, in which it is quite apparent. The type had the skin smooth in the middorsal area, but my specimens are more usually glandular and ridged, only one example failing to show at least a trace of these ridges. A large series from Diquini and neighboring points in Haiti must be collected and studied before it will be possible to tell whether the form from the Dominican Republic deserves a new specific name.

Relationships.-This singular species seems to have but one close relative in the West Indies, Eleutherodactylus ruthae, described by Noble nine years after the description of inoptatus. A discussion of their relationships appears on p. 33. Dr. Barbour remarks that his $E$. inoptatus superficially resembles $E$. insignitus from the Santa Marta Mountains of Colombia.

The young of inoptatus is strikingly similar to the adult of E. ruthae, differing mainly in its snout, which does not project much beyond the front of the lower jaw in the former, and in the presence of the tubercle on the heel.

Specimens examined.-As listed in table 7.

TABLE 7.-Specimens of Eleutherodactylus inoptatus examined

\begin{tabular}{|c|c|c|c|}
\hline Museum No. & Locality & Date & Collector \\
\hline U.S.N.M. & & & \\
\hline $55085,55086 \ldots$ & Dominican Republic........ & 1916 & W. L. Abbott. \\
\hline $65022-65027$ & Laguna, D. R & May $1922 \ldots$ & Do. \\
\hline 65721 & Samaná and Laguna, D. R ... & March 1923... & Do. \\
\hline $65722-65724$ & Las Cañitas, D. R & Feb. $27,1923 \ldots$ & Do. \\
\hline $66981,66982 \ldots \ldots \ldots$ & Laguna, D. R & February 1924 & J. King. \\
\hline $74600-74623$ & Río San Juan, D. R & March 1928.......... & G. S. Miller, Jr. \\
\hline M.C.Z. & & & \\
\hline 3087 (type of $E$. inoptatus)... & Diquini, Haiti . . . . . . . & $1913 \ldots \ldots . . . . .$. & W. M. Mann. \\
\hline 13072 & Mount Rochelle, Haiti.... & Aug. 17, $1927 \ldots$ & W. J. Eyerdam. \\
\hline 13536 & Lake Miragoane, Haiti. & July 25,1927 & Do. \\
\hline $22478 \ldots$ & Sosúa, D. R & -......................... & W. J. Clench. \\
\hline 23522 & Puerto Plata, D. R & June 10,1938 & P. J. Darlington. \\
\hline $23534-23535$ & Sánchez, D. R & July, 1938 & Do. \\
\hline 23547 & $25 \mathrm{Km}$. S. Puerto Plata, D.R & June $10,1938 \ldots$ & Do. \\
\hline F.M.N.H. & Villa Rivas, D. R & Dec. $15,1924 \ldots$ & E. Kaempfer. \\
\hline
\end{tabular}


ELEUTHERODACTYLUS RUTHAE Noble

Figure 8

1923. Eleutherodactylus ruthae Noble, Amer. Mus. Nov., No.61, p. 6.-Cochran, Proc. U. S. Nat. Mus., vol. 66, art. 6, p. 2, 1924.-Barbour and Loveridge, Bull. Mus. Comp. Zool., vol. 69, No. 10, p. 263, 1929.-Barbour, Zoologica, vol. 11, No. 4, p. 76, 1930; vol. 19, No. 3, p. 93, 1935; Bull. Mus. Comp. Zool., vol. 82 , No. 2 , p. $100,1937$.

Description.-U.S.N.M. No. 65715, an adult male from Samaná and Laguna, Dominican Republic, collected in March 1923 by Dr. W. L. Abbott. Tongue moderate in width, emarginate behind; vomerine teeth in two wide, straight patches a considerable distance behind the widely separated choanae, their outer borders reaching about to a line drawn posteriorly from the centers of the choanae,

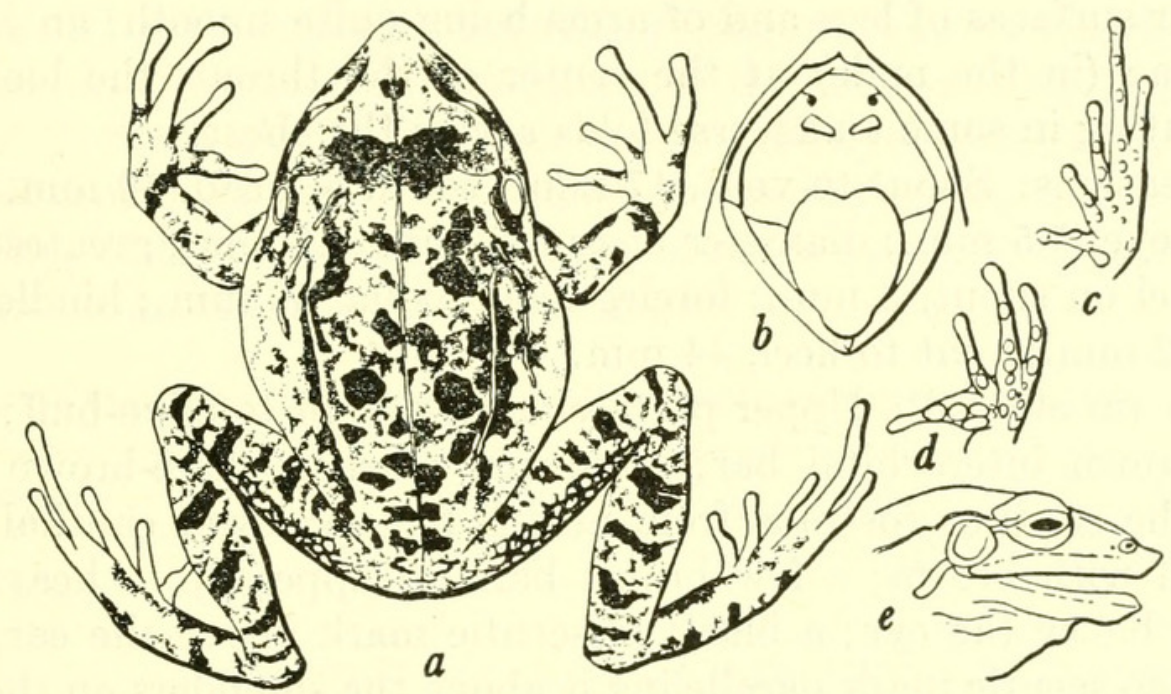

Figure 8.-Eleutherodactylus ruthae: $a$, Dorsal view; $b$, inside of mouth; $c$, underside of hindfoot; $d$, underside of forefoot; $e$, side of head. U.S.N.M. No. 65715, from Samaná and Laguna, Dominican Republic. Natural size.

their inner borders well separated on the median line; head moderate, without ridges; snout pointed, terminating in a very prominent, heavy, shovellike ridge, which at its greatest width is one-half the diameter of the eye; nostril much nearer end of snout than eye, its distance from the eye equaling diameter of latter; upper eyelid about three-fourths the interorbital width; canthus rostralis distinctly marked, canthal region concave; tympanum equal to four-fifths the diameter of the eye, its distance from the eye about one-fourth its own diameter; disks of fingers and toes small, disk of third finger about one-third the diameter of the tympanum, of fourth toe smaller yet; first finger as long as second; toes and fingers with only a vestigial web; first toe moderately long, reaching nearly to the disk of second toe; fifth toe considerably longer than third; subarticular tubercles well developed; two metatarsal tubercles, the outer very weak and scarcely perceptible, the inner elongate and fairly prominent; a few small 
palmar and plantar tubercles; no tarsal ridge or fold; the bent limbs being pressed along the sides, the knee and elbow overlap; the hindlimbs being adpressed, the heel reaches to between the eye and the nostril; the hind limbs being placed vertically to the axis of the body, the heels considerably overlap; skin of upper parts fairly smooth, with some scattered glandules on the back, especially concentrated on the lumbar region and on the sides; a faint dorsal ridge; a heavy glandular dorsolateral fold not extending forward beyond the level of the axilla; a semicircular series of small glands over the ear and ending below and behind it; a diagonal lateral series of elongate glands beginning in front of the dorsolateral fold and extending downward and backward on the side to about one-third the distance from axilla to groin; skin of throat and chest very faintly granular, of belly and lower posterior aspect of thighs heavily granular, the remaining skin of lower surfaces of legs and of arms being quite smooth; an external vocal sac (in the male) at the center of the throat, the loose skin terminating in some transverse folds across the chest.

Dimensions: Snout to vent, $47 \mathrm{~mm}$.; width of head, $19 \mathrm{~mm}$.; diameter of eye, $5.5 \mathrm{~mm}$; diameter of tympanum, $4.5 \mathrm{~mm}$.; greatest width of shovel on snout, $3 \mathrm{~mm}$.; foreleg from axilla, $30 \mathrm{~mm}$.; hindleg from vent, $72 \mathrm{~mm}$.; vent to heel, $44 \mathrm{~mm}$.

Color (in alcohol): Upper parts vinaceous-buff to olive-buff; a wide clove-brown interorbital bar; a sharply marked clove-brown streak along the canthus rostralis from nostril to eye; lower canthal region suffused with brown; a few brown bars on upper lip, a heavier one coming below the eye; a black crescentic mark above the ear, and a similar crescentic mark paralleling it above the shoulders on the back; the dorsolateral fold and the short diagonal glandular lateral fold also marked with clove-brown; back covered with large, roundish, dark spots, a pair of which are especially large and conspicuous on each side of the back just anterior to the lumbar region; limbs with very distinct brown cross bars; the upper posterior aspect of the femur with a coarsely reticulate pattern of dark and light; lower part of hindleg suffused with brown; a light stripe bordered by an irregular dark stripe along the posterior tibia and outside of foot, and a similar dark stripe along the arm and hand; skin of lower parts of body immaculate olive-buff.

Variations.-In our series of 19 frogs there are no young individuals; hence I cannot say what variation occurs in the early periods. The adults are very uniform in color pattern, although in some cases a darker body color prevents the pattern from being so evident as in the light clay-colored ones. The only noteworthy deviation from the described specimen is in the amount of clouding of the ventral surface, which in a few of the specimens, males probably, extends over the chin and throat, to a lesser extent onto the belly and very heavily on the 
lower surfaces of the limbs. In proportions the species is very stable. The shovel is slightly more developed in some cases than in others, while the head may often be broader in relation to its length than in the described specimen. The small glands below and behind the ear are usually quite prominent and are often distinctly yellowish in color, in sharp contrast to the semicircular black ear-patch that limits their upper border.

The species attains a comparatively large size, our largest specimens (U.S.N.M. Nos. 65712 and 65714 ) totaling $53 \mathrm{~mm}$. from snout to vent.

Relationships.-Dr. Noble indicates the relationship of this species to Eleutherodactylus inoptatus, and the one suggests the other in many respects while differing in some details. The habitus of both is more Leptodactylus-like than is the case in most other members of the large genus Eleutherodactylus. In essential color pattern, in the presence of a dorsolateral fold and a subsidiary diagonal row of glands on the sides, and in the relative proportions of the toes the two species are similar. But the absence of a tubercle on the eyelid and the presence of the conspicuous shovel on the snout, as well as its much smaller adult size, distinguish ruthae readily enough from its large relative. Specimens examined.-As listed in table 8.

TABLE 8.-Specimens of Eleutherodactylus ruthae examined

\begin{tabular}{|c|c|c|c|}
\hline Museum No. & Locality & Date & Collector \\
\hline U.S.N.M. & & & \\
\hline $65710-65713 \ldots \ldots$ & Jovéro, D. R & Feb. 4, 1923,...... & W. L. Abbott. \\
\hline $65714-65720$ & Samaná and Laguna, D. R & March 1923 & Do. \\
\hline $66767-65769$ & Samsná Peninsula, D. R & 1923 & Do. \\
\hline 66978,66979 & do & February 1924 & J. King. \\
\hline $74597-74599$ & Río San Juan, D. R & March $1928 \ldots . . . .$. & G. S. Miller, Jr. \\
\hline M.C.Z. & Samaná, D. R . . . & Nov. $8,1922 \ldots . .$. & J. King. \\
\hline
\end{tabular}

\section{ELEUTHERODACTYLUS JUGANS Cochran}

FIGURE 9

1935. Leptodactylus darlingtoni Cochran, Proc. Boston Soc. Nat. Hist., vol. 40, No. 6, p. 372 (part).

1937. Eleutherodactylus jugans Cochran, Journ. Washington Acad. Sci., vol. 27, No. 7, p. 312.-Barbour, Bull. Mus. Comp. Zool., vol. 82, No. 2, p. 98, 1937.

Diagnosis.-Toes without distinct dermal margins; tongue ovoidal, not nicked posteriorly; tympanum equals width of eye; vomerine teeth in two exceedingly heavy, slightly curved series, almost meeting in the center behind the choanae and extending laterally beyond the choanae about one-third their own length; snout short, projecting at the tip, depressed, without a distinctly sharp edge; hindlegs extremely short, 
tibiotarsal articulation barely reaching shoulder when legs are adpressed; ventral surface sepia, coarsely reticulated with white; numerous white dots on throat, chest, and lower surfaces of limbs.

Type.-M.C.Z. No. 19852, an adult from near La Visite, La Selle Range, Haiti, altitude between 5,000 and 7,000 feet, collected September 16 to 23,1934 , by P. J. Darlington.

Description of the type.-Vomerine teeth in two exceedingly heavy, slightly curved series, almost meeting in the center behind the choanae and extending laterally beyond the choanae about one-third their own length; tongue large, ovoidal, not nicked behind; snout

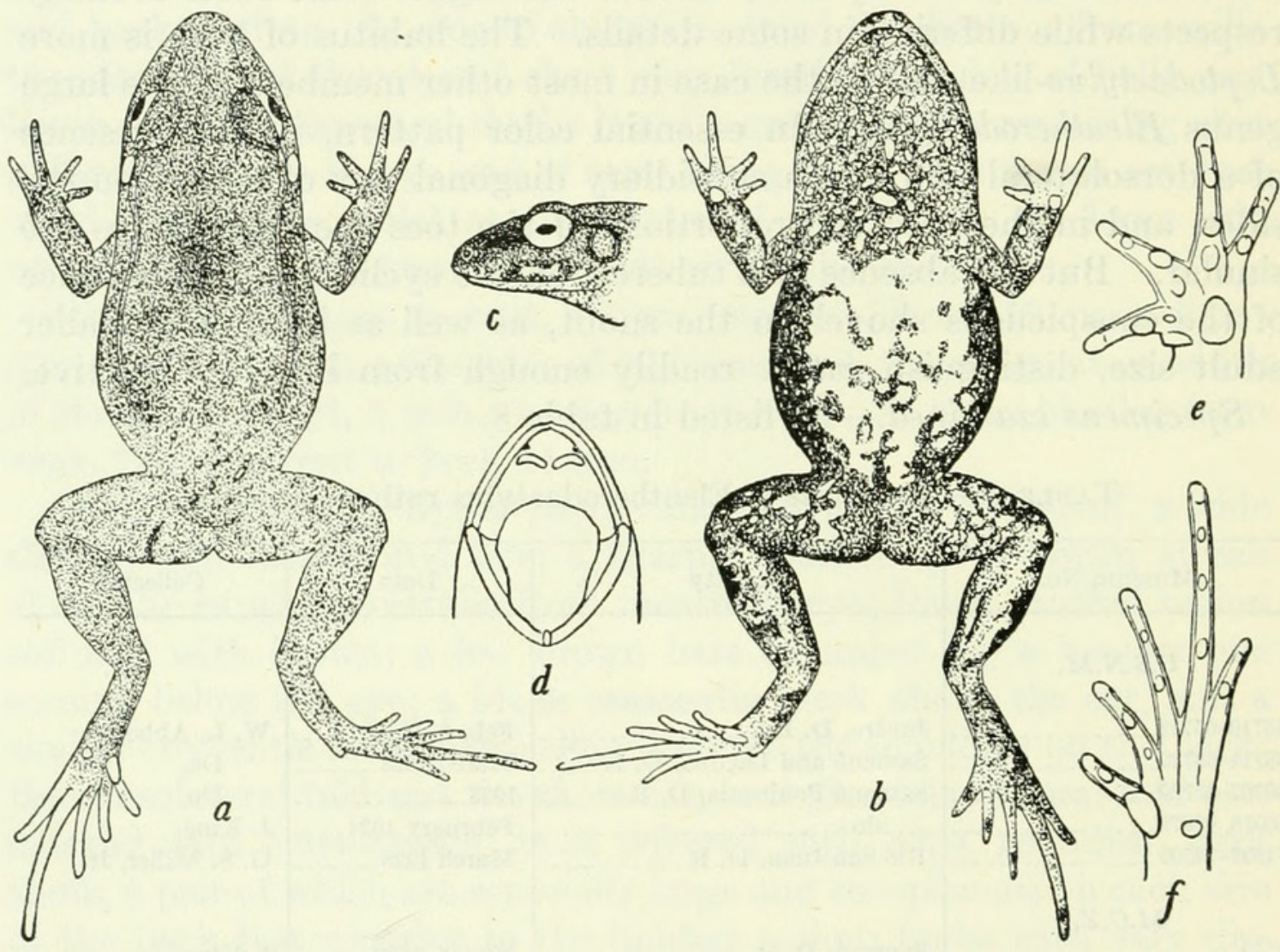

Figure 9.-Eleutherodactylus jugans: $a$, Dorsum; $b$, venter; $c$, profile of head; $d$, inside of mouth; $e$, underside of hand; $f$, underside of foot. U.S.N.M. No. 95425, paratype, from near La Visite, Haiti. One and one-half times natural size.

short, projecting at the tip, depressed, without a distinctly sharp edge; canthus rostralis sharp, prominent, the loreal region distinctly concave; nostrils twice as far from eye as from end of snout; tympanum higher than long, its greatest diameter equaling width of eye; interorbital space one and one-half times the width of upper eyelid; first finger shorter than second, which is slightly shorter than fourth; toes very slightly webbed at base, third much longer than fifth; subarticular tubercles well developed; numerous smaller tubercles in series on the sole; two metatarsal tubercles, the inner almost as long as the inner toe; no tarsal fold; heels just touching when hind limbs are folded at right angles to axis of body; hindlegs extremely short, tibio- 
tarsal articulation barely reaching shoulder when legs are adpressed; skin of the back almost smooth anteriorly, but with numerous glands and pustules on the flanks, on the sacrum, and on the upper surfaces of the legs; a narrow glandular lateral fold originating behind the eye, continuing over the ear and disappearing on the sides midway to the groin; skin smooth on chin and chest, coarsely granular on abdomen, finely granular on lower surface of thighs; traces of an external vocal sac; ventral disk very indistinctly marked.

Dimensions: Tip of snout to vent, $33 \mathrm{~mm}$.; tip of snout to posterior edge of tympanum, $12 \mathrm{~mm}$.; greatest width of head, $14 \mathrm{~mm}$.; foreleg from axilla, $16 \mathrm{~mm}$; hindleg from vent to heel, $22 \mathrm{~mm}$.; hindleg from vent to tip of fourth toe, $38 \mathrm{~mm}$.

Color (in alcohol): Dorsal surface seal brown, the limbs drab with very definite dark cross bands; a very narrow, crooked, pale dorsal line from between the eyes to the vent where it divides and continues on the posterior femur; ventral surface dark drab, very heavily mottled with coarse white spots, which become finer and farther apart on the chin, lips, and lower surfaces of the limbs.

Paratypes.-Topotypes (M.C.Z. Nos. 19853-19857 and U.S.N.M. Nos. 95423-95427), including young.

\section{ELEUTHERODACTYLUS VENTRILINEATUS (Shreve)}

Figure 10

1936. Leptodactylus ventrilineatus Shreve, Proc. New England Zool. Club, vol. 15, p. 98 .

Original description.- "Type, Museum of Comparative Zoölogy, no. 19,857 , an adult female, from Mt. La Hotte, 5,000 ft. to summit, Haiti, collected by P. J. Darlington in October 1934.

"Paratypes: Museum of Comparative Zoölogy, nos. 19,858-19,863, with the same data and history as the type.

"Diagnosis.-Probably most closely related to Leptodactylus darlingtoni $i^{3}$ from which it differs in the shape and position of the vomerine teeth, in its less swollen tips of the digits, and in the ventral coloration. Also this form does not seem to grow as large as darlingtoni.

"Description.-Tongue suboval, not nicked behind; vomerine teeth in two very short, oval, oblique groups behind and between the outer edges of the choanae; snout obtuse, longer than the diameter of the eye; canthus rostralis rather rounded, fairly distinct; loreal region slightly concave and decidedly oblique; nostril nearer tip of snout than eye; interorbital space broader than upper eyelid; tympanum distinct, about two thirds the diameter of the eye; tips of digits very feebly swollen; length of first finger equal to that of second, or first very slightly longer than second; first toe decidedly shorter than second;

${ }^{3}$ See Eleutherodactylus jugans Cochran, page 33. 
toes practically unwebbed at base; two metatarsal tubercles, inner rather elongate and prominent; the tibiotarsal articulation of the adpressed hind limb reaches to the shoulder (between the shoulder and tympanum in the paratypes); smooth above; sides granular; smooth below except for sides of belly.

"Coloration in alcohol.-Very dark brown, almost black, above; below dark brown, but considerably lighter than the dorsal coloration, densely covered with irregularly shaped white spots; medially the spots tend to be elongate and to arrange themselves to form a broken

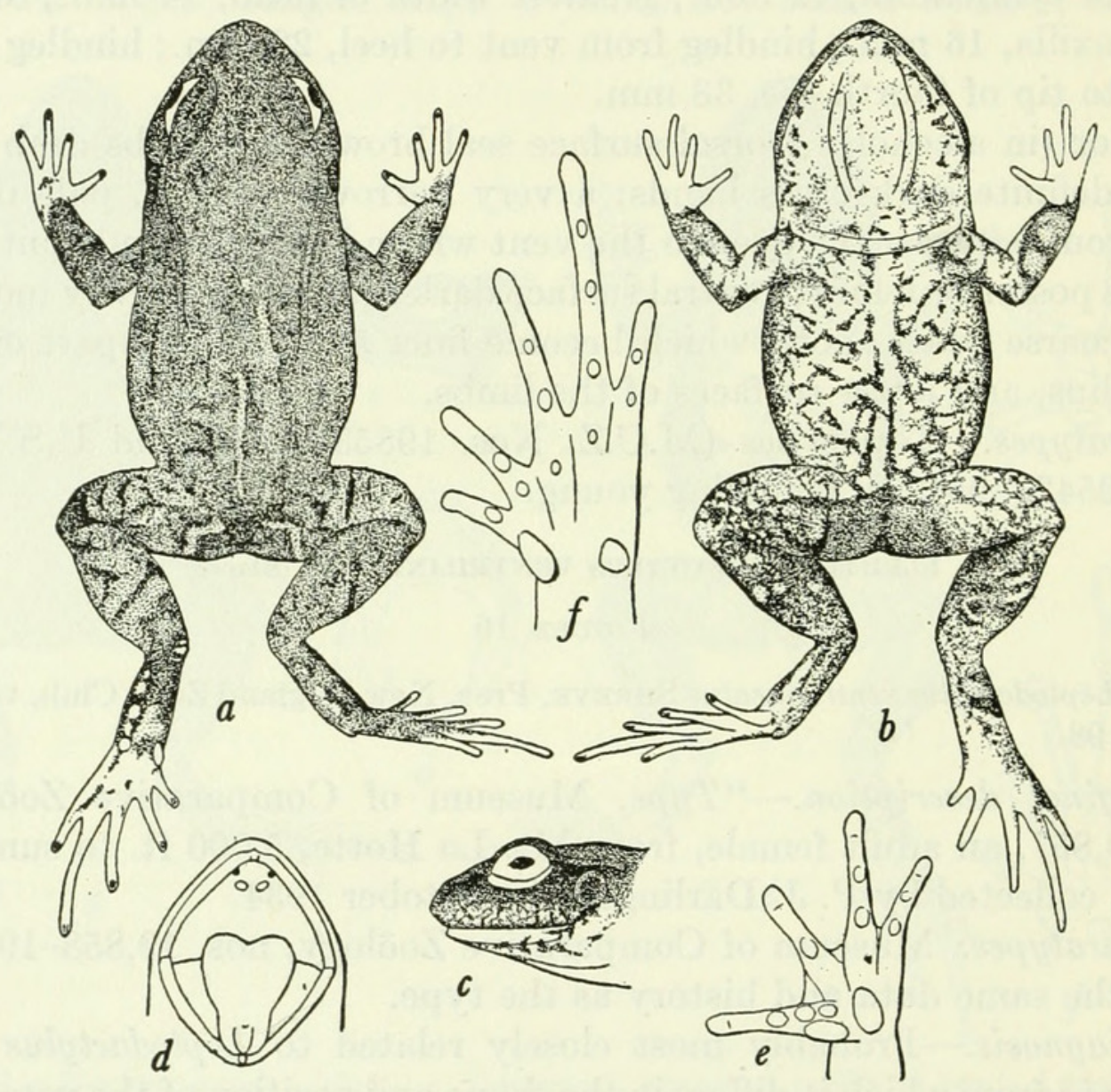

Figure 10.-Eleutherodactylus ventrilineatus: $a$, Dorsum; $b$, venter; $c$, profile of head; $d$, inside of mouth; $e$, underside of hand; $f$, underside of foot. U.S.N.M. No. 95429, from Morne La Hotte, Haiti. $a-d, \times 1 \frac{1}{2} ; e, f, \times 3$.

line starting on the under side of the lower jaw and extending almost to the hindleg.

"In the paratypes the lower side of the under jaw (except in no. $19,863)$ is whitish, marked more or less with the brown of the ventral ground color; the ventral median line may or may not extend onto the head. Also the ventral spots in some paratypes tend to run together. The paratypes also show whitish on the hands and feet, and may also show patches of the same color under the femur and under the fore limbs. The smallest paratype, No. 19,863, shows but little evidence of the ventral median line. This median ventral line, which seems 
to be plainly evident in all but the very young of this new species, appears to be absent or very short and ill defined in darlingtoni [i. e., jugans]. Also the ventral markings of darlingtoni are usually longer and more confluent than in ventrilineatus.

\begin{tabular}{|c|c|c|c|c|}
\hline \multicolumn{5}{|c|}{ “Measurements } \\
\hline & $\begin{array}{l}\text { Length of head } \\
\text { and body }\end{array}$ & Head & Hind limb & 4th toe \\
\hline $\begin{array}{l}\text { Type, no. } 19,857 \\
\text { Paratypes, nos. } 19,858-19,863\end{array}$ & $\begin{aligned} 31 \mathrm{~mm} . \\
29-16 \mathrm{~mm} \text {. }\end{aligned}$ & $\begin{aligned} & 11 \mathrm{~mm} \text {. } \\
& 11-6 \mathrm{~mm}\end{aligned}$ & $\begin{aligned} 37 \mathrm{~mm} . \\
35-20 \mathrm{~mm} .\end{aligned}$ & $\begin{array}{r}8 \mathrm{~mm} \\
7-4 \mathrm{~mm}\end{array}$ \\
\hline
\end{tabular}

"The type series of this new species was included by Miss D. M. Cochran as paratypes of her Leptodactylus darlingtoni (February 1935, Proc. Boston Soc. Nat. Hist., vol. 40, no. 6, p. 372)."

\section{ELEUTHERODACTYLUS FLAVESCENS Noble}

\section{Figure 11}

1923. Eleutherodactylus flavescens Noble, Amer. Mus. Nov., No. 61, p. 2; Nat. Hist., vol. 23, pp.114-115, 1923 (photographs).-Cochran, Proc. U. S. Nat. Mus., vol. 66, art. 6, p. 2, 1924.-Barbour and Loveridge, Bull. Mus. Comp. Zool., vol. 69, No. 10, p. 259, 1929.-BARвоUR, Zoologica, vol. 11, No. 4, p. 80, 1930; vol. 19, No. 3, p. 97, 1935; Bull. Mus. Comp. Zool., vol. 82, No. 2, p. 106, 1937.

Description.-U.S.N.M. No. 65697, an adult male from Laguna and Samaná, Dominican Republic, collected by Dr. W. L. Abbott in March 1923. Tongue broad, emarginate behind; vomerine teeth in two long, slightly oblique, widely separated patches behind and between the choanae, which are very far apart; head moderate, without ridges; nostril much nearer end of snout than eye, its distance from eye equaling diameter of latter; upper eyelid about three-fourths the interorbital space; tympanum equal to two-thirds the diameter of the eye, its distance from the eye a little less than half its own diameter; disks of fingers and toes large, notched; disk of third finger about four-fifths the greatest diameter of the tympanum, of fourth toe slightly smaller; first finger shorter than second, toes and fingers with the mere vestige of a web; first toe long, reaching to base of disk of second toe; fifth toe considerably longer than third; subarticular tubercles well developed; two metatarsal tubercles, the outer very small and weak, the inner elongate and fairly prominent; a few small palmar and plantar tubercules; a faint tarsal ridge, but no tarsal fold; the bent limbs being pressed along the sides, knee and elbow overlap; the hind limbs being adpressed, the heel reaches the tip of the snout; the hind limbs being placed vertically to the axis of the body, the heels barely overlap; skin of upper parts fairly smooth, with some small scattered glandules on the upper eyelids and snout and a row of larger ovoid glands down the sides from ear to groin; a faint dorsal ridge; no dorsolateral fold; skin of throat and lower surfaces of arms smooth; 
belly granular; a large patch of coarse granules on the posterior aspect of the thighs, the remaining skin of the legs being quite smooth; an external vocal sac at the center of the throat, the loose skin terminating in a transverse fold across the chest between the arms.

Dimensions: Snout to vent, $30 \mathrm{~mm}$; width of head, $11 \mathrm{~mm}$.; diameter of eye, $4 \mathrm{~mm}$; diameter of tympanum, $2.5 \mathrm{~mm}$; foreleg from axilla, $21 \mathrm{~mm}$; hindleg from vent, $52 \mathrm{~mm}$.; vent to heel, $31 \mathrm{~mm}$.

Color (in alcohol): Body color olive-gray to drab-gray above and below; an irregular clove-brown interorbital bar; canthus rostralis,

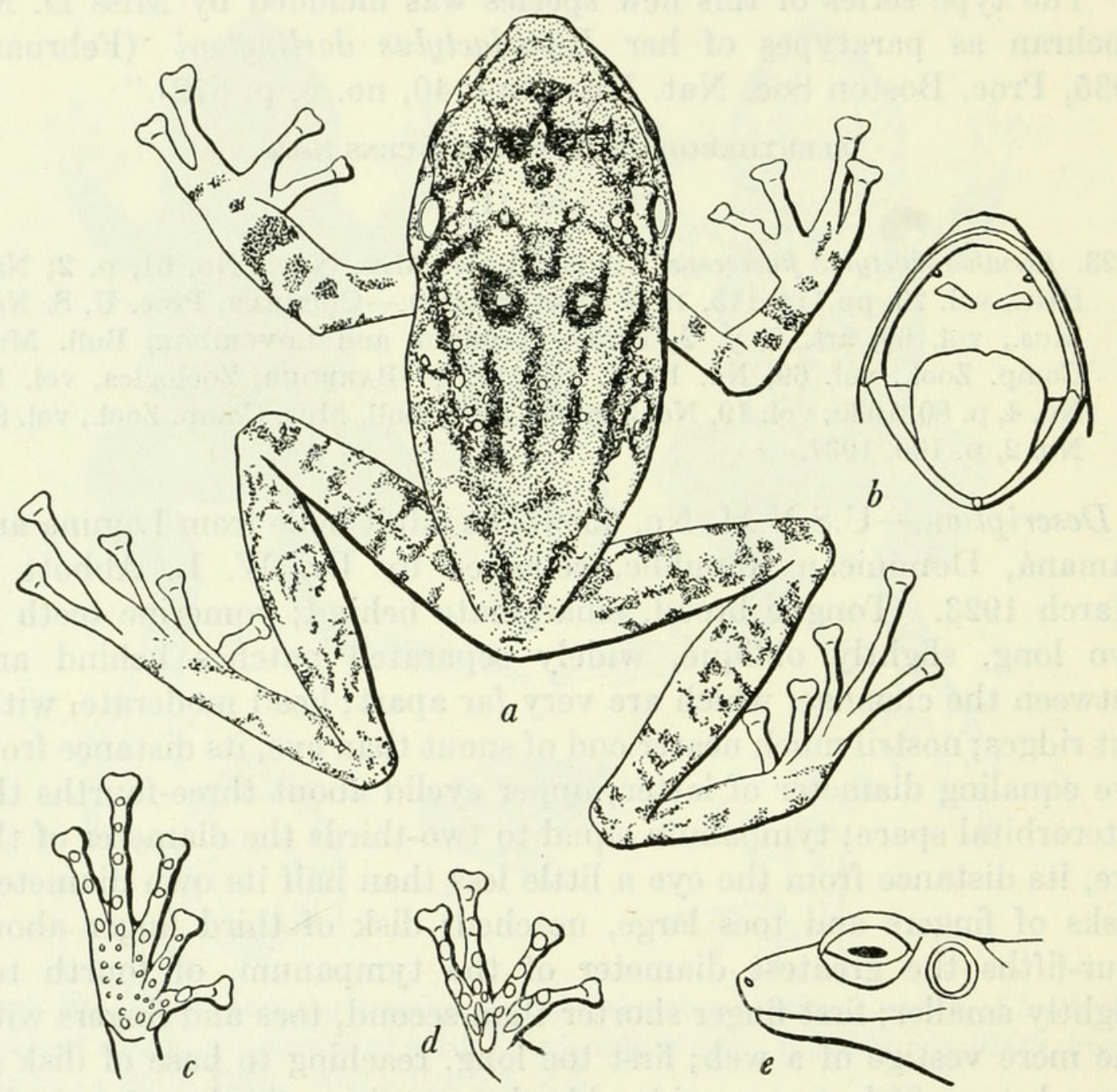

FigUre 11.-Eleutherodactylus flavescens: $a$, Dorsum; $b$, inside of mouth; $c$, underside of foot; $d$, underside of hand; $e$, side of head. U.S.N.M. No. 65697, from Samaná and Laguna. Dominican Republic. Twice natural size.

upper border of ear, center of back, and lateral regions with a more or less coarsely reticulated pattern of clove-brown; upper surfaces of arms and legs with irregular smaller spots of clove-brown, which do not make a definite cross-barred pattern except on the forearm; lower surfaces immaculate except for some spots around the edge of the lower jaw.

Variations.-The largest frog, U.S.N.M. No. 74959, measures 33 $\mathrm{mm}$. from snout to vent. The young have very wide heads in pro- 
portion to the rest of the body, and the color pattern is less pronounced. In some of the adults the body color is so dark that the pattern scarcely shows. In many frogs the chin and throat are mottled with a dusky reticulation, and the belly and thighs are frequently suffused with dark. A variation in the rugosity of the skin is apparent even in specimens preserved under identical conditions, as the glandules stand out on the back in some individuals with considerable prominence and the belly is heavily granular, while the back and belly seem nearly smooth in others. The heel reaches only to the anterior corner of the eye in a few frogs. The disks are conspicuously notched in all specimens, and the disk of the third finger in some frogs is large enough to conceal the tympanum.

TABLE 9.-Specimens of Eleutherodactylus flavescens examined

\begin{tabular}{|c|c|c|c|}
\hline Museum No. & Locality & Date & Collector \\
\hline U.S.N.M. & & & \multirow{10}{*}{$\begin{array}{l}\text { W. L. Abbott. } \\
\text { Do. } \\
\text { G. S. Miller, Jr. } \\
\text { Do. } \\
\text { Do. } \\
\text { P. J. Darlington. }\end{array}$} \\
\hline 65089 & Laguna, D. R & May $11,1922 \ldots .$. & \\
\hline $65697-65705 \ldots \ldots \ldots$ & Samaná and Laguna, D. R & March $1923 \ldots . . . .$. & \\
\hline $74643-74673 \ldots$ & Río San Juan, D. R & March $1928 \ldots . . . . .$. & \\
\hline 74959 & Boca del Infierno, D. R .......... & March 1928 & \\
\hline 74993-75000 & Samaná, D. R & Feb. 22, $1928 \ldots \ldots$ & \\
\hline M.C.Z. & $\begin{array}{l}\text { Mount Diego de O Campo, D. } \\
\text { R. }\end{array}$ & July $1938 \ldots$ & \\
\hline $\begin{array}{l}9393 \text { (paratype of } E \text {. flaves- } \\
\text { cens). }\end{array}$ & Lo Bracita, D. R & Aug. 3, 1922 .... & \\
\hline 23532-23533 & Sánchez, D. R . . & July $1938 \ldots$ & \\
\hline $23456-23460 \ldots$ & $\begin{array}{l}\text { Mount Diego de O Campo, D. } \\
\text { R. }\end{array}$ & July 1938_..... & \\
\hline
\end{tabular}

Relationships.-This is one of the easiest of all Eleutherodactyli to recognize, as the notched toes set it off from all other species except poolei. In many species of the genus, the terminal T-shaped bone of the distal phalanx tends to give a bilobed appearance to the toes in certain preservatives, which cause a shrinkage of the round disk, but this condition is not apparent in freshly preserved or living material, except in this species and poolei.

Specimens examined.-As listed in table 9.

\section{ELEUTHERODACTYLUS POOLEI Cochran}

FigURE 12

1938. Eleutherodactylus poolei Cochran, Proc. Biol. Soc. Washington, vol. 51, p. 93 .

Diagnosis.--Resembles Eleutherodactylus flavescens Noble in having notched digital dilations. Differs in having two small weak patches of vomerine teeth widely separated from each other, larger eyes, a smaller tympanum and more distinct color pattern. 
Type.-U.S.N.M. No. 73999, an adult male from the Citadel of King Christophe, Haiti, collected on February 14, 1928, by A. J. Poole. Paratypes, U.S.N.M. Nos. 74000-74005, with the same data.

Description of the type.- Tongue elongate, narrow, not emarginate behind; vomerine teeth in two short, weak, posteriorly converging, widely separated patches behind the choanae and between their inner levels; head moderate, without ridges; nostril almost at end of snout, its distance from eye a little less than diameter of latter; upper eyelid

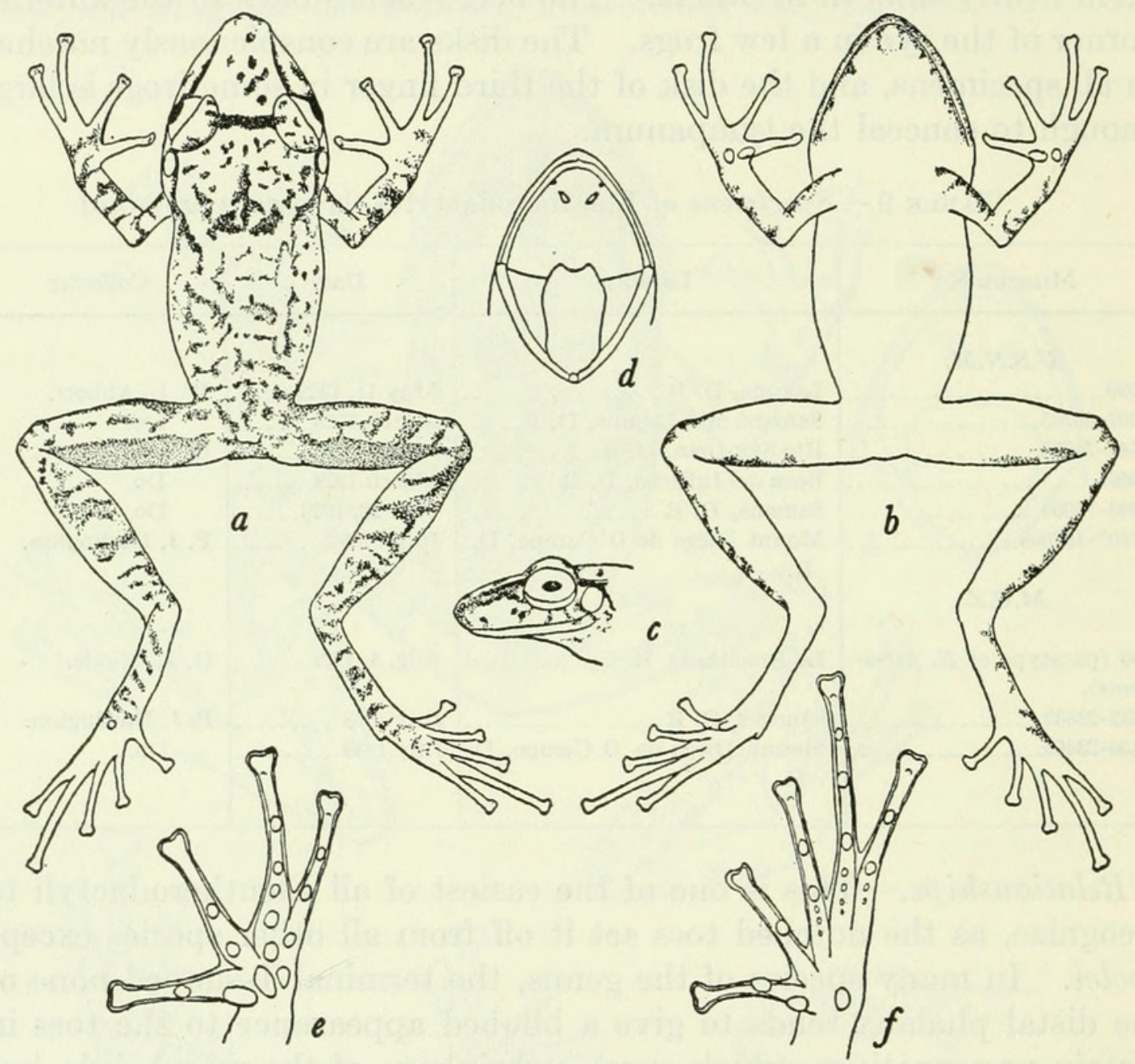

Figure 12.-Eleutherodactylus poolei: $a$, Dorsum; $b$, venter; $c$, profile of head; $d$, inside of mouth; $e$, underside of hand; $f$, underside of foot. U.S.N.M. No. 73999, type, from the Citadel of King Christophe, Haiti. $a-d, \times 1 \frac{1}{2} ; e, f, \times 3$.

broad, equal to interorbital diameter; tympanum equal to one-half the diameter of eye and nearly touching its posterior border; disks of fingers and toes large, notched; disk of third finger nearly as broad as the tympanum, of fourth toe about one-half this distance; first finger slightly shorter than second; toes and fingers unwebbed; first toe long, reaching to base of disk of second toe; fifth toe considerably longer than third; subarticular tubercles well developed; two small metatarsal tubercles, the inner oval, the outer round; a few small plantar and palmar tubercles; a distinct inner tarsal ridge; the bent 
limbs being laid along the sides, knee and elbow are slightly separated; the hind limbs being adpressed, heel reaches nearly to nostril; the hind limbs being placed vertically to axis of body, heels overlap. Skin of upper parts finely shagreened; a median dorsal ridge, less prominent on snout, fading out on sacral region; a glandular ridge over tympanum, and a very fine, branching glandular line just above and behind the shoulder on the side of the body, but no prominent dorsolateral fold; skin of throat and chest smooth; belly and lower surface of thighs minutely granular; an external vocal sac extending across the throat, marked by some small diagonal folds of skin in front of the shoulders when not inflated.

Dimensions: Snout to vent, $28 \mathrm{~mm}$; width of head, $10.5 \mathrm{~mm}$.; diameter of eye, $4.5 \mathrm{~mm}$.; diameter of tympanum, $2 \mathrm{~mm}$.; foreleg from axilla, $19 \mathrm{~mm}$; hindleg from vent, $46 \mathrm{~mm}$.; vent to heel, $27 \mathrm{~mm}$.; tibia, $15.5 \mathrm{~mm}$.; femur, $15 \mathrm{~mm}$.

Color (in alcohol): Dorsum clay color; a narrow chocolate interorbital bar not extending onto the upper eyelids; an irregular W-shaped brown mark behind the occiput, its outer terminations extending onto the posttympanic area; several small brown spots on the snout, and series of similar spots on the back tending to be arranged in short transverse rows; canthus rostralis with a brown stripe, spotted with deeper chocolate; upper lip light raw umber with indistinct dark and light spots; upper surfaces of tibia, foot, and forearm with brown cross bars; upper femur with the bars very indistinct, its posterior surface immaculate; ventral surface immaculate buff, except for some faint dark suffusions on the throat of the male.

Variations.-The five paratypes, all smaller than the type, differ only slightly. The adpressed hind limb reaches sometimes to the anterior corner of the eye, sometimes to the tip of the snout. The vomerine teeth are weak and short in all specimens. The dorsal ground color varies from buff to drab, but the dark pattern is remarkably constant. The dorsal skin is minutely shagreened in all but one specimen, in which it appears to be smooth.

Remarks.-This species differs from the flavescens of the Samaná region in having larger eyes, the eye diameter equaling twice that of the tympanum, while the vomerine teeth are strikingly weak in comparison. The pigment is likewise more distinctly concentrated in a definite pattern of spots on the dorsal surface in these frogs from the Citadel, and the light and dark areas stand out sharply, instead of being blurred and suffused into half tones, as is the case in practically all the frogs from the eastern part of the island.

Specimens examined.-As listed in table 10. 
TABLE 10.-Specimens of Eleutherodactylus poolei examined

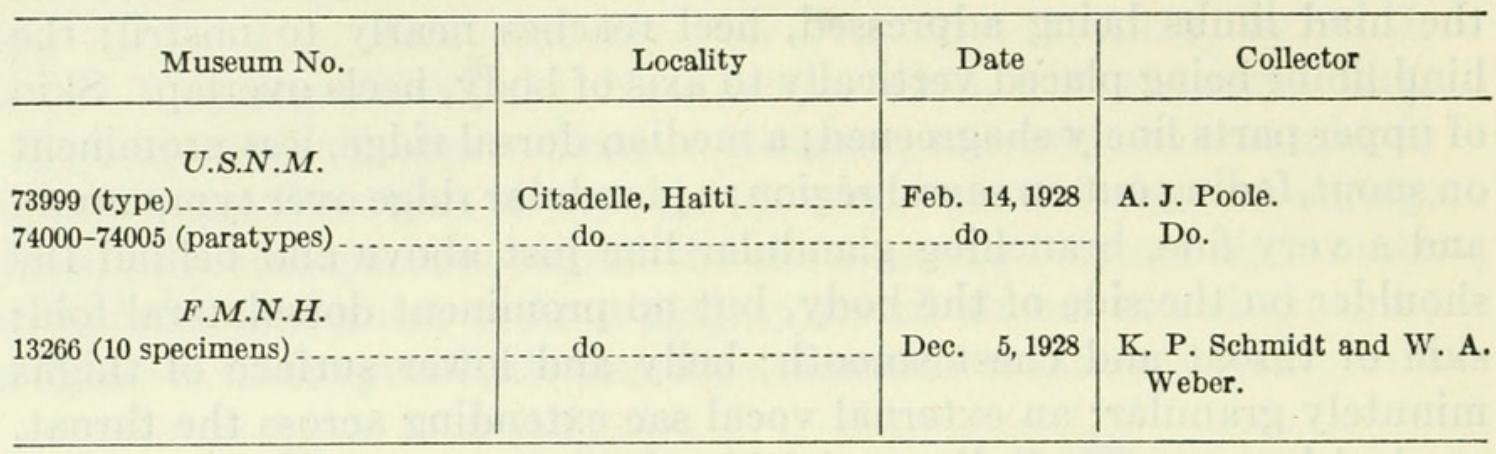

ELEUTHERODACTYLUS GLANDULIFER Cochran

Plate 10, A

1935. Eleutherodactylus glandulifer Cochran, Proc. Boston Soc. Nat. Hist., vol. 40, No. 6, p. 367.-Barbour, Bull. Mus. Comp. Zool., vol. 82, No. 2, p. $99,1937$.

Diagnosis.- Unlike any other West Indian Eleutherodactylus heretofore described in possessing large, compact, conspicuous glands above the arm, in front of the groin, and on the whole posterior surface of the femur. Belly and thighs almost smooth, with a few minute glandules on the belly and some very small granules apparent on the distal lower part of the thighs; upper eyelid without a spinelike tubercle; toes and fingers rounded at the tips; snout relatively long, rounded in profile, not shovel-shaped; tibiotarsal articulation reaching to end of snout; size large, $56 \mathrm{~mm}$. from snout to vent.

Type.-M.C.Z. No. 19851, an adult male from the north and east foothills of Massif de la Hotte, Haiti, between 1,000 and 4,000 feet, collected in October 1934 by P. J. Darlington.

Description of the type.- Tongue subcylindrical, moderately broad, not emarginate behind; vomerine teeth in two heavy, triangular, rather slanting patches behind the choanae, well separated in the midline and extending to the level of the outer margins of the choanae; head moderate, without ridges, its greatest width equal to distance from end of snout to occiput; no apparent subgular pouch or chest fold; nostril separated from eye by three times its distance from end of snout; upper eyelid about one-half the interorbital width; tympanum equal to one-half the diameter of the eye, its distance from the eye about equal to its own diameter; first finger slightly shorter than second, with a rudiment of a web between them; disks of fingers rather small, that of third finger scarcely covering one-quarter of the tympanic area; disks of the toes considerably smaller; toes long, with a very slight web; first toe reaching only to penultimate phalanx of second toe; subarticular tubercles well developed; two metatarsal tubercles, the outer small, the inner large and prominent; no plantar tubercles; a pronounced tarsal ridge; femur relatively long; the limbs being pressed along the sides, the knee and elbow slightly overlap; 
hind limb being extended forward, the heel reaches the tip of the snout; hind limbs being placed vertically to the axis of the body, the heels considerably overlap; a large, prominent, rectangular gland above the shoulder and another smaller one below it in front of the arm; a larger diamond-shaped gland on the flank in front of the hindleg; the largest and longest gland extending along the posterior part of the femur almost to the knee; no dorsolateral line of glands; skin above finely glandular, with very small elongate rows of glands anastomosing in every direction; traces of a median glandular line on top of snout, less noticeable on the back; throat and chest smooth; belly very faintly granular, thighs more heavily granular below the vent. The type is unique.

Dimensions: Tip of snout to vent, $56 \mathrm{~mm}$.; width of head, $20 \mathrm{~mm}$.; tip of snout to posterior tympanum, $20 \mathrm{~mm}$.; diameter of eye, 6.5 $\mathrm{mm}$.; foreleg from axilla, $34 \mathrm{~mm}$; hindleg from vent, $94 \mathrm{~mm}$.; vent to heel, $55 \mathrm{~mm}$.

Color in alcohol: Dorsal surface immaculate seal brown to Indian purple, becoming dark fawn color on the limbs, where faint lighter cross bands may be seen; the large gland above shoulder and in front of groin ochraceous, the femoral gland clay color; ventral suface olivebuff with pale indistinct suffusions on throat and chest, darker suffusions on lower surfaces of hindlegs; head without definite pattern except for a dull light and dark mottling on the upper lip; lower surfaces of hands and feet dark.

\section{ELEUTHERODACTYLUS DARLINGTONI Cochran}

FIGURE 13

1935. Eleutherodactylus darlingtoni Cochran, Proc. Boston Soc. Nat. Hist., vol. 40, No. 6, p. 368.-Barbour, Bull. Mus. Comp. Zool., vol. 82, No. 2, p. 93, 1937.

Diagnosis.-Similar to the species Eleutherodactylus glandulifer in possessing large, conspicuous glands above the arm, in front of the groin, and on the whole posterior surface of the femur. Differs from E. glandulifer in its much shorter and blunter snout, in the shorter toes with larger disks, in the shorter legs, and in its smaller size, 41 $\mathrm{mm}$. from snout to vent.

Type.-M.C.Z. No. 19847, an adult male from near La Visite, La Selle Range, Haiti, collected between September 16 and 23, 1934, at 5,000 to 7,000 feet altitude by P. J. Darlington.

Description of the type.-Tongue subcylindrical, rather broad, very slightly emarginate behind; vomerine teeth in two heavy, triangular, slanting patches behind the choanae, well separated in the midline and extending to the level of the center of the choanae; head blunt and short, without ridges, its greatest width considerably exceeding the distance from end of snout to occiput; no apparent subgular pouch or 
chest fold; nostril separated from eye by three times its distance from end of snout; upper eyelid about three-fifths the interorbital width; tympanum equal to two-thirds the diameter of the eye; its distance from the eye about four-fifths its own diameter; first finger much shorter than second; disks of fingers rather large, that of third finger nearly covering the tympanum; disks of toes somewhat smaller, about half the tympanic area; no webs between fingers or inner toes; toes relatively short, with a very slight web between fourth and fifth; first toe reaching to base of disk of second; subarticular tubercles well

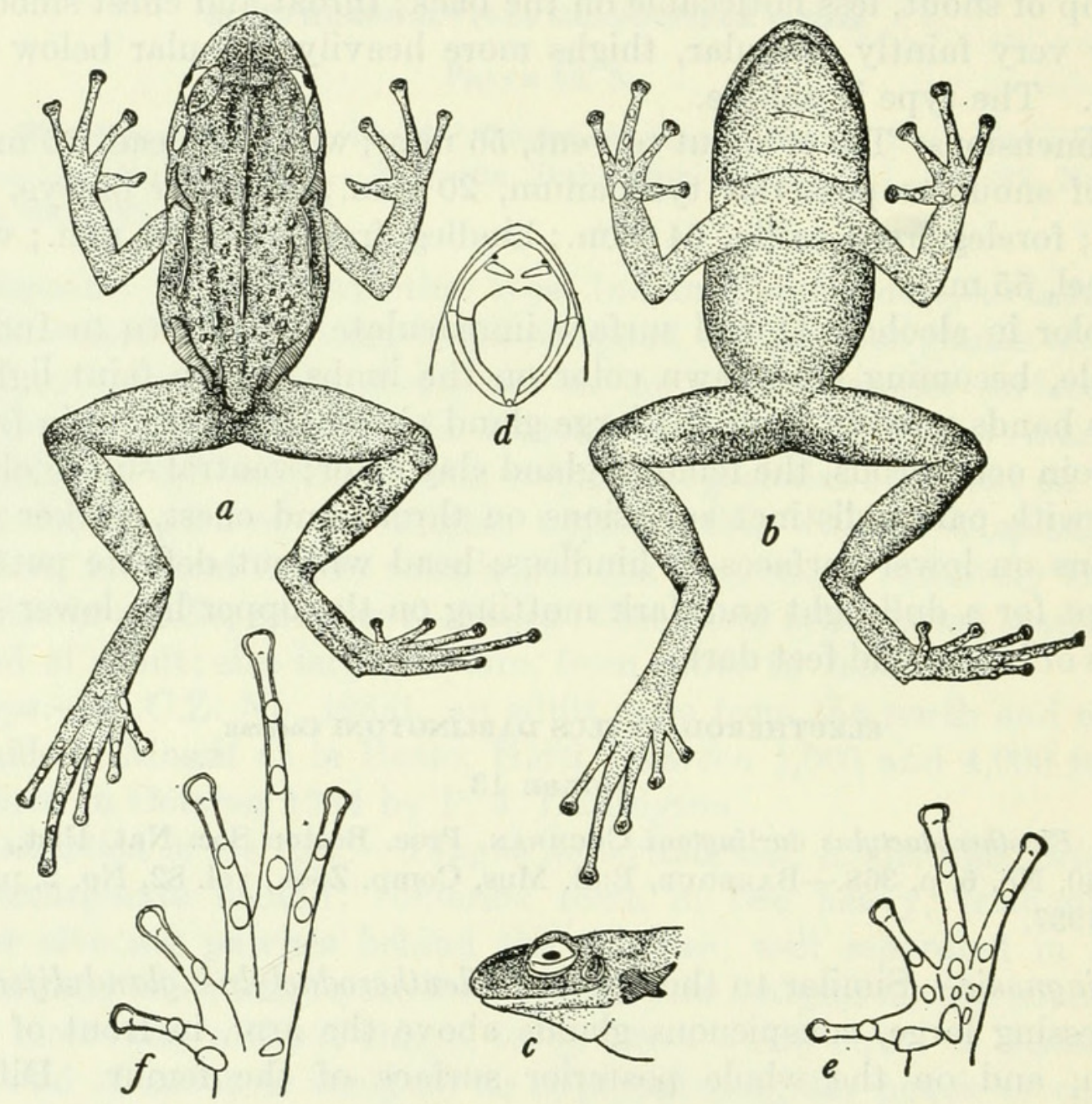

Figure 13.-Eleutherodactylus darlingtoni: $a$, Dorsum; $b$, venter; $c$, profile of head; $d$, inside of mouth; $e$, underside of hand; $f$, underside of foot. U.S.N.M. No. 95422, paratype, from near La Visite, Haiti. $a-d$, Natural size; $e, f$, twice natural size.

developed; two metatarsal tubercles, the outer small, the inner only a little more prominent than the subarticular tubercles; no plantar tubercles; a weak tarsal ridge; femur moderate in length; the limbs being pressed along the sides, the knee and elbow considerably overlap; hind limb being extended forward, the heel reaches the anterior corner of the eye; hind limbs being placed vertically to the axis of the body, the heels greatly overlap; a heavy triangular gland between shoulder and ear with a smaller round one below it; a larger oval one 
on the flank in front of the hindleg; a very elongate gland on the posterior surface of the femur; no pronounced dorsolateral line of large glands; skin above finely glandular, with very small elongate rows of glands anastomosing in every direction; a medium glandular line on top of snout, becoming less distinct posteriorly on the body; throat and chest smooth; belly very faintly granular, thighs more heavily granular below the vent.

Dimensions: Tip of snout to vent, $41 \mathrm{~mm}$.; width of head, $16 \mathrm{~mm}$.; tip of snout to posterior tympanum, $14 \mathrm{~mm}$.; diameter of eye, $4 \mathrm{~mm}$.; foreleg from axilla, $30 \mathrm{~mm}$.; hindleg from vent, $70 \mathrm{~mm}$.; vent to heel, $40 \mathrm{~mm}$.

Color in alcohol: Traces of a pale interorbital area followed by a dark transverse bar; dorsal surface immaculate seal brown to Indian purple, becoming dark fawn color on the limbs, on which there are traces of dark cross bands; large glands above shoulder and in front of groin touched with clay color, the femoral gland partly ochraceous; chin, belly and postanal region dark mouse gray; anterior surface of femur buff-pink with suffusions of olive-gray; remainder of lower surfaces of hindlegs and soles of feet and hands cream-buff also with gray suffusions; no pattern on side of head.

Paratypes.-Four other topotypic specimens (M.C.Z. Nos. 1984819850 and U.S.N.M. No. 95422) resemble the type rather closely. The smallest measures $33 \mathrm{~mm}$. from snout to vent. In two of them the glands are not very conspicuous, as the distinctive coloring is no longer present, but a careful examination shows the blisterlike outlines considerably flatter than in the type.

Named for Dr. Philip J. Darlington, the first zoologist to ascend Morne La Hotte.

ELEUTHERODACTYLUS GLANDULIFEROIDES Shreve

Plate 10, B

1936. Eleutherodactylus glanduliferoides Shreve, Proc. New England Zool. Club, vol. 15, p. 96.-BArbour, Bull. Mus. Comp. Zool., vol. 82, No. 2, p. 99, 1937.

Original description.- "Type, Museum of Comparative Zoölogy, no. 21,597, apparently a half-grown female, from near La Visite, La Selle Range, 5000-7000 ft., Haiti, collected by P. J. Darlington between September 16 and 23, 1934.

"Paratype: Museum of Comparative Zoölogy, no. 21,598, a juvenile specimen, with the same data and history as the type.

"Diagnosis.-Possibly most closely related to Eleutherodactylus glandulifer, from which it differs in shape of the snout, shape and position of the vomerine teeth, and in coloration. This new form is seen also to possess larger lateral glands in front of the groin, when compared with young glandulifer of a more or less similar size.

"Description.-Tongue subtriangular, not nicked behind; vomerine teeth in two short, oblique groups behind the choanae (indefinable 
in the paratype); snout subacuminate, longer than the diameter of the eye; canthus rostralis ill defined; loreal region concave, almost vertical; nostril nearer tip of snout than eye; interorbital space much broader than upper eyelid; tympanum fairly distinct (rather indistinct in the paratype), a bit less than half the diameter of the eye; digital disks small, disk of third finger about a third the diameter of the tympanum (about half in the paratype); first finger shorter than second; first toe shorter than second, toes unwebbed; two metatarsal tubercles; the tibio-tarsal articulation of the adpressed hind limb reaches the tympanum (reaches the posterior corner of the eye in the paratype); smooth above and below; a large diamond-shaped gland on each flank just in front of the hind limb; also an elongate gland on the rear of each femur, occupying about half its length and beginning near the knee, and, in addition to these, four more or less oval ill defined glands, two on each side, in front of, and near, the insertion of the fore limb (only the glands near the hind limb are discernible in the juvenile paratype).

"Coloration in alcohol.-Whitish brown or whitish above, marked with brown; a dark brown streak beginning at the tip of the snout, extending across the loreal region, through the eye, and along the side to the hind limb, this line becoming fainter and more broken posteriorly; a broad dorso-median brown band, darker on the edges, extending about half the length of the body, beginning about on a line with the eyes; a short dorso-lateral brown streak on each side between the median and lateral markings, joining or nearly joining posteriorly the lateral streak; elsewhere on dorsum brown markings, these rather irregularly placed; most of rear surface of femur dark brown; a narrow white dorso-median line, beginning at the tip of the snout, becoming obsolete posteriorly; a similar line on the rear of each femur and on the rear of each tarsus, which latter is also marked with dark brown; below white, dotted with dark brown, especially on the under side of femur; upper lip white; glands not differently marked.

"The coloration of the paratype is essentially the same as that of the type, the more important differences being that the short dorsolateral streaks are absent, the head is darker above, and the femoral, dorso-median, and tarsal white lines are rather faint, and the broad dorso-median streak is rather ill defined.

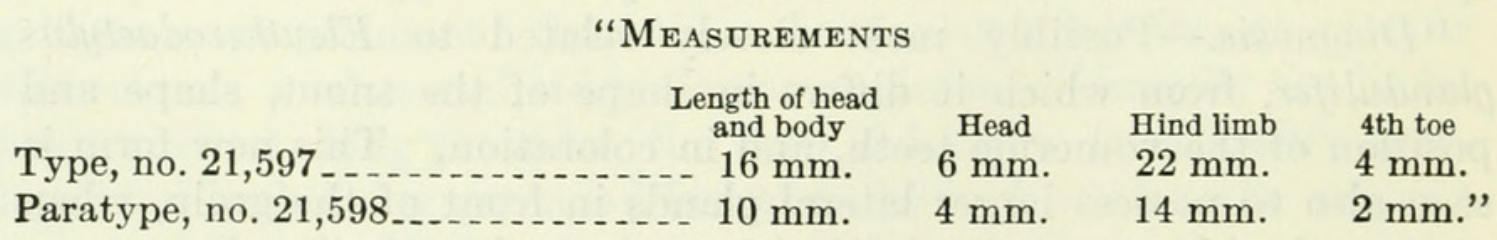




\section{ELEUTHERODACTYLUS MINUTUS Noble}

FigURE 14

1923. Eleutherodactylus minutus Noble, Amer. Mus. Nov., No. 61, p. 4; Nat. Hist., vol. 23, p. 116, 1923 (photograph).-BARBour and Loveridge, Bull. Mus. Comp. Zool., vol. 69, No. 10, p. 261, 1929.-BArbour, Zoologica, vol. 11, No. 4, p. 77, 1930; vol. 19, No. 3, p. 94, 1935; Bull. Mus. Comp. Zool., vol. 82, No. 2, p. 101, 1937.

Original description._-“'Type.-A.M.N.H. No. 11404; adult o; on ferns in dense palm thicket near Paso Bajito, Jarabacoa-Constanza Trail, Dominican Republic; September 4, 1922; G. K. Noble.

"Description of Type.- Head as long as broad, slightly narrower than body; distance between anterior corner of the eye and nostril less than the greatest diameter of the eye, about equal to the interor-
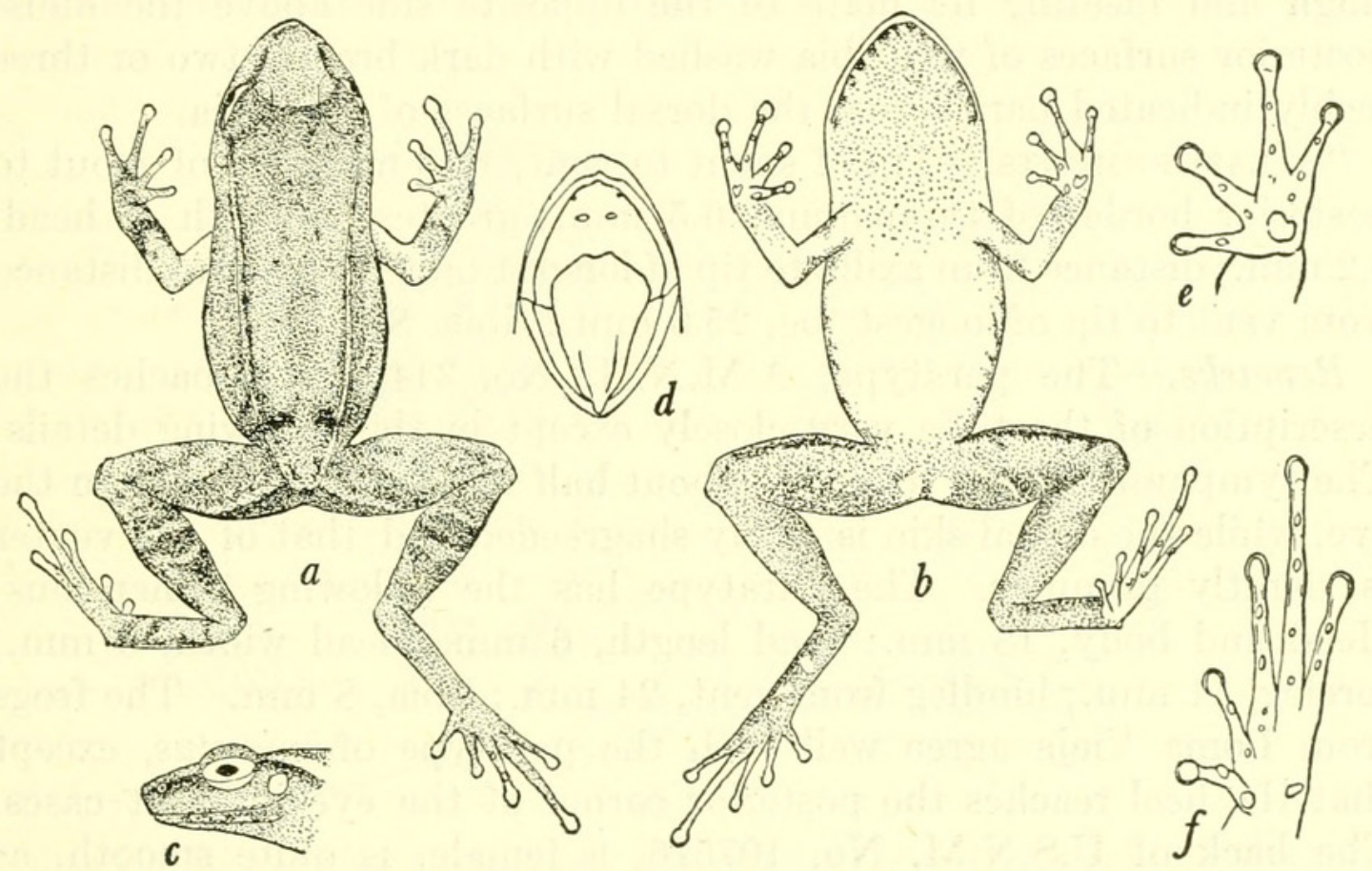

Figure 14.-Eleutherodactylus minutus: $a$, Dorsum; $b$, venter; $c$, profile of head; $d$, inside of mouth; $e$, underside of hand; $f$, underside of foot. A.M.N.H. No. 31406, paratype, from Paso Bajito, Dominican Republic. $a-d, \times 2 \frac{1}{8} ; e, f, \times 41 / 4$.

bital width; distance between the nostril and tip of the snout contained two times in the distance between nostril and eye; canthus rostralis very sharp, the loreal region concave; tympanum distinct; its diameter contained a little over two times in the diameter of the eye; separated from the eye by a space equal to three-fourths of its diameter. Tibio-tarsal joints of either side overlapping slightly when the legs are placed at right angles to the body; tibio-tarsal joint reaches the posterior border of the tympanum. Digital dilations very small, the dises equal to a third or a fourth of the greatest diameter of the tympanum; digits free, second toe slightly longer than the first; no tarsal fold; vomerine teeth in two small, oblique groups far 
behind the choanae and separated from each other by a wide space; tongue elliptical, unemarginate behind. Skin smooth above and below; a glandular dorso-lateral fold extending from the eye to lumbar region.

"Ground tone above flesh-color to pale gray, ventral surfaces slightly paler; a stripe of dark brown extending from the nostrils along the canthus rostralis to eye, broadening out behind the eye to form a conspicuous supra-tympanic crescent, another stripe of dark brown extending along the dorso-lateral fold to anus, the stripe interrupted at a number of points; sides of the body immediately below the dorso-lateral fold mottled or spotted with dark brown; the lower half of the sides feebly stippled with brown, posterior surfaces of the thighs dark brown, a narrow white line running obliquely across each thigh and meeting its mate of the opposite side above the anus; posterior surfaces of the tibia washed with dark brown; two or three feebly indicated bars across the dorsal surfaces of the tibia.

"Measurements.-Tip of snout to vent, $17.5 \mathrm{~mm}$.; tip of snout to posterior border of tympanum, $6.5 \mathrm{~mm}$.; greatest breadth of head, $6.2 \mathrm{~mm}$.; distance from axilla to tip of longest finger, $9.5 \mathrm{~mm}$.; distance from vent to tip of longest toe, $25.0 \mathrm{~mm}$.; tibia, $8.2 \mathrm{~mm}$."

Remarks.-The paratype, A.M.N.H. No. 31406, approaches the description of the type very closely except in the following details: The tympanum of the former is about half its own diameter from the eye, while the dorsal skin is finely shagreened and that of the venter is slightly granular. The paratype has the following dimensions: Head and body, $18 \mathrm{~mm}$; head length, $6 \mathrm{~mm}$; head width, $6 \mathrm{~mm}$.; foreleg, $11 \mathrm{~mm}$; hindleg from vent, $24 \mathrm{~mm}$; tibia, $8 \mathrm{~mm}$. The frogs from Loma Vieja agree well with the paratype of minutus, except that the heel reaches the posterior corner of the eye in most cases. The back of U.S.N.M. No. 107576, a female, is quite smooth, as that of the type is said to be, while that of the male, U.S.N.M. No. 107575 , is very faintly shagreened. The snout of the male is also a trifle shorter than those of the female and paratype. Their hindlegs measure 146 and 141 percent of the total length, respectively, and the tibia 44 percent of the total length in both, in which respects they are very close to the type and paratype. Further collecting should bring out interesting facts regarding the exact distribution of this species and its close relative intermedius from the same mountain range.

Specimens examined.-A.M.N.H. No. 31406, paratype, presumably a male, Paso Bajito, Dominican Republic, September 4, 1922, G. K. Noble; M.C.Z. Nos. 23515-23519, from Loma Vieja, Cordillera Central south of Constanza, Dominican Republic, August 1938, P. J. Darlington; U.S.N.M. Nos. 107575-107576, from Loma Vieja, same data. 


\section{ELEUTHERODACTYLUS WEINLANDI Barbour}

FIGURE 15

1914. Eleutherodactylus weinlandi Barbour, Mem. Mus. Comp. Zool., vol.44, No. 2, p. 246 (type locality, Puerto Plata, San Domingo).-Schмidt, Bull. Amer. Mus. Nat. Hist., vol. 44, art. 2, p. 8, 1921; Scientific Survey of Porto Rico and the Virgin Islands, New York Acad. Sci., vol. 10, pt. 1, pp. 29, 64, 1928.Cochran, Proc. U. S. Nat. Mus., vol. 66, art. 6, p. 1, 1924.-Barbour and Loveridge, Bull. Mus. Comp. Zool., vol. 69, No. 10, p. 264, 1929.-Barbour, Zoologica, vol. 11, No. 4, p. 76, 1930; vol. 19, No. 3, p. 92, 1935. 1923. Hylodes weinlandi Nieden, Das Tierreich, Anura I, p. 418.

1924. Eleutherodactylus schmidti Cochran, Proc. U. S. Nat. Mus., vol. 66, art. 6 , p. 2 (not of Noble).

1937. Eleutherodactylus lentus weinlandi Barbodr, Bull. Mus. Comp. Zool., vol. 82, No. 2, p. 99.

Description.-U.S.N.M. No. 65709, an adult from Las Cañitas, Dominican Republic, collected on February 27, 1923, by Dr. W. L.

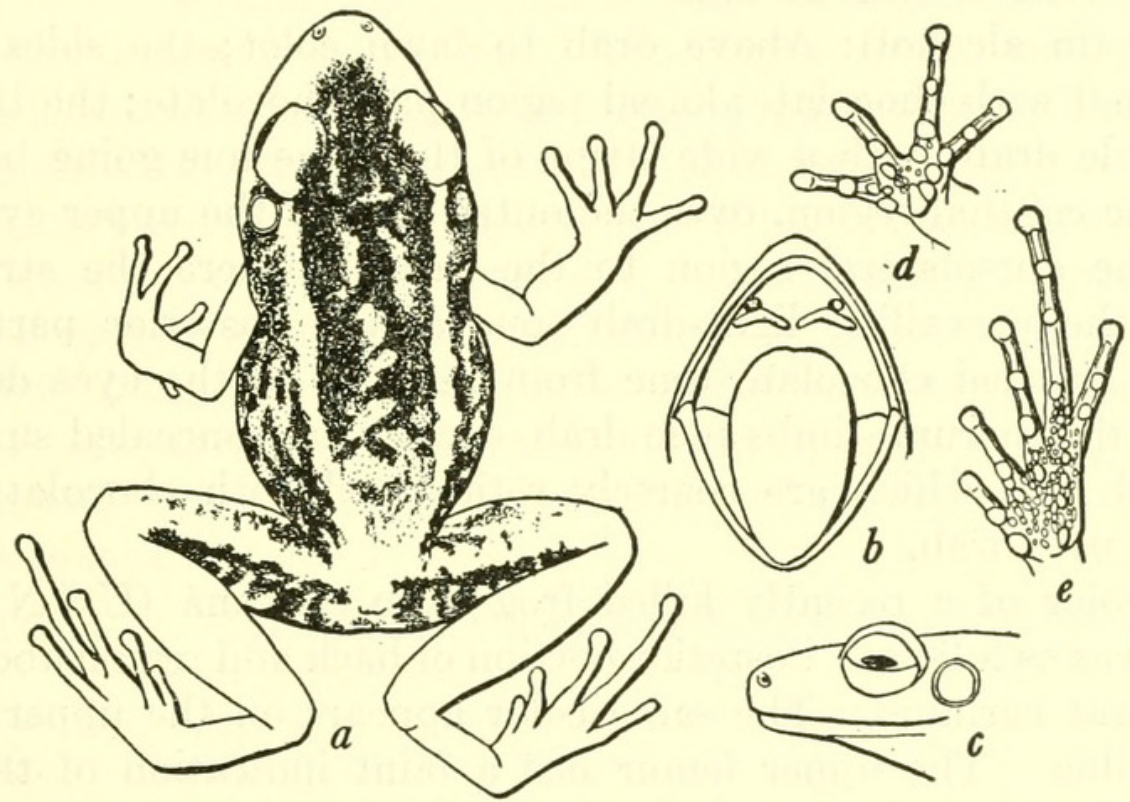

FIGURE 15.-Eleutherodactylus weinlandi: $a$, Dorsal view; $b$, inside of mouth; $c$, side of head; $d$, underside of forefoot; $e$, underside of hindfoot. U.S.N.M. No. 65709, from Las Cañitas, Dominican Republic. $a-c, \times 1 \frac{4}{5} ; d-\ell$, natural size.

Abbott. Tongue rather narrow and long, scarcely emarginate behind; vomerine teeth in two large chevron-shaped patches behind the choanae, their inner ends nearly meeting, their outer ends extending far beyond the choanae; head moderate, without ridges; nostril practically at the tip of the snout, its distance from the eye nearly equaling the diameter of the latter; upper eyelid much narrower than interorbital width, which equals the distance of the nostrils from each other; tympanum equal to two-thirds the diameter of the eye, its distance from eye equal to one-third its own diameter; disks of fingers small; first and second fingers subequal; toes with a vestigial web; disks of toes rather small, that of the fourth toe about one-third the diameter of the tympanum; first toe reaching to well beyond the distal subarticular tubercle of second toe; third toe slightly longer 
than fifth; subarticular tubercles well developed; two strong metatarsal tubercles; a number of small but distinct plantar tubercles; a very weak tarsal ridge; bent limbs being pressed along sides, knee and elbow overlap; hind limb being adpressed, the tibiotarsal articulation reaches the anterior corner of the eye; hind limbs being placed vertically to axis of body, the heels overlap considerably; no dorsolateral glandular fold; skin above shagreened, with scattered irregular glandules especially prominent on back and sides; a faint middorsal glandular ridge extending from in front of the eyes nearly to the anus; ventral surfaces smooth, excepting posterior aspect of femur, which is coarsely granular.

Dimensions: Tip of snout to vent, $26 \mathrm{~mm}$.; width of head, $12 \mathrm{~mm}$.; tip of snout to posterior border of tympanum, $12 \mathrm{~mm}$.; width of eye, $4.5 \mathrm{~mm}$.; width of tympanum, $2.5 \mathrm{~mm}$.; foreleg, $20 \mathrm{~mm}$.; hindleg, $48 \mathrm{~mm}$.; vent to heel, $28 \mathrm{~mm}$.

Color (in alcohol): Above drab to fawn color; the sides heavily reticulated with chocolate; loreal region pale chocolate; the tip of the snout pale drab, with a wide stripe of the same hue going backward along the canthal region, over the outer edge of the upper eyelid and along the dorsolateral region to the sacrum where the stripes are lost in the prevailing light-drab tone of the posterior part of the back; a mottled chocolate tone from in front of the eyes down the back to the sacrum; limbs pale drab, except the concealed surfaces of the hind legs, which are coarsely reticulated with chocolate; lower surfaces pale drab.

The color of a recently killed frog from Samaná (U.S.N.M. No. 74983) was as follows: Posterior portion of back and region above anus light burnt carmine. The same color appears on the upper portion of the tibia. The upper femur has a faint indication of this color toward the knee, but is mostly flesh color. The lateral light stripes anteriorly are light sulphur-yellow. The dark areas are deep chocolate.

Variations.-Its distinctive color pattern makes this frog one of the easiest to identify of all the Eleutherodactyli. There is practically no variation in the general placing of the pattern, and even the youngest frogs are as heavily marked as the adults. In some frogs the chocolate dorsal tone is somewhat more mottled in appearance and invaded posteriorly by the light ground tone. This is substantially the only noticeable variation. The nearly immaculate legs offer an unusual feature in this genus.

The largest specimen (No. 74630 from Río San Juan) measures 41 $\mathrm{mm}$. from snout to vent. From the same collection is a cluster of eggs taken on March 17, 1928. This bunch has 14 adhering eggs of two sizes-a few small ones $4 \mathrm{~mm}$. in diameter, the rest larger, measuring $6 \mathrm{~mm}$. In this latter group the head of theyoung frog is already well developed, and the remainder of the attenuated body may be seen 
coiled around the yolk. Another set of 15 eggs taken in March 1928 range in size from 5 to $7 \mathrm{~mm}$., and these show the tadpoles' bodies developing, with distinct limb buds and a flat tail.

Remarks.-The frog just described from Las Cañitas in the Dominican Republic differs from the description of the type in the following items: The tympanum is two-thirds the diameter of the eye and is separated from the eye by an interval equal to one-half its own diameter; the first toe is fairly long, reaching well beyond the distal subarticular tubercle of the second toe; there are many small plantar tubercles; the adpressed heel reaches to the anterior corner of the eye. The other specimens from the Dominican Republic likewise have the large tympanum close to the eye, and well-developed, small plantar tubercles. The first toe, however, shows a good deal of variation in its length, sometimes reaching midway on the antepenultimate phalanx of the second toe, sometimes only to the distal side of the subarticular tubercle at its base. The length of the hindleg varies also, sometimes having the heel reaching part way to the nostril, sometimes scarcely to the anterior border of the eye.

There are but two Haitian specimens at hand that can be referred to this species. One is in very poor condition and is recognizable only from its very distinctive vomerine teeth. The other, U.S.N.M. No. 60626, from Moron, has similar teeth and very small plantar tubercles. Its tympanum is small, measuring only one-half the eye diameter and separated from the eye by its own diameter, exactly as the type is said to have it.

TABLE 11.-Specimens of Eleutherodactylus weinlandi examined

\begin{tabular}{|c|c|c|c|}
\hline Museum No. & Locality & Date & Collector \\
\hline U.S.N.M. & & & \\
\hline 9856 & "San Domingo"' & & W. Gabb. \\
\hline 12147 & $\begin{array}{l}\text { Within } 25 \text { miles of Port-au- } \\
\text { Prince, Haiti. }\end{array}$ & 1866 & A. C. Younglove. \\
\hline $60626 \ldots \ldots$ & Moron, Haiti & Dec. $23,1917, \ldots .$. & W. L. Abbott. \\
\hline 65054 & Laguna, D. R & May $11-15,1922 \ldots$ & Do. \\
\hline $65706-65708 \ldots$ & Samaná and Laguna, D. R & March $1923 \ldots . . . .$. & Do. \\
\hline 65709 & Las Cañitas, D. R & Feb. 27, 1923 ..... & Do. \\
\hline 66980 & Samaná Peninsula, D. R ........ & February 1924 & J. King. \\
\hline $74624-74642 \ldots$ & Río San Juan, D. R & March 1928 & G. S. Miller, Jr. \\
\hline $74960-1$ & Boca del Infierno, D. R . ......... & March $1928 \ldots . . . .$. & Do. \\
\hline 74983-74992 & Samaná, D. R & Feb. 22, $1928 \ldots .$. & Do. \\
\hline \multicolumn{4}{|l|}{ M.C.Z. } \\
\hline 2050 (type) & Puerto Plata, D. R & $1881 \ldots . . . . .$. & M. A. Frazar. \\
\hline 3123 & Furcy, Haiti & $1913 \ldots$ & W. M. Mann. \\
\hline 23525 & $\begin{array}{l}\text { Mount Quita Espuela, Cord. } \\
\text { Cent., D. R. }\end{array}$ & July $1938 \ldots . . . . . . .$. & P. J. Darlington. \\
\hline $23526 \ldots$ & Puerto Plata, D. R & $\begin{array}{l}\text { Aug. 29-Sept. 2, } \\
1938 .\end{array}$ & Do. \\
\hline $23548-23550$ & 25 kilometers south of Puerto & June $10,1938 \ldots \ldots$ & Do. \\
\hline 22477 & $\begin{array}{l}\text { Plata, D. R. } \\
\text { Mount Isabel de Torres, D. R.. }\end{array}$ & & W. J. Clench. \\
\hline
\end{tabular}


A large series from the type locality, Puerto Plata, must be examined and compared with a series from Haiti and with those from the Dominican Republic to ascertain whether their differences are sufficient to warrant specific separation.

Specimens examined.-As listed in table 11.

ELEUTHERODACTYLUS RUFIFEMORALIS Noble and Hassler

FiguRe 16

1933. Eleutherodactylus rufifemoralis Noble and Hassler, Amer. Mus. Nov., No. 652, p. 4.-BArbour, Zoologica, vol. 19, No. 3, p. 94, 1935; Bull. Mus. Comp. Zool., vol. 82, No. 2, p. 101, 1937.

Original description.- "Diagnostic Characters.-A very small species, closely allied to E. minutus Noble from which it differs in its finely tubercular skin, its dark dorsal and ventral surfaces, and its distinctive thigh coloration. In life the concealed portions of the flexed thighs were red, while in alcohol these are yellow or pink.

“Detalled Description.-Type: A.M.N.H. No. 44556, male. Collected in a ravine above 'Salvation Station' on property of Luis E. del Monte, near Barahona, D. R., at an altitude of 3000 feet, August 4, 1932, by W. G. Hassler.

"Head as long as broad, a little broader than body; distance between anterior corner of the eye and nostril about four-fifths the greatest diameter of the eye, a trifle less than the interorbital width; distance between the nostril and tip of snout contained one and one-half times in distance between nostril and eye; canthus rostralis rounded, the loreal region flat; tympanum distinct, its diameter contained twice in the greatest diameter of the eye, separated from the eye by a space equal to two-thirds of its diameter. Tibiotarsal joints of either side make contact without overlapping when the legs are placed at right angles to the body, tibiotarsal joint extended forward reaches nearly to the anterior border of the eye. Digital dilations very small, the largest of the finger dilations equal to a third the diameter of the tympanum. Digits free; second toe a little longer than the first, no tarsal fold. Vomerine teeth in two oblique groups well behind the choanae and extending outward to about the middle of each opening. Tongue ovoid, not emarginate but extensively free behind. Skin finely tubercular above except for those portions of the skin which are concealed when the appendages are flexed. Ventral surfaces of the thighs, tibial and tarsal surfaces granular; sides of the body granular, but the belly and throat smooth.

"Dorsal surfaces of head and body (in alcohol) a dark chestnutbrown; an interorbital bar and some indication of a broad dorsolateral stripe slightly paler than the ground tone. An irregular bar of dark brown extending backward and ventrally on each side of the body from the ear to the groin; dorsally to this on each side a wedge-shaped 
bar of dark brown bordering the ilium; several spots of dark brown on the sides of the body and bars of the same color across the legs. Concealed portions of the thighs yellowish or slightly pink; posterior surfaces of the thighs below this area brown heavily spotted with dark brown. Ventral surface brown spotted with white, larger spots of white or gray on both upper and lower jaws.

"Dimensions.-Tip of snout to vent, $17.5 \mathrm{~mm}$.; width of head, 6.5 $\mathrm{mm}$; tip of snout to posterior border of tympanum, $6.3 \mathrm{~mm}$.; greatest diameter of eye, $1.5 \mathrm{~mm}$; diameter of tympanum, 1.1

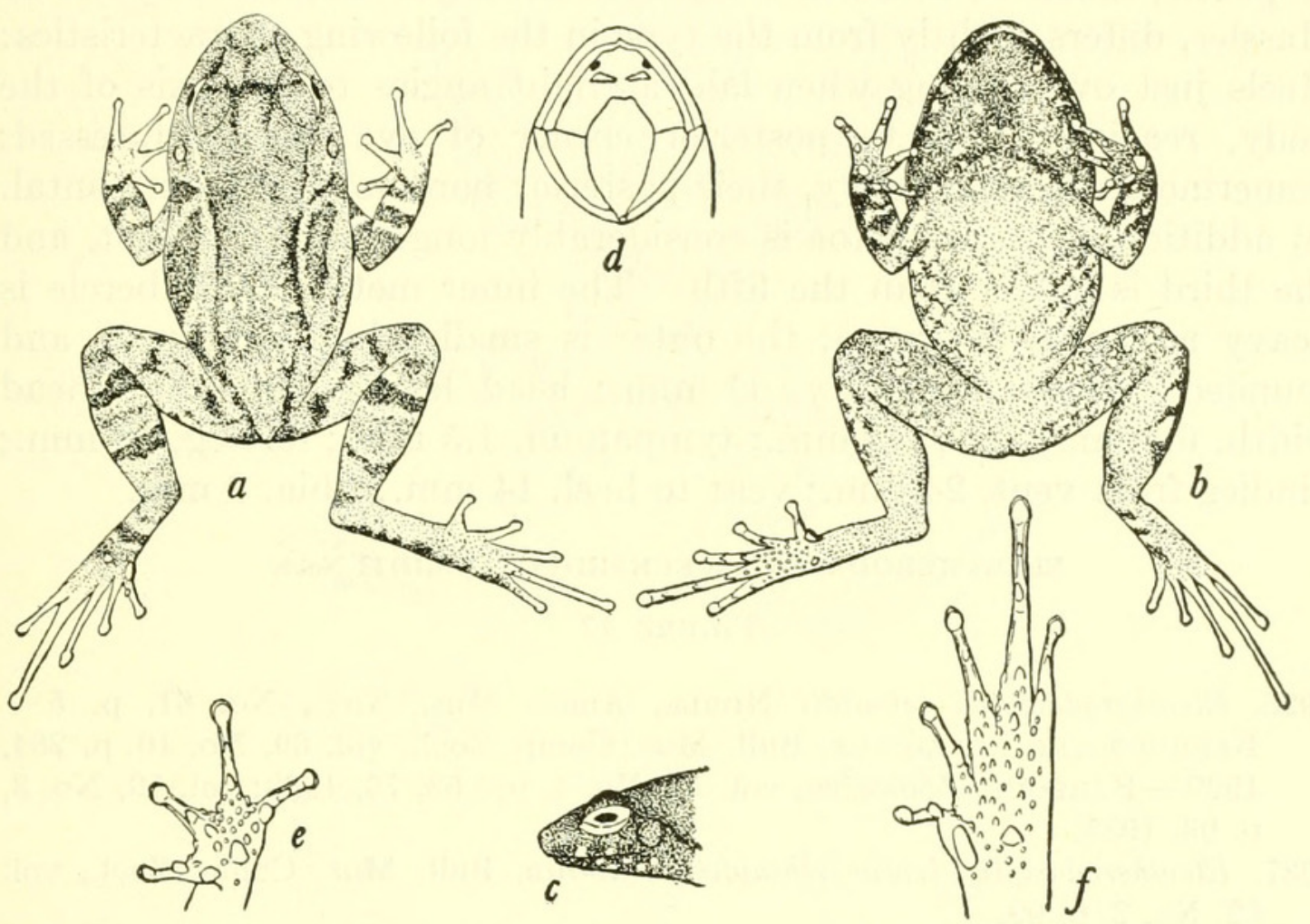

Figure 16.-Eleutherodactylus rufifemoralis: $a$, Dorsum; $b$, venter; $c$, profile of head; $d$, inside of mouth; $e$, underside of hand; $f$, underside of foot. A.M.N.H. No. 44631, paratype, from near Paradis, Dominican Republic. $a-d, \times 2 ; e, f, \times 4$.

$\mathrm{mm}$; foreleg from axilla, $11.5 \mathrm{~mm}$; hindleg from vent, $28 \mathrm{~mm}$; vent to heel, $15.5 \mathrm{~mm}$.

"Variation.-The seven paratypes in the series (A.M.N.H. Nos. $44557,44596,44628-31,44651$ ) vary both in color and in rugosity. In six (in alcohol) there is a distinct dorsolateral stripe of a pale tone and in several there is a series of dark-brown spots on the throat. The double stripe on the side of the body may be broken into spots, but there is always some indication of the upper stripe which borders the ilium. Three of the specimens appear to be nearly smooth above, but these are not so well preserved as the others.

"In life, the dorsal ground color was very dark, mottled with nearly black. The dorsolateral lines frequently formed crescents of dark golden-brown and were bordered above with black. The bar between 
the eyes was nearly black as were those on the legs. The concealed portions of the thighs were suffused with a rich reddish-brown. The ventral surfaces were brown spotted with white.

"НАвітат.- These tiny frogs are apparently widely spread throughout the mountains, though they are not abundant. Besides the type locality, they were found at 2400 feet near Paradis and at 3700 feet near Polo. As a rule they were among damp leaves and stones on the ground, but one was found at the base of a banana leaf."

A paratype, A.M.N.H. No. 44631, from near Paradis, Dominican Republic, taken at 2,400 feet altitude on August 25, 1932, by W. G. Hassler, differs slightly from the type in the following characteristics: Heels just overlapping when laid at right angles to the axis of the body, reaching only to posterior corner of eye when adpressed; vomerine teeth very heavy, their posterior borders nearly horizontal. In addition, the second toe is considerably longer than the first, and the third is longer than the fifth. The inner metatarsal tubercle is heavy and oval in shape; the outer is smaller but prominent and rounded. Head and body, $17 \mathrm{~mm}$; head length, $6.5 \mathrm{~mm}$; head width, $6.5 \mathrm{~mm}$.; eye, $2.5 \mathrm{~mm}$.; tympanum, $1.5 \mathrm{~mm}$.; foreleg, $10 \mathrm{~mm}$.; hindleg from vent, $24 \mathrm{~mm}$; ; vent to heel, $14 \mathrm{~mm}$; tibia, $8 \mathrm{~mm}$.

\section{ELEUTHERODACTYLUS SCHMIDTI SCHMIDTI Noble}

Figure 17

1923. Eleutherodactylus schmidti Noble, Amer. Mus. Nov., No. 61, p. 5.Barbour and Loveridge, Bull. Mus. Comp. Zool., vol. 69, No. 10, p. 264, 1929.-Barbour, Zoologica, vol. 11, No. 4, pp. 63, 76, 1930; vol. 19, No. 3, p. $93,1935$.

1937. Eleutherodactylus lentus schmidti Barbour, Bull. Mus. Comp. Zool., vol. 82, No. 2, p. 99.

Description.-An adult, F.M.N.H. No. 6910 (formerly A.M.N.H. No. A.20852), from Lo Bracita, Prov. Pacificador, Dominican Republic, collected on August 9, 1922, by Dr. G. K. Noble and R. C. Noble. Tongue broad, slightly emarginate behind; vomerine teeth in two heavy, slightly oblique groups, their anterior borders in contact with the posterior rim of the choanae, their inner borders narrowly separated from each other; head moderate, without ridges; nostril much nearer tip of snout than eye, separated from the eye by a distance equal to the diameter of the eye; upper eyelid equal to the interorbital width; tympanum about one-half the diameter of the eye, separated from it by almost its own diameter; disks of fingers relatively small, that of the third finger half as wide as the tympanum; first finger slightly shorter than second; disks of toes larger, that of the fourth toe nearly covering the tympanic membrane; first toe reaching to distal border of subarticular tubercle of second toe; fifth toe equal to the third in length; subarticular tubercles well developed; 
two metatarsal tubercles, the outer faintly discernible and very small, the inner moderately large and prominent; no tarsal fold; the bent limbs being pressed along the sides, knee and elbow overlap considerably; the hind limbs being adpressed, the heel reaches nearly to the nostril; the hind limbs being placed vertically to the axis of the body, the heels greatly overlap; skin of upper parts finely pustular, with a narrow median glandular ridge running from the snout to the anus, and a few less pronounced ones extending from the postoccipital

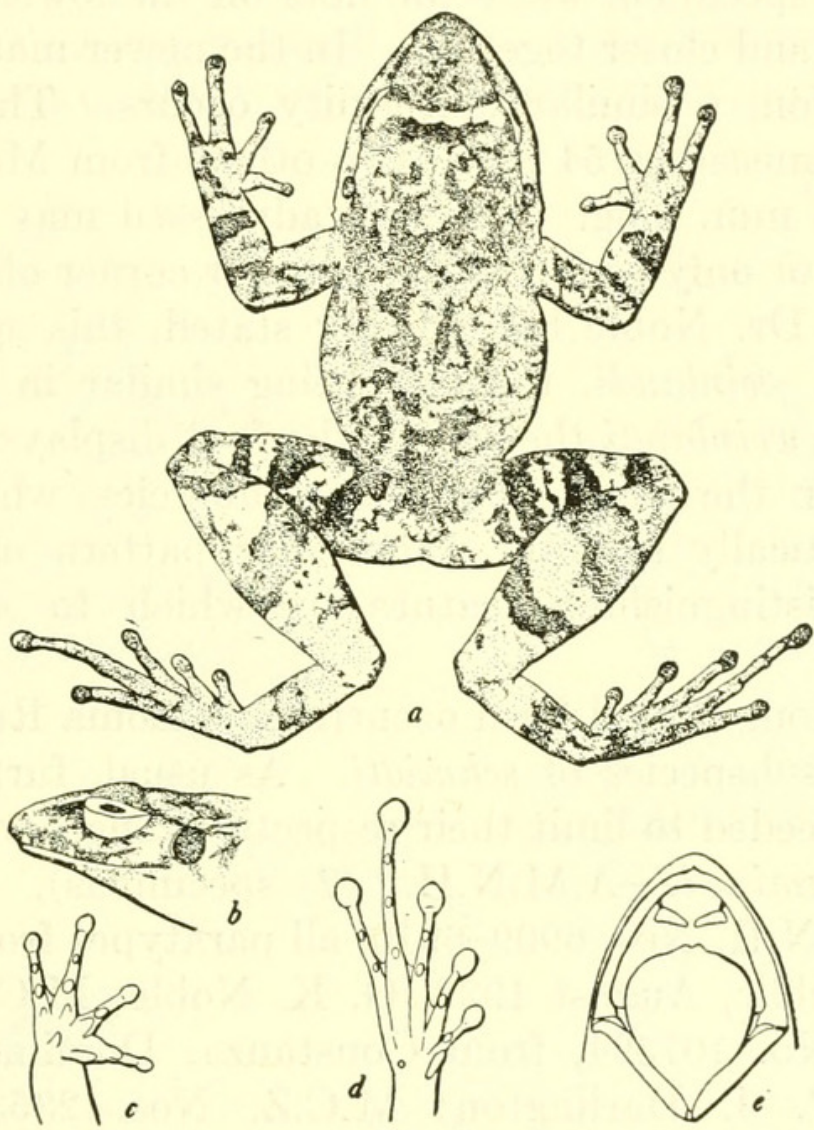

Figure 17.-Eleutherodactylus schmidti schmidti: $a$, Dorsal view; $b$, side of head; $c$, underside of forefoot; $d$, underside of hindfoot; $e$, inside of mouth. F.M.N.H. No.6910, paratype, from Lo Bracita, Dominican Republic. Natural size.

regions backward onto the shoulders; skin of throat, belly, and under surface of limbs smooth; no external throat folds.

Dimensions: Tip of snout to vent, $41 \mathrm{~mm}$.; width of head, $16 \mathrm{~mm}$.; diameter of eye, $5 \mathrm{~mm}$.; diameter of tympanum, $2.5 \mathrm{~mm}$.; foreleg from axilla, $28 \mathrm{~mm}$; hindleg from vent, $69 \mathrm{~mm}$.; vent to heel, $42 \mathrm{~mm}$.

Color (in alcohol): Upper surfaces drab-gray, with seal-brown reticulations and irregular spots all over the back; a pale narrow interorbital line, with a heavy concentration of the seal-brown pigment behind this line; loreal region dark olive-gray; upper surfaces of limbs with wide dark cross bars; anal region pale; ventral surfaces pale ecru-drab, with suffusions of light olive-gray on the chin and chest; belly almost immaculate; lower surfaces of limbs with minute 
seal-brown dots; labial borders pale olive-gray with scattered lighter spots. Scarcely a trace of pale dorsolateral stripes in this specimen. Upper surfaces of the digital disks olive-gray, darker than the rest of the skin of the feet.

Variations.-The six paratypes that I have examined do not vary much from the description of the type in bodily proportions. The snout is slightly more pointed in the figured specimen than in the others. The interorbital bar is wider in F.M.N.H. No. 6909 than in the described specimen, while the dots on the lower surface of its thighs are larger and closer together. In the newer material collected by Dr. Darlington, a similar uniformity occurs. The largest frog from Constanza measures $54 \mathrm{~mm}$.; two others from Mount Diego de O Campo are $48 \mathrm{~mm}$. long. The heel adpressed may extend to the tip of the snout, or only as far as the anterior corner of the eye.

Remarks.-As Dr. Noble has already stated, this species appears to be related to weinlandi, the two being similar in structure and proportions. In weinlandi the sole of the foot displays many minute tubercles between the large subarticular tubercles, while in schmidti the sole is practically smooth. The color pattern of weinlandi is another good distinguishing feature by which to separate them readily.

An extremely long-legged form occurring on Loma Rucilla has been considered as a subspecies of schmidti. As usual, further collecting in the region is needed to limit their respective ranges more definitely.

Specimens examined.-A.M.N.H. (2 specimens), M.C.Z. Nos. 9323-9324, F.M.N.H. Nos. 6909-6910, all paratypes from Lo Bràcita, Dominican Republic, August 1922, G. K. Noble; M.C.Z. No. 23527 and U.S.N.M. No. 107594, from Constanza, Dominican Republic, August 1938, P. J. Darlington; M.C.Z. Nos. 23536-23538 and U.S.N.M. No. 107595 from Los Limones near Janico, Dominican Republic, June 1938, P. J. Darlington; M.C.Z. Nos. 23461-23465 and U.S.N.M. Nos. 107592-107593 from Mount Diego de O Campo, Dominican Republic, July 1938, P. J. Darlington.

\section{ELEUTHERODACTYLUS SCHMIDTI RUCILLENSIS Cochran}

Figure 18

1939. Eleutherodactylus schmidti rucillensis Cochran, Proc. New England Zool. Club, vol. 18, p. 3, 1939.

Diagnosis.-Resembles Eleutherodactylus schmidti Noble but has much longer hindlegs, the knee reaching nearly to the axilla and the heel extending considerably beyond tip of snout when limbs are adpressed; a weak tarsal ridge.

Description of the type.-An adult, M.C.Z. No. 23300, from Loma Rucilla and mountains north, Dominican Republic, 4,000 to 7,000 feet elevation, collected in June 1938 by P. J. Darlington. Tongue 
about three-fourths as wide as mouth opening, not emarginate behind; vomerine teeth in two heavy, slightly oblique groups, their anterior borders in contact with the posterior rim of the choanae, their inner borders narrowly separated, their outer borders extending beyond the choanae; head without ridges, relatively narrow; snout pointed; nostril much nearer tip of snout than eye, separated from eye by an interval equal to three-fourths the eye diameter; upper eyelid a little less than interorbital width; tympanum about three-fifths the eye diameter, separated from eye by slightly more than one-half its own diameter; disks of fingers small, that of third finger covering about one-half the area of the tympanum; first finger shorter than second;

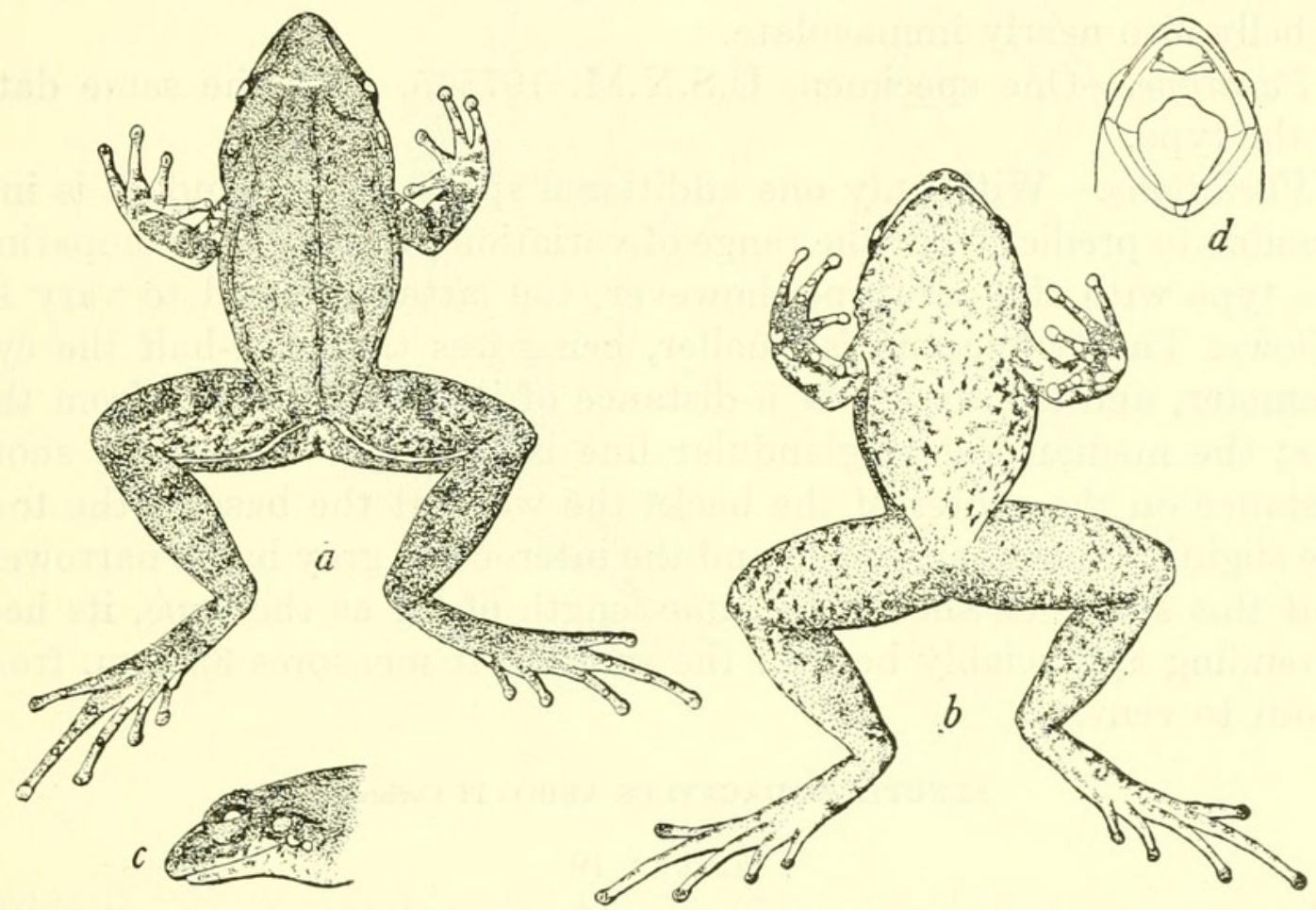

FigURE 18.-Eleutherodactylus schmidti rucillensis: $a$, Dorsum; $b$, venter; $c$, profile of head; $d$, inside of mouth. U.S.N.M. No. 107565, paratype, from Loma Rucilla and mountains north, Dominican Republic. Seven-eighths natural size.

toes webbed at the base, their disks small, scarcely larger than those of fingers; first toe reaching base of penultimate phalanx of second; fifth toe equal to third in length; distinct dermal fringes along the toes, less developed on fingers; subarticular tubercles well developed; two metatarsal tubercles, the outer small, rounded, tubercular, the inner elongate and more prominent, a slight tarsal ridge leading from the base of inner metatarsal tubercle and becoming imperceptible before it reaches the heel; the bent limbs being adpressed, knee reaches to axilla, and heel extends considerably beyond tip of snout; when hindlimbs are placed at right angles to body, heels slightly overlap. Skin of upper parts finely pustular anteriorly, more coarsely so on $226849-41-5$ 
the sacrum and sides of body; a narrow median glandular line running from snout to anus, and a series of broken diagonal glandular lines above and behind the ear and on the sides; skin of throat, belly, and under surfaces of limbs smooth; no external throat folds.

Dimensions: Snout to vent, $41 \mathrm{~mm}$.; width of head, $15 \mathrm{~mm}$.; diameter of eye, $6 \mathrm{~mm}$.; diameter of tympanum, $3 \mathrm{~mm}$.; foreleg from axilla, $26 \mathrm{~mm}$.; hindleg from vent, $72 \mathrm{~mm}$; vent to heel, $44 \mathrm{~mm}$.

Color in alcohol: Dorsum blackish indigo; a gray interocular bar with a black posterior border; indications of wide dark cross bands on the limbs; venter pale olive-buff, with small sepia spots thickly scattered on throat; sides and lower limb surfaces finely spotted, with the exception of the tibia, which has a large immaculate area; center of belly also nearly immaculate.

Paratype.-One specimen, U.S.N.M. 107565, with the same data as the type.

Variations.-With only one additional specimen at hand, it is impossible to predict what the range of variation may be. In comparing the type with the paratype, however, the latter is found to vary as follows: The tympanum is smaller, being less than one-half the eye diameter, and is situated at a distance of its own diameter from the eye; the median dorsal glandular line is apparent only for a short distance on the center of the back; the webs at the base of the toes are slightly better developed, and the interocular gray bar is narrower. But this specimen shows the same length of leg as the type, its heel extending appreciably beyond the snout. It measures $35 \mathrm{~mm}$. from snout to vent.

\section{ELEUTHERODACTYLUS ABBOTTI Cochran}

FIGURE 19

1923. “Abbott's Macito" Noвle, Amer. Mus. Nov., No. 61, p. 4.

1923. Eleutherodactylus abbotti Cochran, Proc. Biol. Soc. Washington, vol. 36, p. 93; Proc. U. S. Nat. Mus., vol. 66, art. 6, p. 2, 1924.-NoвLE, Nat. Hist., vol. 23, pp. 114, 119, 1923 (photographs).-BArвour, Zoologica, vol. 11, No. 4, p. 77, 1930; vol. 19, No. 3, p. 93, 1935; Bull. Mus. Comp. Zool., vol. 82, No. 2, p. 101, 1937.

Original description.- "Type.-U.S.N.M. No. 65055, Laguna, Samaná Peninsula, Dominican Republic; Dr. W. L. Abbott, collector; May, 1922.

"Description of type specimen.-Tongue very broad, emarginate behind; vomerine teeth in two short and very slightly oblique groups some distance behind choanae, their outer ends not extending beyond inner borders of choanae; head moderate, without ridges; a large, loose subgular pouch extending in very prominent folds on sides of throat and forming a strong fold posteriorly between fore limbs; nostril 
much nearer snout than eye, its distance from eye nearly equaling diameter of latter; upper eyelid much narrower than interorbital space; tympanum equal to one-half the diameter of eye; its distance from eye somewhat less than its diameter; disks of fingers large; first finger shorter than second; toes free; disks of toes large; first toe reaching slightly beyond first subarticular tubercle of second toe; subarticular tubercles well developed; two well-developed metatarsal tubercles; no plantar tubercles; no tarsal fold; bent limbs being pressed along sides, knee and elbow overlap; hindlimb being extended along sides, heel reaches beyond eye; hind limbs being placed vertically to

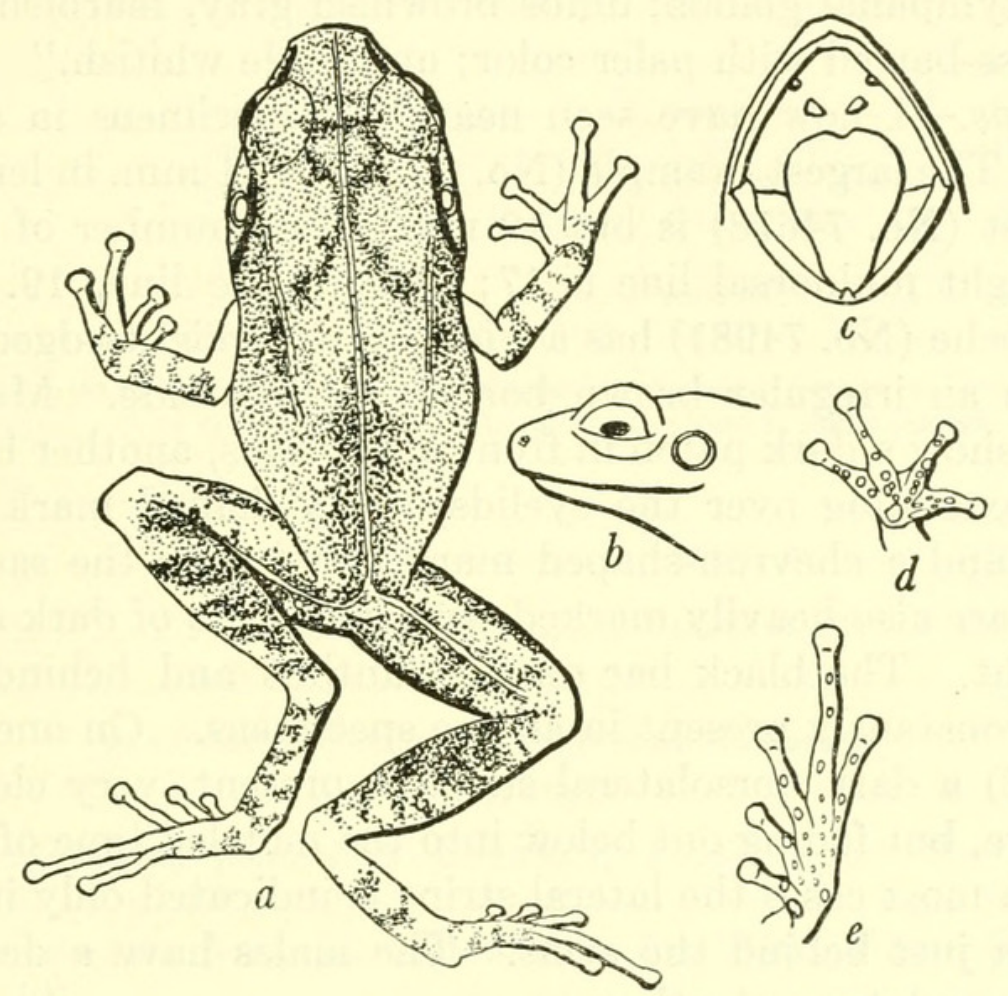

FigURE 19.-Eleutherodactylus abbotti: $a$, Dorsal view; $b$, side of head; $c$, inside of mouth; $d$, underside of forefoot; $e$, underside of hindfoot. Type, U.S.N.M. No. 65055, from Laguna, Dominican Republic. Three times natural size.

axis of body, heels overlap considerably; a series of elongate glands forming an interrupted dorsolateral line from above tympanum to groin; a heavy oblique glandular ridge from posterior angle of eye to shoulder, below which is a shorter one from tympanum to humerus; skin above shagreened, with scattered irregular glandular tubercles especially on the flanks; throat, chest and anterior aspect of femur smooth, rest of underside coarsely granular.

"Dimensions.-Tip of snout to vent, $19 \mathrm{~mm}$.; width of head, $6 \mathrm{~mm}$.; tip of snout to posterior border of tympanum, $7 \mathrm{~mm}$.; diameter of eye, $2.4 \mathrm{~mm}$.; diameter of tympanum, $1.2 \mathrm{~mm}$.; foreleg from axilla, $11 \mathrm{~mm}$.; hindleg from vent, $29 \mathrm{~mm}$; ; vent to heel, $18 \mathrm{~mm}$. 
"Color (in alcohol).-Above brownish gray, with a line between orbits and a much darker X-shaped mark between the shoulders; a pale line from tip of snout, extending over canthus rostralis, outer edge of supraocular and along the glandular dorso-lateral line to the groin; a broad, dark brown band from tip of snout over loreal region to eye; an oblique dark line on supra-tympanal gland, expanding into a wide band on flanks; a very narrow, sharply defined light vertebral line from level of nostrils to vent, intersected above latter by a similar line on posterior aspect of femur, tibia and on sole of foot; lips brown with small pale dots; a pale line from tympanum to humerus extending over post-tympanal glands; limbs brownish gray, marbled and indistinctly cross-barred with paler color; underside whitish."

Variations.-I now have seen nearly 40 specimens in addition to the type. The largest example (No. 65683) is $21 \mathrm{~mm}$. in length, while the smallest (No. 74678) is but $10 \mathrm{~mm}$. The number of individuals with the light middorsal line is 17 ; without the line, 19 . One frog from Bolboche (No. 74981) has a wide, light, straight-edged middorsal stripe with an irregular brown border on each side. Many of the specimens show a dark patch in front of the eyes, another between the eyes and extending over the eyelids, an X-shaped mark above the shoulders, and a chevron-shaped mark just before the sacral region. The limbs are also heavily marked with wide bars of dark and narrow bars of light. The black bar on the canthus and behind the tympanum is constantly present in all the specimens. On one individual (No. 74982) a dark dorsolateral stripe is present, very clear-cut and sharp above, but fading out below into the mottled tone of the lateral region. In most cases the lateral stripe is indicated only in a slightly darker area just behind the arms. The males have a decided powdering of gray dots on the throat.

The species seems to retain its stability outside of the type locality, as two specimens from the Citadel of King Christophe in northern Haiti show no differentiations. A poorly preserved individual from Fonds-des-Nègres, Haiti, has been provisionally referred to this species; also another from Pétionville. Large series from both these localities are necessary before determining them positively.

Relationships.-The short legs, the lack of webbing between toes and fingers, the small adult size, the weak patches of vomerine teeth, and the presence of a dark X-mark on the back link this species closely to $E$. audanti. The short and scarcely projecting snout of the latter and its generally stouter build distinguish it from the species under discussion.

Specimens examined.-As listed in table 12. 
TABLE 12.-Specimens of Eleutherodactylus abbotti examined

\begin{tabular}{|c|c|c|c|}
\hline Museum No. & Locality & Date & Collector \\
\hline U.S.N.M. & & & \\
\hline 65055 (type) & Laguna, D. R & May $151922 \ldots \ldots$ & W. L. Abbott. \\
\hline 65056,65057 (paratypes)... & - do do & ..... do & Do. \\
\hline $65672-65696$ & Samaná and Laguna, D. R & March 1923 & Do. \\
\hline $73997,73998 \ldots \ldots \ldots$ & Citadelle, Haiti . . & February $14,1928 .$. & A. J. Poole. \\
\hline $74674-74678$ & Río San Juan, D. R & March 1928 & G. S. Miller, Jr. \\
\hline 74981, 74982 $\ldots$ & Bolboche, D. R & March 4, $1928 \ldots . .$. & Do. \\
\hline $107586-107587 \ldots \ldots$ & Loma Rucilla, D. R & June 1938 & P. J. Darlington. \\
\hline 107588 & $\begin{array}{l}25 \text { kilometers south of Puerto } \\
\text { Plata, D. R. }\end{array}$ & June 10,1938 & Do. \\
\hline $107589-107591 \ldots$ & Mount Diego de O Campo, D. R. & July 1938_.. & Do. \\
\hline M.C.Z. & & & \\
\hline $23520-23521 \ldots \ldots$ & Loma Vieja, D. R & August 1938 & Do. \\
\hline 23529 & Constanza, D. R & August 1938_... & Do. \\
\hline $23530-23531 \ldots \ldots$ & 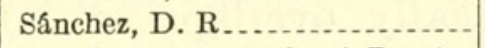 & July $1938 \ldots \ldots$ & Do. \\
\hline $23545-23546 \ldots$ & $\begin{array}{l}25 \text { kilometers south of Puerto } \\
\text { Plata, D. R. }\end{array}$ & June $10,1938 \ldots$ & Do. \\
\hline $23481-23482 \ldots$. & Loma Rucilla, D. R & June 1938... & Do. \\
\hline $23451-23455 \ldots . .$. & Mount Diego de O Campo, D. R & July $1938 \ldots \ldots$ & Do. \\
\hline
\end{tabular}

The identification of the following three specimens is not positive because of their poor condition. They appear, however, to be similar to abbotti in many respects.

\begin{tabular}{|c|c|c|c|}
\hline U.S.N.M. & “San Domingo" & & \\
\hline $59111 \ldots$ & Pétionville, Haiti. & April 1, 1917..... & J. B. Henderson and \\
\hline $72621 \ldots .$. & Fonds-des-Nègres, Haiti......... & March $31,1927 \ldots$ & A. Wetmore. \\
\hline
\end{tabular}

\section{ELEUTHERODACTYLUS FEMUR-LEVIS Cochran}

Plate 10, C

1935. Eleutherodactylus femur-levis Cochran, Proc. Boston Soc. Nat. Hist., vol. 40 , No. 6, p. 371.

1937. Eleutherodactylus femur-laevis Barвodr, Bull. Mus. Comp. Zool., vol. 82, No 2, p. 101.

Diagnosis.-Belly and lower anterior surface of femur smooth; upper eyelid without a spinelike tubercle; fingers rounded, toes pointed at the tips; snout rounded in profile, not shovel-shaped; femur moderate in length; tibiotarsal articulation reaching slightly beyond snout; a light interorbital band; heels greatly overlapping.

Type.-M.C.Z. No. 19836, an adult from Desbarrière, north and east foothills, Massif de la Hotte, about 4,000 feet altitude, collected in October 1934 by P. J. Darlington.

Description.-Tongue broad, not emarginate behind; vomerine teeth in two very long, slanting, $\Lambda$-shaped patches behind the choanae, nearly meeting each other medially, their outer ends extending well beyond the choanae; head moderate, without ridges, its greatest width a little more than distance from end of snout to occiput; no subgular pouch evident; a slight fold across the chest between the forelimbs; nostril much nearer snout than eye, its distance from eye equal to the diameter of the latter; upper eyelid about three-fifths the inter- 
orbital space; tympanum equal to two-thirds the diameter of the eye, its distance from the eye equal to two-thirds its own diameter; disks of fingers rounded, moderate in size, that of the third finger covering about one-third the tympanic area; first finger shorter than second; no webs between fingers or toes; disks of toes very slightly larger than those of fingers, and definitely pointed at the tips; first toe reaching only to beginning of penultimate phalanx of second toe; subarticular tubercles well developed, two metatarsal tubercles, the outer small, the inner very pronounced and larger than the largest toe disk; no large plantar tubercles; no tarsal fold; femur moderate; the limbs being pressed along the sides, the knee and elbow considerably overlap; the hindlimb being extended forward, the heel reaches slightly beyond the tip of the snout; hindlimbs being placed vertically to axis of body, the heels greatly overlap; an interrupted series of elongate glands beginning at the posterior corner of the eye, continuing above the tympanum, and fading out on the side between axilla and groin; a very faint middorsal gland; skin above shagreened with pustules and short glandular ridges, more evident on posterior parts, less distinct anteriorly; throat, chest, belly, and anterior femur smooth; posterior surfaces of femur granular. The type is unique.

Dimensions: Tip of snout to vent, $42 \mathrm{~mm}$.; width of head, $16 \mathrm{~mm}$.; tip of snout to posterior tympanum, $15.5 \mathrm{~mm}$.; diameter of eye, $4 \mathrm{~mm}$.; foreleg from axilla, $24 \mathrm{~mm}$.; hindleg from vent, $72 \mathrm{~mm}$.; vent to heel, $44 \mathrm{~mm}$.

Color (in alcohol): Dorsal ground color drab anteriorly, cream-buff posteriorly; a wide, pale interorbital band edged narrowly with clove-brown on its posterior border; a clove-brown spot in front of the eye on the loreal region; an irregular crescentic clove-brown mark beginning behind the eye and encircling the upper and posterior margins of the tympanum; two or three scattered brown spots above the axilla bordering the glandular lateral line below; some faint gray suffusions on the posterior part of the back; pale gray crossbars on the legs; posterior surface of femur with irregular gray and brown suffusions forming small spots; lower parts of hands and feet suffused with gray; remainder of ventral surface immaculate olive-gray; lips drab, with faint lighter and darker mottlings.

\section{ELEUTHERODACTYLUS PICTISSIMUS Cochran}

Plate 10, D

1935. Eleutherodactylus pictissimus Cochran, Proc. Boston Soc. Nat. Hist., vol. 40, No. 6, p. 371.-BArbour, Bull. Mus. Comp. Zool., vol. 82, No. 2, p. $94,1937$.

Diagnosis.-Belly and thighs smooth; upper eyelid without a spinelike tubercle; toes and fingers rounded at the tips; snout rounded in profile, not shovel-shaped; femur moderate in length; tibiotarsal articulation reaching anterior corner of eye; a light interorbital band; heels considerably overlapping. 
Type--M.C.Z. No. 19846, an adult from Tardieu, Massif de la Hotte, Haiti, about 3,000 feet altitude, collected in October 1934 by P. J. Darlington.

Description of the type.-Tongue broad, rounded, not emarginate behind; vomerine teeth in two long, slanting patches behind the choanae, almost meeting at the midline and extending considerably beyond the outer borders of the choanae; head moderate, without ridges, its greatest width a little more than the distance from tip of snout to occiput; no subgular pouch, although a distinct fold occurs across the chest between the fore limbs; nostril much nearer tip of snout than eye, its distance from eye slightly greater than the diameter of the latter; upper eyelid very narrow, slightly over one-half the width of the interorbital space; tympanum equal to two-thirds the diameter of the eye, its distance from the eye less than one-half its own diameter; disks of fingers globular, rather small in size, that of the third finger covering about one-fourth the tympanic area; first and second fingers equal; no webs between fingers or toes; disks of toes about equal to those of the fingers; first toe reaching halfway along penultimate phalanx of second toe; subarticular tubercles well developed; two distinct but small metatarsal tubercles; no large plantar tubercles; no tarsal fold; femur moderate in length; the limbs being pressed along the sides, the knee and elbow touch; hind limb being extended forward, the heel reaches the center of the eye; hind limbs being placed vertically to axis of body, the heels considerably overlap; no elongate glands on skin; a very faint median dorsal line; some very slight granulations faintly apparent on the lumbar region and between the shoulders; a slight glandular ridge over the tympanum; throat, chest, belly, and lower surfaces of thighs smooth, posterior parts of femur glandular. The type is unique.

Dimensions: Tip of snout to vent, $39 \mathrm{~mm}$.; width of head, $14 \mathrm{~mm}$.; tip of snout to posterior tympanum, $14 \mathrm{~mm}$.; diameter of eye, $4 \mathrm{~mm}$.; foreleg from axilla, $25 \mathrm{~mm}$.; hindleg from vent, $57 \mathrm{~mm}$.; vent to heel, $34 \mathrm{~mm}$.

Color in alcohol: Ground color above French gray; a slate-black lateral longitudinal stripe beginning at the nostril, continuing along the loreal region and over the ear, much interrupted behind the shoulders and widening and breaking up into a coarse anastomosing pattern covering the sides; a similar median slate-black stripe beginning as a triangular blotch on the snout and continuing behind the black irregular interorbital bar as a double series of large and very irregular anastomosing blotches; the pale ground forming a pale interorbital band and two quite regular and distinct dorsolateral stripes between the median and the lateral rows of blotches; upper and posterior surfaces of arms and legs a little more finely vermiculated with slate-black markings; soles of hands and feet mouse gray; 
remainder of ventral surface immaculate pearl-gray; lips also pearlgray, with very indistinct darker suffusions.

\section{ELEUTHERODACTYLUS BREVIROSTRIS Shreve}

Figure 20

1936. Eleutherodactylus brevirostris Shreve, Proc. New England Zool. Club, vol. 15, p. 95.-Barbour, Bull. Mus. Comp. Zool., vol. 82, No. 2, p. 100, 1937.

Original description.- "Type.-Museum of Comparative Zoölogy, no. 21,557 , a female, from northern and eastern foot-hills, Massif de la

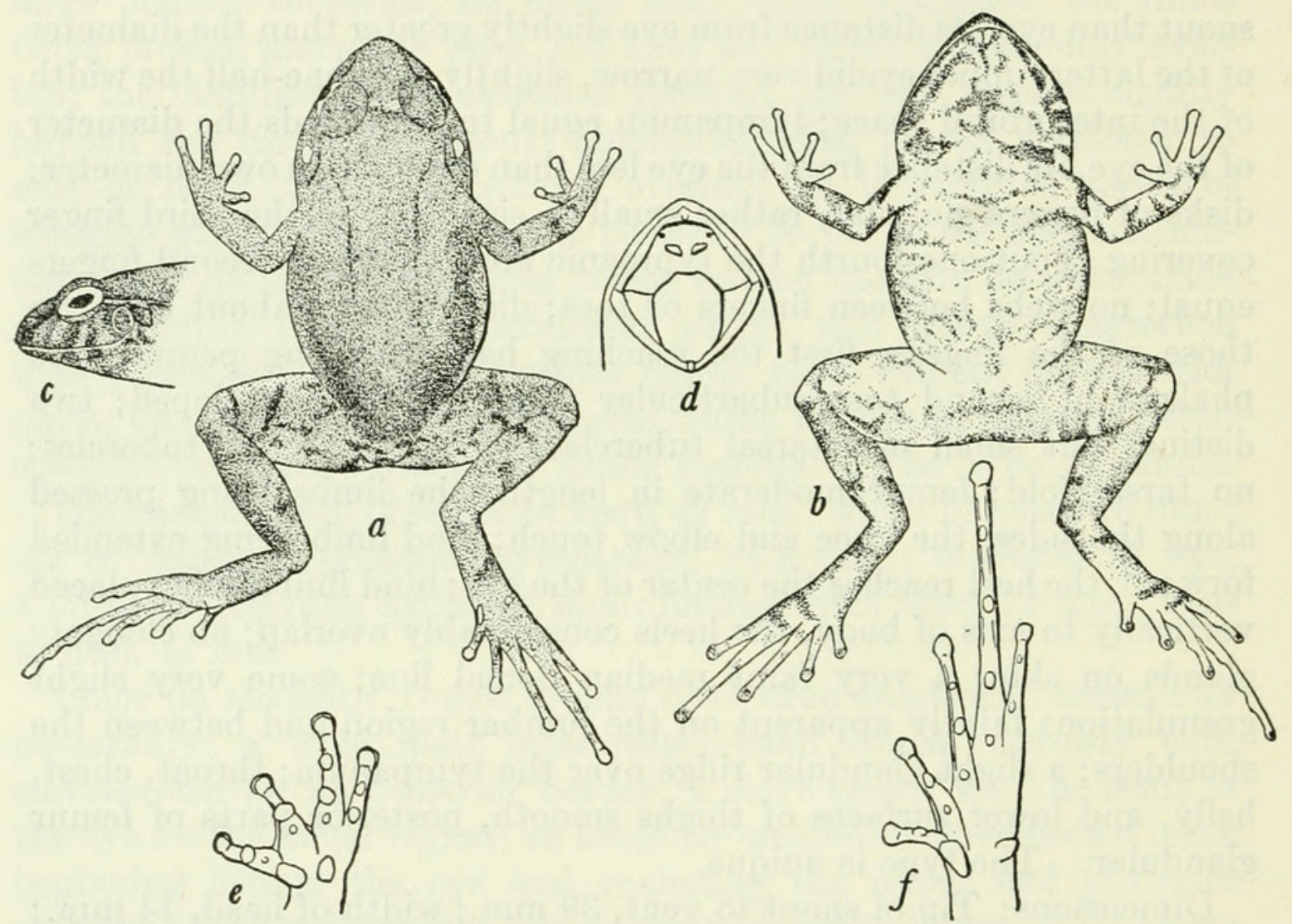

FIGURE 20.-Eleutherodactylus brevirostris: $a$, Dorsum; $b$, venter; $c$, profile of head; $d$, inside of mouth; $e$, underside of hand; $f$, underside of foot. M.C.Z. No. 21573, paratype, from Morne La Hotte, Haiti. $a-d, \times 1 \frac{1}{2} ; e, f, \times 3$.

Hotte, 1000-4000 ft., Haiti, collected by P. J. Darlington in October, 1934.

"Paratypes: Museum of Comparative Zoölogy, nos. 21,558-21,560, with the same data and history as the type, and Museum of Comparative Zoölogy, nos. 21,573-21,574, from Mt. La Hotte, $5000 \mathrm{ft}$. to summit, date and collector the same as that of the type.

"Diagnosis.-Possibly most closely related to Eleutherodactylus schmidti from which it differs in the shape of the head, size of the series of vomerine teeth, in possessing smaller digital disks, and a shorter hind limb; also differs in coloration.

"Description.-Tongue oval, very slightly nicked behind (very slightly nicked, or not nicked, in paratypes); vomerine teeth in two 
rather small, slightly oblique groups behind, and for the most part between, the choanae (vomerine teeth indefinable in one paratype); snout subacuminate, short, longer than the diameter of the eye; canthus rostralis rounded, indistinct; loreal region concave and rather oblique; nostril nearer tip of snout than eye; interorbital space about as broad as the upper eyelid; tympanum distinct, two thirds the diameter of the eye (about three quarters in the smaller paratypes; two thirds in the largest paratype, no. 21,573); digital disks feebly developed; disk of third finger about one third as large as the tympanum (about one third to one quarter in the paratypes); first finger shorter than second; first toe much shorter than second; toes practically unwebbed at base; two metatarsal tubercles; the tibio-tarsal articulation of the adpressed hind limb reaches to the posterior corner of the eye (reaches from posterior to anterior corner of eye in paratypes); finely granular above; smooth below.

"Coloration in alcohol.-Dark brown above; front of humerus grayish, mottled with lighter brown; upper side and rear of femur brown, lighter than dorsal ground color; limbs cross-banded, both above and below, with dark brown or black, even darker than the dorsal ground color; a gray interorbital band; lips brown, marked with dark vertical bands, some of which enter the eye; below brown, minutely punctulated with white, and spotted with darker brown; lower lips dark brown with narrow light vertical bands; proximal half of anterior face of femur white, this color also extending onto the side of the belly and occupying about as large an area there as on the femur; also a white area on the ventral surface of the tibia.

"The paratypes are similar in coloration to the type, but some are so much darker above that the cross-bands on the limbs are obsolete in places. Also the interorbital bar and the light coloration of the humerus of the type are lacking. In addition, the white tibial area is wanting or reduced. The white femoral area in some may be somewhat obscured by brown mottling.

"Measurements

Length of head

Head

Hind limb 4th too body

Type, no. 21,557

$27 \mathrm{~mm}$. $11 \mathrm{~mm}$.

$43 \mathrm{~mm} .10 \mathrm{~mm}$.

Paratypes, nos. 21,558-21,560, $21,573,21,574$

$25-19 \mathrm{~mm} .10-8 \mathrm{~mm}$.

39-32 mm. 9-7 mm."

\section{ELEUTHERODACTYLUS AUDANTI Cochran}

Figure 21

1934. Eleutherodactylus audanti Cochran, Occ. Pap. Boston. Soc. Nat. Hist., vol. 8, p. 164.-Barbour, Zoologica, vol. 19, No. 3, p. 92, 1935; Bull. Mus. Comp. Zool., vol. 82, No. 2, p. 98, 1937.

Diagnosis.-Belly and thighs heavily granular; upper eyelid without a spinelike tubercle; toes and fingers rounded at the tips; snout 
somewhat truncate in profile, not shovel-shaped; femur very short; tibiotarsal articulation usually not reaching eye. Young specimens pink (or white in preservative) spotted very unsymmetrically with brown; older specimens increasingly darker and more evenly colored; adults dark drab-gray, usually with a brown interorbital bar, always with a dark triangular postanal mark extending onto the lower part of the femur.

Original description.- "An adult, M.C.Z. 19704, from Peak La Selle collected by André Audant. Tongue moderately broad, very slightly emarginate behind; vomerine teeth in two very short, straight, widely separated patches between and well behind the choanæ, their outer ends not extending as far as the inner borders of

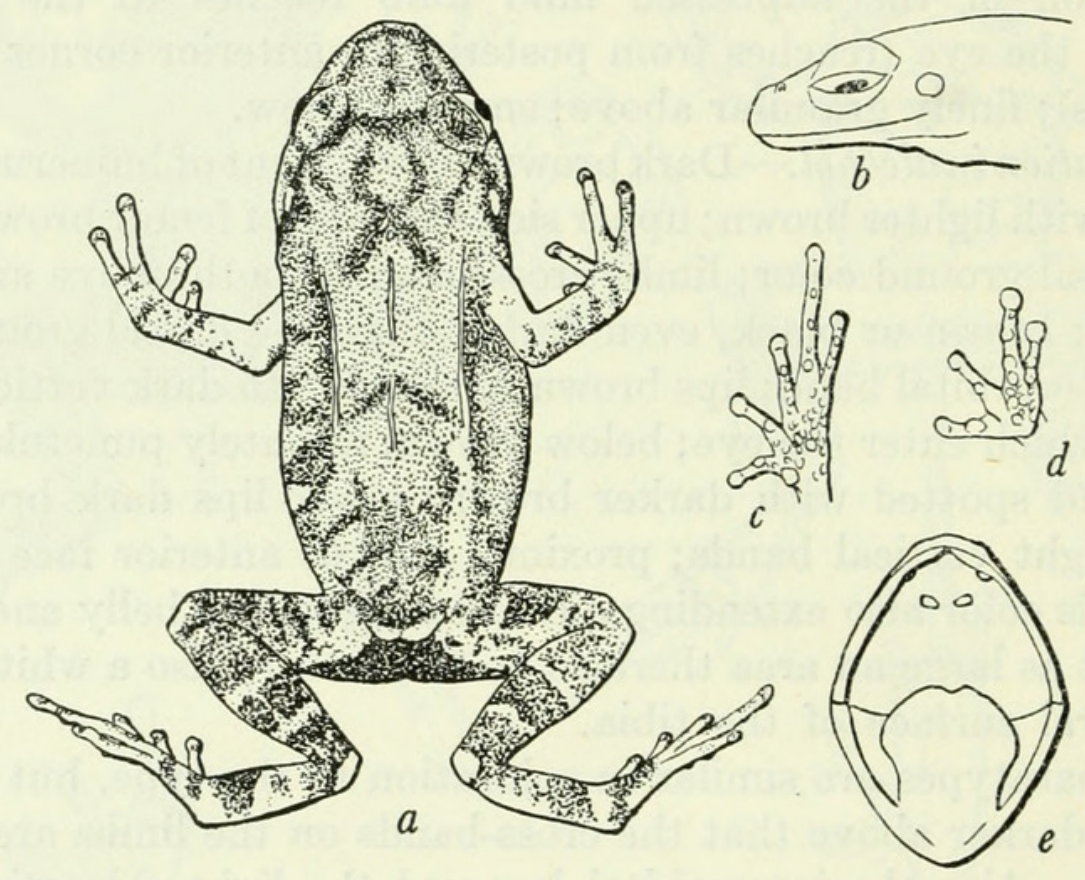

FiguRE 21.-Eleutherodactylus audanti: $a$, Dorsal view; $b$, side of head; $c$, underside of hindfoot; $d$, underside of forefoot; $e$, inside of mouth. M.C.Z. No. 19704, type, from Peak La Selle, Haiti. Twice natural size.

the choanæ; head moderate, without ridges, its greatest width equal to distance from end of snout to occiput; no subgular pouch evident, although a distinct fold occurs across the chest between the forelimbs; nostril much nearer snout than eye, its distance from eye slightly less than the diameter of the latter; upper eyelid much narrower than interorbital space; tympanum equal to one-third the diameter of the eye, its distance from the eye somewhat less than its own diameter; disks of fingers moderate in size, that of the third finger covering about two-thirds the tympanic area; first finger much shorter than second; inner toes free, outer ones with a slight rudiment of a web; disks of toes about equal in size to those of the fingers; first toe reaching almost to base of disk of second toe; subarticular tubercles well developed; two prominent metatarsal tubercles; no plantar tubercles; no tarsal 
fold; femur very short; the limbs being pressed along the side, the knee and elbow are considerably separated; hind limb being extended forward, the heel reaches the tympanum; hind limbs being placed vertically to axis of body, heels just overlap; a series of elongate glands forming an interrupted dorso-lateral line from above tympanum to groin; another series of glands forming a middorsal line from tip of snout to vent; skin above shagreened, with rather regular glandular ridges or tubercles, especially on the sacral region, where they lie diagonally on each side of the midline; throat smooth; chest, belly and thighs heavily granular.

"Dimensions.-Tip of snout to vent, $25 \mathrm{~mm}$.; width of head, $9 \mathrm{~mm}$., tip of snout to posterior tympanum, $9 \mathrm{~mm}$.; diameter of eye, $3 \mathrm{~mm}$.; foreleg from axilla, $13 \mathrm{~mm}$; hindleg from vent, $32 \mathrm{~mm}$.; vent to heel, $7 \mathrm{~mm}$.

"Color in alcohol.-Dorsal surface drab-gray; a seal-brown interorbital bar; canthal region with a dark brown stripe; a narrow brown bar from eye to tympanum; a brown dorso-lateral stripe following the narrow glandular ridges of that region; an X-shaped brown mark behind the occiput and a $\Lambda$-shaped mark across the middle of the back; sides and sacral region with irregular, indistinct dark vertical bars; a wide, dark, light-edged crossband on the femur and another on the tibia, and paler ones on the feet; lower posterior part of femur and entire postanal region covered by a uniform dark seal-brown triangle; a brown diagonal mark on the lower proximal surface of the upper arm; forearm with some irregular dark vermiculations; lower surfaces drabgray to olive gray, immaculate; upper and lower lips with a faint brown spotting.

"Paratypes.-Thirteen additional specimens of half-grown and adult frogs (M.C.Z. 19705-13 and U.S.N.M. 95111-3) were secured at the same time and place as the type. Three half-grown examples (U.S.N.M. 72595-7), rather badly mutilated, were secured at Morne Cabaio, Massif de la Selle on April 10, 1927, by Dr. A. Wetmore. Another young frog (U.S.N.M. 85009), was secured in the Morne La Selle Range at 7000 feet altitude in 1932 by Lt. Comdr. S. S. Cook.

"Variation.-The coloration in the half-grown specimens is rather remarkable because it not only fails to be constant in several individuals but also lacks bilateral symmetry in a single individual. The entire body of a young specimen (M.C.Z. 19705) is a pale pinkish buff (in alcohol), and there are a few pale brown dots on the back and some darker ones on the left leg, although there are no heavy patches of dark color anywhere on the left side. The right femur, on the contrary, has a large dark blotch on its posterior surface, and the anterior part of the right tibia and foot have some lighter blotches which are noticeably greater in area than those on the left tibia. Below the skin is 
pale and immaculate except for some brown spots on the lower aspect of both tibiæ and tarsi, and the dark tips to the toes and fingers. The next example (19706) in the series grading from a light to a dark coloration, is also pale in body color. Its nostrils are outlined with brown; it has an unpaired brown spot on the posterior part of the right eyelid, then a small median occipital brown spot, another slightly larger on the median line between the shoulders, then no more dark pigment except a small brown spot which occurs on the right side of the vent. On the legs a heavy brown blotch appears on the right anterior face of the femur, while the left anterior femur bears a smaller and paler brown spot. No blotches appear on the posterior part of the femur in this specimen. There is a heavy dark band across the left tibia, and a small pale brown spot on the right tibia. The tarsi and feet are faintly spotted with brown. The forearms each have a brown band, that on the right the heavier. The ventral surface is immaculate, excepting the toe- and finger-tips; even the lower surfaces of the legs are free from spots. The next example (19707) in our series shows a considerable widening of the bars on the legs, so that most of the femur is dark, and the tibia has a wide dark median crossbar, while the tarsi are barred and the soles of the feet are dark. In this specimen some of the tips of the toes are pale. The skin of head and body is pale and immaculate, except for a large brown scapular blotch on the left shoulder only. The ventral surface is immaculate except for the continuations of the dark blotches on the legs and arms, and a dark patch at the insertion of the arm. The other examples evidently represent older phases of coloration. Some had a good deal of dark pigment appearing anteriorly on top of the head, while the back is more faintly blotched with dark, and the femur may be pale, crossbarred or dark. In some examples the lower surfaces are heavily spotted, in others only faintly so. The markings at this stage become more symmetrical also, and the dark postanal patch appears in most of the examples. The adult frogs are dark brown above, although a little of the original pale body color may show between the bars on the legs and above the postanal patch on the back of the femur. Some of the adults are more heavily spotted ventrally than is the case in the type specimen, but the variation among the adults is not as great as one might expect, considering the asymmetry of the young. The three young examples taken by Dr. Wetmore show the same peculiar asymmetry as do the young of the type series just described. The example taken by Lt. Commander S. S. Cook (U.S.N.M. 85009), belongs to the intermediate stage when darkening of the skin is well under way. A field note with this individual says that it was 'found under pine logs near the overnight camp' and that when caught it was 'distinctly green in color.'

"The heel in two of the four adult paratypes is like that of the type in reaching the tympanum. The heels of the other two adults, as 
well as those of the young, reach to the posterior corner of the eye. All the adults agree in having a very glandular skin on the back, with a concentration of these glands in a dorso-lateral line, and numerous other patches of glands from the occiput to the sacral region and on the flanks. The skin of the ventral surface in all specimens is highly granular, the granules extending as far forward as the fold across the chest between the arms. In one adult paratype, the width of the head is slightly greater than the distance between snout and occiput.

"Relationships.-The new species falls in the key in the subdivision with $E$. montanus, auriculatoides, wetmorei and armstrongi, all these having short hind legs and a granular belly, and no unusual features in regard to shape of eyelid, snout or toe-tips. E. audanti, however, has a shorter femur than any of the related forms, and its heel does not generally reach beyond the tympanum, although in soft specimens it may be stretched to the posterior corner of the eye. Its unusual juvenile coloration is a feature which distinguishes it also from its allies.

"Since writing the above, I have received twenty additional specimens of all ages from M. Audant, who has supplied the following notes on his collection:-

"'The frogs and skinks [see Wetmorena haetiana] were collected under stones or in earthen tunnels under stones. The skinks were caught in soft soil, while I had to turn the stones to see the little frogs trying to conceal therselves. I am not positive about this, but I believe that these creatures whistle at night, because, while we were over there, we could hear the sounds of the animals, but we did not succeed in capturing them at night while whistling. The specimens were caught near the Rivière des Bois Pins, 200 feet south of the Caballo summit. The little frogs are brown in color and pink spotted when alive. 'That pink changes to white in the preservative.' "

Specimens examined.-As listed in table 13.

TABLE 13.-Specimens of Eleutherodactylus audanti examined

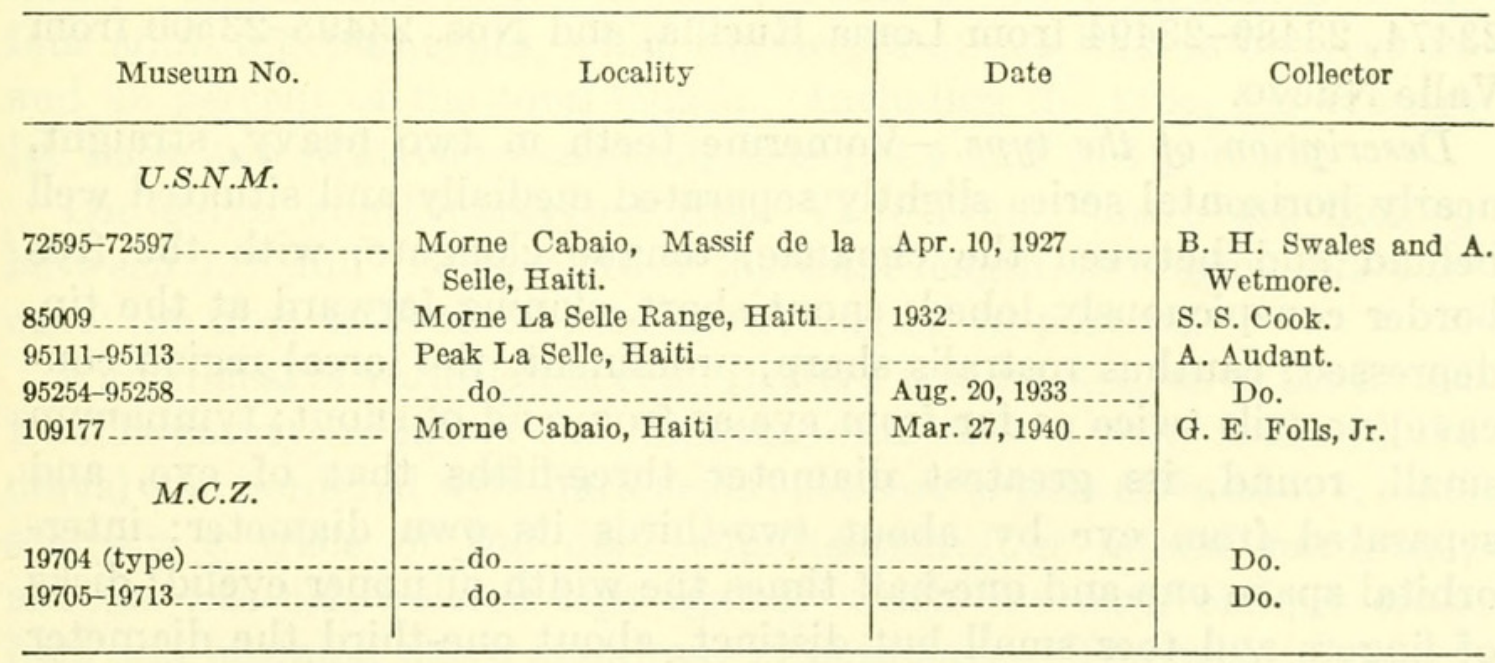


Diagnosis.-Allied to Eleutherodactylus audanti Cochran and to $E$. minutus Noble, differing from the former in its heavier vomerine teeth and from the latter in its shorter snout, shorter hindleg, and granular venter.

Type.-An adult male, U.S.N.M. No. 107566, from Loma Rucilla of the Cordillera Central, Dominican Republic, 8,000 to 10,000 feet altitude, June 1938, Dr. P. J. Darlington. Paratypes, U.S.N.M. Nos. 107567-107571, same data, and Nos. 107572-107574 from the same mountain at 4,000 to 7,000 feet; U.S.N.M. No. $107577-107585$ from Valle Nuevo, southeast of Constanza at 6,000 to 8,000 feet,

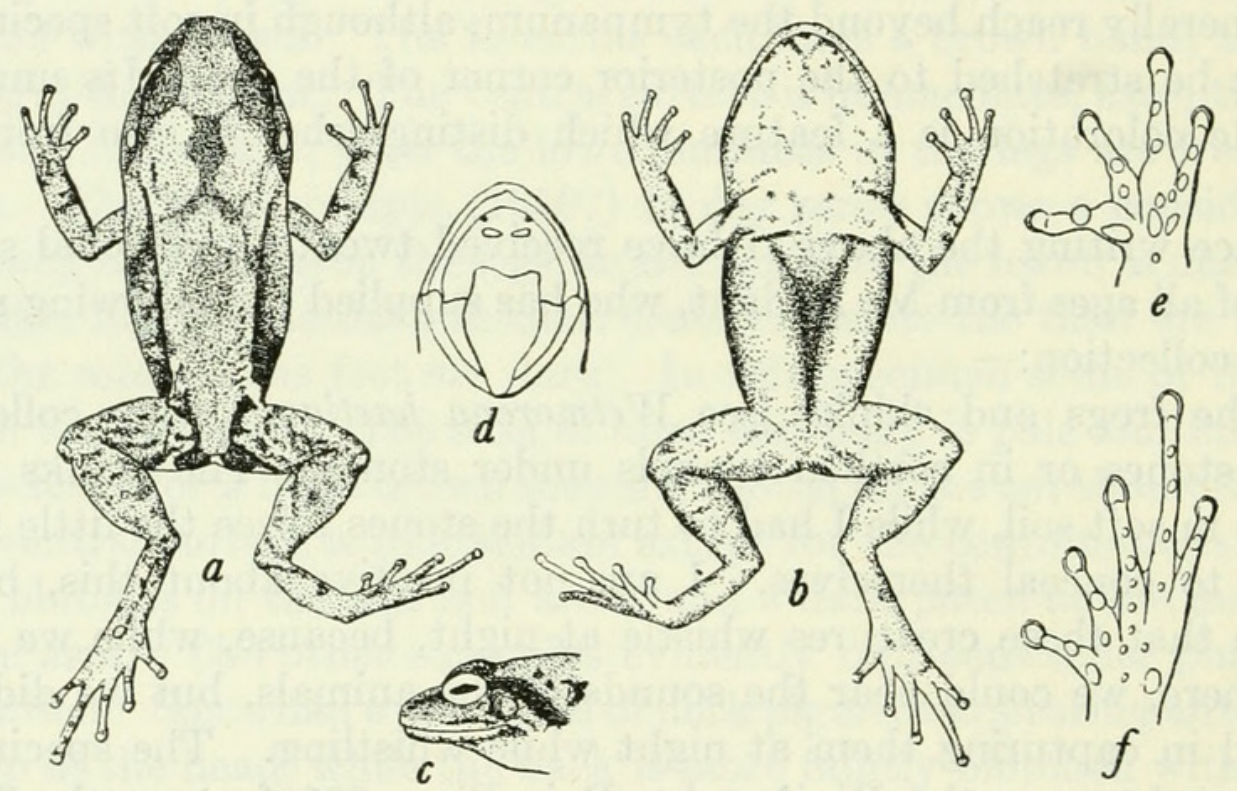

Figure 22.-Eleutherodactylus intermedius: $a$, Dorsum; $b$, venter; $c$, profile of head; $d$, inside of mouth; $e$, underside of hand; $f$, underside of foot. U.S.N.M. No. 107566, type from Loma Rucilla and mountains north, Dominican Republic. $a-d, \times 1 \frac{1}{2} ; e, f, \times 3$.

August 1938, Dr. P. J. Darlington. Additional specimens from both localities are in the Museum of Comparative Zoology, Nos. 2346923474, 23489-23494 from Loma Rucilla, and Nos. 23495-23500 from Valle Nuevo.

Description of the type.-Vomerine teeth in two heavy, straight, nearly horizontal series slightly separated medially and situated well behind and between the choanae; tongue elongate, with the free border conspicuously lobed; snout short, sloping forward at the tip, depressed; canthus rostralis sharp, prominent, the loreal region concave; nostrils twice as far from eye as from end of snout; tympanum small, round, its greatest diameter three-fifths that of eye, and separated from eye by about two-thirds its own diameter; interorbital space one and one-half times the width of upper eyelid; disks of fingers and toes small but distinct, about one-third the diameter 
of the tympanum; fingers not webbed, the first slightly shorter than second, which is equal to fourth; toes very slightly webbed at the base, third scarcely longer than fifth; subarticular tubercles well developed; small tubercles on sole of foot; two metatarsal tubercles, the inner small and oval, the outer a little larger and round; an indistinct tarsal fold; heels just touching when hind limbs are folded at right angles to axis of body; hindlegs short, the tibiotarsal articulation barely reaching to posterior border of tympanum when legs are adpressed; skin of back smooth except for a few elongate glandular ridges on the lumbar region; a narrow glandular fold originating behind the eye, continuing over the tympanum and along the dorsolateral region where it becomes very indistinct; skin of chin and chest smooth. that of belly and posterior femur finely granular; a median depressed area on belly, with a shallow groove leading from it to each arm insertion, and a very heavy lateral disk around it. Apparently no external vocal sac.

Dimensions: Head and body, $21 \mathrm{~mm}$.; head length, $7.5 \mathrm{~mm}$.; head width, $8 \mathrm{~mm}$.; foreleg from axilla, $13 \mathrm{~mm}$; hindleg from vent, 26.5 mm.; tibia, $8 \mathrm{~mm}$.

Color (in alcohol): Dorsal surface drab, with an indistinct, darker shield-shaped mark on occiput, followed by a faint chevron-shaped mark between the shoulders; a wide dark line from the posterior corner of the eve over the tympanum slanting obliquely back and ending at the shoulder; sides below the dorsolateral region dark sepia; an irregular dark crescent from above the groin to side of coccyx, merging with the dark triangular postanal patch, of which the outer posterior angle covers the posterior and lower surface of the femur, which is otherwise wood brown above with a few small dark spots; arm, tibia, and foot with irregular dark cross bars; ventral surfaces olive-buff clouded with minute darker dots; edge of lower lip with small brown spots; knee and lower side of tarsus dark sepia; palms of hands and lower side of fingers and toes pale olive buff.

Variations.-The type is the largest specimen of the examples at hand. The hindleg is 114 to 137 percent of the total length in the four adult topoparatypes, while the length of the tibia is between 35 and 43 percent of the total length. Including the type, the average for these two relative measurements is 124.4 and 38.4 percent.

The seven adult paratypes from Valle Nuevo have the hindleg between 117 and 127 percent of the total length, averaging 122 percent: the tibia is 36 to 43 percent, averaging 40 percent.

A good deal of variation in color pattern is to be seen, as in the Loma Rucilla paratypes two of the immature ones show a very distinct light dorsal line bordered with dark sepia; another is pale olive above, with scarcely a trace of the dark supratemporal or lateral markings; another has clay-colored legs against which the dark oblique cross bars and postanal patch stand out prominently. The belly in one or 
two specimens is practically immaculate; in the others it is covered with small dark spots or suffused dark areas.

One of the Valle Nuevo frogs has a wide white dorsal stripe; another has a wide pale lateral stripe with dark dots above and below it. Most of these still have a vinaceous tone in the dorsal coloring, showing that they must have been pinkish in life.

Relationships.- It seems apparent that this new form is intermediate between Eleutherodactylus audanti Cochran and E. minutus Noble. The vomerine teeth of intermedius and minutus are nearly identical. The teeth of audanti are much weaker, although in color pattern and in leg proportion it is quite close to intermedius. The last-named has a shorter snout than either of its allies, and seems to deserve specific recognition.

In order to allow still further comparisons to be made, a list of measurements of some of the paratypes of intermedius is given in table 14 .

TABLE 14.-Measurements (in millimeters) of 11 paratypes of Eleutherodactylus intermedius

\begin{tabular}{|c|c|c|c|c|c|}
\hline U.S.N.M. No. & $\begin{array}{l}\text { Total } \\
\text { length }\end{array}$ & $\begin{array}{c}\text { Head } \\
\text { length }\end{array}$ & $\begin{array}{l}\text { Head } \\
\text { width }\end{array}$ & $\begin{array}{l}\text { Hindleg } \\
\text { (from } \\
\text { vent) }\end{array}$ & Tibia \\
\hline 107567 & 20.5 & 7 & 7.5 & 26 & 8 \\
\hline 107568 & 19.5 & 6 & 6.5 & 23 & 7 \\
\hline 107569 & 17.5 & 6 & 6 & 20 & 6.5 \\
\hline 107572 & 17.5 & 6 & 6 & 24 & 7.5 \\
\hline 107577 & 19 & 6.5 & 6 & 24 & 8 \\
\hline $107578 \ldots \ldots$ & 19 & 6 & 6.5 & 23 & 7 \\
\hline $107579 \ldots \ldots$ & 16 & 5.5 & 5.5 & 20 & 7 \\
\hline 107580 & 17.5 & 5.5 & 6 & 21 & 7 \\
\hline 107581 & 17.5 & 6 & 6 & 21 & 7 \\
\hline 107582 & 17.5 & 5.5 & 5.5 & 20.5 & 6.5 \\
\hline 107583 & 16. 5 & 5. 5 & 5.5 & 21 & 7 \\
\hline
\end{tabular}

ELEUTHERODACTYLUS SEMIPALMATUS Shreve

Plate 10, E

1936. Eleutherodactylus semipalmatus Shreve, Proc. New England Zool. Club, vol. 15, p. 94.-Barbour, Bull. Mus. Comp. Zool. vol. 82, No. 2, p. 101, 1939.

Original description.- "Type.-Museum of Comparative Zoölogy, no. 21,561, apparently a male, from northern and eastern foot-hills, Massif de la Hotte, 1000-4000 ft., Haiti, collected by P. J. Darlington in October, 1934.

"Diagnosis.-Possibly most closely related to Eleutherodactylus montanus, from which it differs in shape of head, in possessing larger digital disks, more extensively webbed toes, and in coloration.

"Description.--Tongue suboval, very slightly nicked behind; vomerine teeth in two oblique groups behind and between the choanae; snout obtuse, longer than the diameter of the eye; canthus rostralis distinct, straight; loreal region concave, almost vertical; nostril 
nearer tip of snout than eye; interorbital space broader than upper eyelid; tympanum distinct, about a third of the diameter of the eye; digital disks very large, disk of third finger considerably larger than the tympanum; first finger shorter than second; first toe shorter than second; toes distinctly webbed at the base, the web also extending up the side of each digit as a dermal margin; two metatarsal tubercles; the tibio-tarsal articulation of the adpressed hind limb reaches the eye; lightly granular above and below (including chest and gular region); a subgular vocal sac(?).

"Coloration in alcohol.- - Light grayish brown above, marbled with grayish; a triangular spot of the same color connecting the eyes; upper side of limbs indistinctly cross-banded with gray; the rear of each femur with a brown blotch which covers only approximately the outer two thirds; below whitish, immaculate except for a very light stippling with grayish.

“Measurements

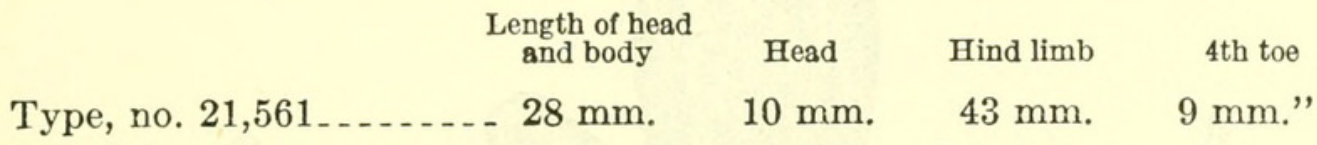

\section{ELEUTHERODACTYLUS MONTANUS Schmidt}

FigURE 23

1919. Eleutherodactylus montanus Schmidt, Bull. Amer. Mus. Nat. Hist., vol. 41, art. 12, p. 519 (type locality, "mountainous interior of the Province of Azua, Santo Domingo"); Bull. Amer. Mus. Nat. Hist., vol. 44, art. 2, p. 9, fig. 3, 1921.-Barbour, Zoologica, vol. 11, No. 4, p. 77, 1930; vol. 19, No. 3, p. 94, 1935; Bull. Mus. Comp. Zool. vol. 82, No. 2, p. 101, 1937.

Original description.-"Diagnostic characters.-Snout obtuse; nostril much nearer the end of the snout than the eye; vomerine teeth in two oval patches well behind the choanæ; tympanum distinct, about onethird the diameter of the eye; toes free; tibio-tarsal articulation reaching the posterior border of the eye; tips of digits considerably dilated; skin rugose above, without longitudinal folds; belly uniformly granular.

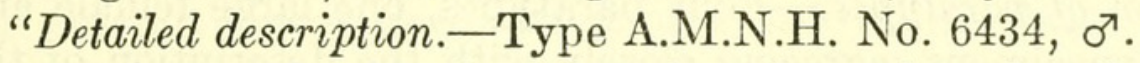

"Head considerably broader than long, broader than the body; snout short, obtuse, its length equal to the interorbital space; canthus rostralis well defined; elbow and knee pressed along sides, overlap slightly; heels overlapping when legs are placed vertically to the body; nostrils closer to the end of the snout than to the eye; tympanum distinct, small, separated from the border of the eye by its own diameter; disks of fingers and toes well developed, about as large as the tympanum; toes with only a vestigial web; inner and outer metatarsal tubercles well developed; a distinct inner and a shorter outer tarsal fold; vomerine teeth in two oval patches, well behind the choanae, the $226849-41-6$ 
space between them less than their diameter; tongue small, oval, very slightly nicked behind; skin rugose above, without glandular folds; belly and lower side of thighs uniformly granular; a very faint median dorsal ridge from end of snout to anus; a subgular vocal sac.

"Dorsum light brown with more or less longitudinal darker markings; a broad dark band from eye to eye; venter grayish yellow; a light yellow spot on the anterior proximal part of the thigh; a similar spot on the distal posterior half, and the inner face of the tibia similarly colored; a line of the dark dorsal color extends along the upper side

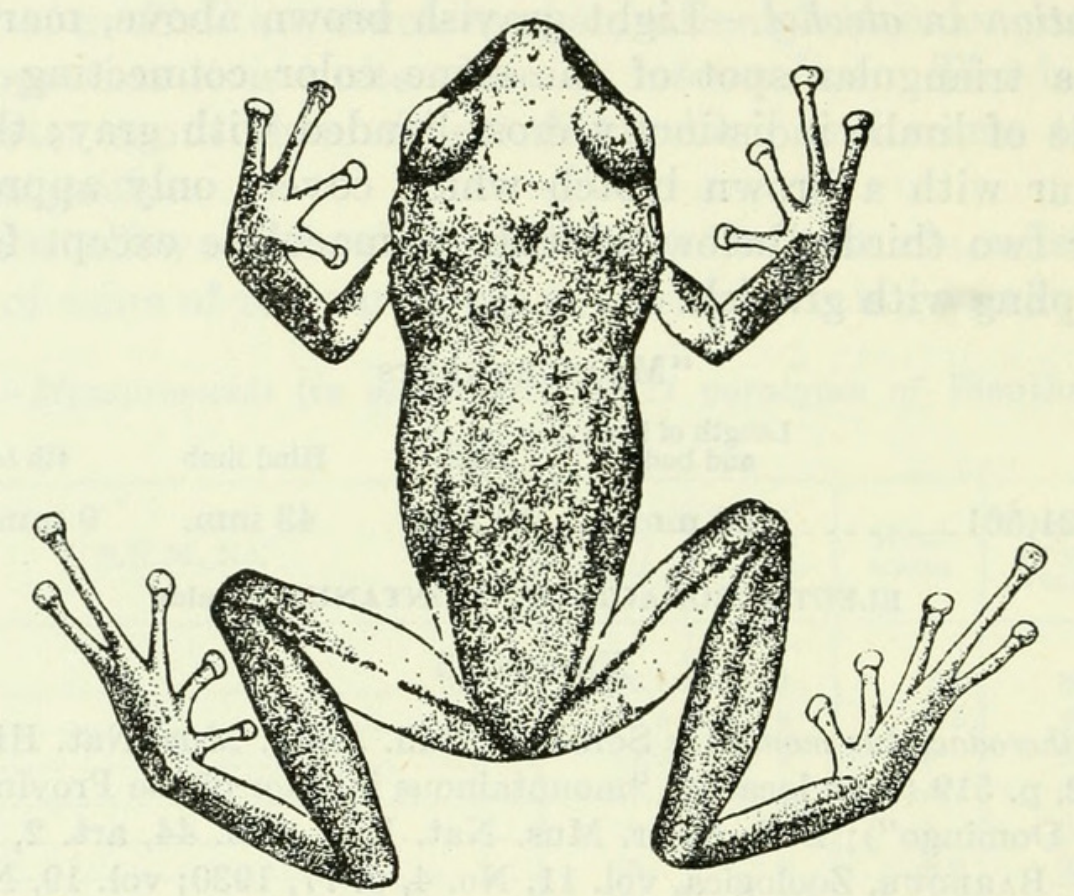

FIGURE 23.-Eleutherodactylus montanus: Specimen from the mountains of the Cibao,

Azua Province, Dominican Republic (A.M.N.H. No. 6435, paratype). Twice natural size. Courtesy of the American Museum of Natural History.

of the thigh, representing the exposed part when the legs are folded; concealed parts of arms also light colored.

"Length, $24 \mathrm{~mm}$.; head, $9 \mathrm{~mm}$. long, $10 \mathrm{~mm}$. broad; leg, $34 \mathrm{~mm}$.; arm, $15 \mathrm{~mm}$.

"Comparison of paratypes.-Four paratypes, one large female and three smaller specimens, agreeing closely with the description of the type. The female is somewhat larger, total length, $28 \mathrm{~mm}$; leg, $43 \mathrm{~mm}$.; arm, $18 \mathrm{~mm}$.

"Collected in the mountainous interior of the Province of Azua, Santo Domingo, by R. H. Beck, January to June 1917."

\section{ELEUTHERODACTYLUS AURICULATUS WETMOREI Cochran}

Figure 24

1924. Eleutherodactylus montanus Cochran, Proc. U. S. Nat. Mus., vol. 66, art. 6, p. 2 (not of Schmidt).

1932. Eleutherodactylus vetmorei Cochran, Proc. Biol. Soc. Washington, vol. 45, p. 191.-Barbour, Zoologica, vol. 19, No. 3, p. 92, 1935; Bull. Mus. Comp. Zool., vol. 92, No. 2, p. 98, 1937. 
Original description.- "Type.-U.S.N.M. No. 72617, an adult from Fonds-des-Nègres, Haiti, taken by Dr. A. Wetmore on April 5, 1927, from the nest of a palm-chat, Dulus dominicus, together with two tree-toads, Hyla dominicensis.

"Description of the type.-Tongue broad, apparently not emarginate behind; vomerine teeth in two long oblique groups some distance behind the choanae, their outer ends not extending beyond the inner borders of the choanae; head moderate, without ridges; no apparent subgular pouch; nostril much nearer tip of snout than eye, its distance from the eye slightly exceeding the diameter of the latter; upper eyelid much narrower than interorbital space; tympanum equal to one-half the diameter of the eye, its distance from the eye somewhat less than its own diameter; disks of fingers large, that of first finger equal to

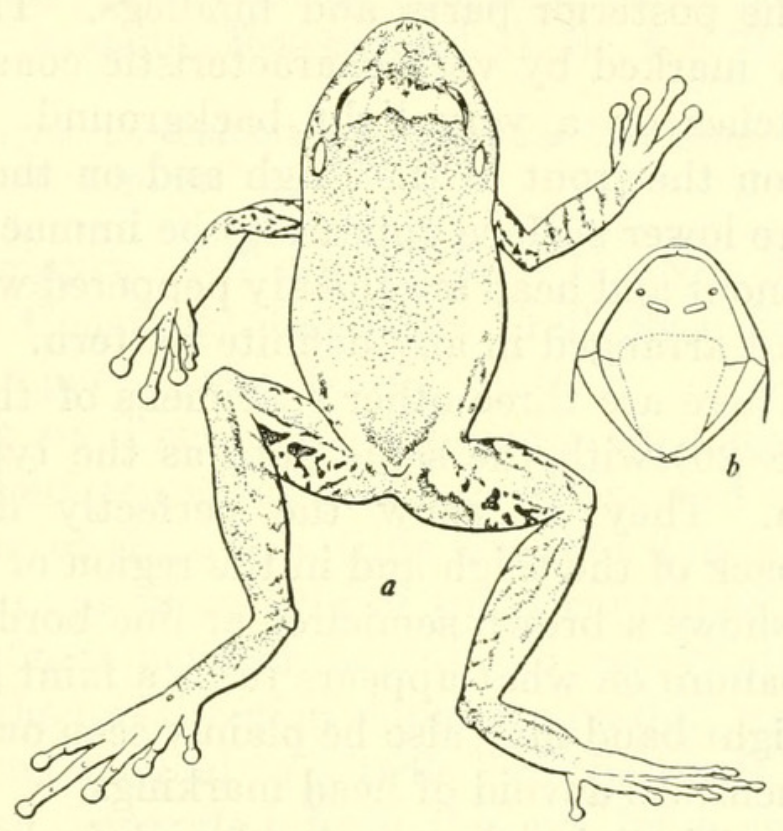

FigURE 24.-Eleutherodactylus auriculatus wetmorei: a, Partly diagrammatic dorsal view; $b$, inside of mouth, with tongue partly restored. U.S.N.M. No. 72617, type, from Fondsdes-Nègres, Haiti. Natural size.

about three-fourths the area of the tympanum; first finger shorter than second; toes with a vestige of a web at the base; disks of toes moderate, slightly smaller than those of the fingers; subarticular tubercles well-developed; apparently a very small inner and a still smaller outer metatarsal tubercle; plantar tubercles weak; apparently no tarsal fold; the bent limbs being pressed along the sides, knee and elbow overlap; the hind limbs being adpressed along the sides, the tibio-tarsal articulation reaches the posterior corner of the eye; the hind limbs being placed vertically to the axis of the body, the heels overlap considerably; apparently no series of elongate glands either above the tympanum or forming a dorsolateral fold; skin very faintly shagreened above; throat and breast smooth; a coarsely granular patch 
of skin between the thighs posteriorly, the granules apparently occurring also in the skin of the belly.

"Dimensions.-Tip of snout to vent, $35 \mathrm{~mm}$.; width of head, 15 $\mathrm{mm}$.; tip of snout to posterior border of tympanum, $12 \mathrm{~mm}$.; diameter of eye, $4 \mathrm{~mm}$.; diameter of tympanum $2.5 \mathrm{~mm}$.; foreleg from axilla, $21 \mathrm{~mm}$.; hindleg from vent, $53 \mathrm{~mm}$.; vent to heel, $32 \mathrm{~mm}$.

"Color (in alcohol).-The ground color has badly bleached and altered, due to poor preservation, and appears now as a pale olivebuff. The color pattern is very distinct, however, and is unlike that of any other known Eleutherodactylus from Hispaniola. A broad pale band between the eyes is emphasized posteriorly by a narrow brown irregular line caused by the grouping of small brown dots which thickly cover the upper anterior parts of the body, the snout and forelegs, less thickly on the posterior parts and hindlegs. The back of the thighs is strongly marked by very characteristic coarsely-reticulated dark brown blotches on a very light background. A few similar blotches appear on the front of the thigh and on the sides near the groin. The entire lower surface appears to be immaculate olive-buff. The sides of the snout and head are thickly peppered with small brown dots which are not arranged in any definite pattern.

"Variation.-There are three other specimens of this species (U.S. N.M. Nos. 72618-20) with the same data as the type, but in even poorer condition. They all show the perfectly distinctive dark blotches on the back of the thigh and in the region of the groin. One of these, 72619 , shows a brown semicircular line bordering the upper part of the tympanum on what appears to be a faint glandular ridge. The interocular light band may also be plainly seen on this frog. The other two specimens are devoid of head markings.

"In 72620, a small individual somewhat less shriveled than the type, the disk of the third finger very nearly covers the tympanum. In 72619 only is the granulation of the belly skin very apparent, the other specimens having suffered considerably in the mutilation of this part of the body. On none of the paratypes can any longitudinal glands or dorsolateral folds be made out, this species evidently being of the smoother skinned ones. The paratypes are all smaller than the type, measuring respectively 28,29 and $32 \mathrm{~mm}$. from snout to vent."

In a series of frogs from Moron evidently referable to this species, a uniform light color is prevalent. Slight traces of a web between the toes are to be seen in some examples. The outline of the snout viewed from above appears less pointed in some individuals than in others.

Relationships.-This form is closely related to E. auriculatoides, being obviously of the same stock as the Cuban auriculatus. It differs from auriculatoides in having a slightly longer eye and a longer 
snout, also in having a more distinct trace of web between the toes, and in having a spotted posterior femur usually.

Specimens examined.-U.S.N.M. No. 72617, Fonds-des-Nègres, Haiti, April 5, 1927, Dr. A. Wetmore, type; U.S.N.M. Nos. 7261872620, same data, paratypes; U.S.N.M. Nos. 60627-60635, Moron, Haiti, December 20, 1917, W. L. Abbott; and U.S.N.M. Nos. 60650 and 60651, Moron, Haiti, December 24, 1917, W. L. Abbott.

\section{ELEUTHERODACTYLUS AURICULATUS AURICULATOIDES Noble}

FigURE 25

1923. Eleutherodactylus auriculatoides Noble, Amer. Mus. Nov., No. 61, p. 3.Schmidt, Amer. Mus. Nov., No. 279, p. 2, 1927; Scientific Survey of Porto Rico and the Virgin Islands, New York Acad. Sci., vol. 10, pt. 1, pp. 29, 50, 1928.-Barbour and Loveridge, Bull. Mus. Comp. Zool., vol. 69, No. 10, p. 257 , 1929.-BARBour, Zoologica, vol. 11 , No. 4, p. 75 , 1930; vol. 19 , No. 3, p. $91,1935$.

1937. Eleutherodaclylus auriculatus auriculatoides Barbour, Bull. Mus. Comp. Zool. vol. 82, No. 2, p. 98.

Original description.-"Type.-A.M.N.H. No. 11403; adult, †; bromeliads near Constanza-Jarabacoa Trail, Paso Bajito, Dominican Republic; September 4, 1922; G. K. Noble.

"Description of Type.- Head broader than long, broader than body; distance between anterior corner of eye and nostril equals the greatest diameter of the eye, a trifle less than the interorbital width; distance between nostril and tip of snout contained a trifle over two times in the distance between nostril and eye; canthus rostralis distinct, although the loreal region slopes gradually; tympanum distinct, its greatest diameter equal to a trifle less than half the greatest diameter of the eye; separated from the eye by a space equal to its diameter. Tibio-tarsal joints of either side overlap when the legs are placed at right angles to the body; tibio-tarsal articulation reaches the posterior corner of the eye. Disks of fingers and toes pronounced, rounded; digits free; second toe (measured with dividers from distal side of its base) longer than first; no tarsal fold. Vomerine teeth in two oblique series well behind choanæ, extending outward not beyond the inner edge of the choanæ; the two series separated from each other by less distance than that which separates them from the choanæ; tongue thick, slightly nicked behind. Skin finely granular above; the granules forming more or less regular rows on the sides; belly, and thighs (except flash surfaces) coarsely granular.

"Ground tone (in alcohol) a pale gray or fiesh-color; tip of snout and parietal region with adjacent parts of eyelids dark reddish brown, thus giving the appearance of a light band across the head in front of the parietal region; a canthal and supratympanic streak of dark reddish brown; back and upper surfaces of limbs diffused with brown, 
leaving only an indistinct $\mathrm{W}$ on the occiput and a) ( mark anterior to the pelvis of the pale ground tone; ventral surfaces straw-color, slightly diffused with brown on the sides.

"Measurements.- Tip of snout to vent, $33.0 \mathrm{~mm}$.; tip of snout to posterior border of tympanum, $12.0 \mathrm{~mm}$.; greatest breadth of head, $14.0 \mathrm{~mm}$.; distance from axilla to tip of longest finger, 18.5

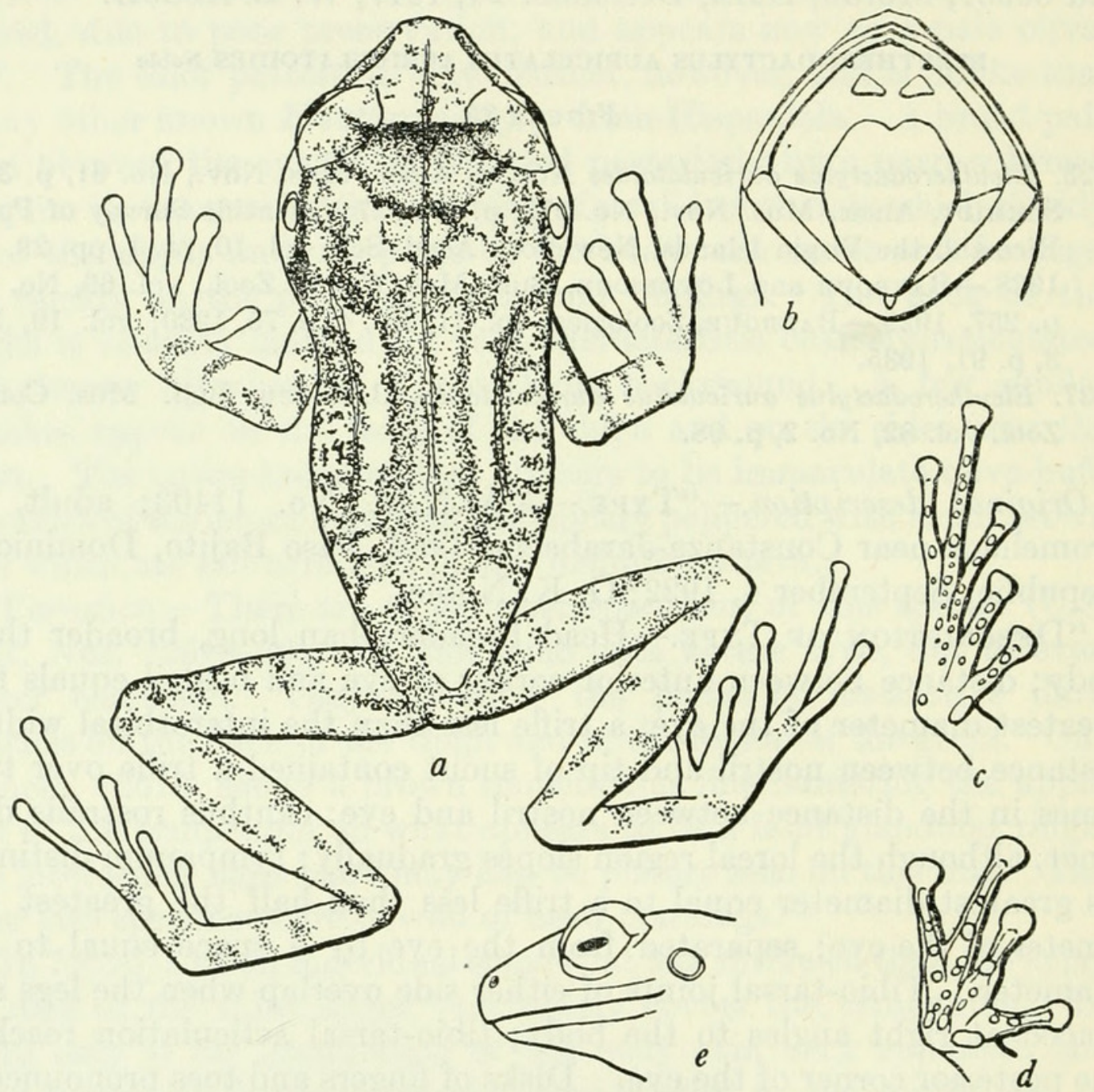

FIGURE 25.-Eleutherodactylus auriculatus auriculatoides: $a$, Dorsal view; $b$, inside of mouth; $c$, underside of hindfoot; $d$, underside of forefoot; $e$, side of head. A.M.N.H. paratype, from Paso Bajito, Dominican Republic. Twice natural size.

$\mathrm{mm}$; distance from vent to tip of longest toe, $51.5 \mathrm{~mm}$; tibia, 16.0 mm."

Specimens examined.-One (A.M.N.H.), a paratype, of E. auriculatoides collected September 4, 1922, at Paso Bajito, Dominican Republic, by G. K. Noble; two (M.C.Z. Nos. 9321 and 9322), same data.

Remarks.-Well-preserved series of frogs showing the characters of both auriculatoides and montanus were secured by P. J. Darlington at Loma Rucilla northwest of Constanza, at Loma Vieja south of the city, and at Valle Nuevo southeast of it. The largest specimen, 
U.S.N.M. No. 107607, measures $41 \mathrm{~mm}$., while the reported maximum of auriculatoides is $33 \mathrm{~mm}$. and of montanus $24 \mathrm{~mm}$. This specimen has an eye diameter exeeding the distance between eye and nostril, and equal to the interorbital width. Its adpressed heel reaches to between eye and nostril, it has a slight tarsal fold, and its toes show a vestigial web, in all of which characters it differs from the type of auriculatoides. The remainder of the specimens vary somewhat as to prominence of eye, length of leg, acuteness of snout, and very much as to color pattern. A brown interorbital band seems to be present in all specimens. Some of the Loma Rucilla frogs have the concealed surfaces of tibia and femur immaculate orange-buff to buff-yellow, a characteristic condition of montanus. In others the leg is clouded with dark pigment in these areas. Some of the specimens from each of the localities show a light )(-shaped dorsal marking, while others are uniformly dark above or show a W-shaped mark between the shoulders. The ventral surface fails to show any definite pattern, being suffused with dark in most examples. The vomerine teeth are quite constant as to position, but are unequally developed. The web between the toes is vestigial, but shows greater reduction in some cases than in others. Wider collecting in this region may eventually cause auriculatoides to be combined with montanus.

Specimens of intermediates between auriculatoides and montanus examined.-M.C.Z. Nos. 23466-23468, 23475-23480, 23483-23488, and U.S.N.M. Nos. 107600-107609, from Loma Rucilla, Dominican Republic, June 1938, P. J. Darlington; M.C.Z. Nos. 23501-23509 and U.S.N.M. Nos. 107610-107617, from Valle Nuevo in the Cordillera Central, August 1938, P. J. Darlington; M.C.Z. Nos. 23510-23514 and U.S.N.M. Nos. 107618-107620, from Loma Vieja south of Constanza, August 1938, P. J. Darlington.

\section{ELEUTHERODACTYLUS ARMSTRONGI Noble and Hassler}

Figure 26

1933. Eleutherodactylus armstrongi Noble and Hassler, Amer. Mus. Nov., No. 652, p. 2.-BARbour, Zoologica, vol. 19, No. 3, p. 92, 1935; Bull. Mus. Comp. Zool., vol. 82, No. 2, p. 98, 1937.

Original description.- "Diagnostic Characters.-Closely allied to $E$. wetmorei Cochran and $E$. auriculatoides Noble but differing from either in the narrower head, more extensive series of vomerine teeth, and distinctive coloration. The vomerine series extend lateral to the choanae. The dorsal surfaces are more or less spotted but the posterior surfaces of the thighs, unlike those of $E$. wetmorei, are uncolored or uniformly toned. Further, the spots are small and do not run together to form blotches except bordering the pale dorsolateral and interorbital stripes. 
"Detailed Descriptions.-Type A.M.N.H. No. 44554, adult female. Collected at 'El Propio Esfuerzo,' coffee finca of Luis E. Del Monte, near Barahona, D. R., at an altitude of 1,800 feet, on August 3, 1932, by W. G. Hassler.

"Head a trifle longer than broad, not so broad as body; distance between anterior corner of eye and nostril a little less than the greatest diameter of the eye, equal to the interorbital width; distance between nostril and tip of snout contained two times in the distance between nostril and eye; canthus rostralis rounded; tympanum well defined,

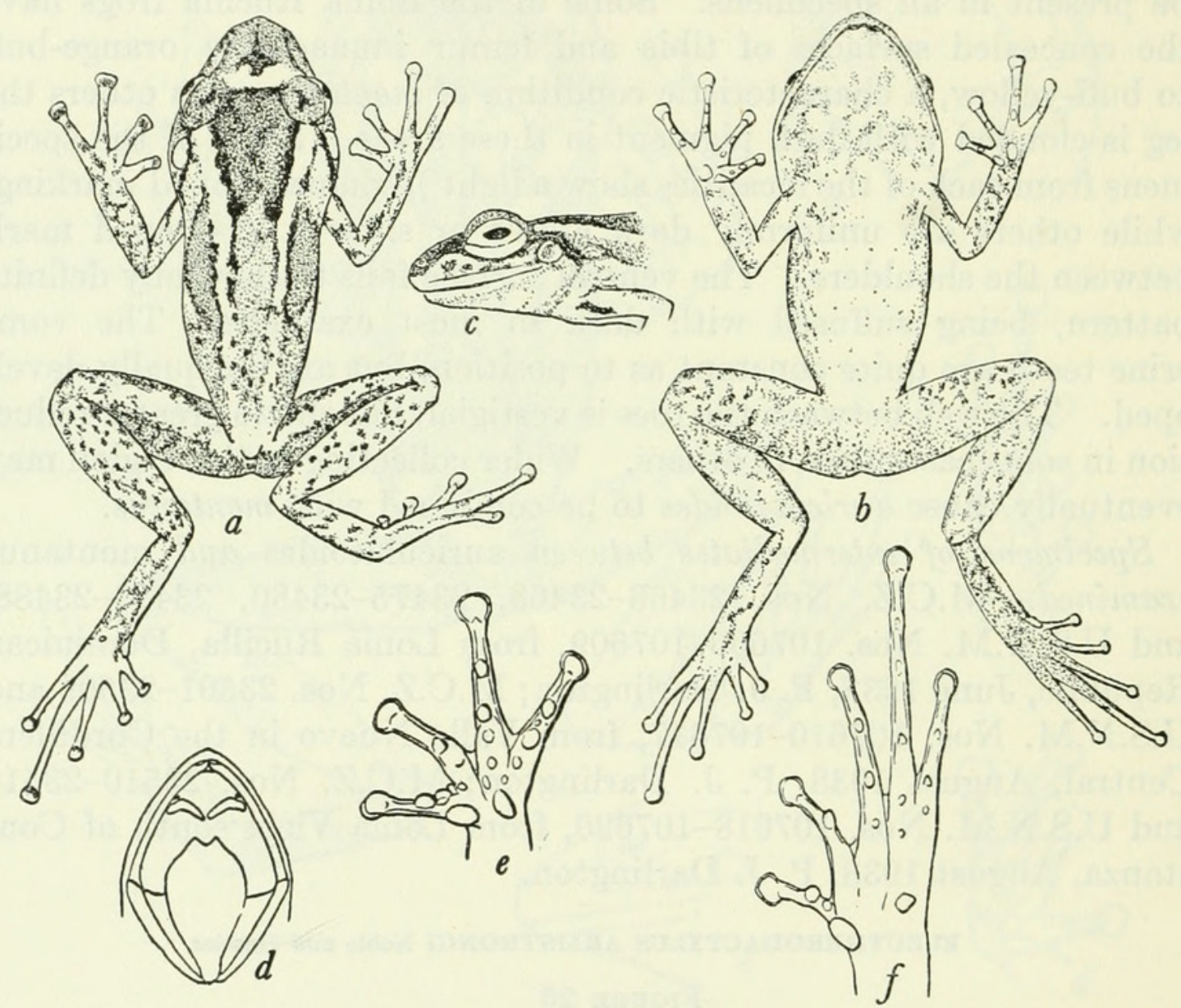

Figure 26.-Eleutherodactylus armstrongi: $a$, Dorsum; $b$, venter; $c$, profile of head; $d$, inside of mouth; $e$, underside of hand; $f$, underside of foot. A.M.N.H. No. 44657, paratype, from north of Polo, Dominican Republic. $a-d, \times 1 \frac{1}{2} ; e, f, \times 3$.

its greatest diameter a little greater than half the diameter of the eye, separated from the eye by a space a trifle less than its diameter. Tibiotarsal joints of either side slightly overlap when the legs are placed at right angles to the body; tibiotarsal articulation reaches the posterior corner of the eye. Discs of the three outer fingers well developed, truncate, that of the outer finger as broad as the diameter of the tympanum; discs of the toes and of the inner finger smaller and rounded. Digits free; no tarsal fold, but a very poorly defined ridge present in the position of a tarsal fold. Vomerine teeth caudal to the choanae, in two arched series which begin lateral to the outer 
margin of the choanae and extend nearly to the midline. Tongue thick, not emarginate behind. Skin very finely granular or irregularly ridged above, belly smooth in the center, slightly granular on the sides, ventral surfaces of the thighs coarsely granular.

"Ground tone (in alcohol) a pale gray or brownish; a pair of dorsolateral stripes and a narrow interorbital band a slightly paler tone. Entire dorsal surface of the head and body except for these stripes and the canthal region of each side spotted with dark brown, the spots tending to run together along either margin of the stripes. Dorsal surface of the appendages more finely spotted with the same color; posterior surfaces of the thighs suffused with brown but not spotted. Ventral surfaces of head and body stippled with grayish brown, the tone nearly uniform on the throat and chest but tending to become blotched on the abdomen, the center of which remains uncolored. Ventral surfaces of the limbs stippled or washed with the same color.

"Dimensions.-Tip of snout to vent, $35 \mathrm{~mm}$.; width of head, 12 $\mathrm{mm}$.; tip of snout to posterior border of tympanum, $12.5 \mathrm{~mm}$.; foreleg from axilla, $23 \mathrm{~mm}$; hindleg from vent, $51 \mathrm{~mm}$.; vent to heel, $28 \mathrm{~mm}$.

"Variation.-The 37 paratypes in the series (A.M.N.H. Nos. $44550,44558-64,44598,44607-8,44633-41,44652-65,44667-9)$ vary considerably in the degree of spotting. In some specimens (in alcohol) the ground tone on the back between the pale dorsolateral stripes is a chestnut brown nearly as dark as the spotting, which may be much reduced. The spots vary in size and in several specimens fail to form a dark margin to the pale stripes. In other specimens the dorsolateral stripes may extend from the head only to the middle of the back or be absent entirely.

"In life the type, when caught at night, was a light yellowish-brown, spotted with darker brown. Next day the dorsal ground tone was a rich golden-brown spotted with very dark brown. The dorsolateral stripes, a region directly over the eyes and extending on either side to the snout, and an irregular bar between the anterior corners of the eyes were clear and translucent. The legs, lateral and posterior portions of the body were light golden-brown with smaller dark spots. The throat was darker than the belly, and brownish. The eyes were yellowish green-gold suffused with brown in the posterior part. The other specimens varied in color, some having a dorsal ground tone of reddish brown with the light areas on the head, the dorsolateral stripes and the arms and legs of a distinct reddish hue; the sides and belly yellowish. Others had a ground color of grayish brown, the dorsolateral stripe and light areas on the head a golden brown; the sides, legs, and throat a grayish brown and the belly white. 
"Habitat.-This species appears to be common throughout the region studied, becoming more abundant as the altitude, and hence humidity, increases. A few specimens were taken at 1800 feet and more between 3000 and 3200 feet near Barahona. Other specimens were taken at 2400 feet near Paradis, 3700 feet near Polo, and 3000 feet at Maniel Viejo. They were usually found in the ends of hollow stems and other cavities such as the base of banana leaves and certain mountain palms though occasionally they were discovered among damp leaves and stones on the ground."

A paratype, A.M.N.H. No. 44657, from north of Polo, Dominican Republic, taken on October 19, 1932, by W. G. Hassler, has the following points of difference from the description of the type: Head as long as broad; tympanum separated from eye by an interval equal to half its own diameter; adpressed heel reaching to center of eye; outer finger disk equal to two-thirds the tympanic diameter; tongue distinctly emarginate behind; posterior surface of thighs wood brown with many small darker spots; abdomen nearly immaculate: Head and body, $28 \mathrm{~mm}$.; head length, $10 \mathrm{~mm}$.; head width, $10 \mathrm{~mm}$.; foreleg, $18 \mathrm{~mm}$; hindleg from vent, $42 \mathrm{~mm}$.; vent to heel, $23 \mathrm{~mm}$.; tibia, 13 mm.; eye, $4 \mathrm{~mm}$.; tympanum, $2 \mathrm{~mm}$.

\section{ELEUTHERODACTYLUS BAKERI Cochran}

Figure 27

1935. Eleutherodactylus bakeri Cochran, Proc. Boston Soc. Nat. Hist., vol. 40, No. 6, p. 369.-BARBour, Bull. Mus. Comp. Zool., vol. 82, No. 2, p. 101, 1937.

Original description.- "Diagnosis.-Belly and thighs heavily granular; upper eyelid without a spinelike tubercle; fingers and toes rounded at the tips; snout blunt, rather truncate in profile, not shovel shaped; femur rather short; tibio-tarsal articulation reaching to posterior corner of eye.

"Type.-M.C.Z. 19,837, an adult from Mt. La Hotte, Haiti, 5,000 to 7,800 feet altitude, collected in October, 1934, by P. J. Darlington.

"Description of the type.-Tongue moderate, scarcely emarginate behind; vomerine teeth in two short, heavy, slanting series behind the choanæ, rather narrowly separated on the midline, their outer borders not extending beyond the center of the choanæ; head very broad, its greatest width about one and one-half times the distance from end of snout to occiput, with a pronounced swelling on each side of the occiput; no subgular pouch evident, although a slight trace of a fold occurs on the chest between the forelimbs; nostril much nearer snout than eye, its distance from eye equal to diameter of the latter; upper eyelid one-half the interorbital width; tympanum equal to two-thirds the diameter of the eye, its distance from the eye equal to its own diameter; fingers and inner toes free; a vestige of a 
web between fourth and fifth toes; disks of fingers large, that of third finger covering over four-fifths of the tympanic area; first finger much shorter than second; disks of toes slightly smaller than those of fingers; first toe reaching to base of disk of second toe; subarticular tubercles well developed; two metatarsal tubercles, the outer small but distinct, the inner large and rather flattened; no enlarged plantar tubercles; a faint tarsal ridge but no fold; femur rather short; the limbs being pressed along the sides, the knee and elbow touch; hind limb being extended forward, the heel reaches the posterior corner of the eye; hind limbs being placed vertically to axis of body, heels slightly

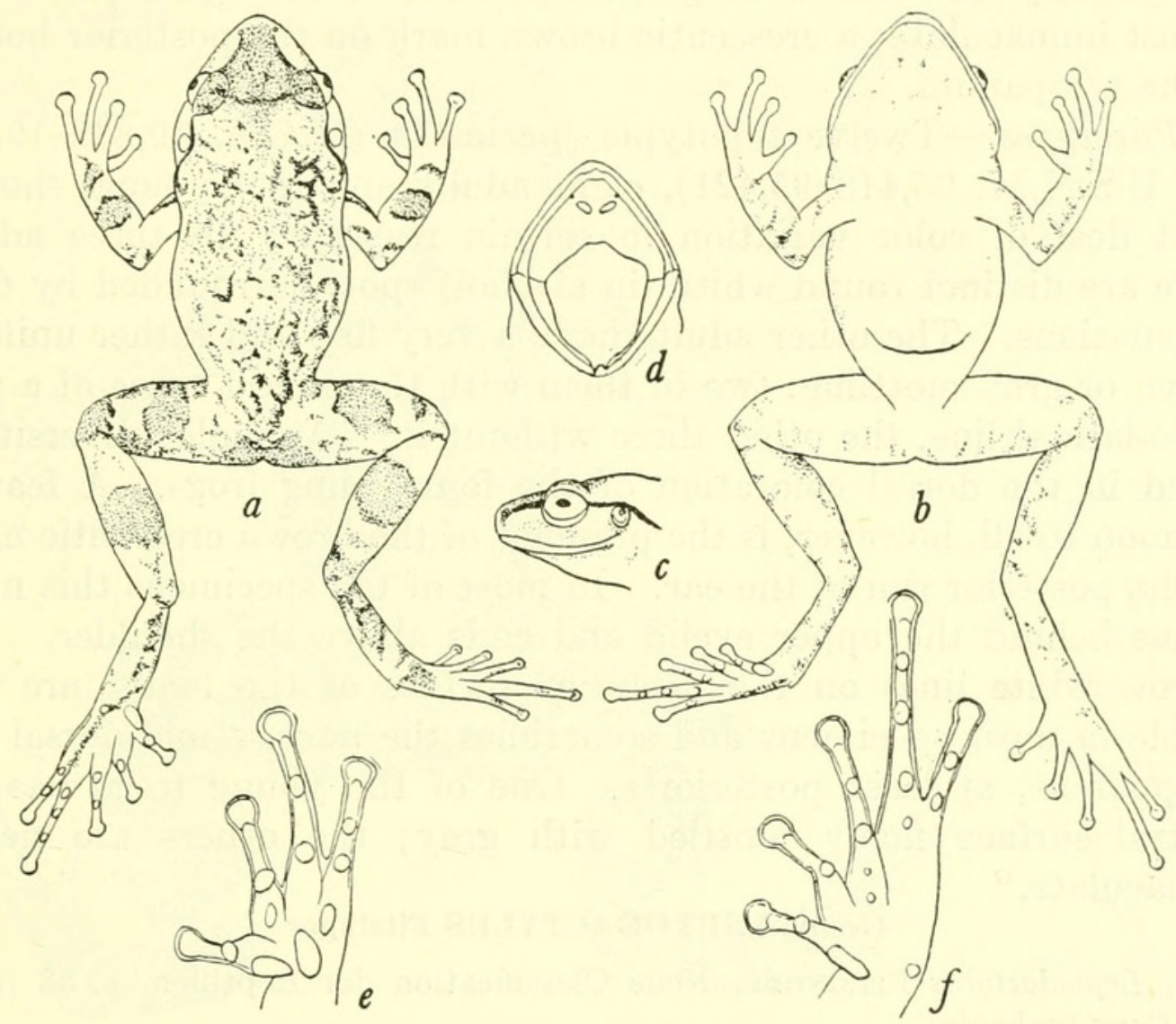

Figure 27.-Eleutherodactylus bakeri: $a$, Dorsum; $b$, venter; $c$, profile of head; $d$, inside of mouth; $e$, underside of hand; $f$, underside of foot. U.S.N.M. No. 95420, paratype, from Morne La Hotte, Haiti. $a-d$, Natural size; $e, f$, twice natural size.

overlap; a few elongate glands on the mid-dorsal line especially pronounced on head, much less so on body; some very narrow elongate glands above the ear and on the sides and anterior part of back; skin above shagreened; eyelids tubercular; chin smooth; chest, belly and thighs heavily granular.

"Dimensions.-Tip of snout to vent, $38 \mathrm{~mm}$.; width of head, 17 $\mathrm{mm}$.; tip of snout to posterior tympanum, $14 \mathrm{~mm}$.; diameter of eye, $4 \mathrm{~mm}$; foreleg from axilla, $24 \mathrm{~mm}$; hindleg from vent, $58 \mathrm{~mm}$.; vent to heel, $32 \mathrm{~mm}$. 
"Color in alcohol.-Ground color drab-gray, tinged with olive-buff on the legs; upper part of snout mouse-gray; a broad Y-shaped sealbrown mark between the eyes, prolonged over the back into an irregular wide mottled area, edged laterally by a few small darker spots and with a broken light mid-dorsal line down the center which forks above the vent and continues down the back of the femur; lower parts of sides mottled with mouse-gray, the upper lateral regions more or less immaculate pale drab-gray; the swellings on each side of the occiput also pale drab-gray; upper surfaces of limbs with wide gray crossbars; ventral surfaces immaculate olive-buff, the soles of the feet slightly suffused with gray; lips and loreal region pale-drab, almost immaculate; a crescentic brown mark on the posterior border of the tympanum.

"Paratypes.-Twelve topotypic specimens (M.C.Z. 19,838-19,845 and U.S.N.M. 95,418-95,421), eight adults and four young, show a great deal of color variation in certain respects. In three adults there are distinct round white (in alcohol) spots surrounded by dark reticulations. The other adults have a very fine and rather uniform brown or gray mottling, two of them with the merest trace of a pale dorso-lateral line, the other three without it. A similar diversity is found in the dorsal coloration of the four young frogs. A feature common to all, however, is the presence of the brown crescentic mark on the posterior rim of the ear. In most of the specimens this mark begins behind the upper eyelid and ends above the shoulder. The narrow white lines on the posterior surface of the femur are also visible in most specimens and sometimes the narrow mid-dorsal line is apparent, at least posteriorly. One of the young frogs has the ventral surface finely mottled with gray; the others are nearly immaculate."

\section{Genus LEPTODACTYLUS Fitzinger}

1826. Leptodactylus Fitzinger, Neue Classification der Reptilien, p. 38 (type, Rana typhonia).

The discovery of a member of this genus in Hispaniola established one more bond linking the fauna of this island with that of Puerto Rico, although the distinctness of the two species involved gives evidence of the long physical separation of Hispaniola.

\section{LEPTODACTYLUS DOMINICENSIS Cochran}

FIGURE 28

1923. Leptodactylus dominicensis Cochran, Journ. Washington Acad. Sci., vol. 13, No. 9, p. 184.- Sснміdт, Scientific Survey of Porto Rico and the Virgin Islands, New York Acad. Sci., vol. 10, pt. 1, pp. 24, 29, 38, 40; fig. 7, p. 39, 1928.-BARBour, Zoologica, vol. 11, No. 4, p. 80, 1930; vol. 19, No. 3, p. 97; 1935; Bull. Mus. Comp. Zool. vol. 82, No. 2, p. 107, 1937.

Original description.-“Type.-U.S.N.M. No. 65670, Las Cañitas, Dominican Republic; February 25, 1923; Dr. W. L. Abbott, collector. 
"Description of type specimen.-Vomerine teeth in two long curved series beginning behind the middle of the choanae, separated by the width of the choanae; tongue moderate in size, heart-shaped; snout pointed, depressed, sharp-edged, declining rapidly from the eyes to the tip; when viewed in profile, upper lip projects considerably beyond lower lip; canthus rostralis sloping and very indistinct; nostrils a little nearer to end of snout than to eye; tympanum longer than high, its greatest diameter very slightly more than half the diameter of eye; interorbital space equals width of upper eyelid; first finger much

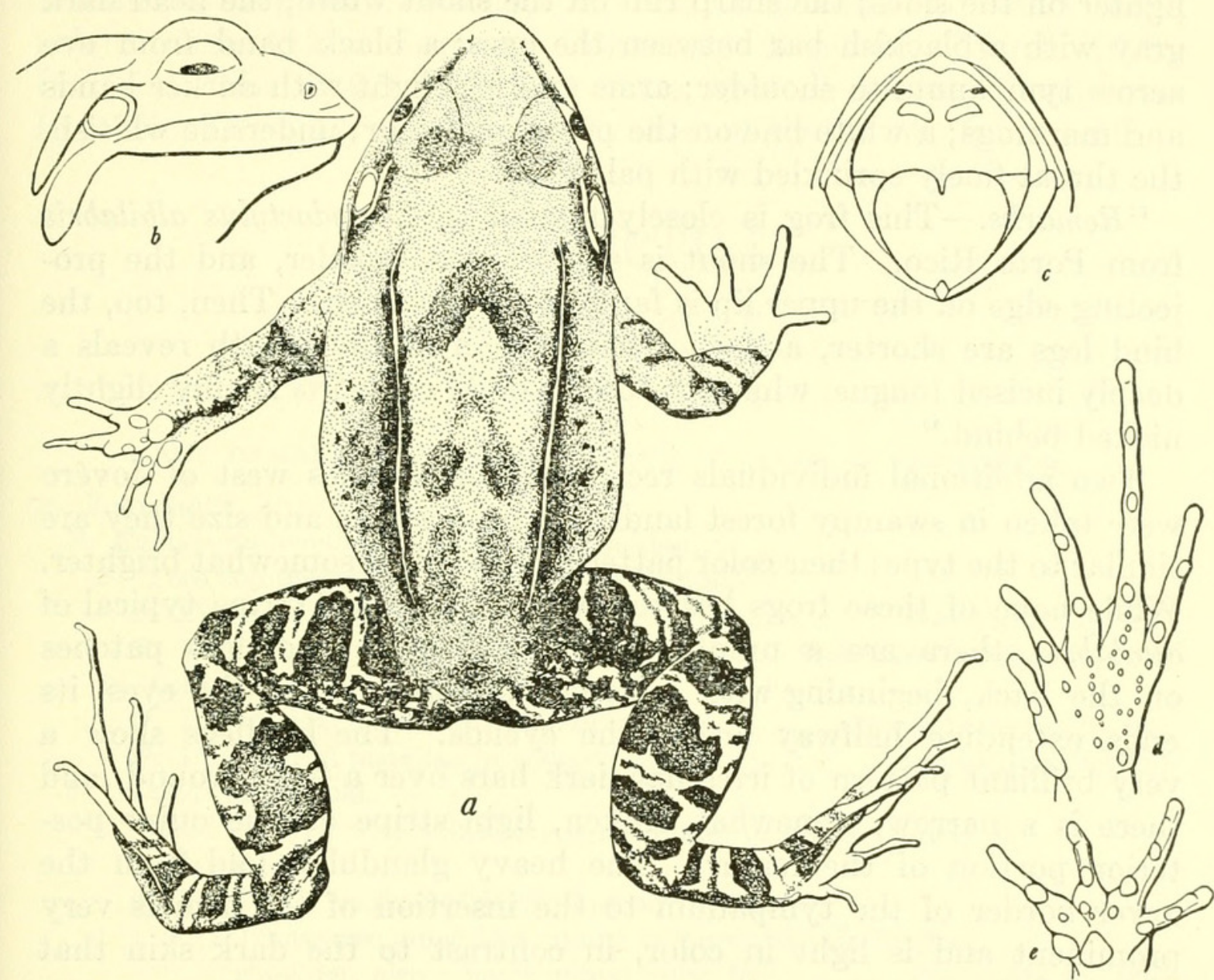

Figure 28.-Leptodactylus dominicensis: $a$, Dorsal view; $b$, side of head; $c$, inside of mouth; $d$, underside of hindfoot; $e$, underside of forefoot. U.S.N.M. No. 65670, type, from Las Cañitas, Dominican Republic. Twice natural size.

longer than second, which equals fourth; toes slightly webbed at base; third much longer than fifth; subarticular tubercles well developed; numerous smaller tubercles in series on the sole; two metatarsal tubercles, the inner connected with a very distinct tarsal fold; heels just touching when hind limbs are folded at right angles to axis of body; tarsometatarsal joint reaching anterior border of tympanum when hind limbs are carried forward along the body; skin smooth above and below; numerous small, pointed glands on the 
outer surface of the tibia; a narrow dorso-lateral glandular fold, and a few elongate glands on the sides; a strong glandular fold from posterior angle of eye over tympanum to shoulder; ventral disk plainly marked by dermal folds.

"Dimensions.-Tip of snout to vent, $36 \mathrm{~mm}$.; tip of snout to posterior edge of tympanum, $13 \mathrm{~mm}$.; greatest width of head, $13 \mathrm{~mm}$.; foreleg from axilla, $19 \mathrm{~mm}$.; hindleg from vent to heel, $26 \mathrm{~mm}$.; hindleg from vent to tip of fourth toe, $49 \mathrm{~mm}$.

"Coloration (in alcohol).-Body dark bluish-gray above, becoming lighter on the sides; the sharp rim on the snout white; the head dark gray with a blackish bar between the eyes; a black band from eye across tympanum to shoulder; arms and legs light with darker bands and markings; a white line on the posterior femur; underside whitish, the throat finely sprinkled with pale gray.

"Remarks.-This frog is closely related to Leptodactylus albilabris from Porto Rico. The snout is shorter and broader, and the projecting edge on the upper lip is far more pronounced. Then, too, the hind legs are shorter, and the examination of the mouth reveals a deeply incised tongue, while the tongue of $L$. albilabris is only slightly nicked behind."

Two additional individuals received from 4 miles west of Jovéro were taken in swampy forest land. In proportions and size they are similar to the type; their color pattern, however, is somewhat brighter. While none of these frogs has the wide light dorsal stripe typical of albilabris, there are a number of irregularly shaped dark patches on the back, beginning with a large chevron between the eyes, its ends extending halfway across the eyelids. The hindlegs show a very brilliant pattern of irregular dark bars over a light ground, and there is a narrow, somewhat broken, light stripe on the outer posterior portion of the femur. The heavy glandular fold from the lower border of the tympanum to the insertion of the arm is very prominent and is light in color, in contrast to the dark skin that surrounds it.

A tadpole from Laguna collected in March 1923 is now provisionally referred to this species. Its arms and legs are fully formed, and its head shows that it is rapidly becoming a frog. Its tail is exceedingly long, measuring $24 \mathrm{~mm}$., while the head and body taken together measure only $15 \mathrm{~mm}$. Evidently the absorption of the tail does not commence until the limbs are fully functional. It is interesting to find that Noble's ${ }^{4}$ figure of the larva of Leptodactylus albilabris has almost precisely the same proportion of tail and body, although it is much less advanced and has no limb buds. This proportion likewise agrees with Stejneger's figure ${ }^{5}$ of the tadpole of albilabris on which the hind limbs have just appeared.

' Ann. New York Acad. Sci., vol. 30, p. 87, 1927.

s Rep. U. S. Nat. Mus. for 1902, p. 577, 1904. 
This species belongs to a different group from that containing $L$. validus of Grenada and St. Vincent, the latter group being characterized by a pair of black spines on the first finger of the male as well as by a rounded snout. In $L$. dominicensis, and several others related to albilabris, no finger spines are found in the male, while the snout in profile shows a more or less distinct rim. The femur is also much shorter in dominicensis than in validus, while the color pattern is dissimilar.

Specimens examined.-U.S.N.M. No. 65670 (type), Las Cañitas, Dominican Republic, February 25, 1923; U.S.N.M. No. 65671 (tadpole), Samaná and Laguna, Dominican Republic, March 1923; U.S.N.M. Nos. 66675, 66676, 4 miles west of Jovéro, Dominican Republic, December 4, 1923. All collected by Dr. W. L. Abbott.

\section{Class REPTILIA Order SQUAMATA}

\section{Suborder SAURIA}

KEY TO GENERA OF LIZARDS KNOWN TO OCCUR IN HISPANIOLA

$a^{1}$. Four limbs.

$b^{1}$. Eyelids undeveloped (family Gekkonidae).

$c^{1}$. Toes compressed; pupil round or subelliptical.

$d^{1}$. Toes undilated at tip._.......... Gonatodes (p. 88)

$d^{2}$. Toes dilated at tip only _............ Sphaerodactylus (p. 103)

$c^{2}$. Toes dilated at base; pupil vertical.

$d^{1}$. Infradigital lamellae in a double series_...... Hemidactylus (p. 91)

$d^{2}$. Infradigital lamellae in a single series.......... Aristelliger (p. 96)

$b^{2}$. Eyelids functional.

$c^{1}$. Head covered with relatively small scales or plates (family

Iguanidae).

$d$. Toes with marked dilations but no "combs."

$e^{1}$. A transverse gular fold ending in heavy folds in front of shoulder, also a longitudinal gular fold....... Audantia (p. 188)

$e^{2}$. Usually a longitudinal gular fold only (except in Anolis hendersoni).

$f^{1}$. Compressed distal phalanges inserted at end of expanded part of digit............ Chamaelinorops (p. 126)

$f^{2}$. Compressed distal phalanges arising above expanded part of digit.

$g^{1}$. Tail prehensile_... Anolis (p. 128)

$g^{2}$. Tail not prehensile

$d^{2}$. Toes not dilated, but outer ones with lateral "combs."

$e^{1}$. A dorsal crest.

$f^{1}$. Tail heavily verticillated; size large.......... Cyclura (p. 195)

$f^{2}$. Tail not verticillated; size relatively small_ Leiocephalus (p. 202)

$e^{2}$. No dorsal crest......... Hispaniolus (p. 241) 
$c^{2}$. Head covered with relatively large regular shields.

$d^{1}$. Occipital shield present (family Anguidae).

$e^{1}$. External ear opening present.

$f^{1}$. Limbs strong, 5-toed. Celestus (p. 243)

$f^{2}$. Limbs weak, 4-toed Sauresia (p. 255)

$e^{2}$. No external ear opening.

Wetmorena (p. 259)

$d^{2}$. Occipital shield absent.

$e^{1}$. Ventral scales rounded, imbricate (family Scincidae)_.Mabuya (p. 303)

$e^{2}$. Ventral scales in squarish series, scarcely imbricate

(family Teiidae)

Ameiva (p. 262)

$a^{2}$. No limbs (family Amphisbaenidae) ........... Amphisbaena (p. 297)

Of the 17 genera listed above, 4 are endemic-Audantia and Hispaniolus of the family Iguanidae and Wetmorena and Sauresia of the family Anguidae. The species of Hemidactylus-brookii and mabouia-were introduced, and probably Sphaerodactylus cinereus also.

\section{Family GEKKONIDAE}

\section{Genus GONATODES Fitzinger}

1843. Gonatodes Fitzinger, Systema reptilium, pp. 18, 91 (type, Gymnodactylus albogularis Duméril and Bibron).

Representatives of this genus occur in tropical regions of the Old World as well as in tropical America and the West Indies. One species is known from Hispaniola, where it seems to be rare. Much more collecting will have to be done before its range, variation, and habits can be satisfactorily discussed.

\section{GONATODES NOTATUS (Reinhardt and Lütken)}

\section{Figure 29}

1863. Gymnodactylus notatus Reinhardt and Lütren, Vid. Medd. Nat. Foren. (Kjöbenhavn), 1863, p. 280, extr. p. 128 (type locality, Acquin, Haiti; type, Mus. Copenhagen No. 18; collector, H. Koch).

1888. Gonatodes albogularis Fischer, Jahrb. Hamburg Wiss. Anst., vol. 5, p. 24 (Gonaïves, Haiti; H. Rolle, collector) (not of Duméril and Bibron).-MeerWARTH, Mitth. Nat. Mus. Hamburg, vol. 18, p. 16, 1901 (Port-au-Prince, Haiti).

1914. Gonatodes notatus Barbour, Mem. Mus. Comp. Zool., vol. 44, No. 2, p. 256; Zoologica, vol. 11, No. 4, p. 81, 1930; vol. 19, No. 3, p. 99, 1935; Bull. Mus. Comp. Zool., vol. 52, No. 2, p. 108, 1937.-Stejneger, Proc. U. S. Nat. Mus., vol. 53, p. 264, 1917.-Barbour and Ramsden, Mem. Mus. Comp. Zool., vol. 47, No. 2, p. 115, 1919.-Cochran, Proc. Biol. Soc. Washington, vol. 41, p. 54, 1928.

Description.-U.S.N.M. No. 74013, an adult male from Diquini Cave near Port-au-Prince, Haiti, collected on March 20, 1928, by A. J. 
Poole. Head fairly short, rather high; pupil vertically elliptical; snout obtusely rounded, very slightly longer than the distance from the eye to the ear opening, which is very minute and rounded; forehead slightly concave; limbs and body moderate; digits slender, narrow at the base, the scales under the basal joint slightly enlarged; 19 lamellae under the fourth toe; upper parts covered with small even granules, about 27 to 30 dorsal ones equaling the distance between the end of the snout and the center of the eye; granules on the snout slightly larger; rostral approximately triangular, with the apex cut off, and a long median cleft; nostril between the rostral and three or four surrounding scales, of which the supranasals are considerably enlarged and separated from each other by two granules; five upper and four lower labials, suceessively diminishing to a point beneath the center of the eye; posterior labials ill defined; mental very large, truncate behind, in contact with
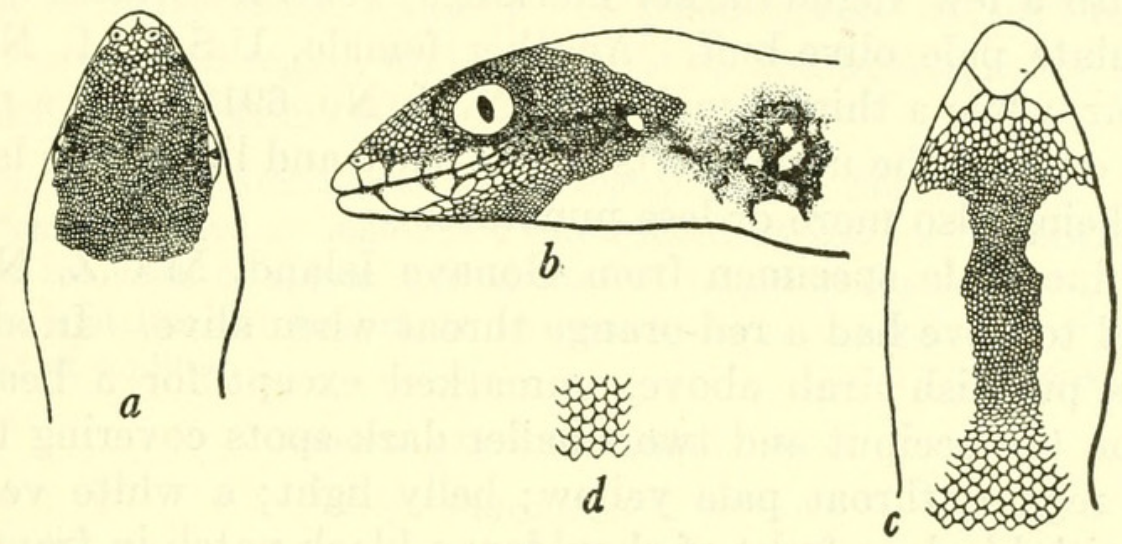

Figure 29.-Gonatodes notatus: $a$, Top of head; $b$, side of head and scapular pattern; $c$, chin and throat; $d$, ventral scales. U.S.N.M.No.74013, from Diquini Cave, Haiti. Three times natural size.

three slightly enlarged chin shields followed by others passing gradually into the minute granules of the gular region. Ventral scales larger than dorsals, about 13 or 14 equaling the distance between the end of the snout and the center of the eye, flat, rounded, and imbricating. Tail (partly reproduced) cylindrical, tapering, blunt at the tip, a little longer than head and body, covered above with uniform, small, slightly imbricate scales, inferiorly with larger scales, those of the median series enlarged and irregular in shape. Subfemoral scales large, equal in size to the largest of the postabdominals, and abruptly changing to the very small granular scales of the postfemoral regions.

Color (in alcohol): Dorsum olive-gray, darkening slightly toward snout. Throat white with lateral reticulations of geranium pink. Belly pale olive-gray; bottom of tail white. Upper and posterior lower labials with black markings. In front of shoulder a very irregu- 
lar patch of white, bordered all around by black, which gradually merges into the olive-gray dorsal color. A larger and less well-defined white patch on each side of the throat directly below the shoulder patches, these latter bordered faintly with gray spots, which tend to form a transverse band across the throat by fusing their inner borders. A large black patch on the groin, roughly triangular in shape.

Dimensions: Head and body, $32 \mathrm{~mm}$.; snout to center of eye, $5 \mathrm{~mm}$.; snout to posterior border of ear, $9 \mathrm{~mm}$.; diameter of eye, $2.5 \mathrm{~mm}$.; tail, $35 \mathrm{~mm}$.

Variations.-The difference in coloration between the two sexes is striking. An adult female, U.S.N.M. No. 74014, from the same locality as the male just described, is grayish white above, with six longitudinal series of about seven black spots each, which get larger posteriorly and fade out above the hindlegs; upper surface of tail and head with a few vague darker markings; ventral surfaces and labials immaculate pale olive-buff. Another female, U.S.N.M. No. 75899, is similar, while a third female, U.S.N.M. No. 69125 , has a powdering of dark dots on the upper parts of the body and limbs, the labials and throat being also more or less punctate.

The fine male specimen from Gonave Island, M.C.Z. No. 25424, was said to have had a red-orange throat when alive. In alcohol the body is purplish drab above, unmarked except for a heart-shaped patch on the occiput and two smaller dark spots covering the supraorbital region; throat pale yellow; belly light; a white vertical bar edged with black in front of shoulder; a black patch in front of groin, becoming lighter and disappearing before it reaches halfway to the axilla; tail above very faintly vermiculated, becoming lighter toward the tip. The scalation on this specimen is similar to that of U.S.N.M. No. 74013 .

TABLE 15.-Specimens of Gonatodes notatus examined

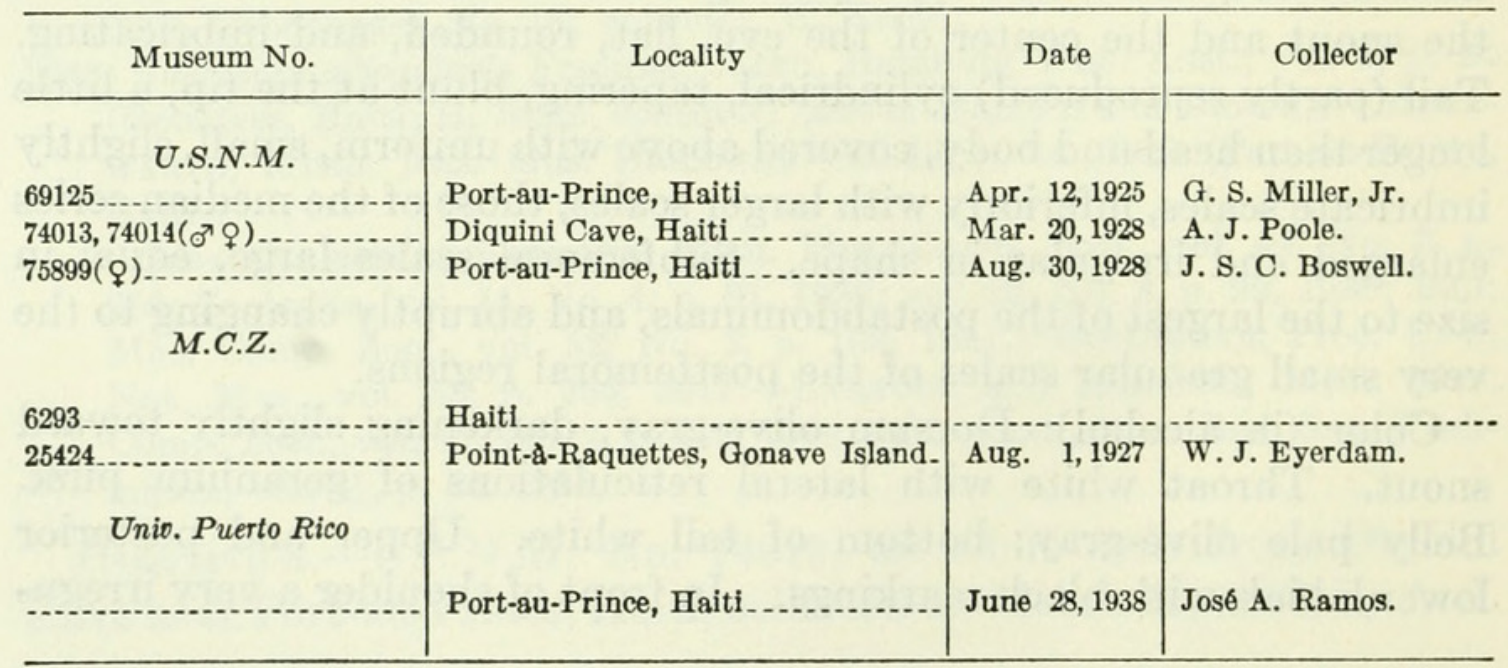


Relationship.-Dr. Stejneger has satisfactorily discussed the relationships of Gonatodes notatus to the Cuban fuscus. The smaller scales of the Cuban form separate it readily enough from the Hispaniolan lizard, which has conspicuously coarser scalation on the belly.

More material is needed before making an adequate study of the mainland relationships of Gonatodes notatus.

Specimens examined.-As listed in table 15.

\section{Genus HEMIDACTYLUS Oken}

1817. Hemidactylus Oken, Isis, 1817, p. 1183 (based on Cuvier's Hémidactyles, type, "Gecko tuberculeux Daudin").

The species Hemidactylus mabouia and H. brookii are so easily confused that some of the literature pertaining to Hispaniolan records of the one may really be attributable to the other. Maj. Chapman Grant has recently made a study ${ }^{6}$ of these two forms as they occur in the Puerto Rican region and his key is copied below, as it is applicable to the same forms in Hispaniola:

$a^{1}$. Six rows of spines around base of tail, dorsal pattern four black

V's; femoral pores of males not interrupted at midline_mabouia (p. 94)

$a^{2}$. Eight or ten rows of spines around base of tail, dorsal pattern

brown, mottlings or four rings; femoral pores of males inter-

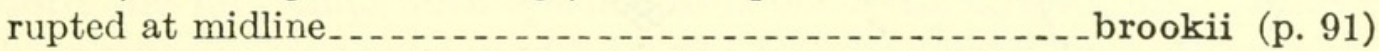

\section{HEMIDACTYLUS BROOKII Gray}

Figure 30

1844. Hemidactylus brookii Gray, The zoology of the voyage of H. M. S. Erebus and Terror, pl. 15, fig. 2, "Australia, Borneo"; Catalogue of the specimens of lizards in the collection of the British Museum, p. 152, 1845.-BARBour, Zoologica, vol. 11, No. 4, p. 82, 1930; vol. 19, No. 3, p. 99, 1935; Bull. Mus. Comp. Zool., vol. 82, No. 2, p. 109, 1937.-Grant, Journ. Dept. Agr. Puerto Rico, vol. 16, No. 1, p. 52, 1932.-Mertens, Senckenbergiana, vol. 20, No. 5, p. 333, 1938; Publ. Inst. Cient. Domínico-Alemán, vol. 1, p. 84, 1939.

1901. Hemidactylus brookii haitianus Meerwarth, Mitt. Nat. Mus. Hamburg, vol. 18, p. 17 (Haiti, Port-au-Prince).

1924. Hemidactylus mabouia Cochran, Proc. U. S. Nat. Mus., vol. 66, art. 6, p. 3 (not of Moreau de Jonnès).

1939. Hemidactylus brooki Böker, Publ. Inst. Cient. Domínico-Alemán, vol. 1, p. 16.

Description.-U.S.N.M. No. 65782, adult female from Samaná and Laguna, Dominican Republic, collected in March 1923 by W. L. Abbott. Rostral much broader than high, rectangular, with a nick in the posterior margin for the anterior angle of the internasal and a median cleft extending forward for more than one-half the height of the shield, in contact with two supranasals and a small internasal; first supralabial in contact with lower postnasal and reaching the

- The hemidactyls of the Porto Rican region. Journ. Dept. Agr. Puerto Rico, vol. 16, No. 1, pp. 51-57, pl. 101932 . 
nostril on left side but separated by a granular scale on right side of head; nostril between the rostral, first supralabial (on left side) and three scales behind and above, the upper one (supranasal) being much the larger; 10 upper labials, the last becoming very small and merging into the other granules, the suture between the eighth and ninth falling below the center of the eye; 8 lower labials, the last ones gradually becoming smaller; top of head covered with granules, which are largest on the snout, especially on the canthus rostralis, with a few coarser tubercles between the eyes; eye a little nearer to the ear than to the end of the snout, its diameter about two-thirds the length of the snout; ear opening vertical, oval, its maximum diameter greater than the height of the largest supralabial; temples granular like the top of the head, with scattered, keeled tubercles; mental triangular, as wide
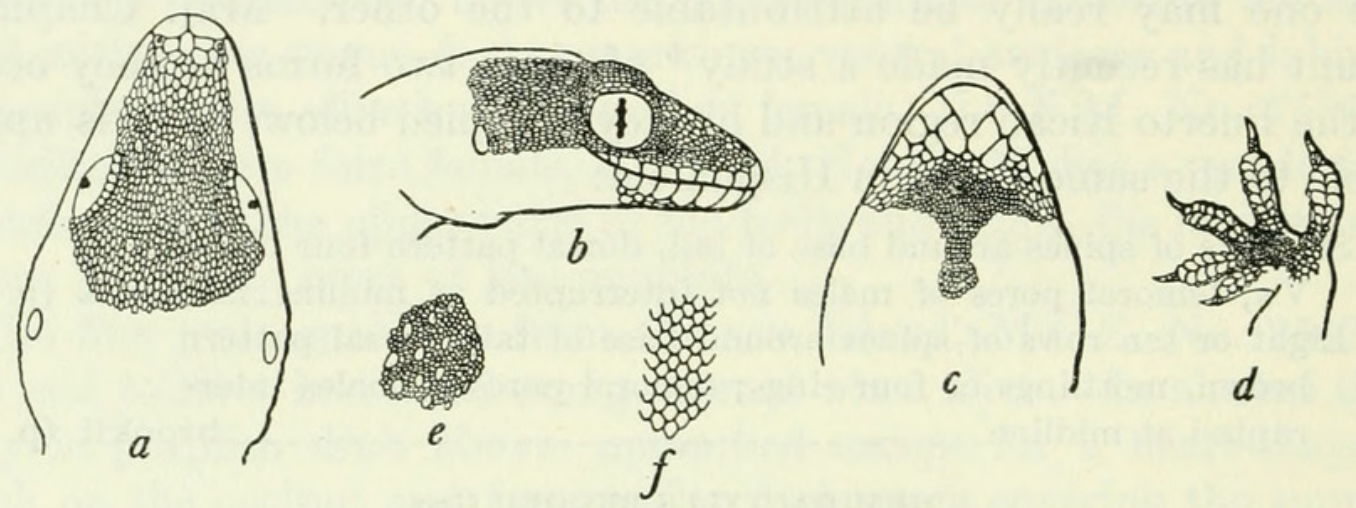

Figure 30.-Hemidactylus brookii: $a$, Top of head; $b$, side of head; $c$, chin; $d$, underside of hindfoot; $e$, dorsal scales; $f$, ventral scales. U.S.N.M. No. 65782, from Laguna and Samaná, Dominican Republic. Two and one-half times natural size.

as rostral, its free border not twice as wide as nearest infralabial; two chin shields on each side, the median pair much the larger, irregularly hexagonal, their inner anterior angle fitting into the corner between mental and first infralabial, rather narrowly in contact with each other on the median line and followed behind by small shields alternating with other smaller granules shortly merging into those of the throat; upper surface of body and flanks covered with granules a little larger and rounder than those of the back of the head, interspersed with large, convex, heavily keeled tubercles, each about as long as three or four granules; these tubercles show a tendency to form irregular longitudinal rows, there being about 16 across the middle of the back; throat covered with small, flat, uniform granules strongly contrasting with the imbricate cycloid scales of the rest of the under side and of the legs; abdominal scales are a little larger than the dorsal tubercles, about six contained in the distance from nostril to eye; on the under side of the thighs the single outer series of scales is larger, but without femoral pores in this (female) specimen; fingers and toes free, all with long, compressed, angularly raised and clawed 
distal phalanges; basal dilated portion with five pairs of lamellae under the inner toe and seven under the middle one in addition to the large unpaired terminal one; tail cylindrical, somewhat depressed, covered above with small flattened granules slightly larger than those on the snout; tail at the base with eight, distally with six, longitudinal rows of conical tubercles in whorls about six scales apart; under side with a median series of large plates about two to a whorl; the regenerated tip of the tail with irregularly arrayed scales without regular plates below.

Dimensions: Snout to posterior ear, $17 \mathrm{~mm}$. ; head and body, $58 \mathrm{~mm}$.; tail (tip reproduced), $60 \mathrm{~mm}$.

Color (in alcohol): Drab above, mottled with fine darker spots; generally cream-buff below, immaculate; upper labials with a few heavier dark markings most prominent on the upper margins.

Relationships.-This genus is one that establishes itself readily in new situations. Found on the west coast of Africa, it was undoubtedly carried to the West Indies by the slave trade and now appears to be established on Hispaniola, as well as in Cuba and Puerto Rico. To assign limits to the ranges of Hemidactylus mabouia and $H$. brookii remains for a more general faunistic study than this one. It suffices to record the fact that both species now occur in Hispaniola. Meerwarth's haitianus, it seems, had best not be recognized as a subspecies, as the chances are negligible that a fixed subspecies could have been evolved in so short time even in the new environment. An adequate study of variations can be significant only from one who is in a position to make a survey of the genus as a whole.

Specimens examined.-As listed in table 16.

TABLE 16.-Specimens of Hemidactylus brookii examined

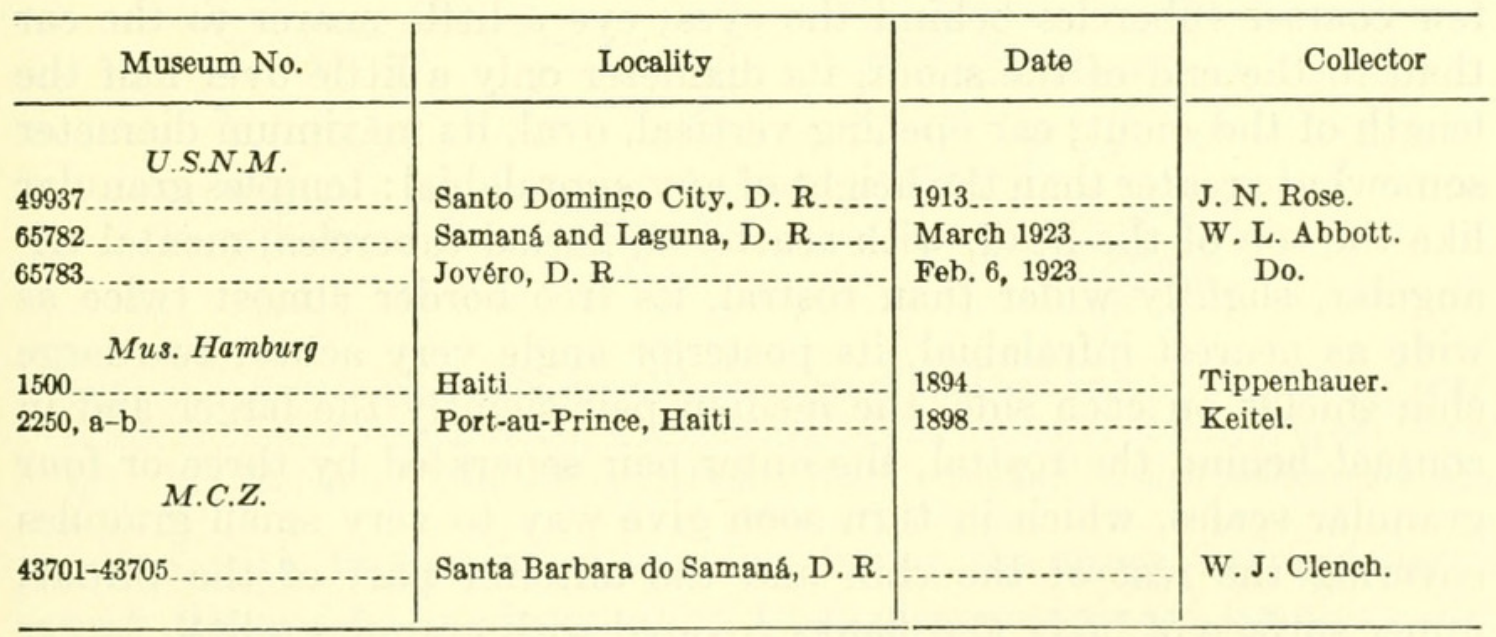




\section{HEMIDACTYLUS MABOUIA (Moreau de Jonnès)}

\section{FIGURE 31}

1818. Gecko mabouia Moreau De Jonnès, Bull. Soc. Philom. Paris, 1818, p. 138 (type locality, St. Vincent).

[As a complete synonymy of this species to 1902 has been given by Dr. Stejneger in his "Herpetology of Porto Rico," Rep. U. S. Nat. Mus. for 1902, pp. 549-724, 1904, it is necessary to cite here only those references pertaining to the West Indies subsequent to that year.]

1914. Hemidactylus mabouia Barbodr, Mem. Mus. Comp. Zool., vol. 44, No. 2, p. 22; Zoologica, vol. 11, No. 4, p. 82; 1930; vol. 19, No. 3, p. 99, 1935; Bull. Mus. Comp. Zool., vol. 82, No. 2, p. 109, 1937.-Stejneger, Proc. U. S. Nat. Mus., vol. 53, p. 267, 1917.-Barbour and Ramsden, Mem. Mus. Comp. Zool., vol. 47, No. 2, p. 117, 1919.-Grant, Journ. Dept. Agr. Puerto Rico, vol. 16, No. 1, p. 55, 1932.

Description.-M. C. Z. No. 1327, an adult male from Port-au-Prince, Haiti, collected on May 20, 1863, by O. Ackerman. Rostral much broader than high, rectangular, with a very small nick in the posterior margin for the anterior part of the very minute internasal and a median cleft extending forward for more than one-half the height of the shield, in contact with two large supranasals on each side of the small internasal; first supralabial narrowly entering the nostril, and in contact behind with the lower postnasal; nostril between the rostral, first supralabial and three scales behind and above, the upper one (supranasal) being much the larger; 11 or 12 upper labials, the last becoming very small and merging into the other granules, the suture between the tenth and eleventh falling below the center of the eye; 9 lower labials on the right side, 10 on the left, the last ones gradually becoming smaller; top of head covered with granules, which are largest on the snout, especially on the canthus rostralis, with a few coarser tubercles behind the eyes; eye a little nearer to the ear than to the end of the snout, its diameter only a little over half the length of the snout; ear opening vertical, oval, its maximum diameter somewhat greater than the height of any supralabial; temples granular like the top of the head, with scattered, keeled tubercles; mental triangular, slightly wider than rostral, its free border almost twice as wide as nearest infralabial, its posterior angle very acute; two large chin shields on each side, the median pair slightly the larger and in contact behind the rostral, the outer pair separated by three or four granular scales, which in turn soon give way to very small granules covering the rest of the chin and the anterior part of the throat; upper surface of body and flanks covered with granules a little larger than those of the back of the head, interspersed with large, convex, heavily keeled tubercles, each about as long as three granules; these tubercles show a tendency to form irregular longitudinal rows, there being about 12 across the middle of the back; under parts of body and 
limbs covered with imbricate cycloid scales contrasting with the minute granules on the chin and anterior part of the throat; abdominal scales considerably larger than the dorsal tubercles, about 9 contained in the distance from nostril to eye; on the under side of the thighs the outer row of scales is larger, bearing 32 femoral pores, which are not interrupted in the middle; fingers and toes free, all with long, compressed, angularly raised and clawed distal phalanges; basal dilated

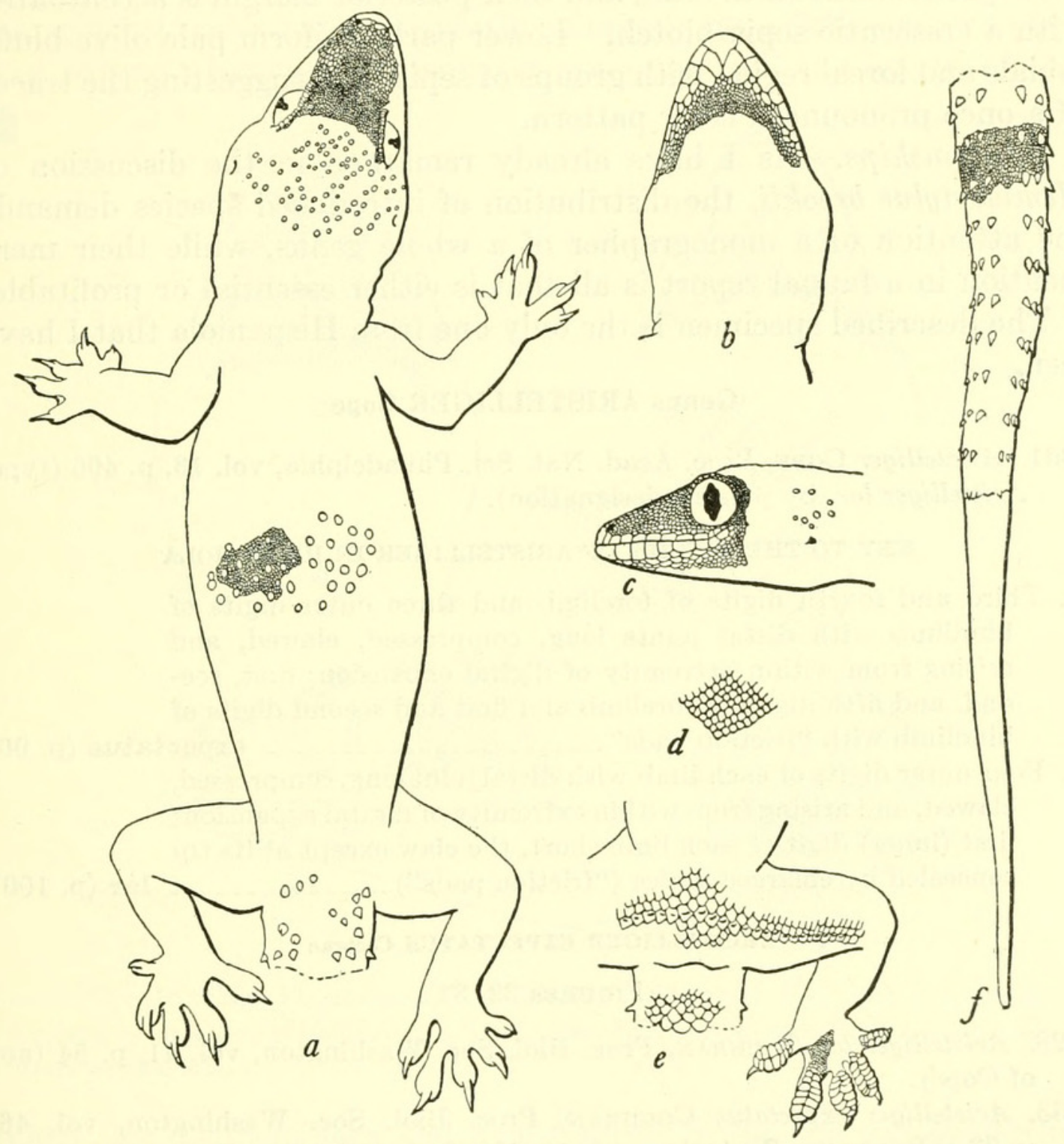

FIGURE 31.-Hemidactylus mabouia: $a$, Dorsal view of head and body; $b$, underside of head; $c$, side of head; $d$, ventral scales; $e$, femoral region and underside of foot; $f$, upper side of tail. M.C.Z. No. 1327, from Port-au-Prince, Haiti. One and one-half times natural size.

portion with five pairs of lamellae under the inner toe and seven under the middle one in addition to the large unpaired terminal one; tail cylindrical, distinctly depressed, covered above with small granules a little larger than tbose on the back of the head; tail at the base with six longitudinal rows of conical tubercles, and more distally with the same number of very elongate tubercles in whorls eight or nine scales 
apart; underside with a median series of large plates about two to a whorl; the regenerated tip granular above and without tubercles, below with irregular platelike scales.

Dimensions: Snout to posterior ear, $17.5 \mathrm{~mm}$; head and body, 64 $\mathrm{mm}$.; tail (tip reproduced), $69 \mathrm{~mm}$.

Color (in alcohol): Drab above, with wide cross bands of olive, beginning on the occiput and continuing posteriorly; these become more pronounced on the tail, and their posterior margin is accentuated with a crescentic sepia blotch. Lower parts uniform pale olive-bluff; labials and loreal region with groups of sepia dots suggesting the traces of a once pronounced color pattern.

Relationships.-As I have already remarked in the discussion of Hemidactylus brookii, the distribution of introduced species demands the attention of a monographer of a whole genus, while their mere mention in a faunal report is all that is either essential or profitable.

The described specimen is the only one from Hispaniola that I have seen.

\section{Genus ARISTELLIGER Cope}

1861. Aristelliger Cope, Proc. Acad. Nat. Sci. Philadelphia, vol. 13, p. 496 (type, Aristelliger lar, by present designation).

KEY TO THE SPECIES OF ARISTELLIGER IN HISPANIOLA

$a^{1}$. Third and fourth digits of forelimb and three outer digits of hindlimb with distal joints long, compressed, clawed, and arising from within extremity of digital expansion; first, second, and fifth digits of forelimb and first and second digits of hindlimb with "friction pads" .................. expectatus (p. 96)

$a^{2}$. Four outer digits of each limb with distal joint long, compressed, clawed, and arising from within extremity of digital expansion; first (inner) digit of each limb short, the claw except at its tip concealed by enlarged scales ("friction pads")

\section{ARISTELLIGER EXPECTATUS Cochran}

Figures 32,33

1928. Aristelliger lar Cochran, Proc. Biol. Soc. Washington, vol. 41, p. 54 (not of Cope).

1933. Aristelliger expectatus Cochran, Proc. Biol. Soc. Washington, vol. 46, p. 33.-Barbour, Zoologica, vol. 19, No. 3, p. 100, 1935; Bull. Mus. Comp. Zool., vol. 82, No. 2, p. 110, 1937.

The original description is quoted in full:

"Description of the type.-U.S.N.M. 75908, an adult male from Jacmel, Haiti, collected in 1928 by J. S. C. Boswell on a low palm tree. Rostral much broader than high, with a posterior median cleft extending forwards for one-half the height of the shield, in contact above with the supranasal and the single internasal; nostril rather large, touching the outer posterior border of the rostral, its lower rim widened and in contact with the first supralabial, posteriorly bordered by two postnasal 
scales, the upper the smaller; about seven upper and five lower labials to a point below the center of the eye, the few behind this point becoming smaller (the upper labials on both sides have suffered a slight injury); upper surfaces covered with granular scales which are smaller middorsally, larger on the flanks and on the snout, and largest on the tail where they merge into overlapping hexagonal scales arranged in symmetrical transverse rows; about 27 lateral scales and about 30 dorsal scales equal to the distance between tip of snout and center of eye; canthal scales not particularly enlarged; eye a little nearer to ear than to end of snout, its diameter not quite half the length of the

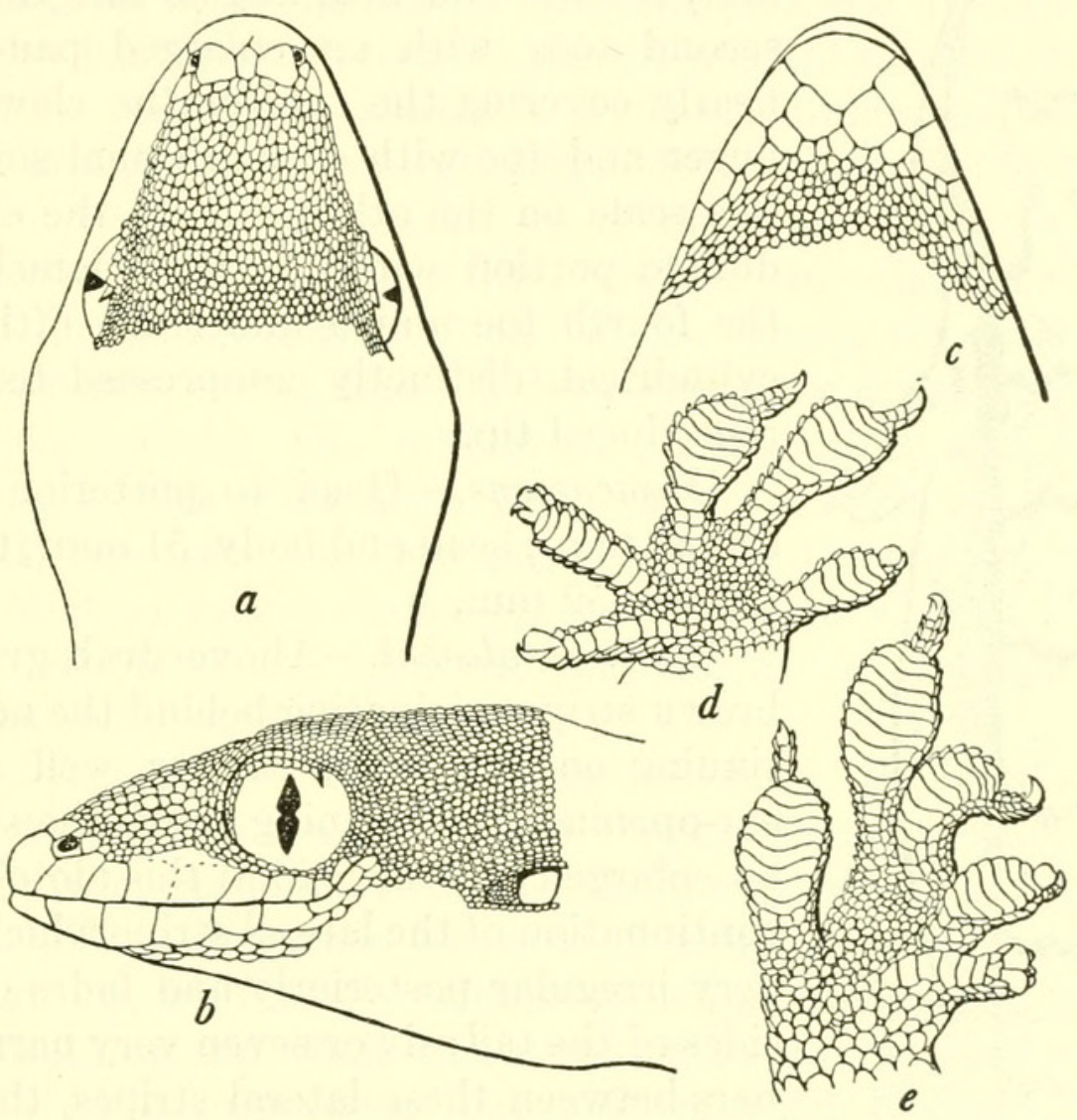

Figure 32.-Aristelliger expectatus: $a$, Top of head; $b$, side of head; $c$, chin; $d$, underside of forefoot; $e$, underside of hindfoot. U.S.N.M. No. 75908, type, from Jacmel, Haiti. Three times natural size.

snout; 5 or 6 superciliary scales on the eyelid, the last one projecting as a short palpebral spine above the eye; ear-opening irregularly oval, its greatest diameter about once and a half the height of the first supralabial, its distance from the eye equal to the distance between eye and nostril; temples very minutely granular; mental broad, triangular, considerably wider than the rostral, its labial margin almost three times as wide as the first infralabial; two pairs of chinshields, the inner ones in contact with each other behind the mental, the scales following these and bordering the infralabials small, rather abruptly merging into the minute granules which cover the entire throat; 
remainder of underside of body and legs covered with smooth, cycloid, imbricate scales; about 14 abdominal scales included in the distance between end of snout and center of eye; the scales on underside of thighs grading down to very small ones; no femoral pores; the scales beneath the tail large, rectangular, arranged in transverse rows, each one equivalent to two of the upper caudal rows in length and much wider than long; fingers and toes slightly but definitely webbed, all with long, angularly raised and clawed distal phal-

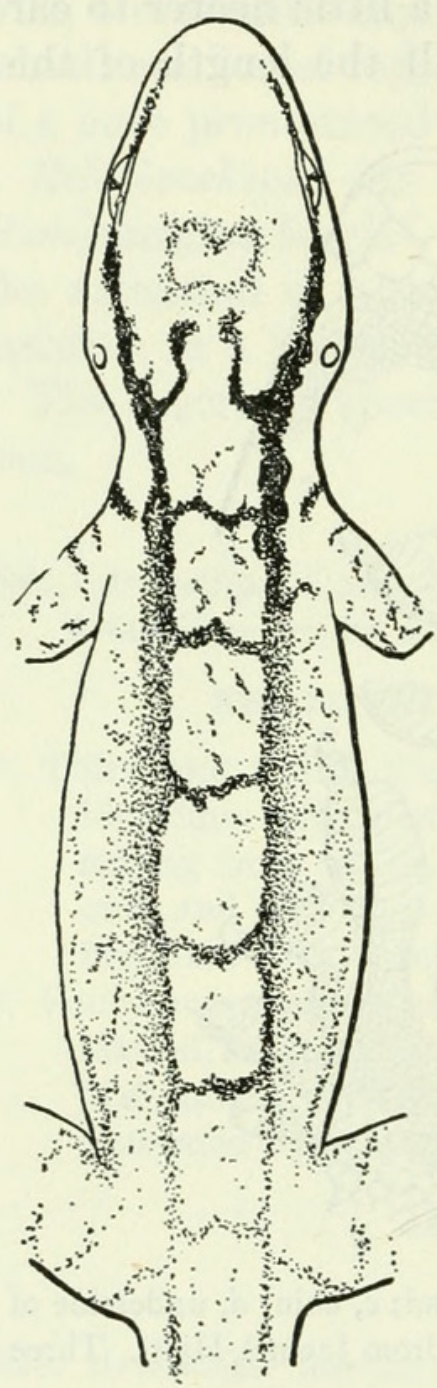

Figure 33.-Diagram of color pattern of Aristelliger expectatus. anges, those of the third and fourth fingers and the three outer toes compressed, those of the first, second, and fifth fingers and the first and second toes with an enlarged pad-like scale nearly covering the side of the claw, the first finger and toe with an additional smaller padlike scale on the other side of the claw; basal dilated portion with 11 single lamellae under the fourth toe and 9 under the fifth toe; tail cylindrical, distinctly compressed towards the reproduced tip.

"Dimensions.-Head to posterior border of ear, $15 \mathrm{~mm}$.; head and body, $51 \mathrm{~mm}$.; tail (reproduced), $59 \mathrm{~mm}$.

"Color in alcohol.-Above drab gray; a seal brown stripe originating behind the nostril, continuing on the lores, passing well above the ear-opening and widening above the shoulder as an enlarged blotch; behind this blotch a fainter continuation of the lateral stripe which becomes very irregular posteriorly and fades out on the sides of the tail; six or seven very narrow dorsal bars between these lateral stripes, the anterior interrupted in the middle and ending as a forward-curving blotch on each side of the nape, the remaining bars somewhat similar in shape but paler; a faint irregular roundish marking on the occipital region; traces of wavy crossbars on the upper limb surfaces; upper and lower lips minutely spotted with pale dots; lower surfaces immaculate pale olive buff darkening slightly below the tail.

"Paratypes.-M.C.Z. 25425 from Pte. à Raquettes, Gonave Island, collected in 1927 by W. J. Eyerdam, is similar to the type in proportions and generally in coloration, although the pattern of dorsal crossbars is stronger than in the type specimen, and the entire body is darker in hue. The upper and lower labials are dark, and the lower surface of the body is heavily powdered with gray dots. This para- 
type has six upper and six lower labials on the right side of the head to a point beneath the center of the eye; on the left side of the head there are seven upper and six lower labials. The chinshields in this specimen fail to meet behind the mental, being separated by a single small scale. The postnasals are much smaller and more irregular. There are about 16 ventral scales and 26 lateral and 28 dorsal granules in the distance between tip of snout and center of eye. M.C.Z. 13847, also from Gonave Island, collected in 1919 by G. M. Allen, is very pale in color and practically devoid of pattern except for a faint suggestion of the wide stripe along the side of the head and neck. It has six upper labials on both sides, six and five lower labials on right and left respectively; the chinshields fail to meet, being separated by one scale; the postnasals are small, numerous and regular and there are about 13 ventral scales and 23 lateral and 26 dorsal granules in the distance between tip of snout and center of eye. A third paratype, M.C.Z. 13322 from Thomazeau, Haiti, collected in 1919 by G. M. Allen, is very similar to the type in coloration, except that in this paratype the dark bands on the limbs are somewhat more heavily accentuated. This individual has six upper and five lower labials on both sides of the head; the chinshields are in contact behind the mental; there are but two postnasals, and these are relatively large, followed by much smaller granules; there are about 13 ventral scales and 24 lateral and 28 dorsal granules in the distance between tip of snout and center of eye.

"Relationships.-As I have already indicated, the new species is very close to the Navassa and Great Inagua species because of their similarity in the arrangement of the terminal phalanges of the digits. From Aristelliger cochranae of Navassa the new species differs decidedly in color pattern, in having a somewhat longer snout, and in having larger granules on top of the snout and between the eyes as well as on the back. From the Great Inagua form, which Noble and Klingel named Aristelligella barbouri, the Haitian species differs in having more lamellae under the toes, and apparently also in having a weaker color pattern.

"These three species differ from Aristelliger lar of Hispaniola, A. praesignis of Jamaica and $A$. irregularis of Cozumel in having more of the digits with 'friction pads' at their terminations." 
TABLE 17.-Specimens of Aristelliger expectatus examined

\begin{tabular}{|c|c|c|c|}
\hline Museum No. & Locality & Date & Collector \\
\hline U.S.N.M. & \multirow{6}{*}{ 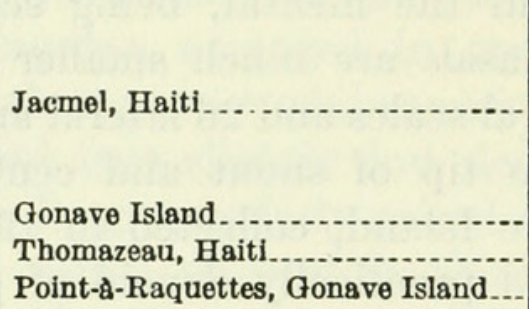 } & \multirow{5}{*}{$\begin{array}{l}1928 \\
1919\end{array}$} & \multirow{6}{*}{$\begin{array}{l}\text { J. S. C. Boswell. } \\
\text { G. M. Allen. } \\
\text { Do. } \\
\text { W. J. Eyerdam. }\end{array}$} \\
\hline 75908 (type) & & & \\
\hline M.C.Z. & & & \\
\hline $13847 \ldots . .$. & & & \\
\hline 13322_...- & & & \\
\hline $25425 \ldots \ldots$ & & 1927 & \\
\hline
\end{tabular}

\section{ARISTELIIGER LAR Cope}

Figure 34

1861. Aristelliger lar Cope, Proc. Acad. Nat. Sci. Philadelphia, 1861, p. 497 (near Jérémie, Haiti; collector, D. F. Weinland).-Boulenger, Catalogue of the specimens of lizards in the collection of the British Museum, ed. 2, vol. 1, p. 147, 1885.-Garman, Bull. Essex Inst., vol. 19, p. 18, 1887.-Barbour, Bull. Mus. Comp. Zool., vol. 52, No. 18, p. 290, 1910; Mem. Mus. Comp. Zool., vol. 44, No. 2, p. 258, 1914; Zoologica, vol. 11, No. 4, p. 82, 1930; vol. 19, No. 3, p. 100, 1935; Bull. Mus. Comp. Zool., vol. 82, No. 2, p. 110, 1937.-Barbour and Loveridge, Bull. Mus. Comp. Zool., vol. 69, No. 10, p. 225, 1929.

1888. Aristelliger praesignis Fischer, Jahrb. Hamburg Wiss. Anst., vol. 5, p. 23

(Gonaĩves, Haiti; H. Rolle, collector) (not of Hallowell).

This is one of the largest of the geckos. The type in the Museum of Comparative Zoology measures $316 \mathrm{~mm}$. in length, the tip of the tail being reproduced. It is probably not plentiful anywhere, and few examples have yet found their way to museum collections.

Description.-U.S.N.M. No. 62362, an adult from Sánchez, Dominican Republic, taken on August 23, 1919, by Dr. W. L. Abbott. Rostral much broader than high, with a posterior median cleft extending forward for one-half the height of the shield, in contact above with the supranasals and three smaller internasals; nostril rather large, touching the outer posterior border of the rostral, separated from the first supralabial by the first two of a series of about five granular scales which border the nostril posteriorly and reach the rather small supranasals; nine upper and seven lower labials, the last ones increasingly smaller, the suture between seventh and eighth upper labials coming directly below the center of the eye; upper surfaces covered with uniform, minute, granular scales, which are largest on the snout and on the base of the tail, where they are arranged in symmetrical transverse rows dorsally, and laterally in fairly symmetrical diagonal rows; canthal scales not particularly enlarged; eye a little nearer to ear than to end of snout, its diameter about one-half the length of the snout; a short palpebral spine above the eye; ear opening elongate, very oblique, its greatest diameter twice the height of the first supra- 
labial; temples granular like the top of the head, with a patch of very minute granules between the eye and ear; mental broad, triangular, considerably wider than rostral, its labial margin almost three times as wide as the first infralabial; two pairs of chin shields, the inner ones in contact with the mental and separated from each other by a small median scale, the scales following gradually merging into the very fine granules covering the throat; remainder of under side and of legs

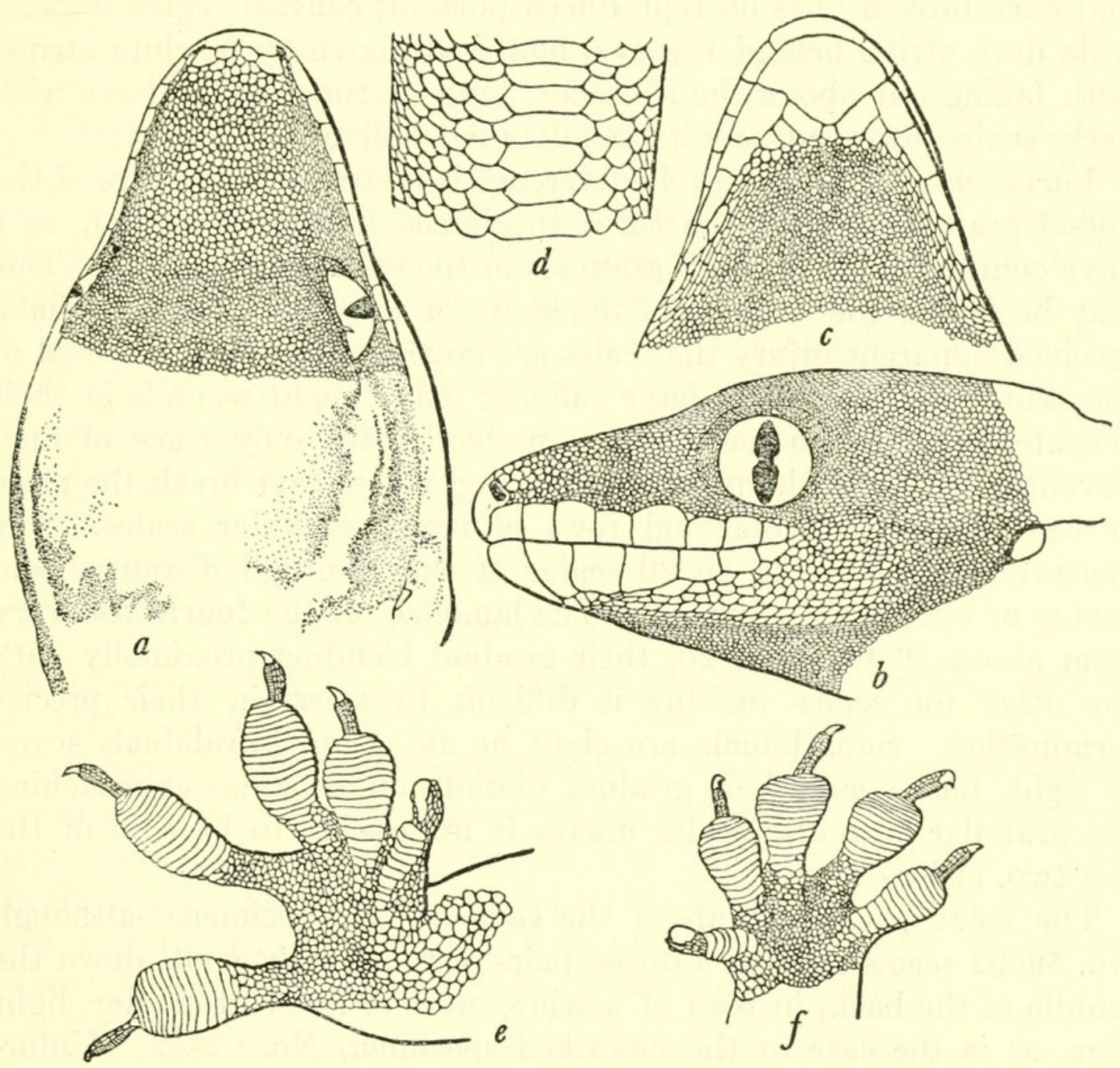

Figure 34.-Aristelliger lar: $a$, Top of head, showing traces of temporal pattern; $b$, side of head; $c$, chin; $d$, underside of tail; $e$, underside of hindfoot; $f$, underside of forefoot. U.S.N.M. No. 62362, from Sánchez, Dominican Republic. One and one-half times natural size.

covered with smooth, cycloid, imbricate scales; about 19 abdominal scales included in the distance between end of snout and center of eye; those on under side of thighs smaller, without femoral pores; those beneath the tail transversely enlarged even in the reproduced portion; fingers and toes free, all with long, compressed, angularly raised, clawed distal phalanges; the claw of the inner digit inserted at one side and in front of the terminal scale, and with one or two enlarged padlike scales beside it; basal dilated portion with 16 or 17 
single lamellae under the fourth toe and 14 under the fifth toe; tail cylindrical, distinctly compressed toward the tip, which is reproduced.

Dimensions: Head to posterior border of ear, $35 \mathrm{~mm}$.; head and body, $126 \mathrm{~mm}$.; tail (reproduced), $167 \mathrm{~mm}$.

Color (in alcohol): Above drab-gray, with very indistinct darker traces of six or seven transverse bars separating squarish areas of distinctly lighter hue; tail with diminishing bars at base and longitudinal dark broken lines on reproduced portion; canthal region dark; a wide dark stripe behind the eye, bordered above by a white stripe, both fading out above the shoulder; limbs vermiculated above with dark; entire lower surfaces immaculate light olive-buff.

Variations.-A considerable difference is met with in the size of the dorsal granules among the three specimens I have examined, as I have counted from 36 to 45 granules in the standard distance. This may be due to the bruising of the skin, for on all portions that have received apparent injury the scales are much finer than on the rest of the skin. The specimens have suffered many slight wounds in their delicate skins, which have healed perfectly, the only trace of misadventure being in the patches of tiny granules that break the more or less symmetrical diagonal rows of larger granular scales. The ventral scales show 17 to 20 scales in the standard distance from center of eye to tip of snout. The lamellae on the fourth toe vary from about 16 to about 20 , their gradual blending proximally with the other toe scales making it difficult to ascertain their precise termination. Supralabials are eight or nine, and infralabials seven or eight; here again their gradual diminution to a size approaching the granular temporal scales makes it impossible to be sure of the last two, at least.

The color pattern is about the same in all specimens, although No. 59092 seems to have a dozen pairs of round light spots down the middle of the back, instead of a wide, more or less rectangular, light area, as is the case in the described specimen, No. 62362. Unfortunately, the Museum of Comparative Zoology specimen is badly bleached.

Relationships.-More material is needed before it will be possible to discuss definitely the relationships of this Hispaniolan lizard and the Jamaican form, Aristelliger praesignis. The size of the dorsal granules is about the same. The number of labials and of lamellae varies so much that nothing can be adduced from the data on so few specimens, while the mandibular teeth seem to have the same arrangement in both forms. The ventral scales appear to be slightly smaller in the Jamaican form. The Hispaniolan lizard has 17 to 20 ventral scales in the standard distance from center of eye to tip of snout in the three specimens I have recorded; the Jamaican lizard likewise has 17 to 20 in the four unmutilated examples in our collection. 
TABLE 18.-Specimens of Aristelliger lar examined

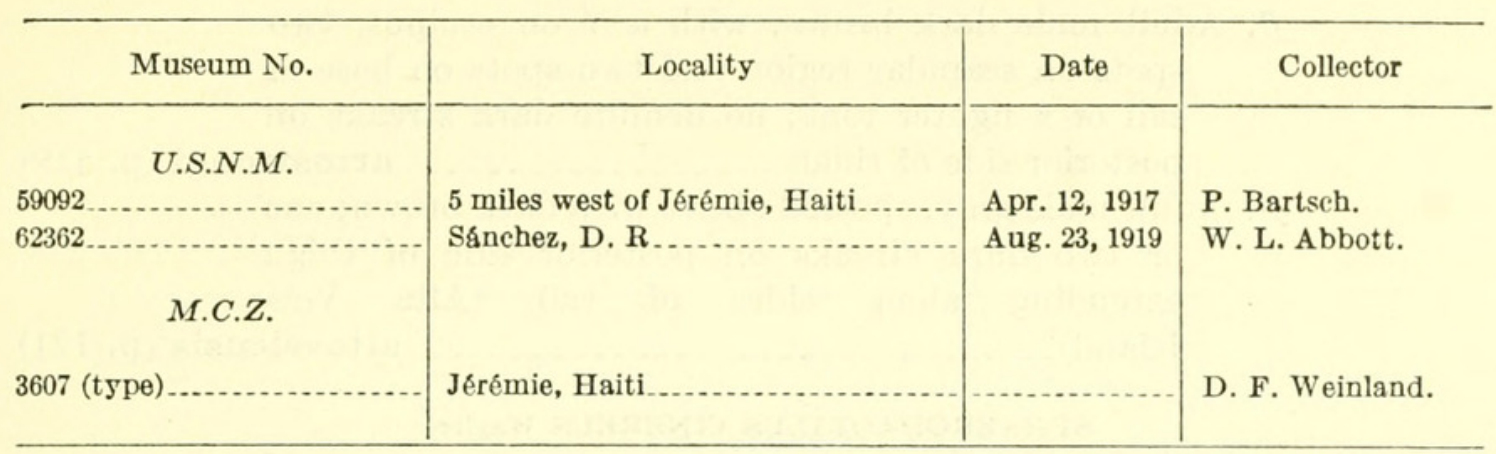

Whatever may be the ultimate decision as to the identity of the Jamaican and Hispaniolan forms, it is safe to say that neither of them is closely related to Aristelliger irregularis Cope of Cozumel Island, in which the subdigital lamellae on the fourth toe are 15 in number, while the upper labials are 9 or 10 and the lower labials 9 on both sides, the posterior ones always very small. If Bocourt's figure of the type of georgensis is correctly drawn, then this species also possesses the large dorsal granules and should be related to irregularis on this score and not to the Jamaican or Hispaniolan species.

Specimens examined.-As listed in table 18.

\section{Genus SPHAERODACTYLUS Wagler}

1830. Sphaerodactylus WAGLER, Natürliches System der Amphibien, p. 143 (type, S. sputator Cuvier).

This genus is one of the most difficult in the entire fauna of tropical America. Dr. Barbour's monograph has helped greatly in clearing up some problems and in pointing the way for further research. The descriptions by Dr. Barbour of Sphaerodactylus copei and S. difficilis have been taken word for word from his monograph, and his superb figures of copei have likewise been "borrowed" outright.

\section{KEY TO HISPANIOLAN SPECIES OF SPHAERODACTYLUS}

$a^{1}$. Dorsals granular, about 23 in standard distance between center of eye and tip of snout. cinereus (p. 104) $a^{2}$. Dorsals imbricate, at least posteriorly.

$b^{1}$. A distinctly differentiated middorsal zone of small granules, remaining dorsals large and keeled, 5 to 9 in standard distance. copei (p. 107)

$b^{2}$. No conspicuously differentiated middorsal granular zone.

$c^{1}$. Dorsals smooth, indistinctly imbricate anteriorly, about 14

to 16 in standard distance. stejnegeri (p. 109) $c^{2}$. Dorsals keeled.

$d^{1}$. Markings transverse samanensis (p. 112)

$d^{2}$. Markings not transverse.

$e^{1}$. Central throat scales small, flat, not granular, larger and smooth on lower neck and chest. 
$e^{2}$. Central throat scales keeled.

$f^{1}$. Adult male dark brown, with a $V$ on occiput, two spots on scapular region and two spots on base of tail of a lighter tone; no definite dark streaks on posterior side of thigh.............. armstrongi (p. 119)

$f^{2}$. Adult male gray, spotted above with dark brown; one or two dark streaks on posterior side of thigh extending along sides of tail (Alta Vela Island) ............ altavelensis (p. 121)

\section{SPHAERODACTYLUS CINEREUS Wagler}

\section{Figure 35}

1830. Sphaeriodactylus cinereus WAGLER, Natürliches System der Amphibien, p. 143 (based on Lacépède's sputateur) (type locality, Haiti).-Sphaerodactylus cinereus Coctead, in de la Sagra's Historia fisica, politica y natural de la Isla de Cuba, vol. 4 (Rept.), p. 166, pl. 17, 1843.-GraY, Catalogue of the specimens of lizards in the collection of the British Museum, p. 168, 1845.Cope, Proc. Acad. Nat. Sci., 1861, p. 498 (Cuba, Hayti).-Stejneger, Proc. U. S. Nat. Mus., vol. 53, p. 266, 1917.-Cochran, Proc. Biol. Soc. Washington, vol. 41, p. 54, 1928; Occ. Pap. Boston Soc. Nat. Hist., vol. 8, p. 167, 1934.-Barbour, Zoologica, Vol. 11, No. 4, p. 83, 1930; vol. 19, No. 3, p. 101, 1935; Bull. Mus. Comp. Zool., vol. 82, No. 2, p. 111, 1937.

1835. Sphaeriodactylus punctatissimus Dumeril and Bibron, Erpétologie générale, vol. 3 , p. 405 (type locality, San Domingo).-Dumeril, Catalogue méthodique de la collection des reptiles (Mus. Hist. Nat. Paris), p. 42, 1851 (part) (Hayti).-Sphaerodactylus punctatissimus Bodlenger, Catalogue of specimens of lizards in the collection of the British Museum, vol. 1, p. 220, 1885.Strauch, Mém. Acad. St. Petersbourg, ser. 7, vol. 35, No. 2, p. 35, 1887 (Portau-Prince, Hayti).-Fischer, Jahrb. Hamburg Wiss. Anst., vol. 5, p. 23, 1888 (Cape Haytien).-Boettger, Katalog der Batrachier-Sammlung im Museum der Senckenbergischen naturforschenden Gesellschaft in Frankfurt am Main, pt. 1, p. 39, 1893.

1834. Sphaeriodactylus elegans Macleay, Proc. Zool. Soc. London, 1834, p. 12 (type locality, Cuba).-Sphaerodactylus elegans Reinhardt and LütKen, Vid. Medd. Nat. Foren. Kjöbenhavn, 1862, p. 275, 1863.-Bodlenger, Catalogue of the specimens of lizards in the collection of the British Museum, ed. 2, vol. 1, p. 220, 1885.-Boettger, Katalog der Batrachier-Sammlung im Museum der Senckenbergischen naturforschenden Gesellschaft in Frankfurt am Main, pt. 1, p. 39, 1893.-Barbour, Mem. Mus. Comp. Zool., vol. 44, No. 2, p. 261, 1914.-Stejneger, Proc. U. S. Nat. Mus., vol. 53, p. 266, 1917.

1861. Sphaerodactylus alopex Cope, Proc. Acad. Nat. Sci., Philadelphia, 1861, p. 499 (type locality, near Jérémie, Hayti).-Boulenger, Catalogue of the specimens of lizards in the collection of the British Museum, ed. 2, vol. 1, 1885 , p. 222.-Garman, Bull. Essex Inst., vol. 19, p. 18, 1887.-Fischer, Jahrb. Hamburg Wiss. Anst., vol. 5, p. 23, 1888.-Barbour, Mem. Mus. Comp. Zool., vol. 44, No. 2, p. 263, 1914.-BArbour and Loveridge, Bull. Mus. Comp. Zool., vol. 69, No. 10, p. 339, 1929.

1880. Sphaeriodactylus argus Gunduach, Contribucion a la erpetologia Cubana, p. 59 (not of Gosse).

1888. Sphaerodactylus oxyrrhinus Fischer, Ber. Nat. Mus. Hamburg for 1887, p. 23 (Haiti) (not of Gosse).

1914. Spharodactylus cinereus Barbodr, Mem. Mus. Comp. Zool., vol. 44, No. 2, p. 261. 


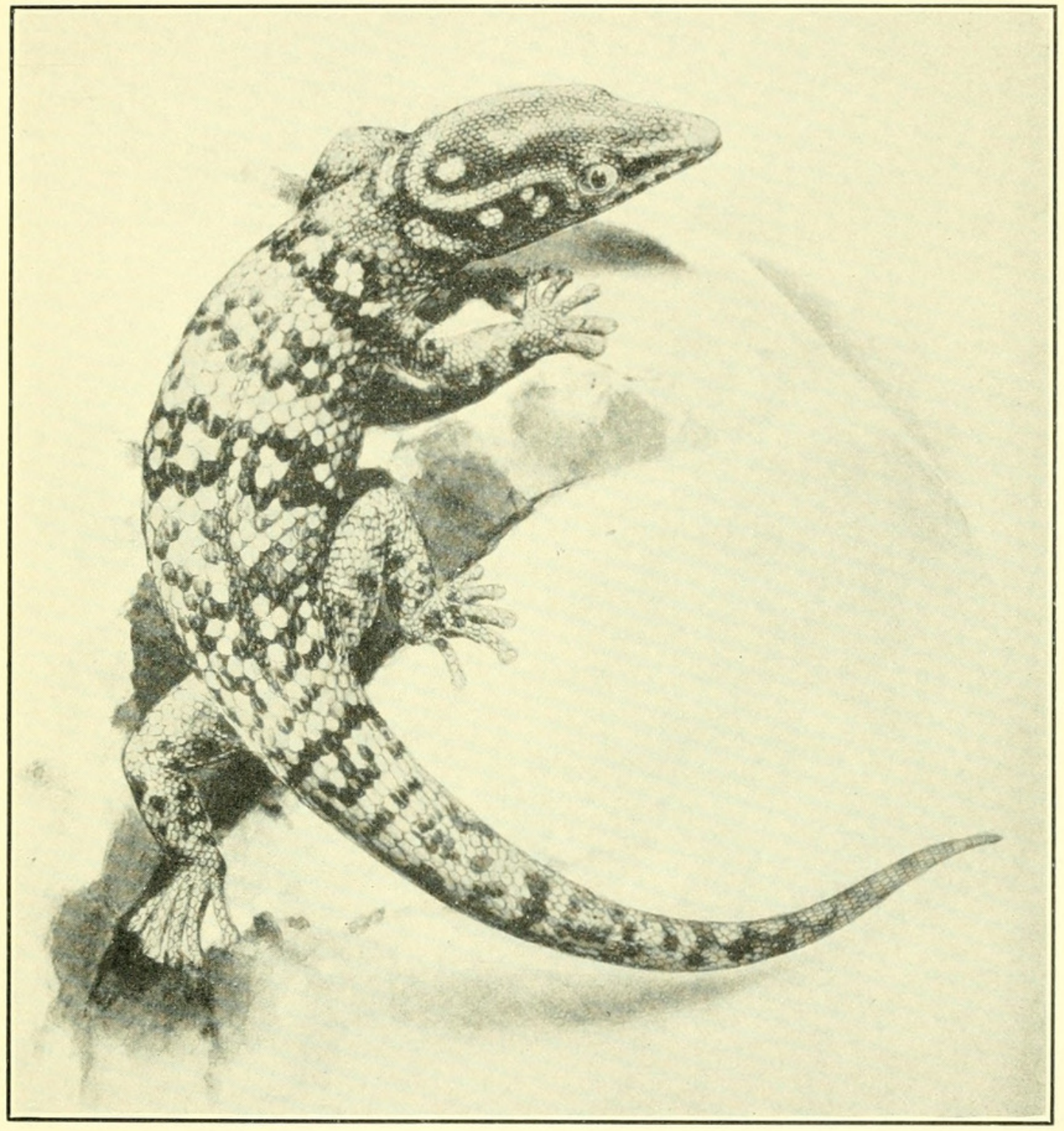

SPHAERODACTYLUS COPEI

Dorsal view, showing color pattern, of M.C.Z. No. 3342, from Grand Anse River, Haiti; type of S. picturatus Garman. (After Barbour, Mem. Mus. Comp. Zool., vol. 47, No. 3, 1921.) 

1919. Sphaerodactylus intermedius Barbour and Ramsden, Mem. Mus. Comp. Zool., vol. 47, p. 211 (type locality, Sierra de Hato Nuevo, Cuba).-BArBodr, Mem. Mus. Comp. Zool., vol. 47, No. 3, p. 235, 1921; Bull. Mus. Comp. Zool., vol. 69, No. 10, p. 342, 1929.

Description.-U.S.N.M. No. 52407, an adult from Jérémie, Haiti; collected by D. F. Weinland, one of the cotypes of Sphaerodactylus alopex Cope. Snout rather flat and pointed, the distance from the tip to the eye being slightly longer than the distance from eye to ear opening and more than twice the diameter of the eye; rostral large, with median groove behind; nostril between rostral, first supralabial, a small postnasal and a much larger supranasal, which is separated from its fellow on the opposite side by a single much
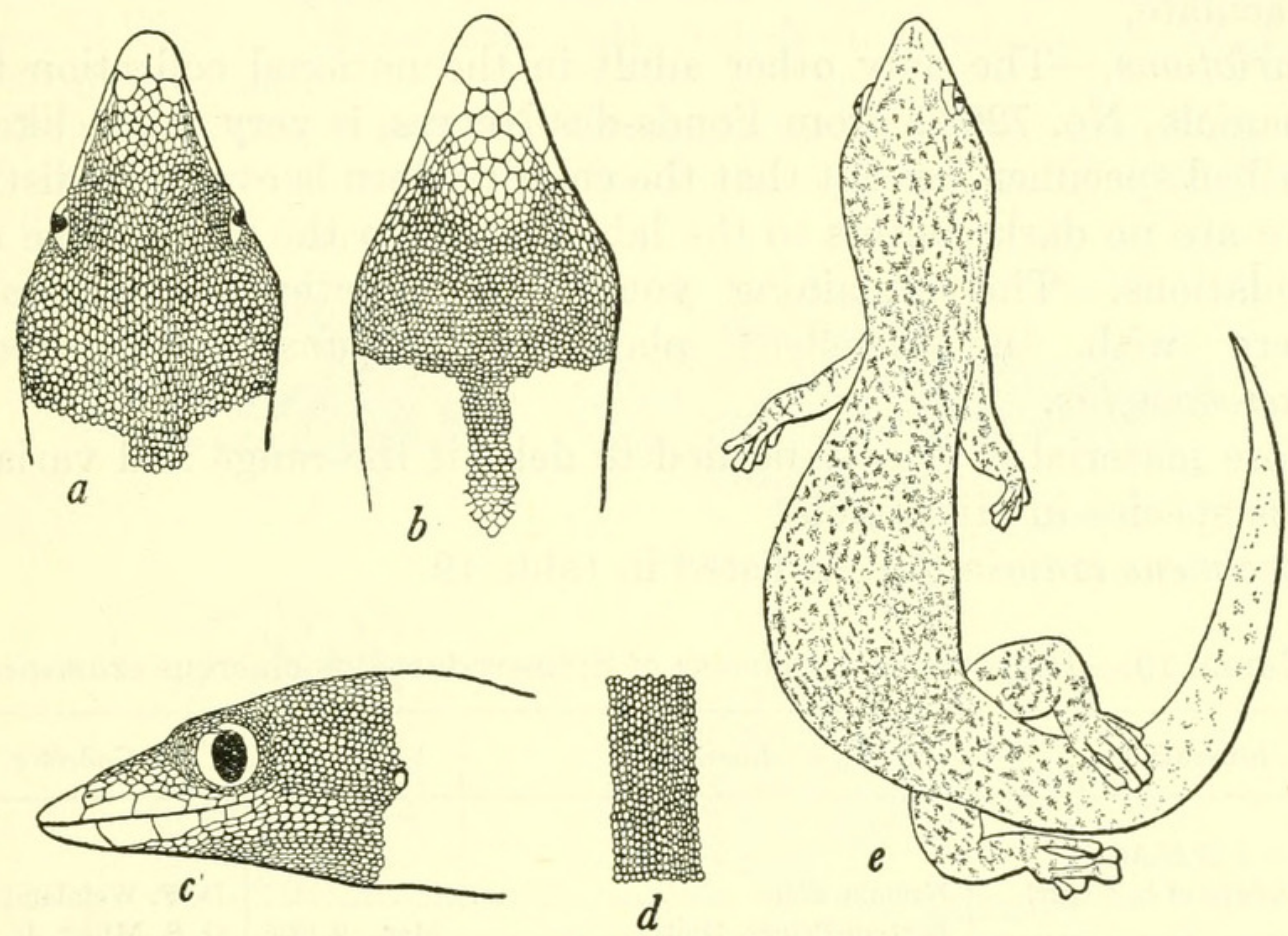

Figure 35.-Sphaerodactylus cinereus: $a$, Top of head; $b$, chin and throat; $c$, side of head; $d$, middorsal scales; $e$, dorsal view showing color pattern. U.S.N.M. No. 52407, from Jérémie, Haiti (cotype of $S$. alopex). $a-d, \times 3 ; e, \times 2$.

smaller median scale, these three bordering the rostral above; four large supralabials to the center of the eye; three infralabials to the same point, followed by a fourth smaller one; a spine on the superciliary margin over the center of the eye; head above and on sides covered with very fine granules, those of the snout much enlarged and flattened; scales on back small and granular, about 23 equaling the distance from tip of snout to center of eye; mental large, larger than rostral; two small roughly pentagonal chin shields which are followed by similar, flat, polygonal scales which pass rather abruptly into tiny round scales of the middle throat; belly with enlarged smooth, rounded, imbricate scales, about 11 contained in the standard $226849-41-8$ 
distance; limbs covered above with granules, below with round imbricate scales like the ventrals; 14 smooth lamellae under the fourth toe; tail with smooth, imbricating, rectangular scales above and on the sides, and a median series of transversely enlarged plates below.

Dimensions: Head and body, $32.5 \mathrm{~mm}$.; tail (broken) about $28 \mathrm{~mm}$.; width of head, $6 \mathrm{~mm}$.; tip of snout to ear, $8.5 \mathrm{~mm}$.; foreleg, $7.5 \mathrm{~mm}$.; hindleg, $11 \mathrm{~mm}$.

Color: Body fawn-color turning to wood brown on the head; lighter below. A very faint reticulation or dotting of a slightly paler hue over the back and head. Limbs with darker reticulations. Upper and lower labials with dark central areas. Lower surfaces immaculate.

Variations.-The only other adult in the national collection from Hispaniola, No. 72622, from Fonds-des-Nègres, is very much like the described specimen, except that the color pattern is even less distinct. There are no dark centers to the labials, nor do the limbs have dark reticulations. The remaining young are practically identical in pattern with the excellent plate of "elegans" in Barbour's Sphaerodactylus.

More material is greatly needed to delimit the range and variation of this species in Hispaniola.

Specimens examined.-As listed in table 19.

TABLE 19.-Hispaniolan specimens of Sphaerodactylus cinereus examined

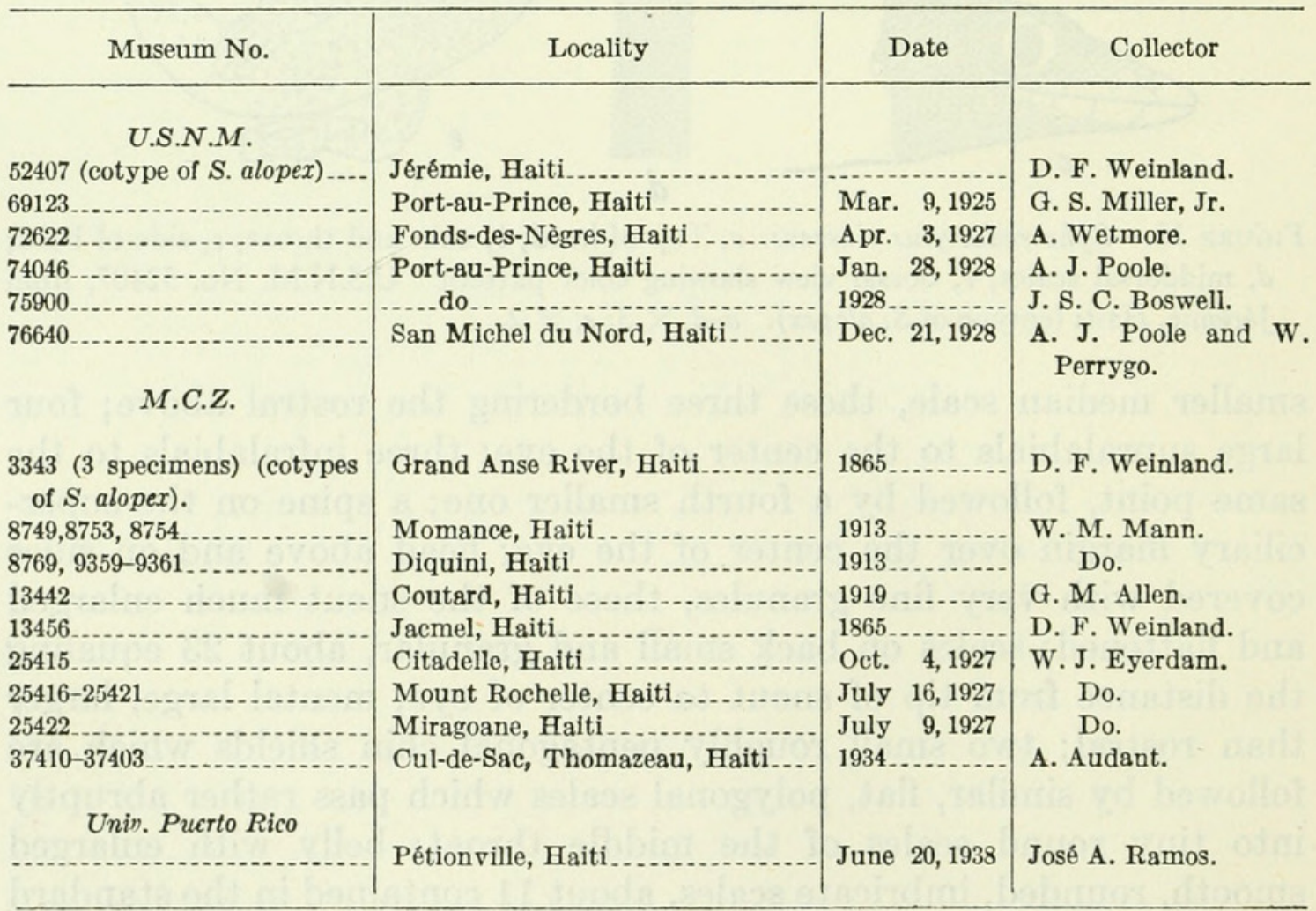




\section{SPHAERODACTYLUS COPEI Steindachner}

Figure 36 ; Plate 1

1869. Sphaerodactylus copei Steindachner, Reise Novara, Vertebrates, vol. 1, p. 18, pl. 1, fig. 5 (type locality ?).-Barbour, Mem. Mus. Comp. Zool., vol. 47, No. 3, p. 259, pl. 7, fig. 2, pl. 21, figs. 5-8, 1921; Zoologica, vol. 11, No. 4, p. 84, 1930; vol. 19, No. 3, p. 104, 1935; Bull. Mus. Comp. Zool., vol. 82 , No. 2, p. 114, 1937.-Cochran, Proc. Biol. Soc. Washington, vol. 41, p. 54, 1928.

1887. Sphaerodactylus picturatus Garman, Bull. Essex Inst., vol. 19, p. 19 (type locality, Grand Anse River, western Hayti).-Barbour, Proc. Biol. Soc. Washington, vol. 28, p. 74, 1915.-BArbour and Loveridge, Bull. Mus. Comp. Zool., vol. 69, No. 10, p. 343, 1929.

1889. Sphaerodactylus anthracinus Boulenger, Catalogue of the specimens of lizards in the collection of the British Museum, vol 1, p. 225 (San Domingo) (not of Cope).-Meerwarth, Mitt. Nat. Mus. Hamburg, vol. 18, p. 19, 1901 (S. Domingo).

1863. Sphaeriodactylus fantasticus Reinhardt and Lütken, Vid. Med. Nat. Foren. Kjöbenhavn, 1862, p. 277; extr. p. 125 (Acquin, Hayti) (not of Duméril and Bibron).

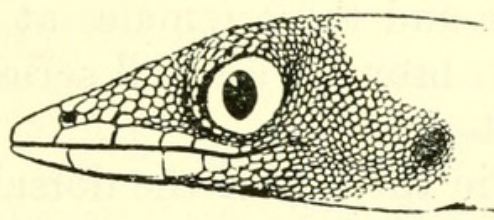

$a$

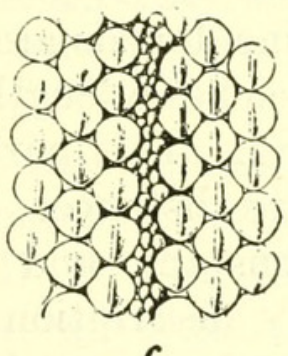

c
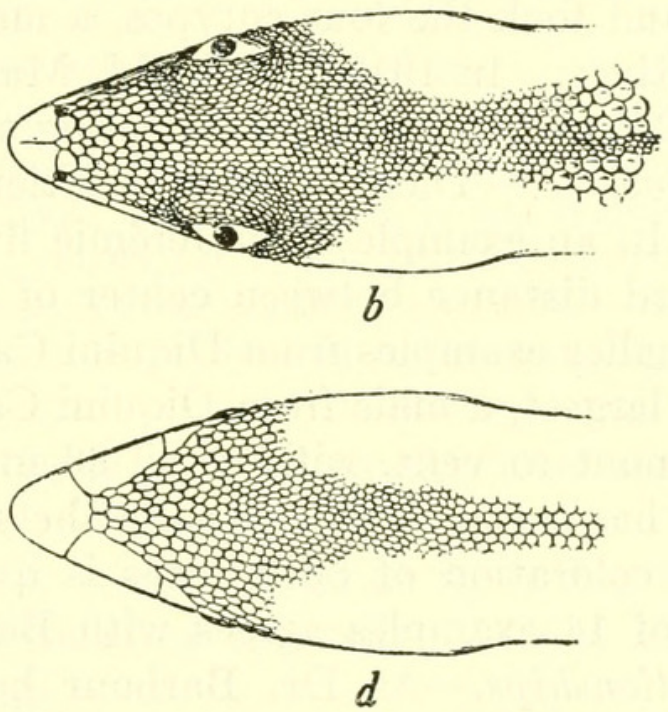

FIGURE 36.-Sphaerodactylus copei: $a$, Side of head; $b$, top of head; $c$, middorsal scales; $d$, chin and throat. M.C.Z. No. 3342, from Grand Anse River, Haiti (type of S. picturatus Garman). (After Barbour.) Three times natural size.

The description of the largest of the three female cotypes of Garman's picturatus, now M.C.Z. No. 3342, is copied from Dr. Barbour's Sphaerodactylus as follows:

"Snout rather long, head distinctly narrow; the eye a very little nearer the tip of snout than the ear; rostral large with a median groove; nostril between rostral, first supralabial, a large supranasal and one or two small scales; a small scale separates the supranasal of each side; the fifth supralabial, a very small one, below the centre of the eye; superciliary spine present but very small and feeble; head above and on sides covered with small granules which are not flat nor yet distinctly keeled, rather sharply swollen, slightly enlarged in snout; 
scales of sides of neck enlarged, passing on the shoulders into the very large tectiform dorsals about six of which equal the distance of tip of snout from centre of eye; a prominent middorsal granular zone; mental larger than rostral, followed by many slightly enlarged scales; gular scales very small juxtaposed; scales of chest and belly larger, rounded, slightly imbricate, smooth; scales of limb enlarged, overlapping, smooth or very feebly keeled; tail with scales small and irregular; enlarged inferiorly.

"Colour:-Male uniform metallic iron-gray, with no markings. Females conspicuously streaked on head with light longitudinal markings and decorated on the body with irregular dark cross-bars which include transverse series of white spots. The ground-colour is reddish often flecked with small spots of darker and lighter.

"Dimensions:-Adult male M.C.Z. 3,341. Tip of snout to vent, $34 \mathrm{~mm}$.; vent to tip of tail, $39 \mathrm{~mm}$.; greatest width of head, $6.2 \mathrm{~mm}$.; tip of snout to ear, $9.5 \mathrm{~mm}$.; foreleg, $10 \mathrm{~mm}$.; hindleg, $13 \mathrm{~mm}$.

"Remarks:-Like its close allies, copei is rare in collections. Dr. Weinland took the four cotypes, a male and three females at Grand Anse River. In 1913 Dr. W. M. Mann brought a small series back from Diquini, taken while collecting ants."

Variations.-There is some variation in the size of the dorsal granules. In an example from Jérémie five dorsals are contained in the standard distance between center of eye and tip of snout, while in two smaller examples from Diquini Cave, nine dorsals are found.

The largest, a male from Diquini Cave, reaches a length of $39 \mathrm{~mm}$. from snout to vent, with a tail $36 \mathrm{~mm}$. long. This particular individual has seven dorsal scales in the standard distance.

The coloration of both sexes is quite constant, and the present series of 14 examples agrees with Barbour's description and figure.

Relationships.--As Dr. Barbour has already pointed out in his "Herpetology of Cuba" (p. 128), Sphaerodactylus copei is closely related to the Cuban scaber. It seems likewise to be related to becki from Navassa Island but has stronger keels on the large dorsals, according to Dr. Barbour's notes on the type of becki.

Specimens examined.-As listed in table 20. 
TABLE 20.-Specimens of Sphaerodactylus copei examined

\begin{tabular}{|c|c|c|c|}
\hline Museum No. & Locality & Date & Collector \\
\hline U.S.N.M. & & & \\
\hline 14839 & "San Domingo"? & & G. Marx. \\
\hline $59176-59178 \ldots \ldots$ & Jêrémie, Haiti & Apr. 10, 1917 & $\begin{array}{l}\text { J. B. Henderson and } \\
\text { P. Bartsch. }\end{array}$ \\
\hline $69120-69122 \ldots$ & Cave at Diquini, Haiti..... & Mar. 7,1925 & G. S. Miller, Jr. \\
\hline $74006-74012$ & . do do & Mar. 20, 1928 & A. J. Poole. \\
\hline 80930 & West of Bon Bon, Haiti & Aug. 16, 1929 & C. R. Orcutt. \\
\hline M.C.Z. & & & \\
\hline 3341,3342 (4 specimens) ..... & Grand Anse River, Haiti........... & 1865 & D. F. Weinland. \\
\hline 8771 & Diquini, Haiti . & 1913 & W. M. Mann. \\
\hline $25411-25413 \ldots \ldots$ & Miragoane, Haiti & 1927 & W. J. Eyerdam. \\
\hline
\end{tabular}

\section{SPHAERODACTYLUS STEJNEGERI Cochran}

\section{FigURE 37}

1885. Sphaerodactylus sputator Bodlenger, Catalogue of the specimens of lizards in the collection of the British Museum, vol. 1, p. 219 (part) (San Domingo) (not of Sparrman).

1914. Sphaerodactylus torrei Barbour, Mem. Mus. Comp. Zool., vol. 44, No. 2, p. 260 (part) (Santo Domingo) (not of Barbour); Mem. Mus. Comp. Zool., vol. 47, No. 3, p. 230, 1921 (part) (Thomazeau, Haiti).-BArbour and Ramsden, Mem. Mus. Comp. Zool., vol. 47, No. 2, p. 85, 1919 (part).Cochran, Proc. U. S. Nat. Mus., vol. 66, art. 6, p. 3, 1924 (Southwest Haiti). 1931. Sphaerodactylus stejnegeri Cochran, Copeia, 1931, No. 3, p. 90.-Barbodr, Zoologica, vol. 19, No. 3, p. 101, 1935; Bull. Mus. Comp. Zool., vol. 82, No. 2, p. 111, 1937.

As no new material has been taken recently, nothing has been added to the original description, which follows:

"Type.-U. S. Nat. Mus. No. 76640, an adult from San Michel, Département du Nord, Haiti, collected December 21-31, 1928, by A. J. Poole and Watson Perrygo.

"Description of the type.-Snout moderately short and broad, its length two and one-half times the diameter of the eye; eye slightly nearer ear than tip of snout; rostral large, with a median groove behind; nostril between rostral, one large supranasal, a postnasal and the first supralabial; supranasals separated from each other by a single scale; superciliary spine moderate in size; four moderately large and a very small fifth supralabial to a point below the center of the eye; four infralabials up to the same point followed by a fifth very small one, the whole series decreasing in size regularly; top of head covered with smooth, flat, polygonal scales which are fairly equal in size on snout and on occiput, becoming small only on the supraocular region; scales of back small, smooth, slightly imbricate, about 14 equalling the standard distance from tip of snout to center of eye; no mid-dorsal granular zone; mental large, followed by two enlarged postmentals; scales of gular region very small, smooth, imbricate; scales 
of chest and belly smooth, rounded, imbricate, about 10 ventral scales to the standard distance, not perfectly regular in size; scales of limbs anteriorly and below like those of the belly, much smaller and granular posteriorly; 14 smooth lamellae under the fourth toe; scales of tail above smooth, rounded, slightly imbricating, below on the
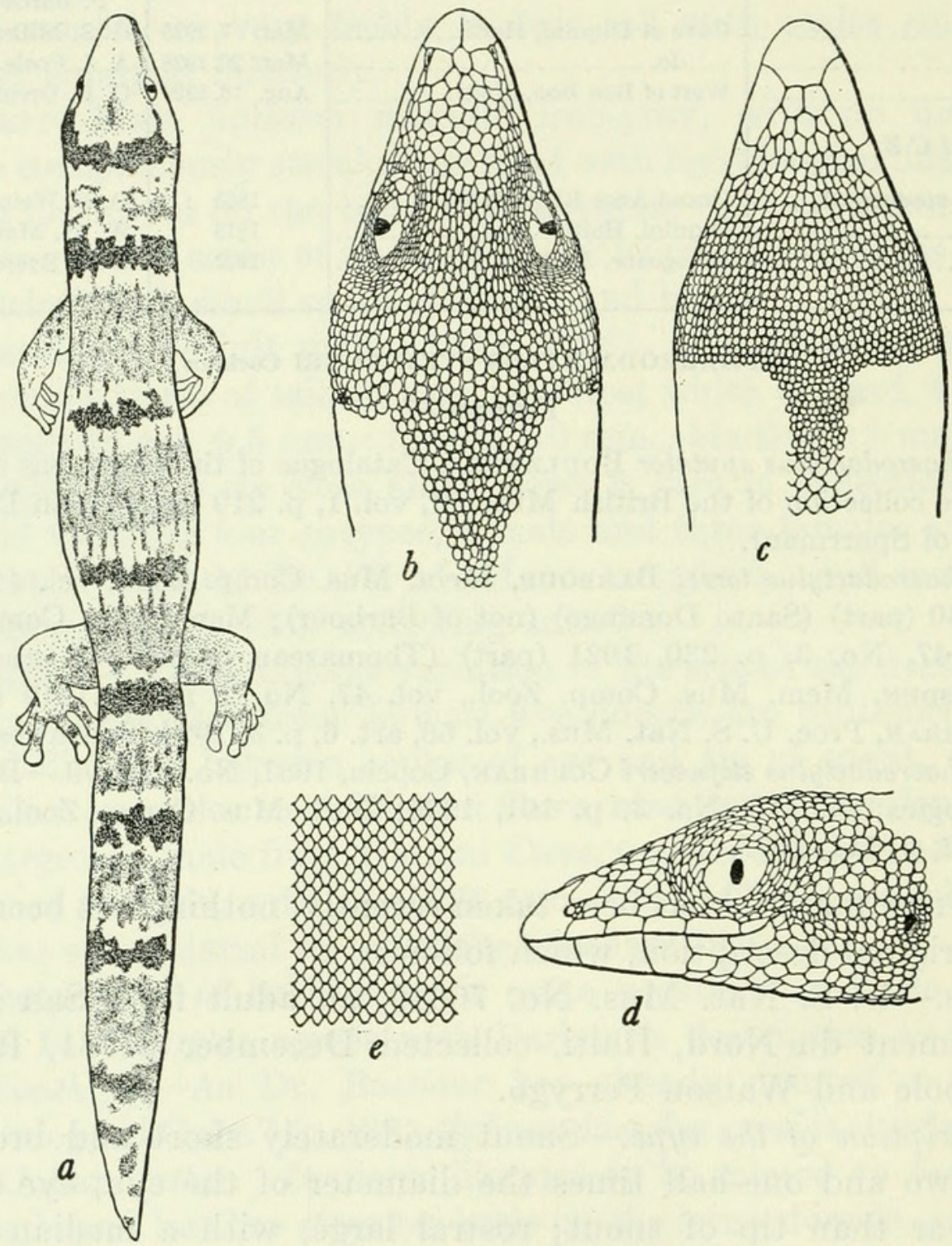

e

FigURE 37.-Sphaerodactylus stejnegeri: $a$, Dorsal view showing color pattern; $b$, top of head; $c$, chin; $d$, side of head; e, middorsal granules. U.S.N.M. No. 76640, type, from San Michel, Département du Nord, Haiti. $a-c, \times 2 ; d, e, \times 5$.

median line enlarged transversely into a series of very irregularly shaped plates.

"Dimensions.-Head and body, $31 \mathrm{~mm}$; tail, $27 \mathrm{~mm}$.; width of head, $5 \mathrm{~mm}$.; tip of snout to ear, $7.5 \mathrm{~mm}$.; foreleg, $7 \mathrm{~mm}$.; hindleg, $9 \mathrm{~mm}$.

"Coloration in alcohol.-Upper parts drab with a powdering of minute sepia dots; a sepia line beginning on the tip of the snout, continuing on the canthus and widening abruptly behind the eye, where 
it soon merges with a wide transverse bar of the same hue which crosses the occiput leaving the entire top of the head from occiput to tip of snout light; a second transverse sepia bar across the neck in front of the shoulders and two similar ones on the body; all the transverse bars with rather irregular outlines, bordered in front and behind by a light area, the interspace between these areas punctate with light sepia markings, and slightly exceeding in extent a single sepia bar with its light bordering areas; tail with five dark bars similar to those on the body, interrupted beneath; lower surfaces of body uniform pale drab, with a faint suggestion on the throat of the continuation of the two anterior sepia bars; labials without any color pattern, but with a heavy powdering of minute sepia dots; limbs with pale sepia markings above; a short longitudinal sepia line between the eyes.

"Paratypes.-A lizard from southwestern Haiti, U. S. Nat. Mus. No. 60617, collected by Dr. W. L. Abbott, is quite similar to the type in scalation; the dorsals are slightly smaller, however, about 16 to the standard distance, and on the anterior part of the body they are perhaps less imbricate. The dark crossbars, while identical in number and position, are much wider and heavier in the paratype, and their outlines are very regular. They extend a little further down the sides toward the ventral region in the paratype, and likewise are far more obvious on the throat, the occipital band completely crossing the throat, and the band following it having but a narrow interruption on the middle line. The dark lines on the canthus and between the eyes are also accentuated and broadened in this individual. The labials have scarcely any concentration of pigment on them, and the markings on the upper surfaces of the limbs are very inconspicuous. The much mutilated individual collected by Dr. G. M. Allen in Thomazeau (now Mus. Comp. Zool. No. 13481) is clearly of this species also.

"Relationships.-When the lizard now named as a paratype of stejnegeri, 60617, was first examined, both Dr. Barbour and I considered it the same as the Cuban Sphaerodactylus torrei and I called it so in the report on the Abbott collection. Closer study proved them to be quite distinct, however. The pattern of torrei, at first glance so similar to the Hispaniolan form, upon analysis proves to be different. For example, there are three, or traces of three, wide dark-edged bars on the body of females of torrei, separated by a narrow, uniformly light area. In stejnegeri, we find two uniformly dark and relatively narrow bars, having light borders and separated by relatively wide interspaces which are spotted with pale brown dots and markings. The head pattern is equally definite in the two species,-torrei has a definite white band preceding the dark occipital bar, with nearly the entire region in front of this dark, while in stejnegeri, the whole head 
in front of the occipital bar is light. The Cuban form has much smaller dorsals - 18 to 23 equaling the standard distance-but the new species has larger dorsals which are imbricate, at least on the posterior part of the body. The Cuban species has smaller scales on top of the head, on the center of the throat and between the eye and ear, while the new Hispaniolan lizard has comparatively larger scales in these areas. The snout of the adult cotype of torrei is relatively longer and more pointed than is the case in any of the Hispaniolan lizards. The fourth toe of torrei has more lamellae also.

"The new form, having small, smooth imbricate scales, falls next to glaucus from Mexico in Dr. Barbour's key although it can scarcely be regarded as an actual derivative of glaucus. It is much more likely that it was derived from one of the West Indian forms having no differentiated mid-dorsal zone and more or less weakly keeled scales."

Specimens examined.-U.S.N.M. No. 76640, San Michel du Nord, Haiti, December 21-31, 1938, A. J. Poole and Watson Perrygo; U.S.N.M. No. 60617, southwestern Haiti, 1917-18, Dr. W. L. Abbott; M.C.Z. No. 13481, Thomazeau, Haiti, Dr. G. M. Allen.

\section{SPHAERODACTYLUS SAMANENSIS Cochran}

Figure 38

1932. Sphaerodactylus samanensis Cochran, Proc. Biol. Soc. Washington, vol. 45, p. 183.-BARBour, Zoologica, vol. 19, No. 3, p. 104, 1935.

1937. Sphaerodactylus samaensis Barbour, Bull. Mus. Comp. Zool., vol. 82, No. 2, p. 214.

Original description.- "Diagnosis.-Dorsals imbricate; no differentiated middorsal zone; dorsals keeled, 7 or 8 (in adults) in standard distance; scales of posterior malar region faintly keeled; scales of gular region, chest and belly smooth; body with six wide clove-brown bars arranged in pairs, the interscapular pair enclosing two white spots; a dark frontal spot usually present; occiput usually crossed by two dark crescentic markings.

"Type.-U.S.N.M. No. 74970, an adult male from Boca del Infierno, Samaná Bay, Dominican Republic, collected on February 28, 1928, by Gerrit S. Miller, Jr.

"Description of the type.-Snout moderately short and broad, its length about twice the diameter of the eye; eye slightly nearer ear than tip of snout; rostral large, with a median groove behind; nostril between rostral, one large supranasal, two postnasals and the first supralabial; supranasals broadly in contact behind the rostral; superciliary spine moderate in size; three large supralabials, the third longest and extending past the center of the eye, followed by a very minute fourth supralabial not much larger than the granules surrounding it; three infralabials, the first much the largest; head above with granular, distinctly keeled, non-imbricating scales which are conspicuously 
enlarged on the snout; scales of back large, keeled, tectiform, imbricating, about eight equaling the distance from tip of snout to center of eye, not perfectly uniform in size and shape, the large ones not extending forward beyond the shoulders; no middorsal granular zone; mental large, followed by two enlarged postmentals; scales of gular region very small, smooth, imbricate; scales below the posterior infralabials and on posterior malar region larger, faintly keeled, juxtaposed;
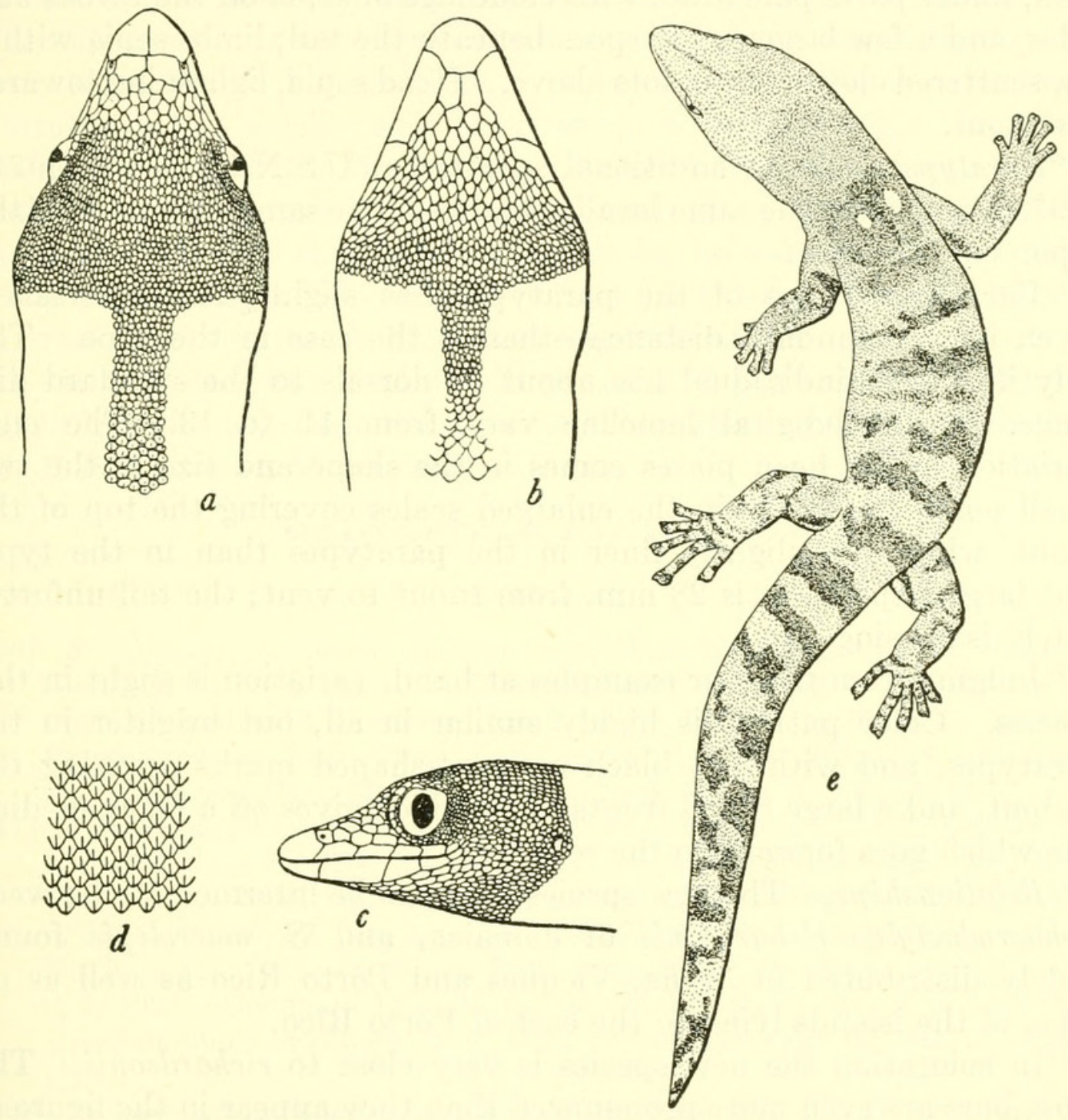

Figure 38.-Sphaerodactylus samanensis: $a$, Top of head; $b$, chin; $c$, side of head; $d$, middorsal region; $e$, dorsal view showing color pattern. U.S.N.M. No. 74970, type, from Boca del Infierno, Dominican Republic. $a-d, \times 5 ; e, \times 21 / 2$.

scales of chest and belly smooth, rounded, slightly smaller than dorsals, about nine ventrals to the standard distance; scales of limbs enlarged, keeled and imbricate above, smooth below, very small posteriorly; 13 smooth lamellae under the fourth toe; scales of tail large, faintly keeled, imbricating, very irregular in size and shape above, without definite whorls but enlarged into smooth transverse and fairly regular plates below. 
"Dimensions.-Head and body, $27 \mathrm{~mm}$.; tail, $25 \mathrm{~mm}$.; width of head, $5 \mathrm{~mm}$.; tip of snout to ear, $7 \mathrm{~mm}$.; foreleg, $7 \mathrm{~mm}$.; hindleg, $10 \mathrm{~mm}$.

"Coloration in alcohol.-Upper surfaces sepia; body with six wide, clove-brown bars arranged in pairs, the anterior pair between the shoulders and enclosing two very conspicuous round white spots; tail with about eight transverse, unpaired, irregular, clove-brown crossbars; under parts pale drab, with cloudings of sepia on the throat and sides, and a few larger sepia spots beneath the tail; limbs sepia with a few scattered clove-brown dots above. Head sepia, lightening towards the snout.

"Paratypes.-Three additional specimens, U.S.N.M. Nos. 7497174973 , come from the same locality and bear the same data as does the type.

"Variations.-One of the paratypes has slightly larger dorsalsseven in the standard distance-than is the case in the type. The only immature individual has about 10 dorsals to the standard distance. The subdigital lamellae vary from 11 to 13 . The only variation in the head plates comes in the shape and size of the two small post-nasals, and in the enlarged scales covering the top of the snout, which are slightly finer in the paratypes than in the type. The largest specimen is $28 \mathrm{~mm}$. from snout to vent; the tail unfortunately is missing.

"Judging from the four examples at hand, variation is slight in this species. Color pattern is highly similar in all, but brighter in the paratypes, and with two black crescent-shaped marks covering the occiput, and a large round frontal spot which gives off a black median line which goes forward to the rostral.

"Relationships.-The new species seems to be intermediate between Sphaerodactylus richardsonii of Jamaica, and S. macrolepis found widely distributed in Mona, Vieques and Porto Rico as well as on some of the islands lying to the east of Porto Rico.

"In coloration the new species is very close to richardsonii. The cross-bars are even more pronounced than they appear in the figure of richardsonii (Barbour, Mem. Mus. Comp. Zool., vol. 47, No. 3, 1921, plate 5, fig. 3), but are essentially similar in arrangement. The dark frontal spot, barely suggested in the figure of richardsonii, is very prominent in three of the four examples of samanensis, while these three likewise possess two black crescent-shaped marks crossing the occiput. But in macrolepis, only a very partial resemblance in pattern may be traced with samanensis. There is no dark frontal spot in macrolepsis; instead, there is a prominent dark occipital spot, which often is bounded by longitudinal markings instead of transverse crescents as in samanensis. While the dark interscapular band containing the two white spots is found in both species, macrolepis is 
without the remaining dark paired bars on the body which occur in samanensis.

"In details of scalation, however, samanensis is a little closer to macrolepis than to richardsonii. In fact, the smaller and more numerous labial plates of the Jamaican species, as well as the extremely small scales on top of the snout, serve at once to separate this species from samanensis. The number and proportions of the labial plates in macrolepis, however, are almost identical to those in samanensis. The supranasals in samanensis are larger and in mutual contact in the four examples at hand, although this character may prove to be unstable in this species, as it is known to be in macrolepis. The true difference between the two species is apparent on examining the dorsal scales. Not only are the enlarged dorsal scales appreciably smaller in samanensis, but they extend only as far forward as the shoulders, while in macrolepis they appear on the nuchal region, and give way to granular scales just behind the occiput itself."

Specimens examined.-U.S.N.M. No. 74970 (type) and Nos. 7497174973 (paratypes), Boco del Infierno, Dominican Republic, February 28, 1928, Gerrit S. Miller, Jr.

\section{SPHAERODACTYLUS DIFFICILIS Barbour}

Figure 39

1901. Sphaerodactylus notatus Meerwarth, Mitt. Naturh. Mus., vol. 18, p. 20, (part) (Bai von Samana, S. Domingo) (not of Baird).-Stejneger, Batrachians and land reptiles of the Bahama Islands, p. 331, 1905 (part).Barbour, Mem. Mus. Comp. Zool., vol. 44, No. 2, p. 264, 1914.-Barbour and Ramsden, Mem. Mus. Comp. Zool., vol. 47, No. 2, p. 85, 1919.

1914. Sphaerodactylus difficilis Barbour, Mem. Mus. Comp. Zool., vol. 44, No. 2, p. 265 (type locality, Santiago de la Vega, Dominican Republic); Mem. Mus. Comp. Zool., vol. 47, No. 3, p. 241, 1921; Zoologica, vol. 11, No. 4, p. 83, 1930; vol. 19, No. 3, p. 101, 1935; Bull. Mus. Comp. Zool., vol. 82, No. 2, p. 111, 1937.-Schmidt, Bull. Amer. Mus. Nat. Hist., vol. 44, art. 2, p. 9, 1921.-Cochran, Proc. U. S. Nat. Mus., vol. 66, art. 6, p. 3, 1924.Barbour and Loveridge, Bull. Mus. Comp. Zool., vol. 69, No. 10, p. 341, 1929.

1888. Sphaerodactylus nigropunctatus Garman, Bull. Essex Inst., vol. 19, p. 18 (Samaná) (not of Gray).

1888. Sphaerodactylus macrolepis Garman, Bull. Essex Inst., vol. 19, p. 21 (not of Günther).

The redescription of the type, M.C.Z. No. 7834, from Santiago de la Vega, Dominican Republic, is quoted fron Barbour (Mem. Mus. Comp. Zool., vol. 47, No. 3, p. 241, 1921):

"Snout rather short, not conspicuously acute; distance of eye from tip of snout and ear about equal; rostral moderate with median groove; nostril between rostral, first supralabial, a large supranasal and two smaller scales; two small scales border the rostral behind with thesupranasals; three large and one small supralabial to below centre of eye; superciliary spine present; head above and on sides covered with 
small elongate, juxtaposed, keeled scales, those on snout enlarged; scales on back enlarged, elongate, slightly keeled, imbricate, about nine or ten equaling the distance from tip of snout to centre of eye; mental large, nearly same size as rostral; two large infralabials followed by a small one to below centre of eye; two small, squarish chinshields behind mental, followed by flat smaller scales, which cover throat, enlarged but smooth on neck and chest, still larger on belly; limbs with smaller, keeled, imbricate scales; similar on upper surface
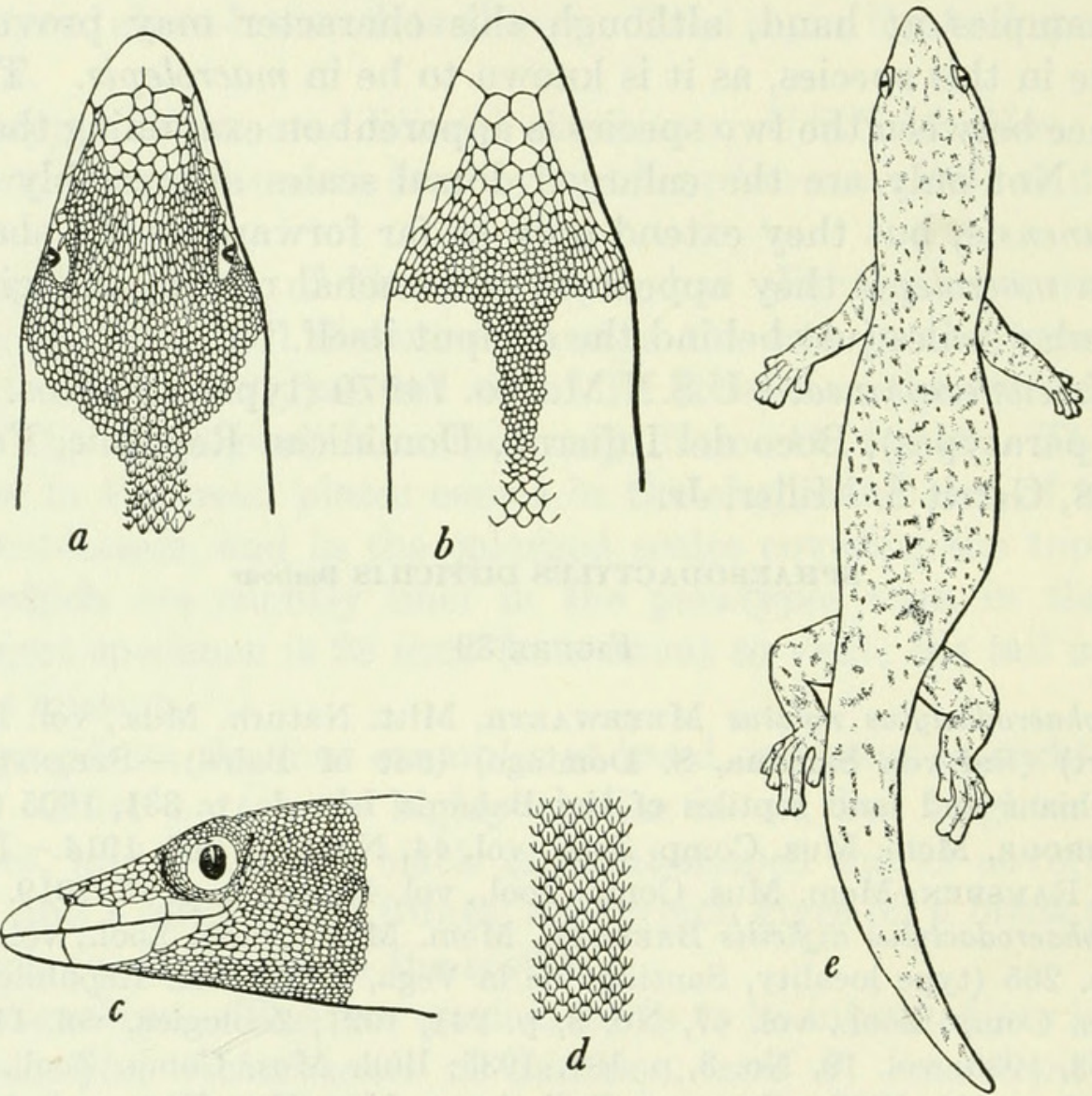

Figure 39.-Sphaerodactylus difficilis: $a$, Top of head; $b$, chin; $c$, side of head; $d$, middorsal scales; e, dorsal view showing color pattern. U.S.N.M. No. 75001, from Samaná, Dominican Republic. $a-d, \times 4 ; e, \times 2$.

of tail, but smooth below, enlarged irregular transverse plates below. "Colour.-Gray flecked with brown spots, often with longitudinal dark markings on head and neck. Shoulders with or without a pair of white dots, which may or may not be ringed with darker to form a spectacle-like mark. There may be a faint similar mark on the sacral region.

"Dimensions.-Tip of snout to vent, $28 \mathrm{~mm}$.; vent to tip of tail, $31 \mathrm{~mm}$.; greatest width of head, $5 \mathrm{~mm}$.; tip of snout to ear, $8 \mathrm{~mm}$.; foreleg, $8 \mathrm{~mm}$.; hindleg, $9.5 \mathrm{~mm}$.

"Remarks.-This species is very closely related to notatus and is probably annectent between that species and macrolepis. It is widespread throughout San Domingo and Haiti." 
The species is somewhat more variable than Dr. Barbour's original specimens led him to believe. The dorsal scales present an enormous variation in size, there being 7 to 14 enlarged dorsals in the standard distance from center of eye to tip of snout. The keels on these scales are often quite well developed. Sometimes there are distinct keels present on the chest, as in four rather small individuals from Boca del Infierno and a young one from Río San Juan. In most adults a faint trace of these keels may be found on the chest scales toward the sides even when those in the middle are quite smooth. The six lizards from Muertos Island have perfectly smooth chests, however.

The body color may range from pinkish buff through sepia. Small darker spots are thickly scattered over it, and in some specimens these spots tend toward a linear arrangement on the head and neck, and often also on the sacral region.

The length of head and body in the largest individuals of difficilis is $33 \mathrm{~mm}$., in No. 74942 from Río San Juan and No. 65781 from Samaná. The tail of the latter when intact measured at least 37 $\mathrm{mm}$. The largest notatus at hand is No. 42898 from Baracoa, Cuba, measuring $28 \mathrm{~mm}$. from snout to vent, with a tail length of $30 \mathrm{~mm}$. Dr. Barbour's statement as to the greater adult size and longer tail in difficilis is therefore corroborated in this respect by the additional material at hand.

The light lateral stripes on the nuchal region, when present, are as a rule considerably wider in specimens of notatus and narrower and less regular in difficilis. A heavier pigmentation of the labials is found in difficilis, while Cuban notatus have very pale labials with the merest traces of clouded markings or a very fine powdering of minute gray dots. A specimen of notatus from Paradise Key, Fla., has as much pigment on the labials, however, as do most of the Hispaniolan difficilis.

The only three examples of difficilis from the western part of Hispaniola show a single large black spot between the shoulders. In No. 76722, a half-grown individual from Muertos Island off northern Haiti, a small black spot is found in the same position. In this individual, as well as in another from the same place, there are five dark longitudinal stripes on the body. In the other four specimens from the same place, the spots on the body assume a corresponding linear arrangement. In none of the present series of difficilis from Hispaniola is found the pair of white shoulder spots encircled by dark, which Dr. Barbour mentioned as sometimes occurring. The pattern in both notatus and difficilis is so variable that without a great many more specimens of each species it would be impossible to delimit it accurately. 
Of the five Sánchez specimens (F.M.N.H. No. 5963), three are adults and two are young. All have a conspicuous, white, darkbordered patch on the posterior femur and adjoining part of body. One of the young has two light, dark-bordered dorsal ocelli above the base of the tail. Otherwise their coloration is spotted as in the described specimen. They do not appear to be males, as there is no ventral "escutcheon' of scales. The two young measure 22 and $21 \mathrm{~mm}$. in head and body length, respectively; their tails are partly missing.

The snout scales are well keeled in one adult, less so in one and not at all in the third.

The dorsal scales are very unequal so that those in the standard distance may be from 11 to 14 on the first adult listed, depending on where they are counted. The second adult is more equal in scales, but they seem slightly smaller, yet 12 to 14 may be counted anywhere on back or side. The third adult has smaller scales and 15 may often be counted.

The 22-mm. young has 14 to 15 scales in the standard distance, rather more than in the adults seemingly, while the $21-\mathrm{mm}$. young has finer scales than any, with 15 to 16 in the standard distance.

The chest scales are entirely smooth in all five specimens.

TABLE 21.-Specimens of Sphaerodactylus difficilis examined

\begin{tabular}{|c|c|c|c|}
\hline Museum No. & Locality & Date & Collector \\
\hline U.S.N.M. & & & \\
\hline $9850,9852-9855,9857$. & "San Domingo"...... & & W. M. Gabb. \\
\hline 59179 & Port-au-Prince, Haiti......... & Apr. 24, 1917 & $\begin{array}{l}\text { J. B. Henderson and } \\
\text { P. Bartsch. }\end{array}$ \\
\hline $59185 \ldots$ & Pétionville, Haiti. . . & Apr. $1,1917 \ldots$ & Do. \\
\hline $65781 \ldots \ldots$ & Samaná and Laguna, D. R & March $1923 \ldots . .$. & W. L. Abbott. \\
\hline 69124 & Mon Repos, Haiti & Mar. 5,1925 & G. S. Miller, Jr. \\
\hline $74942,74943 \ldots \ldots$ & Río San Juan, D. R & March 1928 & Do. \\
\hline 74974-74977 & Boca del Infierno, D. R & Feb. $28,1928 \ldots$ & Do. \\
\hline 75001, 75002 & Samaná, D. R & Feb. $22,1928 \ldots . .$. & Do. \\
\hline $76718-76723$ & Muertos Island, Sept Frères. & Jan. 28-Feb. 5,1929. & A. J. Poole and W. \\
\hline M.C.Z. & & & Perrygo. \\
\hline 7834 (type of $S$. difficilis) & Santiago de la Vega, D. R & 1910 & A. H. Verrill. \\
\hline 7835 (paratype of S. difficilis). & do & $1910 \ldots$ & Do. \\
\hline $\begin{array}{l}5444 \text { ( } 2 \text { specimens, paratypes } \\
\text { of } S \text {. difficilis). }\end{array}$ & Puerto Plata, D. R & 1885 & M. A. Frazar. \\
\hline 5451 & Samaná, D. R . . . . . . & 1885 & Do. \\
\hline 8750 & Grand Rivière............. & 1913 & W. M. Mann. \\
\hline $9365,9366 \ldots \ldots$ & do & 1913 & Do. \\
\hline 13458 & Ferronai. & 1919 & G. M. Allen. \\
\hline $43664-43666,44400 \ldots$ & Sosúa, D. R. & August 1937. . & W. J. Clench. \\
\hline $43706-43709$ & $\begin{array}{l}\text { Santa Barbara do Samaná, } \\
\text { D. R. }\end{array}$ & - & Do. \\
\hline $44379-44380 \ldots$ & $\begin{array}{l}\text { Mount Diego de O Campo, } \\
\text { D. R. }\end{array}$ & July 1938 & P. J. Darlington. \\
\hline $44395-44396 \ldots$ & Sánchez, D. R & July $1938 \ldots$ & Do. \\
\hline F.M.N.H. & & & \\
\hline $5963(3)$ & do. & $1924 \ldots$ & E. Kaempfer. \\
\hline
\end{tabular}


In contrast to these Sánchez specimens, the Samaná female (U.S.N.M. No. 75001) chosen for illustration has the dorsal scales quite regular in size and arrangement.

Specimens examined.-As listed in table 21.

\section{SPHAERODACTYLUS ARMSTRONGI Noble and Hassler}

FIGURE 40

1933. Sphaerodactylus armstrongi Noble and Hassler, Amer. Mus. Nov., No. 652, p. 5.-Barbour, Zoologica, vol. 19, No. 3, p. 101, 1935; Bull. Mus. Comp. Zool., vol. 82, No. 2, p. 111, 1937.

"Diagnostic Characters.-A small species, adult males approximately $50 \mathrm{~mm}$. in total length; scales on upper surface of snout and head strongly keeled, two to three times as large as those on the occiput; scales on the upper surface of the body imbricate and keeled, those on the throat, chest, and sides of the body also keeled, while those on the center of the abdomen are smooth. Adult male very dark brown in color with a wide open $V$ on the occiput, two spots on the scapular region, two spots on the base of the tail of a lighter tone. The light spots more or less surrounded with smaller spots of dark brown; some very feeble blotches of dark brown poorly indicated on the upper surface of the head. A dark streak along the side of the head and through the eye; sides of the head lighter than the occiput; a dark streak on the side of the head directly before and behind the eye.

"Detailed Description.-Type: A.M.N.H. No. 51470, adult male. Collected on mountain top on property of G. Herrmann near Paradis, Barahona Province, D. R., 2400 feet, August 25, 1932, by W. G. Hassler.

"Snout a trifle less than twice as long as the greatest diameter of the eye; distance from tip of snout to center of eye approximately equal to distance from center of eye to posterior margin of the ear opening; rostral plate rounded with a very feeble lateral ridge or canthus, rostral with a single median cleft behind; nostril surrounded by the rostral, first supralabial, enlarged supranasal, and two other scales of which the more ventral is only one-sixth to one-seventh as large as the dorsal; a single scale separating the supranasals in the midline a trifle larger than the scales covering the forehead; three enlarged supralabials; the most posterior extending well behind the center of the eye; scales on the upper surface of the head posterior to the supranasals keeled, diminishing gradually in size posteriorly, those immediately behind the supranasals only a third to a fourth larger than those between the eyes, but two to three times as large as those on the occiput; six scales in a line between the supranasals and a groove forming the anterior border of the orbit, three or four scales in the anterior part of this row two to three times as large as the small scales immediately behind; nineteen scales in a row across 
the snout from supralabial to supralabial immediately in front of the anterior border of the orbits; scales covering the upper surfaces of the body strongly keeled and imbricate; ten scales on the side of the body between the front and hind legs contained in the distance between the tip of snout and center of eye. Longitudinal axis of mental a third longer than same axis of rostral; three enlarged infralabials, the first a little less than twice as long as the second, the second a little less than twice as long as the third. Scales on the ventral surface of

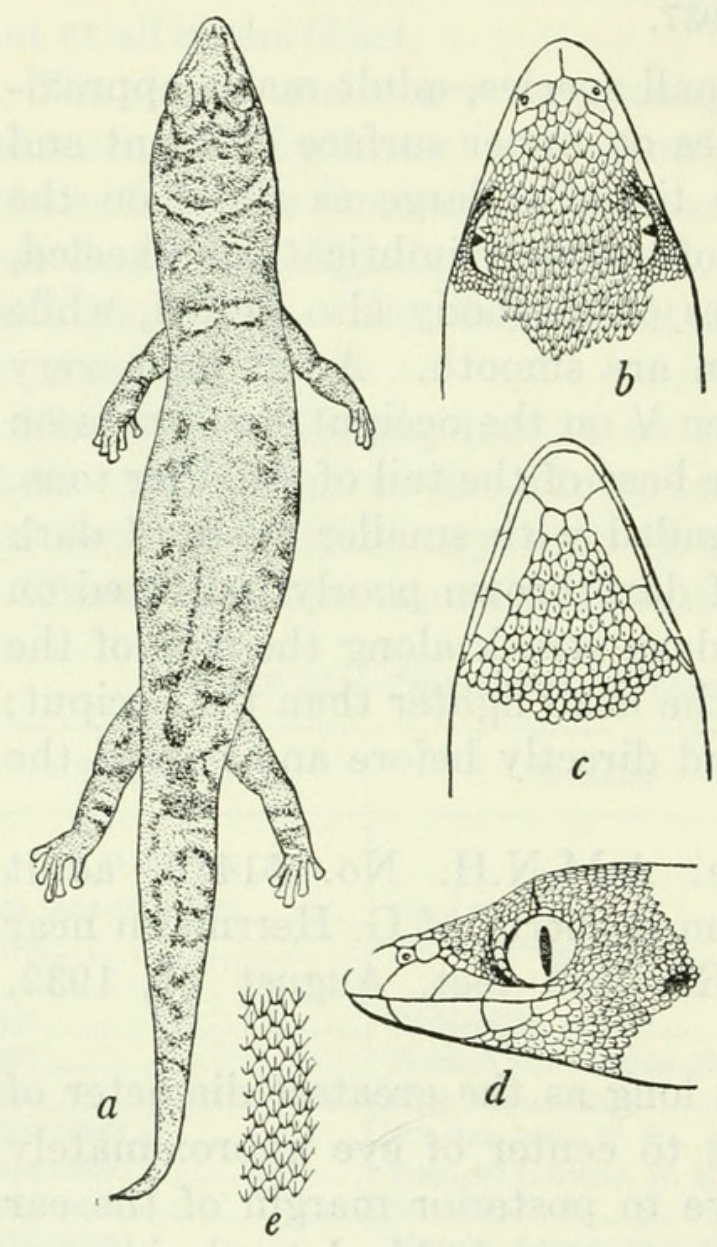

Figure 40.-Sphaerodactylus armstrongi: a,

Dorsum, showing color pattern; $b$, top of head; $c$, chin; $d$, profile of head; $e$, middorsal scales. A.M.N.H. No. 51469, paratype, from near Paradis, Barahona Province, Dominican Republic. $a, \times 2 ; b-e, \times 4$. the throat, chest, and sides of abdomen keeled; those on the middle of the abdomen smooth, scales gradually decreasing in size from the infralabials toward the throat, rapidly increasing in size immediately behind the throat; the scales on the chest and abdomen two to three times as large as the scales on the throat. A broad band of keeled imbricate scales on the outer surface of the fore limbs, these scales nearly as large as those on the chest; the otherscales on the fore limbs small and tubercular; scales on the outer surface of the upper segment of the hind limb similar to the dorsals but smaller, merging gradually into those of the posterior surface of the leg which are much smaller and tubercular; scales on the ventral side of the hind limbs (except for the hypertrophied preanal scales) keeled like those on the sides of the abdomen, but diminishing in size distally. Scales on the dorsal surface of the tail similar to the dorsal body scales but about one-third larger on the anterior part of the tail; ventral scales smooth, varying considerably in size, the average scale measuring about one-third larger than those of the abdomen.

"Uniform dark brown above (in alcohol), slightly paler on the snout and sides of the head; a dark streak from the rostral plate through the eye and fading out on the temporal region; a pale, widely opened $V$ on the nape of the neck; two light spots on the scapular region margined with a few spots of dark brown; a few feeble spots of 
the same tone on the occiput and upper surface of the neck; a pale streak on the lower half of the side of the tail margined above by a streak of dark brown; a few irregular and indistinct spots of dark brown along the ventral margin of the same streak; throat and under surface of neck spotted with brown; ventral surface of limbs and abdomen suffused with the same tone.

"Dimensions.-Head and body, $27 \mathrm{~mm}$.; tail, $23 \mathrm{~mm}$.; snout to posterior edge of ear, $6.5 \mathrm{~mm}$.; snout to center of eye, $3.5 \mathrm{~mm}$.; width of head, $5 \mathrm{~mm}$.; fore limb from axilla, $7 \mathrm{~mm}$.; hind limb from groin, $8 \mathrm{~mm}$.

"VARIATION.-The only paratype in the series is another adult male (A.M.N.H. No. 51469) which is identical to the type, except that a pair of light spots is visible on the dorsal surface of the tail base. These spots like those of the scapular region are more or less margined with a few dark brown blotches. The general ground tone of the upper surface is slightly lighter than the type, and the few small spots of dark brown scattered over the upper surface of the head and body are better indicated. In life this species was characterized by its dark tone. The color did not change greatly on preservation.

"Haвiтat.- These two specimens were both found under stones about twelve feet apart, in the deep channel cut by a small stream. There was no standing water, but the stream bed and steep sides were very damp. The mountain top in the vicinity was covered with rain forest."

The paratype A.M.N.H. No. 51469 has these dimensions: Head and body, $28 \mathrm{~mm}$.; tail, $17 \mathrm{~mm}$.; head length, $6.5 \mathrm{~mm}$.; snout to center of eye, $3.5 \mathrm{~mm}$.; head width, $4.5 \mathrm{~mm}$.; foreleg, $6 \mathrm{~mm}$.; hindleg, $10 \mathrm{~mm}$. In addition to the color variation noted in the original description, the chest scales in the paratype arrear to be entirely smooth. The preanal patch is about 5 scales high by 18 wide and is bluntly rounded in front, while its posterior extremities extend for four or five scales' distance onto the femur.

\section{SPHAERODACTYLUS ALTAVELENSIS Noble and Hassler}

Figure 41

1933. Sphaerodactylus altavelensis Noble and Hassler, Amer. Mus. Nov., No. 652 , p. 7.-Barbour, Zoologica, vol. 19 , No. 3, p. 102, 1935; Bull. Mus. Comp. Zool., vol. 82, No. 2, p. 112, 1937.

Original description.- "Diagnostic Characters.-A small species, approximately $50 \mathrm{~mm}$. in total length, very closely related to $S$. difficilis Barbour but differing in a combination of characters. Posterior part of throat covered with a broad band of keeled scales. Ten scales on the side of the body in a distance between that of the tip of snout and center of eye. One or two dark streaks on the posterior side of the thigh extending along the sides of the tail. Adult male and female gray and spotted with dark brown. A 'mask' 
formed by a dark blotch and a pair of white spots well defined on the shoulders of the immature and feebly developed in the adult female. Streaks on the sides of the head and occiput region of the immature and of most females.

“Detailed Description.-Type: A.M.N.H. No. 51488, adult male. Collected on Alta Vela Island, D. R., October 9-10, 1932, by W. G. Hassler.

"Snout a trifle less than twice as long as greatest diameter of the eye; distance from tip of snout to center of eye greater than distance from eye to ear opening; rostral plate rounded but with a distinct lateral ridge or canthus; rostral with a single median cleft behind; nostril surrounded by the rostral, first supralabial, supranasal, and two other scales of which the more ventral is only about one-tenth as large as the more dorsal. A single scale separating the supranasals in the midline a trifle larger than the scales immediately posterior to it; three enlarged supralabials followed by three much smaller suboculars; the posterior supralabial not reaching the center of the eye. A cluster of three or four scales on the superciliary margin directly over the dorsal anterior border of the eye distinctly larger

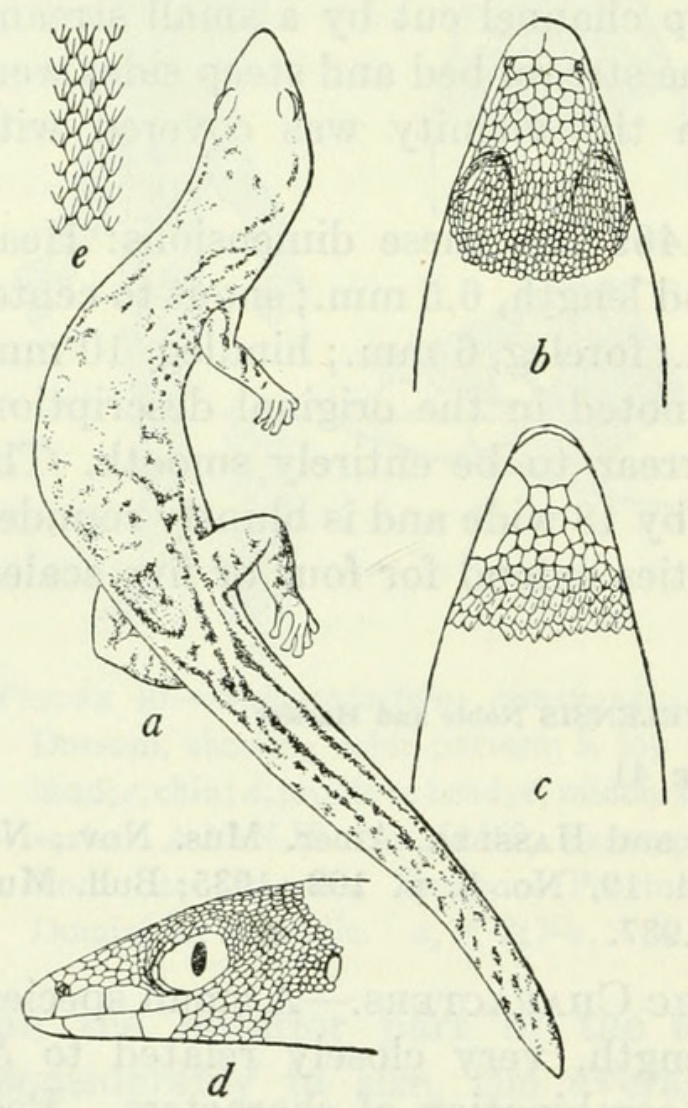

Figure 41.-Sphaerodactylus altavelensis: a, Dorsum, showing color pattern; $b$, top of head; $c$, chin; $d$, profile of head; $e$, middorsal scales. A.M.N.H. No. 51487, paratype, from Alta Vela Island, Dominican Republi c. $a, \times 2 ; b-e, \times 4$. than the superciliary scales posterior to them, one of the scales in the group forming an outwardly directed spine; scales on the upper surface of the head posterior to the supranasals keeled, except for two or three scales on the most anterior row; scales between the anterior half of the orbits slightly longer than those on the snout, but only a half or two-thirds as broad; scales on the upper surface of the head behind the orbits diminishing rapidly in size to form a series of very small scales on the greater part of the occiput. Six scales in a line between supranasals and a groove forming the anterior border of the orbit; seventeen scales in a row across the snout from supralabial to supralabial immediately in front of the anterior border of the orbits. Scales covering the upper surface of the body strongly keeled and imbri- 
cate; no enlarged scales in the midline; ten scales on the side of the body between the front and hindlegs contained in the distance between the tip of snout and center of eye. Mental a little longer than broad, about twice as long as the rostral; three enlarged infralabials, the first approximately twice as long as the second; the second twice as long as the third; the scales in a broad band across the throat and along the sides of the abdomen keeled; those in the middle of the abdomen smooth; scales on the abdomen two or three times as large as those on the throat. A broad band of scales on the upper surface of the fore limbs covered with keeled imbricated scales on both upper and lower arm, the remaining scales small and tubercular; a similar band of enlarged scales on the entire length of the hindlegs keeled and imbricated like the dorsals, but these scales greatly diminishing in size on the lower leg; scales on the posterior part of the thighs small and tubercular; scales on the ventral surface of the hind limb keeled like those on the sides of the abdomen and decreasing in size distally on the leg; a patch of hypertrophied preanal scales forming a triangular patch anterior to the cloaca. Dorsal scales on the regenerated tail keeled like the body scales and on the anterior part of the tail a trifle smaller than these; scales on the ventral surface of the tail smooth; scales forming the ventral midline of the regenerated portion very broad.

"Ground tone (in alcohol) a pale grayish-brown, slightly redder on the tail and head; a series of conspicuous dark brown spots on the entire upper surface; these spots on the upper surface of the head few and of about the same size as the pupil, increasing in number on the occiput, becoming numerous on the body where they average about one-half the size of those on the neck; the dark spots tend to arrange themselves in rows on the posterior body region and are transferred into a dark streak in the inguinal region; another streak of dark brown on the posterior surface of each thigh extending back along the side of the tail for only a short distance (due to the regenerated tail). Ventral surfaces grayish or straw-color spotted with dark brown on the throat and sides of the body, irregularly streaked with the same tone on the chest and abdomen.

"Dimensions.-Head and body, $26.5 \mathrm{~mm}$; ; tail (regenerated), 26 $\mathrm{mm}$.; snout to posterior edge of ear, $6.5 \mathrm{~mm}$.; snout to center of eye, $3.5 \mathrm{~mm}$.; width of head, $5 \mathrm{~mm}$.; fore limb from axilla, $7 \mathrm{~mm}$.; hind limb from groin, $9.5 \mathrm{~mm}$.

"VARIATION.-An adult female is usually more streaked than a male, and exhibits a 'mask' in the scapular region. This mask is formed by a large blotch of dark brown surrounding a pair of white spots. Some adult females are nearly identical in color pattern to adult males but the spots are smaller and tend to streak more. The spotting on the head tends to streak, and in the immature of both sexes as well as in adult females these streaks form a conspicuous 
crescent on the occiput and have a narrow median stripe extending forward between the eyes. There are also two other dark streaks more or less well defined extending backward from the orbit. Two or three streaks are found anterior to each thigh and two conspicuous ones along the posterior aspect of the thigh and along the tail. The spotting of the ventral surface varies considerably, but in the females there is usually more streaking than in the males.

"The dorsal color of these lizards varied in life from light to dark brown. The lighter ones had a decidedly orange tinge on the head and tail. The belly was usually a light yellowish-brown or grayish color.

"Навітат.- Specimens of this species were first found under loose rough chunks of limestone on the rocky headland, thirty to fifty feet above sea-level at the southeast end of Alta Vela. They were later found under rocks and in crevices in outcropping limestone in the low field at the northern end of the island. Still others were taken from under loose rocks high on the ridges in the center of the island.

"Remarks.-We have compared our series of twenty paratypes (A.M.N.H. Nos 51472-87, 51489-92) with Sphaerodactylus from various parts of the adjacent mainland and have found no specimens which exhibit the combination of characters seen in the Alta Vela series. No doubt several species have been confused under the name difficilis, but until the variation of this species has been determined the exact relationships of altavelensis cannot be fully stated."

A male paratype, A.M.N.H. No. 51487, differs slightly from the type description, as it has eight or nine scales to the standard distance; the interval between center of eye and tip of snout equals that between center of eye and posterior ear; the nostril on left side is followed by three small subequal scales in addition to supranasal; the single scale between supranasals equal to scales following it; mental two-thirds as long as broad; four infralabials, the last very small; preanal patch of male arrow-shaped, about 6 scales high and 13 wide, the posterior angles continuing for two or three scales' distance onto the femur. Head and body, $25 \mathrm{~mm}$; tail (incomplete), $23 \mathrm{~mm}$; head length, $6.5 \mathrm{~mm}$.; snout to center of eye, $3.5 \mathrm{~mm}$.; head width, $4.5 \mathrm{~mm}$.; fore limb, $5 \mathrm{~mm}$; hind limb, $10 \mathrm{~mm}$.

\section{Family IGUANIDAE \\ Genus XIPHOCERCUS Fitzinger}

1843. Xiphocercus Fitzinger, Systema reptilium, p. 67 (type, Anolis valenciennesii Duméril and Bibron).-Barbour, Proc. New England Zool. Club, vol. 7, p. 62, 1920 (emend.).

The finding of an example of this genus in southwestern Haiti is one more proof of the close relationship of this region with Jamaica. 


\section{XIPHOCERCUS DARLINGTONI Cochran}

Plate 11, A

1935. Xiphocercus darlingtoni Cochran, Proc. Boston Soc. Nat. Hist., vol. 40, No. 6, p. 373.-Barbour, Bull. Mus. Comp. Zool., vol. 82, No. 2, p. 117, 1937.

Original description.- "Diagnosis.-Differs from Xiphocercus valenciennesii of Jamaica in having definite rows of small scales covering gular skin, in having a relatively narrower and longer snout, in the different size and arrangement of the scales covering the snout, in having smaller granules on the sides of the neck and in having larger scales on the anterior surfaces of the limbs.

"Type.-M.C.Z. 38,251 an adult male from Roche Croix, Massif de la Hotte, Haiti, at about 5000 feet altitude collected in October, 1934, by P. J. Darlington.

"Description of the type.-Head large, twice as long as broad, nearly twice as long as the tibia; top of snout with two low, indistinct ridges, covered with large smooth shields; interorbital semicircles separated by one series of small scales; occipital twice as long as broad, much larger than the ear-opening, separated from the supraorbital semicircles by one row of scales; supraocular disk composed of three large, very faintly keeled scales and two or three smaller smooth ones, the latter separated from the superciliaries by about four rows of small irregular scales; canthus rostralis very sharp, canthal scales four or five; two or three loreal rows of flat, elongate scales; nostril just above the canthus rostralis; seven smooth upper labials to below the center of the eye; ear-opening very small. Gular appendage large, extending on the chest well behind the level of the axillæ, covered closely by many rows of small, somewhat tubercular scales. Body compressed, with a nuchal fold topped by scales a little larger than the surrounding granules; the body scales flat, enlarging on the sides, partly separated by very minute grains; belly scales squarish, smooth, imbricate, arranged in transverse rows. Limbs rather short, the adpressed hind limb reaching the shoulder; 23 lamellæ under second and third phalanges of fourth toe. Scales on anterior surfaces of limbs relatively large, hexagonal, keeled faintly. Tail compressed, with a very slight suggestion of a crest proximally, its length slightly exceeding that of head and body. Male with irregularly enlarged postanal scales. The type is unique.

"Color in alcohol.-Ground color of dorsal parts drab-gray, lightening somewhat on the tail; a large square clove-brown patch over the entire temporal region from the posterior orbit to the anterior border of the ear; each of these square patches is bordered above by a crescentic lilac-gray mark; the occipital region between these pale crescents sepia, lightening to wood-brown on the snout; supraocular region olive-gray; a chevron-shaped seal-brown mark leaving the dark 
occipital area and passing backward and downward to end in front of the shoulder; four other wide brown chevron-shaped markings across the back, breaking up on the sides into a number of irregular, diagonal, wavy brown stripes; tail encircled by six wide brown bands; fore and hind limbs with brown crossbands which break up into irregular dark lines; upper and lower lips lilac-gray, the area in front of and behind the ear white; an indefinite wide, seal-brown stripe along the sub-labial region; chin and gular scales plumbeous, the gular skin blackish slate. Belly and lower surfaces of limbs pearl-gray, with a few scattered lilac-gray spots.

"Dimensions.-Head and body, $75 \mathrm{~mm}$.; head to posterior border of ear, $25 \mathrm{~mm}$.; width of head, $12.5 \mathrm{~mm}$.; fore limb from axilla, $26 \mathrm{~mm}$.; hind limb from groin, $38 \mathrm{~mm}$.; tibia, $14 \mathrm{~mm}$.; tail, $90 \mathrm{~mm} . "$

\section{Genus CHAMAELINOROPS Schmidt}

1919. Chamaelinorops Schmidt, Bull. Amer. Mus. Nat. Hist., vol. 41, p. 523.

This genus was first taken on Navassa Island. A second species was discovered by Dr. Wetmore in the southwestern peninsula of Haiti, giving another proof of its connection in former times with Navassa.

\section{CHAMAELINOROPS WETMOREI Cochran}

FigURE 42

1928. Chamaelinorops wetmorei Cochran, Proc. Biol. Soc. Washington, vol. 41, p. 45.-BARBour, Zoologica, vol. 11, No. 4, p. 86, 1930; vol. 19, No. 3, p. 106, 1935; Bull. Mus. Comp. Zool., vol. 82, No. 2, p. 117, 1937.

"Diagnosis.-Differs from Chamaelinorops barbouri in having shorter limbs, in possessing a lateral series of enlarged spinose scales, in having small scales instead of granules in the area between this lateral series of enlarged scales and the enlarged dorsals, and in possessing a transverse gular fold which reaches almost to the nuchal region.

"Type.-U.S.N.M. No. 72630, a young individual collected at Fond-des-Nègres, 20 kilometers southwest of Miragoane, Département du Sud, Haiti, on April 4, 1927, by Dr. Alexander Wetmore.

"Description.-Head V-shaped in outline, very angular; canthus rostralis sharp, composed of two large scales, merging evenly into the supraciliary border where three scales may be counted, the second the longest and very wide; loreal region concave; four rows of loreal scales; nostrils lateral, somewhat elevated; four scales between the supranasals; rostral very broad and low, separated from the nasals by two rows of small scales; frontal region without ridges, flat; a patch of four or five unequal, enlarged supraocular scales, separated from the superciliaries by smaller scales and granules; ridges of the supraorbital semicircles prominent, covered with large keeled scales, and separated from each other by three rows of small smooth scales; occipital plate slightly larger than the scales immediately surrounding it, elongate, the pineal body very apparent; three scales between the supraorbital 
semicircles and the occipital; a very strong lateral ridge from the middle of the posterior orbital border extending horizontally backwards and ending in a heavy tuberculated knob above the ear; several enlarged spinose scales above this ridge; two weak ridges running parallel with these, and extending from the posterior border of the supraorbital ridges to the occiput; a faint transverse ridge across the occiput joining the posterior portions of all the ridges; nine upper and nine lower labials to a point directly beneath the center of the eye; all the head scales with a sharp keel or a spinose tubercle in the center, excepting the occipital and the scales between the supraorbital semicircles which are smooth; ear-opening with scarcely any indication of a ridge in front of it, oval, about half the length of the eye-opening. A short gular fan, and a decided transverse fold behind it extending on
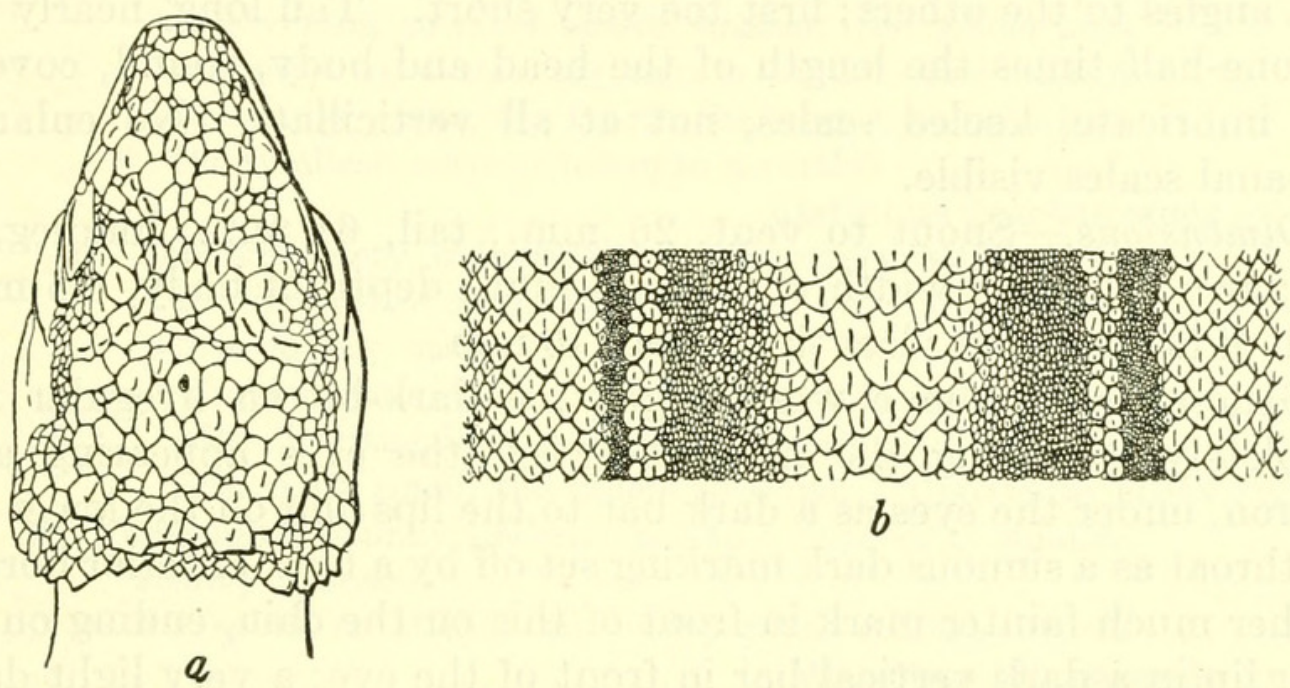

Figure 42.-Chamaelinorops wetmorei: $a$, Top of head; $b$, scales around middle of body: U.S.N.M. No. 72630, type, from Fonds-des-Nègres, Haiti. Four and one-half times natural size.

the sides of the neck up to the knob above the ear and nearly onto the nuchal region; throat covered with rows of very small keeled scales.

"Body extremely compressed, the sides vertical or concave, over twice as deep as wide at mid-body; no trace of a dorsal or caudal crest. Lepidosis heterogeneous; six rows of large dorsal scales; the two middle rows narrower than long, each scale with a distinct keel ending in a raised elevation posteriorly; the next two rows the largest, the scales about as wide as long and with their keels ending in elevations which are even more pronounced and which form in profile an irregular saw-toothed line; the two outer dorsal rows like the middle pair in size and carination; below these and merging gradually into them is a band of small, rather smooth but very irregular dorsolaterals about 12 scales in width; below these comes a lateral band of two rows of large, tubercular scales beginning in front of the shoulder, running above it and straight along the sides to the groin; below these and sharply separated from them is a latero- 
ventral band of smooth granularscales; thesein turn suddenly give place to about fourteen rows of very large, heavily keeled ventral scales, the two or three median ventral rows much smaller than the others. The hindleg being adpressed, the tip of the fourth toe reaches a point halfway between the tympanum and the eye; the arm being laid back along the sides, the finger-tips extend about four-fifths of the way to the groin; limbs entirely covered with imbricate scales, the keels usually continuous. Digits medium in length, slightly depressed and very slightly expanded, the terminal phalanx of each digit compressed at the joint, then expanded before the claw is reached. Claws strong, inserted at the end of the expanded portion of the digits; third and fourth fingers nearly equal in length; fourth toe much the longest, with 25 lamellae beneath it; fifth toe as long as second, and set in at right angles to the others; first toe very short. Tail long, nearly two and one-half times the length of the head and body, round, covered with imbricate, keeled scales, not at all verticillate. No enlarged post-anal scales visible.

"Dimensions.-Snout to vent, $26 \mathrm{~mm}$; tail, $61 \mathrm{~mm}$.; hindleg, 19 mm.; arm, $11 \mathrm{~mm}$.; width of body, $3 \mathrm{~mm}$.; depth of body, $6.5 \mathrm{~mm}$.; width of head, $6 \mathrm{~mm}$.; length of head, $10 \mathrm{~mm}$.

"General color above whitish gray; a dark-brown irregular ring completely encircling the head, between the eyes appearing as a chevron, under the eyes as a dark bar to the lips and on the lower jaw and throat as a sinuous dark marking set off by a light anterior border; another much fainter mark in front of this on the chin, ending on the upper lip in a dark vertical bar in front of the eye; a very light darkedged longitudinal stripe on the frontal region, and another $U$-shaped one behind the dark chevron. Three light-brown vertical bars on each side of the body; a small dark triangular blotch just above the groin. Ventral surfaces dark grayish-brown, with irregular streaks of lighter color on the belly and lower surfaces of the limbs. Throat on either side of fan and in front of transverse fold intensely black; center of fan brown. Tail nearly white above, bluish-gray below, with about a dozen light bands edged with darker gray, these scarcely visible when seen from above. Occasional jet-black tips on the spinose tubercles and elevations on head and back."

\section{Genus ANOLIS Daudin}

1802. Anolis Daudin, Histoire naturelle . . des reptiles, vol. 4, p. 50 (type, A. bullaris-carolinensis).

KEY TO THE SPECIES OF ANOLIS FROM HISPANIOLA

$a^{1}$. Dorsal scales entirely separated from each other by several circles of granules. ricordii (p. 130) 
$a^{2}$. Dorsal scales juxtaposed or imbricated.

$b^{1}$. Dorsal scales enlarged, flat, keeled, and imbricate on midline, very much like ventrals.

$c^{1}$. Scales of gular fan relatively fine, skin between them light . .

$c^{2}$. Scales of gular fan coarse, interstitial skin usually dark___olssoni (p. 137)

$b^{2}$. Dorsal scales (all or except two rows on median line) granular or tubercular, differing but little, if at all, from laterals, but very much from ventrals, which are larger.

$c^{1}$. A fairly regular median paired series of scales on upper anterior part of snout; usually two or more supraorbital scales fully in contact with their fellows (distichus group).

$d^{1}$. A distinct preoccipital scale nearly as large as occipital usually present.

$e^{1}$. Tail with well-marked verticils, every ninth vertical row consisting of enlarged, elongate, pointed scales, intervening rows of scales smaller, the whole surmounted by a strongly serrate caudal crest with 5 triangular scales, the fourth the largest and the first the smallest, corresponding to a verticil

distichus dominicensis (p. 141)

$e^{2}$. Tail with very indistinct verticils, every eleventh or twelfth row of scales more vertical but not enlarged, intervening scales in curving or irregular rows, whole surmounted by a weakly serrate caudal crest with 5 triangular scales to a verticil, the first and fifth quite small, the others subequal___distichus juliae (p. 148)

$d^{2}$. Preoccipital usually broken up into a number of smaller scales, or absent.

$e^{1}$. No spots or stripes on body; color reddish brown

distichus altavelensis (p. 151)

$e^{2}$. Spots or stripes present; ground color grayish.

$f^{1}$. Four small round black spots usually present in a transverse row behind occipital_.._distichus wetmorei (p. 154)

$f^{2}$. A black shoulder patch bordered above and below by parallel light stripes............ distichus caudalis (p. 156)

$c^{2}$. Median snout scales not in a paired series on snout; not more than two paired supraorbital scales (sometimes none) in contact with their fellows on midline.

$d^{1}$. Head short and broad, body stout, limbs heavy (cybotes group).

$e^{1}$. Tail scales relatively finer, usually 6 to 9 vertical rows of scales to every verticil; snout generally more blunt.

$f^{1}$. Belly scales relatively coarse, median dorsals small; heel not reaching beyond shoulder when hindlimb is adpressed cybotes cybotes (p. 159)

$f^{2}$. Belly scales quite small, median dorsals longer than in preceding form; heel reaching nearly to posterior border of ear cybotes longitibialis (p. 164)

$e^{2}$. Tail scales relatively coarser, usually 4 to 6 vertical rows

to a verticil; snout generally more elongate_cybotes doris (p. 167) 
$d^{2}$. Head longer and narrower, body much more slender, limbs more delicate.

$e^{1}$. Upper head scales keeled.

$f^{1}$. Head almost twice as long as broad monticola (p. 169)

$f^{2}$. Head about $1 \frac{1}{2}$ times as long as broad. darlingtoni (p. 170)

$e^{2}$. Upper head scales smooth.

$f^{1}$. Width of head nearly as great as distance from occipital shield to end of snout; dewlap distinct in male.

$g^{1}$. Gular skin black; gular scales relatively coarse, about three equaling length of eye aperture

chloro-cyanus (p. 173)

$g^{2}$. Gular skin light; gular scales relatively fine, about

6 equaling eye aperture............... coelestinus (p. 177)

$f^{2}$. Width of head but slightly more than half as great as distance from occipital shield to end of snout; dewlap much reduced or absent.

$g^{1}$. Body granules relatively coarse; tip of snout

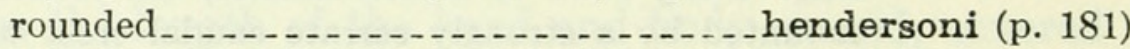

$g^{2}$. Body granules very minute; tip of snout truncate

bahorucoensis (p. 184)

\section{ANOLIS RICORDII Duméril and Bibron}

\section{Figure 43}

1837. Anolis ricordii DUMérIL and Bibron, Erpétologie générale, vol. 4, p. 167 (type locality, San Domingo, W. I.; type in Mus. Paris, coll. Ricord).Bodlenger, Catalogue of the specimens of lizards in the collection of the British Museum, vol. 2, p. 22, 1885 (San Domingo, Brit. Mus.).-Garman, Bull. Essex Inst., vol. 19, p. 27, extr. p. 3, 1887 (Samaná, S. Domingo; Mus. Comp. Zool. Cambridge; coll. Frazar).-Meerwarth, Mitth. Naturh. Mus. Hamburg, vol. 11, p. 21, 1900 (1901).-StejNeger, Rep. U. S. Nat. Mus., 1902, p. 629, 1904.-Barbodr, Mem. Mus. Comp. Zool., vol. 44, p. 273, 1914; Bull. Mus. Comp. Zool., vol. 70, No. 3, p. 138, 1930; Zoologica, vol. 11, No. 4, p. 87, 1930; vol. 19, No. 3, p. 107, 1935; Bull. Mus. Comp. Zool., vol. 82, No. 2, p. 119, 1937.-Schmidt, Bull. Amer. Mus. Nat. Hist., vol. 44, p. 10, 1921.-Cochran, Proc. U. S. Nat. Mus., vol. 66, art. 6, p. 4, 1924.Böker, Publ. Inst. Cient. Domínico-Alemán, vol. 1, p. 16, 1939.

Description.-Adult male, U.S.N.M. No. 62105, from El Río, Jimenòn River, Dominican Republic, collected on May 13, 1919, by Dr. W. L. Abbott. Head large, the sides and top approximately equal in area and shaped like a triangle with rounded apex; scales of canthus, snout, and supraorbital semicircles large, rugose, bulging, conical; those of occipital region quite small but equally conical; two or three scales separating the supraorbital semicircles, and three scales between the supraorbital semicircle and the occipital shield, which is small, flat, and inconspicuous; palpebral scales hexagonal, small in comparison with the snout scales; superciliaries two; seven loreal rows, those adjoining the canthus bulging and conical, the lower ones smooth and flat; 10 and 12 upper labials on opposite sides of head, 9 to a point below the center of the eye; ear opening oval, considerably smaller than the eye opening; a strong ridge continuing 
backward from the upper eyelid onto the temporal region; this ridge covered with somewhat enlarged and slightly bulging scales; the temporal region between this ridge and the ear covered with uniform small hexagonal scales, each with a low keel; 12 lower labials to a point below the center of the eye; symphysial large, semicircular, partially divided by a suture posteriorly; a row of four or five enlarged scales just below the infralabials, merging gradually with the throat scales, which are tubercular and nonimbricate; gular fan very large, the inner portion appearing nearly naked but really covered with very indistinct and small scales, the outer bordered with very small but distinct scales, which are imbricate. A dorsal crest of one row of mucronate scales beginning just behind the occiput, continuing along the back, becoming greatly diminished at the beginning of the tail, then continuing on the tail as a "fin" supported on bony rays
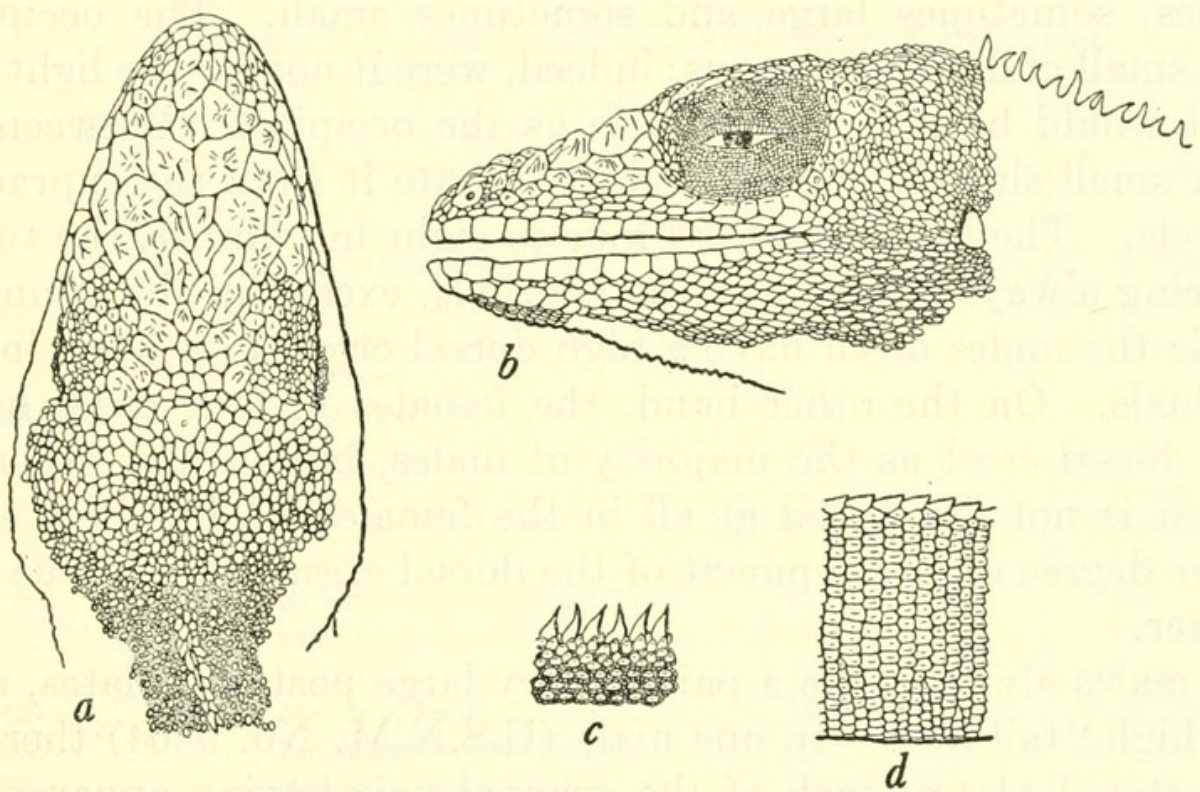

Figure 43.-Anolis ricordii: $a$, Top of head; $b$, side of head; $c$, skin on side of neck and nuchal crest; $d$, side of tail. U.S.N.M. No. 62105, from El Río, Dominican Republic. Natural size.

from the caudal vertebrae occurring at about every fourth series of scales. Scales of the back and sides heterogeneous, composed of single, oval, tubercular scales separated by two or three rows of exceedingly minute, granular scales; belly covered with smooth imbricate scales about as large as the lateral "tubercles" into which they merge insensibly; upper parts of arms and legs with large, hexagonal, keeled scales; sides of tail with regularly arranged rows of small rectangular scales, each bearing a low median keel; scales beneath the tail considerably larger, hexagonal and sharply keeled; male with enlarged postanal plates; about 33 lamellae under the enlarged portion of the fourth toe.

Color (in alcohol).- - Top and sides of head wood brown; body, limbs, and tail above sepia, with a few small, unevenly shaped, slate- 
colored blotches arranged in four or five more or less irregular vertical rows on the sides of the body; limbs and feet with heavy, slate-colored cross bars; lower surface of body olive-buff, of tail drab; throat suffused with cloudings of olive-gray; reticulations of slate color extending over lateroventral region and a few spots scattered on lower parts of limbs; traces of a light temporal patch bordered above by a black streak; skin and scales of gular fan pale straw yellow; a pale infraorbital stripe fading out just back of the commissure of the jaws.

Dimensions.-Head and body, $137 \mathrm{~mm}$; tail, $290 \mathrm{~mm}$.; snout to center of eye, $27 \mathrm{~mm}$.; snout to posterior ear, $44 \mathrm{~mm}$.; foreleg, $61 \mathrm{~mm}$.; hindleg, $106 \mathrm{~mm}$.

Variations.-In the series of specimens in the National collection there is considerable uniformity in head scalation. Between the supraorbital semicircles there are two, three, or four irregular series of scales, sometimes large and sometimes small. The occipital is always small and inconspicuous; indeed, were it not for the light pineal body it would be indistinguishable as the occipital. Between three and six small sharply conical scales separate it from the supraorbital semicircle. The loreal rows are four to eight in number, the topmost ones being always rugose like the canthals, except in the young.

While the males often have a high dorsal crest, it is weak in a few individuals. On the other hand, the females in four cases have as high a dorsal crest as the majority of males, but in four other cases the crest is not developed at all in the females. Thus it is evident that the degree of development of the dorsal crest is not a true sexual character.

The males always have a pair of very large postanal plates, as well as the high "tail fin." In one male (U.S.N.M. No. 9804) there were four postanal plates, each of the original pair having apparently divided longitudinally. The females have neither the postanal plates nor the tail fin.

The variation in pattern is considerable. While some of the specimens show no pronounced pattern, others have a definite black marking, very irregular in outline, which extends across the nape, branches forward to cover the temporal and most of the supraocular regions and extends with more or less interruption on the shoulders and anterior lateral region as a series of very uneven large and small patches. One of the lizards from San Juan River (U.S.N.M. No. 74941) is azure blue and mauve above, and pale blue below including the scales of the gular fan, the skin of which, in this individual, is slate color anteriorly, fading out to a fine powdering of very minute light gray dots posteriorly. This specimen has a few indistinct dorsal and lateral spots, but the main pattern appears on head and neck, where the dark slate-colored supratemporal streak appears, and the irregular dark occipital and nuchal markings are in evidence. No limb bars 
occur in this specimen, although the toes and fingers become gradually slate colored, and the tail in its distal portion turns from dull azure blue to sepia. The other specimen from San Juan River (U.S.N.M. No. 74940) is much darker, being a dull Indian purple above, with traces of lighter dull azure dorsal saddles and with very conspicuous light bars on the seal-brown tail. No distinct head markings or limb bars can be made out in this individual. A light supraorbital spot appears in both specimens, while the color of the gular fan is the same in both.

Relationships.-As Dr. Stejneger has already pointed out the relationships of Anolis ricordii to Anolis cuvieri of Puerto Rico, I have nothing to add to his discussion. The two species are perfectly distinct, although obviously closely related.

Specimens examined.--As listed in table 22.

TABLE 22.-Specimens of Anolis ricordii examined

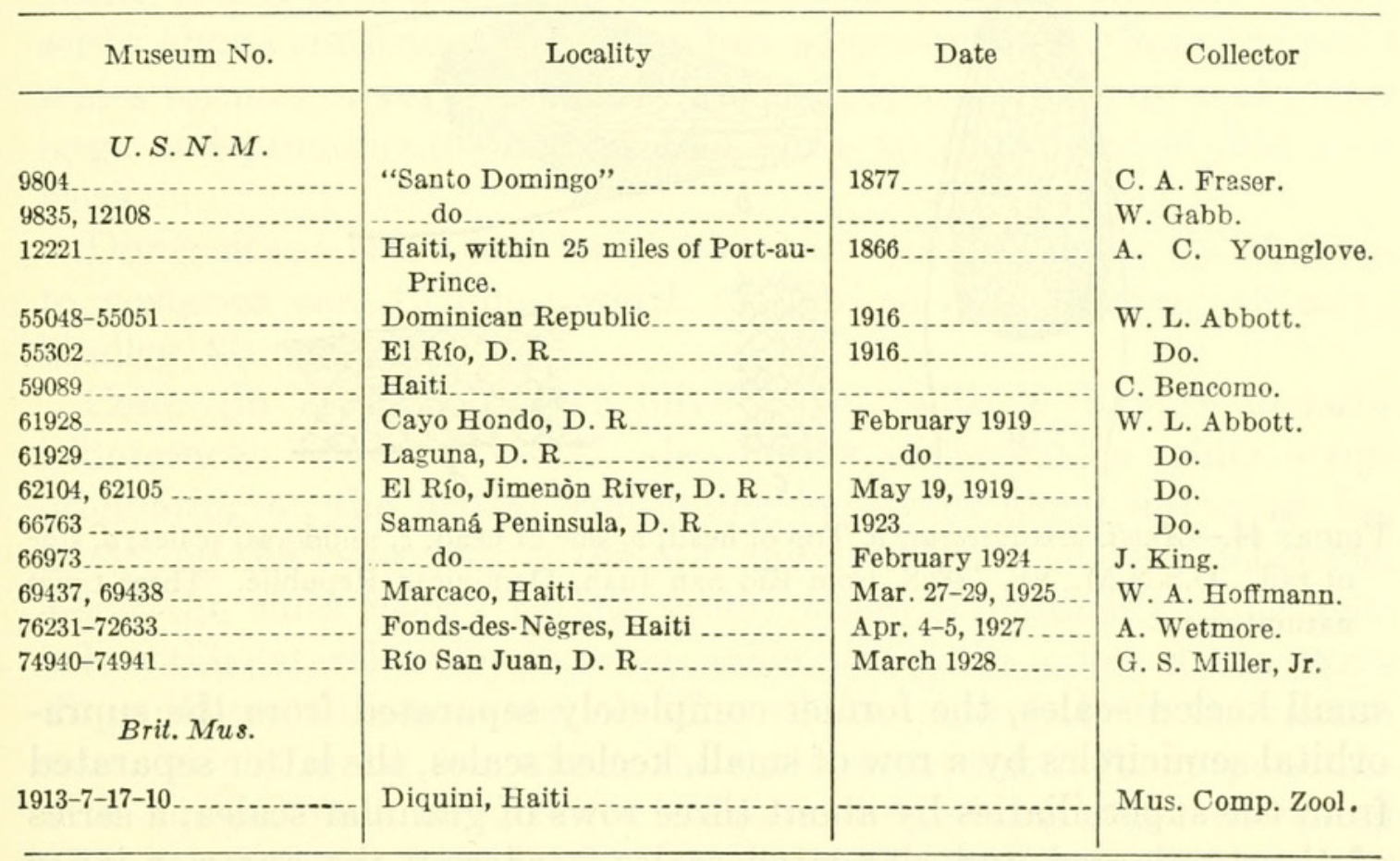

\section{ANOLIS SEMILINEATUS Cope}

Figure 44

1864. Anolis semilineatus Cope, Proc. Acad. Nat. Sci. Philadelphia, 1864, p. 171 (type locality, Haiti; type in Brit. Mus.).-Boulenger, Catalogue of the specimens of lizards in the collection of the British Museum, ed. 2, vol. 2, p. 68, pl. 5, fig. 1-1a, 1885.-Garman, Bull. Essex Inst., vol. 19, p. 49 (extr. p. 35), 1887.-Meerwarth, Mitth. Naturh. Mus. Hamburg, vol. 11, p. 26, 1900 (1901).-Barbour, Mem. Mus. Comp. Zool., vol. 44, p. 291, 1914 (part), (Samaná).-Schmidt, Bull. Amer. Mus. Nat. Hist., vol. 44, art. 2, p. 10, 1921.-Cochran, Proc. Biol. Soc. Washington, vol. 41, p. 54, 1928.Barbour, Bull. Mus. Comp. Zool., vol. 70, No. 3, p. 141, 1930; Zoologica, vol. 11, No. 4, p. 91, 1930; vol. 19, No. 3, p. 112, 1935; Bull. Mus. Comp. Zool., vol. 82, No. 2, p. 124, 1937.-Böker, Publ. Inst. Cient. DomínicoAlemán, vol. 1, p. 16, 1939. 
I include Meerwarth's record of semilineatus from Port-auPrince with considerable doubt as to its correctness, since in our own copious collection of lizards from Port-au-Prince I have not yet encountered the species. A closer examination might prove Meerwarth's specimens to be olssoni, which is known to occur there.

Description.-Adult male, U.S.N.M. No. 74868, from Río San Juan, Dominican Republic, collected in March 1928, by G. S. Miller, Jr. Top of head with two slightly curved low frontal ridges bordering a very shallow frontal hollow; head scales distinctly keeled and relatively small; six scales in a row between the supranasals; supraocular semicircles separated by two rows of scales (in this specimen); occipital medium-sized, about equal to the ear opening in size, separated from the supraocular semicircle by two or three wrinkled scales; supraocular disk composed of one or two large and three or four
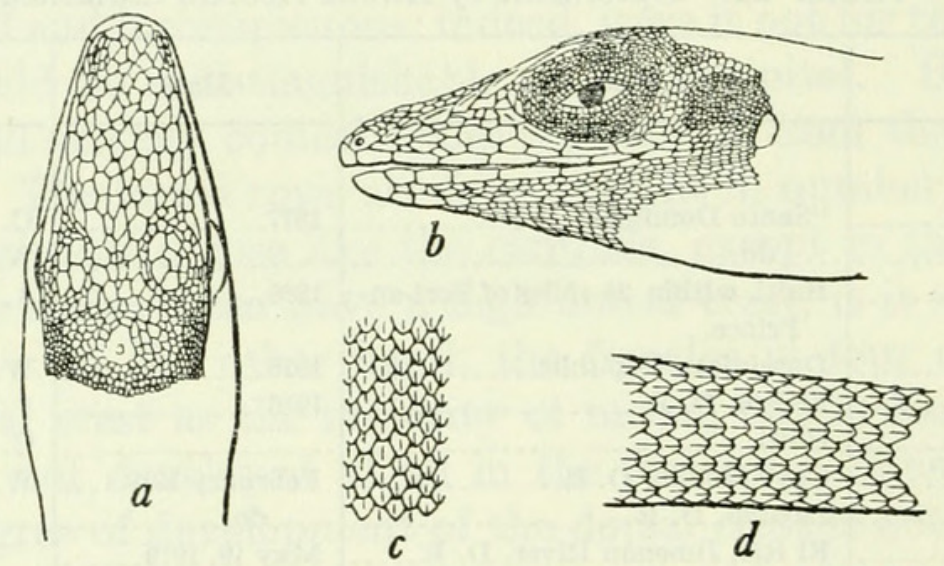

Figure 44.-Anolis semilineatus: $a$, Top of head; $b$, side of head; $c$, middorsal scales; $d$, side of tail. U.S.N.M. No. 74868, from Río San Juan, Dominican Republic. Three times natural size.

small keeled scales, the former completely separated from the supraorbital semicircles by a row of small, keeled scales, the latter separated from the superciliaries by about three rows of granular scales; a series of three enlarged and elongated scales bordering the anterior inner portion of the first superciliary; canthus rostralis projecting over the loreal region, composed of four elongate narrow shields, the second and third the longest; superciliary ridge consisting of one very long and narrow anterior shield followed by a shorter one, which is in turn followed by a double row of small elongate scales separating the supraocular granules from those surrounding the eye; loreal rows four or five; subocular semicircle composed of about five keeled scales, the second and third much the longest, the third and fourth in contact with the supralabials; seven supralabials, the suture between the fifth and sixth coming below the center of the eye; temporals minutely granular, with a patch of irregular, larger scales marking off the supratemporal region; dorsal scales arranged in about 10 longitudinal rows 
of enlarged, keeled scales, the inner ones about as large as the ventrals, the outer rows becoming smaller and merging rapidly with the lateral granules, which in their turn give way to the medium-sized, keeled, and imbricate ventrals; about 17 or 18 scales along the middle of the back equal the standard distance from tip of snout to center of eye; scales of gular fan scarcely longer than ventrals and only half as wide, wrinkled and set in longitudinal series on the naked skin of the gular fan, the edge of which is slightly thickened; throat scales quite small, mostly rectangular, bluntly keeled; arms above covered with keeled scales as large as the ventrals; femur with some scales considerably larger than the ventrals; scales covering hands and feet very strongly pluricarinate; digits very long and slender, expansion moderate; 20 lamellae under the second and third phalanges of fourth toe, 33 under the entire toe; tail very long, more than $2 \frac{3 / 4}{4}$ times the length of the head and body, moderately compressed, covered by large, imbricate, keeled scales with but slight indications of verticils, and the median series above consisting of similar but somewhat more heavily keeled scales forming a very feebly serrated edge; a pair of postanal plates large and prominent. Nuchal fold quite apparent, dorsal fold very weak.

Dimensions: Head and body, $38 \mathrm{~mm}$.; tail, $105 \mathrm{~mm}$.; tip of snout to posterior ear, $12 \mathrm{~mm}$; width of head, $6 \mathrm{~mm}$; foreleg, $13 \mathrm{~mm}$.; hindleg, $30 \mathrm{~mm}$.

Color (in alcohol): Above olive-brown, with a distinct metallic iridescence; below olive-buff, also highly iridescent; a white stripe originating on the rostral, continuing backward along the upper lip, involving the lower half of the ear, and continuing sharply demarked along the sides nearly to the groin, where it gradually fades out; below this lateral stripe between axilla and groin a few dusky mottlings of light olive-brown set it off much less sharply from the ventral color; skin of gular fan white, the scales besetting it finely punctate with minute black dots; lower labials and adjoining scales powdered with many small black dots mostly concentrated on the anterior portions of the scales; upper portions of limbs with similar powderings of dots, which on the hindlegs form themselves into broad indistinct dark bars and which appear on the tail even less distinctly; a very distinct dark-brown diagonal bar across the temporal region.

Variations.-In 162 individuals, all from Río San Juan, the supraorbital semicircles were in contact in only 3 cases; there was one row of scales between the semicircles in 77 cases; two scale rows in 80 cases, and 3 scale rows in 2 cases.

The maximum size of this species is apparently attained by a male, U.S.N.M. No. 74829, of which the head and body taken together measure $40 \mathrm{~mm}$. and the tail $116 \mathrm{~mm}$. 
The coloration of this species is exceedingly constant. The dark metallic head and back are well accented by the brilliant light lateral stripe. Practically every specimen has the dark temporal bar. A few specimens have a row of spots continuing behind the lower labials for a short distance along the throat. Some have more or less of the light brown vermiculations on the lateroventral area.

Relationships.-On the whole this dainty and elegant lizard seems to be one of the stablest in its characters of all the great Anolis group. Its nearest relative appears to be olssoni, more coarsely scaled and a little larger than semilineatus but obviously of the same group.

Boulenger's figure of the type of Anolis semilineatus is not sufficiently clear to distinguish it from olssoni. Being in doubt as to which of the two Hispaniolan lizards should receive the name of semilineatus, I sent a pair of each species to the British Museum for comparison and received a reply from $\mathrm{H}$. W. Parker under date of June 2, 1928: "I have compared your four specimens of Anolis with the type of Anolis semilineatus and as a result of my comparisons have no doubt that your specimens 74938 and 74939 [from Río San Juan, Dominican Republic] belong to the same species. The measurements of the type [of semilineatus] for which you ask are: Tip of snout to posterior border of ear, $11.5 \mathrm{~mm}$.; posterior border of ear to vent, $27 \mathrm{~mm}$; ; vent to tip of tail, $103.5 \mathrm{~mm}$. This figure is one larger than that given in Boulenger's Catalogue, but as the tail is detached from the specimen there is always a possibility of error in measuring such an object. I find that as well as the type we have one female of semilineatus and, in addition, referred to the same species by Boulenger, 3 males and 2 females of the other species represented in the specimens you sent us, i. e., the species with the larger gular scales and the dark interstitial skin of the gular fan. The locality will not help you much, I am afraid; it is just Hayti."

Specimens examined.-As listed in table 23.

TABLE 23.-Specimens of Anolis semilineatus examined

\begin{tabular}{|c|c|c|c|}
\hline Museum No. & Locality & Date & Collector \\
\hline U.S.N.M. & & & \\
\hline $9849(\uparrow) \ldots \ldots$ & "San Domingo"'..... & & W. Gabb. \\
\hline $74778-74937 \ldots \ldots$ & Río San Juan, D. R & March 1928 & G. S. Miller, Jr. \\
\hline 74968, 74969_.. & Boca del Infierno, D. R & $\ldots$ do & Do. \\
\hline $76641\left(\sigma^{7}\right) \ldots$ & San Michel du Nord, Haiti........ & Dec. $21,1928 \ldots$ & $\begin{array}{l}\text { A. J. Poole and W. } \\
\text { Perrygo. }\end{array}$ \\
\hline $25524 \quad$ M.C.Z. & Miragoane, Haiti........ & July $11,1927 \ldots \ldots$ & W. J. Eyerdam. \\
\hline & Samaná, D. R ............. & June $1882 \ldots$ & M. A. Frazar. \\
\hline 44397 & Sánchez, D. R ............ & July $1938 \ldots \ldots$ & P. J. Darlington. \\
\hline
\end{tabular}




\section{ANOLIS OLSSONI Schmidt}

FigURE 45

1888. Anolis semilineatus Fischer, Jahrb. Hamburg Wiss. Anst., vol. 5, p. 24 (Cape Haitien; Rolle, collector) (not of Cope).-Barbour, Mem. Mus. Comp. Zool., vol. 44, p. 291, 1914 (part) (Diquini).

1919. Anolis olssoni Sснмidt, Bull. Amer. Mus. Nat. Hist., vol. 41, p. 522 (type locality, El Morro de Monte Criste; type, A.M.N.H. No. 13400; collector, Axel Olsson); vol. 44, p. 11, figs. 6-7, 1921.-Cochran, Proc. U. S. Nat. Mus., vol. 6, art. 6, p. 4, 1924; Proc. Biol. Soc. Washington, vol. 41, p. 54, 1928; Occ. Pap. Boston Soc. Nat. Hist., vol. 8, p. 171, 1934.-Barbour, Bull. Mus. Comp. Zool., vol. 70, No. 3, p. 135, 1930; Zoologica, vol. 9, No. 4, p. 91, 1930; vol. 19, No. 3, p. 112, 1935; Bull. Mus. Comp. Zool., vol. 82, No. 2, p. 124, 1937.

Description.-U.S.N.M. No. 69171, an adult male from San Michel, Département du Nord, Haiti, collected by Gerrit S. Miller, Jr., on April 6, 1925. Top of head with two slightly curved low frontal
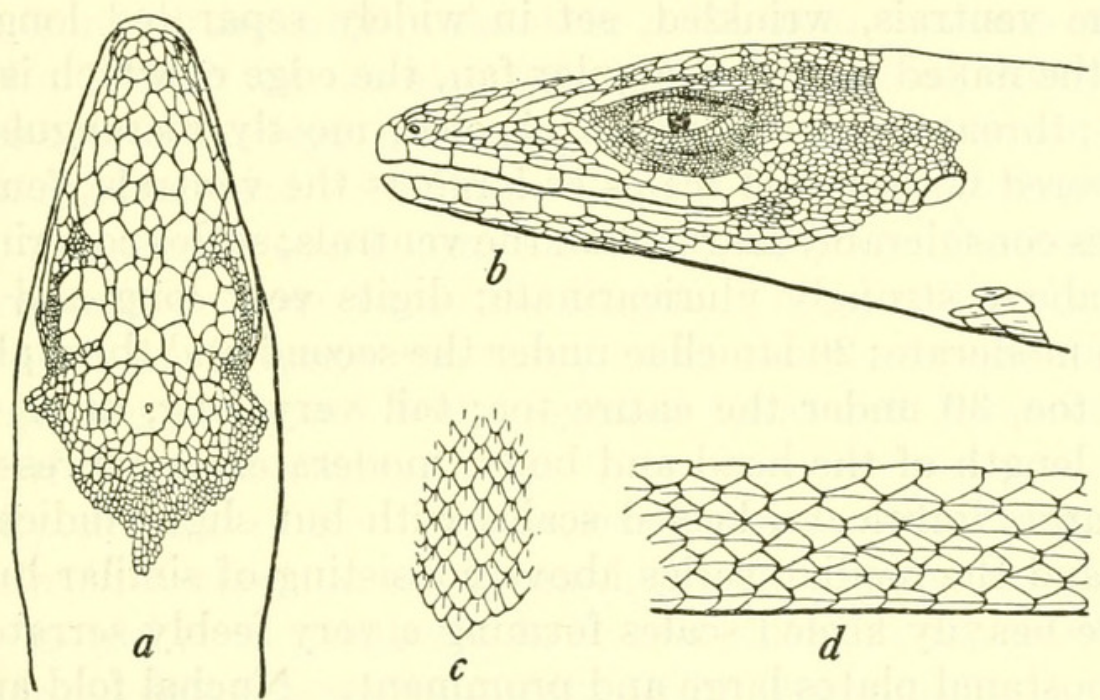

Figure 45.-Anolis olssoni: $a$, Top of head; $b$, side of head; $c$, middorsal scales; $d$, side of tail. U.S.N.M. No. 69171, from San Michel du Nord, Haiti. Three and one-half times natural size.

ridges bordering a very shallow frontal hollow; head scales distinctly keeled and medium sized; five scales in a row between the supranasals; supraocular semicircles very narrowly in contact (in this specimen) but mostly separated by a single row of scales; occipital large, about twice the size of the ear opening, separated from the supraorbital semicircle by two flat scales; supraocular disk composed of two very large, keeled scales accompanied by four or five smaller ones, the former separated only partially from the supraorbital semicircles by a single incomplete row of small scales, the latter separated from the superciliaries by about three rows of minute, almost granular scales; a series of three or four enlarged and elongated scales bordering the anterior inner portion of the first superciliary, followed by granular scales continued as far as the supraocular disk; canthus rostralis projecting over 
the loreal region, composed of four elongate, narrow shields, the second and third much longer than the others; superciliary ridge consisting of one very long and narrow anterior shield followed by a double row of small elongate scales separating the supraocular granules from those surrounding the eye; loreal rows five; subocular semicircle composed of about six keeled scales, the fourth much the longest, the third, fourth, and fifth in contact with the supralabials; eight or nine supralabials, the sixth coming below the center of the eye; temporals granular, with a well-developed double supratemporal line of scales; dorsal scales arranged in 10 longitudinal rows of enlarged, keeled scales, the inner ones about as large as the ventrals, the outer rows becoming smaller and merging rapidly with the lateral granules which in turn give way to the enlarged, keeled, imbricate ventrals; about 14 scales along the middle of the back equal the standard distance from tip of snout to center of eye; scales of gular fan elongate, at least thrice the size of the ventrals, wrinkled, set in widely separated longitudinal series on the naked skin of the gular fan, the edge of which is slightly thickened; throat scales quite small, keeled, mostly rectangular; arms above covered with keeled scales as large as the ventrals; femur with some scales considerably larger than the ventrals; scales covering hands and feet above strongly pluricarinate; digits very long and slender, expansion moderate; 20 lamellae under the second and third phalanges of fourth toe, 30 under the entire toe; tail very long, more than $2 \frac{1}{2}$ times the length of the head and body, moderately compressed, covered by large, imbricate, keeled scales with but slight indications of verticils, and the median series above consisting of similar but somewhat more heavily keeled scales forming a very feebly serrated edge; a pair of postanal plates large and prominent. Nuchal fold apparent, dorsal fold very weak.

Dimensions: Head and body, $40 \mathrm{~mm}$.; tail, $96 \mathrm{~mm}$.; tip of snout to posterior ear, $12 \mathrm{~mm}$.; width of head, $6 \mathrm{~mm}$.; foreleg, $15 \mathrm{~mm}$.; hindleg, $35 \mathrm{~mm}$.

Color (in alcohol): Ground color above ecru-drab changing to pinkish buff on snout and tail; a clearly marked white lateral stripe originating below the eye and set off above and below along the sides by black vermiculations, which are densest above the shoulder; below immaculate pale olive-buff; the skin of the gular fan black, the large scales white; on the scapular region the black vermiculations appear as a pair; otherwise the middorsal area is light and unspotted, like the head in this specimen; arms, legs, and tail very faintly marked with brown.

Variations.-On many of the specimens the pair of black scapular markings is very obvious, taking the shape of a crescent or oval on each side of the middorsal line. In addition, most of the specimens have a pair of small round spots, one on either side of and a little 
behind the occipital. Sometimes the dark lateral vermiculations form a triangular pattern, the apex of each triangle pointing toward its fellow of the opposite side, the bases forming a continuous dark line delimiting the light lateral stripe on its upper border. There is frequently a wide brown stripe on the anterior part of the forearm, and another on the posterior surface of the hindleg. Below the light lateral stripe there are sometimes a few very small black spots. The head in all cases is immaculate except for the black postoccipital markings. Females have no gular fan or enlarged postanals. In life the scales of the gular fan range from yellow to orange and brick red, while the gular skin is often deep maroon-red. On a freshly collected example from San Michel (U.S.N.M. No. 74135) the skin of the gular fan was Indian yellow, becoming dark clay color toward the body, while the scales adorning it were pale cream color. The tail behind the vent was salmon color, while a very light tint of this suffused the sides in front of the groin. Another male from the same place (U.S. N.M. No. 74136) was similar but darker, the gular skin being dark salmon on its distal edge, becoming dark olive-green nearest the throat.

The maximum size (U.S.N.M. No. 74149, an adult male from San Michel) appears to be $43 \mathrm{~mm}$. for head and body, the tail being 133 $\mathrm{mm}$. long or over three times the length of head and body combined. This proportion is quite constant, as in those examples having the entire tail the head and body together measured from 21.3 to 28.7 percent of the total length.

In only two out of my large series of lizards were the supraorbital semicircles in contact; in all others they were separated by one row of scales. Loreal rows number 3 to 5 , with 4 by far the most frequent. The enlarged dorsal rows vary from 10 to 12 in number.

There may be one, two, or three scales separating the supraorbital semicircles from the occipital shield. The supraocular disk is sometimes in contact with the supraorbital semicircles but much oftener separated by a single row of small scales.

With some doubt I place with Anolis olssoni a single adult male (U.S.N.M. No. 62103) collected by Dr. W. L. Abbott in the hills 5 miles south of Constanza. This individual has much smaller scales on the gular fan than does typical olssoni from San Michel, Haiti. It does not approach semilineatus, however, in fineness of scales. In fact, while the gular scales are finer, the dorsal and ventral scales of the Constanza lizard are actually perceptibly coarser than they are in the San Michel specimens. The color pattern of this Constanza specimen shows none of the definite black markings that so often appear on true olssoni. It is lilac-gray above, tinged with china blue on the supraocular region; the dorsal tone shades into drab above the lateral light stripe, which is very sharply marked anteriorly but less so after it passes the shoulder, back of which it fades out almost 
completely. The only definite head marking is a black diagonal bar across the temporal region midway between eye and ear. This does not occur in olssoni but is found in every specimen of semilineatus. A series of examples from Constanza will be needed to determine whether these characters are stable and definite, meriting specific separation, or whether they represent an aberrant or hybridized olssoni with some of the semilineatus characters.

Apparently the paratype of olssoni (A.M.N.H. No. 15300) is correctly identified in the original description. The specimen itself is in bad condition. At the time I noted its differences from the type ${ }^{7} \mathrm{I}$ had seen very few individuals of the species and consequently did not estimate its variability. The two examples from Gonave Island do not appear to differ from those found on the mainland at Port-auPrince and at San Michel du Nord.

I add Fischer's record of a Cap-Haïtien specimen to this species rather than to semilineatus, since I have seen true olssoni from CapHaïtien, but as yet I have no evidence that semilineatus occurs there.

TABLE 24.-Specimens of Anolis olssoni examined

\begin{tabular}{|c|c|c|c|}
\hline Museum No. & Locality & Date & Collector \\
\hline U.S.N.M. & & & \\
\hline 59209 & St. Marc, Haiti... & Apr. $21,1917 \ldots$ & J. B. Henderson and \\
\hline $62103 \ldots$ & $\begin{array}{l}\text { Hills } 5 \text { miles south of Constanza, } \\
\text { D. } R \text {. }\end{array}$ & Apr. $29,1919 \ldots$ & $\begin{array}{l}\text { P. Bartsch. } \\
\text { W. Lbbott. }\end{array}$ \\
\hline $66682,66683 \ldots$ & Guarabo, D. R & Nov. $23,1923 \ldots$ & Do. \\
\hline $66684-66686 \ldots$ & Dominican Republic & $1923 \ldots \ldots$ & Do. \\
\hline $69164-69169 \ldots$ & Mon Repos, Haiti............ & Mar. 3-9, 1925 & G. S. Miller, Jr. \\
\hline 69170 (†) $\ldots . .$. & Pilbury Hill, Haiti.......... & Apr. $7,1925 \ldots$ & Do. \\
\hline $69171-69174$ & San Michel du Nord, Haiti. . & Apr. 6, 1925 $\ldots$ & Do. \\
\hline 74017-74023 & Port-au-Prince, Haiti............ & Dec. $10-15,1927 \ldots$ & A. J. Poole. \\
\hline $74094(\uparrow) \ldots$ & Cap-HaItien, Haiti.................. & Mar. 3-6, 1928_.... & Do. \\
\hline 74135-74160 & San Michel du Nord. Haiti. .... & $\begin{array}{l}\text { Dec. 20, 1927-Mar. } \\
15,1928 .\end{array}$ & Do. \\
\hline $75885,75886 \ldots$ & Damien, Port-au-Prince, Haiti.. & $1928 \ldots \ldots$ & J. S. C. Boswell. \\
\hline 75896-75898 & Port-au-Prince, Haiti & $1928 \ldots \ldots$ & Do. \\
\hline $76642(q) \ldots . .$. & San Michel du Nord, Haiti ..... & Dec. $21-31,1928$ & $\begin{array}{l}\text { A. J. Poole and W. } \\
\text { Perrygo. }\end{array}$ \\
\hline $76785 \ldots \ldots$ & Cerca-la-Source, Haiti...... & March 1929 & Do. \\
\hline $76797,76798 \ldots .$. & En Café, Gonave Island............ & .... do & Do. \\
\hline M.C.Z. & & & \\
\hline $8759-8768 \ldots$ & Diquini, Haiti......... & $1913 \ldots \ldots$ & W. M. Mann. \\
\hline 13760 & Thomazeau, Haiti & $1919 \ldots \ldots$ & G. M. Allen. \\
\hline $13761-13768 \ldots \ldots$ & Port-au-Prince, Haiti . . . . . . . & 1919 & Do. \\
\hline 25529 & Citadelle, Cap-HaItien, Haiti... & Oct. $4,1927 \ldots \ldots$ & W. J. Eyerdam. \\
\hline $37521 \ldots \ldots$ & Anse à Galets, Gonave Island... & April $1934 \ldots \ldots$ & Utowana Expedition. \\
\hline $37522 \ldots \ldots$ & Thomazeau, Haiti & 1934 & A. Audant. \\
\hline
\end{tabular}

7 Proc. U. S. Nat. Mus., vol. 66, art. 6, p. 5, 1924. 
Relationships.-As I have said under the discussion of semilineatus, that species and olssoni apparently are related to each other more closely than to others of the group of grass lizards having enlarged dorsals. At first glance poncensis of Puerto Rico suggests olssoni in its dorsal and ventral scalation as well as in the style of coloration, but closer examination reveals many differences, among them the regular scaling of the gular fan, which allows none of the gular skin to be seen. Furthermore, poncensis is more sturdily built and attains a greater size than does the Hispaniolan lizard.

Specimens examined.-As listed in table 24.

\section{ANOLIS DISTICHUS DOMINICENSIS Reinhardt and Lütken}

Figures 46,48

1863. Anolis dominicensis Reinhardt and Lütken, Vid. Medd. Nat. Foren. Kjöbenhavn, 1862, p. 261, extr. p. 109 (type locality, Haiti; collector, Herr Riise; type in Mus. Kjöbenhavn).-Barbour, Bull. Mus. Comp. Zool., vol. 70, No. 3, p. 122; 1930; Zoologica, vol. 9, pp. 66, 94, 1930.

1870. Anolis brevirostris Bocourt, Bull. Nouv. Arch. Mus., vol. 6, p. 11 (type locality, Haiti); Mission scientifique au Mexique et dans l'Amérique Centrale, recherches zoologiques, Reptiles, book 2, pl. 14, fig. 6, 1873.

1885. Anolis distichus Boulenger, Catalogue of the specimens of lizards in the collection of the British Museum, vol. 2, p. 33 (San Domingo) (not of Cope).Garman, Bull. Essex Inst., vol. 19, p. 42, extr. p. 18, 1887 (Jérémie, Isle des Vaches, Samaná, Puerto Plata).-Fischer, Jahrb. Hamburg Wiss. Anst., vol. 5, p. 24, 1888 (Cape Haytien, Marmelade, Plaisance, Hayti; H. Rolle, collector).-Müller, Verh. Naturf. Ges. Basel, vol. 10, ser. 1, p. 211, 1892 (Aux Cayes, Haiti).-Meerwarth, Mitth. Nat. Mus. Hamburg, vol. 18, p. 23 1901, (part).-Barbour, Mem. Mus. Comp. Zool., vol. 44, No. 2, p. 282, 1914 (part).-Sснмidт, Bull. Amer. Mus. Nat. Hist., vol. 44, art. 2, p. 12, 1921.-Cochran, Proc. U. S. Nat. Mus., vol. 66, art. 6, p. 4, 1924; Proc. Biol. Soc. Washington, vol. 41, p. 54, 1928.

1901. Anolis biauritus Meerwarth, Mitth. Nat. Mus. Hamburg, vol. 18, p. 23, pl. 1, figs. 3-5 (type locality, Haiti; collector, Herr Tippenhauer; cotypes in Hamburg Mus. No. 1486 a-c).

1934. Anolis dominicensis dominicensis Cochran, Occ. Pap. Boston Soc. Nat. Hist., vol. 8, p. 168.-Barbour, Zoologica, vol. 19, No. 3, p. 113, 1935.

1937. Anolis distichus dominicensis Barbour, Bull. Mus. Comp. Zool., vol. 82, No. 2, p. 126.-Mertens, Senckenbergiana, vol. 20, No. 5, p. 336, 1938; Publ. Inst. Cient. Domínico-Alemán vol. 1, p. 86, 1939.-Böker, Publ. Inst. Cient. Domínico-Alemán, vol. 1, p. 16, 1939.

1938. Anolis distichus subsp. inc. Mertens, Senckenbergiana, vol. 20, No. 5, p. 336, figs. 4-5; Publ. Inst. Cient. Domínico-Alemán, vol. 1, p. 86, 1939.Böker, Publ. Inst. Cient. Domínico-Alemán, vol. 1, p. 16, 1939.

Description.-An adult male, U.S.N.M. No. 69149, from Mon Repos, Haiti, collected on March 6, 1925, by G. S. Miller, Jr. Head short, with two weakly developed ridges diverging forward from between the eyes; forehead slightly concave between these ridges; head scales more or less rugose but not keeled; rostral very low, much narrower than the mentals; four scales between the nostrils; a 
paired median series of rather rectangular, somewhat enlarged scales on the snout from the rostral to the juncture of the supraorbital semicircles, which are closely in contact with each other but with a few small scales interpolated here and there between them and between the paired median series on the snout also; occipital as large as ear opening, triangular in shape, very prominent, with a somewhat smaller but equally noticeable preoccipital in contact with the supraorbital semicircles and completely filling the area between them and the occipital; the extreme outer points of the occipital narrowly in contact with the posterior part of the supraorbital semicircles; supraocular disk composed of seven or eight polygonal smooth scales,

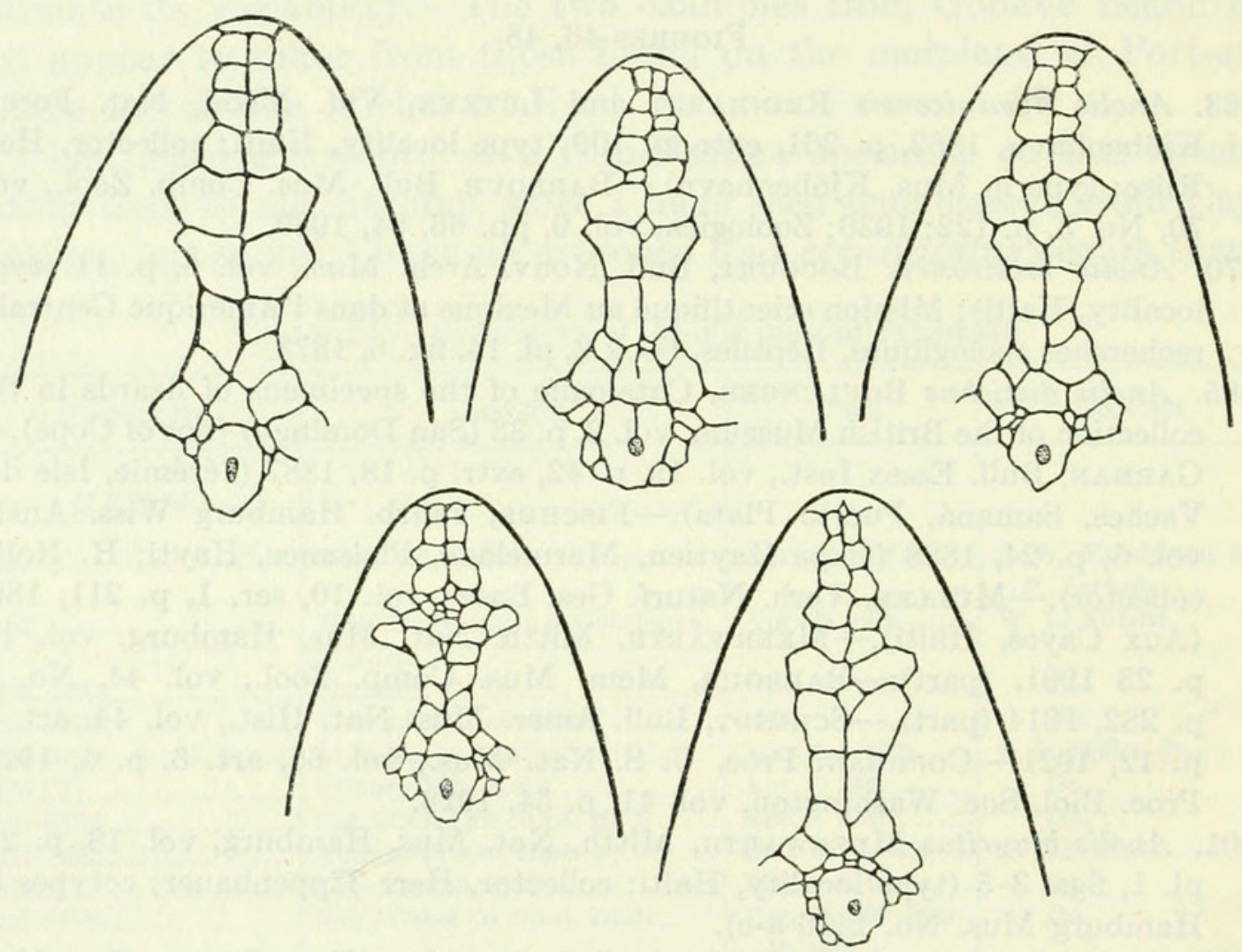

Figure 46.-Variations in head shields of a single population of Anolis distichus dominicensis from San Michel du Nord, Haiti. (U.S.N.M. Nos. 74451, 74453, 74442, 74479, 74475.)

incompletely separated from the semicircles by a row of granular scales; one comparatively large shield bordering the inner anterior edge of the first superciliary and surrounded by the supraocular granules; canthus rostralis only moderately developed, the four enlarged scales that distinguish it having a comparatively low median ridge not projecting over the loreal region; superciliary ridge indistinctly continuous with the scales of the canthus rostralis, composed of one.very elongate and sharply keeled scale followed by a double series of small but differentiated tubercular scales, the anterior of which are separated from the supraocular disk by about four or five rows of granules; loreal rows four: scales of the subocular semicircle 
keeled, broadly in contact with the upper labials; supralabials nine, the last three very small, the suture between the fifth and sixth coming directly below the center of the eye; temporal granules perceptibly smaller than the dorsals, with a rather poorly marked double series of small scales forming the supratemporal line; back and sides covered with granules, the dorsals a little larger and flatter, the laterals smaller and more tubercular; no conspicuously enlarged series of median dorsal scales; ventrals small, smooth, highly imbricate, almost rectangular, each scale being broader than long; throat covered with small flat granules; forelegs covered with small smooth granular scales, about four series on the anterior face of the lower arm being greatly enlarged, more than twice as large as the largest ventrals; anterior scales of femur and tibia smooth, similarly enlarged,
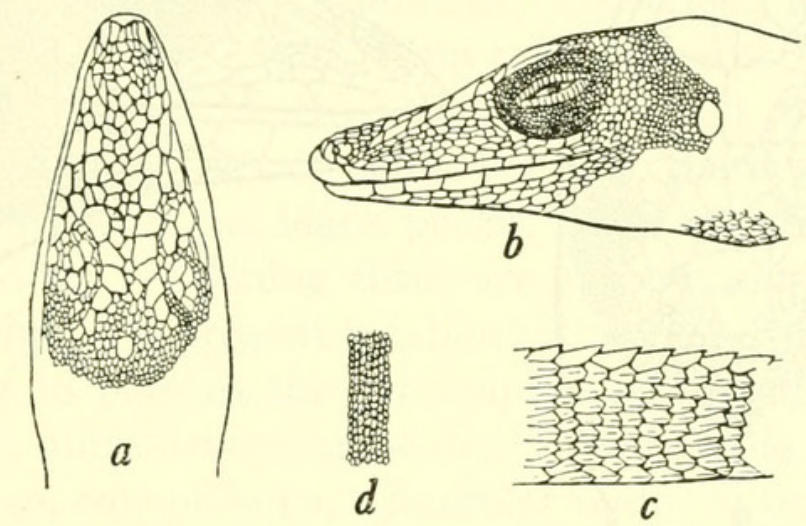

Figure 4/.-Anolis bahorucoensis: $a$, Top of head; $b$, profile of head; $c$, side of tail; $d$, middorsal granules. A.M.N.H. No. 51107, paratype, from the valley of Polo, Barahona Province, Dominican Republic. Twice natural size.

gradually diminishing posteriorly and below; scales covering hands and feet above enlarged, perfectly smooth; digital expansion wide, about 20 lamellae under second and third phalanges of fourth toe, about 33 under the whole toe; tail moderate, slightly compressed, with well-marked verticils, every ninth vertical row consisting of somewhat enlarged, elongate, pointed scales, the intervening rows of scales smaller, the whole surmounted by a strongly serrate caudal crest with five triangular, keeled, and pointed scales, the fourth the largest and the first the smallest, corresponding to a verticil; skin of gular fan naked, set with distant series of flat rectangular scales a little larger than the ventrals, edge not thickened posteriorly; postanal scales well developed; a slight nuchal fold losing itself behind the shoulders.

Dimensions: Head and body, $51 \mathrm{~mm}$.; tail (tip reproduced), $72 \mathrm{~mm}$.; snout to posterior ear, $15 \mathrm{~mm}$; snout to center of eye, $10 \mathrm{~mm}$.; width of head, $11.5 \mathrm{~mm}$.; foreleg, $26 \mathrm{~mm}$.; hindleg, $40 \mathrm{~mm}$.

Color (in alcohol): Above mouse gray, darker on sides, indistinctly mottled on limbs; below pale wood brown, throat slightly darker and 
clouded with gray; scales of the entire lower surface with scattered small gray dots; the tail is pale gray with a darker suffusion on the peaks of the caudal crest.

Variations.-The color of freshly preserved and living animals is extremely variable. Mr. Eyerdam notes that those collected by him at Miragoane were black above, with a brick-red throat, and that the under side of the tail was orange. In other freshly preserved ones, the upper parts may be bottle green to cerulean or any tone of brown or gray, while the gular fan and under surface of tail are a brilliant citron yellow. In many specimens the occipital scale is pale blue, and

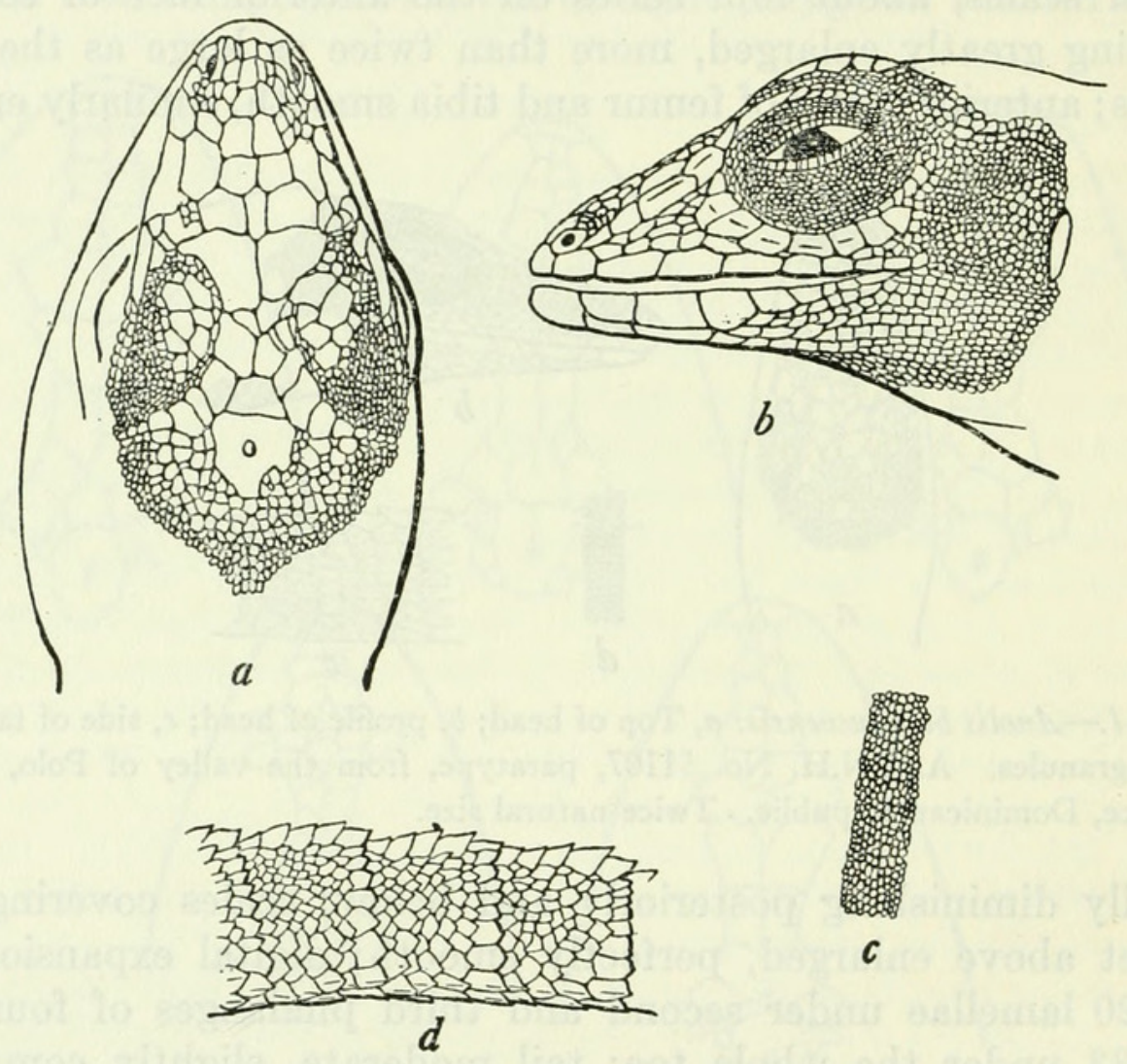

Figure 48.-Anolis distichus dominicensis: $a$, Top of head; $b$, side of head; $c$, middorsal scales; $d$, side of tail. U.S.N.M. No. 69149, from Mon Repos, Haiti. Two and one-half times natural size.

the suborbital semicircles are of the same tone. Most specimens showing any head pattern at all have a transverse narrow brown bar across the head through the supraocular region, while most of the head scales are narrowly outlined in brown, and there often appears a brown nuchal marking. Sometimes the body is highly mottled with short dark stripes of irregular shape on a lighter ground. Occasionally a specimen will be found having a fairly definite light lateral stripe bordered above and below by darker pigment, as in U.S.N.M. No. 59115, an adult female from Pétionville.

A young female from Jérémie, U.S.N.M. No. 60625, has a pale blue band from the corner of the mouth running diagonally upward over the ear and ending above the shoulder; in addition there are some light- 
blue irregular spots on the nuchal region, set off by the chocolatebrown pigment surrounding them; down the back there are four or five light-blue rectangular areas more or less completely rimmed by chocolate; the sides are more or less regularly mottled by short blue and chocolate streaks; the limbs are banded by rows of dark spots on a lighter ground; the breast and belly are immaculate, with a blue and green iridescence; the throat is heavily vermiculated with brown; the tail verticils are faintly set off with brown rings. This specimen is much like the type of biauritus described by Meerwarth.

No shoulder marking of any kind is evident in about 88 percent of the Hispaniolan lizards; about 8 percent have a light blue line, while only 4 percent have a black scapular patch like those on Gonave Island. Those having the black patch are: F.M.N.H. No. 13253, from between St. Marc and Gonaïves; U.S.N.M. No. 80762, from Baradères; U.S.N.M. No. 59152, from near Cabaret; and two young ones from Jérémie, U.S.N.M. Nos. 59255 and 59256. From this same small collection of eight lizards from Jérémie there are, besides the two just mentioned with the black patch, three others with a trace of a light line, while the remaining three are without shoulder markings.

A large preoccipital is present in about 82 percent of the specimens. In the remaining 18 percent the preoccipital is broken up into two or more small and quite irregular scales. ${ }^{8}$ When the preoccipital is normal it is a large, conspicuous, triangular scale whose base meets the anterior border of the occipital and whose sides may or may not touch the supraorbital semicircles. The occipital touches the semicircles in about 50 percent of the cases; in about 44 percent they fail to meet, while in 6 percent both conditions are found on opposite sides of the head of the same individual.

The tail is quite finely scaled, there being 8 to 10 lateral rows of scales to a verticil, the last row distinctly elongate; above these there is a serrated crest of usually five unequal scales, the last two of which are the largest.

The median patch of scales on the snout just in front of the juncture of the supraorbital semicircles contains one to four scales as a rule, with two scales most often found. In less than 2 percent of the cases there is no such patch of scales present, while in only 10 percent of the cases are there more than four scales in this median group.

Relationships.-In order to understand the relationships of Anolis distichus dominicensis it is first necessary to discuss the affinities of the other forms to which it is comparable. Anolis distichus dominicensis somewhat resembles $A$. lucius of Cuba, as Reinhardt and Lütken observed, although the likeness is not extreme. The Cuban lizard is slenderer in body and limbs, while its head is much more elongate

8 This condition was noted in the single female specimen from Constanza (Senckenberg Mus. No. 91) mentioned by Mertens (1938, pp. 336-337.) 
than is the case with the Hispaniolan lizard. The coloration is so varied in dominicensis that it is possible to match an occasional specimen to the lucius pattern, which seems to be considerably more stable, so that both species may sometimes have essentially similar styles of coloration. The large occipital plate of lucius distinctly reminds one of dominicensis, although there is no preoccipital in the Cuban species. The median groove on the snout, so apparent in dominicensis and its close allies, is conspicuously absent in lucius, where the snout scales are all more or less uniform in size and fairly hexagonal in shape, without any indication of repeating scale for scale to establish bilateral symmetry along the snout.

It is with distichus of New Providence and distichoides of Andros that the closest relationships of dominicensis are found.

Anolis distichus distichus Cope, of New Providence Island, is obviously related to dominicensis on the one hand and to lucius on the other, being fairly intermediate between the two in its characters. The true distichus has nearly the same head and body proportions as does dominicensis, both of them readily contrasted with the more elongate lucius. In adult examples of distichus there are distinct keels on the enlarged scales of the femur, while in dominicensis these scales are always smooth, and in lucius neither Dr. Barbour nor I have ever observed them to be anything but smooth, although Duméril and Bibron speak of "des écailles rhomboidales, carénées, qui revêtent le dessus des membres." In distichus the contact of the supraocular semicircles and of the median snout scales preceding them is relatively less complete than in dominicensis, there being usually but one or two small interpolated scales, if any at all, in the Hispaniolan lizard, while in the New Providence form there is a patch of small scales just in front of the semicircles and often one or more similar small scales interpolated between the semicircles, so that the midline contact along the top of the head is not very continuous in its posterior half.

Specimens examined.-As listed in table 25.

TABLE 25.-Specimens of Anolis distichus dominicensis examined

\begin{tabular}{|c|c|c|c|}
\hline Museum No. & Locality & Date & Collector \\
\hline \multicolumn{4}{|l|}{ U.S.N.M. } \\
\hline $9846,9848 \ldots$ & "San Domingo"-... & & W. Gabb. \\
\hline $10268 \ldots \ldots \ldots$ & Puerto Plata, D. R & $1878 \ldots$ & C. A. Fraser. \\
\hline $25808-25814$ & $\begin{array}{l}\text { Port-au-Prince, Haiti (within } 25 \\
\text { miles of). }\end{array}$ & $1866 \ldots \ldots$ & A. C. Younglove. \\
\hline $35986-35991 \ldots \ldots$ & San Francisco Mountains, D. R & September $1905 \ldots$ & A. Busck. \\
\hline 49936 & Santo Domingo City, D. R ..... & 1913 & J. N. Rose. \\
\hline $55058-55067$ & Rojo Cabo, D. R & August 1916 & W. L. Abbott. \\
\hline $59115,59118,59121,59122 \ldots$ & Pétionville, Haiti. ................. & Apr. 1, 1917....... & $\begin{array}{l}\text { J. B. Henderson and } \\
\text { P. Bartsch. }\end{array}$ \\
\hline $59191 \ldots$ & Thomazeau, Haiti......... & Apr. 3, $1917 \ldots . .$. & Do. \\
\hline 59219 & St. Mare, Haiti ............. & Apr. $21,1917 \ldots \ldots$ & Do. \\
\hline
\end{tabular}


TABLE 25.-Specimens of Anolis distichus dominicensis examined-Continued

\begin{tabular}{|c|c|c|c|}
\hline Museum No. & Locality & Date & Collector \\
\hline U.S N.M.-Continued & & & \\
\hline $59248,59249 \ldots$ & Port-au-Prince, Haiti_... & Apr. 8, 1917 ..... & J. B. Henderson and \\
\hline $59250-59256$ & Jérếmie, Haiti.. & Apr. $15,1917 \ldots$ & $\begin{array}{l}\text { P. Bartsen. } \\
\text { Do. }\end{array}$ \\
\hline $625 \ldots$ & ..._do & Dec. $10,1917 \ldots$ & W. L. Abbott. \\
\hline 769 & Jovéro, D. R & Feb. $16,1923 \ldots$ & Do. \\
\hline $687-66691$ & Dominican Republic........ & - & Do. \\
\hline $146-69151 \ldots \ldots$ & Mon Repos, Haiti. ........ & Mar. 5,1925 & G. S. Miller, Jr. \\
\hline 69152 & Cabaret, Haiti & Mar. 10, 1925 ...... & Do. \\
\hline $72624,72625,72628$ & Fonds-des-Nègres, Haiti....... . & $\begin{array}{l}\text { Mar. 31-Apr. 12, } \\
1927 .\end{array}$ & A. Wetmore. \\
\hline 72650,72651 . & Sánchez, D. R . . & May $6,1927 \ldots \ldots$ & Do. \\
\hline 7 & $\mathrm{R}$ & May $21,1927 \ldots \ldots$ & Do. \\
\hline $73380 \ldots \ldots . . . .$. & Miragoane, Haiti & Sept. $26,1927 \ldots$ & W. J. Eyerdam. \\
\hline $74015,74016 \ldots \ldots$ & $\begin{array}{l}\text { Port-au-Prince, Haiti (Diquini } \\
\text { Cave). }\end{array}$ & Dec. $10,1927 \ldots$ & A. J. Poole. \\
\hline 74026,74027 & -...do do & Mar. 20, 1928_..... & Do. \\
\hline $74429-74495 \ldots$ & San Michel du Nord, Haiti... & $\begin{array}{l}\text { Dec. 20, 1927-Mar. } \\
15,1928 .\end{array}$ & Do. \\
\hline $74712 \ldots$ & Río San Juan, D. R... & March $1928 \ldots . . .$. & G. S. Miller, Jr. \\
\hline-74965 & R & _....do_._. & Do. \\
\hline $75003-75005$ & D. R & Feb. $22,1928 \ldots$ & Do. \\
\hline $75923 \ldots \ldots$ & Artibonite Valley, Haiti....... & $1928 \ldots$ & J. S. C. Boswell. \\
\hline 76673-76705 & Dondon, Haiti. & Jan. $18-20,1929 \ldots$ & $\begin{array}{l}\text { A. J. Poole and W. } \\
\text { Perrygo. }\end{array}$ \\
\hline $76781-76784 \ldots$ & Cerca-la-Source, Haiti...... & March $1929 \ldots$ & Do. \\
\hline 77 & Jacm & 1929 & A. E. Vinson. \\
\hline ................ & Cap-HaItien, Haiti... & 1929 & Do. \\
\hline 77076 & ti............. & 1927 & W. J. Eyerdam. \\
\hline $80801-80808 \ldots$ & Petit Trou de Nippes, Haiti . .... & Apr. 8, $1930 \ldots$ & $\begin{array}{l}\text { L. H. Parish and W. } \\
\text { Perrygo. }\end{array}$ \\
\hline $80814-80818 \ldots$ & Petite Cayemite Island, Haiti & Apr. $12,1930 \ldots$ & Do. \\
\hline $83867-83869 \ldots$ & Derocher, Haiti. & Apr. $18,1931 \ldots$ & $\begin{array}{l}\text { A. Wetmore and F. C. } \\
\text { Lincoln. }\end{array}$ \\
\hline $90345 \ldots$ & Santa Barbara, D. R..... & February 1933... & $\begin{array}{l}\text { Johnson-Smithsonian } \\
\text { Expedition. }\end{array}$ \\
\hline 95121 & Tortue Island, Haiti. . . & Apr. $2,1934$. & Utowana Expedition. \\
\hline & & & \\
\hline $3346,3620 \ldots$ & Jêrêmie, Haiti..... & & D. F. Weinland. \\
\hline 3623 (13 specimens) & do & & Do. \\
\hline $5442 \ldots \ldots \ldots$ & Puerto Plata, D. R .... & - n & M. A. Frazar. \\
\hline 5448 & Samaná, D. R. & - & Do. \\
\hline $5546 \ldots \ldots$ & “Haiti"'-........ & $1886 \ldots$ & Peabody Mus. \\
\hline 6170 (6 specimens) & Tiburon, Haiti........ & - non & S. Garman. \\
\hline $\begin{array}{l}8696-8700,8703,8705,8708 \\
8710,8712,8714-8718 .\end{array}$ & Diquini, Haiti....... & $1913 \ldots \ldots$ & W. M. Mann. \\
\hline $25487,25488 \ldots$ & Citadelle, Haiti (Cap-Haltien) .. & Oct. $4,1927 \ldots$ & W. J. Eyerdam. \\
\hline $25489-2$ & Mirago & July 1927 & Do. \\
\hline $25499-25$ & Hinche, & June 1927 & Do. \\
\hline $25504-25508$ & $\begin{array}{l}10 \text { miles southwest of Miragoane, } \\
\text { Haiti. }\end{array}$ & July $16,1927 \ldots \ldots$ & Do. \\
\hline $25519 \ldots \ldots$ & Grande Cayemite Island, Haiti . & Aug. $20-23,1927 \ldots$ & Do. \\
\hline $37483-37492 \ldots$ & Cap-Haitien, Haiti & Mar. $30-31,1934 \ldots$ & Utowana Expedition. \\
\hline $37493-37494 \ldots$ & Tortue Island, Haiti....... & Apr. 2, $1934 \ldots \ldots$ & Do. \\
\hline $37495-37496$ & Thomazeau, Haiti.......... & $1934 \ldots \ldots \ldots$ & A. Audant. \\
\hline $37497-37506$ & Sánchez, D. R.............. & Ap: $6,1934 \ldots \ldots$ & Utorcana Expedition. \\
\hline 43670 & Sosúa, D. R & $1937 \ldots \ldots \ldots$ & W. J. Clench. \\
\hline $43681 \ldots \ldots$ & Monte Cristi............. & $1937 \ldots$ & Do. \\
\hline $43699 \ldots \ldots . . . .$. & $\begin{array}{l}\text { Santa Barbara do Samana, D. } \\
\text { R. }\end{array}$ & $1937 \ldots \ldots . . . . .$. & Do. \\
\hline
\end{tabular}


TABLE 25.-Specimens of Anolis distichus dominicensis examined-Continued

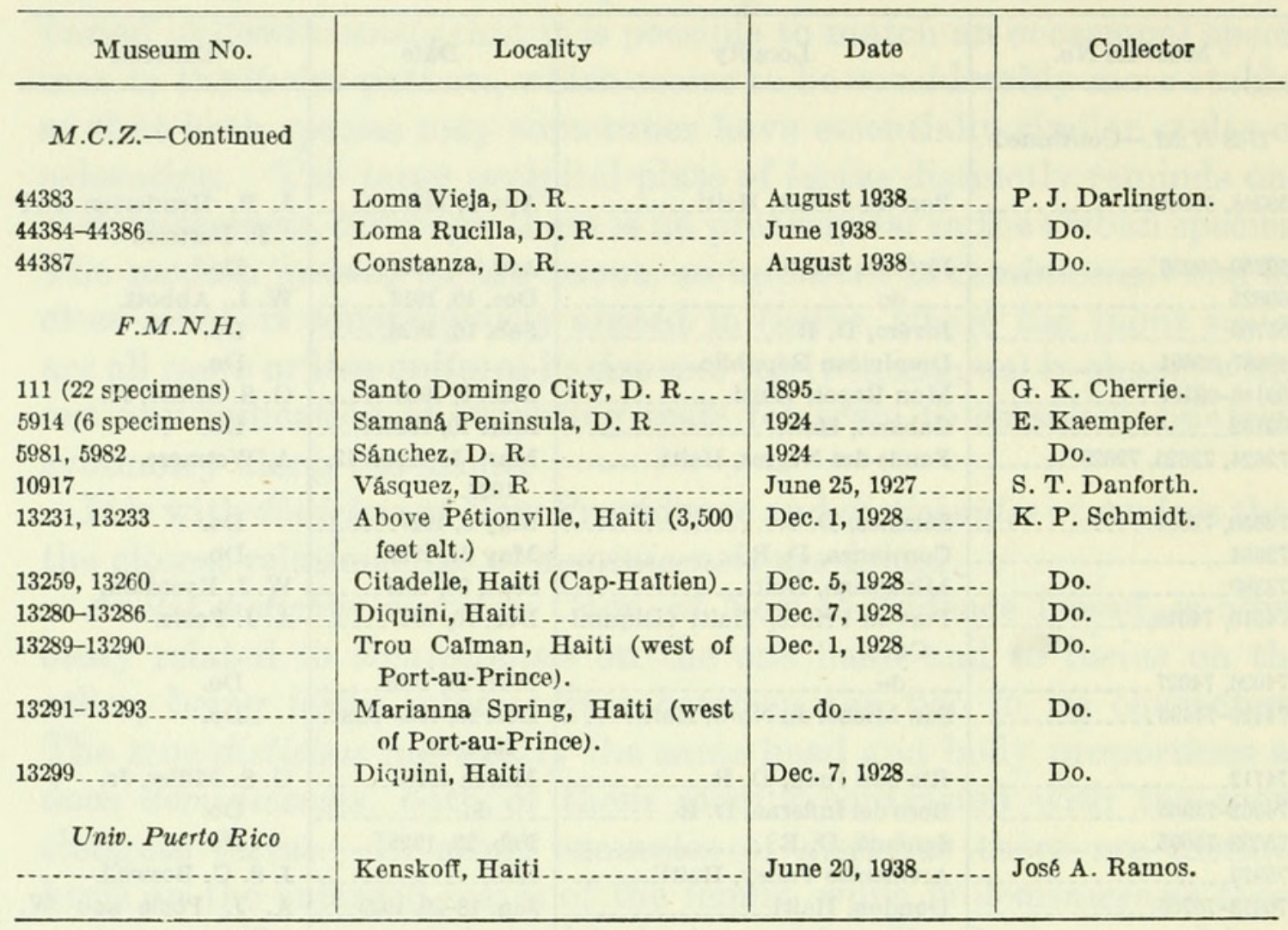

\section{ANOLIS DISTICHUS JULIAE Cochran}

FigURE 49

1934. Anolis dominicensis juliae Cochran, Occ. Pap. Boston Soc. Nat. Hist., vol. 8, p. 169; Barbodr, Zoologica, vol. 19, No. 3, p. 113, 1935.

1937. Anolis distichus juliae BArBour, Bull. Mus. Comp. Zool., vol. 82, No. 2, p. 126.

Original description._- "Diagnosis.-Dorsal scales juxtaposed, imbricate, granular, unlike the ventrals which are larger; a fairly regular paired median series of scales on the upper anterior portion of the snout; a distinct preoccipital scale half as large as the occipital itself; tail with very indistinct verticils, every ninth or tenth row of scales more vertical but not enlarged, the intervening scales in curving or irregular rows, the whole surmounted by a weakly serrate caudal crest with five triangular, keeled and pointed scales to a verticil, the first and fifth quite small, the others subequal.

"Type.-An adult male, M.C.Z. 37517 from Isle Vache, Haiti, collected April 12, 1934, by the Utowana Expedition. Head short, with two very weakly developed ridges which slightly diverge in front of the eyes; forehead slightly concave between these ridges; head scales smooth, somewhat rugose around rostral, which is low and about half the width of the mentals; four scales between the nasals; a paired median series of rather rectangular, somewhat enlarged scales on the snout from the rostral to the middle of the frontal depression, where there is a median patch of smaller scales, the posterior ones not paired; 
supraorbital semicircles closely in contact; occipital slightly larger than ear opening, roughly circular in shape, with a smaller but cqually noticeable preoccipital in contact with the supraorbital semicircles and completely filling the area between them and the occipital; the extreme outer points of the occipital nearly completely separated from the supraorbital semicircles by a small scale on each side; supraocular disk composed of nine or ten smooth polygonal scales of very unequal size, separated from the supraorbital semicircles by two to three rows of granularscales anteriorly, and by four rows posteriorly; two mediumsized scales bordering the inner anterior edge of the second superciliary
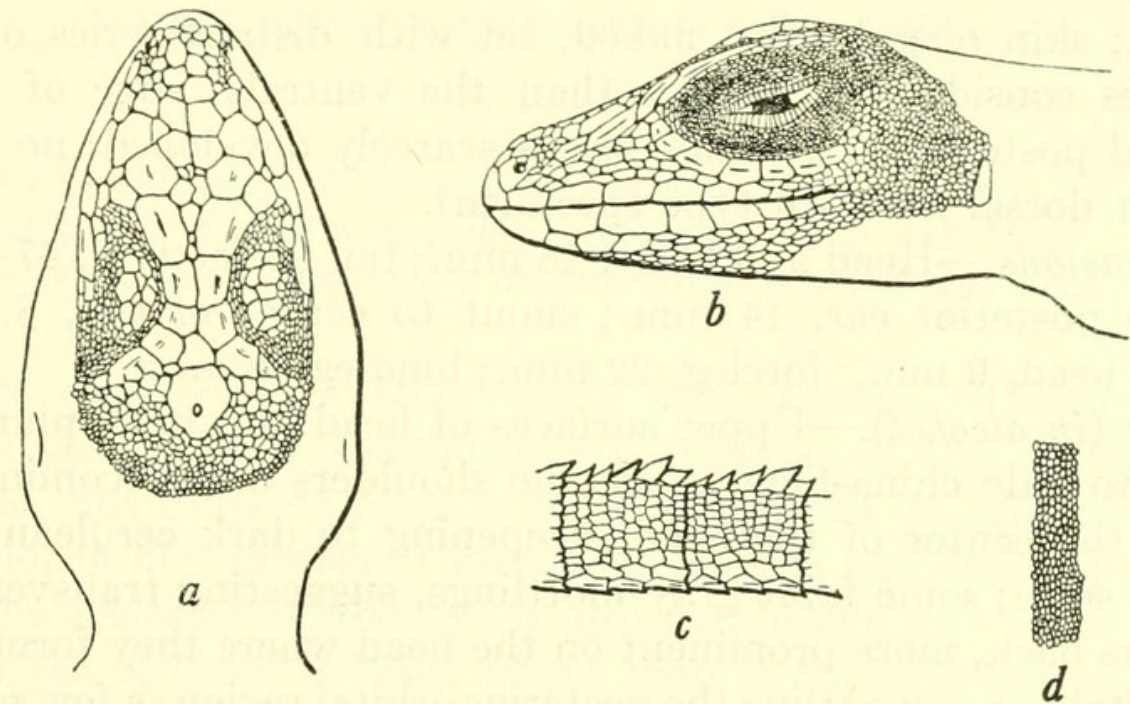

Figure 49.-Anolis distichus juliae: $a$, Top of head; $b$, side of head; $c$, middorsal scales; $d$, side of tail. M.C.Z. No. 37517, type, from Île à Vache, Haiti. Three times natural size.

and surrounded by the supraocular granules; canthus rostralis rather strongly developed, the posterior two of the four enlarged scales which distinguish it having a comparatively heavy median ridge which projects over the loreal region; superciliary ridge continuous with the scales of the canthus rostralis, composed of one very elongate and sharply keeled scale followed by a double series of small but differentiated scales, the anterior of which is separated from the supraocular disk by four or five rows of granules; scales of the subocular semicircle keeled, narrowly in contact with the upper labials; supralabials about ten, the last four very small, the seventh coming below the center of the eye; temporal granules slightly smaller than the dorsals, with a rather poorly-marked double series of small scales forming the supratemporal line; back and sides covered with granules, the dorsals about the same size and structure as the laterals; no enlarged series of median dorsal scales; ventrals small, smooth, imbricate, quite irregular in shape but often approximately square, only the most anterior being broader than long; throat covered with small, flat granules; skin of leg granular, with about five series of enlarged scales on the anterior 
face of the lower arm, none of these scales being much larger than the largest of the ventrals; anterior scales of femur and tibia smooth, similarly enlarged, gradually diminishing posteriorly and below; scales covering hands and feet above enlarged, perfectly smooth; digital expansion wide, about nineteen lamellæ under second and third phalanges of fourth toe, about thirty-five under the whole toe; tail moderate, slightly compressed, with very indistinct verticils, every ninth or tenth row of scales more vertical but not enlarged, the intervening scales in curving or irregular rows, the whole surmounted by a weakly serrate caudal crest, with five triangular, keeled and pointed scales to a verticil, the first and fifth quite small, the others subequal; skin of gular fan naked, set with distant series of small, flat scales considerably smaller than the ventrals; edge of fan not thickened posteriorly; postanal scales scarcely developed; no distinct nuchal or dorsal folds (in type specimen).

"Dimensions.-Head and body, $48 \mathrm{~mm}$.; tail (defective), $47+\mathrm{mm}$.; snout to posterior ear, $14 \mathrm{~mm}$; snout to center of eye, $8.5 \mathrm{~mm}$; width of head, $9 \mathrm{~mm}$.; foreleg, $22 \mathrm{~mm}$.; hindleg, $40 \mathrm{~mm}$.

"Color (in alcohol).-Upper surfaces of head and back plumbeous, turning to pale china-blue above the shoulders and becoming azure blue on the center of the head, deepening to dark cerulean on the occipital scale; some faint gray mottlings, suggesting transverse bars across the back, more prominent on the head where they form a dark interorbital bar and outline the posterior orbital region; a few scattered gray marks on the temporal region; upper parts of legs and tail pale olive gray with faint irregular darker spots and bars; ventral surface pearl gray, the scales powdered with minute black dots; skin of dewlap claret brown on the sides lightening to buff pink posteriorly and in the center, its scales pearl gray with minute dark dots.

"Paratypes.-Three adult specimens, all of them males, were taken at the same time and place as the type (M.C.Z. 37518-9 and U.S.N.M. 95122).

"Relationships.-The new subspecies shows its close relationship to Anolis distichus dominicensis of the mainland of Hispaniola particularly in its coloration, as it lacks the prominent scapular spots and lines which usually characterize the subspecies from Beata and Gonave Islands respectively. The scaling of the tail, the projection of the canthus rostralis and other features separate the Isle Vache species clearly from its neighbors on the mainland."

Specimens examined.-As listed in table 26. 
TABLE 26.-Specimens of Anolis distichus juliae examined

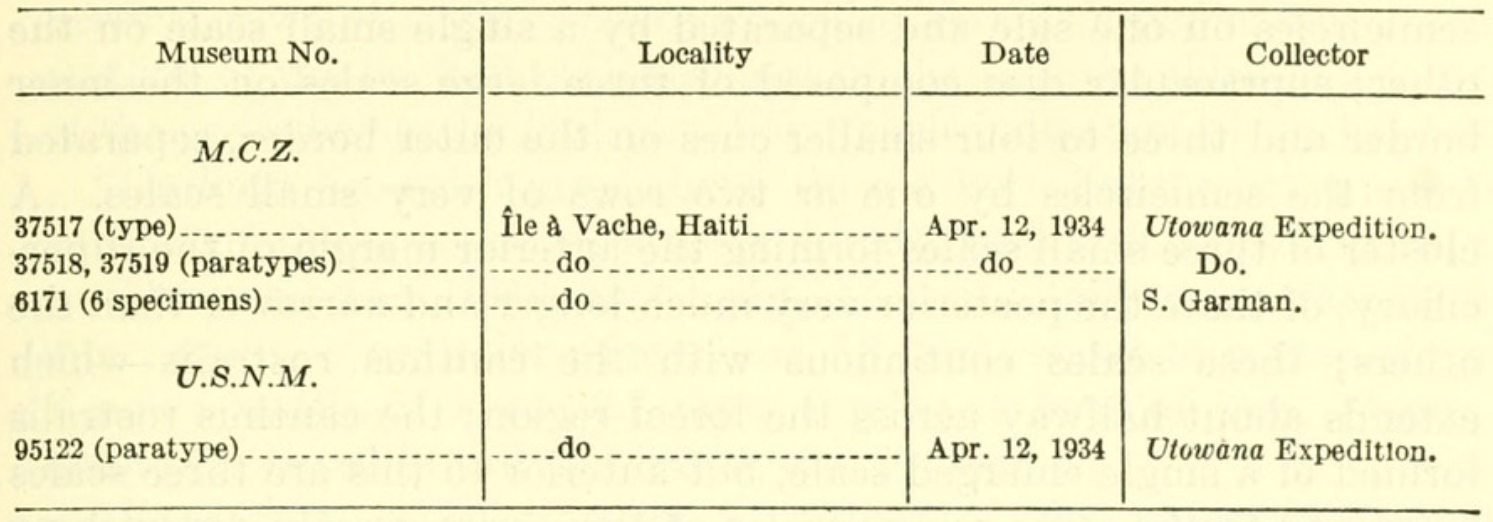

\section{ANOLIS DISTICHUS ALTAVELENSIS Noble and Hassler}

Figure 50

1933. Anolis dominicensis altavelensis Noble and Hassler, Amer. Mus. Nov., No. 652, p. 9.-BARBodr, Zoologica, vol. 19, No. 3, p. 113, 1935.

1937. Anolis distichus altavelensis Barbour, Bull. Mus. Comp. Zool., vol. 82, No. 2. p. 126.

Original description.- "Diagnostic Characters.-Closely allied to Anolis dominicensis Reinhardt and Lütken of the mainland of Hispaniola, but differing from it conspicuously in its bright reddishbrown color in life; preserved specimens being a pale tan or brownish gray. The scalation of the tail is also distinctive, the scales on the upper surface of the side being larger than in dominicensis and gradually increasing in size from the anterior to the posterior margin of each segment. The crest of the tail is lobulated, owing to the fact that the third and fourth scales in each segment are larger than the other scales forming the crest of that segment.

"Detailed Description.-Type: A.M.N.H. No. 51050, adult male. Collected at Alta Vela Island, D. R., October 9-10, 1932, by W. G. Hassler.

"Head slightly narrower than that of $A$. dominicensis; frontal ridges weakly developed, extending slightly anterior to the orbit; rostral small, one-third narrower than the mentals; four scale-rows between the scales that are pierced by the nostrils; six irregular pairs of roughly rectangular scales on the snout extending from the rostral to the supraorbital semicircles and forming a continuous series with them; these gradually increasing in size posteriorly and each pair making contact in the midline, except for the most posterior pair which are separated by a small scale; supraorbital semicircles on each side making a broad contact with one another in the interorbital region; the anterior pair of scales in the combined series separated for about one-half their length by a small scale which is approximately the size of the scale separating the most posterior pair of enlarged scales on the snout; occipital slightly longer than ear opening and 
twice as wide, roughly egg-shaped, in contact with the supraorbital semicircles on one side and separated by a single small scale on the other; supraocular disc composed of three large scales on the inner border and three to four smaller ones on the outer border, separated from the semicircles by one or two rows of very small scales. A cluster of three small scales forming the anterior margin of the superciliary, of these the posterior very much longer and narrower than the others; these scales continuous with the canthus rostralis which extends about halfway across the loreal region; the canthus rostralis formed of a single enlarged scale, but anterior to this are three scales belonging to the same series; scales of this series greatly diminishing in size anteriorly; loreal rows four. Scales of the subocular semicircle feebly keeled or slightly tubercular, three of the central scales of this series in broad contact with the supralabials; supralabials eight or nine, but the last scale which lies behind the midpoint of the eye is
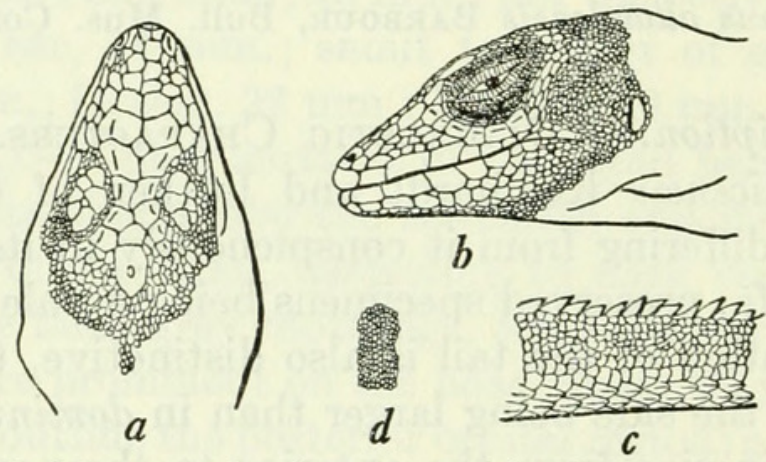

Figure 50.-Anolis distichus altavelensis: $a$, Top of head; $b$, profile of head; $c$, side of tail; $d$, middorsal granules. A.M.N.H. No. 51045, paratype, from Alta Vela Island, Dominican Republic. Twice natural size.

smaller than the anterior supralabials. Temporal granules approximately the same size as the dorsals except for those in the midline of the back; temporals gradually increasing in size toward the occipital and toward the supratemporals which form a double row of large scales extending from above the ear to the border of the orbit. Back and sides covered with small, slightly tubercular granules; those of the midline of the back being slightly larger than the others. Ventral surface covered with large smooth imbricate scales; each scale ovoid and three to four times as large as the dorsal granules; throat covered with flat granules slightly larger than the scales on the abdomen; fore limbs covered with small smooth scales except for the anterior margin of the forearm which is covered with a row of scales slightly larger than the largest scales of the dewlap; anterior scales of femur and tibia smooth, similarly enlarged, gradually diminishing in size on the dorsal and ventral surface of the appendage; scales covering hands and feet above enlarged, perfectly smooth. Digital expansions moderate, about sixteen lamellae under second and third phalanges of fourth toe, about twenty-seven under the whole toe. Tail slightly compressed with barely defined verticils, the limits of each being 
marked by a feebly indicated vertical groove and by two or three vertical rows of slightly enlarged scales; five enlarged spines on the midline of the back in each segment of the tail, the third and fourth of the series being the largest. Very feeble indication of nuchal fold.

"Uniform brownish gray above (in alcohol), lighter below; under surface of the appendages straw-colored; dewlap tinged with orange.

"Dimensions.-Head and body, $47 \mathrm{~mm}$; t tail (regenerated), 50 $\mathrm{mm}$.; snout to posterior edge of ear, $13 \mathrm{~mm}$.; snout to center of eye, $8 \mathrm{~mm}$.; width of head, $8.3 \mathrm{~mm}$.; foreleg to base of toes, $14 \mathrm{~mm}$.; hindleg to base of third and fourth toe, $24.5 \mathrm{~mm}$.

"Variation.-The thirteen paratypes of the series (A.M.N.H. Nos. 51037-49), agree with the type in color. They were all reddish brown in life and have faded to a pale fawn tone in alcohol. The headscales exhibit considerable variance but no greater than has been observed in typical specimens of dominicensis. Altavelensis is an island form of dominicensis exhibiting a constant color difference and apparently constant differences in the scalation of the tail. The peculiar color of this lizard in life is difficult to describe. Specimens were matched in the field as nearly as possible with tints of Winsor and Newton's water-colors. These adapted to Ridgway's nomenclature of colors would be as follows: The dorsal surface most often approached an ochraceous rufous but ranged to nearly a gallstone yellow. The ventral surfaces varied from gallstone yellow to deep chrome. The dewlap in the males was a dragon's blood red. There were no dark markings on the dorsal or ventral surfaces except occasionally in a very dark individual. In such an individual a faint pattern of fine dark veining was sometimes visible all over the body.

"HABITAT.-This species was fairly common throughout the small island of Alta Vela, where individuals were seen running on rocks, trees, and bushes from about sunrise until long into the dusk. During the hotter part of the day they remained in shady places. They were very wary and difficult to approach."

A male paratype, A.M.N.H. No. 51045, has four irregular pairs of snout scales between rostral and supraorbital semicircles; a small azygous scale separating the last pair of snout scales as well as the first pair of scales in the semicircles; a triangular preoccipital over half the length of the occipital, separating it from the posterior semicircle scales; seven supralabials to beneath center of eye; 34 lamellae under fourth toe; tail verticils composed of eight rows of smooth irregular scales on the sides and four subequal pointed scales on top of the tail (five posteriorly). Head and body, $47 \mathrm{~mm}$; head length, $14 \mathrm{~mm}$.; snout to center of eye, $8.5 \mathrm{~mm}$.; head width, $9 \mathrm{~mm}$.; foreleg, $20 \mathrm{~mm}$.; hindleg, $36 \mathrm{~mm}$; tail, $52 \mathrm{~mm}$. No enlarged postanals occur in the male. The dewlap is cream-colored in the preserved specimen. 


\section{ANOLIS DISTICHUS WETMOREI Cochran}

FigURE 51

1931. Anolis dominicensis wetmorei Cochran, Proc. Biol. Soc. Washington, vol. 44, p. 89 (type locality, Beata Island, Dominican Republic); Occ. Pap. Boston Soc. Nat. Hist., vol. 8, p. 169, 1934.-BArbour, Zoologica, vol. 19, No. 3, p. $113,1935$.

1937. Anolis distichus wetmorei Barbour, Bull. Mus. Comp. Zool., vol. 82, No. 2, p. 126.

Original description.- "Description of the type.-U.S.N.M. No. 83881, an adult male from Beata Island, Dominican Republic, collected on May 13, 1931, by Dr. A. Wetmore and Mr. F. C. Lincoln. Head very short, the weakly developed frontal ridges becoming indistinct just in front of the orbit; forehead concave; head scales smooth;
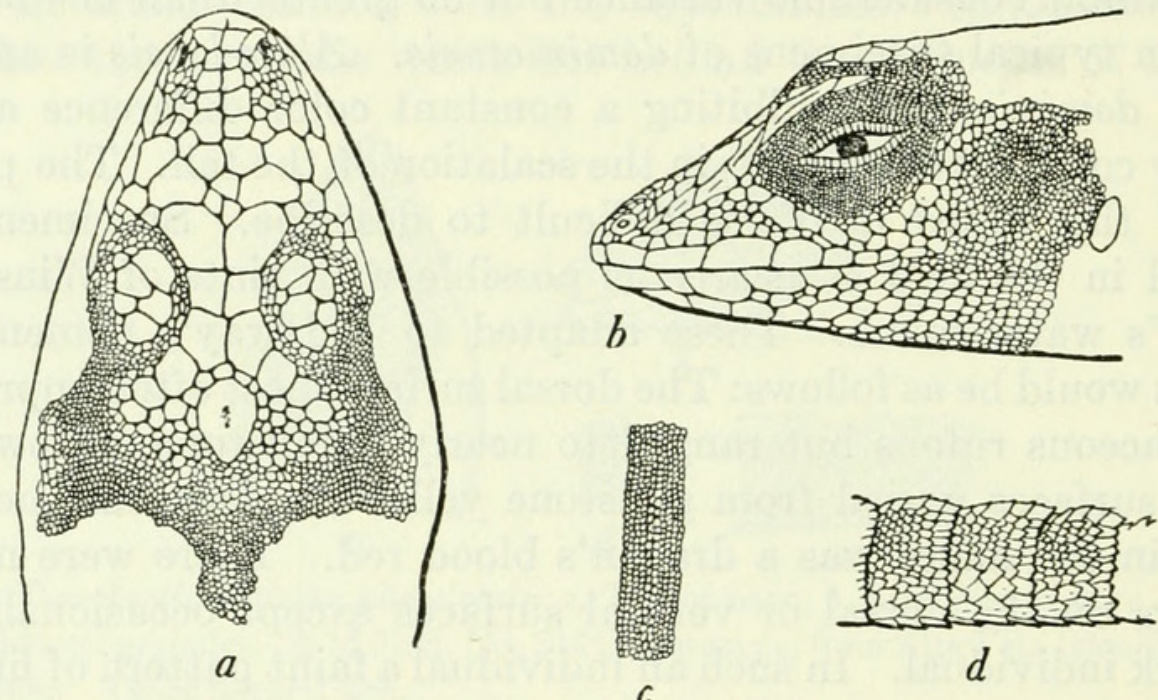

FiguRe 51.-Anolis distichus wetmorei: $a$, Top of head; $b$, side of head; $c$, middorsal scales; $d$, side of tail. U.S.N.M. No. 83881, type, from Beata Island, Dominican Republic. Three times natural size.

rostral very low, narrower than the mentals; four scales between the nostrils; a median series of six pairs of rectangular, enlarged scales on the snout from the rostral to the juncture of the supraorbital semicircles which are closely in contact between the eyes; a single small scale where the supraorbital series separates; occipital larger than the ear opening, nearly diamond-shaped, very prominent, completely separated from the supraorbital semicircles by a single row of small scales; supraocular disk composed of five polygonal smooth scales, separated from the semicircles by two rows of granular scales; a group of three small scales bordering the inner anterior edge of the superciliary; canthus rostralis moderately developed, the four enlarged scales which distinguish it having a low median ridge which projects slightly over the loreal region; superciliary ridge distinctly continuous with the scales of the canthus, composed of one very elongate and sharply keeled scale followed by a double row of small but differenti- 
ated tubercular scales, the anterior of which are separated from the supraocular disk by four or five rows of granules; loreal rows four; scales of the subocular semicircle keeled, almost completely separated from the upper labials by a nearly continuous row of small scales; supralabials eight or nine, the last very small and indistinct, the suture between the seventh and eighth coming distinctly below the center of the eye; temporal granules scarcely smaller than the dorsals, with a double series of well-marked, small, rectangular scales forming the supratemporal line; back and sides covered with granules, the dorsals and laterals tubercular, about equal in size; a mid-dorsal area of very slightly enlarged scales; ventrals small, smooth, highly imbricate, hexagonal, their width and length approximately the same; throat covered with small flat granules; forelegs covered with small smooth granules, about four series on the anterior face of the lower arm being considerably enlarged, somewhat larger than the largest ventrals; anterior scales of femur and tibia smooth, similarly enlarged, gradually diminishing posteriorly and below; scales covering hands and feet above enlarged, perfectly smooth; digital expansion moderate, about 16 lamellae under second and third phalanges of fourth toe, about 27 under the whole toe; tail moderate, slightly compressed, with well-marked verticils, every ninth vertical row being somewhat enlarged, the intervening rows consisting of polygonal, nearly smooth scales arranged in about 8 irregular horizontal series, the whole surmounted by a strongly serrated edge of 5 spines, the first two small and inconspicuous, the third and fourth enlarged and pointing diagonally upwards, the fifth equally large but recurved and pointing nearly directly backwards; skin of gular fan naked, closely set with rows of relatively large, flat, semicircular scales which are twice as large as any of the ventrals; edge of fan apparently not thickened posteriorly; post-anal scales well developed; no apparent nuchal fold.

"Dimensions.-Head and body, $38 \mathrm{~mm}$.; tail (fragmented), $62 \mathrm{~mm}$.; snout to posterior ear, $12 \mathrm{~mm}$.; snout to center of eye, $7 \mathrm{~mm}$.; width of head, $9 \mathrm{~mm}$.; foreleg, $18 \mathrm{~mm}$.; hind leg, $28 \mathrm{~mm}$.

"Color (in alcohol).-Above olive-gray, lightening on the head, limbs and tail to pearl gray; faint bars of olive-gray across the limbs; a transverse row of four small round black spots at the posterior border of the occipital plate; a faint gray interorbital cross-bar; under surfaces pale olive-gray; scale and skin of gular fan olive buff, with a very fine powdering of gray dots which extends over the ventral scales and the tail."

Relationships.-This form is close to the true Anolis distichus dominicensis found on the mainland of Hispaniola. It differs from the latter in having four small round black spots in a transverse row just behind the occipital plate; in having slightly smaller scales on the sides of the tail and a more pronounced scalloping of the crest, 
which has relatively larger scales; in the absence of a preoccipital, the occipital being completely separated from the supraorbital semicircles by one row of small scales; in the somewhat shorter snout; and in the larger scales of the gular fan. While some deviations will naturally be found in a series, it is probable that the scaling of the tail, the color pattern on the neck, and the larger scales on the gular fan will prove to be fairly stable.

A second specimen was secured by the Utowana Expedition when it touched at Beata Island on April 11, 1934. This example is now M.C.Z. No. 37520.

Specimens examined.-U.S.N.M. No. 83881 (type), Beata Island, Dominican Republic, May 13, 1931, Dr. A. Wetmore and F. C. Lincoln; M.C.Z. No. 37520, Beata Island, April 11, 1934, Utowana Expedition.

\section{ANOLIS DISTICHUS CAUDALIS Cochran}

\section{Figure 52}

1928. Anolis distichus Cochran, Proc. Biol. Soc. Washington, vol. 41, p. 54 (Point-à-Raquettes, Gonave Island) (not of Cope).

1930. Anolis dominicensis Barbour, Bull. Mus. Comp. Zool., vol. 70, No. 3, p. 123 (Gonave Island) (not of Reinhardt and Lütken).

1932. Anolis dominicensis caudalis Cochran, Proc. Biol. Soc. Washington, vol. 45, p. 185; Occ. Pap. Boston Soc. Nat. Hist., vol. 8, p. 168, 1934.-BARBour, Zoologica, vol. 19, p. 113, 1935.

1937. Anolis distichus caudalis Barbour, Bull. Mus. Comp. Zool., vol. 82, No. 2 , p. 126.

Diagnosis.-Obviously close to dominicensis but distinguished from it by having a black shoulder patch bordered above by parallel light stripes, the lower continuing from below the ear to beyond the axilla; in having larger scales on the tail and a less-pronounced scalloping of the crest; in not usually having a large preoccipital; and finally in having, on the average, more scales in the median patch just anterior to the juncture of the supraorbital semicircles.

Description of the type.-U.S.N.M. No. 76801, male from En Café, Gonave Island, collected in March 1929 by A. J. Poole and W. M. Perrygo. Head short, with two short and very weakly developed frontal ridges diverging forward and becoming indistinct at a third of the distance from the eyes to the end of the snout; forehead slightly concave between these ridges; head scales smooth; rostral very low, narrower than the mentals; four to six scales between the nostrils, the inner two of these scales the foremost in a paired median series of rather rectangular, somewhat enlarged scales, which are in contact as far as the concave region in front of the eyes where the series separate to enclose a patch of about eight irregular scales; three scales of the supraorbital semicircles in contact behind this patch; occipital a little larger than the ear opening, elliptical, shield-shaped, 
barely in contact with the supraorbital semicircles; no conspicuoulsy enlarged preoccipital; supraocular disk composed of six large, smooth, polygonal scales, separated from the semicircle by a row of scales reduced in size but not granular; one or two fairly large shields bordering the inner anterior edge of the superciliary, and separated from the supraocular disk by small scales; the scales in front of the supraocular disk all small but not granular; true granular scales behind the supraocular disk; canthus rostralis only moderately developed, the four enlarged scales that distinguish it distinctiy keeled, projecting only slightly over the loreal region; superciliary ridge completely continuous with the scales of the canthus rostralis, composed of one very elongate and sharply keeled scale followed by a double series of small but differentiated tubercular scales, the
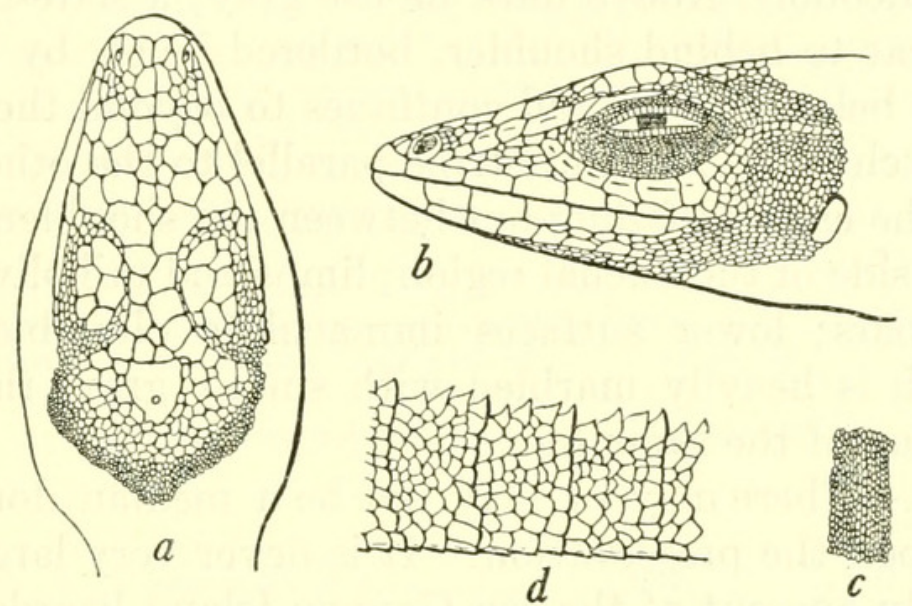

Figure 52.-Anolis distichus caudalis: $a$, Top of head; $b$, side of head; $c$, middorsal scales; $d$, side of tail. U.S.N.M. No. 76801, type, from En Café, Gonave Island. Three times natural size.

anterior of which are separated from the supraocular disk by three or four rows of granules; loreal rows four; subocular semicircle keeled, broadly in contact with the upper labials; supralabials eight, the sixth directly below the center of the eye, the last two very small; temporal granules somewhat smaller than the median dorsals, with a double series of small scales forming the supratemporal line; back and sides covered with granules, the dorsals a little larger and flatter, the laterals smaller and more tubercular; median dorsals only slightly larger than the rest of the dorsal granules; ventrals small, smooth, scarcely imbricate posteriorly, hexagonal, longer than broad; throat covered with small flat granules; forelegs covered with small smooth granules, about three series on the anterior face of the lower arm being greatly enlarged, more than twice as large as the largest ventrals; anterior scales of femur and tibia smooth, similarly enlarged, gradually diminishing posteriorly and below; scales covering hands and feet above perfectly smooth; digital expansion wide, about 19 lamellae under second and third phalanges of fourth toe, about 31 under the whole toe; tail 
moderate, compressed, with very well marked verticils consisting of vertical series of large squarish scales, which are quite truncate at the tips, separated by five or six rows of slightly smaller scales on the sides of the tail; a slightly serrate crest on the tail, with four triangular, keeled and pointed scales, the first and fourth slightly smaller than the others which are subequal and the whole four corresponding to a verticil; skin of gular fan naked, set with distant series of flat, crescent-shaped scales a little longer but much narrower than the ventrals; edge not thickened posteriorly; postanal 'scales well developed. A nuchal fold, diminishing on the shoulders; a strong dorsal fold.

Dimensions: Head and body, $41 \mathrm{~mm}$.; tail defective; snout to posterior ear, $13 \mathrm{~mm}$; snout to center of eye, $8 \mathrm{~mm}$.; width of head, $8 \mathrm{~mm}$.; foreleg, $21 \mathrm{~mm}$; hindleg, $34 \mathrm{~mm}$.

Color (in alcohol): Above dark mouse gray; a slate-black elongate patch from ear to behind shoulder, bordered below by a light stripe, which begins below the ear and continues to beyond the axilla; above the black patch a similar light stripe parallel to the other, and beginning above the ear and fading out between the shoulders; a faint pale area on each side of the nuchal region; limbs and tail olive above, with dark sepia bars; lower surfaces immaculate olive-buff except the throat, which is heavily marbled with smoky gray, the skin of the gular fan being of the same hue.

Variations.-There may or may not be a median dorsal skin fold, depending upon the preservation. It is never very large, even at its best. In only one out of the ten Gonave Island lizards belonging to the U. S. National Museum collection is there a single large preoccipital - the others have 2 to 6 small scales anterior to the occipital. Seven out of these ten have five to eight small scales in the median group anterior to the junction of the supraorbital semicircles; there are four scales in two of the individuals, and two scales in only one individual. Thus the average seems to be considerably higher than in the mainland dominicensis, where two scales is the most constant condition. There are five crest scales to each verticil of the tail in a paratype, No. 77080 (erroneously called the type in the original discussion of variation), of the new species, but the other six males in the National collection have only four scales, the first and fourth of which are only slightly smaller than the other two. There are but seven vertical lateral rows to a whorl in all but one specimen, which has eight. A direct comparison of the tails of Gonave Island and Hispaniolan lizards makes it at once evident that the former have much more coarsely scaled tails than do the latter, while there is less pronounced scalloping because of the greater uniformity of the crest scales.

The conspicuous black shoulder patch set off by light lines above and below is apparently a constant feature of Gonave Island lizards, 
since every specimen shows the markings to varying degrees, even the females and young.

When I examined the Eyerdam specimens collected for the Museum of Comparative Zoology, I failed to attach sufficient importance to the slight variations noted in those particular specimens, which were the only ones from Gonave that I had seen at that time. The subsequent discovery by Dr. A. Wetmore of a distinct subspecies on Beata Island brought about a reexamination of the status of the Gonave Island form, while fresh material from different sources gave proof of the stability of its color pattern and of the arrangement of its caudal scales.

Specimens examined.-As listed in table 27.

TABLE 27.-Specimens of Anolis distichus caudalis examined

\begin{tabular}{|c|c|c|c|}
\hline Museum No. & Locality & Date & Collector \\
\hline U.S.N.M. & & & \\
\hline $\begin{array}{l}76799-76800 \text { (paratypes) } \ldots . . \\
76801 \text { (type) }\end{array}$ & En Café, Gonave Island. & $\begin{array}{l}\text { March } 1929 . . . \\
\end{array}$ & $\begin{array}{l}\text { A. J. Poole and W. Per- } \\
\text { rygo. } \\
\text { Do. }\end{array}$ \\
\hline 77080-77082 (paratypes).... & Point-à-Raquettes, Gonave Island. & $1927 \ldots \ldots \ldots$ & W. J. Eyerdam. \\
\hline $\begin{array}{l}80386-80389 \text { (paratypes) .... } \\
80390 \text { (paratype) . . . . . . }\end{array}$ & $\begin{array}{l}\text { Anse \& Galets, Gonave Island..... } \\
\text { Petite Gonave Island............ }\end{array}$ & $\begin{array}{l}\text { Mar. } 23,1930 \ldots \\
\text { Mar. } 19,1930 \ldots\end{array}$ & $\begin{array}{l}\text { L. H. Parish and W. } \\
\text { Perrygo. } \\
\text { Do. }\end{array}$ \\
\hline M.C.Z. & & & \\
\hline $13783-13789 \ldots$ & Gonave Island & 1919 & G. M. Allen. \\
\hline $25509-25518 \ldots \ldots . . . . .$. & Point-à-Raquettes, Gonave Island & $1927 \ldots \ldots \ldots$ & W. J. Eyerdam. \\
\hline $29046-29050$ & Anse a Galets, Gonave Island... . & Feb. 10, 1929_.. & T. Barbour. \\
\hline $37507-37516 \ldots$ & . do do - n & April $1934 \ldots . .$. & Utowana Expedition. \\
\hline F.M.N.H. & $\begin{array}{l}\text { Between St. Marc and Gonalves, } \\
\text { Haiti. }\end{array}$ & Dec. $4,1928 \ldots$ & K. P. Schmidt. \\
\hline $13255,13256 \ldots$ & Gonave Island ........................... & & J. S. C. Boswell. \\
\hline
\end{tabular}

\section{ANOLIS CYBOTES CYBOTES Cope}

Figure 53

1862. Anolis cybotes Cope, Proc. Acad. Nat. Sci. Philadelphia, 1862, p. 177 (type locality, near Jérémie, Haiti; collector, Dr. Weinland; types, M. C. Z. Nos. 3619, 14346, 14347); Proc. Amer. Philos. Soc., vol. 9, p. 164, 1869.-BoulENGER, Catalogue of the specimens of lizards in the collection of the British Museum, ed. 2, vol. 2, p. 34, pl. 1, fig. 5, 1885.-Garman, Bull. Essex Inst.. vol. 19, p. 42 (extr., p. 18), 1887.-Fischer, Jahrb. Hamburg Wiss. Anst., vol. 5, p. 24, 1888.-MüLler, Verh. Naturf. Ges. Basel, vol. 10, p. 211, 1892.Meerwarth, Mitth. Nat. Mus. Hamburg, vol. 18, p. 24, 1901.-Barbour, Mem. Mus. Comp. Zool., vol. 44, No. 2, p. 283, 1914; Zoologica, vol. 11, No. 4, p. 93, 1930; vol. 19, No. 3, p. 114, 1935; Bull. Mus. Comp. Zool., vol. 82, No. 2, p. 128, 1937.-Noble, Nat. Hist., vol. 23, pp. 111-113, 1923.Cochran, Proc. U. S. Nat. Mus., vol. 66, art. 6, p. 4, 1924; Proc. Biol. Soc. Washington, vol. 41, p. 54, 1928.-BArBour and Loveridge, Bull. Mus. Comp. Zool., vol. 69, No. 10, p. 218, 1929. 
1864. Anolis citrinellus Cope, Proc. Acad. Nat. Sci. Philadelphia, 1864, p. 170, pl. 1, fig. 3 (type locality, Haiti; type in Brit. Mus.).-Boulenger, Catalogue of the specimens of lizards in the collection of the British Museum, ed. 2, vol. 2, p. 35, 1885.-Garman, Bull. Essex Inst., vol. 19, p. 42 (extr., p. 18), 1887.-Barboun, Mem. Mus. Comp. Zool., vol. 44, art. 2, p. 283, 1914.-Sснміdт, Bull. Amer. Mus. Nat. Hist., vol. 44, art. 2, p. 12, 1921.Mertens, Senckenbergiana, vol. 20, No. 5, p. 333, 1938.

1887. Anolis haetianus Garman, Bull. Essex Inst., vol. 19, p. 42 (extr., p. 18) (type locality, Tiburon, Haiti; collector, S. Garman; type, M. C. Z. No. 6191).-Barbour, Mem. Mus. Comp. Zool., vol. 44, No. 2, p. 283, 1914.

1934. Anolis cybotes cybotes Cochran, Occ. Pap. Boston Soc. Nat. Hist., vol. 8, p. 168.-Mertens, Senckenbergiana, vol. 20, No. 5, p. 333, 1938; Publ. Inst. Cient. Domínico-Alemán, vol. 1, p. 84, 1939.-Böker, Publ. Inst. Cient. Domínico-Alemán, vol. 1, p. 16, 1939.

1938. Anolis cybotes saxatilis Mertens, Senckenbergiana, vol. 20, No. 5, p. 334, figs. 1-3; Publ. Inst. Cient. Domínico-Alemán, vol. 1, p. 84, 1939.-BöкER, Publ. Inst. Cient. Domínico-Alemán, vol. 1, p. 16, 1939.

Description.-Adult male, U.S.N.M. No. 75894, collected at Port-au-Prince, Haiti, in 1928 by J. S. C. Boswell. Top of head with
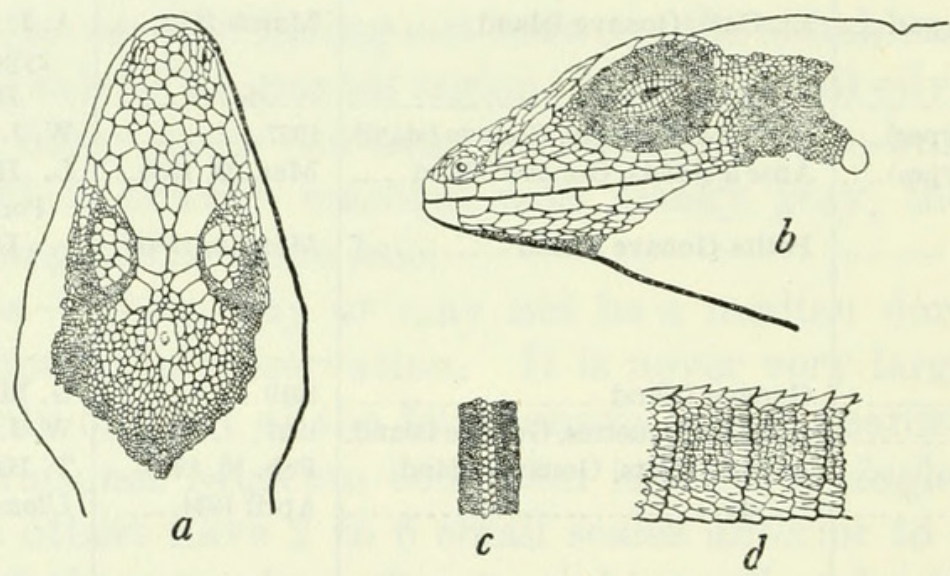

Figure 53.-Anolis cybotes cybotes: $a$, Top of head; $b$, side of head; $c$, middorsal scales; $d$, side of tail. U.S.N.M. No. 75894, from Port-au-Prince, Haiti. One and one-half times natural size.

two ()-shaped frontal ridges, disappearing before reaching the level of the nostrils and enclosing a frontal hollow; head scales rough, usually keeled or wrinkled; the distance between the anterior parts of the orbits very nearly equaling that from the orbit to the end of the snout; rostral low, slightly narrower than the mentals; six scales in a row between the narrow scales bordering each nostril above; supraorbital semicircles composed of six enlarged scales, the second the largest, the third in close contact with its fellow for nearly its entire length, the next ones separated by one scale; occipital one-half the size of the ear opening, separated from the supraorbital semicircle by two or three rows of scales; a single scale at the anterior margin of the occipital plate a little larger than the surrounding scales; the scales posterior to the occipital irregular; supraorbital disk composed of about a dozen polygonal keeled scales, narrowly separated from the semicircle by 
one row of very small granules, which in front of the disk form a patch of gradually enlarging granules; canthus rostralis sharp, consisting of three elongated shields of which the middle one is slightly the longer; superciliary ridge consisting of one elongate scale followed by a very small one, this in turn being followed behind by a double row of differentiated scales larger than the granules above and below them; loreal rows six; subocular semicircles keeled, not in contact with the supralabials; supralabials 10 , the seventh under the center of the eye, the following ones increasingly smaller; temporal granules about the size of the dorsolaterals; a well-marked double series of small scales forming the supratemporal line; dorsal and lateral granules minute, tubercular; a median enlarged series of scales down the center of the back beginning on the nuchal region, diminishing slightly on the sacrum and continuing on the tail as a low, serrate ridge; ventral scales relatively large, imbricate, rounded behind, smooth, those on the throat very small and bluntly tuberculate; anterior face of forelegs and hindlegs covered with large keeled scales about the same size as the ventrals; scales covering hands and feet above unicarinate to multicarinate; digital expansion wide, with about 20 lamellae under the second and third phalanges of the fourth toe, 32 under the entire toe; tail short, compressed, with well-marked verticils of somewhat enlarged rectangular scales, those between being pointed and smaller, in about eight vertical, somewhat irregular series, all imbricate, not keeled, surmounted by a strongly serrate edge of enlarged scales, triangular in profile, three to every verticil, the last one enlarged slightly; dewlap naked, with many close-set series of rather small, weakly multicarinate or entirely smooth scales, edge thickened and set with larger scales; postanal plates slightly developed; a skin fold on the neck and back.

Dimensions: Snout to vent, $67 \mathrm{~mm}$.; tail, $112 \mathrm{~mm}$; orbit to tip of snout, $10 \mathrm{~mm}$.; orbit to orbit, $9 \mathrm{~mm}$.; snout to posterior ear, $23 \mathrm{~mm}$.; snout to center of eye, $13 \mathrm{~mm}$.; width of head, $15 \mathrm{~mm}$.; foreleg, $32 \mathrm{~mm}$.; hindleg, $59 \mathrm{~mm}$; tibia, $18 \mathrm{~mm}$.

Color (in alcohol): Above sepia, suffused on head and back with dull heliotrope-purple, lower parts olive-buff, darker on the tail; all the ventral scales including those of dewlap very finely punctate with minute black dots.

Variations.-In the 375 examples of this species now in the National collection almost every possible variation exists. Some of the specimens have heavy keels on the ventral plates; in others from precisely the same locality taken at the same time the ventrals are perfectly smooth. The loreal rows vary all the way from 4 to 10 in number. The supraorbital semicircles may be broadly in contact or widely separated. The scales on the snout may be very small or unusually large, the two extremes well shown in the Pétionville specimens, 
U.S.N.M. Nos. 59113 and 59119. The ventrals are usually smaller than the largest supraoculars, but sometimes they are fully as large. The supraorbitals may be large and distinct, with the third one on each side somewhat larger than the others, or they may all be small and rugose as in many old males, and scarcely distinguishable from the other head plates. The suborbitals may or may not be separated from the upper labials. The snout in the young and half-grown specimens is as a rule much shorter and broader at the tip than seems to be the case in adult males, where the heavy swelling of the temporals brings about a decided change in head proportion. Many specimens show no trace of nuchal and dorsal ridges; in others these ridges are quite obvious. Furthermore, the middorsal area often presents no enlarged scales at all; in other specimens one sees several rows of pronouncedly larger scales along the nuchal and dorsal ridges.

In many of the 211 specimens from San Michel (U.S.N.M. Nos. 74218-74428) there is a tendency toward the slight enlargement of a single scale bordering the occipital anteriorly, very much as happens to a much greater extent in dominicensis but with the difference that here the preoccipital is not in contact with the supraorbitals. Not all specimens from San Michel have a preoccipital readily distinguishable as such, while occasional examples from other localities do have it. This variation is paralleled by others in other characters, and nowhere is it possible to find a stable variant of even subspecific importance on the Hispaniolan mainland. The names haetianus and citrinellus have been applied to individual variations, the occurrence of which is not even localized.

When actual segregation has taken place, as in the case of the Gonave and Beata Island forms, a true differentiation may occur with the fixation of the tendency toward local variation, which is evident in this group of lizards. The Gonave Island lizard has a longer head, while the canthi are relatively more nearly parallel, instead of angularly divergent as in most of the mainland lizards. I cannot find that the posterior occipital scales of Gonave Island lizards are appreciably enlarged when compared with a large and variable series of those from the mainland. The Beata Island lizard is more distinct, possessing markedly larger dorsolateral granules and much smaller ventral scales, a considerably longer tibia, fewer lamellae under the fourth toe, and several other minor differentiating characters.

Specimens examined.-As listed in table 28. 
TABLE 28.--Specimens of Anolis cybotes cybotes examined

\begin{tabular}{|c|c|c|c|}
\hline Museum No. & Locality & Date & Collector \\
\hline \multicolumn{4}{|l|}{ U.S.N.M. } \\
\hline $9805,9809-9812 \ldots . .$. & "San Domingo"... & $1877 \ldots$ & C. A. Frazer. \\
\hline $9838,9844,9847,9851$ & . . . do do . . & & W. Gabb. \\
\hline $10265 \ldots \ldots \ldots$ & Puerto Plata, D. R & $1878 \ldots$ & C. A. Frazer. \\
\hline $25797-25807 \ldots$ & $\begin{array}{l}\text { Port-au-Prince, Haiti (within } 25 \\
\text { miles of). }\end{array}$ & $1866 \ldots$ & A. C. Younglove. \\
\hline $35983-35985 \ldots$ & San Francisco Mountains, D. R. & September 1905 & A. Busck. \\
\hline 49944 & San Pedro de Macoris, D. R & Mar. $31,1913 \ldots$. & J. N. Rose. \\
\hline $55068-55084 \ldots$ & Rojo Cabo, D. R & Aug $28,1916 \ldots$ & W. L. Abbott. \\
\hline $55303-55305 \ldots . .$. & Jarabacca, D. R & Oct. 16,1916 & Do. \\
\hline $59109 \ldots \ldots . . . . . .$. & St. Marc, Haiti. ........... & Apr. 21, 1917... & $\begin{array}{l}\text { J. B. Henderson and } \\
\text { P. Bartsch. }\end{array}$ \\
\hline $\begin{array}{r}59113,59114,59116,59117, \\
59119,59120,59123,59128 .\end{array}$ & Pétionville, Haiti. . & Apr. $1,1917 \ldots$ & Do. \\
\hline 59172 & Jérémie, Haiti & Apr. $15,1917 \ldots$ & Do. \\
\hline $59173 \ldots \ldots$ & $\begin{array}{l}\text { Village No. 2, } 5 \text { miles west of Jé- } \\
\text { rémie, Haiti. }\end{array}$ & Apr. 12, 1917... & Do. \\
\hline 59174 & Port-au-Prince, Haiti............ & Apr. 8, 1917_. . & Do. \\
\hline $59175 \ldots . . .$. & Thomazeau, Haiti . . . . . . . . & Apr. $3,1917 \ldots$ & Do. \\
\hline $59186 \ldots \ldots$ & Morne à Cabrits, Haiti........... & Apr. $24,1917 \ldots$ & Do. \\
\hline $59189-59190 \ldots .$. & Thomazeau, Haiti & Apr. $3,1917 \ldots . .$. & Do. \\
\hline $59205,59206 \ldots$ & St. Mare, Haiti................... & Apr. $21,1917 \ldots$. & Do. \\
\hline $60624 \ldots \ldots$ & Moron, Haiti.......... & Dec. $20,1917 \ldots$ & W. L. Abbott. \\
\hline $65763,65765 \ldots$ & Jovéro, D. R & Feb. $19,1923 \ldots$ & Do. \\
\hline $65766,65767 \ldots \ldots$. & Liali, D. R & Feb. 10, $1923 \ldots$ & Do. \\
\hline $65768,66692,66693$ & Dominican Republic & 1923 & Do. \\
\hline $65795 \ldots \ldots \ldots . . . . . . . .$. & Puerto Plata, D. R................ & $1878 \ldots \ldots . . .1 .1$. & C. A. Frazer. \\
\hline $69126-69134 \ldots$ & Mon Repos, Haiti. ... . . . . . & Mar. $5,1925 \ldots . . .$. & G. S. Miller, Jr. \\
\hline 69135-69141_... & San Michel du Nord, Haiti...... & Mar. $23,1925 \ldots . .$. & Do. \\
\hline $69142 \ldots \ldots$ & Cabaret, Haiti .................... & Mar. 10, 1925 ...... & Do. \\
\hline $69143 \ldots \ldots$ & San Francisque, Haiti & Mar. $14,1925 \ldots . .$. & Do. \\
\hline $69144 \ldots . . . . . .$. & Hills above Rivière Froide, Haiti & Mar. 4, 1925_...... & Do. \\
\hline $69145 \ldots \ldots . . . .$. & Haiti & 1925 & Do. \\
\hline $70639 \ldots$ & Ennery, Haiti............. & $\begin{array}{l}\text { Nov. 1925-Mar. } \\
\text { 1926. }\end{array}$ & E. C. Leonard. \\
\hline $72605 \ldots . .$. & $\begin{array}{l}\text { Massif de la Selle, Haitl (Morne } \\
\text { La Visite). }\end{array}$ & Apr. 11, 1927..... & A. Wetmore. \\
\hline $72606 \ldots . . . .$. & $\begin{array}{l}\text { Massif de la Selle, Haiti (Jardin } \\
\text { Bois Pin). }\end{array}$ & Apr. 14, 1927..... & Do. \\
\hline $72641-72649$ & Sánchez, D. R & May $6-7,1927 \ldots$ & Do. \\
\hline $72653 \ldots \ldots$ & Constanza, D. R & May $24,1927 \ldots \ldots$ & Do. \\
\hline $74028-74045 \ldots$ & $\begin{array}{l}\text { Port-au-Prince, Haiti (Diquini } \\
\text { Cave). }\end{array}$ & Dec. $10-15,1927 \ldots$ & A. J. Poole. \\
\hline 74087-74093_.... & Cap-Haitien, Haiti & Mar. 3-6, 1928_.... & Do. \\
\hline 74218-74428 & San Michel du Nord, Haiti...... & $\begin{array}{l}\text { Dec. } 20,1927 \text {-Mar. } \\
15,1928 .\end{array}$ & Do. \\
\hline $74713-74715$ & Río San Juan, D. R ... & March $1928 \ldots . . . .$. & G. S. Miller, Jr. \\
\hline $75006-75013 \ldots$. & Samaná, D. R. & $\begin{array}{l}\text { February-March } \\
1928 .\end{array}$ & Do. \\
\hline $75883 \ldots \ldots$ & Mariani, Port-au-Prince, Haiti.. & 1928 & J. S. C. Boswell. \\
\hline $75894,75895 \ldots$ & Port-au-Prince, Haiti............. & $1928 \ldots \ldots$ & Do. \\
\hline $75903 \ldots \ldots$ & Aux Cayes, Haiti............... & $1928 \ldots \ldots$ & Do. \\
\hline $766663-76672$ & Don Don, Haiti ....... & Jan. $18-20,1929$ & $\begin{array}{l}\text { A. J. Poole and W. } \\
\text { Perrygo. }\end{array}$ \\
\hline $77056-77058 \ldots$ & Citadelle, Haiti..... & 1929 & A. E. Vinson. \\
\hline $77073-77074 \ldots . .$. & Miragoane, Haiti ............ & 1927 & W. J. Eyerdam. \\
\hline $80840 \ldots \ldots . . . . . . .$. & Île à Vache, Haiti............. & May $1,1930 \ldots . .$. & $\begin{array}{l}\text { L. H. Parish and W. } \\
\text { Perrygo. }\end{array}$ \\
\hline
\end{tabular}


TABLE 28.-Specimens of Anolis cybotes cybotes examined-Continued

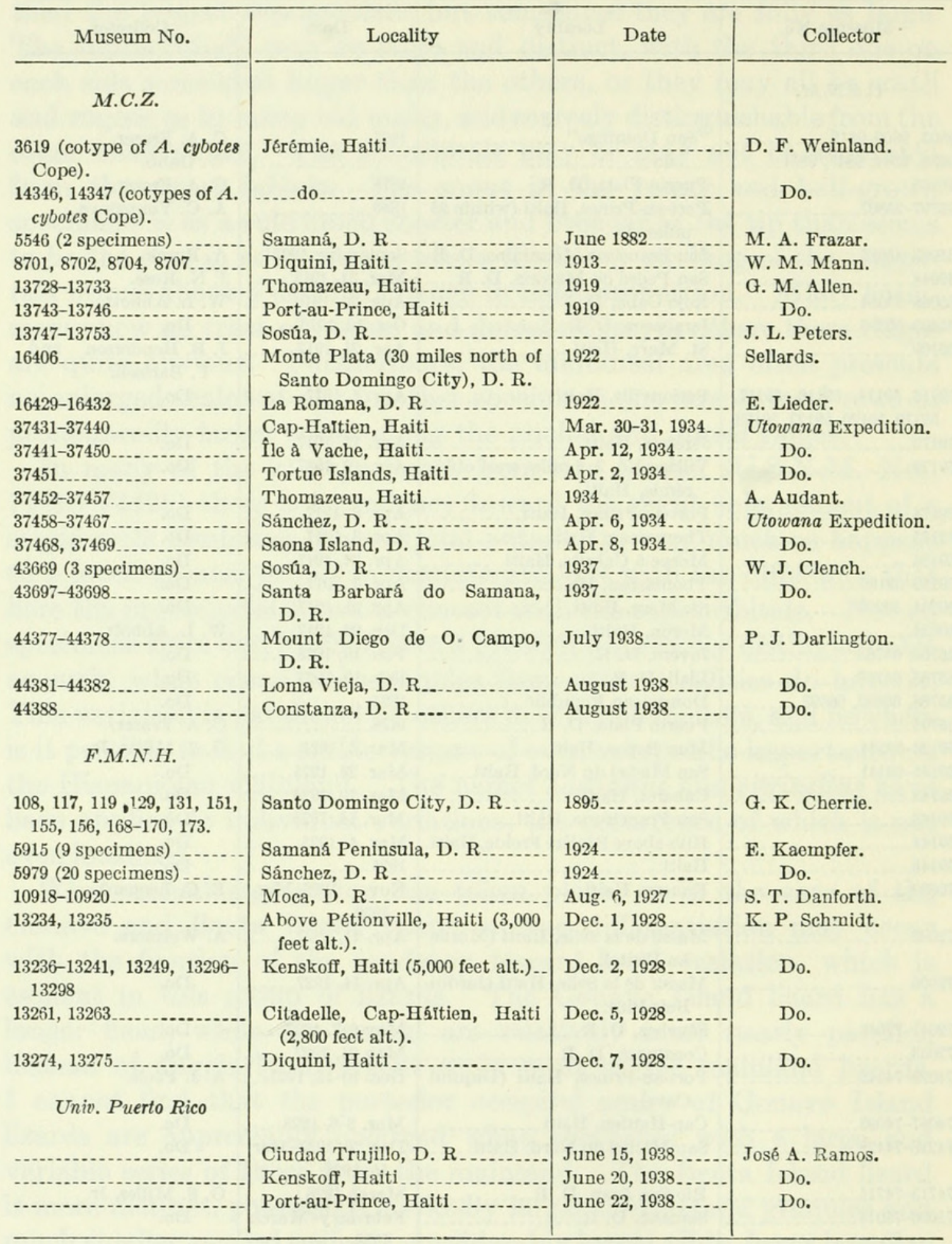

\section{ANOLIS CYBOTES LONGITIBIALIS Noble}

Figure 54

1923. Anolis longitibialis Noble, Amer. Mus. Nov., No. 64, p. 4.-Barbour and Loveridge, Bull. Mus. Comp. Zool., vol. 69, No. 10, p. 221, 1929.-Barbour, Zoologica, vol. 11, No. 4, p. 92, 1930; vol. 19, No. 3, p. 114, 1935.

1934. Anolis cybotes longitibialis Cochran, Occ. Pap. Boston Soc. Nat. Hist., vol. 8, p. 168.-Barbour, Bull. Mus. Comp. Zool., vol. 82, No. 2, p. 128, 1937.

Description.-U.S.N.M. No. 83880, a male from Beata Island, Dominican Republic, taken by Dr. A. Wetmore and F. C. Lincoln on 
May 11, 1931. Top of head with two ()-shaped frontal ridges, disappearing before reaching the level of the nostrils and enclosing a frontal hollow; head scales nearly smooth, only those of the supraorbital disks with a keel; the distance between the anterior portions of the orbits very nearly equaling that from the orbit to the end of the snout; rostral low, slightly narrower than the mentals; five or six scales between the narrow scales bordering each nostril above; supraorbital semicircles composed of six enlarged scales, the second much the largest, the third and fourth in close contact with their fellows for nearly their entire length; occipital about three-fourths the size of the ear opening, separated from the supraorbital semicircle by one row of scales; a single scale of the anterior margin of the occipital plate a little larger than the surrounding scales; the scales posterior to the occipital irregular; supraorbital disk composed of about seven polygonal keeled scales, separated from the semicircle by one or two rows of relatively large granules, which in front of the disk enlarge to form a patch of small but distinct scales; canthus rostralis sharp, consisting of four elongate shields of which the middle two are the longer; superciliary ridge consisting of one very elongate scale followed by a short one, this in turn being followed by a double row of differentiated scales larger than the granules above and below them; loreal rows five; subocular semicircle keeled, not in contact with the supralabials; supralabials eight or nine, the suture between the seventh and eighth under the center of the eye, the ninth very small indeed; temporal granules slightly smaller than the dorsolaterals; a well-marked double series of small scales forming the supratemporal line; dorsal and lateral granules relatively much larger than in Anolis cybotes cybotes, flattened, not tubercular; a median enlarged series of keeled scales down the center of the back beginning just behind the occipital scale, not diminishing on the sacrum and continuing on the tail as a low, serrate ridge; ventral scales relatively very much smaller than those of Anolis cybotes cybotes, imbricate, rounded behind, smooth, those on the throat small and bluntly tuberculate; anterior face of forelegs and hindlegs covered with large faintly keeled scales, those on the anterior femur considerably larger than the largest ventrals; scales covering hands and feet above faintly unicarinate or practically smooth; digital expansion wide, with about 16 lamellae under the second and third phalanges of the fourth toe, 26 under the entire toe; tail short, compressed, with well-marked verticils of slightly enlarged rectangular scales, those between being rounded and smaller, in about seven vertical, somewhat irregular series, slightly imbricate, heavily keeled, surmounted by a strongly serrate edge of enlarged triangular scales, three to every verticil, the last one the largest; dewlap naked, with many close-set series 
of quite small scales, edge thickened and set with larger scales; postanal plates very well developed; a skinfold on the neck and back.

Dimensions: Snout to vent, $58 \mathrm{~mm}$; tail, $84 \mathrm{~mm}$.; orbit to tip of snout, $9 \mathrm{~mm}$.; orbit to orbit, $7.5 \mathrm{~mm}$.; snout to posterior ear, $20 \mathrm{~mm}$.;
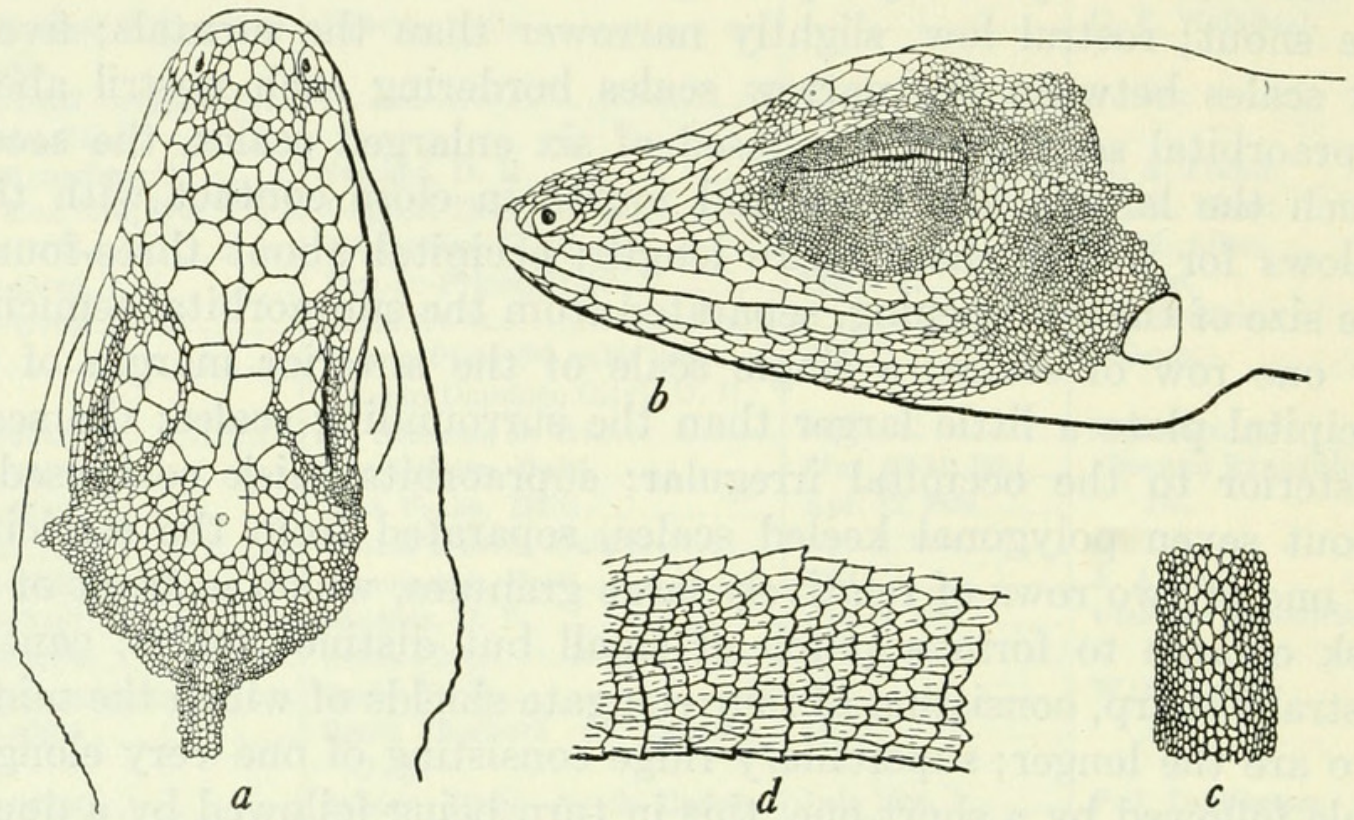

Figure 54.-Anolis cybotes longitibialis: $a$, Top of head; $b$, side of head; $c$, middorsal scales; $d$, side of tail. U.S.N.M. No. 83880, from Beata Island, Dominican Republic. Two and one-half times natural size.

snout to center of eye, $12 \mathrm{~mm}$; width of head, $12 \mathrm{~mm}$.; foreleg, 29 $\mathrm{mm}$.; hindleg, $52 \mathrm{~mm}$.; tibia, $18 \mathrm{~mm}$.

Color (in alcohol): Olive-gray above, lightening to drab on tail and limbs; below lilac-gray on throat and belly, olive-buff on legs and tail; some small brown spots in a transverse series above the shoulder, and a few scattered dots on the occiput and back; upper proximal surface of tail with a few median brown spots; skin of dewlap lilac-gray, the scales white.

Variations.-From the examples before me, no adequate concept of the variation of this form may be obtained. No. 83878 is much like the one described above, differing chiefly in the lesser degree of spotting. The same coarse dorsolateral granules occur in both specimens, and this character alone is probably sufficient to separate this subspecies definitely from its representative on the mainland of Hispaniola, Anolis cybotes cybotes, great as the variation undoubtedly is in the latter species.

Specimens examined.-U.S.N.M. Nos. 83878, 83879, Beata Island, Dominican Republic, May 13, 1931, Dr. A. Wetmore and F. C. Lincoln; U.S.N.M. 83880, same data except collected May 11, 1931; M.C.Z. Nos. 37480-37482, Beata Island, April 11, 1934, Utowana Expedition. 


\section{FigURE 55}

1925. Anolis doris Barbour, Proc. Biol. Soc. Washington, vol. 38, p. 101; Zoologica, vol. 11, No. 4, p. 93, 1930.-Barbour and Loveridge, Bull. Mus. Comp. Zool., vol. 69, No. 10, p. 219, 1929.

1934. Anolis cybotes doris Cochran, Occ. Pap. Boston Soc. Nat. Hist., vol. 8, p. 168.-Barbour, Zoologica, vol. 19, No. 3, p. 114, 1935; Bull. Mus. Comp. Zool., vol. 82, No. 2, p. 128, 1937.

Description of a paratype.-A nearly grown male, formerly M.C.Z. No. 13741, now U.S.N.M. No. 69384, from Gonave Island, collected by Dr. G. M. Allen in August 1919. Top of head with two ( )-shaped frontal ridges, disappearing just before the level of the nostrils is reached and inclosing a frontal hollow; head scales smooth or slightly rugose, the supraocular patch with fairly heavy keels; the distance becween the anterior portions of the orbits considerably less than that from the orbit to the end of the snout; rostral low, slightly narrower than the mentals; four scales in a row between the narrow scales bordering each nostril above; supraorbital semicircles composed of six or seven enlarged scales, the second the largest, the third in close contact with its fellow for nearly its entire length, the next ones separated by one scale; occipital over one-half the size of the ear opening, separated from the supraorbital semicircles by two or three scales; a single larger scale at the anterior border of the occipital and a similar scale posterior to the occipital, which is followed by other irregularly larger and smaller scales; supraorbital disk composed of about nine polygonal keeled scales, incompletely separated from the semicircle by a single row of granules, which in front of the disk form a patch of gradually enlarging granules with a few somewhat larger ones lying near the superciliaries; canthus rostralis sharp, consisting of three elongated subequal shields; superciliary ridge consisting of one very elongate scale, followed by one shorter and four or five rather small ones; loreal rows six; scales of subocular semicircles keeled, rather small and relatively undifferentiated, separated from the upper labials by one row of scales; supralabials 10 , the seventh under the center of the eye, the last rather small; temporal granules about the size of the dorsolaterals; a well-marked double series of scales forming the supratemporal line; dorsal and lateral granules minute, keeled, a median enlarged series of scales down the center of the back, beginning on the nuchal region, diminishing slightly on the sacrum and continuing on the tail as a low, serrate ridge; ventral scales relatively large, imbricate, rounded behind, smooth, those on the throat small and swollen into round knobs; anterior face of fore limbs and hindilimbs covered with large keeled scales somewhat larger than the ventrals; scales covering hands and feet above unicarinate to multicarinate; digital expansion wide, with about 18 lamellae under 
the second and third phalanges of the fourth toe, 28 under the entire toe; tail short, compressed, with well-marked verticils of somewhat enlarged rectangular scales, those between being pointed and smaller, in about six vertical, somewhat irregular series, all imbricate and keeled, surmounted by a strongly serrate edge of enlarged triangular scales, three to every verticil, the last one slightly the largest; dewlap naked, with many close-set series of rather small, smooth scales, edge thickened and set with larger scales; postanal scales pronounced; a skin fold on the neck, less distinct on the back.

Dimensions: Tip of snout to vent, $48 \mathrm{~mm}$.; tail incomplete; snout to posterior ear, $17 \mathrm{~mm}$.; snout to center of eye, $9 \mathrm{~mm}$.; orbit to tip
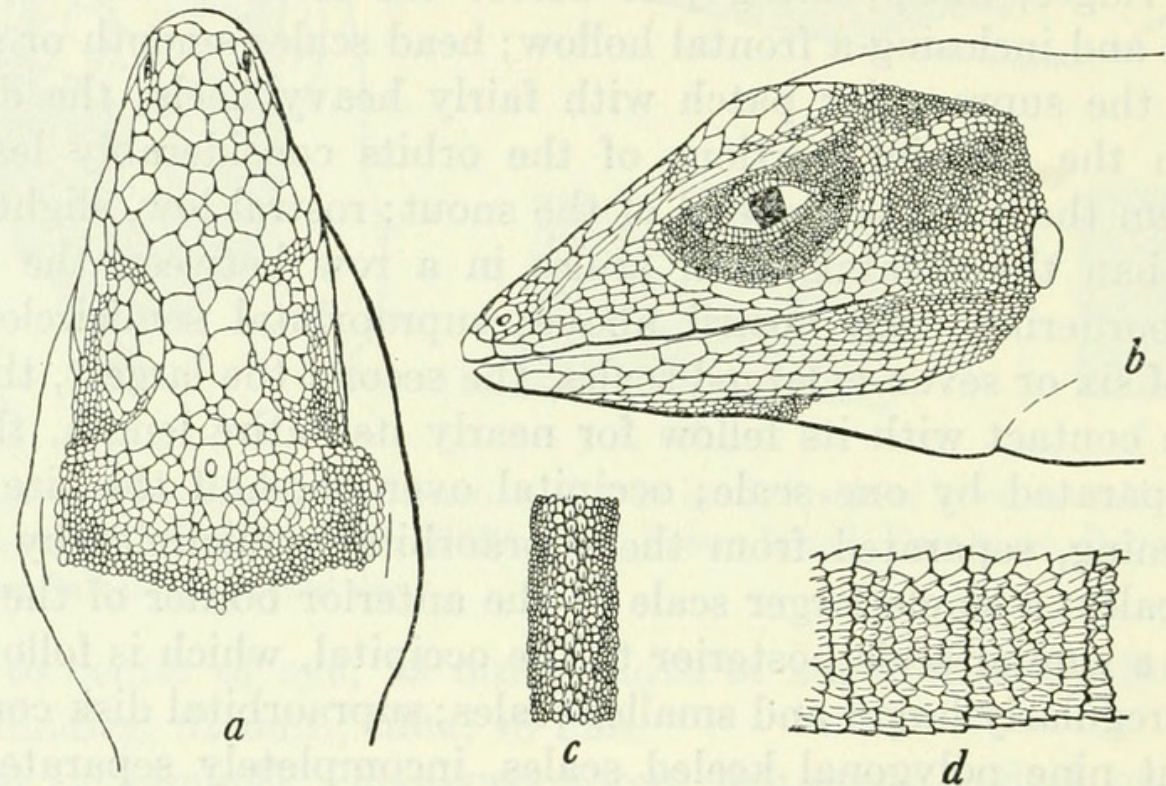

Figure 55.-Anolis cybotes doris: $a$, Top of head; $b$, side of head; $c$, middorsal scales; $d$, side of tail. U.S.N.M. No. 69384 (formerly M.C.Z. No. 13741), paratype, from Gonave Island. Three times natural size.

of snout, $7.5 \mathrm{~mm}$; orbit to orbit, $6.5 \mathrm{~mm}$.; width of head, $10.5 \mathrm{~mm}$.; foreleg, $23 \mathrm{~mm}$.; hindleg, $40 \mathrm{~mm}$.

Color (in alcohol): Above drab-gray, with five narrow sepia chevrons across the back between neck and end of body; lower parts lighter, the ventral scales and the dewlap powdered with very minute gray dots.

Variations.-Regarding its variations, I find that the postoccipital scales may be larger or smaller, according to the individual, and in this respect there is scarcely a valid difference between the Gonave Island lizard and that on the Hispaniolan mainland. The distance from the anterior edge of the orbit to the tip of the snout in the former is on an average about one-sixth greater than the distance between the two orbits measured from the edge of the canthus directly above them, while in the latter the two dimensions are practically equal, this giving a rather elongate and more pointed appearance to the snout of the Gonave Island lizard, while the Hispaniolan form exhibits 
a blunt and squarish snout generally. Not every specimen conforms to these proportions, however. A female from Gonave Island (U.S.N.M. No. 77072) has a snout almost as broad as long, while the described specimen of cybotes (U.S.N.M. No. 75894) has a snout slightly longer than broad. The scales of the tail verticils are larger in the Gonave Island lizard, there being four to six vertical rows to every verticil in the Gonave Island form, while true cybotes has usually finer scales in six to nine rows to a verticil. These differences are not great, it is true, but they seem sufficient to allot subspecific rank to the Gonave Island lizard, which is evidently on its way to becoming a full species through the effects of isolation.

Specimens examined.-As listed in table 29.

TABLE 29.-Specimens of Anolis cybotes doris examined

\begin{tabular}{|c|c|c|c|}
\hline Museum No. & Locality & Date & Collector \\
\hline \multicolumn{4}{|l|}{ U.S.N.M. } \\
\hline $\begin{array}{l}69384 \text { (paratype of } A . \text { doris } \\
\text { Barbour) }\end{array}$ & Gonave Island & August 1919 & G. M. Allen. \\
\hline 77072 & $\begin{array}{l}\text { Point-â-Raquettes, Gonave Is- } \\
\text { land. }\end{array}$ & $1927 \ldots$ & W. J. Eyerdam. \\
\hline 80381-80384 & West Point, Gonave Island..... & Mar. 21, 1930_..... & L. H. Parish and W. \\
\hline 80385 & Gonave Island . . . . & Mar. 23, $1930 \ldots$ & Do. \\
\hline $80391,80392 \ldots$ & Petite Gonave Island................ & Mar. $19,1930 \ldots . .$. & Do. \\
\hline \multicolumn{4}{|l|}{ M.C.Z. } \\
\hline $\begin{array}{l}\text { 13734-13736 (paratype of } \\
\text { A. doris Barbour) }\end{array}$ & Gonave Island ................ & 1919 & G. M. Allen. \\
\hline $\begin{array}{l}13737 \text { (type of } A \text {. doris } \\
\text { Barbour) }\end{array}$ & ................. & $1919 \ldots$ & Do. \\
\hline $\begin{array}{r}13738-13740,13742 \text { (para- } \\
\text { type of } A \text {. doris Barbour) }\end{array}$ & . do do...................... & $1919 \ldots$ & Do. \\
\hline 25525-25527 & $\begin{array}{l}\text { Point-â-Raquettes, Gonave Is- } \\
\text { land. }\end{array}$ & $1927 \ldots$ & W. J. Eyerdam. \\
\hline 25528 & Anse a Galets, Gonave Island... & August 1927....... & Do. \\
\hline $37470-37479$ & - do $0_{2}$ & April 1934 & Utow ana Expedition. \\
\hline
\end{tabular}

\section{ANOLIS MONTICOLA Shreve}

Plate 11, B

1936. Anolis monticola Shreve, Proc. New England Zool. Club, vol. 15, p. 93.

Original description.- "Type.-Museum of Comparative Zoology, no. 38,296 , a male, apparently adult, from northern and eastern foothills, Massif de la Hotte, 1000-4000 ft., Haiti, collected by P. J. Darlington in October, 1934.

"Diagnosis.-Possibly most similar to Anolis sagrei of Cuba, from which it differs in possessing much smaller head scales, in having three rows of scales separating the supraorbitals, instead of one or two, in having decidedly smaller dorsals and ventrals, a slighter general build, 
a smaller dewlap, narrower digital dilations, and fewer lamellae under the second and third phalanges of the fourth toe. It also differs in coloration. Possibly it will eventually be found that some of the characters enumerated above are not constant.

"Description.-Head almost twice as long as broad, longer than the tibia; forehead concave; upper head scales very small, sharply keeled, some multicarinate; scales of supraorbital semi-circles enlarged, separated by three rows of scales; approximately nine, enlarged, keeled, supraocular scales, separated from the supraorbitals by a row of granules; occipital about the same size as the ear opening, separated from the supraorbitals by four series of scales; canthus rostralis distinct, canthal scales five; loreal rows seven or nine; seven upper labials to below the center of the eye; ear opening suboval; gular appendage small, gular scales keeled; body compressed; no dorsonuchal fold; dorsal scales granular, decidedly enlarged and keeled on the vertebral line; ventral scales rather small, much larger than the granular dorsals, subimbricate, and strongly keeled; the adpressed hind limb reaches beyond the eye; digits rather feebly keeled; seventeen lamellae under phalanges two and three of the fourth toe; male with enlarged postanal scales.

"Coloration in alcohol.-Dorsum dark gray; upper side of limbs, head, and base of tail, grayish brown. Dorsum, base of tail, and limbs, with darker cross-bands above, those of the dorsum and fore limbs barely discernible, while those of the hind limbs and base of tail, though faint, are readily visible; belly gray; under sides of limbs yellowish brown; digital dilations, both above and below, dark brown; under side of base of tail grayish brown; throat, dewlap, chest, and under side of lower jaw strongly suffused with light blue.

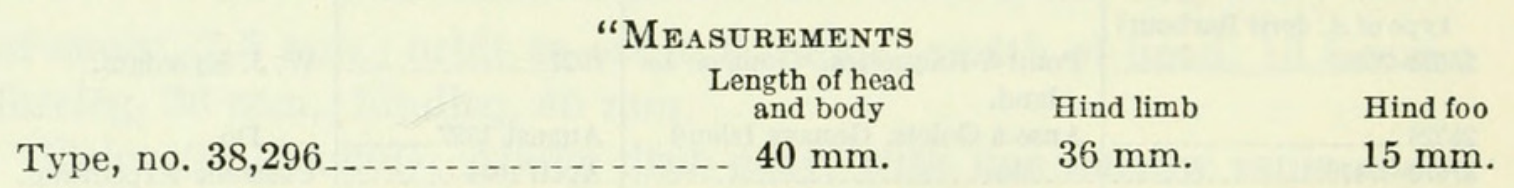

"The tail is broken off near the base and is missing."

ANOLIS DARLINGTONI Cochran

Figure 56

1939. Anolis darlingtoni Cochran, Proc. New England Zool. Club, vol. 18, p. 1.

Diagnosis.-Allied to Anolis monticola Shreve but having the head slightly more than one and one-half times as long as broad, as long as the tibia; occipital less than one-half the area of the ear opening; six loreal rows; sixth upper labial below center of eye; body scales on middorsal line not differentiated; adpressed hindlimb reaching to tip of snout; 24 lamellae under fourth toe.

Description of the type.-M.C.Z. No. 44360, an adult male from Loma Vieja, Cordillera Central (south of Constanza), Dominican 
Republic, altitude 6,000 feet, collected in August 1938 by P. J. Darlington. Head slightly more than one and one-half times as long as broad, depressed, with broad low ridges on the snout on each side of the concave frontal region; head scales polygonal, rather small, more or less subequal, all unicarinate, nearly granular around the occipital region; rostral more than twice as wide as high, slightly narrower than the mentals; five scales bordering rostral between supranasals; no regular paired series of scales on the anterior part of the snout; supraorbital semicircles composed of scales not differing greatly in size from the other snout scales, separated from each other by three rows of scales, and from the occipital by three or four scales, some of which are almost granular; occipital about one-fourth the area of the ear opening, inconspicuous, oval in shape, bordered by scales which are nearly granular; supraocular disk composed of four or five larger and seven or eight smaller keeled scales, separated
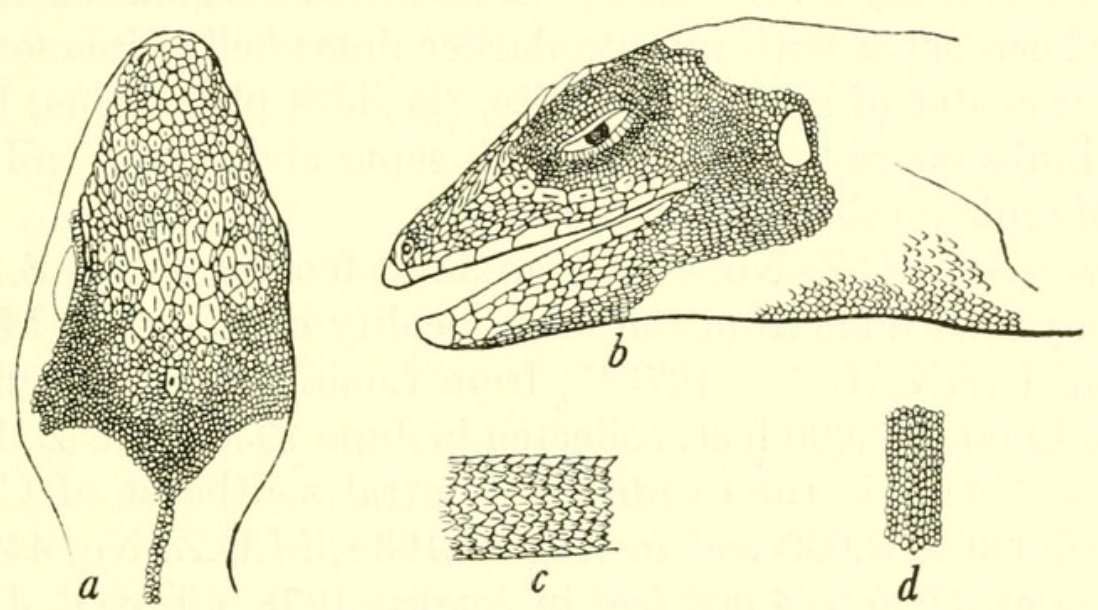

Figure 56.-Anolis darlingtoni: $a$, Top of head; $b$, profile of head; $c$, side of tail; $d$, middorsal granules. Paratype, U.S.N.M. No. 107566, from Loma Vieja, Cordillera Central, Dominican Republic. Two and one-half times natural size.

from the supraorbital semicircles by one row of small scales, from the superciliaries by two rows; canthus rostralis strongly projecting, covered by five sharply keeled scales increasing in size posteriorly, followed by one or two longer ones on the superciliary border; loreal rows six; seven or eight scales in the subocular semicircle scarcely enlarged, separated from supralabials by one row of scales; supralabials seven, the sixth coming below center of eye; temporal granules about equal to the dorsals, with a double line of larger, flatter ones forming the supratemporal line; back and sides covered with small, heavily keeled granules, those of the midline not, or scarcely, differentiated, about 50 granules along the dorsolateral region equaling the distance between tip of snout and center of eye; ventral scales about twice as large as the dorsal granules, smooth, imbricate, squarish; throat covered with small keeled granules, which gradually are replaced on the gular fan by small, smooth scales like those of the belly; 
edge of gular fan not thickened posteriorly; limbs covered anteriorly by imbricate, keeled scales, posteriorly by granules; upper surfaces of hands and feet covered by small keeled scales; digital expansions narrow, about 24 lamellae under the fourth toe; tail long, nearly two and one-half times the length of head and body, slightly compressed, not definitely verticillate, the upper median scale row larger and more heavily keeled but not serrate in profile; scales beneath the tail larger and strongly keeled; postanal scales of male well developed; a faint nuchal fold.

Dimensions: Head and body, $42 \mathrm{~mm}$; tail, $100 \mathrm{~mm}$; snout to posterior ear, $13 \mathrm{~mm}$.; snout to center of eye, $8 \mathrm{~mm}$.; width of head, $8 \mathrm{~mm}$.; foreleg, $19 \mathrm{~m}$.; hindleg, $41 \mathrm{~mm}$.

Color (in alcohol): Ground color of upper surfaces sepia, with fine mottlings of clove brown all over the body tending to form about five irregular, dark-edged, light-centered saddles, extending over the back and narrowing on the sides; tail also with irregular dark and light patches; head sepia with minute darker dots; belly cinereous; throat pale gray; center of gular fold white, its sides plumbeous; lower surfaces of limbs coarsely reticulate with sepia and white; tail with suffusions of sepia on the paler ground color.

Paratypes.-M.C.Z. No. 44361, an adult female, and U.S.N.M. No. 107556 , a young male from the same locality as the type; M.C.Z. No. 44362 and U.S.N.M. No. 107557, from Loma Rucilla and mountains north, at 4,000 to 7,000 feet, collected in June 1938; M.C.Z. No. 44364 from Valle Nuevo in the Cordillera Central southeast of Constanza, taken at 6,000 to 8,000 feet in August 1938; M.C.Z. No. 44363, from Constanza at 3,000 to 4,000 feet in August 1938, all by P. J. Darlington.

Variations.-The six paratypes vary slightly as follows: Internasals bordering the rostral four or five, those directly between the nasals six to eight, irregularly arranged; loreal "rows" six to nine, also very irregular, especially the uppermost, and not always arranged in rows even toward the labials; supraorbital semicircles separated from each other by two or three rows of smaller scales, and from the occipital by three to five uneven scales; four to seven supralabials to center of eye, the total number being six to eight, of which the last one or two may be very small; infralabials six or seven; malar rows four to six, composed of fairly regular scales; lamellae under free part of fourth toe 23 to 27 ; tail not verticillate distally, but sometimes a pair of very indistinct verticils separated by five or six rows of irregular scales may be made out proximally. The largest male is the type; the largest female, M.C.Z. No. 44361, measures $44 \mathrm{~mm}$. in head and body length. This female has a dorsal pattern of four saddlelike brown blotches, with two smaller ones on the neck and some on the tail. The other three females have a dorsal light stripe flanked by two brown stripes, 
without the transverse dark saddles. One of the males is uniform brown above, while the other shows only a very weak pattern of dark saddles. The gular fan of the male is dark slate-gray at the base, nearly white on the center of the fan. The only individual having a complete tail is M.C.Z. No. 46364, in which the tail measures 98 mm., about two and one-half times the length of the head and body, $38 \mathrm{~mm}$. in this specimen.

\section{ANOLIS CHLORO-CYANUS Duméril and Bibron}

Figure 57

1837. Anolis chloro-cyanus Duméril and Bibron, Erpétologie générale, vol. 4, p. 117 (type localities, Martinique and San Domingo).-DumériL, Catalogue méthodique de la collection des reptiles (Paris), p. 57, 1851.-REINHARDT and Lütken, Vid. Medd. Nat. Foren. Kjöbenhavn, 1862, p. 266, extr. p. 114, 1863 (S. Domingo).-Boulenger, Catalogue of the specimens of lizards in the collection of the British Museum, ed. 2, vol. 2, p. 44, 1885 (S. Domingo).Garman, Bull. Essex Inst., vol. 19, p. 48, 1887 (Samaná, S. Domingo).Fischer, Jahrb. Hamburg Wiss. Anst., vol. 5, p. 30, 1888 (Cape Haïtien, Hayti; H. Rolle, collector).-Müller, Verh. Naturf. Ges. Basel, vol. 10, No. 1, p. 211, 1892 (Cape Haytien).-Meerwarth, Mitth. Naturh. Mus. Hamburg, vol. 11, p. 25, 1900 (1901).-Barbour, Mem. Mus. Comp. Zool., vol. 44, p. 295, 1914; Zoologica, vol. 11, No. 4, p. 87, 1930; vol. 19, No. 3, p. 108, 1935; Bull. Mus. Comp. Zool., vol. 82, No. 2, p. 120, 1937.- Сснміdт, Bull. Amer. Mus. Nat. Hist., vol. 44, p. 11, fig. 8, 1921.-. Cochran, Proc. U. S. Nat. Mus., vol. 66, art. 6, p. 4, 1924; Proc. Biol. Soc. Washington, vol. 4, p. 54, 1928; Occ. Pap. Boston Soc. Nat. Hist., vol. 8, p. 167, 1934.-Mertens, Senckenbergiana, vol. 20, No. 5, p. 333, 1938; Publ. Inst. Cient. Domínico-Alemán, vol. 1, p. 84, 1939.-Böker, Publ. Inst. Cient. Domínico-Alemán, vol. 1, p. 16, 1939.

1845. Anolis bullaris Gray, Catalogue of the specimens of lizards in the collection of the British Museum, p. 206 (Martinique; from Museum, Paris) (not of Linnaeus?).

1856. Anolis laeviceps Lichtenstein, Nomenclator reptilium et amphibiorum Musei Zoologici Berolinensis, p. 7 (type locality unknown).

Description.--An adult male, U.S.N.M. No. 59204, from St. Marc, Haiti, collected on April 21, 1917, by Dr. Paul Bartsch and J. B. Henderson. Head elongate, depressed, with very weakly developed ridges appearing on the snout anterior to the frontal region, and with a shallow concavity behind these ridges; head scales polygonal, fairly large, more or less subequal, some of them slightly rugose but entirely unkeeled; rostral very low, equal to the mentals in width; four scales between the supranasals; no regular paired series of scales on the anterior part of the snout; supraorbital semicircles composed of rather irregularly shaped large scales becoming smaller posteriorly, separated from each other by a row of small scales, and from the occipital by two scales; occipital about the size of the ear opening, inconspicuous, polygonal in shape, bordered posteriorly by scales that become smaller and rapidly merge into those of the back; supraocular disk composed of two large scales surrounded by 9 or 10 small flat scales, which are 
separated from the supraorbital semicircles and from the superciliaries by one row of somewhat smaller scales; canthus rostralis strongly projecting over the loreal region, and covered by four sharply keeled scales succeeded by two others on the anterior superciliary border, the last of this series much the longest and not followed by any differentiated scales; loreal rows three, the five scales of the subocular semicircle very elongate, broadly in contact with the upper labials, the first three heavily keeled, the fifth small; supralabials nine, the suture between the seventh and eighth coming directly beneath the center of the eye; temporal granules about equal to the dorsals, with a rather indistinctly differentiated patch of larger ones forming the supratemporal line; back and sides covered with bluntly tubercular granules, those of the four median dorsal rows with somewhat larger and more elongate granules which seem to have traces of a keel, about 40 to 45 granules along the dorsolateral region equaling the distance between
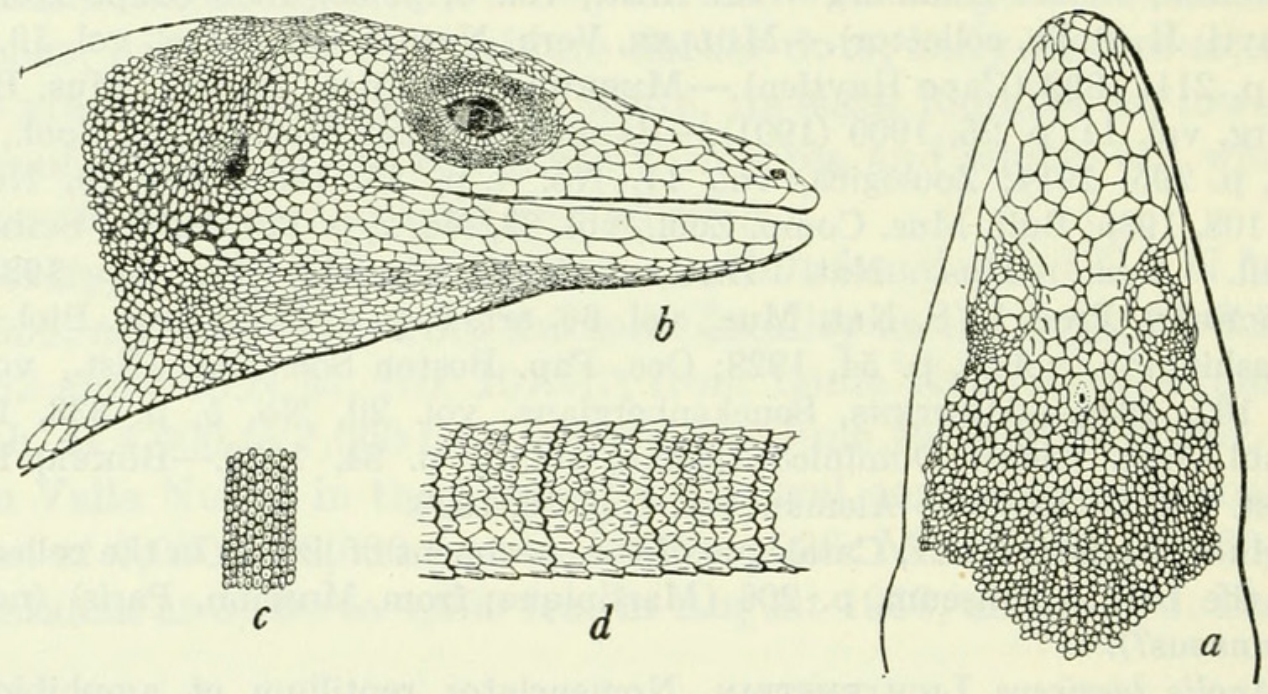

Figure 57.-Anolis chloro-cyanus: $a$, Top of head; $b$, side of head; $c$, middorsal scales; $d$, side of tail. U.S.N.M. No. 59204, from St. Marc, Haiti. Twice natural size.

tip of snout and center of eye; ventral scales about twice as large as the dorsal granules, perfectly flat, not or but slightly imbricate, almost square; throat covered with small rounded granules; limbs covered above with small scales, three faintly keeled and enlarged series appearing on the anterior face of foreleg and on tibia; scales covering hands and feet above enlarged, multicarinate; digital expansion wide, about 29 lamellae under the second and third phalanges, about 45 under the whole toe; tail fairly long, round, the median scales enlarged but not crested; the laterals arranged in well-marked verticils composed of about four vertical rows of polygonal, keeled scales followed by a final row of larger scales and topped by five of the enlarged median scales; the scales beneath the tail considerably enlarged and heavily keeled; skin of the gular fan naked, set with distant rows of diamondshaped scales, which are swollen toward their tips; edge of fan not 
thickened posteriorly; postanal scales well developed; no nuchal or dorsal fold.

Dimensions: Head and body, $71 \mathrm{~mm}$.; tail, $151 \mathrm{~mm}$.; snout to posterior ear, $22 \mathrm{~mm}$.; snout to center of eye, $13 \mathrm{~mm}$.; width of head, 13 $\mathrm{mm}$. ; foreleg, $29 \mathrm{~mm}$; hindleg, $48 \mathrm{~mm}$.

Color (in alcohol): Entire upper surfaces Nile blue, deepening to lilac and azure on the lateral regions and lightening beneath to pale turquoise blue on throat and chest and changing to pinkish buff on the hind legs and tail. From the eyes forward the snout is light clay color. No spots or vermiculations of any kind are evident except on the sides of the legs and tail, where indistinct vermiculations of a slightly deeper tone of Nile blue may be made out. Skin of gular fan jet black, the scales pale blue in startling contrast.

Variations.-In a genus where an immense amount of variation in the species is the rule, rather than the exception, it is gratifying to find a species that is quite constant in coloration and squamation, as is the case with Anolis chloro-cyanus. A remarkably uniform head scalation exists in this species. There may be one or two rows of scales separating the supraorbital semicircles from each other, and three or four small scales separating the occipital plate from the supraorbital semicircle. The loreal rows may be either three or four in number, the former number being about twice as frequently met with. The occipital plate is always small and inconspicuous.

In coloration nearly the same degree of uniformity is found. Occasionally a young lizard will have a fairly broad light dorsal stripe; otherwise head and body are immaculate. The tail often has the median crest scales with alternate light and dark spots, and the sides of the tail have some dark vermiculations as do the legs and arms in certain examples.

The skin of the gular fan is invariably black even in the youngest specimens, and the fan is but little less prominent in females than in males, so that one has to ascertain the presence of enlarged postanal scales in order to be certain of the sex in some cases. The postanal scales are frequently bordered with black posteriorly.

The two lizards from Point-à-Raquettes, Gonave Island, M.C.Z. Nos. 25522 and 25523 , are a little different from their mainland relatives. One of these has larger scales and granules everywhere on the body and limbs than the mainland chloro-cyanus. The snout is not quite so long, and there is but one series of scales between the supraorbital semicircles. The tail becomes suddenly black just behind the anus. The other, the smaller of the two, has also one row of scales between the supraorbital semicircles, as well as larger ventral scales and dorsal granules. Its entire coloration is a very dark purplish drab, and the tail is not darker than the rest of the body. 
I have not yet seen any female specimen that measured over 55 $\mathrm{mm}$. in the combined length of head and body, while the largest male, the specimen described, was $71 \mathrm{~mm}$. A peculiarity of the very young of this species is a median depression between the nostrils, which almost suggests the median groove met with in Anolis distichus dominicensis. This depression becomes less marked in older examples, however, and soon is unnoticeable, since the boundaries of the snout scales are in no way concerned with it.

TABLE 30.-Specimens of Anolis chloro-cyanus examined

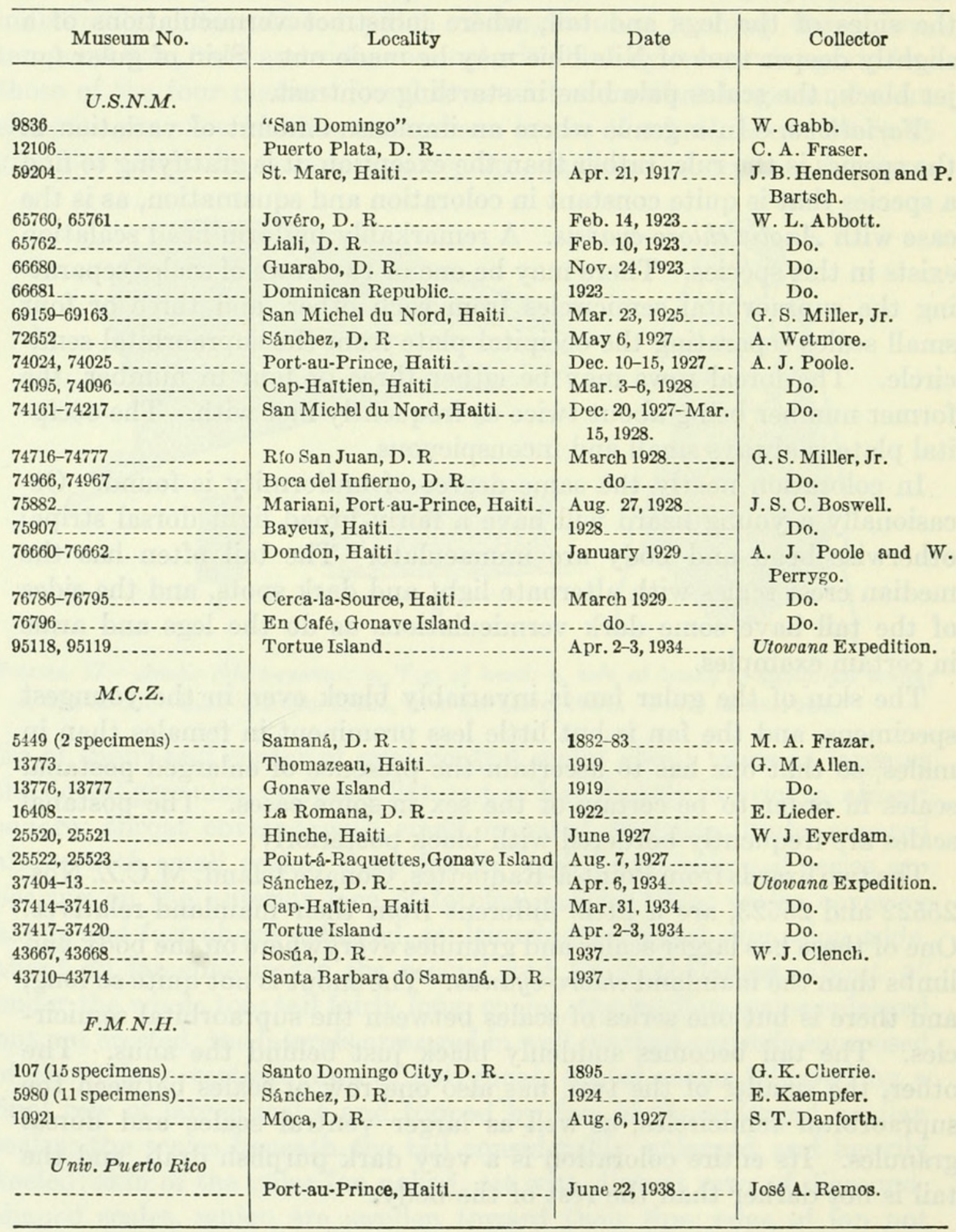


Relationships.-The closest relative of Anolis chloro-cyanus is A. coelestinus, which lives in the western portion of Hispaniola. Their mutual affinities have been dealt with under the discussion of coelestinus.

Specimens examined.-As listed in table 30.

\section{ANOLIS COELESTINUS Cope}

Figure 58

1862. Anolis (Ctenocercus) coelestinus Cope, Proc. Acad. Nat. Sci., Philadelphia, 1862, p. 177 (type locality, near Jérémie, Haiti; type, M.C.Z. No. 1500); Proc. Amer. Philos. Soc., vol. 18, p. 272, 1879 (Port-au-Prince, Haiti; collector, Gabb).-Garman, Bull. Essex Inst., vol. 19, p. 48, 1887 (Tiburon, Haiti).-Cochran, Proc. Biol. Soc. Washington, vol. 41, p. 54, 1928 (Cape Haïtien and Miragoane, Haiti; Grande Cayemite Island); Occ. Pap. Boston Soc. Nat. Hist., vol. 8, p. 168, 1934.-Barbour and Loveridge, Bull. Mus. Comp. Zool., vol. 69, No. 10, p. 217, 1929.-BARbour, Zoologica, vol. 11, No. 4, p. 92, 1930; vol. 19, No. 3, p. 113, 1935; Bull. Mus. Comp. Zool., vol. 82 , No. 2, p. 125, 1937.

1914. Anolis chloro-cyanus Barbour, Mem. Mus. Comp. Zool., vol. 44, p. 295 (not of Duméril and Bibron) (part).
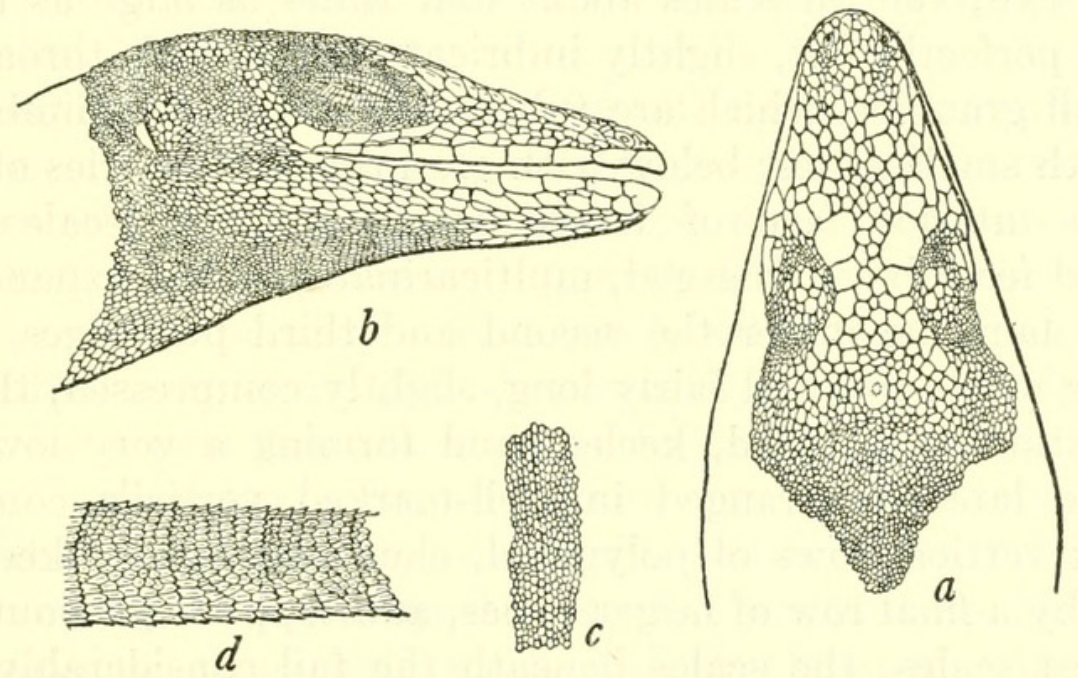

Figure 58.-Anolis coelestinus: $a$, Top of head; $b$, side of head; $c$, middorsal scales; $d$, side of tail. U.S.N.M. No. 59180, from Port-au-Prince, Haiti. Twice natural size.

Description.-An adult male, U.S.N.M. No. 59180, from Port-auPrince, Haiti, collected on April 6, 1917, by J. B. Henderson and Dr. Paul Bartsch. Head elongate, depressed, with rather weakly developed ridges appearing on the snout anterior to the frontal region and with a shallow concavity behind these ridges; head scales diversified in size, the very small ones being found on the median area of the snout, with larger ones approaching the canthus, all of them without keels but some slightly rugose; rostral very low, equal to the mentals in width; five scales between the supranasals; no regular series of scales on the anterior part of the snout; supraorbital semicircles composed of rather irregularly shaped large scales becoming smaller posteriorly, separated from each other by two rows of small scales and 
from the occipital by four very small scales; occipital about the size of the ear opening, conspicuous only because it is surrounded by much smaller scales, polygonal in shape, bordered posteriorly by minute scales which rapidly merge into the dorsal granules; supraocular disk composed of about a dozen unevenly matched flat scales, which are separated from the supraorbital semicircles by one or two series of small scales and from the superciliaries by two or three more or less irregular series; canthus rostralis strongly projecting over the loreal region and covered by six sharply keeled scales succeeded by two others on the superciliary border, the last of this series much the longest and not followed by any differentiated scales; loreal rows five; five scales in the subocular semicircle, the fourth the smallest; nine supralabials, the suture between the eighth and ninth coming directly beneath the center of the eye; temporal granules smaller than the dorsal granules, with an indistinctly differentiated patch of larger ones forming the supratemporal line; back and sides covered with very small, bluntly tubercular granules, about 50 to 55 rows along the dorsolateral region equaling the distance between tip of snout and center of eye; ventral scales about four times as large as the dorsal granules, perfectly flat, slightly imbricate, hexagonal; throat covered with small granules, which are tubercular and ridged; limbs covered above with small scales; below with granules, a few series of enlarged scales on interior face of foreleg and on tibia; scales covering hands and feet above enlarged, multicarinate; digital expansion wide, about 28 lamellae under the second and third phalanges, about 47 under the whole toe; tail fairly long, slightly compressed, the median scales distinctly enlarged, keeled, and forming a very low serrated crest; the laterals arranged in well-marked verticils composed of about six vertical rows of polygonal, elongate, slightly keeled scales followed by a final row of larger scales, and topped by about five subequal crest scales; the scales beneath the tail considerably enlarged and heavily keeled; skin of the gular fan set with numerous minute scales among which are scattered irregularly many small, slightly tubercular scales, not placed in regular rows but much more crowded together on the outer portions of the skin folds; edge of fan not thickened posteriorly; postanal scales very well developed; a very faint indication of a nuchal fold; no dorsal fold.

Dimensions: Head and body, $64 \mathrm{~mm}$; tail, $138 \mathrm{~mm}$.; snout to posterior ear, $20 \mathrm{~mm}$.; snout to center of eye, $12 \mathrm{~mm}$.; width of head, $12.5 \mathrm{~mm}$.; foreleg, $27 \mathrm{~mm}$.; hindleg, $45 \mathrm{~mm}$.

Color (in alcohol): Head Nile blue above, shoulders and back pearl blue with suffusions of heliotrope; limbs and tail heliotrope with bars of pinkish buff especially conspicuous proximally; sides of neck and body with numerous vertical olive-buff reticulations and spots; a wide white stripe originating beneath the eye and continuing 
under the ear and over the shoulder as far as the axilla, where it fades out; throat pale Nile blue; remainder of ventral surface olivebuff, immaculate; fingers and toes faintly ringed with light olivegray; skin of gular fan pale olive-gray, its scales pale Nile blue.

Variations.-There appears to be a somewhat greater degree of variation among the individuals of this species than in its close ally A. chloro-cyanus. In 22 examples of coelestinus that have been examined, the supraorbital semicircles are separated by one row of scales in 7 cases, by two rows in 13 cases, and by three rows in 2 cases. A considerable variation is shown in the number of scales separating the supraorbital semicircles from the occipital, ranging all the way from three to seven, but with three and four most commonly met with. Loreal rows number four to seven, with five found most frequently. Sometimes the ventral scales are entirely smooth as in the individual just described; often they have faint keels, while in a young example from Grande Cayemite Island (M.C.Z. No. 25483 B) they are heavily keeled. Most specimens have the white line below the eye, although it may be faint, as in the type (M.C.Z. No. 3347), or not visible at all, as in the adult from Grande Cayemite (M.C.Z. No. 25483 A).

A young lizard from the Citadel of King Christophe (M.C.Z. No. 25485) showed the following color pattern: Above mottled with d,ark gray and sepia; a light dorsal line with diamond-shaped dark brown patches approaching it from each side at intervals and set off by light posterior margins; a dark scalloped band on the nape of the neck, with a very definite dark posterior margin, which is further accented by a pale tan area directly following it; a butterfly-shaped dark spot across the occipital region; two dark bands across the supraorbital region; top and sides of snout marbled with dark and light; a wide light gray stripe leaving the posterior border of the ear and continuing about halfway to the shoulder, at which point it abruptly ends; a light stripe, issuing from beneath this ending, continues above the shoulders and fades out gradually behind the axilla; limbs marbled with tan and brown; tail dark gray above, rather uniform; under surfaces of arms, legs, and tail pale yellowish white, throat with pale-brown reticulations over it; belly light blue-green, highly iridescent; heavy brown marblings all over lower labials and sides of chin; center of throat with two pale brown stripes marking off each side of where the gular fan later will develop. The newly hatched young from the same locality has traces of these markings. In addition, the light line begins under the eye, and very distinctly passes over the lower half of the ear and above the shoulder, fading out halfway to the groin.

The two examples from Grande Cayemite are high in scale count, each having three rows of scales between the supraorbital semicircles, 
and six loreal rows. Furthermore, the smaller one has seven scales between the occipital and supraorbital semicircles, where three or four ordinarily occur. The white line under the eye is not present at all in the larger example; the smaller has a faint light mark there as the only remaining trace of it. Whether these characters may prove to be fixed enough to separate this as a subspecies distinct from the form found on Haiti itself is a point that only additional material can settle.

TABLE 31.-Specimens of Anolis coelestinus examined

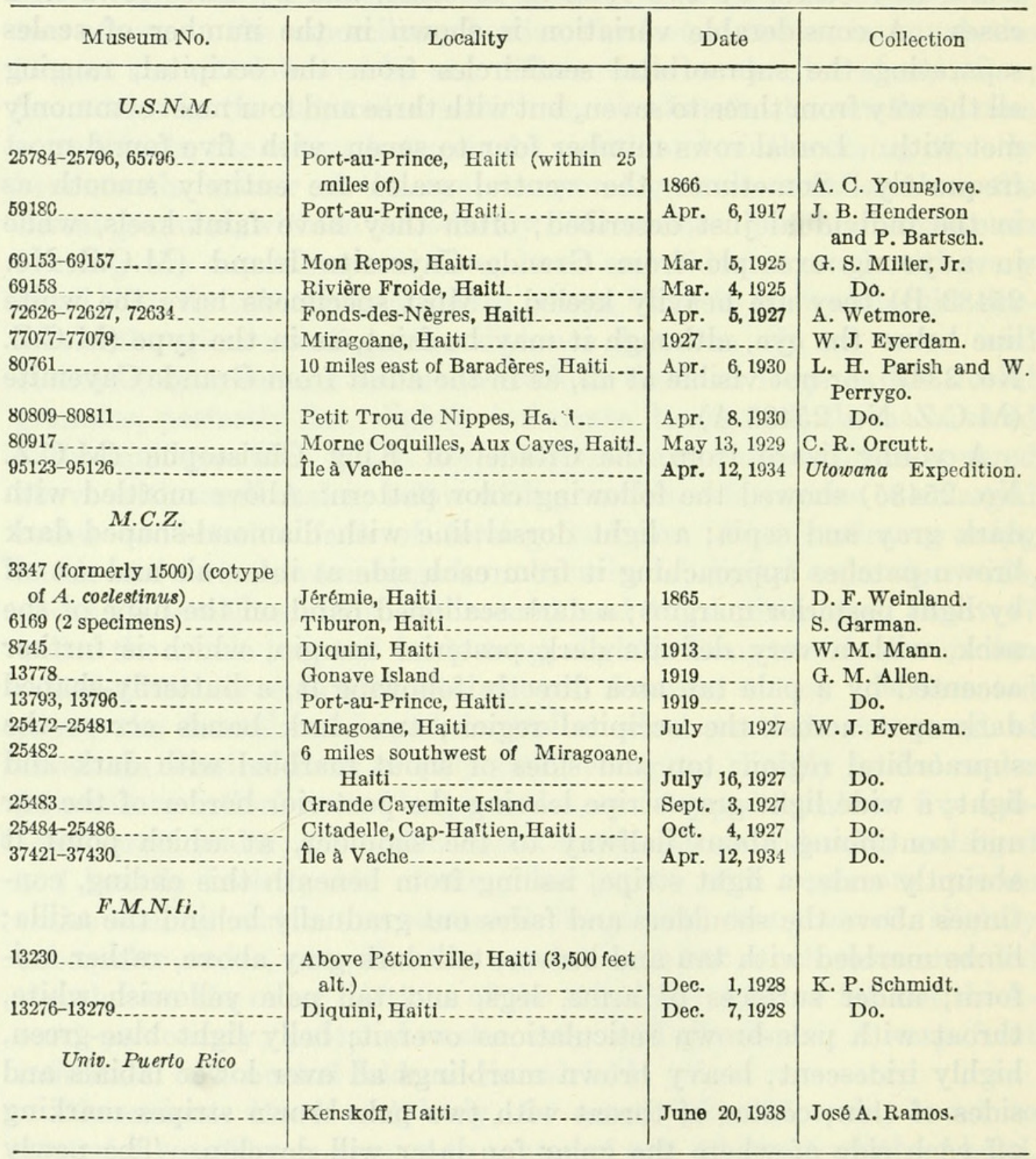

Relationships.-A. coelestinus resembles A. brunneus of the Bahamas in having very minute gular scales. In the head scalation, brunneus, porcatus, and carolinensis all have the distinctly coarser plates of chloro-cyanus, rather than the smaller scales of coelestinus. But neither coelestinus nor chloro-cyanus has the enlarged plates going for- 
ward from the anterior borders of the supraorbital semicircles, which are so characteristic of both porcatus ind brunneus. We therefore must conclude that coelestinus and chloro-cyanus are more closely related to each other than either is to the remaining members of the group.

Specimens examined.-As listed in table 31.

\section{ANOLIS HENDERSONI Cochran}

Figure 59

1923. Anolis hendersoni Cochran, Journ. Washington Acad. Sci., vol. 13, No. 11, p. 225 (type locality, Pétionville, Haiti).-Barbour, Bull. Mus. Comp. Zool., vol. 70, No. 3, p. 127, 1930; Zoologica, vol. 11, No. 4, p. 91, 1930; vol. 19, No. 3, p. 112, 1935; Bull. Mus. Comp. Zool., vol. 82, No. 2, p. 124, 1937.

Description of the type.--U.S.N.M. No. 59210, an adult male from Pétionville, Haiti, collected on Apr. 1, 1917, by J. B. Henderson and Dr. Paul Bartsch. Head elongate, its greatest width contained twice in distance from ear to tip of snout; nostrils lateral, their distance from tip of snout equaling one-sixteenth of head length; top of head with two very low, diverging frontal ridges, reaching nearly to nostrils and enclosing an elongate depression; head scales without keels, except the seven or eight enlarged supraoculars having blunt keels; rostral rather large, its superior border curved; six or seven narrow scales in a row between nostrils; supraorbital semicircles composed of five large scales diminishing in size posteriorly, separated from each other in the median line by a single row of small scales and from supraoculars by one row of very small scales; occipital considerably smaller than ear opening, separated from supraorbital semicircles by about four rows of scales; six elongate scales on canthus rostralis; superciliary ridge consisting of one extremely long shield and some granules; loreal rows six or seven; scales of suborbital semicircles bluntly keeled, broadly in contact with supralabials; six supralabials to a point below center of eye; seven lower labials; one pair of mental shields, wider than the rostral; temporal granules about the size of laterals; a well-marked series of small scales forming the supratemporal line; a distinct dermal fold from occiput to tail, covered by four or five rows of enlarged granular scales, with the median row keeled; the remaining dorsal scales granular; the laterals extremely minute; granules on nuchal region between occiput and shoulders coarse, nearly as large as the largest dorsals; ventral scales moderately large, flat, transversely oblong or pentagonal; scales on throat and breast smaller and slightly keeled; forelegs with small keeled scales above; anterior scales of femur enlarged, keeled, gradually diminishing posteriorly and below; scales covering hands and feet above multicarinate; digital expansion wide, 35 lamellae under fourth toe and 17 under fourth finger; tail long, very slightly compressed, 
without verticils or serrated edge; postanal scales well developed; gular pouch rather small, probably not very extensible; a transverse fold across throat and two others in front of shoulder; hindlimb reaches to front of eye; forelimb reaches three-fourths the distance to groin.

Dimensions: Total length, $174 \mathrm{~mm}$.; tip of snout to vent, $46 \mathrm{~mm}$.; vent to tip of tail, $128 \mathrm{~mm}$.; tip of snout to ear, $16 \mathrm{~mm}$.; tip of snout to center of eye, $10 \mathrm{~mm}$.; width of head, $8 \mathrm{~mm}$.; foreleg, $17 \mathrm{~mm}$.; hindleg, $36 \mathrm{~mm}$.; tibia, $12 \mathrm{~mm}$.; anterior border of nostril to tip of snout, $1 \mathrm{~mm}$.

Color (in alcohol): Top of head and neck drab; a dark lateral streak from rostral, turning to purple behind eye and suddenly narrowing
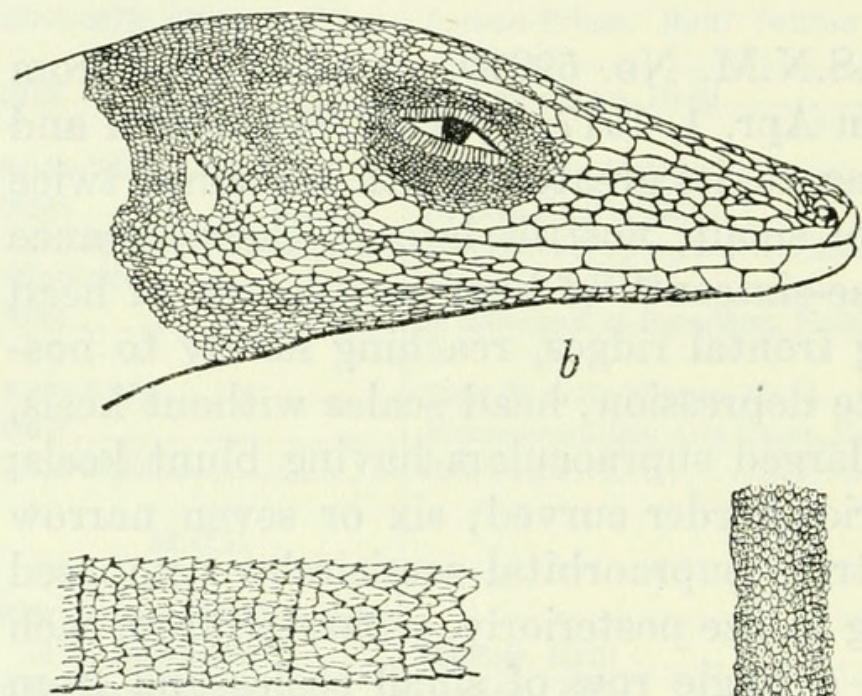

d

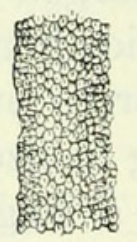

$c$

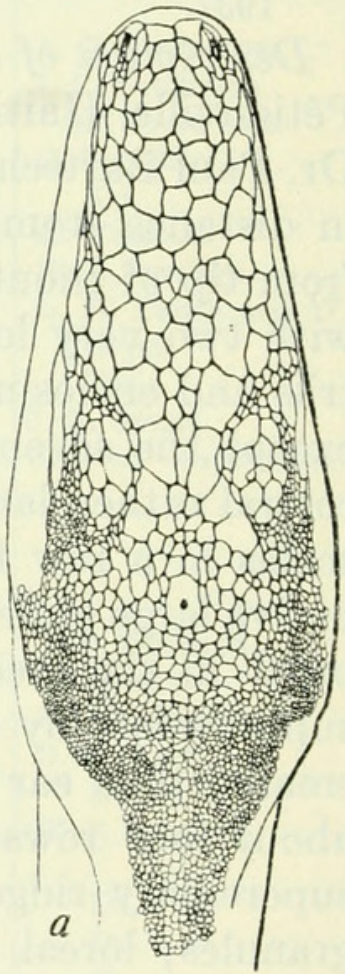

Figure 59.-Anolis hendersoni: $a$, Top of head; $b$, side of head; $c$, middorsal scales; $d$, side of tail. U.S.N.M. No. 59210, type, from Pétionville, Haiti. Three times natural size.

above the shoulder to a black line continuing to groin; the nuchal region between these dark streaks marbled with dark bluish gray to the shoulders, where the marblings suddenly cease, leaving the back and tail a uniform unspotted gray; below the dark lateral streak a sharply defined white stripe beginning on upper lip below eye and continuing backward to hindleg, bordered beneath from axilla to groin by a narrow dark line, the lower edge of which is produced into dark grayish-blue marblings, in which are anastomosing white spots; ventral surface pale blue; the lower labials white flecked with light gray marblings; limbs pale and unspotted, with dusky bands across the digits above. 
Variations.--Since the original description appeared, I have come upon only six additional specimens. In all the females the color pattern is very faint, being darkest in M.C.Z. No. 13794, the largest, where the white lateral line is very distinct to halfway between axilla and groin. The color of the male from Fonds-des-Nègres is similar to that of the type. In two of the females from Port-au-Prince there are two rows of scales separating the supraorbital semicircles; in the other four specimens there is a single row. There are five to seven loreal rows, while 3 or 4 scales separate the supraorbital semicircles from the occipital. The male from Fonds-des-Nègres has 35 lamellae under the fourth toe, 21 of which fall under the second and third phalanges, just as in the type specimen. The same weak development of the gular fan is likewise noticeable in No. 72629. So far as I can judge from the known specimens, the species is very constant in its characters.

Remarks.- $A$. hendersoni has a close ally in A. bahorucoensis, as they are both distinguished by the same elongated head and body. Although at first glance the immaculate dorsum of hendersoni does not suggest an alliance with the heavily banded bahorucoensis, other details of coloration are much more suggestive of the relationship. The lips are spotted in a nearly identical manner. The white lateral line, so striking a feature of hendersoni, is developed in a slighter degree in bahorucoensis. The peculiarly crowded appearance of the scales just behind the mentals, and their extreme convexity which make them appear to be ridged without actually being keeled, is duplicated exactly in both species. Their differences are equally distinct, and set them off in very much the same way that chloro-cyanus and coelestinus are differentiated. The very fine body granules of bahorucoensis and its rather square snout are not to be confused with the coarser body scales and more rounded profile of hendersoni.

While Anolis hendersoni has a superficial resemblance in body build and color to A. pulchellus, a careful comparison reveals little real similarity in details of scalation. The heavy gular fold and the unpaired median snout scales of pulchellus are not characteristic of the Hispaniolan lizard.

The types of the Cuban Anolis alutaceus have been compared with hendersoni, and there is a similarity in the shape of the head and in the bodily proportions. A. alutaceus, however, has a heavier gular fold, wider and smoother canthal scales, no paired median snout scales, a less concave loreal region, a different color pattern, and is distinctly smaller in size, in all of which respects it differs from hendersoni. 
TABLE 32.-Specimens of Anolis hendersoni examined

\begin{tabular}{|c|c|c|c|}
\hline Museum No. & Locality & Date & Collector \\
\hline U.S.N.M. & & & \\
\hline 59210 (type) & Pétionville, Haiti.................. & Apr. 1,1917 & $\begin{array}{l}\text { J. B. Henderson and } \\
\text { P. Bartsch. }\end{array}$ \\
\hline 72629 & Fonds-des-Nègres, Haiti....... & Apr. $\quad 4.1927$ & A. Wetmore. \\
\hline $82586(\uparrow)$ & Aux Cayes, Haiti............... & 1930 & C. R. Orcutt. \\
\hline M.C.Z. & & & \\
\hline $13792,13794,13795,13797$. & Port-au-Prince, Haiti_......... & $1919 \ldots \ldots$ & G. M. Allen. \\
\hline
\end{tabular}

The presence of transverse throat folds in hendersoni leads me to compare it with both species of Deiroptyx from Cuba, but it does not appear to be like them in any other characters.

Specimens examined.-As listed in table 32.

\section{ANOLIS BAHORUCOENSIS Noble and Hassler}

FigURE 47 (143)

1933. Anolis bahorucoensis Noble and Hassler, Amer. Mus. Nov., No. 652, p. 11. 1935. Anolis bohorucoensis Barbour, Zoologica, vol. 19, No. 3, pp. 81, 108; Bull. Mus. Comp. Zool., vol. 82, No. 2, pp. 85, 120, 1937.

Original description.- "Diagnostic Characters.-This species is not closely allied to any other Anolis in Hispaniola. It differs from other slender-bodied Anolis of the Island in being heavier and having a less well-defined band of enlarged scales in the mid-dorsal line of the back. It also differs from these in its smooth ventral scales and in the absence of a dewlap. The very marked sexual dichromatism of the species is another of its distinctive features.

"Detailed Description.-Type: A.M.N.H. No. 51128, adult male. Collected in the Valley of Polo, Barahona Province, D. R., September 14-19, 1932, by W. G. Hassler.

"Habitus slender, body compressed, head elongate with sharp canthus rostralis; greatest diameter of the eyes contained three and one-third times in the distance from tip of snout to eye-slit; distance across the head immediately anterior to the orbits contained twice in the distance between the tip of snout and center of eye; frontal ridges very weak, diverging anterior to the eye and then slightly converging to end immediately behind and medial to the nostril on either side; frontal region slightly concave between these ridges; scales on the upper surface of the head anterior to the orbits smooth, scales on the supraorbital semicircles and of the supraorbital discs keeled. Rostral low, about two and one-half times as wide as high; ventral margin of subnasal scale in contact with rostral, nostrils separated from the rostral by a prenasal scale which is larger than the nostril; prenasals 
separated from one another by a pair of internasals which are slightly larger than either prenasal; a pair of scales immediately behind the internasals, slightly larger than them and making broad contact with them behind and slight contact with one another in the midline; three or four large scales forming the posterior two-thirds of the frontal ridges, these scales two to three times as large as the other scales on the top of the snout which are irregularly polygonal; supraorbital semicircles separated from each other by a single scale at their midpoint and by a wedge of scales immediately before and behind this point; occipital scale about five-sixths as long and three-fourths as broad as the ear opening; occipital scale entirely surrounded by small scales and separated from the supraorbital semicircles by from four to six rows of these small scales; supraorbital discs composed of eight enlarged scales, six of these being much larger than the other two; supraorbital dises separated from the supraorbital semicircles for almost their entire length by a single row of small elongate scales; a single narrow keeled scale longer than the greatest length of the supraorbital disc forming the anterior superciliary margin of the orbit, this scale continuous with a row of seven strongly keeled overlapping scales which form the canthus rostralis of either side; a single enlarged scale mesial to the anterior part of the elongate superciliary scale, this scale separated by two or three rows of small scales from the supraorbital disc; supraorbital region posterior to the elongate superciliary scale and the supraocular disc covered with many small granular scales. Loreal region covered with regular rows of ovoid scales, the rows increasing from two in front to seven immediately before the orbit; subocular semicircles formed of five or six enlarged keeled scales and a series of smaller ones, which form the posterior part of each semicircle; three of these enlarged scales in contact with the supralabials; supralabials 7 or 8 , the sixth and seventh and part of the fifth below the eye. Temporal granules about the same size as those on the sides of the body, distinctly smaller than those along the midline of the back; supratemporal line formed of two to three rows of scales only slightly larger than the adjacent temporals; these supratemporal scales about half or a third as large as the small scales forming the posterior section of the subocular semicircle. A band of from two to four enlarged keeled scales extending the length of the back in the midline; scales on the sides of the body only one-half to one-third as large as the mid-dorsal scales, but gradually increasing in size toward the midline; a very feeble indication of a nuchal fold. Scales on the abdomen smooth, imbricate, two to three times as long and three to four times as broad as the enlarged scales of the mid-dorsal line; scales on the throat ovoid; much smaller on the sides of the throat than near the midline; an average scale near the midline of the throat about onehalf as large as the abdominals; scales on the extreme anterior part of 226849-41- 13 
the throat, that is directly behind the mentals, about twice as long as wide, about two or three times as long as the more posterior throat scales. No dewlap. Upper surface of the fore limbs covered with imbricate keeled scales; under surface of the forearms with smooth scales of approximately the same size; under surface of the upper arm covered with granules; pre-axial surface of the upper leg covered with large scales which are keeled on the upper surface of the limb and smooth on the ventral surface; post-axial surfaces of the upper limb covered with granules; lower leg covered with small keeled scales above and much larger smooth or slightly keeled scales on the ventral surface. Digits of fore limb with relatively smaller enlargements than occur in the hind limb; seventeen lamellae under the fourth finger; thirty-four lamellae under the fourth toe. Tail very slender, approximately two and one-half times as long as the distance from snout to vent; tail only slightly compressed and with a barely differentiated crest; in the center section of the tail the scales on this crest only one-third to one-fourth larger than the scales on the side; about six vertical scale-rows on the side of the tail between one cleavage groove and the next; two enlarged post-anal plates.

"Ground tone of the dorsal surface (in alcohol) a slate gray; four broad bars of reddish brown extending across the back between the fore and hind limbs, each bar edged with very dark brown; an oval spot of gray marking each cross-bar at its intersection of the middorsal line; the lower sides of the body dark brown spotted with gray or white; some ill-defined grayish spots on the neck and back of the head, the most conspicuous of these forming a semicircular bar behind the orbit; upper and lower eyelids white; legs and tail brownish gray above and on the sides feebly cross-barred or blotched dark brown and white; ventral surface of the throat and abdomen white suffused with gray on the lower jaw and posterior part of the throat; under surfaces of the appendages white tinged with brown, especially on the posterior limbs.

"Dimensions.-Head and body, $46.5 \mathrm{~mm}$.; tail, $113.5 \mathrm{~mm}$.; snout to posterior edge of ear, $15.5 \mathrm{~mm}$.; snout to center of eye, $10.5 \mathrm{~mm}$.; width of head, $8 \mathrm{~mm}$.; foreleg to base of toes, $14 \mathrm{~mm}$.; hindleg to base of third and fourth toe, $29 \mathrm{~mm}$.

"VARIATION.-The seventy-five paratypes (A.M.N.H. Nos. 51081$127,51129-56$ ) show marked sexual dichromatism. Thirty-four are males, thirty-nine are females, and two are sexually immature. The males are uniformly cross-barred but the females show variations of a longitudinal striping or an approach toward the cross-bars but never the complete broad saddles of the males. In some of the males these cross-bars are not interrupted on the mid-dorsal line as in the type. The females are more uniformly brown in tone and in life do not show the vivid green of the males. In some females the junction of the 
lighter color of the back and the dark of the sides forms nearly straight dorsolateral lines. In others these dorsolateral lines are wavy and in a few the dark brown extends up from the sides at intervals and very nearly reaches the center of the back, or does so in a few places.

"The females do not attain the size of the males, the longest one in the collection measuring $41 \mathrm{~mm}$. from snout to vent as against $49 \mathrm{~mm}$., the longest male. Moreover, the head is proportionately shorter in the females. Usually the females are distinguished from the males by the absence of the two enlarged scales just posterior to the vent on the under surface of the tail. Some females, such as A.M.N.H. No. 51114, verified by dissection as to sex, may have a pair of large post-anal scales but these are not so well developed as in adult males. In the majority of females, however, these enlarged scales are either entirely lacking or are very small.

"In life, the male is an extremely beautiful lizard. In its usual and brightest phase the dorsal surface of the head is an olive-green; the neck a lighter green, spotted with brown. The back is a bluer green while the four broad saddles or cross-bars are a tone of burnt umber. The dorsal surface of the tail, for the anterior two-thirds, is a yellowish green with several dark brown bars. The posterior end of the tail is brown. The side of the head is greenish brown back to the eye. The upper eyelid may be a vivid golden yellow. The posterior corner of the lower lid may be blue or purplish. Just posterior to the eye is a narrow patch of dark brown, followed by a crescent of light blue or white. Posterior to this the side of the head is a brownish green merging into the lighter green of the side of the body which is peppered and veined with brown. Extending from a point on the upper labials anterior to the eye along the sides of the body nearly to the hind leg is a slightly broken white or cream-colored line edged with brown and suffused in the region over the front leg with yellowish green. The legs are light brown above with slightly darker bars. They are nearly white beneath. The ventral surface of the abdomen is cream-colored, faintly tinted with brown and green. The throat is the same color with several rows of very faint brown spots along the sides.

"This species changes color rapidly and to a marked degree. When the lizard is caught or frightened these colors may almost instantly become darker, the green changing to gray or dark brown with the brown cross-bars growing darker and almost black edged. The head becomes dark brown and the labials greenish. The pineal region becomes white and very conspicuous. The ventral surfaces turn green ish or yellowish and the spots become more distinct."

A paratype, A.M.N.H. No. 51107, was compared with the type of $A$. hendersoni, the very close relationship of the two species being apparent in their similar head and body proportions and in such details as the scales under the chin, which are highly convex and crowded 
together in both species, and in the presence of a lateral light line and other peculiarities. They differ in the much finer body granules of bahorucoensis, as well as in its squarer snout and in the possession of the dark dorsal saddles.

This paratype has a slight longitudinal gular fold and very weak indications of some transverse folds. The tail verticils are poorly marked but seem to have about five scales on top and eight very irregular rows directly below, decreasing to six rows laterally.

\section{Genus AUDANTIA Cochran}

1934. Audantia Cochran, Occ. Pap. Boston Soc. Nat. Hist., vol. 8, p. 171 (type, A. armouri).

Diagnosis.-Femoral pores absent; digits dilated and depressed, with smooth transverse lamellae inferiorly, the distal joint narrower and compressed, raised above the penultimate; lateral teeth tricuspid; tail apparently not prehensile, compressed; tympanum distinct; body distinctly depressed, covered with small keeled granules above and with imbricate smooth scales below; no nuchal or dorsal crests and only a very slight serration on the tail. Male with both a transverse and a longitudinal gular fold; the transverse fold sometimes rather indistinct in preserved specimens; the short longitudinal fold often prominent, obscuring somewhat the presence of the transverse fold; sides of neck much wrinkled, with a transverse fold extending downward in front of the shoulders. The genus is named for its collector, André Audant, zoologist at the Government Agricultural School at Damien.

KEY TO AUDANTIA

No enlarged nuchal scales_......................... 188)

A patch of distinctly enlarged nuchals

shrevei (p. 192)

\section{AUDANTIA ARMOURI Cochran}

Figure 60

1934. Audantia armouri Cochran, Occ. Pap. Boston Soc. Nat. Hist., vol. 8, p. 171.-Barbour, Bull. Mus. Comp. Zool., vol. 82, No. 2, p. 117, 1937.

Type.-M. C. Z. No. 37523, an adult male from Peak La Selle, Haiti; collector, André Audant.

Original description of type.- "Head relatively short and blunt, the distance from anterior corner of eye to tip of snout slightly more than one-half the greatest width of the head (just anterior to the ears); canthus rostralis sharp, composed of three or four keeled scales of which the second is considerably enlarged, the last merging indistinguishably into the superciliary ridge which has two very elongate scales followed posteriorly by a double row of much smaller ones; loreal region slightly concave, with six transverse rows of keeled, 
rectangular scales, the lowest one continued backwards, completely separating the suboculars from the upper labials; nostrils lateral, somewhat elevated, with four rugose scales between the supranasals; rostral nearly four times as broad as deep, a little narrower than the mentals, incompletely separated from the nasal scales by a row of small scales; frontal region with broad low ridges covered with large, nearly smooth, rhomboidal scales which converge anteriorly and surround a median group of six smaller, very unequal scales; scales of the frontal ridges continuous posteriorly with those of the supraorbital semicircles which are in contact; supraorbital region covered with three longitudinal rows of keeled scales, the inner (largest) row incompletely separated from the supraorbital semicircles by a partial row of small scales, the outer (smallest) row
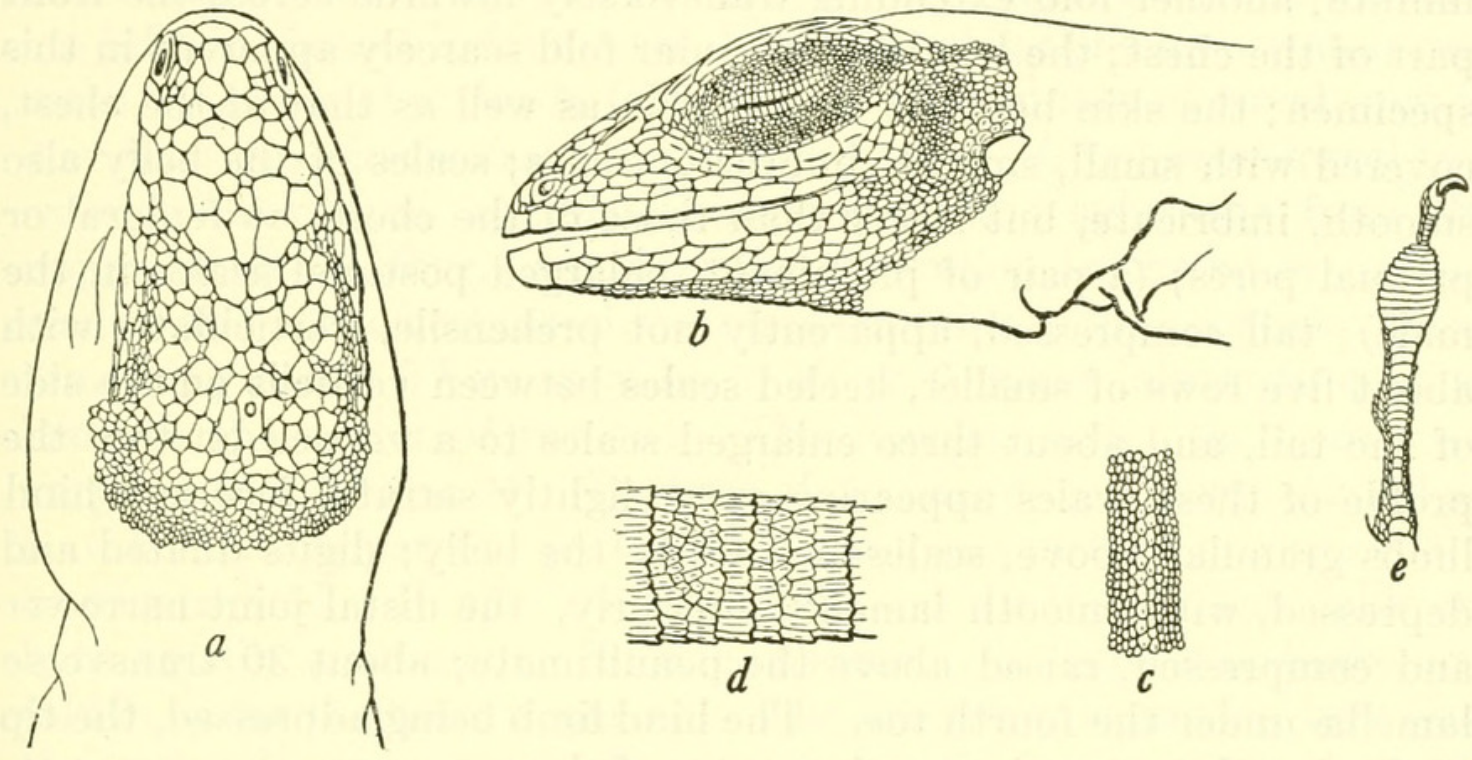

Figure 60.-Audartia armouri: $a$, Top of head; $b$, side of head; $c$, middorsal scales; $d$, side of tail; $e$, lower surface of fourth toe. M.C.Z. No. 37523, type, from Peak La Selle, Haiti. Three times natural size.

separated from the superciliaries by two or three rows of granular scales; occipital scale moderate in size, separated from the supraorbital semicircles by two scales; eight supralabial scales, each with a deep longitudinal median groove bordered below by a sharp keel in all except the two anterior ones; suture between sixth and seventh supralabial below center of eye; subocular semicircle composed of eight or nine keeled scales, separated from the supralabials by one row of elongate, keeled scales; a pair of triangular mentals closely in contact medially, their outer borders extending slightly beyond those of the rostral; eight or nine smooth infralabials, the first six subequal, the last ones quite small; a row of malar scales, quite distinct anteriorly where they border the mental and infralabials, becoming indistinct posteriorly and merging with the other rows of scales which border the posterior infralabials; temporal region granu- 
lar; a weak lateral ridge extending from the posterior corner of the eye, covered with a double row of hexagonal scales, some of which are keeled; a group of enlarged, keeled scales in front of the tympanum, which is equal to half the eye-opening at its greatest diameter; no projecting scales on the tympanic border.

"Body stout, distinctly depressed, its dorsal surface covered with tubercular granules with the two middorsal rows enlarged and keeled from the shoulder-level almost to that of the groin; no nuchal or dorsal folds; laterals granular, very small, not differentiated from the dorsolaterals; chin covered with rounded granules, large anteriorly, becoming much smaller posteriorly; a heavy gular fold running across the throat and behind the ears and ending in front of the shoulders in numerous heavy, plicate wrinkles, in which the granules are very minute; another fold extending transversely inwards across the front part of the chest; the longitudinal gular fold scarcely apparent in this specimen; the skin between these folds, as well as that of the chest, covered with small, smooth, imbricate scales; scales of the belly also smooth, imbricate, but larger than those of the chest; no femoral or preanal pores; (a pair of prominent, enlarged postanal scales in the male); tail compressed, apparently not prehensile, verticillate, with about five rows of smaller, keeled scales between verticils on the side of the tail, and about three enlarged scales to a verticil on top, the profile of these scales appearing very slightly serrate; fore and hind limbs granular above, scales below like the belly; digits dilated and depressed, with smooth lamellæ inferiorly, the distal joint narrower and compressed, raised above the penultimate; about 30 transverse lamellæ under the fourth toe. The hind limb being adpressed, the tip of the fourth toe reaches to the center of the eye.

"Dimensions.-Snout to vent, $46 \mathrm{~mm}$.; tail (reproduced), $43 \mathrm{~mm}$.; hindleg, $37 \mathrm{~mm}$.; foreleg, $23 \mathrm{~mm}$.; width of body, $14 \mathrm{~mm}$.; depth of body, $10 \mathrm{~mm}$.; width of head, $10 \mathrm{~mm}$.; snout to posterior border of tympanum, $14 \mathrm{~mm}$.

"Coloration in alcohol.-Upper surfaces darp sepia, with a paler sepia area along the mid-dorsal region; a waxy clove brown band beginning behind the eyes and running upwards and backwards to fade out at the pale sepia area on the nuchal region; a pair of small clove brown spots anterior to them on the nape; four pairs of large, irregular, rhombic clove brown spots on the body, the anterior pair the most irregular in outline, the others larger and more definite; a continuation of these paired spots on the tail for a short distance; dark crossbars on upper surfaces of fore and hind limbs; labial scales with a brown spot in the middle of each; throat and ventral surfaces heavily mottled with light and dark drab; scales between the folds across the throat dull burnt umber; a wide band of black turning posteriorly to indigo blue across the anterior half of the belly; lower surfaces of tail dark drab. 
"Paratypes.-Another example of this interesting new form, M.C.Z. 37524 , accompanied the type specimen, having been given to Dr. Barbour by Monsieur Audant. Two additional specimens, which are the property of the museum at the Agricultural School at Portau-Prince, have recently been sent to me by M. Audant for examination. In 1927 Dr. A. Wetmore secured four which unfortunately reached the National Museum in poor condition. These are U.S.N.M. 72593-4 from the head of Rivière Chotard, and U.S.N.M. 72598-9 from Morne Cabaio, both localities in Massif de la Selle. An immature individual, now U.S.N.M. 85008, was taken also on Morne La Selle at 7,000 feet by Lt. Comdr. S. S. Cook in 1932.

"Variation.-With a series now numbering nine individuals, some attention may by given to variation. The keeling of the supraocular disks may be distinct, faint or absent. The supraorbital semicircles are fully in contact in four cases, barely touching in one case and separated by a row of scales in four cases. The number of loreal rows is 4 in one case, 5 in six cases, and 6 in two cases. The lowest loreal row extends backwards, completely separating the subocular from the upper labials in four examples; the separation is partial in one instance, and the lowest loreal row stops anterior to the subocular in the remaining four. There may be $5,5 \frac{1}{2}$ or 6 upper labials to a point beneath the center of the eye. The lamellæ under the fourth toe vary between 27 and 31 . In three of the lizards the longitudinal fold is the more apparent, partly or almost completely obscuring the transverse fold. In one, the transverse and the longitudinal folds are both equally prominent. In one specimen, the type, the transverse fold is by far the more apparent. The other four examples, including the two males, were too badly preserved in the region of the throat to show any characters there. The degree to which either the longitudinal or the transverse fold shows apparently depends a great deal on the preservation.

"The two males (U.S.N.M. 72593 and 72594), having a pair of prominent, enlarged postanals, measure $44 \mathrm{~mm}$. and $59 \mathrm{~mm}$. respectively from snout to vent. The five females are between $43 \mathrm{~mm}$. and $50 \mathrm{~mm}$.; while the two young specimens without enlarged postanals (U.S.N.M. 72599 and 85008 ) are $36 \mathrm{~mm}$. and $37 \mathrm{~mm}$. respectively from snout to vent.

"The verticils on the tail are only slightly apparent in any of the specimens. Each verticil is composed of a straight vertical row of somewhat enlarged and more regular scales, preceded by four or five very irregular curving and sometimes incomplete rows of scales.

"The four transverse sets of two or three dark rhombic or quadrangular spots on each side of the mid-dorsal region are evident in most of the specimens. In two, the spots are reduced to several narrow, elongate, dumbbell-shaped marks which join across the back, 
with the wide light dorsal stripe very apparent. In one young example, U.S.N.M. 72599, the light dorsal stripe is bordered on each side by two dark stripes which do not yet show a tendency to break up into rhombs or squares.

"Relationships.-While the possession of dilated toes allies the new genus indisputably to Anolis and its close relatives, the squat flattened body and the wrinkles on the side of the neck suggest at first glance a Leiocephalus or a Plica, to neither of which genera can Audantia be truly closely related. The possession of the transverse gular folds might suggest a closer correlation to Deiroptyx, but as a matter of fact these two genera do not resemble one another closely when actually seen together.

"In body build, as well as somewhat in coloration, Audantia armouri is slightly suggestive of Anolis cybotes cybotes also of Hispaniola, but there the resemblance ends, for the well-developed longitudinal gular. fold of the latter, as well as its distinctly verticillate tail and many other details, separate them readily.

"Audantia is the third new genus of lizard to be described from Haiti in the past seven years, and one of the two others (Wetmorena) also came from Massif de la Selle."

Specimens examined.-As listed in table 33.

TABLE 33.-Specimens of Audantia armouri examined

\begin{tabular}{|c|c|c|c|}
\hline Museum No. & Locality & Date & Collector \\
\hline \multicolumn{4}{|l|}{ U.S.N.M. } \\
\hline 72593,72591 (paratypes) & $\begin{array}{l}\text { Massif de la Selle, Haiti (head } \\
\text { of Rivière Chotard). }\end{array}$ & Apr. $12,1927 \ldots$. & A. Wetmore. \\
\hline 72598,72599 (paratypes) ... & $\begin{array}{l}\text { Massif de la Selle, Haiti (Morne } \\
\text { Cabaio). }\end{array}$ & Apr. $10,1927 \ldots$. & Do. \\
\hline 85008 (paratype) .. & $\begin{array}{l}\text { Morne La Selle (7,000 feet), } \\
\text { Haiti. }\end{array}$ & $1932 \ldots$ & S. S. Cook. \\
\hline 95253 & Peak La Selle, Haiti. . . . & Aug. $30,1933 \ldots$ & A. Audant. \\
\hline $95431,95432 \ldots \ldots$ & La Visite, La Selle Range, Haiti & Sept. $16-23,1934$ & P. J. Darlington. \\
\hline 109173,109174 & Mount Bourette, Furcy, Haiti.. & Mar. 23,1940 & G. E. Folk, Jr. \\
\hline $109175,109176 \ldots$ & Kenskoff, Haiti & Mar. 29,1940 & Do. \\
\hline 109177 & Pétionville, Haiti ................... & Mar. $30,1940 \ldots$ & Do. \\
\hline M.C.Z. & & & \\
\hline $\begin{array}{l}37523 \text { (type), } 37524 \text { (para- } \\
\text { type). }\end{array}$ & Peak La Selle, Haiti. .............. & & A. Audant. \\
\hline
\end{tabular}

\section{AUDANTIA SHREVEI Cochran}

Figure 61

1939. Audantia shrevei Cochran, Proc. New England Zool. Club, vol. 18, p. 2.

Diagnosis.-Resembles Audantia armouri, but having a large nuchal patch of enlarged keeled scales, having a darker and more uniform coloration, and attaining a larger adult size; frontal scales keeled. 
Description of the type.-An adult male, M.C.Z. No. 44365, from Valle Nuevo, in the Cordillera Central, southeast of Constanza, Dominican Republic, at 6,000 to 8,000 feet elevation, collected in August 1938 by P. J. Darlington. Head short and blunt, the distance from anterior corner of eye to tip of snout slightly more than one-half the greatest width of the head (just anterior to the ears); canthus rostralis sharp, composed of three keeled scales, the second slightly the largest; two narrow superciliaries, the first very long, the second short and followed by a double row of small elongate scales; loreal region slightly concave, with five transverse rows of keeled rectangular scales, the lowest row continued backward, completely separating the suboculars from the upper labials; nostrils lateral, scarcely elevated, with six keeled scales between the nasals; rostral about $2 \frac{1}{2}$ times as broad as deep, a little narrower than the mentals, in contact with the nasals; frontal region with two broad, low ridges covered with large
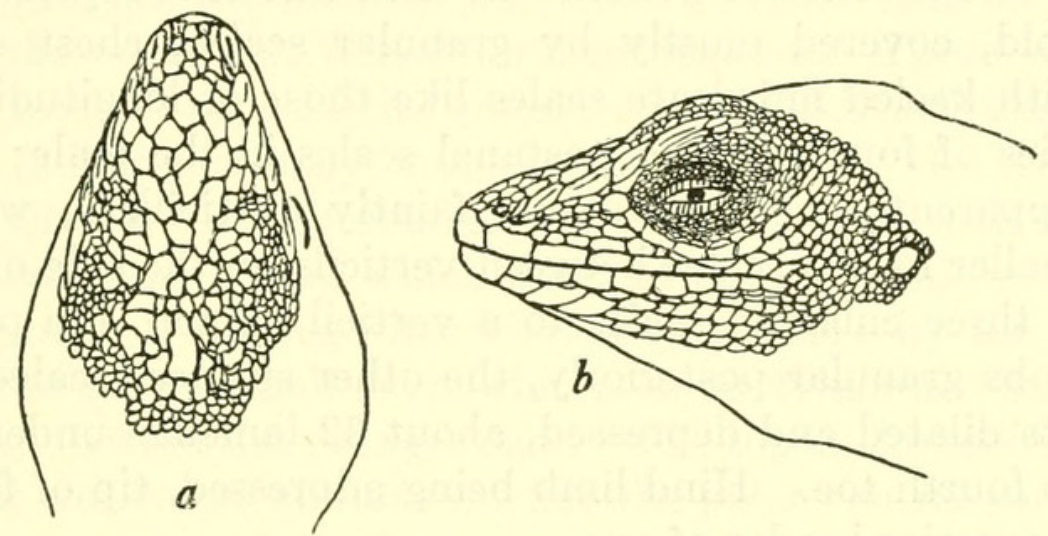

Figure 61.-Audantia shrevei: $a$, Top of head; $b$, profile of head. U.S.N.M. No. 107558, paratype, from Valle Nuevo, southeast of Constanza, Dominican Republic. Twice natural size.

keeled rhomboidal scales converging anteriorly and surrounding a median group of six subequal keeled scales; supraorbital semicircles separated by one row of scales; supraocular region covered by a patch of enlarged keeled scales arranged more or less in three longitudinal rows, the outer (smallest) row separated from the superciliaries by three rows of very small scales, the inner (largest) from the supraorbital semicircle by one row of scales; occipital scale quite small, separated from the semicircles by two rows of scales; eight supralabials, the posterior ones with a faint longitudinal keel, suture between sixth and seventh falling below center of eye; subocular semicircle composed of six or seven keeled scales, separated from the supralabials by one row of very elongate, keeled scales; a pair of triangular mentals closely in contact medially, their outer borders extending slightly beyond those of rostral; eight infralabials decreasing in size posteriorly, smooth except for a deep hollow in the median ones; one large and two or three smaller rows of malar scales, very distinct where they border 
the mental and infralabials, merging with the other throat scales posteriorly; temporal region with tubercular keeled scales; a series of very apparent folds on the side of the neck and in front of the shoulder, continuing downward to the gular fold and backward along the side to the groin, not covered by differentiated scales; scales in front of tympanum tubercular and slightly keeled, but not projecting; tympanum nearly as large as eye opening.

Body moderately stout, not depressed, its dorsal surface covered with tubercles intermingled with very minute granules, the five or six dorsal rows enlarged into imbricate, keeled scales; a very definite nuchal patch of enlarged keeled scales about 15 scales long by 17 wide, the row on each side of the midline a little smaller; a slight nuchal ridge diminishing on the body; laterals granular, small, not differentiated from the dorsolaterals; chin covered with elongate keeled scales in regular longitudinal rows; a very pronounced longitudinal gular fold, and a series of wrinkles on each side of it representing the traverse fold, covered mostly by granular scales; chest and belly covered with keeled imbricate scales like those of longitudinal gular fold; a series of four enlarged postanal scales in the male; tail compressed, apparently not prehensile, faintly verticillate, with three rows of smaller keeled scales between verticils on the side of the tail, and about three enlarged scales to a verticil on top, the profile not serrate; limbs granular posteriorly, the other surfaces scaled like the belly; digits dilated and depressed, about 32 lamellae under the free part of the fourth toe. Hind limb being adpressed, tip of fourth toe reaches to anterior border of eye.

Dimensions: Snout to vent, $58 \mathrm{~mm}$; tail, $116 \mathrm{~mm}$; hindleg, 49 mm.; foreleg, $27 \mathrm{~mm}$.; width of body, $13 \mathrm{~mm}$.; depth of body, $13 \mathrm{~mm}$.; width of head, $14 \mathrm{~mm}$; snout to posterior border of tympanum, $19 \mathrm{~mm}$.

Color (in alcohol): Entire upper surfaces uniform slate-black; ventral surfaces light drab, with a very heavy, uniform powdering of slate-gray on all the scales.

Paratypes.-M.C.Z. Nos. 44366 and 44367 and U.S.N.M. No. 107558, from the same locality as the type; M.C.Z. No. 44373 and U.S.N.M. No. 107563, from Loma Rucilla, altitude 8,000 to 10,000 feet, collected in June 1938 by P. J. Darlington; M.C.Z. Nos. 4436844372 and U.S.N.M. Nos. 107559-107561, from Loma Pelona (near Loma Rucilla), June 1938, P. J. Darlington.

Variations.-In the paratypes the number of scales between the nasals is five to seven, subequal or with the median scales much smaller, as in U.S.N.M. No. 107558. The loreal rows are three in number, with a single scale representing a fourth "row" as in U.S.N.M. No. 107560 , or with four or five distinct rows and one or two additional scales below the canthus. The frontal group of scales between the 
anterior extensions of the supraorbital semicircles are 4 to 13 , with a single row of scales usually separating the semicircles between the eyes and with narrow contact between them in two cases. The occipital is usually separated from the semicircles by two scales, rarely by one or three irregular ones. Supralabials number six to nine, with the fifth to the eighth coming under the center of the eye. Infralabials are six to nine also, but the posterior ones are often very small. Malar scales are usually in three subequal rows, sometimes in four. The tail has four vertical rows between verticils as a rule, but sometimes there are five rows in the proximal region, and in one instance only three. Lamellae under the free part of the fourth toe are between 23 and 30 . The largest male is the type, with a length of $58 \mathrm{~mm}$.; the largest female is $50 \mathrm{~mm}$. long. Most of the larger ones are completely black above, without traces of the original pattern. The younger ones may have four wide longitudinal sepia stripes on a slate-gray ground, the median pair close together near the center of the back, the outer pair dorsolateral in position. There is a narrow slate-gray lateral stripe of the ground color, and below this the sides are sepia, fading gradually into the ventral color. In some of the specimens the dark longitudinal stripes are broken up with still darker irregular transverse spots, which descend on the sides wherever the sepia color occurs, although interrupted completely by the slate-gray stripes. The anterior half of the chin is squarely marked off with pale slate-gray in most of the younger ones. The top of the head frequently shows dark transverse markings, while the paler ventral surfaces may be heavily spotted with dark.

\section{Genus CYCLURA Harlan}

1824. Cyclura Hartan, Journ. Acad. Nat. Hist. Philadelphia, vol. 4, p. 250 (type, C. carinata).

Hispaniola and its outlying islets support two species of ring-tailed iguana. These may be distinguished by the following characters:

Snout with conspicuously enlarged conical tubercles_..._._cornuta (p. 195) No conspicuously enlarged scales on snout ricordii (p. 199)

\section{CYClURA CORNUTA CORNUTA (Bonnaterre)}

\section{Figure 62}

1789. Lacerta cornuta Bonnaterne, Tableau encyclopédique et méthodique des trois règnes de la nature . . Erpétologie, p. 40, pl. 4, fig. 4 (type locality, “dans les mornes de l'hôpital, entre l'Artibonite et les Gonaives," Santo Domingo [now Haiti]).-Bechstein, Herrn De La Cepede's Naturgeschichte der Amphibien . . . , vol. 1, p. 499, 1801.

1789. Iguana cornuta LAĆ́PÈDE, Histoire naturelle des quadrupèdes ovipares et des serpents, vol. 2, p. 493.-DAUDin, Histoire naturelle générale . . de des reptiles, vol. 3 , p. 282, 1802.-Latreille, Histoire naturelle des reptiles . . . , vol. 2 , p. 267,1801 . 
1830. Metopoceros cornutus WAgLer, Natürliches System der Amphibien . . . , p. 147.-Wiegmann, Herpetologia Mexicana . . . , vol. 1, p. 16, 1834.Duméril and Bibron, Erpétologie générale, vol. 4, p. 211, 1837.-Gray Catalogue of the specimens of lizards in the collection of the British Museum, p. 188, 1845.-Cope, Proc. Acad. Nat. Sci. Philadelphia, vol. 18, p. 124, 1866 (part); Amer. Nat., vol. 19, p. 1006, 1885.-GüNTher, Trans. Zool. Soc. London, vol. 11, p. 218, pls. 43, 44, 1882.-Boulenger, Catalogue of the specimens of lizards in the collection of the British Museum, ed. 2, vol. 2, p. 188, 1885 (part).-Fischer, Jahrb. Hamburg Wiss. Anst., vol. 5, p. 24, 1888.Müller, Verh. Naturf. Ges. Basel, vol. 10, pt. 1, p. 211, 1892.-Boettger, Katalog der Batrachier-Sammlung im Museum der Senckenbergischen naturforschenden Gesellschaft in Frankfurt am Main, pt. 1, p. 63, 1893.Meerwarth, Mitth. Naturh. Mus. Hamburg, vol. 18, p. 26, 1901 (part).

1843. Hypsilophus (Metopoceros) cornutus Fitzinger, Systema reptilium, p. 54. 1886. Cyclura cornuta Cope, Proc. Amer. Philos. Soc., vol. 23, p. 263.-Garman, Bull. Essex Inst., vol. 19, p. 50, extr. p. 26, 1887 (part, Jérémie).-STtejneGer, Rep. U. S. Nat. Mus. for 1902 p. 670, 1904.-Barbour, Bull. Mus. Comp. Zool., vol. 44, No. 2, p. 299, 1914 (part); Zoologica, vol. 11, No. 4, p. 96,1930 ; vol. 19 , No. 3, p. 118, 1935.-Barbour and Noble, Bull. Mus. Comp. Zool., vol. 60, No. 4, p. 160, pl. 10, 1916.-Cochran, Proc. U. S. Nat. Mus., vol. 66, art. 6, p. 8, 1924; Proc. Biol. Soc. Washington, vol. 41, p. 54, 1928.

1937. Cyclura cornuta cornuta Barbour, Bull. Mus. Comp. Zool., vol. 82, No. 2, p. 132.-Mertens, Senckenbergiana, vol. 20, No. 5, p. 337, 1938; Publ. Inst. Cient. Domínico-Alemán, vol. 1, p. 88, 1939.-Böкer, Publ. Inst. Cient. Domínico-Alemán, vol. 1, p. 18, 1939.

Description.-U.S.N.M. No. 82107, a half-grown individual collected on Petite Gonave Island by Lee H. Parish and Watson Perrygo in May 1930. Rostral twice as wide as high, as wide as mental, narrowly separated from the nasals by a single row of small scales; nasal large, irregularly rhomboidal, slightly wider than high, perforated by an ovoid nostril equal in width to three-fourths the height of the rostral; no postnasals; nasals separated from each other by two or three rows of scales; two pairs of conical hornlike prefrontal scales, the anterior in contact with the nasal; a median conical frontal enlarged into a horn, and separated from the posterior prefrontal by two rows of small scales; the remainder of the top of the head covered by smaller scales, which are all heavily keeled; a well-marked supraorbital semicircle composed of larger polygonal scales separated from its fellow by about five rows of smaller scales; directly bordering this semicircle a patch of enlarged supraocular scales, which grade into very small scales just before reaching the superciliary border; occipital region swollen and elevated above the surrounding region; length of occipital scale nearly equaling height of rostral, separated from the posterior portion of the supraorbital semicircles by three rows of small scales; a series of suboculars continued backward to the anterior border of the ear, bluntly tubercular and most prominent under the posterior half of the eye; the remaining scales between eye and ear exceedingly small, except for a large conical tubercle and two smaller ones just 
above the commissure of the jaws; eight or nine supralabials to a point below the center of the eye, the last ones hornlike, the anterior ones quite smooth; tympanum elliptical, erect, large; eight lower labials to the center of the eye, the posterior ones bluntly ridged and swollen; a series of enlarged malar scales, the posterior ones swollen and heavily ridged and separated from the lower labials by one (anteriorly) to five (posteriorly) rows of scales mostly of very small size; dorsal and ventral scales rhomboidal, obliquely keeled, the keels pointing toward the median line; dorsal scales very small, about 60 scales measured posteriorly from the axilla contained in the distance from end of snout to anterior edge of tympanum; ventral scales slightly larger than dorsals but less heavily keeled; from the occiput along the median line of the body and tail a series of enlarged scales
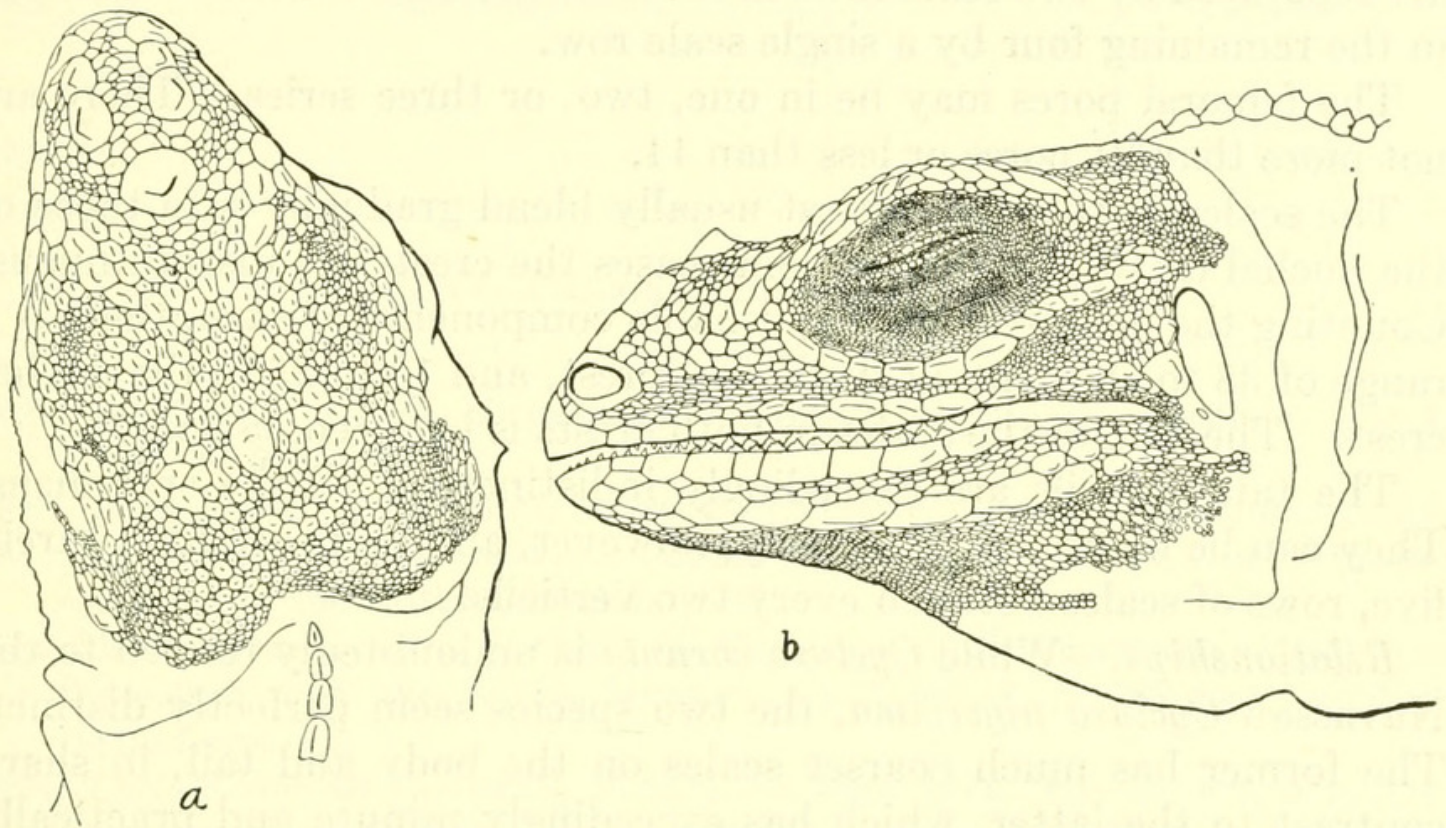

Figure 62.-Cyclura cornuta cornuta: $a$, Top of head; $b$, side of head. U.S.N.M. No. 82107, from Petite Gonave Island, Haiti. Natural size.

forming a high serrated crest, which is greatly reduced on the neck and on the rump; scales of the caudal crest somewhat larger and heavier than the others; about 21 scales in the nuchal and 48 in the dorsal portions of the crest; throat covered with scales smaller and smoother than the ventrals; sides of neck with numerous folds; a large longitudinal gular fold, with a smaller transverse fold behind it; a rather weakly developed lateral fold; upper surfaces of forelimbs and hindlimbs with slightly imbricate keeled scales much larger than the dorsals, on the lower arm about three and on the tibia about two scales to the height of the rostral; no highly spinose tibial scales; a double series of femoral pores, about 19 in the upper row; inner side of second toe with one comb, of third toe with two combs, the proximal the larger; a tendency to form a comb on the three distal joints of the fourth toe; nails long, sharp; tail covered with rectangular keeled 
scales in vertical rows, every fifth one of which is very slightly enlarged to form very indistinct verticils.

Dimensions: Snout to vent, $270 \mathrm{~mm}$.; tail, $410 \mathrm{~mm}$.; tip of snout to ear, $53 \mathrm{~mm}$.; width of head, $42 \mathrm{~mm}$.; fore limb, $110 \mathrm{~mm}$.; hind limb, $180 \mathrm{~mm}$.; vertical diameter of tympanum, $10 \mathrm{~mm}$.

Color (in alcohol): Head and body above and below slate-gray, lightening to French gray on the snout and chin; tail drab to wood brown, lightening beneath.

Variations.- Since discussing the arrangement of the scales on the snouts of the 9 lizards collected by Dr. Abbott, I have found the same variability in 11 from Petite Gonave-eight have the nasals separated from the rostral; two have them in contact with the rostral, and in one individual both conditions are found. The frontal and prefrontals are separated by two scale rows in seven of the Petite Gonave iguanas; in the remaining four by a single scale row.

The femoral pores may be in one, two, or three series. There are not more than 21 pores or less than 14 .

The scales of the dorsal crest usually blend gradually into those of the nuchal crest, although in some cases the crests are discontinuous. Counting the definitely distinguishable components of each, there is a range of 38 to 58 scales in the dorsal crest, and 15 to 25 in the nuchal crest. The sum of the scales in both crests is between 55 and 79 .

The tail verticils are exceedingly indistinct on all the specimens. They can be made out proximally, however, and there are four, rarely five, rows of scales between every two verticils.

Relationships.-While Cyclura cornuta is undoubtedly related to the Navassan Cyclura nigerrima, the two species seem perfectly distinct. The former has much coarser scales on the body and tail, in sharp contrast to the latter, which has exceedingly minute and practically keelless scales on body and tail. The scales covering the top of the head in the Navassan lizard are likewise smaller, while the rows between the enlarged prefrontals are more numerous, and the malar scales are conspicuously smaller. The labial scales, however, are fewer and larger in the Navassan form.

Cyclura cornuta is very close indeed to the Mona Island form, Cyclura stejnegeri. A real difference seems to exist, however, in the number of scale rows between verticils on the tail, there being usually only three such rows in stejnegeri, while four and sometimes five occur in cornuta.

Specimens examined.-As listed in table 34. 
TABLE 34.-Specimens of Cyclura cornuta cornuta examined

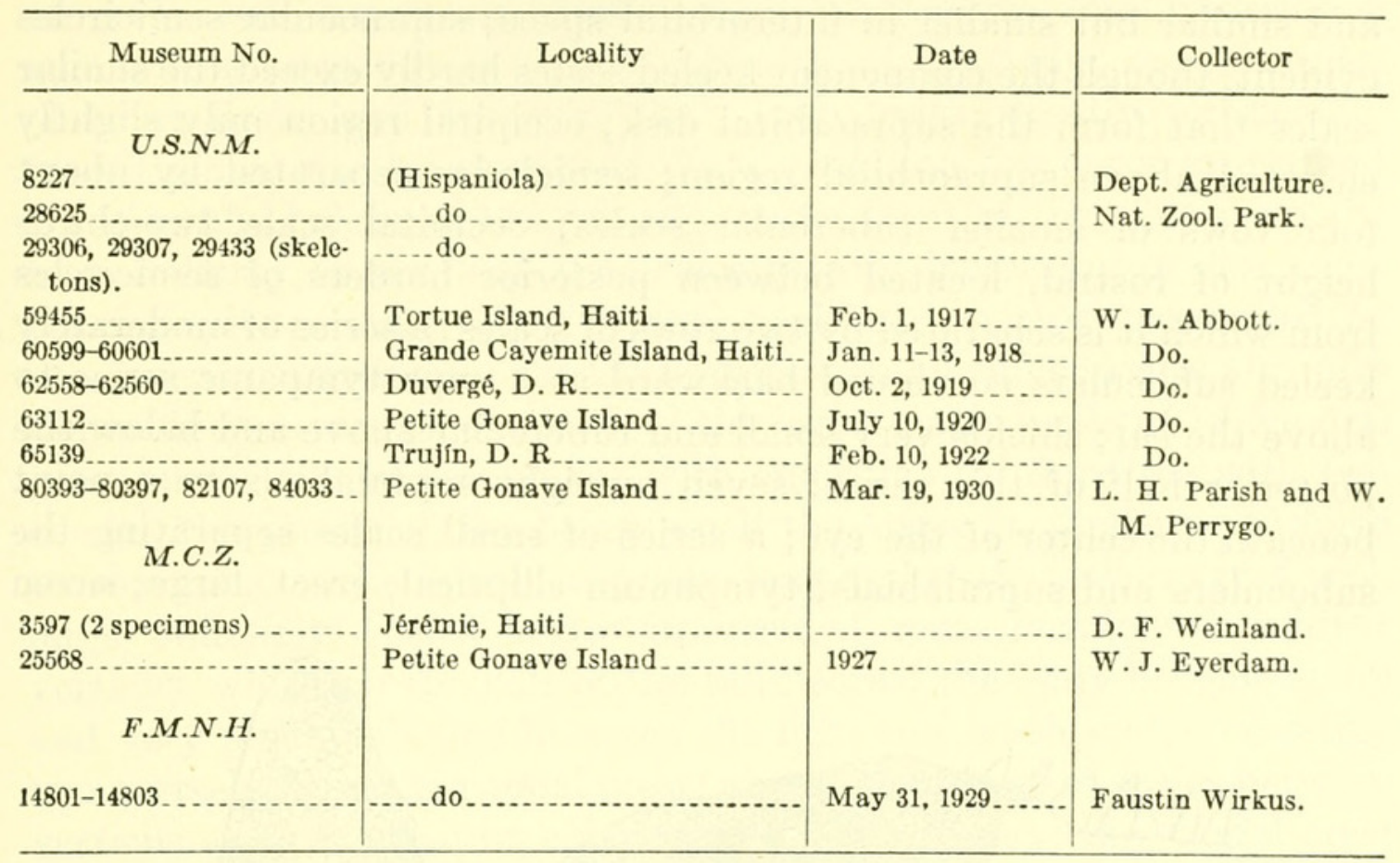

\section{CYCLURA RICORDII (Duméril and Bibron)}

FigURE 63

1837. Aloponotus ricordii Duméril and Bibron, Erpétologie générale, vol. 4, p. 190, pl. 38.

1843. Hypsilophus (Aloponotus) ricordii Fitzinger, Systema reptilium, p. 54. 1845. Aloponotus ricardi Gray, Catalogue of the specimens of lizards in the collection of the British Museum, p. 187.

1885. Metopoceros cornutus Bodlenger, Catalogue of the specimens of lizards in the collection of the British Museum, ed. 2, vol. 2, p. 188 (part) (not of Bonnaterre).

1924. Cyclura ricordii Cochran, Proc. U. S. Nat. Mus., vol. 66, art. 6, p. 5.Barbour, Zoologica, vol. 11, No. 4, p. 97, 1930; vol. 19, No. 3, p. 119, 1935; Bull. Mus. Comp. Zool., vol. 82, No. 2, p. 134, 1937.

No new alcoholic material has come under my observation since my redescription of the specimen collected in 1919 by Dr. Abbott, which was the first one to be brought to a scientific institution since the type was taken in 1784 . The redescription follows, with some slight changes from my first account.

Description.-Adult male, U.S.N.M. No.62557, Duvergé, Dominican Republic; October 3, 1919; W. L. Abbott, collector. Rostral one and one-half times as wide as high, as wide as mental, broadly in contact with nasals; nasal large, irregularly rectangular, slightly higher than wide, perforated by a round nostril equal in diameter to one-half the height of the rostral; postnasal large, two-thirds size of nasal and broadly in contact with it; nasals in contact with each other in middle line of snout behind rostral for about half their width, when they are separated by a single flat, triangular shield; no conical hornlike scales on snout; the top of the head covered by irregularly polygonal shields, 
rather larger and wrinkled on snout, more tubercular on frontal region, and similar but smaller in interorbital space; supraocular semicircles evident, though the component keeled scales hardly exceed the similar scales that form the supraorbital disk; occipital region only slightly elevated above supraorbital region; semicircles separated by about four rows of smaller tubercular scales; occipital scale two-thirds height of rostral, located between posterior borders of semicircles from which it is separated by two rows of scales; a series of moderately keeled suboculars continued backward as a supratympanic series to above the ear; shields very small and tubercular above and below the posterior half of this series; seven or eight supralabials to a point beneath the center of the eye; a series of small scales separating the suboculars and supralabials; tympanum elliptical, erect, large; seven
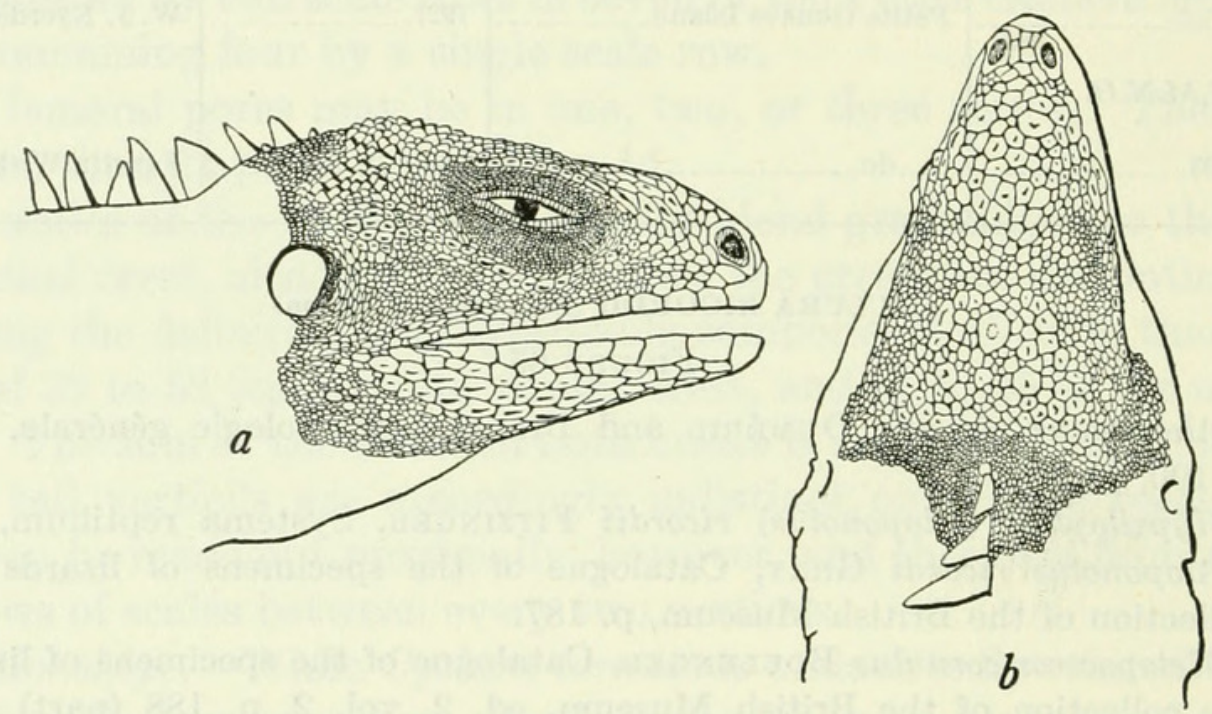

FigURE 63.-Cyclura ricordii: $a$, Side of head; $b$, top of head. U.S.N.M. No. 62557, from Duvergé, Dominican Republic. One-half natural size.

or eight lower labials to center of eye; a series of enlarged malar scales, the posterior ones moderately keeled and separated from the lower labials by one or two rows of flat scales as large as the anterior malars; dorsal and ventral scales rhomboidal, obliquely keeled, the keels pointing toward the median line; dorsal scales very small, about 110 scales measured posteriorly from the axillary contained in the distance from end of snout to anterior edge of tympanum; ventral scales slightly larger than dorsals and more distinctly keeled; from the occiput along the median line of the neck and back a series of enlarged, strongly keeled scales forming a high serrated crest, which is much reduced on the shoulders and on the rump but is continuous with the caudal crest; scales of nuchal crest narrower and appreciably longer than those of dorsal crest; height of the crest scales on the middle of the back one and one-quarter times the height of the rostral, six to the distance from end of snout to anterior edge of tympanum; about 35 scales in the dorsal crest between shoulder and rump; 
throat covered with scales similar to the ventrals but smaller; sides of neck with numerous folds; a large transverse fold underneath neck and a longitudinal one on each side of the body; upper surface of front limbs and femur of hind limbs with slightly imbricated, keeled scales, much larger than the dorsals; on the lower arm about seven to the height of the rostral; on the front of the tibia from the knee halfway to the foot the scales greatly increasing in size, each bearing a long, sharp spine pointed backward, partly surrounded by small, irregularly placed shields bearing a small spine; scales abruptly diminishing in size on the back of the leg; a single series of 18 femoral pores; inner side of second toe with one comb, of third toe with two combs, the proximal one being much the larger; a tendency to form three combs on the fourth toe; nails long and sharp; tail covered with large obliquely keeled scales in vertical rows forming prominent verticils, which on the half of the tail nearest the body become spiny and very much enlarged between the fifth and tenth scales, counting transversely from the caudal crest; about three rows of scales between verticils at their greatest enlargement and five near the caudal crest and beneath the tail where the verticils are less prominent; verticils becoming less well-marked toward extremity of tail.

Dimensions: Total length, $756 \mathrm{~mm}$; tip of snout to vent, 326 $\mathrm{mm}$.; vent to tip of tail, $430 \mathrm{~mm}$.; tip of snout to ear, $70 \mathrm{~mm}$.; width of head, $50 \mathrm{~mm}$.; fore limb, $136 \mathrm{~mm}$.; hind limb, $186 \mathrm{~mm}$.; vertical diameter of tympanum, $12 \mathrm{~mm}$.

Coloration: Head and nuchal region light; throat black; forelimbs black above, lighter underneath; a light patch on shoulder bordered behind with dark extending to base of nuchal crest; on the back a pattern of about nine light bands bordered with dark arising from the dorsal crest; five of these extending obliquely downward on sides; pattern indistinct on sides becoming marked beneath in five or six dark transverse streaks alternating with broader bands of light; sides, back and anterior surface of femur spotted with black; hindlegs and tail light.

Relationships.-Cyclura ricordii is not closely related to any of the West Indian iguanas having enlarged snout scales. The only known species of Cyclura from the West Indies having fairly small and uniform snout scales is carinata, and to this species ricordii is apparently related. In coloration, in the spinose verticils of the tail, and in the enlarged spinose scales on the outer surface of the tibia Cyclura ricordii suggests some of the Ctenosaura rather than Cyclura carinata. The presence of large combs on the toes of ricordii definitely relegates it to the genus Cyclura, however. 


\section{Genus LEIOCEPHALUS Gray}

1827. Leiocephalus Gray, Philos. Mag., ser. 2, vol. 2, p. 207 (type, L. carinatus). 1837. Holotropis Duméril and Bibron, Erpétologie générale, vol. 4, p. 259 (same type).

1838. Pristinotus Gravenhorst, Nova Acta Acad. Caes. Leop.-Carol., vol. 18, pt. 2, p. 738 (type, P. schreibersii).

1843. Steironotus Fitzinger, Systema reptilium, p. 70 (type, S. schreibersii).

1862. Liocephalus Cope, Proc. Acad. Nat. Sci. Philadelphia, 1862, p. 182 (emend.).

This genus is one of the most complex of those occurring on Hispaniola. The presence of an unexpectedly large number of quite definite subspecies belonging to the personatus group proves that the island has been the scene of drastic geographic changes, which have tended to isolate portions of it at one period as islands, perhaps to reunite them with the mainland as peninsulas at a later date.

Two primary stocks of Leiocephali occur in Hispaniola. The one to which I have just referred, represented here by the personatus group, contains the big-scaled, bristling lizards without a lateral fold, the lateral scales having nearly the same slant and size as the dorsolaterals. The other stock, to which both melanochlorus and schreibersii belong, dissimilar in other respects as they may be, is characterized by the presence of a lateral fold, the scales on the sides of the body being therefore much different in size and direction from the dorsolaterals.

The description of the various subspecies of personatus on Hispaniola is probably not yet complete, as additional collecting from many hitherto unvisited regions will undoubtedly show in the future. The forms herein discussed are readily defined even with the rather scanty material at hand. Some of the obvious relationships may be summarized here.

In color pattern semilineatus and beatanus apparently are somewhat similar, as the wide dark lateral stripe is found in both, together with an almost complete suppression of cross bands. The throat and breast are immaculate in semilineatus but heavily spotted in beatanus.

A similarity also exists between mentalis and scalaris, in which the adult males are characterized by a nearly uniformly colored body, all the contrasting pigment being concentrated on the sides of the head, where white spots appear to interrupt and emphasize the dark area. The chin is heavily spotted. The true personatus from the extreme southwestern peninsula resembles both mentalis and scalaris but goes one step farther in intensifying the dark color on the sides of the head by extending it farther back on the neck and in addition well onto the chin, while there is no interruption by light spots. Like the other two forms, the body of the adult male personatus shows very little pattern. L. barahonensis appears to belong in the group with mentalis and scalaris. 
L. vinculum has the sides of the head no darker than the body itself. Instead it has a rather characteristic throat pattern of longitudinal dark lines.

The dwarf species semilineatus is separable from all the others at once on its small adult size alone. The short hindleg of scalaris, as well as its unusually bristling appearance, distinguishes it from the more slender and sleek subspecies.

L. lunatus is somewhat like mentalis in having the mental shield edged with sepia but differs from the latter in other details of coloration; lunatus is rather more similar to louisae from the island of Saona in its dorsal coloration, although the Saona Island form does not have the black crescentic shoulder markings that sometimes appear in adult males from the neighboring mainland.

The swollen nose of adult males of aureus suggests the similar phenomenon found in personatus personatus, its neighbor on the west, but in dorsal and ventral coloration it strongly suggests the Beata Island form, beatanus.

Although the number of subspecies of the personatus group occurring on Hispaniola and its neighboring islets is now brought up to 11, it is safe to predict the eventual discovery of still others in more or less segregated areas where little collecting has been done. The coloration of the adult males appears to be the most conspicuous of the characters separating them. Other good characters appear in the number of the dorsal scales, the size of the parietals, and the relative proportion of the hindleg to body length.

\section{KEY TO LEIOCEPHALUS OF HISPANIOLA AND ADJOINING ISLETS}

$a^{1}$. A distinct lateral fold; 4 scales between rostral and supraocular ring.

$b^{1}$. Sides of neck behind ear covered with small, sharply granular scales; body scales relatively very small_........ schreibersii (p. 204)

$b^{2}$. Sides of neck behind ear covered with scales keeled and imbricated like dorsals; body scales relatively large_ melanochlorus (p. 209)

$a^{2}$. No lateral fold; 3 scales between rostral and supraocular ring (personatus group).

$b^{1}$. Frontals and prefrontals smooth.

$c^{1}$. Frontals usually in contact with canthals; throat immaculate..... personatus semilineatus (p. 217)

$c^{2}$. Frontals usually separated from canthals by a wedge-shaped scale; throat not immaculate.

$d^{1}$. Upper surface of head not conspicuously spotted.

$e^{1}$. Throat and chin heavily spotted with dark brown in adult male; venter greenish gray; outer parietals twice as broad as inner ones._._._. p. barahonensis (p. 219)

$e^{2}$. Throat with a series of about 4 regular transverse rows of spots running across it, the posterior ones continued as stripes onto labials and nearly to upper part of head; under surfaces of legs and tail gamboge yellow; outer parietals 3 times as broad as inner ones 
$d^{2}$. Upper surface of head conspicuously spotted; throat in adult male dark bluish black with white spots_p. altavelensis (p. 220)

$b^{2}$. Frontals and prefrontals ridged.

$c^{1}$. Throat, chin, lips, and sides of head black in adult male p. personatus (p. 212)

$c^{2}$. Throat not solid black in adult male.

$d^{1}$. Hindleg reaching to between shoulder and ear.-.p. scalaris (p. 225)

$d^{2}$. Hindleg reaching to between ear and eye.

$e^{1}$. Scales relatively larger, $10-14$ in a head length in adult.

$f^{1}$. Mental shield of adult male solidly edged with black or brown.

$g^{1}$. Remainder of throat pale china blue, with a few very minute pale-brown spots confined mostly to single scales....... mentalis (p. 228)

$g^{2}$. Remainder of throat and chest very heavily spotted with large brown spots in about a dozen transverse series.................. lunatus (p. 231)

$f^{2}$. Mental shield not solidly edged with black -- p. beatanus (p. 234) $e^{2}$. Scales relatively smaller, 14-16 in a head length.

$f^{1}$. Inner parietals about two-thirds as large as outer...... vinculum (p. 236)

$f^{2}$. Inner parietals larger than outer ones_-- p. louisae (p. 239)

\section{LEIOCEPHALUS SCHREIBERSII (Gravenhorst)}

Figures 64, 65a

1826. Tropidurus schreibersii Fitzinger, Neue Classification der Reptilien, p. 49 (from San Domingo; nomen nudum).

1838. Pristinotus schreibersii Gravenhorst, Nova Acta Acad. Caes. Leop.-Carol., vol. 18 , pt. 2, p. 739 , pl. 54, figs. 15, 16 (type locality, San Domingo; type in Breslau Mus.).

1868. Liocephalus schreibersii Cope, Proc. Aca- Nat. Sci. Philadelphia, vol. 20, p. 123 (Mus. Leyden).-Boulenger, Catalogue of the specimens of lizards in the collection of the British Museum, ed. 2, vol. 2, p. 162, 1885 (S. Domingo).-Fischer, Jahrb. Hamburg Wiss. Anst., vol. 5, p. 29, 1888 (Gonaives, Hayti; collector, H. Rolle).-MüLler, Verh. Naturf. Ges. Basel, vol. 10, pt.. 1, p. 211, 1892 (Gonaives, Hayti; Basel Mus.).-Meerwarth, Mitth. Naturh. Mus. Hamburg, vol. 18, p. 26, 1901.

1914. Leiocephalus schreibersii Barbour, Mem. Mus. Comp. Zool., vol. 44, No. 2, p. 301 (part) (Manneville, Haiti); Zoologica, vol. 11, No. 4, p. 97, 1930 (part); vol. 19, No. 3, p. 120, 1935; Bull. Mus. Comp. Zool., vol. 82, No. 2, p. 135, 1937.-Cochran, Proc. U. S. Nat. Mus., vol. 66, art. 6, p. 9, 1924; Proc. Biol. Soc. Washington, vol. 41, p. 54, 1928; Occ. Pap. Boston Soc. Nat. Hist., vol. 8, p. 179, 1934.-Mertens, Senckenbergiana, vol. 20, No. 5, p. 338, 1938: Publ. Inst. Cient., Domínico-Alemán, vol. 1, p. 88, 1939.Böker, Publ. Inst. Cient. Domínico-Alemán, vol. 1, p. 18, 1939.

Description.-U.S.N.M. No. 59130, a young male from Thomazeau, Haiti, collected by J. B. Henderson and Dr. Paul Bartsch on April 1, 1917. Head shields large, ridged except those bordering the rostral; four scales (an internasal and three prefrontals) in a line between the rostral and the beginning of the supraorbital ring; prefrontals and internasals embracing a medial series of two scales, the first the smaller and not touching the rostral; prefrontals separated from the 
canthals by a series of fairly large scales; two rather small canthal scales, the first one a little shorter and wider than the second, which is followed by five superciliaries, the third the longest, the last two rather small; six bluntly ridged supraoculars, separated from the frontals by a single row of keeled scales and from the superciliaries by two rows of scales except in the anterior portion where the prolongation of the first superciliary crowds out part of the second row of separating scales; frontals moderate in size, mutually in contact along their entire inner border; occipital small, bordered on each side by two distinct parietals, the inner a little smaller than the outer, which is almost twice as large as the occipital; four upper and five lower labials to a point below the center of the eye; temporal scales rather

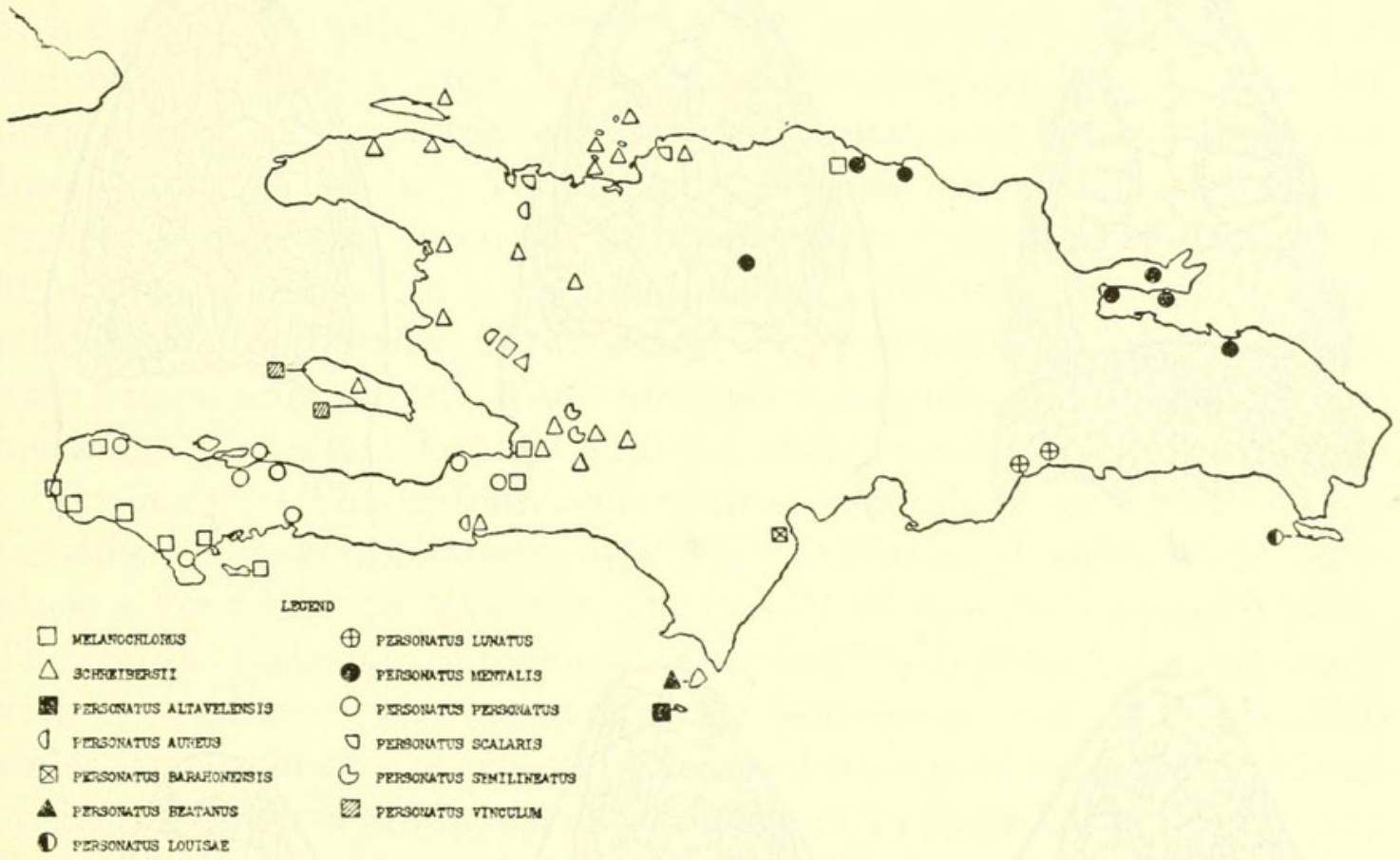

Figure 64.-Distribution of Leiocephalus in Hispaniola.

irregular in size anteriorly, the lower ones smooth but swollen, the upper ones bluntly keeled, with a single slightly enlarged scale above the ear; anterior border of the ear with five unequal projecting scales, the longest reaching to halfway across the tympanum. Dorsal scales small, imbricate, mucronate; laterals very much smaller than the dorsals, the gradation in size being rather rapid; ventrals somewhat larger than the dorsals, smooth, their posterior borders scarcely denticulate; about 88 dorsal scales from the occiput to a point directly above the vent; about 20 dorsal scales equivalent to the distance from snout to occiput; nuchal scales small, those behind the ear very minute and sharply tubercular; those in the shoulder folds keeled like the dorsals but rather small; a distinct lateral fold present. The adpressed hind limb reaches to the center of the eye. Digits compressed, the fourth toe with 25 tricarinate 


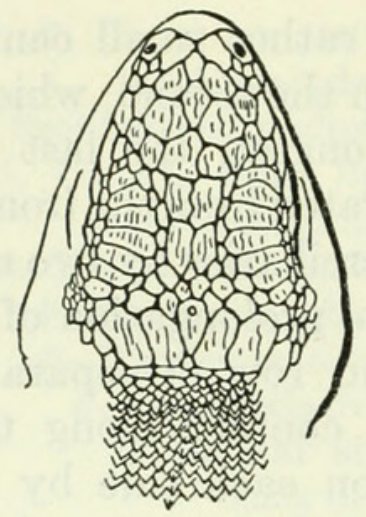

$a$

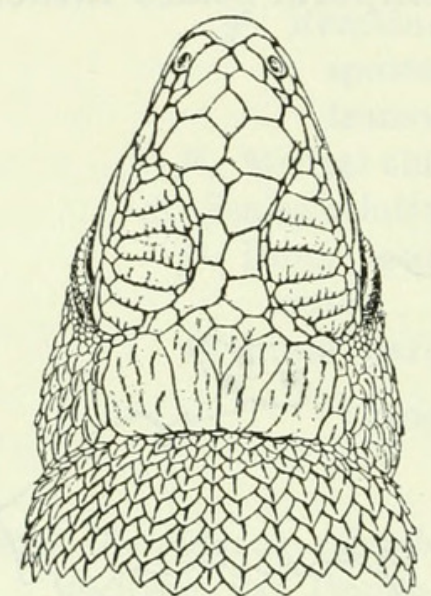

$d$

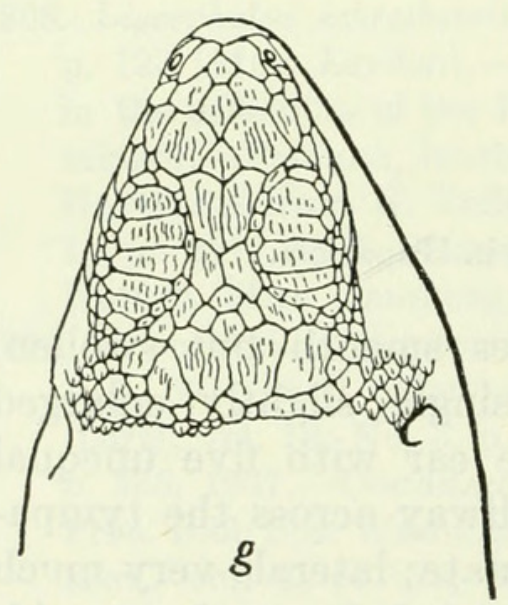

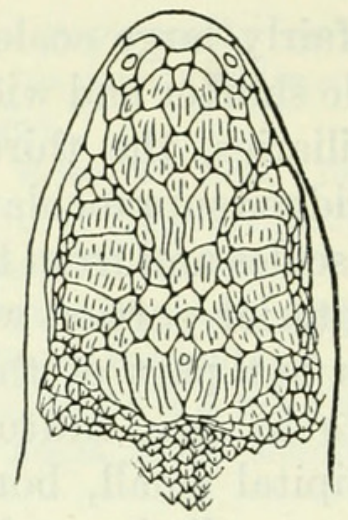

$b$

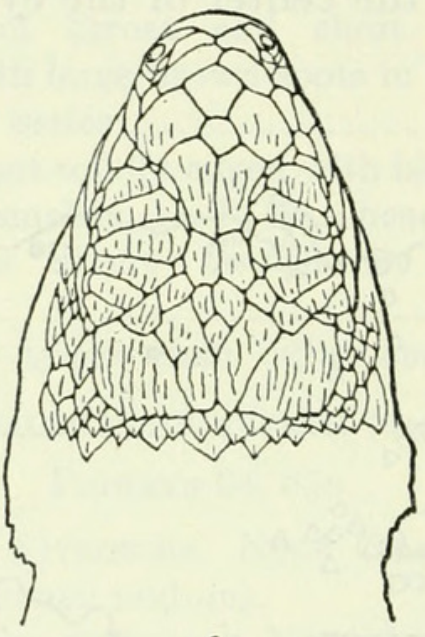

$\boldsymbol{e}$

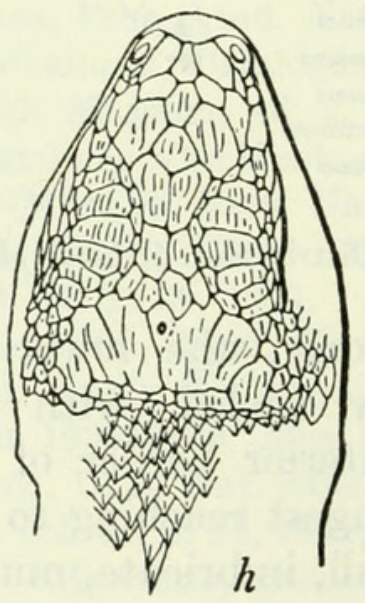

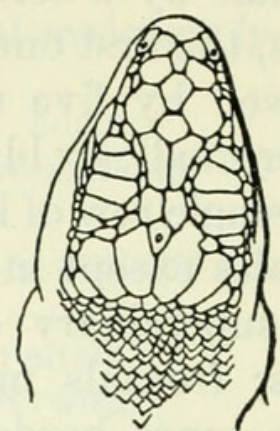

C
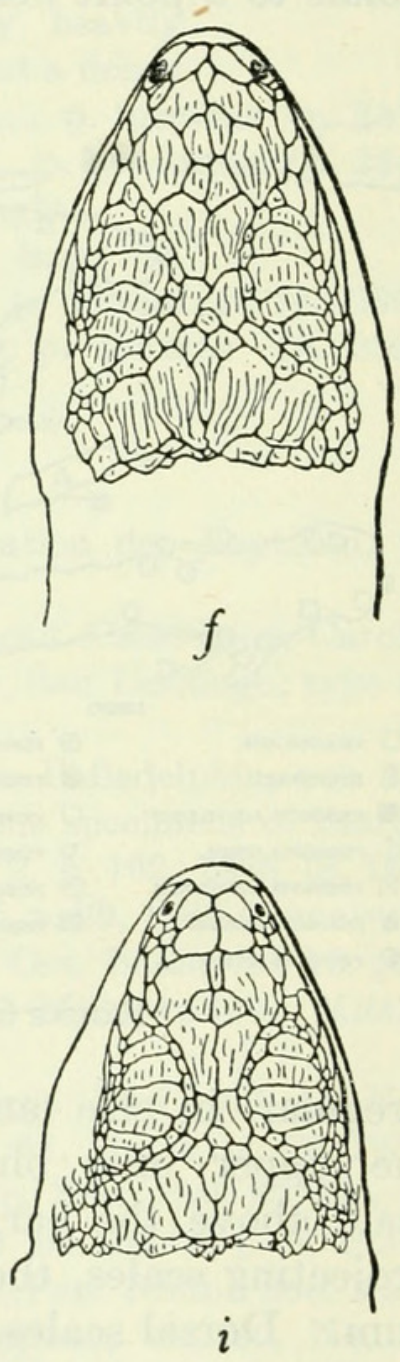

Figure 65.-Tops of heads of Leiocephalus: a, L. schreibersii, U.S.N.M. No. 59130, from Thomazeau, Haiti; $b$, L. melanochlorus, U.S.N.M. No. 52402, cotype, from Jérémie, Haiti; c, L. personatus semilineatus, U.S.N.M. No. 59144, from Morne à Cabrits, Haiti; $d, L$. p. barahonensis, A.M.N.H. No. 2736, type, from Barahona, Dominican Republic (figure from Bull. Amer. Mus. Nat. Hist., vol. 44, art. 2, p. 15, 1921); e, L. p. aureus, U.S.N.M. No. 75909 , type, from Jacmel, Haiti; $f, L$. p. personatus, U.S.N.M. No. 80790 , from Petit Trou de Nippes, Haiti; g, L. p. scalaris, U.S.N.M. No. 74054, type, from Cap-Haitien, Haiti; $h, L$. p. mentalis, U.S.N.M. No. 65772, type, from Jovéro, Haiti; $i, L$. p. lunatus, F.M.N.H. No. 166, type, from Santo Domingo City, Dominican Republic. Twice natural size. (See also fig. 66, p. 221.) 
lamellae. A very distinct but low dorsal crest beginning at the occiput and continuing unbroken to the end of the tail, not increasing in height on the body, slightly higher on the tail; the caudal scales keeled and mucronate; no verticils; tail compressed. The keels of the dorsal scales are directed straight backward; those of the lateral region are directed obliquely upward and backward. There are about 25 longitudinal rows of dorsal scales across the back. A transverse series of four conspicuously enlarged postanals in the male.

Dimensions: Snout to vent, $63 \mathrm{~mm}$; head to posterior ear, $17 \mathrm{~mm}$.; tail, $83 \mathrm{~mm}$. (reproduced); foreleg, $30 \mathrm{~mm}$.; hindleg, $55 \mathrm{~mm}$.; width of head, $13 \mathrm{~mm}$.

Color (in alcohol): Body color olive-buff; about six crescentic sepia markings across the back, each one distinctly contrasted on its posterior edge by a pale buff border, which is prolonged and enlarged at the sides to form a wide, light, dorsolateral stripe, below which the dark lateral color is again evident, with a series of light lateral spots from axilla to groin. Ventral surface pale olive-buff, the lateroventral region with about six transverse bars composed of alternating light brown and white (pale blue) scales. Throat with an indistinct reticulation of narrow brown lines. Upper parts of limbs spotted with brown and white. Tail with very pronounced crescentic brown markings across it. Labials outlined with brown.

Variations.-This species seems fairly constant in its major characteristics. The supraocular scales may number six to eight, with sometimes a tendency to divide in the middle in the most anterior ones. The frontal plates are of moderate and uniform size and fully in contact with each other. The last prefrontal sometimes touches the canthal scales; this tendency is especially marked in lizards from Ratas Island of the Sept Frères group, and a little less so in those from Tercero and Tortue Islands. Most of the lizards on the mainland of Hispaniola have the prefrontals completely separated from the canthals by small scales. There is a median series of 10 or more usually azygous scales between the two series of prefrontals; the foremost of these azygous scales usually fits into the angle behind the internasals; rarely the rostral touches this scale, thus separating the internasals. In lizards from Ratas Island the internasals tend to divide longitudinally. The tail crest in these same lizards, as well as in the adults from Tercero and Tortue Islands, seems to be higher and spinier than in those from the Hispaniolan mainland; these slight variations may in sufficient time become numerous and pronounced enough to allow the island forms to be designated as subspecies.

There are 24 to 28 subdigital lamellae on the fourth toe, while 18 to 23 dorsal scales are equivalent to the distance from snout to occiput. Usually four upper labials lie between the rostral to a point beneath the center of the eye. The ear scales may be considerably enlarged, in 
which case there are usually but three or four, or they may be fairly small and six or seven in number. The occipital scale is always smaller than the parietals. Sometimes the parietals are equal in size; sometimes either the inner or the outer may be the larger.

TABLE 35.-Specimens of Leiocephalus schreibersii examined

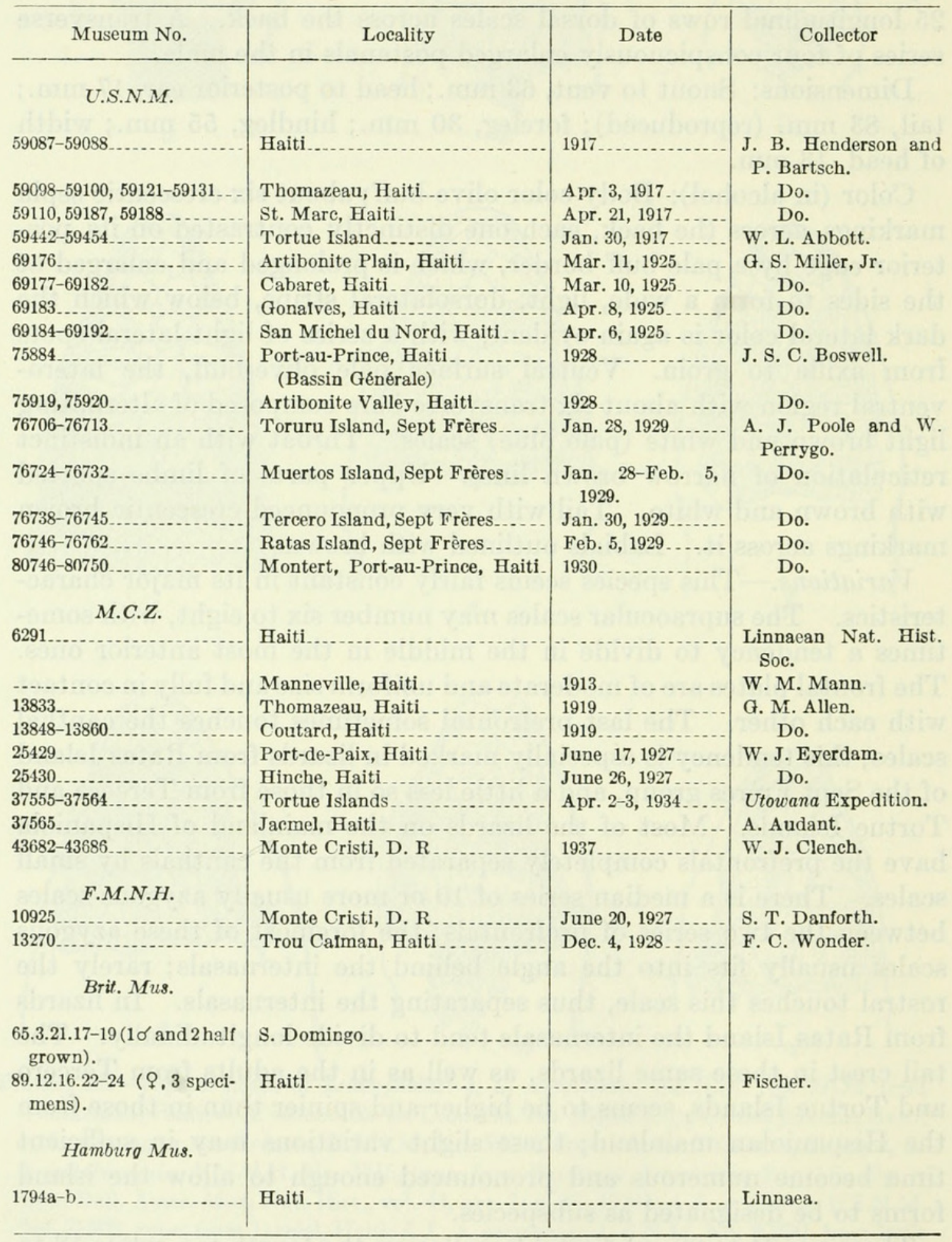

The coloration is fairly constant. The young are always highly spotted and lined in appearance and most of them show the distinct black axillar patch. The adults are much less pronounced in pattern, 
but their small scales are individually colored with brightest blue, rose, and green, which soon fade in alcohol to muddy brown and buff. The throat of the adult males is suffused with gray. The largest one in our collection (U.S.N.M. No. 75919) from the mainland of Hispaniola measures $92 \mathrm{~mm}$. from snout to vent and has no trace of the complicated juvenile pattern except on the sides, where a few dark scales in series are the only remainder of the transverse lateroventral bars.

Remarks.-The occurrence of Leiocephalus schreibersii on the western end of Hispaniola, and of the closely related Leiocephalus inaguae on Great Inagua, while no relatives of either are in eastern Hispaniola or in Puerto Rico, is another argument in favor of the diversification of the eastern and western portions of Hispaniola. At one time it is evident that the western half of the island was definitely linked up with the Bahamas, with Navassa, and with Cuba, while the eastern half was cut off from these islands but was connected in some way with Mona and Puerto Rico.

Specimens examined.-As listed in table 35.

\section{LEIOCEPHALUS MELANOCHLORUS Cope}

Figures $64,65 b$

1862. Liocephalus melanochlorus Cope, Proc. Acad. Sci. Philadelphia, 1862, p. 184 (type locality, near Jérémie, Hayti; type in Mus. Comp. Zool.; collector, Dr. F. Weinland); 1868, p. 122.-Boulenger, Catalogue of the specimens of lizards in the collection of the British Museum, ed. 2, vol. 2, p. 164, 1885.Garman, Bull. Essex Inst., vol. 19, p. 49 (extr. p. 25), 1887 (Jérémie, Tiburon, Hayti; collector, Garman).-MüLler, Verh. Naturf. Ges. Basel, vol. 10, pt. 1, p. 211, 1892, (Aux Cayes, Haiti; Basel Mus.).-Meerwarth, Jahrb. Hamburg Wiss. Anst., vol. 18, p. 26, 1901.

1914. Leiocephalus melanochlorus Barbour, Bull. Mus. Comp. Zool., vol. 44, art. 2, p. 301; Zoologica, vol. 11, No. 4, p. 97, 1930; vol. 19, No. 3, p. 120, 1935; Bull Mus. Comp. Zool., vol. 82, No. 2, p. 135, 1937.-CochraN, Proc. U. S. Nat. Mus., vol 66, art. 6, p. 9, 1924; Occ. Pap. Boston Soc. Nat. Hist., vol. 8, p. 175, 1934.-Barbour and Loveridge, Bull. Mus. Comp. Zool., vol. 69, No. 10, p. 289, 1929.

Description of a cotype.-A young male, U.S.N.M. No. 52402 (formerly M.C.Z. No. 3598), collected near Jérémie, Haiti, by Dr. F. Weinland. Head shields enlarged, conspicuously ridged except those bordering the rostral; four scales (an internasal and three prefrontals) in a line between the rostral and the beginning of the supraorbital ring; the prefrontals and internasals embracing a medial series of seven scales, the first one large and in contact with the rostral thus widely separating the internasals, two single ones following, and lastly a patch of four; prefrontals separated from the canthals by a few fairly large scales; two canthal scales, the first one very short and wide, the second much longer, followed by five superciliaries, the first three of which are exceedingly long and narrow and overlapping, the last two rather small; six bluntly ridged supraoculars, 
separated from the superciliaries and from the frontals by a single row of keeled scales; frontals moderate in size, in contact for the posterior portion of their length; occipital small, bordered on each side by two distinct parietals, the inner almost twice as large as the outer and about four times as large as the occipital; four upper and four lower labials to a point below the center of the eye; temporal scales keeled, rather irregular anteriorly, with four larger semitubercular scales in a vertical row in front of the ear, the upper the largest; anterior border of the ear with two or three very long projecting scales which nearly cover the tympanum. Dorsal scales very large, imbricate, and highly mucronate; laterals somewhat smaller than the dorsals; ventrals about equal to the dorsals in size, smooth, their posterior edges scarcely denticulate; about 40 to 44 scales around the middle of the body; about 54 scales from the occiput to a point directly above the vent; about 11 dorsal scales equivalent to the distance from snout to occiput; nuchal scales small, those behind the ear small and sharply tubercular; those in the shoulder folds keeled like the dorsals but very minute; two or three abruptly enlarged smooth scales on the edge of the fold directly in front of the shoulder; a distinct lateral fold present. The adpressed hind limb reaches to the posterior corner of the eye. Digits compressed, the fourth toe with 28 tricarinate lamellae. A distinct dorsal crest beginning at the occiput and increasing somewhat on the beginning of the tail, then decreasing; the other caudal scales keeled and mucronate; no verticils. The keels of the laterals and dorsals are directed straight backward, the keels of the latter forming fairly regular rows; the three or four rows of scales within the lateral fold are smaller than those above or below them. Tail slightly compressed. A pair of widely separated crescentic postanals in the male, which are not very noticeable, since all the scales surrounding them are large.

Dimensions: Snout to vent, $73 \mathrm{~mm}$.; head to posterior ear, $17 \mathrm{~mm}$.; tail (tip reproduced), $111 \mathrm{~mm}$.; foreleg, $32 \mathrm{~mm}$.; hindleg, $57 \mathrm{~mm}$.; width of head, $12 \mathrm{~mm}$.

Color (in alcohol).-Body color pale olive-green above turning to olive-buff below. A dorsal series of seven or eight black chevrons across the back between the two light dorsolateral stripes, these markings continuing on the tail as a series of regularly spaced and symmetrical tail bars; between the eye and the groin a lateral series of light oval spots, quite regularly spaced, with dark areas above and below. A few scattered dark spots on upper surfaces of limbs. Lower parts heavily spotted with dark dots, those on the central region of throat and breast anastomosing into a pair of longitudinal stripes, those on the chin and lips into short transverse bars; others often with a sort of honeycomb pattern, and those on the tail with fairly regular rings. Top of head without markings except for some 
small spots on the occiput; sides of head with three dark vertical stripes, the first reaching diagonally backward from the anterior corner of the eye, the second from beneath the center, and the last from the posterior corner of the eye. This species keeps its juvenile pattern throughout the adult stage. Our smallest specimen, U.S.N.M. No. 80863, in which the head and body together measure $32 \mathrm{~mm}$., has the same pattern as does No. 80843, which is $108 \mathrm{~mm}$. long, except that the white lateral stripe is relatively much lighter in the young, and the dark markings are also everywhere more definite.

Variations.-There is singularly little variation in this, the largest of the Hispaniolan Leiocephali. There are always five fairly large supraocular shields, with one or two somewhat smaller ones in addition. The two pairs of parietals are nearly equal in size, and both are a little larger than the interparietal. The frontals usually are in contact for at least their posterior half; in No. 59105, however, they are completely separated by a single row of small scales. The prefrontals do not touch the canthals except in rare instances. There are always three pairs of prefrontals between the internasals and the supraoculars. The internasals in almost all cases have divided, sometimes across, sometimes longitudinally; the cotype is unusual in having a single pair of large internasals. Occasionally the foremost of the median series of azygous scales lying between the prefrontals will touch the rostral, but usually the inner prefrontals are in contact and prevent it from doing so. The projecting scales in front of the ear are usually conspicuous, as are the semitubercular enlarged scales there. The patch of two or three enlarged scales on the fold directly in front of the shoulder is evident in all the specimens. This character does not appear in other species of Leiocephalus from Hispaniola.

In coloration great uniformity prevails. The juvenile pattern is retained in males and females alike even in the largest adults, with only a slight diminution in intensity. The males do not lose the reticulation on the throat, as do the males of other species in which the throat becomes a uniform gray or black in maturity. In the young, which usually have a more highly contrasted pattern than do the adults, the lateral series of white oval spots extending from the ear and above the shoulder to the groin stands out from the surrounding dark areas with a rather startling brilliance.

The most careful inspection fails to reveal any differences between the lizards from Ile à Vache and those from the neighboring peninsula of Haiti. The separation has evidently been too recent, or the stability of the species too great, to have allowed the formation of recognizable differences as yet.

Specimens examined.-As listed in table 36. 
TABLE 36.-Specimens of Leiocephalus melanochlorus examined

\begin{tabular}{|c|c|c|c|}
\hline Museum No. & Locality & Date & Collector \\
\hline U.S.N.M. & & & \\
\hline 52402 (cotype) & Jérémie, Haiti ............ & & D. F. Weinland. \\
\hline $59101-59106 \ldots \ldots \ldots$ & do & Apr. 10,1917 & $\begin{array}{l}\text { J. B. Henderson and P. } \\
\text { Bartsch. }\end{array}$ \\
\hline 60621 & do & Nov. 22,1917 & W. L. Abbott. \\
\hline $75904,75905 \ldots$ & Aux Cayes, Haiti. . . . & 1928 & J. S. C. Boswell. \\
\hline $75917,75918 \ldots \ldots$. & Artibonite Valley, Faiti.... & $1928 \ldots \ldots$ & Do. \\
\hline 80760 & $\begin{array}{l}10 \text { miles south of Port-au- } \\
\text { Prince, Haiti. }\end{array}$ & May 26,1930 & L. H. Parish and W. Perrygo. \\
\hline 80841,80842 & Bigie, Haiti .................. & Apr. 23,1930 & Do. \\
\hline $80343-80863 \ldots$ & Île à Vache, Haiti... & April $1930 \ldots$ & Do. \\
\hline $80920 \ldots$ & do & June 5,1929 & C. R. Orcutt. \\
\hline 80921-50927 & Coteaux, Haiti............... & July 26,1929 & Do. \\
\hline 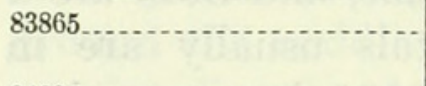 & La Cour Z'Anglais, Haiti.... & Apr. 11,1931 & $\begin{array}{l}\text { A. Wetmore and F. C. Lin- } \\
\text { coln. }\end{array}$ \\
\hline $81237 \ldots$ & Île à Vache, Haiti. & 1930 & L. H. Parish and W. Perrygo. \\
\hline M.C.Z. & & & \\
\hline - & Puerto Plata, D. R . & & M. A. Frazar. \\
\hline 3598 (12 cotypes) ... & Jérémie, Haiti...... & n. & D. F. Weinland. \\
\hline 6027 & Tiburon, Haiti.... & $1880 \ldots \ldots$ & S. Garman. \\
\hline $8671-8676 \ldots \ldots \ldots$ & Furcy, Haiti........ & $1913 \ldots \ldots$ & W. M. Mann. \\
\hline $37525-37534$ & Île à Vache, Haiti............... & Apr. 12,1934 & Utowana Expedition. \\
\hline Brit. Mus. & & & \\
\hline 89.3.20.38-41 (ه্', ᄋ, and young) & "Hayti".. & & H. Rolle. \\
\hline
\end{tabular}

\section{LEIOCEPHALUS PERSONATUS PERSONATUS Cope}

Figures 64, 65f; Plate 3

1862. Liocephalus personatus Cope, Proc. Acad. Nat. Sci. Philadelphia, 1862, p. 1862, p. 182 (type locality, near Jérémie, Hayti; type in Mus. Comp. Zool.; collector, D. F. Weinland); 1868, p. 122; Proc. U. S. Nat. Mus., vol. 10, p. 438, 1887.-Boulenger, Catalogue of the specimens of lizards in the collection of the British Museum, ed. 2, vol. 2, p. 164, 1885 (San Domingo).Garman, Bull. Essex Inst., vol. 19, p. 49, extr. p. 25, 1887 (part) (Jérémie).Barbour and Loveridge, Bull. Mus. Comp. Zool., vol. 69, No. 10, p. 296, 1929.

1914. Leiocephalus personatus Barbodr, Mem. Mus. Comp. Zool., vol. 44, No. 2, p. 302 (part; Jérémie); Zoologica, vol. 11, No. 4, p. 97, 1930 (part).-CocHRAN, Proc. Biol. Soc. Washington, vol. 41, p. 54, 1928 (Bellevue).

1862. Liocephalus trigeminatus Cope, Proc. Acad. Nat. Sci. Philadelphia, 1862, p. 183 (type locality, near Jérémie, Hayti; type in Mus. Comp. Zool.; collector, D. F. Weinland); 1868, p. 122; Proc. U. S. Nat. Mus., vol. 10, p. 438, 1887.

1928. Leiocephalus semilineatus Cochran, Proc. Biol. Soc. Washington, vol. 41, p. 54 (Hinche, Haiti) (part; not of Dunn).

1935. Leiocephalus personatus personatus BARBour, Zoologica, vol. 19, No. 3, p. 120; Bull. Mus. Comp. Zool., vol. 82, No. 2, p. 135, 1937.

Description.-An adult male, U.S.N.M. No. 80790, from Petit Trou de Nippes, Haiti, collected on April 8, 1930, by Lee H. Parish 
and Watson Perrygo. Head shields enlarged, strongly ridged, the posterior ones with more closely set ridges than the anterior; three scales (an internasal and two prefrontals) between the rostral and the beginning of the supraorbital ring, the posterior one very large; nasal in contact with rostral; internasals somewhat elongate, in contact with each other; the prefrontals and internasals embracing a medial series of five scales, the first one between the posterior parts of the internasals, the others in contiguous sets of two between the prefrontals; prefrontals in contact with the canthals on one side of the head, separated by an elongate scale on the other (normal) side; two heavy rounded canthal scales, followed by three long and narrow superciliaries and two very small terminal ones; six ridged supraoculars separated from superciliaries and from frontals by a single row of small keeled scales; frontals large, widely in contact; occipital small, bordered by two distinct pairs of parietals on each side, the inner as large as the outer and about three times as large as the occipital; four upper and five lower labials to a point below the center of the eye; temporal scales increasing regularly in size, the last one, just above and in front of the ear, the largest and most conspicuous; anterior border of the ear with four coarse projecting scales. Dorsal scales large, imbricate, and highly mucronate; laterals considerably smaller than the dorsals; ventrals slightiy larger than the dorsals, smooth, their posterior edge slightly denticulate; about 45 scales around the middle of the body; about 62 scales from the occiput to a point directly above the vent; about 15 dorsal scales the equivalent of the distance from snout to occiput; nuchal scales rather small, those on the sides of the neck like the dorsals, those behind the ear keeled and imbricate, not granular. Shoulder folds present, but no lateral folds. The adpressed hind limb reaches to the anterior border of the ear. Digits compressed; the fourth toe with 25 tricarinate lamellae. A high distinct crest beginning at the occiput, equally developed on the back and on the proximal portion of the tail but decreasing as the tail tapers; the other caudal scales keeled and mucronate; no verticils. The keels of the lateral and dorsal scales are directed upward and backward so that the scale rows converge strongly on the back. Tail highly compressed. Adult male with top of snout swollen and decidedly convex; a transverse series of several enlarged and elongate postanals.

Dimensions Snout to vent, $72 \mathrm{~mm}$; head to posterior ear, 18 $\mathrm{mm}$.; tail, $122 \mathrm{~mm}$; foreleg, $28 \mathrm{~mm}$; hindleg, $58 \mathrm{~mm}$; width of head, $14 \mathrm{~mm}$.

Color (in alcohol) : Body color above pale china blue on back, arms and legs turning to drab on the neck, with tinges of light madder brown along the sides; each scale on the sides and up to the middorsal region with a black outer posterior border, which causes the 
sides to appear very finely striped with oblique black stripes; a wide light middorsal stripe involving the crest and a rather faint light lateral stripe from axilla to groin; these stripes are due to the absence of the black outer mark on the scales of the region in question; top of head to occiput vandyke brown; sides of head, snout, and throat black, this shade continuing unbroken past the ear to the origin of the shoulder fold; traces of three chevron-shaped black bars across the nuchal region; limbs without definite bars but with some blackcentered scales; tail with very faint suggestions of wide dark vertical bars; entire ventral surface immaculate pale china blue, except for the black throat; some of the scales on lower parts of sides, limbs, and tail white-centered.

Variations.-The head plates of this species do not appear to vary much in rugosity or in arrangement. They are always ridged, the occipitals rather coarsely, the supraoculars more finely and evenly, and the frontals and prefrontals more lightly. There is a median series of scales on top of the snout, separating the prefrontals from the corresponding scales on the other side. The first one of this median series appears as a small scale sometimes touching the rostral and separating the supranasals entirely from each other. Next come one or two single scales, and finally a pair of scales side by side, or sometimes a little group of four or five scales. In every one of my specimens I find three scales between the rostral and the beginning of the supraorbital ring. These are separated from the canthals posteriorly by a wedge-shaped scale in almost every instance; in the described specimen there is a contact on one side of the head only. The supraoculars are normally six in number; sometimes five or seven are found. In the largest male at hand, U.S.N.M. No. 80775, which measures $77 \mathrm{~mm}$. from snout to vent, the tail is 1.6 times the length of the head and body. The variation here is from 1.5 to 1.8 , with the majority falling on 1.7. Subdigital lamellae on the fourth toe number from 22 to 26, always tricarinate. The great irregularity of the rows of body scales makes it impracticable to give definitely the range of scales at midbody or in a longitudinal series.

The adult males are all characterized by the conspicuous black throat and face, the black area always extending considerably beyond the ear-in fact, it reaches halfway to the shoulder, involving the shoulder folds. Frequently on young males there is a light spot below the eye and another in front of the ear, as well as a larger light patch behind and below the ear. The top of the head is brown, sometimes with faint minute darker spots emphasizing the ridges, sometimes with the dark pigment concentrated in larger spots on the central frontal region or on the inner borders of the supraoculars. The older males give a decided impression of striping, with the wide light dorsal stripe and the two lateral stripes and frequently an additional dorsolateral 
stripe as well, while all that remains of the juvenile barred coloration is the group of four or five chevrons across the nuchal region. In a young male, U.S.N.M. No. 80765, the traces of the bars are faintly discernible the entire length of the body, and appear on the tail as definite crossbars. This young specimen shows the transition coloring equally well about the head, as the posterior throat and chest still has pale remnants of spots, while the fusion of spots and concentration of pigment is already beginning on the edges of the jaws and on the side of the head. Cope's trigeminatus was described probably from a female specimen. U.S.N.M. No. 80763, a female apparently quite typical as to coloration, has four longitudinal stripes, as did Cope's type - a dorsolateral and a lateral on each side. From occiput well onto the tail occurs a series of black bars, sometimes chevron-shaped, sometimes broken in the midline. Between the dorsolateral and lateral light strips there is a wide brown area with many diagonal black more or less irregular markings corresponding in general to the dorsal chevrons. The whole ventral surface is heavily spotted with black, including the limbs, tail, and chin, the spots becoming smaller on the sides and somewhat lighter on the tail. Those on the chin and throat are never arranged in regular transverse series, as is the case in beatanus. The head is brown above with small dark spots intermittently bordering the head plates, as in the males. The largest female of which $I$ have record measures $54 \mathrm{~mm}$. from snout to vent, small as compared to the largest male which is $77 \mathrm{~mm}$.

The very youngest specimens display a highly complicated pattern quite dissimilar to that of the adult males. The lateral and dorsolateral light stripes are in evidence but fade out anteriorly so that the sides of the head in front of the eyes are light, while scattered black spots appear on the throat and pale gray markings on the labial sutures.

The dorsal chevrons number about 16 (sometimes one or two more or less) from the occiput to the base of the tail, but there is a decided tendency in alternate chevrons to lose their distinctness, appearing only as a series of dark spots bordering the dorsolateral stripe between the outer ends of the remaining seven or eight chevrons, which retain their distinctness in most of the females. The males, on the contrary, lose practically all of the body pattern except for a few black scales on the nuchal region where the first three chevrons used to be.

The ventral surface in females and young is heavily spotted with black. Relatively large, roundish spots arranged in fairly regular longitudinal series occur at least on the chest and more or less irregularly on the throat. On the belly much smaller and more elongate spots tend to be arranged in slightly oblique transverse series merging laterally into the dark area below the lateral light line and still showing some influence of the longitudinal occurrence. The lower surface of the limbs is heavily spotted in the young, while the pos- 
terior femur has three or more light spots and above them a light stripe, and the anterior femur has a similar light stripe, which is the continuation of the lateral light line. This lateral line forks on the shoulder, part of it running forward onto the side of the neck, while part of it goes onto the upper arm in a more or less broken and irregular light marking.

Even in the young the light longitudinal stripes are partially invaded by the dark pigment from the areas above and below them and fail to present the clean-cut delineation found in semilineatus and beatanus in the adult stage.

Specimens examined.-As listed in table 37.

TABLE 37.-Specimens of Leiocephalus personatus personatus examined

\begin{tabular}{|c|c|c|c|}
\hline Museum No. & Locality & Date & Collector \\
\hline U.S.N.M. & & & \\
\hline $72607-72612 \ldots \ldots$ & L'Acul, Haiti. ..... & Apr. $11,1927 \ldots$ & A. Wetmore. \\
\hline 72613 & Aquin, Haiti & Apr, 13. 1927 . & Do. \\
\hline $80763-80766$ & 10 miles east of Baradères, Haiti. & Apr. $6-7,1930 \ldots$ & $\begin{array}{l}\text { L. H. Parish and W. } \\
\text { Perrygo. }\end{array}$ \\
\hline 80774-80787_.......... & Gran Boucan, Haiti & Apr. $11,1930 \ldots .$. & Do. \\
\hline 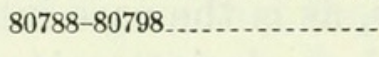 & Petit Trou de Nippes, Haiti..... & Apr. 8, $1930 \ldots$ & Do. \\
\hline M.C.Z. & & & \\
\hline $\begin{array}{l}3615 \text { ( } 2 \text { cotypes of } L . \text { per- } \\
\text { sonatus. }\end{array}$ & Jêrémie, Haiti... & & D. F. Weinland. \\
\hline $8720,8722-8725 \ldots$ & Furcy, Haiti. & 1913 & W. M. Mann. \\
\hline 13834-13838 & Léogane, Haiti.................... & 1919 & G. M. Allen. \\
\hline
\end{tabular}

TABLE 38.-Possibly intergrading examples of Leiocephalus personatus

\begin{tabular}{|c|c|c|c|}
\hline Museum No. & Locality & Date & Collector \\
\hline U.S.N.M. & & & \\
\hline $72636,72637 \ldots$ & Caracol, Haiti & Apr. $27,1927 \ldots$ & A. Wetmore. \\
\hline 75906 & $\begin{array}{l}\text { Bayeux, near Port-au-Prince, } \\
\text { Haiti. }\end{array}$ & 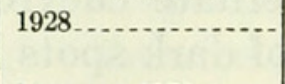 & J. S. C. Boswell. \\
\hline 76651 & L'Atalaye, Haiti & January $1929 \ldots . . .$. & $\begin{array}{l}\text { A. J. Poole and W. } \\
\text { Perrygo. }\end{array}$ \\
\hline 76714 & Monte Chrio Island, Sept Fréres. & Jan. $28,1929 \ldots \ldots$ & Do. \\
\hline $76764-76769$ & Fort Liberté, Haiti & February $1929 \ldots$ & Do. \\
\hline 76777-76779 & Cerca-la-Source, Haiti........... & 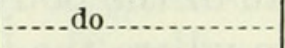 & Do. \\
\hline M.C.Z. & 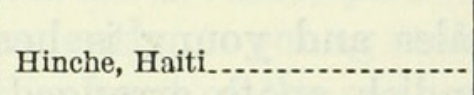 & June $25,1927 \ldots .$. & W. J. Eyerdam. \\
\hline
\end{tabular}

The status of the specimens listed in table 38 cannot as yet be accurately determined until more material has been secured to show the variation on a complete series from young to adult in every one of the named localities as well as in some of the intervening territory. It is to be expected that intergrading forms will be found in these 


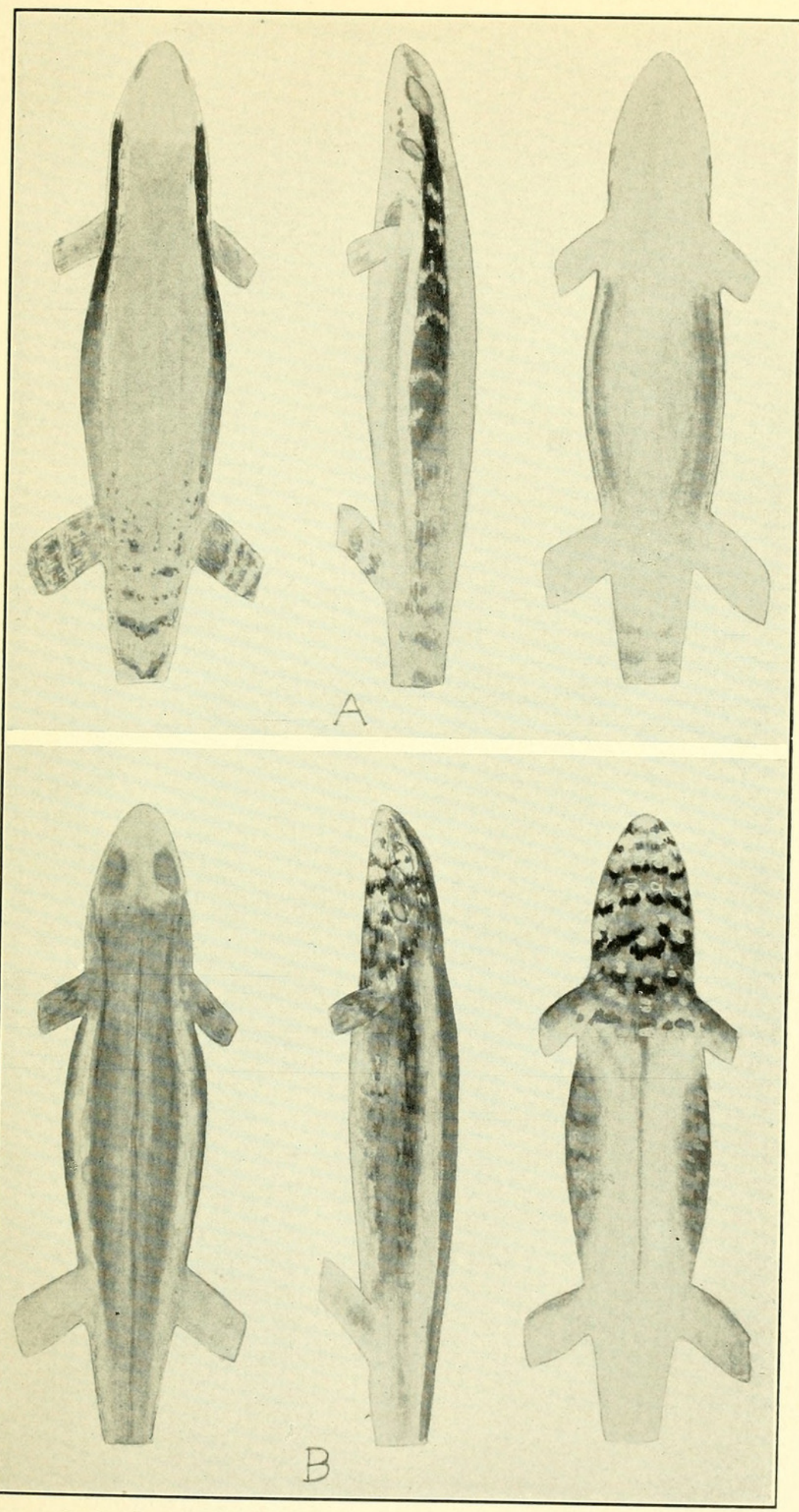

iagrams of color pattern of (A) Leiocephalus personatus semilineatus (male) and (B) L. p. aureus (male). 


$$
\begin{aligned}
& \text { A! } \\
& \text { HI }
\end{aligned}
$$




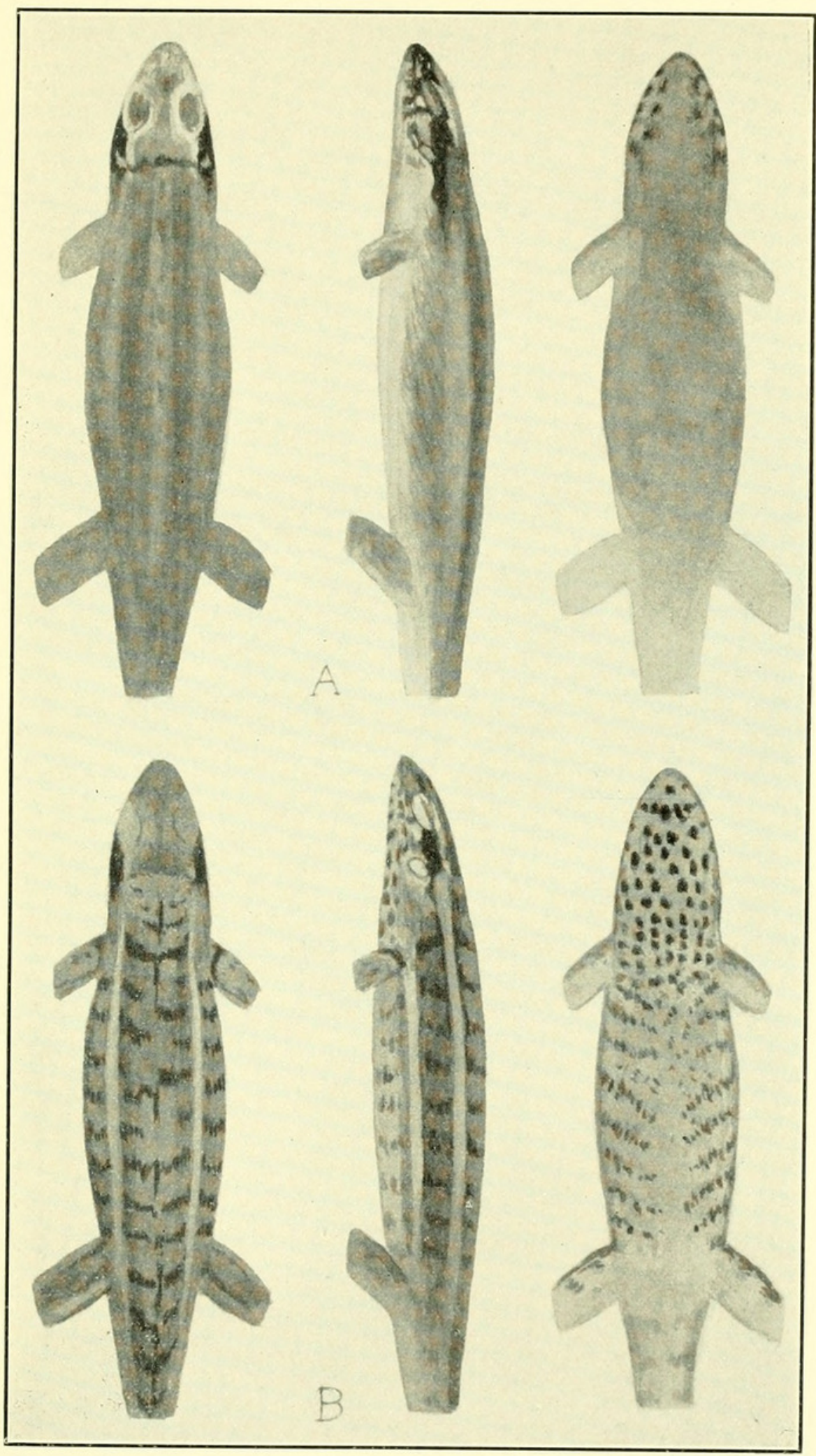

Diagrams of color pattern of Leiocephalus personatus scalaris: A, male; B, female. 


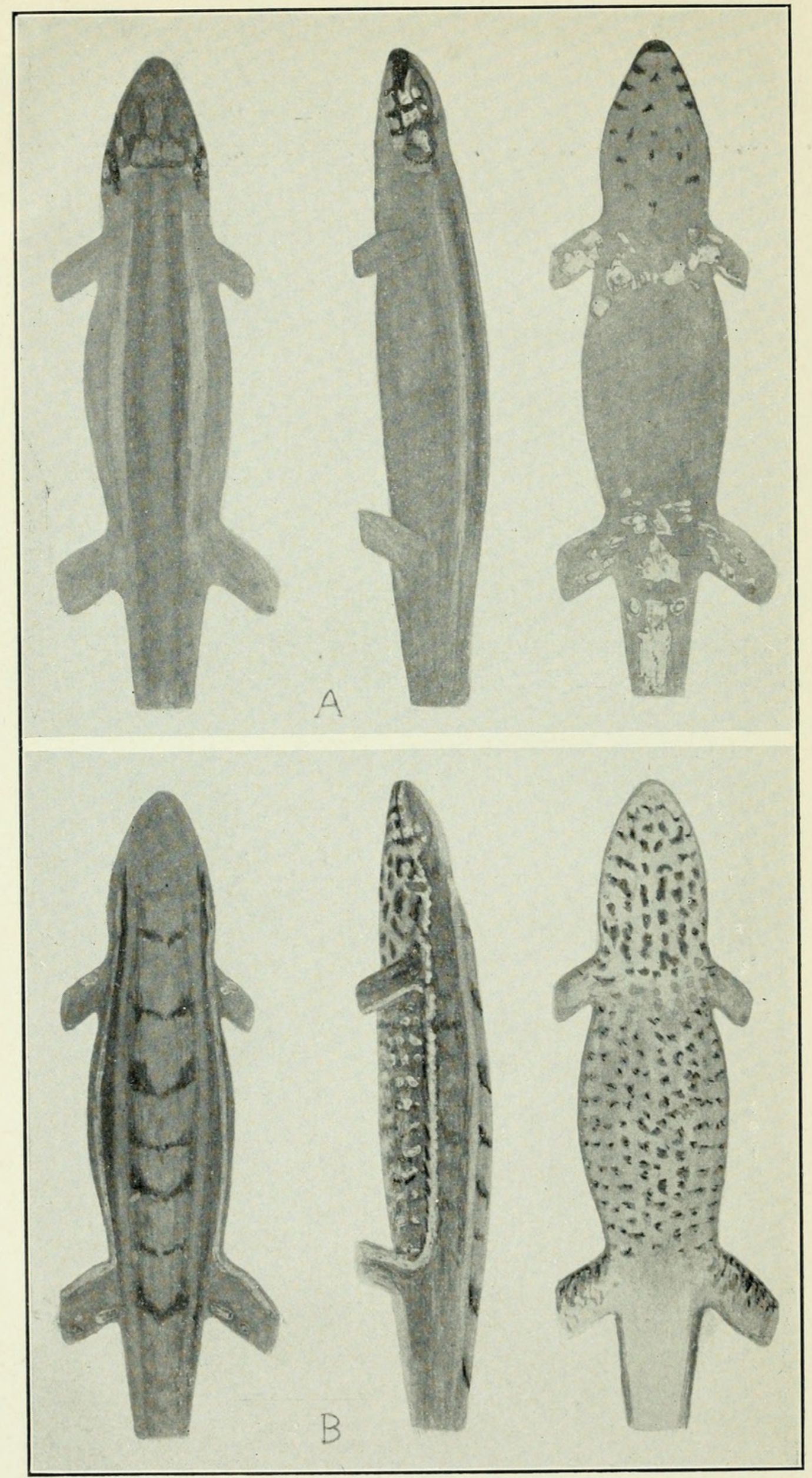

Diagrams of color pattern of Leiocephalus personatus mentalis: A, male; B, female. 


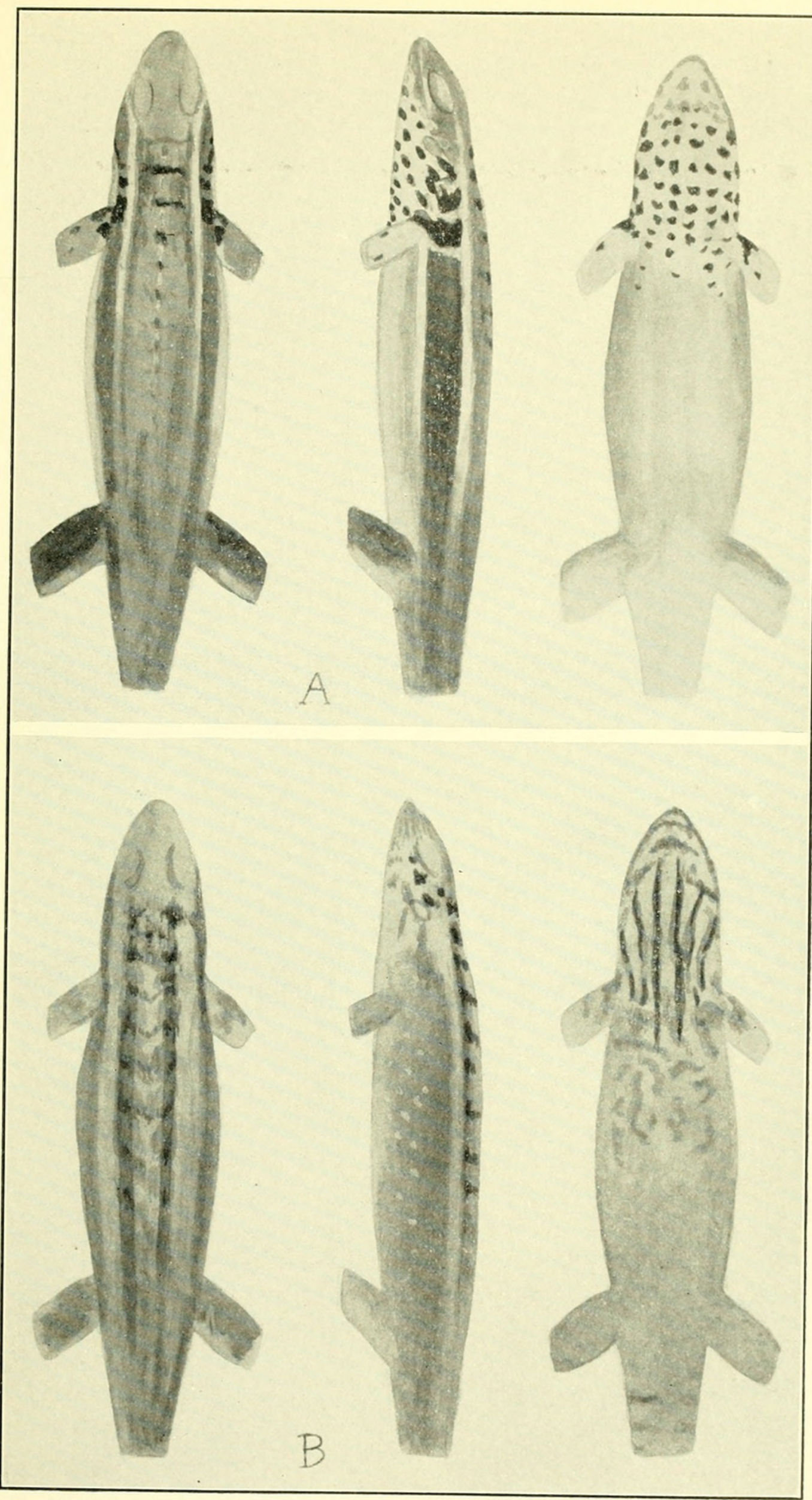

Diagrams of color pattern of (A) Leiocephalus personatus lunatus (male) and (B) L. p. vinculum (male). 


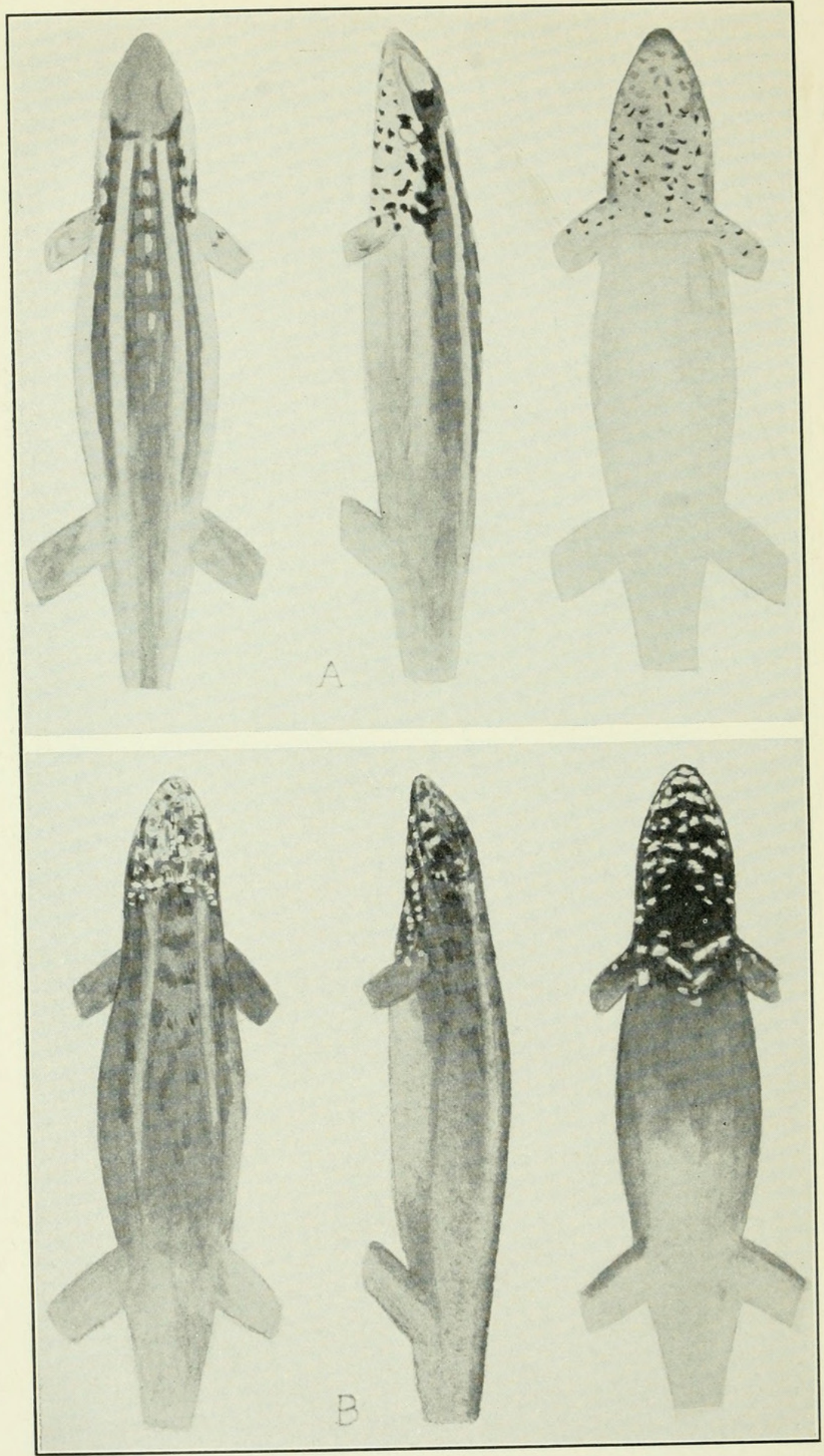

Diagrams of color pattern of (A) Leiocephalus personatus louisae (male) and (B) L. p. altavelensis (male). 
regions that perhaps will never be satisfactorily assignable to one of the known subspecies, as isolation has not yet played the part in the main central portion of Hispaniola that it has so obviously done upon the outlying insular and peninsular forms such as typical personatus at the extreme soutbwest and mentalis in the northeast.

The lizards from northern Haiti have some of the characters of scalaris, mentalis, or barahonensis without being very definitely any one of them. The Hinche specimen, M.C.Z. No. 25431, was once recorded by me as semilineatus. I now believe that it may represent an intergrading form toward beatanus.

\section{LEIOCEPHALUS PERSONATUS SEMILINEATUS Dunn}

Figures 64, 65c; Plate 2, A

1920. Leiocephalus semilineatus Dunn, Proc. New England Zool. Club, vol. 7, p. 33 (type locality, Thomazeau, Haiti).-Cochran, Proc. Biol. Soc. Washington, vol. 41, p. 54, 1928 (part) (Morne à Cabrits).-BARBour, Zoologica, vol. 11, No. 4, p. 99, 1930; vol. 19, No. 3, p. 122, 1935; Bull. Mus. Comp. Zool., vol. 82, No. 2, p. 137, 1937.-BArbour and Loveridge, Bull. Mus. Comp. Zool., vol. 69, No. 10, p. 289, 1929.

Description.--U.S.N.M. No. 59144, an adult male from Morne à Cabrits, Haiti, collected by J. B. Henderson and Dr. Paul Bartsch on April 24, 1917. Head shields large, entirely smooth, three scales (an internasal and two prefrontals) in a line between the rostral and the beginning of the supraorbital ring; prefrontals and internasals embracing a medial series of three contiguous scales, the anterior smallest and not in contact with the rostral, the central scale the largest; posterior prefrontals much the larger; both pairs of prefrontals directly in contact with the canthals; two canthal scales, the first one short and wide, the second much longer, followed by five superciliaries, the first three of which are exceedingly long, narrow, and overlapping, the last two rather small; five supraoculars, separated incompletely from the superciliaries and from the frontals on either side by a single interrupted series of small scales; frontals moderately large, in contact along their entire inner margin; occipital very small, bordered laterally by two pairs of parietals, the inner slightly the larger and about four times as large as the occipital; four upper and five lower labials to a point directly beneath the center of the eye; temporal scales smooth in front of the ear; an enlarged smooth scale accompanied by one or two slightly smaller ones on the upper anterior corner of the ear; the scales between them and the parietals small and keeled; anterior margin of the ear with four enlarged projecting scales. Dorsal scales moderately large, imbricate, and somewhat mucronate, the rows converging along the center of the back; laterals slightly smaller than the dorsals, their keels directed upward and backward; ventrals about equal to the dorsals in size, smooth, their posterior edges $226849-41-15$ 
scarcely denticulate; about 42 scales around the middle of the body; about 55 scales from the occiput to a point directly above the vent; about 16 dorsal scales equivalent to the distance from snout to occiput; nuchal scales moderate, those behind the ear and in the shoulder folds quite small but keeled like the dorsals; the only trace of the lateral fold is a short axillary fold which does not extend beyond the adpressed elbow. The adpressed hindlimb reaches to the anterior corner of the eye. Digits compressed, the hindtoe with 21 tricarinate lamellae. A low but distinct dorsal crest beginning on the occiput, increasing somewhat on the distal portion of the tail; the other caudal scales heavily keeled and highly mucronate; no verticils. Tail round. A group of enlarged postanals in the male.

Dimensions: Snout to vent, $47 \mathrm{~mm}$; head to posterior ear, 12.5 mm.; tail, $68 \mathrm{~mm}$.; foreleg, $21 \mathrm{~mm}$.; hindleg, $39 \mathrm{~mm}$.; width of head, $9.5 \mathrm{~mm}$.

Color (in alcohol): Body color olive-buff above, with a pale emerald iridescent stripe on the dorsolateral region, bordering a wide sepia stripe that begins behind the eye and contains a few scattered small green spots; this sepia stripe is set off below by a white stripe, which begins on the upper lip and continues backward along the body nearly to the groin; below this the olive-buff lateral color is checkered by short transverse series of light scales, probably green or pale blue in life. Ventral surface immaculate light olivebuff with a greenish iridescence. Tail pale cinnamon above, with narrow chevron-shaped sepia cross bars. Upper surfaces of arms and legs spotted with sepia; posterior surface of femur with dark reticulations enclosing round white spots. Lips and throat immaculate white.

Variations.-This dwarf species seems to have a fairly constant and regular arrangement of the head plates. The supraoculars are usually five in number though occasionally six when they are smaller than usual. The internasals usually meet each other behind the frontal; sometimes the first of the median azygous series meets the rostral instead. In this median series there are usually three scales. The posterior prefrontal is always large, sometimes indeed even larger than the frontal. The occipital, on the other hand, is rather small and seldom separates the inner parietals for more than one-third of their length. The projecting ear scales are usually prominent, with the second and third much larger than the others. In the patch of enlarged scales at the upper anterior corner of the ear one scale is sometimes larger than the rest, or there may be two of equal size in this position.

The color pattern is very constant. The pale wide dorsal area with the sharply marked sepia stripes produces a coloration that sets 
semilineatus off from most other Hispaniolan Leiocephali. The pattern of the young is retained through the adult stages and is the same in male and female.

The species does not seem to be widespread in Haiti, since it has been secured at only two places up to the present.

Schmidt ${ }^{9}$ maintains that semilineatus agrees with melanochlorus rather than with personatus in having the same number of shields between the rostral and the supraorbital ring, owing to his mistaken understanding as to the actual number of such shields in the three species named. As a matter of fact, both semilineatus and personatus have three shields, while melanochlorus has four. Furthermore, the last-named species belongs to that group having a lateral fold and therefore is very sharply distinct from the other two.

Specimens examined.-As listed in table 39.

TABLE 39.-Specimens of Leiocephalus semilineatus examined

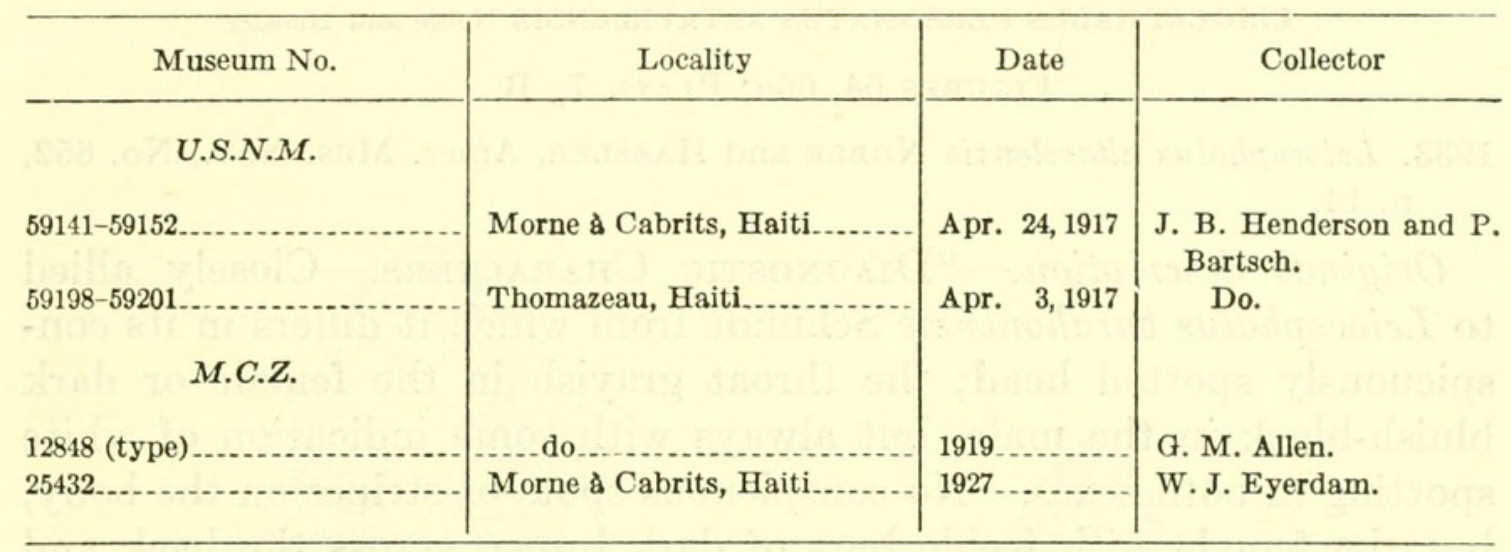

LEIOCEPHALUS PERSONATUS BARAHONENSIS Schmidt

Figures $64,65 d$

1921. Leiocephalus barahonensis Sснмірт, Bull. Amer. Mus. Nat. Hist., vol. 44, art. 2, p. 15, fig. 12.-Barbour and Loveridge, Bull. Mus. Comp. Zool., vol. 69, No. 10, p. 289, 1929.-BArbour, Zoologica, vol. 11, No. 4, p. 99, 1930; vol. 19, No. 3, p. 122, 1935; Bull. Mus. Comp. Zool., vol. 82, No. 2, p. $138,1937$.

1938. Leiocephalus personatus barahonensis Mertens, Senckenbergiana, vol. 20, No. 5, p. 338; Publ. Inst. Cient. Domínico-Alemán, vol. 1, p. 88, 1939.Böker, Publ. Inst. Cient. Domínico-Alemán, vol. 1, p. 16, 1939.

Original description.-"Type.-A.M.N.H. No. 2736; Barahona, Santo Domingo; J. L. Phillips; 1912.

"Description of type.-Head scales well developed; three scales between the rostral and the first supraocular; a pair of frontals, a pair of prefrontals, and a pair of supranasals; each of these scales in contact with its fellow, but enclosing a series of three small median

' Bull. Amer. Mus. Nat. Hist., vol. 44, art. 2, p. 15, 1921. 
scales; frontals and prefrontals separated from the canthal scales by an elongate rhomboidal scale; three pairs of supraorbitals; seven supraoculars on each side; a small occipital, bordered by a pair of narrow parietals, followed on each side by a broad parietal twice as broad as the inner; anterior head shields smooth, supraoculars and parietals striate; five upper and five lower labials. Dorsal and lateral scales sharply keeled, slightly mucronate; ventral scales smooth; about forty scales around the middle of the body; scales of the sides of the neck like the dorsals; dorsal and caudal crests low.

"Back greenish gray, nearly uniform; sides darker; venter lighter greenish gray, throat and chin heavily spotted with dark brown.

"Notes on Paratypes.-The two paratypes agree in essential characters with the type. The smaller specimen has a faint dorsolateral line anteriorly. Both have only two scales in the median series, between the frontals and prefrontals."

\section{LEIOCEPHALUS PERSONATUS ALTAVELENSIS Noble and Hassler}

Figures 64, 66a; Plate 7, B

1933. Leiocephalus altavelensis Noble and Hassler, Amer. Mus. Nov., No. 652, p. 14.

Original description.- "Diagnostic Characters.-Closely allied to Leiocephalus barahonensis Schmidt from which it differs in its conspicuously spotted head; the throat grayish in the female or dark bluish-black in the male, but always with some indication of white spotting in both sexes. No conspicuous spots or stripes on the body, but the female with feeble bars of dark brown across the back and frequently some indication of a pale dorsolateral stripe. Scales behind ear keeled and imbricate, not granular. Three scales on each side between the rostral and supraorbital ring; the posterior separated from the canthus by a wedge-shaped scale. About fifty scales around the middle of the body; hind leg reaching between the ear and eye.

"Detailed Description.--Type: A.M.N.H. No. 51055, adult male. Collected on Alta Vela Island, D. R., October 9-10, 1932, by W. G. Hassler.

"Anterior head-shields smooth, posterior ridged; three enlarged scales, a supranasal, a prefrontal and a frontal on each side of the snout between rostral plate and supraorbital ring; the posterior of these three scales more than twice as large as either of the anterior; these three scales on each side separated from the homologous row on the opposite side by a median row of three scales; the supranasals narrowly in contact anteriorly; nasals and supranasals in broad contact with rostral; frontal separated from the canthus by an elongate wedge-shaped scale; two or three scales between this elongate scale and the nasal; two heavy rounded canthus scales followed by four long and very narrow superciliaries, the first three of which greatly 
overlap; a single small scale between the anterior canthus and the nasal; six enlarged supraoculars separated from the superciliaries by a single row of small scales except anteriorly where one or two extra scales are intercalated; three pairs of enlarged scales between the supraorbital rings, the anterior pair much larger than the others; occipital small and separated from the two posterior pairs of these enlarged interorbital scales by a row of three small scales; a pair of

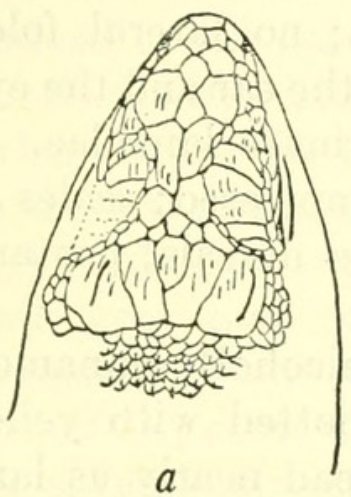

$a$

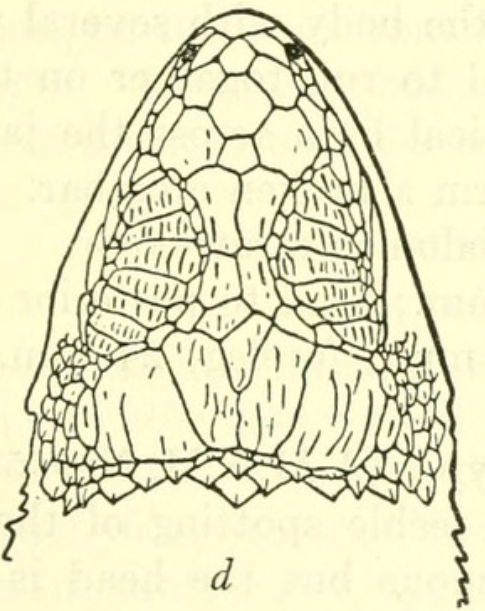

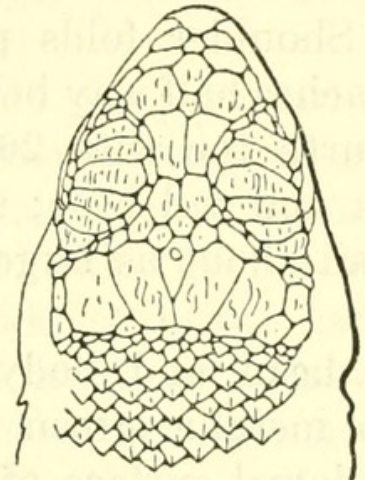

$b$

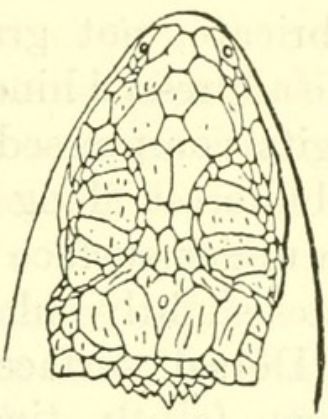

$c$

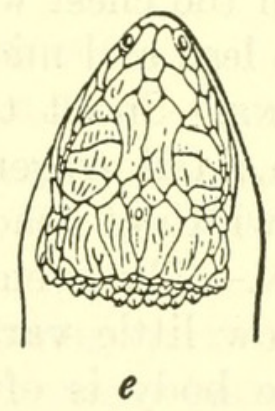

Figure 66.-Tops of heads of Leiocephalus and Hispaniolus: a, L. personatus altavelensis, A.M.N.H. No. 51069, paratype, from Alta Vela Island, Dominican Republic; $b, L$. $p$. vinculum, M.C.Z. No. 25435, type, from Point-à-Raquettes, Gonave Island, Haiti; $c, L$. $p$. louisae, M.C.Z. No. 37551, type, from Saona Island, Dominican Republic; $d$, L. p. beatanus, U.S.N.M. No. 86864, from Beata Island, Dominican Republic; $e$, Hispaniolus pratensis, U.S.N.M. No. 69189, type, from San Michel du Nord, Haiti. Twice natural size.

(See also fig. 65 , p. 206.)

elongate parietals on either side, the median pair making broad contact behind the occipital; four or five scales, half the size of the occipital or less, between the lateral pair of parietals and the small temporal scales. Four upper labials and four and a half lower labials to a point below the center of the eye; temporal scales increasing gradually in size, the last one, just above and in front of the ear, the largest and most conspicuous; anterior border of the ear opening with three or four coarse projecting scales. Dorsal scales large, imbricate, 
mucronate; the laterals about two-thirds as large as the dorsals, becoming smoother and more rounded toward the lower portions of the sides; ventrals approximately as large as the dorsals, smooth, their posterior edges slightly denticulate; about fifty scales around the middle of the body; about fifty-eight scales from the occiput to a point directly above the vent, sixteen dorsal scales the equivalent of the distance from snout to occiput; nuchal scales small, those on the sides of the neck like the dorsals, those behind the ear keeled and imbricate, not granular. Shoulder folds present; no lateral folds. The adpressed hind limb reaches half way between the ear and the eye. Digits compressed; the fourth toe with 26 tricarinate lamellae. A feeble crest along the back and tail base; tail compressed; scales on the under surface of the tail about as large as the dorsals; postanal scales slightly enlarged.

"Dorsal surface of the head and body (in alcohol) cinnamonbrown faintly tinged with metallic green and spotted with yellow or gray; the spots on the dorsal surface of the head nearly as large as the scales, while those on the back are much smaller and those on the posterior surfaces barely distinct; sides of the head, neck and body as well as the whole throat a blue-gray; sides of the head, throat and chest spotted with white; sides of the body with several vertical rows of pale blue spots; the spots tend to run together on the side of the head where they form two vertical bars across the jaws and eyelids and on the chest where they form a broken crossbar. Under surface of the legs and middle of the abdomen straw-color.

"Dimensions.- Snout to vent, $60 \mathrm{~mm}$; head to posterior edge of ear, $15.5 \mathrm{~mm}$; tail (regenerated), $38 \mathrm{~mm}$.; foreleg, $24 \mathrm{~mm}$; hindleg, $44 \mathrm{~mm}$.; width of head, $11.5 \mathrm{~mm}$.

"VAriation.-The twenty-two paratypes (A.M.N.H. Nos. 51051-4, 51056-73) show little variation. The feeble spotting of the dorsal surface of the body is often inconspicuous but the head is always distinctly spotted both above and below. In the female a series of transverse bars or widely opened V's of dark brown are frequently found on the back; the throat is always much paler gray than the male's but the white spots may be more numerous and smaller. The tail of the type is regenerated and does not show the crest which in the unregenerated tail is better developed than along the middle of the back.

"In life, the yellowish-brown dorsal color was overlaid with a golden-bronze sheen. The head was slightly darker, almost every scale being edged with dark brown while the sides of the head were darker still. Usually there was no distinct pattern on the back. One adult male, just before shedding, showed faint cross-lines on the back but these were less distinct after shedding. The dorsal surface of the legs was darker than that of the body and showed light spots 
but no bars. The tail was light yellowish-brown, lighter than the body and with extremely faint, narrow cross-lines. The side of the body was a greenish hue with scattered spots of a bright metallic green covering individual scales. The throat was a bronzy, dark brownish black with small white spots, often running together. Toward the chin the throat became less bronzy. The belly was yellowish with sometimes a slightly green tint. In young specimens the tail was more orange. No marked sexual dichromatism was noticed in the field.

"Habitat.- This species was common on the island of Alta Vela, living among the rocks, leaves and grass along the coast and ranging to the top of the higher ridge in the center of the island."

A male paratype, A.M.N.H. No. 51069, has a ground color of dark gray over lower side of head, neck, and chest; white spots arranged in one or two irregular transverse bars on chin; throat unspotted; chest with white spots arranged in a wide V-shape. There are seven supraoculars on right side of head; inner pair of parietals about two-thirds the width of outer pair; five upper and four and one-half lower labials to below center of eye; 54 scales around body at middle, and about 61 a little anterior to this point; 63 dorsal scales from occiput to above vent; 16 dorsal scales in distance from snout to occiput. Head and body, $47 \mathrm{~mm}$; head length, $15.5 \mathrm{~mm}$.; head width, $12 \mathrm{~mm}$.; foreleg, $24 \mathrm{~mm}$.; hindleg, $43 \mathrm{~mm}$.; tail (regenerated), $70 \mathrm{~mm}$.

\section{LEIOCEPHALUS PERSONATUS AUREUS Cochran}

Figures 64, 65e; Plate 2, B

1934. Leiocephalus personatus aureus Cochran, Occ. Pap. Boston Soc. Nat. Hist., vol. 8, p. 175.-BARBour, Zoologica, vol. 19, No. 3, p. 120, 1935; Bull. Mus. Comp. Zool., vol. 82, No. 2, p. 136, 1937.

Original description.- "Diagnosis.-Anterior part of snout much swollen (in adult male), appearing highly convex when seen in profile; no lateral fold; three scales between rostral and supraocular ring; frontals and prefrontals smooth; frontals separated from canthals by a wedge-shaped scale; throat with a series of about four regular transverse rows of spots running across it, the posterior ones continued as stripes onto the labials and nearly to the upper part of the head; under surfaces of legs and tail gamboge yellow.

"Type.-An adult male, U.S.N.M. 75909, from Jacmel, Haiti, collected by J. S. C. Boswell in 1928.

"Description of the type.-Headshields enlarged, the posterior distinctly ridged, the anterior smooth; anterior part of snout much swollen (in adult male), appearing highly convex when viewed in profile; three scales (an internasal and 2 prefrontals) between the rostral and the supraorbital ring; posterior prefrontals much the larger; nasals in contact with rostral; internasals in contact with each other 
behind rostral, broader than long; prefrontals separated from the canthals by a wedge-shaped scale; two heavy rounded canthal scales followed by four elongate superciliaries; six distinctly ridged supraoculars, the posterior one quite small, separated from the superciliaries by one row of small keeled scales; occipital very small, bordered by two distinct pairs of parietals on each side, the inner about eight times the area of the occipital and about one-third that of the outer pair; no distinctly enlarged latero-nuchals beyond the outer parietals; three very elongate upper and five lower labials to a point below the center of the eye; temporal scales increasing posteriorly in size, the last one, just above and in front of the ear, abruptly larger and very conspicuous; anterior border of the ear with three large, coarse, projecting scales. Dorsal scales large, imbricate and moderately mucronate, laterals considerably smaller than the dorsals; ventrals equal to dorsals in size, smooth, their posterior edges denticulate; about 44 scales around middle of body; about 48 scales from occiput to a point directly above the vent; about 11 dorsal scales the equivalent of the distance from snout to occiput; nuchal scales small, those on the sides of the neck like the dorsals, those behind the ear keeled and imbricate, not granular. Shoulder folds present; no lateral folds. The adpressed hind limb reaches almost to the posterior corner of the eye. Digits compressed; the fourth toe with 23 tricarinate lamellae. A distinct crest beginning on the occiput, moderately developed on the back and becoming a little higher on the proximal part of the tail; the other caudal scales mucronate and keeled above, smooth below; no verticils. The keels of the lateral and dorsal scales are directed upwards and backwards, so that the scale rows converge on the posterior part of the back; the convergence is less pronounced anteriorly. Tail somewhat compressed proximally, so that its section would appear squarish. A pair of enlarged postanals in the male.

"Dimensions.-Snout to vent, $68 \mathrm{~mm}$.; head to posterior ear, 17 mm.; tail (reproduced), $82 \mathrm{~mm}$.; foreleg, $25 \mathrm{~mm}$; hindleg, $40 \mathrm{~mm}$.; width of head, $14 \mathrm{~mm}$.

"Color in alcohol.-Body color dull sage green above, with a wide light dorsolateral stripe beginning behind the eye,running above the ear and continuing along the sides onto the tail; this light stripe bordered above and below by wide sepia stripes; scarcely any traces of dorsal crossbars in the adult male; throat indigo blue with a series of about four regular transverse rows of spots running across it, the posterior ones continued as stripes onto the labials and nearly to the upper part of the head; mental and rostral shields with pale buff immaculate borders; chest and belly wax yellow, the under surfaces of fore and hind legs and tail deepening to gamboge yellow; sides of body dull indigo with some brighter china-blue scales edged with sepia; no spots or bars on posterior part of body or tail or on upper 
parts of limbs (in adult male); no dark axillary spots; top of head and loreal region dull drab with a powdering of minute gray dots.

"Paratypes.-Four other adults, U.S.N.M. 75910-13, and two young ones, U.S.N.M. 75914-5, were collected at the same place and time as the type specimen. Four fine half-grown individuals, now M.C.Z. 37535-8, were taken at Jacmel, the type locality, by M. André Audant. An example from the Artibonite Valley, Haiti, U.S.N.M. 75916, collected by J. S. C. Boswell, also appears to belong to this subspecies although it may represent an intergrading form.

"Relationships.-Because of the peculiarly swollen nose, this subspecies strongly suggests its close neighbor Leiocephalus personatus personatus, which likewise has a highly convex profile in the adult male. But this subspecies is even more suggestive of the one found on Beata Island, Leiocephalus personatus beatanus, for both have essentially the same coloration-wide dark and light stripes on the body without crossbands in the adult, and with the spots on the chin arranged regularly in transverse rows which continue on the sides of the head. The hindlegs and tail of the Beata lizard are suffused with a brilliant cadmium orange or cinnamon, while these regions of the Jacmel lizard are similarly but less vividly colored with gamboge. The coloring everywhere is brighter in the Beata lizard, and the dark crossbars in that race occur not only on the throat but well back onto the chest also, unlike the condition in aureus."

\section{LEIOCQEPHALUS PERSONATUS SCALARIS Cochran}

Figures 64, 65g; Plate 4

1932. Leiocephalus personatus scalaris Cochran, Proc. Biol. Soc. Washington, vol. 45, p. 181.-Barbour, Zoologica, vol. 19, No. 3, p. 121, 1935; Bull. Mus. Comp. Zool., vol. 82, No. 2, p. 135, 1937.

"Original description.-Diagnosis.-Color pattern somewhat similar to that of L. p. mentalis but less definite; 20-24 lamellae on the fourth toe; adpressed hindleg of the adult reaches between ear and shoulder, very rarely in front of ear; 57 to 64 very spinose dorsal scales between occiput and beginning of tail; occipital scale usually much reduced in size and pushed forward so that the inner parietals are in nearly complete contact with each other.

"Description of the type.-U.S.N.M. No. 74054, an adult male from Cap-Haïtien, Haiti, taken by A. J. Poole from March 3 to 6, 1928. Head shields enlarged, ridged excepting those bordering the rostral; three scales (an internasal and 2 prefrontals) between the rostral and the supraorbital ring; posterior prefrontals much the larger; nasals in contact with rostral; internasals somewhat elongate, in contact narrowly with each other behind the rostral; internasals, prefrontals and anterior parts of the frontals embracing a median series of three contiguous scales; prefrontals separated from the canthals 
by a relatively large wedge-shaped scale; two heavy rounded canthal scales followed by three long and narrow superciliaries and two small terminal ones; six (on one side five) distinctly ridged supraoculars separated from superciliaries and from frontals by a row of small keeled scales; occipital exceedingly small, lying at the anterior border of the inner parietals but scarcely shortening their suture, and not distinguishable from the surrounding scales except by its position; the inner and outer parietals approximately equal in size; no conspicuously enlarged latero-nuchal scales; four upper and four lower labials to a point below the center of the eye; temporal scales increasing gradually in size, the last one just above and in front of the ear being the largest and most conspicuous; anterior border of the ear with four rather short projecting scales. Dorsal scales relatively smaller than in the allied forms, imbricate and highly mucronate, the length of the spiny scale-tips giving to the animal a very bristling appearance; laterals as large as dorsals; ventrals larger than either dorsals or laterals, smooth, their posterior edges denticulate; about 46 scales around the middle of the body; about 64 scales from the occiput to a point directly above the vent; about 14 dorsal scales the equivalent of the distance from snout to occiput; nuchal scales small, those on the sides of the neck like the dorsals, those behind the ear keeled and imbricate, not granular. Shoulder folds present; no lateral folds. The adpressed hind limb barely reaches the ear. Digits compressed, the fourth toe with 22 tricarinate lamellae. A very prominent dorsal crest beginning on the occiput, the sharply pointed elongate scales about equally developed along the back and on the distal portion of the tail, then decreasing; the other caudal scales keeled and very highly mucronate; no verticils. The keels of the lateral and dorsal scales are directed upwards and backwards, so that the scale-rows converge strongly on the back. Tail highly compressed. A pair of enlarged post-anals in the male.

"Dimensions.-Snout to vent, $75 \mathrm{~mm}$; head to posterior ear, 17 $\mathrm{mm}$.; tail defective; foreleg, $27 \mathrm{~mm}$.; hindleg, $57 \mathrm{~mm}$.; width of head, $13 \mathrm{~mm}$.

"Color in alcohol.-Body color dull sage green above, glaucous blue to china blue below; a wide light dorsolateral stripe; another similar light lateral stripe from axilla to groin; indications of sepia crossbars on the nape of the neck; the body-scales above and below the light dorsolateral line with sepia posterior borders, and sometimes the upper half of each scale dark also; tail with faint indications of sepia cross bars at regular intervals; limbs sage green, without bars or spots; the lower lip spotted with triangular sepia markings which coincide with the sutures between the lower labials; mental plate edged anteriorly with sepia; a few sepia spots along the chin below the labials; the remainder of the throat immaculate china blue; sides of head from 
tip of snout to a little above and behind the ear sepia, with two or three pale cream spots on the upper lip, the last of these continuing backwards to the ear and fading out as a light streak a little way behind the ear; top of head olive; the rostral and internasals and nasals sepia; a sepia spot between the posterior prefrontals and an indistinct marking of the same hue on the frontals and supraoculars.

"Paratypes.-U. S. N. M. Nos. 74047-53, 74055-74, all from the same place and collected on the same date as the type specimen.

"Variations.-The species under consideration, like the others of its group in Haiti, has two prefrontals. The medial series of scales on top of the snout are most often three in number, although two, four and even five are known to occur. Supraoculars are usually six, although some individuals have but five. The dorsal scales counted from the occiput to the beginning of the tail range from 57 to 66 in number, while around the body there are from 41 to 49 uneven diagonal rows. There are usually 14 or 15 dorsal scales in the distance from tip of snout to occiput; exceptional specimens have 12 and 13 up to 17 scales in that distance. The subdigital lamellae are from 20 to 24 in number, with 23 occurring most often.

"The proportion of the head and body to the length of the hind leg is between $60 \%$ and $79 \%$ in the lizards above $50 \mathrm{~mm}$. in length, the average leg length being $72 \%$ of the head and body in eighteen cases. The hind leg when adpressed very seldom reaches beyond the anterior border of the ear, and most often falls considerably behind the ear, while sometimes it just reaches the shoulder. In five lizards under $43 \mathrm{~mm}$. in length the leg proportion averaged $75.4 \%$.

"While the coloration of L. p. scalaris strongly resembles that of $L$. $p$. mentalis in a general way, yet the specific differences, in adult males at least, are well marked. The latter subspecies has the very dark patch on the side of the head ending sharply at the upper border of the ear or a scale or two behind it, while there is no distinct dark lateral stripe continuing backwards from it. In the former subspecies the dark area on the side of the head is rather ill defined, although behind the ear it may be seen to merge with the dark lateral stripe, which remains more or less distinct in the adult. The heavily mucronate body scales of scalaris give it a much more bristling aspect than is the case with the much sleeker mentalis. Both species have a similar pattern on the mental and labials, and the relation between them seems to be rather close, although the short hindleg and more mucronate scales of scalaris separate it readily from its ally. The young, however, are practically indistinguishable."

Specimens examined.-As listed in table 40. 
TABLE 40.-Specimens of Leiocephalus personatus scalaris examined

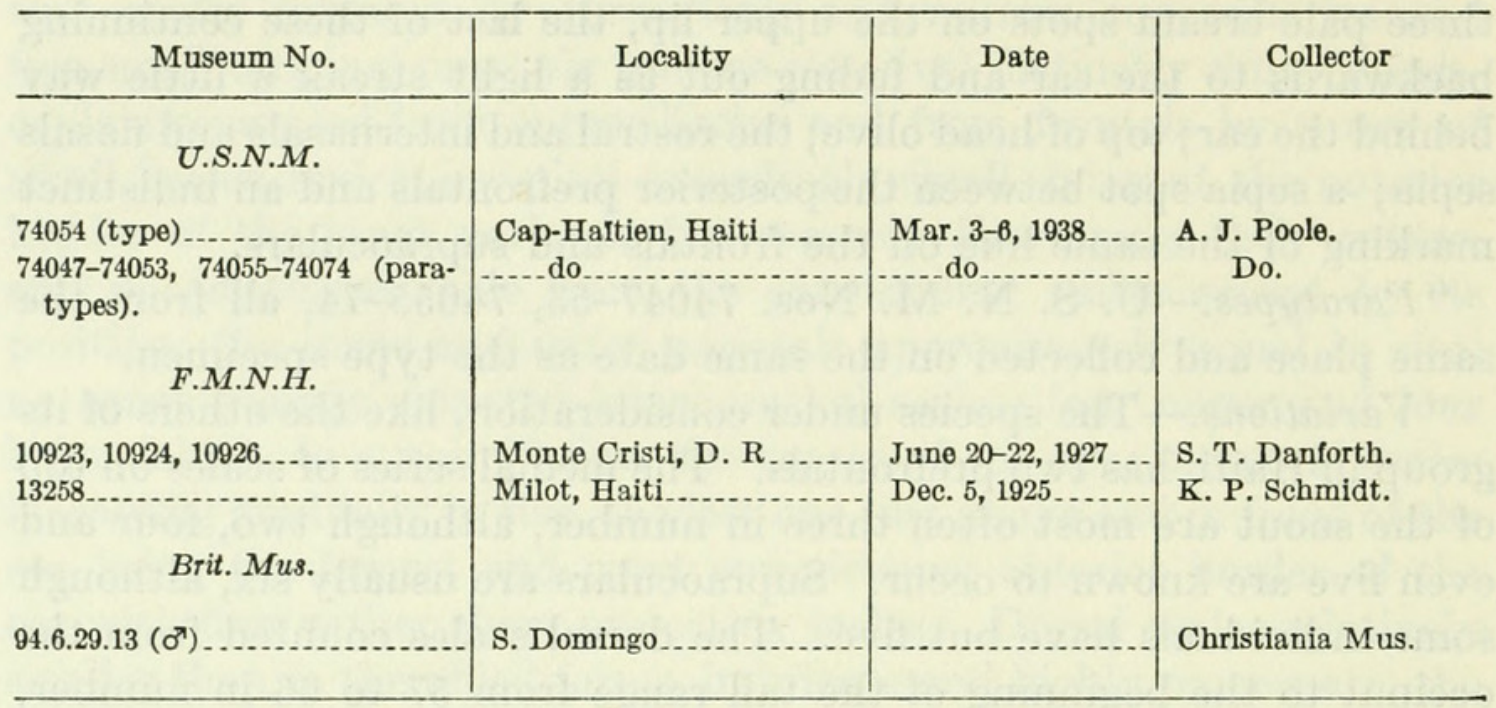

LEIOCEPHALUS PERSONATUS MENTALIS Cochran

Figures 64, 65h; Plate 5

1887. Liocephalus personatus Garman, Bull. Essex Inst., vol. 19, p. 49, extr. p. 25 (part) (Puerto Plata; collector, M. A. Frazar).

1914. Leiocephalus personatus BArbour, Mem. Mus. Comp. Zool., vol. 44, No. 2, p. 302 (part) (Puerto Plata).-?Schмidt, Bull. Amer. Mus. Nat. Hist., vol. 44, art. 2, p. 14, 1921 (Monte Cristi, Puerto Plata, Sánchez, Sabaneta).Cochran, Proc. U. S. Nat. Mus., vol. 66, art. 6, p. 10, 1924 (Jovéro).

1932. Leiocephalus personatus mentalis Cochran, Proc. Biol. Soc. Washington, vol. 45, p. 178.-BARBodr, Zoologica, vol. 19, No. 3, p. 120, 1935; Bull. Mus. Comp. Zool., vol. 82, No. 2, p. 136, 1937.-Mertens, Senckenbergiana, vol. 20, No. 5, p. 338, 1938; Publ. Inst. Cient. Domínico-Alemán, vol. 1, p. 88, 1939.-Böker, Publ. Inst. Cient. Domínico-Alemán, vol. 1, p. 18, 1939 .

Original description.- "Diagnosis.-Mental shield and lower lips of adult males sepia; remainder of throat pale china blue, immaculate or with a few very minute pale brown spots confined mostly to single scales; sides of head from tip of snout to above the ear sepia, with one or two large pea-green spots below the eye; sometimes a small brown spot just behind the ear; prefrontals seldom touching the canthals; $22-26$ lamellae on the fourth toe; hind leg adpressed reaches to the eye or to between ear and eye; 54 to 62 scales between the occiput and the tail, not highly mucronate or noticeably bristling.

"Description of the type.-U.S.N.M. No. 65772, an adult male from Jovéro, Dominican Republic, collected on Feb. 19, 1923, by Dr. W. L. Abbott. Headshields enlarged, the posterior distinctly ridged, the anterior more faintly; three scales (an internasal and 2 prefrontals) between the rostral and the supraorbital ring; posterior prefrontals much the larger; nasals in contact with rostral; internasals somewhat elongate, barely separated from each other by the first of the series of three medial scales; prefrontals separated from the canthals by a relatively large wedge-shaped scale; two heavy rounded canthal scales 
followed by three long and narrow superciliaries and two small terminal ones; six distinctly ridged supraoculars separated from the superciliaries anteriorly by 2 rows of small keeled scales and posteriorly by but one row, and from the frontals by a single row; occipital small, bordered by two distinct pairs of parietals on each side; the inner about four times the size of the occipital and a little larger than the outer; an enlarged latero-nuchal scale beyond the outer parietal which is almost half its area; four upper and five lower labials to a point below the center of the eye; temporal scales increasing gradually in size, the last one, just above and in front of the ear, the largest and most conspicuous; anterior border of the ear with five coarse projecting scales, the middle ones the largest. Dorsal scales large, imbricate and moderately mucronate; laterals considerably smaller than the dorsals; ventrals equal to or slightly larger than the dorsals, smooth, their posterior edges denticulate; about 50 scales around the middle of the body; about 56 scales from the occiput to a point directly above the vent, about 14 dorsal scales the equivalent of the distance from snout to occiput; nuchal scales small, those on the sides of the neck like the dorsals, those behind the ear keeled and imbricate, not granular. Shoulder folds present; no lateral folds. The adpressed hind limb reaches to half-way between the ear and the eye. Digits compressed; the fourth toe with 24 tricarinate lamellae. A distinct crest beginning on the occiput, equally developed on the back and on the proximal portion of the tail but decreasing as the tail tapers; the other caudal scales keeled and mucronate; no verticils. The keels of the lateral and dorsal scales are directed upwards and backwards so that the scale-rows converge strongly on the back. Tail highly compressed. A pair of enlarged post-anals in the male.

"Dimensions.-Snout to vent, $64 \mathrm{~mm}$.; head to posterior ear, 16.5 mm.; tail, $92 \mathrm{~mm}$.; foreleg, $25 \mathrm{~mm}$.; hindleg, $48 \mathrm{~mm}$.; width of head, $13 \mathrm{~mm}$.

"Color in alcohol.-Body color sage green above, pale china blue to Nile blue below; very faint indications of sepia crossbars on the nape of the neck; the body-scales above and below the light dorsolateral line with sepia posterior borders, darker towards the center of the back than on the sides of the body; tail with faint indications of sepia crossbars at regular intervals; limbs without bars or spots, but each scale having a powdering of minute sepia spots on its posterior margin; mental shield and lower lips sepia; remainder of throat pale china blue with a few very minute pale brown spots confined mostly to single scales; sides of head from tip of snout to above the ear sepia, with two large pea-green spots below the eye; a small brown spot just behind the ear; top of head olive, with irregular darker markings on most of the scales. 
"Variations.-As to the numbers of prefrontal scales, this species invariably has two. The median snout scales are three in most cases, usually in a single median series, the anterior the smallest and ordinarily separated from the rostral. Sometimes two scales lie side by side, making four and rarely five in the median series.

"The supraoculars are six in nearly all cases, although sometimes seven and rarely five are to be counted. The prefrontals usually do not touch the canthals, but sometimes on one side of the head they may do so, while in one instance they touch on both sides. The dorsal scales counted parallel to the dorsal crest from occiput to the beginning of the tail vary between 54 and 62 , while from 13 to 15 scales equal the distance between occiput and tip of snout in the adult and from 16 to 17 scales in the young. The scales around the body range approximately between 43 and 52, but the slanting of the scalerows and the interpolation of new ones makes it nearly impossible to get the same count twice in succession on one individual.

"The subdigital lamellae are 22 to 26 , usually 23 . The ratio of the length of the hind limb compared to the total length of the head and body varies somewhat with the age and sex of the specimen being studied. Two very young ones obviously just out of the egg, both measuring $27 \mathrm{~mm}$. in combined length of head and body, have the hind legs $85 \%$ of that length. The largest adult measuring $83 \mathrm{~mm}$. in length has a hind leg ratio of $72 \%$. In individuals of the same approximate size, the relative length of the hind limb varies as much as $18 \%$; in the specimens measuring from $50 \mathrm{~mm}$. up to the maximum of $83 \mathrm{~mm}$., the hind leg is anywhere from $67 \%$ to $85 \%$ of that length the average being $76 \%$ in four specimens. In every case, however, the adpressed hind limb reaches at least as far as the anterior border of the ear, and in most cases to between the ear and the eye, and even occasionally as far as the eye itself.

"The coloration of adult males is quite uniform. There is an almost total reduction of body pattern, while in contrast to this is the brilliant pattern of dark and light on the lips. The mental shield in all cases is black on the upper border in adult males although the females and young are often nearly immaculate in this region. The top of the head in males is olive-brown, often with darker sepia spots at the posterior supraocular region and on the temporals, and sometimes with light round dots especially concentrated along the canthus and superciliary border. The females and young show a pattern quite similar to that of young personatus but slightly coarser. The spots on the throat and chest tend to be arranged in longitudinal series, while on the belly, when they are present, they assume a transverse arrangement towards the sides, as a continuation of the dark spots which usually show in the dark lateral band."

Specimens examined.-As listed in table 41. 
TABLE 41.-Specimens of Leiocephalus personatus mentalis examined

\begin{tabular}{|c|c|c|c|}
\hline Museum No. & Locality & Date & Collector \\
\hline U.S.N.M. & & & \\
\hline $\begin{array}{l}10262-10264,10266,10269 \\
10271 .\end{array}$ & Puerto Plata, D. R & 1878 & C. A. Fraser. \\
\hline $\begin{array}{l}65770-65771,65772 \text { (type), } \\
65773 .\end{array}$ & Jovéro, D. R & Feb. $1,1923 \ldots$ & W. L. Abbott. \\
\hline 65774 & Samaná and Laguna, D. R...... & March 1923_........ & Do. \\
\hline $65775-65779 \ldots \ldots$ & Jovéro, D. R. & Feb. 6, 1923 ....... & Do. \\
\hline $66694-66707$ & Dominican Republic & $1923 \ldots \ldots$ & Do. \\
\hline $66708,66709,66712 \ldots \ldots$ & Jovéro, D. R & Nov. $30,1923 \ldots$ & Do. \\
\hline $66710,66711 \ldots \ldots \ldots$ & Guarabo, D. R & Nov. $21,1923 \ldots$ & Do. \\
\hline M.C.Z. & Samaná Peninsula, D. R......... & $1923 \ldots \ldots$ & Do. \\
\hline 5443 (2 specimens) & Puerto Plata, D. R & $\ldots$ & M. A. Frazar. \\
\hline $13679-13691$ & Sosúa, D. R & $1916 \ldots$ & J. L. Peters. \\
\hline F.M.N.H. & 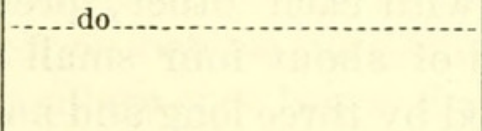 & $1937 \ldots \ldots$ & W. J. Clench. \\
\hline Brit. Mus. & Sánchez, D. R.... & 1924 & E. Kaempfer. \\
\hline $\begin{array}{l}\text { 51.10.11.17-19 }\left(\sigma^{7} \sigma^{7}\right) \text {, } \\
\text { 51.10.11.20 (q). }\end{array}$ & "S. Domingo"..... & & M. Sallé's coll. \\
\hline 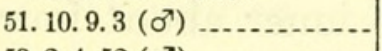 & ...... do & & Zool. Soc. coll. \\
\hline $\begin{array}{l}\text { U3.2.4. } 52\left(\sigma^{7}\right) \\
\text { Univ. Mus. Copenhagen }\end{array}$ & ......do do............... & $-1+2-2-2.0-1$ & \\
\hline Univ. Puerto Rico & Puerto Plata, D. R & Nov. 18, 1887...... & Baron Eggers. \\
\hline | & Santiago, D. R.... & March 26, 1936.... & S. del Rosario. \\
\hline
\end{tabular}

\section{LEIOCEPHALUS PERSONATUS LUNATUS Cochran}

Figures 64, 65i; Plate 6, A

1934. Leiocephalus personatus lunatus Cochran, Occ. Pap. Boston Soc. Nat. Hist., vol. 8, p. 153.-Mertens, Senckenbergiana, vol. 20, No. 5, p. 338, 1938; Publ. Inst. Cient. Domínico-Alemán, vol. 1, p. 88, 1939.-Böker, Publ. Inst. Cient. Domínico-Alemán, vol. 1, p. 18, 1939.

Original description.-“Type.-Field Mus. Nat. Hist. no. 166; an adult male from Santo Domingo City, Dominican Republic, collected in 1895 by George K. Cherrie.

"Paratypes.-Seven other specimens from the same place and by the same collector are now catalogued as F.M.N.H. 109, 125, 136, 139, 152, 158, 163. Another example, F.M.N.H. 10,922, came from Jaina, a little coastal town to the southwest of Santo Domingo City, and was secured by S. T. Danforth.

"Diagnosis.-Resembles Leiocephalus personatus mentalis in having the mental shield edged with sepia; differs from it in having the 
remainder of the throat and chest very heavily spotted with large brown spots in about a dozen transverse series; sides of head nearly immaculate or more or less heavily spotted or striped with sepia, the infraocular region usually pale; in adult males usually three crescentic sepia markings in front of the shoulder, the two posterior ones the largest and corresponding to the hollows behind the skinfolds occurring between ear and shoulder; prefrontals not touching the canthals; 23-28 lamellae on the fourth toe; hindleg adpressed reaches to between ear and eye; $57-68$ scales between the occiput and the tail, not highly mucronate or noticeably bristling.

"Description.-Head shields enlarged, the posterior distinctly ridged, the anterior nearly smooth; three scales (an internasal and 2 prefrontals) between the rostral and the supraorbital ring; posterior prefrontals much the larger; nasals in contact with rostral; internasals somewhat elongate, broadly in contact with each other; prefrontals separated from the canthals by a series of about four small scales; two heavy rounded canthal scales followed by three long and narrow superciliaries and two small terminal ones; six distinctly ridged supraoculars separated from the superciliaries by one row of small keeled scales anteriorly and posteriorly, with two rows between them in the middle of the series, and from the frontals by a single row; occipital small, bordered by two distinct pairs of parietals on each side, the inner about four times the size of the occipital and a little larger than the outer; an enlarged latero-nuchal scale beyond the outer parietal which is almost two-thirds its area; four upper and five lower labials to a point below the center of the eye; temporal scales increasing gradually in size, the last one, just above and in front of the ear, the largest and most conspicuous; anterior border of the ear with five coarse projecting scales, the middle ones the largest. Nuchal scales rather small; dorsal scales large, imbricate and moderately mucronate; laterals only slightly smaller than the dorsals; ventrals slightly larger than the dorsals, smooth, their posterior edges slightly denticulate; about 50 scales around the middle of the body; about 66 scales from the occiput to a point directly above the vent; about 17 dorsal scales the equivalent of the distance from snout to occiput; nuchal scales small, those on the sides of the neck like the dorsals but smaller, those behind the ear very small, keeled and imbricate, not granular. Shoulder folds present, very distinct; no lateral folds. The adpressed hind limb reaches to the posterior border of the eye. Digits compressed; the fourth toe with 28 tricarinate lamellae. A distinct crest beginning on the occiput increasingly developed on the back and prominent on the proximal part of the tail, then decreasing distally; the other caudal scales keeled and mucronate; no verticils. The keels of the lateral and dorsal scales are directed upwards and backwards so that the 
scale-rows converge on the back. Tail scarcely compressed. A pair of postanals in the male.

"Coloration (in alcohol).-Body color pale olive green above, chromium green below; very faint indications of sepia crossbars on the nape of the neck; the body-scales above and below the light dorsolateral line only slightly tinted with sepia; tail without crossbars or markings of any kind in the adult male; hind limbs immaculate; fore limbs with a few small sepia spots on the upper part, and faint traces of crossbars on the wrists; mental shield edged with sepia; sutures between the labials sepia; remainder of throat heavily dotted with large sepia spots in about ten or twelve irregular transverse rows from the chin to the chest; sides of head from tip of snout to above the ear (in the type specimen) pale olive, almost immaculate; two small brown spots just behind the ear, followed by three prominent crescentic sepia markings, the two posterior ones the largest and corresponding to the hollows behind the skinfolds occurring between ear and shoulder; a black axillary spot below the last of these spots; top of head pale olive, without markings.

"Measurements.-Snout to vent, $64 \mathrm{~mm}$.; head to posterior ear, $16 \mathrm{~mm}$; tail (reproduced), $78 \mathrm{~mm}$; foreleg, $25 \mathrm{~mm}$; hindleg, 49 $\mathrm{mm}$.; width of head, $12 \mathrm{~mm}$.

"Variation.-Among the series of nine there is considerable variation, as one might expect. The dorsal scales from occiput to above vent range between 57 and 70, with a corresponding variation of 13 to 17 dorsals in a head-length. There are about 44 to 52 scales around the body, but as is always the case, this count is never made twice alike, due to the slanting of the lateral rows. The lamellae under the fourth toe vary between 23 and 28 . The length of the hindleg is between 74 and 83 per cent of the combined length of head and body. The median snout scales are constantly present as a patch of 2 to 4 scales. There are six supraoculars in every case but one, in that one there are five large and two small supraoculars. Not every adult male shows the crescentic sepia or black shoulder patches which give the subspecies its name. F.M.N.H. 139, for instance, lacks the black shoulder patches and the axillary spot; it is, however, heavily pigmented with sepia on the side on the head and neck above a faint pale lateral stripe beginning on the loreal region. Below this lateral light stripe is another intense concentration of sepia on the jaw in front of the ear, while the sutures of some of the labials are heavily marked with sepia. The dorsal region of this specimen is likewise suffused with sepia, and traces of dark crossbands are apparent almost to the sacral region."

Relationships.-While this subspecies is related to Leiocephalus personatus mentalis, the type locality of which is Jovéro, D. R., it is still more closely related to louisae from Saona Island.

$226849-41-16$ 
Since the above description was published, another fine male has turned up in the collection belonging to the University of Puerto Rico. It was captured at Santo Domingo City on June 10, 1934, by S. T. Danforth.

\section{LEIOCEPHALUS PERSONATUS BEATANUS Noble}

Figures 64, 66d

1923. Leiocephalus beatanus Noвle, Amer. Mus. Nov., No. 64, p. 5 (type locality, Beata Island, Dominican Republic).-Barbour and Loveridge, Bull. Mus. Comp. Zool., vol. 69, No. 10, p. 289, 1929.-BArBour, Zoologica, vol. 11, No. 4, p. 99, 1930; vol. 19, No. 3, p. 122, 1935; Bull. Mus. Comp. Zool., vol. 82, No. 2, p. 138, 1937.

1934. Leiocephalus personatus beatanus Cochran, Occ. Pap. Boston Soc. Nat. Hist., vol. 8, p. 177.

Description.-U.S.N.M. No. 86864, an adult male from Beata Island, Dominican Republic, collected by Dr. A. Wetmore and F. C. Lincoln between May 11 and 13, 1931. Head shields enlarged, not very heavily ridged anteriorly, slightly more so posteriorly; three scales (an internasal and two prefrontals) between the rostral and the beginning of the supraorbital ring, the posterior one the largest; nasal in contact with the rostral; internasals somewhat elongate, barely separated from each other; the prefrontals and internasals embracing a medial series of three scales, the first one in contact with the rostral between the internasals, the others successively following behind; prefrontals separated from the canthals by an elongate scale; two heavy rounded canthal scales followed by three long and narrow superciliaries and a slightly shorter terminal one; seven ridged supraoculars, the anterior very small, separated from the superciliaries by one (anteriorly) or two (posteriorly) rows of small keeled scales, and from the frontals by a single row of similar scales; frontals large, widely in contact; occipital small, bordered by two distinct pairs of parietals on each side, the inner about half as large as the outer, and about four times the area of the occipital, which fails to separate the inner parietals posteriorly; four upper and five lower labials to a point below the center of the eye; temporal scales increasing regularly in size, the last one just above and in front of the ear the largest and most conspicuous; anterior border of the ear with four coarse projecting scales. Dorsal scales large, imbricate, and highly mucronate; laterals only slightly smaller than the dorsals but much less mucronate; ventrals slightly larger than the dorsals, smooth, their posterior edge highly denticulate; about 38 scales around the middle of the body; about 47 scales from the occiput to a point directly above the vent; about 11 scales the equivalent of the distance from snout to occiput; nuchal scales moderately large, those on the sides of the neck and behind the ear like the dorsals, keeled and imbricate, not granular. Shoulder folds rather poorly developed; no lateral folds. The ad- 
pressed hind limb reaches to the anterior border of the ear. Digits compressed, the fourth toe with 22 tricarinate lamellae. A relatively rather low crest beginning at the occiput, becoming somewhat higher and more conspicuous on the tail; the other caudal scales keeled and mucronate; no verticils. The keels of the lateral and dorsal scales are directed upward and backward so that the scale rows converge strongly on the back. Tail only slightly compressed. A pair of enlarged and elongate postanals in the male.

Dimensions: Snout to vent, $75 \mathrm{~mm}$.; head to posterior ear, $18 \mathrm{~mm}$; tail (reproduced), $88 \mathrm{~mm}$.; foreleg, $29 \mathrm{~mm}$.; hindleg, $54 \mathrm{~mm}$.; width of head, $15 \mathrm{~mm}$.

Color: The color of one of the Beata Island lizards brought alive by Dr. Wetmore to the National Zoological Park was as follows: Above iridescent ochraceous to buff, the dorsal and lateral dark areas olive to seal brown, the sides with occasional pale Nile blue spots on the lateral scales. Top of head fawn color. Sides of head black and white; throat pale drab; chest drab turning to ochre-yellow on the center of the belly and becoming vinaceous-buff across posterior abdomen and lower parts of tibiae and feet, with a darker ochraceousbuff tone on the inferior femur. A mottling of ochraceous-rufous to rufous on the posterior sides where the pale Nile blue spots on the scales are in evidence. Tail uniform vinaceous-cinnamon above and below. Hindlimbs the same above; forelimbs with a suffusion of olive. Spots on head and neck black.

In alcohol the ochraceous tones of the body turn to a plumbeous tone. The spots on the throat and the dorsolateral striping show up as clearly as they do on the living animal.

Variations.-The paratype M.C.Z. No. 17737 has a medial series of two scales on the snout, the anterior the larger, and well separated from the rostral. The frontals and prefrontals are only partially separated from the canthals by a small elongate scale. There are about 40 scales around the middle of the body, while 52 dorsals may be counted from the occiput to the base of the tail, and 13 dorsals are contained in the distance between the occiput and the tip of the snout. Shoulder folds are present but no lateral folds. The adpressed hind limb barely reaches the posterior border of the eye. There are 22 keeled lamellae beneath the fourth toe. The dorsal crest is low but distinct, and the caudal crest is a little higher. The distance from snout to vent is $72 \mathrm{~mm}$.; the head is $20 \mathrm{~mm}$. The other details of body structure are essentially like those of the type specimen.

Some of the adult males of this species, as well as of personatus personatus, have a swollen place just behind the nostrils on top of the snout. This changes the profile of the head considerably, as in U.S.N.M. No. 75910 . 
The coloration of a young lizard only $31 \mathrm{~mm}$. in length from snout to vent is as follows: Body color pale olive-buff; a sepia lateral stripe originating quite definitely just behind the eye and continuing over the ear and along the body and fading out on the tail; above and below, this sepia stripe bordered by a wide light stripe; faint traces of the ends of dark cross bars on the back, appearing as about a dozen dark irregular spots in a longitudinal row above the dorsolateral light stripe; a narrow dark lateroventral stripe; belly immaculate; throat and chest with about seven or eight transverse rows of large black spots extending up onto the sides of the neck and lips; mental and rostral shields conspicuously light and immaculate; top of head unmarked excepting for some minute sepia dots at the junctions of the head plates; two conspicuous white bars leaving the superciliary border and crossing the eyelid, with a brown bar between them, which is a continuation of one of the transverse rows of throat spots; arms and legs faintly marked with sepia above. The adult coloration is very similar although dulled. The throat of adult males is clouded with gray, through which the cross banding of spots can usually be made out. The pattern of stripes instead of bars in the young suggests a connection with semilineatus, in which the striped pattern predominates even in the young.

Specimens examined.-As listed in table 42.

TABLE 42.-Specimens of Leiocephalus personatus beatanus examined

\begin{tabular}{|c|c|c|c|}
\hline Museum No. & Locality & Date & Collector \\
\hline U.S.N.M. & & & \\
\hline $\begin{array}{l}83872-83877,84283,85059,86864 \text {, } \\
89374 . \\
\text { M.C.Z. }\end{array}$ & Beata Island, D. R & May $11-13,1931 \ldots$ & $\begin{array}{l}\text { A. Wetmore and F. C. } \\
\text { Lincoln. }\end{array}$ \\
\hline $\begin{array}{l}17737 \text { (paratype of } L . \text { beatanus) } \\
37539-37550\end{array}$ & - do do & $\begin{array}{l}\text { Oct. } 3,1922 \\
\text { Apr. } 11,1934\end{array}$ & $\begin{array}{l}\text { G. K. Noble. } \\
\text { Utowana Expedition. }\end{array}$ \\
\hline
\end{tabular}

\section{LEIOCEPHALUS PERSONATUS VINCULUM Cochran}

Figures 64, 66 $b$; Plate 6, B

1928. Leiocephalus vinculum Cochran, Proc. Biol. Soc. Washington, vol 41, p. 54 (type locality, Gonave Island).-Barbour and Loveridge, Bull. Mus. Comp. Zool., vol. 69, No. 10, p. 290, 1929.-BARBour, Zoologica, vol. 11, No. 4, p. 99, 1930; vol. 19, No. 3, p. 122, 1935; Bull. Mus. Comp. Zool., voi. 82, No. 2, p. 138, 1937.

Original description of the type.-M.C.Z. No. 25435, adult male collected by Walter J. Eyerdam on August 5, 1927, at Point-àRaquettes, Gonave Island. "Head-shields enlarged, the anterior ones very weakly ridged, the supraorbitals and posterior ones a little more heavily ridged; three scales between the rostral and the first supra- 
ocular, the posterior very large; nasal in contact with rostral; internasals not unusually elongate, separated from each other; the frontals, prefrontals and internasals embracing a median series of three contiguous scales, the central one slightly the largest, the anterior one in contact with the rostral; frontals and prefrontals separated from the canthals by an elongate scale; three superciliaries; six supraoculars; occipital small, bordered by two distinct pairs of parietals on each side, the inner about two-thirds as large as the outer; four (on left side of head only three) upper labials and five lower labials to a point below the center of the eye; a conspicuously enlarged, heavily keeled scale on the temporal region just above and in front of the ear opening; anterior border of the ear with four large projecting scales. Dorsal scales large, imbricate but not mucronate except towards the tail, some of the dorsals near the median line being hexagonal in shape with the tips squarely cut off; laterals slightly smaller than dorsals; ventrals larger than dorsals, smooth, their posterior edges highly denticulate; about 46 scales around the middle of the body; about 57 scales from occiput to a point directly above the vent; about 14 dorsal scales to a head-length; nuchal scales quite small; those on the side of the neck like the dorsals; those behind the ear keeled and imbricate, not granular. Shoulder folds present, but no lateral folds. The adpressed hindleg reaches to about the center of the eye. Digits compressed; the fourth toe with 26 keeled lamellae. A low but distinct dorsal crest and a higher caudal crest; the other caudal scales mucronate. The keels of the lateral and dorsal scales are directed backwards and upwards, so that the longitudinal scalerows converge strongly on the back. Tail highly compressed.

"Dimensions.-Snout to vent, $65 \mathrm{~mm}$; head, $14 \mathrm{~mm}$.; tail (tip reproduced), $87 \mathrm{~mm}$.

"Color (in alcohol).-Head brown; back iridescent bronze-green with indications of cross-bands on the nuchal region; traces of a darkbrown, much interrupted lateral stripe leaving the eye, continuing over the shoulder and onto the side of the tail where it persists only as a series of small brown spots widely separated; upper surfaces of arms and legs bronze. Chin and throat with alternating dark brown and light bronze stripes which are somewhat irregular and tend to anastomose. Remainder of under surface tan, with occasional bluish scales. Beneath the eye two light patches, set off by dark vertical marks.

"Variations.--In the two paratypes, secured under the same conditions as the type specimen, not much variation is shown. The scales around the body seem to be 45 to 49 in number in these two paratypes, but as the longitundinal rows are exceedingly uneven, due to the convergence on the back, the count varies at practically every scale. The number of scales from the occiput to a point directly 
above the vent is 58 and 60 , and the number of dorsal scales in a head-length is 14 and 15 . While the medial series of scales on the snout is continuous in the type, it is discontinuous in one of the paratypes. The other paratype has an old injury on the snout in this region.

"In coloration the same essential features are present in all three specimens. One of the paratypes is much more brightly colored than the type, however, and has some brilliant pale green scales edging the darker cross-bars over the neck, and likewise accenting the lower edge of the dark lateral stripe. Below this the sides appear purplish brown, with the occasional bright blue scales mingled there."

In addition to the original specimens on which the description of the species was based, three others have since come under my observation. These are very similar indeed to the type and paratypes. The supraoculars are six in all cases, and the prefrontals two in number. There are 44 or 45 scales around the body, 15 or 16 in a head length, and 58 to 60 along the back from occiput to base of tail. On two of them a distinct light lateral stripe may be found that originates behind the last supraocular and passes backward above the brown lateral stripe onto the tail. The indications of cross bands in the nuchal region are present in all the specimens, and down the back there are fairly regular markings that may be the remainder of a full set of cross bars, which the young probably possesses. So far none but fully adult specimens have been collected, but it is safe to say that this is one of the species in which the juvenile pattern is far more pronounced and brilliantly contrasted than the subdued and darkened tone of the adults.

The postanal scales are very poorly differentiated from the scales that surround them, and for this reason it is exceedingly hard to tell the sex from exterior inspection alone.

Specimens examined.-As listed in table 43.

TABLE 43.-Specimens of Leiocephalus personatus vinculum examined

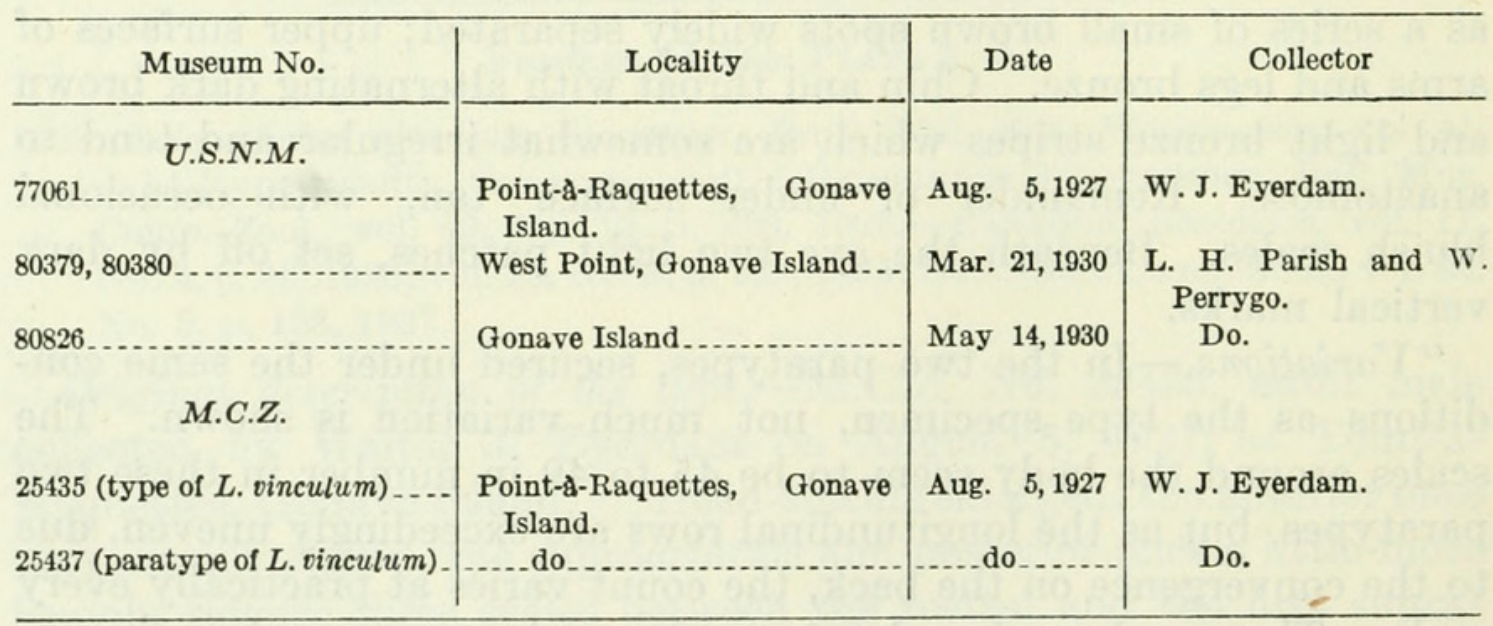




\section{LEIOCEPHALUS PERSONATUS LOUISAE Cochran}

Figures $64,66 c$; Plate 7, A

1934. Leiocephalus peronatus louisae Cochran, Occ. Pap. Boston Soc. Nat. Hist., vol. 8, p. 177.-BArbour, Zoologica, vol. 19, No. 3, p. 121, 1935; Bull. Mus. Comp. Zool., vol. 82, No. 2, p. 136, 1937.

Original description.- "Diagnosis.-No lateral fold; three scales between rostral and supraocular ring; frontals and prefrontals rugose; throat with numerous scattered black crescentic spots, each extending over one or two scales; hindleg reaching to between ear and eye; dorsal scales relatively small, about 15 in a head-length.

"Type.-An adult male, M. C. Z. 37551, from Saona Island, Dominican Republic, collected April 8, 1934, by the Utowana Expedition.

"Description of the type.-Head shields enlarged, the anterior slightly rugose, the posterior ones more strongly ridged; three scales (an internasal and 2 prefrontals) between the rostral and the supraorbital ring; posterior prefrontals much the larger; nasals in contact with rostral; internasals somewhat elongate, barely separated from each other by the first of a series of three median scales; prefrontals separated from the canthals by a wedge-shaped scale; two heavy, rounded canthals followed by three long and narrow superciliaries which precede a short one and a longer terminal one; six distinctly ridged supraoculars separated from the superciliaries by two irregular rows of small keeled scales, and from the frontals by a single, quite regular row of scales; occipital small, bordered by two distinct pairs of parietals on each side, the outer the smaller; the inner parietal plate about four times the size of the occipital, and in contact with its fellow behind the occipital; a group of five or six small latero-nuchal scales, none of them more than one-fourth the area of the outer parietal; four upper labials to a point below the center of the eye, middle of fifth lower labial under center of eye; temporal scales gradually increasing in size, the last one, just above and in front of the ear, the largest and most conspicuous; anterior border of the ear with five coarse projecting scales, the middle ones the largest. Dorsal scales moderate in size, imbricate and mucronate; laterals somewhat smaller than the dorsals; ventrals considerably larger than the dorsals, smooth, their posterior edges denticulate; about 48 scales around the middle of the body; about 58 scales from the occiput to a point directly above the vent; about 15 dorsal scales the equivalent of the distance from snout to occiput; nuchal scales small, those on the sides of the neck like the dorsals, those behind the ear keeled and imbricate, not granular. Shoulder folds present; no lateral folds. The adpressed hind limb reaches to half-way between the ear and the eye. Digits compressed, the fourth toe with 24 tricarinate lamellæ. 
A pronounced crest beginning on the occiput, equally developed on the back and on the proximal part of the tail; the other caudal scales mucronate, keeled above, faintly keeled below; no verticils. The keels of the lateral and dorsal scales are directed upwards and backwards so that the scale rows converge strongly on the back. Tail (stump) slightly compressed. A pair of enlarged post-anals in the male. Size rather small.

"Dimensions.-Snout to vent, $55 \mathrm{~mm}$.; head to posterior ear, 15 $\mathrm{mm}$.; tail incomplete; foreleg, $22 \mathrm{~mm}$; hindleg, $41 \mathrm{~mm}$.; width of head, $12 \mathrm{~mm}$.

"Coloration in alcohol.-Body color pea green above, with a prominent dorso-lateral light stripe beginning on the upper temporal region and continuing to the end of the body where it gradually fades out; the dorsal scales between these light stripes mottled with sage green, with traces of black pale-edged crossbands appearing on neck and above shoulders; a pale olive-buff lateral stripe beginning on the loreal region, continuing beneath the eye and through the ear, and gradually fading out in the groin; the area between the lateral and dorso-lateral light stripes sepia, with many of the scales tipped with cadmium orange or turquoise blue; four or five irregular black spots in the anterior part of this sepia strip, the foremost covering the scales over the ear, the last one above the shoulder, followed by a small black axillary spot; top of head pale drab, immaculate, except for a pair of sepia spots on the outer parietals; labials pale olive buff clouded with drab, with a few sepia spots near the commissure of the lips and on the sutures of the lower labials; mental and rostral shields drab; ventral surfaces pale blue, deepening in color on the belly; throat with numerous scattered black crescentic spots, each extending over one or two scales; region about groin and under surface of tail heavily spotted with cadmium orange, with this same color appearing in some of the lateral scales together with turquoise blue; upper part of limbs sage green suffused with gray mottlings, the forearms with black spots on the elbows; the crest of the tail sage green mottled with turquoise blue, the other caudal scales suffused with dull orange.

"Paratypes.-There are four paratypes, including two young, taken at the same time and place as the type (M.C.Z. $37552-4$, and U.S.N.M. 95117)."

Relationships-This subspecies is undoubtedly derived from lunatus, as the peculiar pattern on the throat and sides of neck testifies. But the spotting on the throat is not so heavy in louisae, nor are the spots on the side of the neck so regular in shape. The mainland form is larger in size, while the scales appear to be more mucronate. 


\section{Genus HISPANIOLUS Cochran}

1928. Hispaniolus Cochran, Proc. Biol. Soc. Washington, vol. 41, p. 49 (type, $H$. pratensis).

The similarity of this genus to Leiocephalus in head scalation and in general proportions is fairly evident on comparison. The complete absence of dorsal or caudal crests in Hispaniolus serves to separate the two genera completely, however. The color pattern is likewise highly dissimilar. The range of Hispaniolus is not yet known to extend for more than a few miles from the actual type locality.

\section{HISPANIOLUS PRATENSIS Cochran}

Figure $66 e$

1928. Hispaniolus pratensis Cochran, Proc. Biol. Soc. Washington, vol. 41, p. 50.-Barbour, Zoologica, vol. 11, No. 4, p. 99, 1930; vol. 19, No. 3, p. 122, 1935; Bull. Mus. Comp. Zool., vol. 82, No. 2, p. 138, 1937.

Original description.- "Type.-U.S.N.M. No. 69189, an adult male collected at the Atalaye plantation near St. Michel, Département du Nord, Republic of Haiti, on March 23, 1925, by Gerrit S. Miller, Jr.

"Description of the type.-Head-shields enlarged, all ridged excepting the internasals, which are smooth; nasal in contact with rostral; two scales between the rostral and the first supraocular; internasals very elongate; the frontals, prefrontals and internasals embracing a medial series of two subequal scales which completely separate the prefrontals but which do not reach the rostral; prefrontals separated from the canthals by an elongate scale; three supraorbitals; five supraoculars on each side, the fifth very small; occipital plate small, bordered laterally by two pairs of distinct parietals, the outer pair considerably larger than the inner pair; four upper and four lower labials to middle of eye. Dorsal scales large, uniform, extremely imbricate and mucronate; laterals slightly smaller, keeled; ventrals smooth, their posterior edges not denticulate; about 41 scales around the middle of the body; about 42 scales from occiput to a point directly above the vent; about 10 dorsal scales to a head-length; scales of the neck like the dorsals, those behind the ear keeled and imbricate, not granular; anterior auricular margin with two well-developed projecting scales. Shoulder folds present, but no lateral folds. The hind leg adpressed reaches only to a point a little in front of the shoulder. Digits compressed; fourth toe with 24 keeled lamellae. No dorsal or caudal crests, the scales of the middorsal region like the surrounding scales in size and carination; the keels of the lateral and dorsal scales directed backwards and upwards, so that the longitudinal scale-rows strongly converge on the back. Tail round, about twice as long as the head and body taken together.

"Dimensions.-Length of head, $11 \mathrm{~mm}$.; body, $36 \mathrm{~mm}$.; tail, $90 \mathrm{~mm}$.; arm, $17 \mathrm{~mm}$.; leg, $30 \mathrm{~mm}$.; width of head, $8 \mathrm{~mm}$. 
"Head olive-gray with some round black spots on the sutures of the head-shields; body light olive-gray, with ten dark brown stripes on back and sides running from the head onto the tail; three lateral white stripes between the brown ones on each side, the lowest white stripe running from in front of the shoulder to the groin and down the hindleg; the middle white stripe beginning in front of the eye, passing through the eye, through the ear and along the body onto the tail; the uppermost white stripe beginning at the upper posterior border of the eye, passing above the ear and along the body onto the tail. Ventral scales peppered with very minute gray dots, some of the scales with light bluish centers. Throat iridescent pale violet and green, with some small widely scattered gray spots. Upper and lower lips edged with black.

"Variations.-In five paratypes from the same locality taken by the same collector the scalation shows remarkably little variation, as all without exception conform in number of supraoculars, in number and position of medial scales on the center of the snout and in having ten dorsal scales in a head-length. The scales around the body are about 40 or 41 in number, although the excessive irregularity of the longitudinal rows make it difficult to be definite about this count, as it will differ if taken a quarter of an inch away in either direction. There are from 40 to 42 scales in a row from the occiput to a point directly above the vent. In two of the paratypes (69184 and 69185) the internasal plates, which are very elongate in the other four specimens, have divided transversely so that there are two scales between the first supraocular and that portion of the internasal actually in contact with the rostral. The largest individual, 69184, has a headlength of $12 \mathrm{~mm}$. and from occiput to base of tail it measures $42 \mathrm{~mm}$.

"The stripes of some of the paratypes are not so evenly developed as in the type. In two specimens, the middle one of the three white lateral stripes is almost obsolete, while the brown stripe above the uppermost white lateral stripe is broadened and emphasized. The borders to the lips are not conspicuously darkened in some cases and the gray spots on the throat are not always evident, the throat being suffused with gray occasionally. None of the specimens show any traces whatever of the black bars or chevrons across the back which are usually so pronounced in most species of the genus Leiocephalus."

Since the original description appeared we have been fortunate in securing 33 additional examples from San Michel and two others from L'Atalaye. Two of the San Michel females as well as both of the L'Atalaye specimens show absolutely no pattern whatsoever. The entire upper surfaces are a uniform bister-brown, fading gradually to an immaculate olive-buff below, with the throat faintly suffused with olive-gray. Sixteen other topotypes are females of all sizes from $32 \mathrm{~mm}$. in length up to the maximum for females of $52 \mathrm{~mm}$. -in 
these specimens the pattern is as clear and brilliant as in the males in all except No. 74113, where only traces of the light and dark stripes remain. The largest male, No. 74100 , measures $62 \mathrm{~mm}$. from snout to beginning of tail.

The internasal plates are elongate and undivided in 13 of the topotypes, while they are transversely divided in 14 individuals. In two others they are divided on one side of the head only. From these figures we may see that there is just about as much tendency for the internasals to split as there is for the persistence of the single plate. In other respects the species is not subject to any conspicuous variations.

Specimens examined.-As listed in table 44.

TABLE 44.-Specimens of Hispaniolus pratensis examined

\begin{tabular}{|c|c|c|c|}
\hline U.S.N.M. No. & Locality & Date & Collector \\
\hline $\begin{array}{l}69184-69188 \ldots \ldots \\
69189 \text { (type) } \\
74100-74132 \ldots \ldots \\
76652,76653 \ldots \ldots\end{array}$ & $\begin{array}{l}\text { L'Atalaye, near San Michel du } \\
\text { Nord, Haiti. }\end{array}$ & $\begin{array}{l}\text { Mar.-Apr. } 1925 \ldots \\
\text { Mar. } 23,1925 \ldots \\
\text { Dec. } 27,1927-\text { Mar. } \\
\text { 15, 1928. } \\
\text { January } 1929 \ldots \ldots\end{array}$ & $\begin{array}{l}\text { G. S. Miller, Jr. } \\
\text { Do. } \\
\text { A. J. Poole. } \\
\text { A. J. Poole and W. Per- } \\
\text { rygo. }\end{array}$ \\
\hline
\end{tabular}

\section{Family ANGUIDAE}

KEY TO THE ANGUID GENERA FOUND ON HISPANIOLA

$a^{1}$. Ear opening present.

$b^{1}$. Limbs well developed, pentadactyle Celestus (p. 243)

$b^{2}$. Limbs weak, tetradactyle Sauresia (p. 255) $a^{2}$. No ear opening

Wetmorena (p. 259)

No particular difficulties appear to be presented by either Wetmorena or Sauresia, in which a considerable degree of fixation of characters has been attained. The genus Celestus, however, throughout its range presents a multiplicity of diversification among individuals of the same species, so that much confusion has arisen wherever its exceedingly variable characters have been noted.

\section{Genus CELESTUS Gray}

1838. Celestus Gray, Ann. Nat. Hist., vol. 2, p. 288 (type, C. striatus).

The earliest known Hispaniolan Celestus is costatus. It has been called variously by many names, and much confusion has resulted therefrom. Its closest relationships are in Jamaica. It is distinguished from either of the two Jamaican species, however, by its usually longer and heavier limbs, the hindleg of costatus being 25 (in only 12 cases) to 35 percent (in 35 cases) of the length of the head and body, while in both the Jamaican species it ranges from 20 to 30 percent. The heavier foot structure of costatus is expressed in the 
larger number of subdigital lamellae on the fourth toe-17 to 22 , averaging 19.7 in 33 examples. The two Jamaican species show a variation of 12 to 15 for occiduus and 13 to 18 for impressus.

It cannot be doubted, however, that costatus is related to the Jamaican occiduus. The coloration is practically identical in both species. The middorsal light area with its dark bordering stripes is particularly prominent in most of the Hispaniolan costatus and extends sometimes almost as far back as the hindleg. The proportions of length to width in costatus also approach occiduus, rather than the blunt-headed impressus.

\section{KEY TO CELESTUS OF HISPANIOLA}

Dorsum with dark splotches or chevrons, sometimes forming stripes on nuchal region; subdigital lamellae 17 to 22 ; scale rows 35 to 47 ;

forelimbs and hindlimbs nearly meet when laid along body_-costatus (p. 244)

Dorsum with 10 longitudinal dark stripes, central ones more or less

broken up; subdigital lamellae 12 to 16 ; scale rows 37 to 38 ;

forelimbs and hindlimbs widely separated........... darlingtoni (p. 253)

CELESTUS COSTATUS (Cope)

FigURE 67

1861. Panolopus costatus Cope, Proc. Acad. Nat. Sci. Philadelphia, 1861, p. 494 (type locality, Jérémie, Hayti; collector, Dr. Weinland; type in Mus. Comp. Zool.).-Boulenger, Catalogue of the specimens of lizards in the collection of the British Museum, ed. 2, vol. 2, p. 295, 1885.-BARBour and LoveRIDGe, Bull. Mus. Comp. Zool., vol. 69, No. 10, p. 313, 1929.-Diploglossus costatus Garman, Bull. Essex Inst., vol. 19, p. 23, 1887 (type).-Celestus costatus Barbour, Mem. Mus. Comp. Zool., vol. 44, No. 2, p. 306, 1914; Proc. New England Zool. Club, vol. 7, pp. 11-13, 1919; Zoologica, vol. 11, No. 4, p. 99, 1930; vol. 19, No. 3, p. 123, 1935; Bull. Mus. Comp. Zool., vol. 82, No. 2, p. 139, 1937.-Sснміdт, Bull. Amer. Mus. Nat. Hist., vol. 44, art. 2, p. 16, 1921.-Cochran, Proc. U. S. Nat. Mus., vol. 66, art. 6, p. 10, 1924; Proc. Biol. Soc. Washington, vol. 41, p. 54, 1928.

1862. Diploglossus stenurus Cope, Proc. Acad. Nat. Sci. Philadelphia, 1862, p. 188 (type locality, Jérémie, Hayti; collector, Dr. Weinland; type in Mus. Comp. Zool.).-Barbour and Loveridge, Bull. Mus. Comp. Zool., vol. 69, No. 10, p. 253, 1929.-Celestus stenurus Cope, Proc. Acad. Nat. Sci. Philadelphia, 1868, p. 126 (Gonave Island, Hayti).-Boulenger, Catalogue of the specimens of lizards in the collection of the British Museum, ed. 2, vol. 2, p. 289, 1885.-Barbour, Proc. New England Zool. Club, vol. 7, pp. $12-13,1919$.

1868. Celestus phoxinus Cope, Proc. Acad. Nat. Sci. Philadelphia, 1868, p. 125 (type locality, Jérémie, Hayti; collector, Dr. Weinland; type in Mus. Comp. Zool.).-Boulenger, Catalogue of the specimens of lizards in the collection of the British Museum, ed. 2, vol. 2, p. 289, 1885.-Barbour, Mem. Mus. Comp. Zool., vol. 44, No. 2, pp. 305-307, 1914; Proc. New England Zool. Club, vol. 7, pp. 11-13, 1919.-Barbour and Loveridge, Bull. Mus. Comp. Zool., vol. 69, No. 10, p. 237, 1929.

1868. Celestus weinlandii Cope, Proc. Acad. Nat. Sci. Philadelphia, 1868, p. 125 (type locality, [said to be Gonave Island] within 25 miles of Port-au-Prince, Hayti; type, U. S. N. M. No. 12145; collector, A. C. Younglove).-BoulenGER, Catalogue of the specimens of lizards in the collection of the British 
Museum, ed. 2, vol. 2, p. 289, 1885.-Barbour, Proc. New England Zool. Club, vol. 7, pp. 11-13, 1919.

1879. Celestus rugosus Cope, Proc. Amer. Philos. Soc., vol. 18, p. 272 (type locality, Puerto Plata, San Domingo; type, U. S. N. M. No. 10260; collector Fraser).-Diploglossus rugosus Boulenger, Catalogue of the specimens of lizards in the collection of the British Museum, ed. 2, vol. 2, p. 288, 1885.Meerwarth, Mitth. Naturh. Mus. Hamburg, vol. 18, p. 27, pl. 1, figs. 1-2, 1901 (Puerto Plata, San Domingo).-Barbour, Mem. Mus. Comp. Zool., vol. 44, No. 2, p. 305, 1914; Proc. New England Zool. Club, vol. 7, p. 13, 1919; Zoologica, vol. 11, No. 4, p. 99, 1930; vol. 19, No. 3, p. 123, 1935; Bull. Mus. Comp. Zool., vol. 82, No. 2, p. 138, 1937.

1886. Diploglossus (Celestus) ohlendorffi Fischer, Jahrb. Wiss. Anst. Hamburg, vol. 3, p. 17, extr. p. 1, pl., figs. 1-1c (type locality, Hayti; type, Mus. Hamburg No. 855a).

1887. Diploglossus striatus Garman, Bull. Essex Inst., vol. 19, p. 21 (Jérémie, Hayti).-Fischer, Jahrb. Hamburg Wiss. Anst., vol. 5, p. 29, 1888 (Gonaĩves, Haiti; collector, H. Rolle).-Meerwarth, Mitth. Naturh. Mus. Hamburg, vol. 18, pp. 27-29, 1901 (Hayti; San Domingo).

1898. Diploglossus nuchalis Bodlenger, Proc. Zool. Soc. London, 1898, p. 920, pl. 56, fig. 1 (type locality ?; presented by Dr. F. Werner).-Werner, Mitth. Naturh. Mus. Hamburg, vol. 27, p. 27, 1910 (Port-au-Prince, Hayti).

It should be noted that Cope was in error when he gave "Gonave Island" as the type locality of Celestus weinlandii. This specimen, as well as all the other herpetological material and most of the birds collected by A. C. Younglove in 1866, came from within 25 miles of Port-au-Prince, and Younglove's detailed letters to Professor Baird contain no reference whatever to Gonave Island.

Description.-U.S.N.M. No. 61931 from Laguna, near Samaná, Dominican Republic, taken on March 10, 1919, by Dr. W. L. Abbott. Head moderately elongate; its width abouth three-fourths its length measured from the posterior border of the ear. Rostral pentagonal, much wider than high, not touching the nasal, in contact with the first supralabial and followed by a pair of supranasals broadly in contact; a pair of frontonasals larger than the supranasals; prefrontal undivided, roughly convex in outline anteriorly, concave posteriorly, where it forms a broad suture with the anterior border of the frontal; frontal twice as long as broad, wider than the supraoculars, in contact broadly with the second and third, very narrowly with the first on one side only; a pair of frontoparietals separated from each other by the posterior prolongation of the frontal; parietals large, about twice the size of the interparietal, separated from the supraoculars by two small shields and the frontoparietals and from each other by the heartshaped interparietal and the nearly triangular occipital, which very nearly equals the interparietal in size; five supraoculars, the second much the largest; a single nasal in contact with the first upper labial, which separates it completely from the rostral; three loreals in a row between nasal and preocular, first in contact above with supranasal and frontonasal; second with frontonasal, prefrontal, first supraocular 
and first superciliary; third with first superciliary; a long subocular lying above the sixth and seventh (or seventh and eighth) supralabiaIs, which it scarcely displaces; 10 supralabials on the left side, 9 on the right; four temporals in the first row, forming a semicircle behind the eye; mental very small, not differentiated except by position from the neighboring infralabials, followed by a large unpaired postmental;
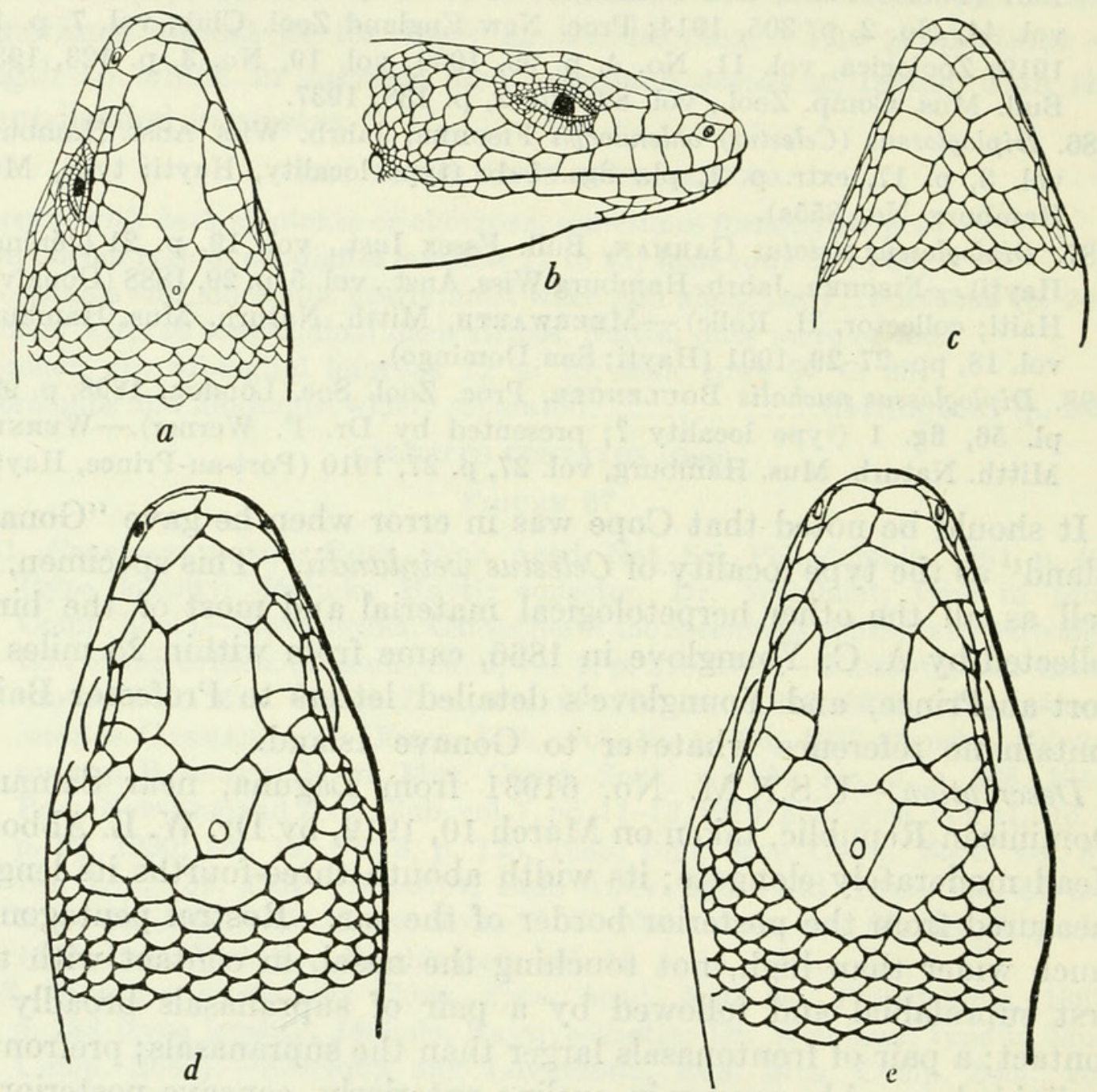

Figure 67.-Celestus costatus: $a-c$, Top of head (a), side of head (b), and chin (c) of U.S.N.M. F. No. 61931, from Laguna, near Samaná, Dominican Republic, $\times 1 \frac{1}{2} ; d$, top of head of U.S.N.M. No. 10260, from Puerto Plata, Dominican Republic (type of $C$. rugosus Cope), $\times 2$; e, top of head of U.S.N.M. No. 12145, from near Port-au-Prince, Haiti (type of $C$. weinlandii Cope), $\times 2$.

four pairs of chin shields, the first two pairs of which are in contact with the infralabials; ear opening roundish, about one-half the diameter of the eye opening on the left side of the head, smaller still on the other side; body elongate, the tips of the adpressed fore limbs and hind limbs just failing to meet; 43 scales around the body anteriorly, 39 posteriorly; 100 dorsal scales in a straight line between the occipital and a point directly above the vent; 60 ventrals from the anal plates to the center of the breast level with the axillae; dorsals and laterals 
each having a very heavy median keel in addition to about 30 fine striae; preanal scales scarcely if at all enlarged; limbs strong and well developed, the foreleg longer than the distance from the tip of the snout to the posterior border of the ear; five moderately long fingers, the third very slightly longer than the fourth, both having 12 subdigital lamellae; toes five in number, long, the fourth the longest, with 19 subdigital lamellae; scales on sole of foot not spinose, but very much rounded and almost tubercular in appearance; tail nearly cylindric, ending in a point, longer than head and body, covered with scales like those of the body but with gradually lessening keels; the two median scale rows underneath the tail very slightly larger than the others.

Dimensions: Head to posterior border of ear, $25 \mathrm{~mm}$; head and body, $126 \mathrm{~mm}$.; tail, $204 \mathrm{~mm}$. ; hindleg, $44 \mathrm{~mm}$.; foreleg, $27 \mathrm{~mm}$.; width of head, $18 \mathrm{~mm}$.

Color (in alcohol): Body color olive above, clay color below. A seal-brown lateral stripe, beginning behind the eye, much interrupted with light spots and gradually almost disappearing behind the arm, but at intervals down the sides to the tail insertion reappearing as darkened areas of pigment forming dark patches set off by lighter scales; a pair of seal-brown stripes beginning on the nuchal region and bordering a pale, immaculate median dorsal stripe; at midbody the seal-brown borders tend to break up and appear as wing-shaped markings alternating down each side of the back. Tail with regularly spaced small dark blotches representing a continuation of the diminished body pattern. Arms and legs heavily marbled above with seal brown. Lips and temples with dark-centered scales; top of head immaculate.

Variations.-This species is exceedingly variable in its scalation as well as in its coloration. In the specimens I have had the privilege of examining, the scale rows vary in number from 35 to 47 . On these scales every variation between the minutest striae and the heaviest keeling is apparent. Some specimens, such as the type of Panolopus costatus, M.C.Z. No. 2606, have about a dozen striae with no median enlarged keel whatsoever, so that seen by the unaided eye the scales appear as smooth and slippery as a skink's. Again, others may have twice as many striae and no enlarged one. But some, such as No. 61931, which I have just described, and the type of rugosus, U.S.N.M. No. 10260, as well as the largest costatus I have yet seen, No. U.S.N.M. 59435, have immensely developed median keels and present a decidedly rugose impression to the touch as well as to the sight. The number of striae in this genus does seem to depend partly on the age of the individual. ${ }^{10}$

\footnotetext{
${ }^{10}$ In the series of 16 galliwasps from Arntully, Jamaica (U.S.N.M. Nos. 79651-79665, 73357), all much the same in size, some individuals have twice as many striae as others, but it is only on the large ones not of this series that the greatest number of striae occurs.
} 
The subdigital lamellae range between 17 and 22 with an average of 19.7. The head scales are remarkably constant with the exception of those on the occiput. The interparietal is usually onethird to one-half the size of the parietals, but sometimes it is twothirds, and in the young type of rugosus it is fully as large as the parietals. The occipital scale may be either a little larger or a little smaller than the interparietal.

Color variation in this species is apparent, though certain patterns predominate at certain ages. In the costatus of Hispaniola, when graded according to size, it is noted generally that the larger individuals have the larger splotches of dark color, while the smaller $(100 \mathrm{~mm}$. and less) have a much finer spotting as a rule. But this is not inevitably the case, for No. 59086 (107 mm.) has rather heavy blotches for its size. The markings of the smaller lizards consist of chevron-shaped narrow dorsal bands (about 12 to 16 between axilla and groin), which are continued down the sides, becoming darker and broader and being greatly emphasized by occasional white scales, which appear on the posterior margin there. From the shoulder to the eye there is a broad brown stripe punctuated by vertical white bars (about four between arm and ear) or white spots, and as these become less distinctly joined on the sides they make the lateral continuation of the dorsal chevrons as described.

A trace of longitudinal marking becomes first evident on the nuchal region, where two dark parallel stripes appear, fading out in the young between the shoulders.

In larger specimens the chevrons wholly disappear, the only remaining traces being the squarish large dark blotches, which are the thickened remains of the original chevron end. The nuchal lines have lengthened down the back and broadened greatly, extending even on to the tail in some individuals, while in others the alternating (or opposite) blotches meet at the center of the back. The pattern of the sides does not change much, except that the stripe on the side of the head tends to acquire a central light area. But even in the young this happens also.

In the two smallest Hispaniolan specimens that I have yet seen, (F.M.N.H. Nos. 13246 and 13247 from Kenskoff, Haiti), measuring $42 \mathrm{~mm}$. and $45 \mathrm{~mm}$., respectively, the chevron pattern on the smaller specimen is retained as diagonal series of small dots in the shape of chevrons on the back and tail, while the nuchal lines are suggested by a heavier longitudinal series of spots. The larger specimen is much less spotted in appearance, the diagonal series of dots having almost entirely disappeared except for a single longitudinal row of dots, which continues down each side of the back from the nuchal markings, which appear more definitely as lines in this specimen, owing apparently to the fusion of the heavier spots. 
Relationships.-In order to understand the Hispaniolan form, it is needful to know something of the variation of other Celesti on nearby islands. The Cuban and Puerto Rican forms are unlike costatus in build, resembling Sauresia sepsoides in their weak legs and very elongate body.

There remain the Jamaican forms and the one from Navassa. The two Jamaican Celesti, occiduus and impressus, can scarcely be distinguished biometrically from each other, as they are practically identical in scalation and in proportion. There is one difference between them, however, that can be reduced to figures - the proportion of width to length of head. In occiduus the head is relatively long for its width, being scarcely swollen in the region of the temples. In impressus the snout seems much shorter in comparison, while the temporal region is much heavier, even in the very young. In taking actual measurements I found that the greatest width of the head in occiduus when applied from the posterior border of the ear-opening, reached to the anterior corner of the eye or very slightly beyond. In impressus the same measurement reached over halfway from the anterior corner of the eye to the nostril.

In coloration there seems to be no difficulty whatsoever in distinguishing at once the two Jamaican species. As Dr. Barbour once described it," impressus may be told by its "narrow brown bars, from eighteen to twenty in number, which are broken and alternate at the median line." There is little trace of the dark lateral stripe behind the shoulder even in the very young. There is an increased area of dark pigmentation, however, on the side of the neck in front of the shoulder. The other Jamaican species, occiduus, of which Dr. Barbour and I both consider crusculus to be a synonym, has a very distinct dark lateral stripe in all the young and half-grown specimens, while even the large adults have dark patches on the sides, which are prolongations of the uneven and much broken dorsal chevrons. The exact pattern of the back in the adult of this species is subject to great variation as to the width and length of the dorsal markings. One constant feature in the adult is the occurrence of a light longitudinal stripe with a dark brown stripe on either border; this begins at the occiput in full, strong colors, continuing backward and gradually fading out somewhere above the arm insertion. The very young are almost without dark pigment on the back; the series of 16 halfgrown galliwasps from Arntully shows well the appearance first of the small dark chevron-shaped bars and the eventual concentration of pigment anteriorly at the borders of a central light area, which assumes the form of a fairly unbroken median light stripe with the dark borders not always very sharply divided from the adjacent halves

${ }^{11}$ Bull. Mus. Comp. Zool., vol. 52, No. 15, p. 298, 1910. 


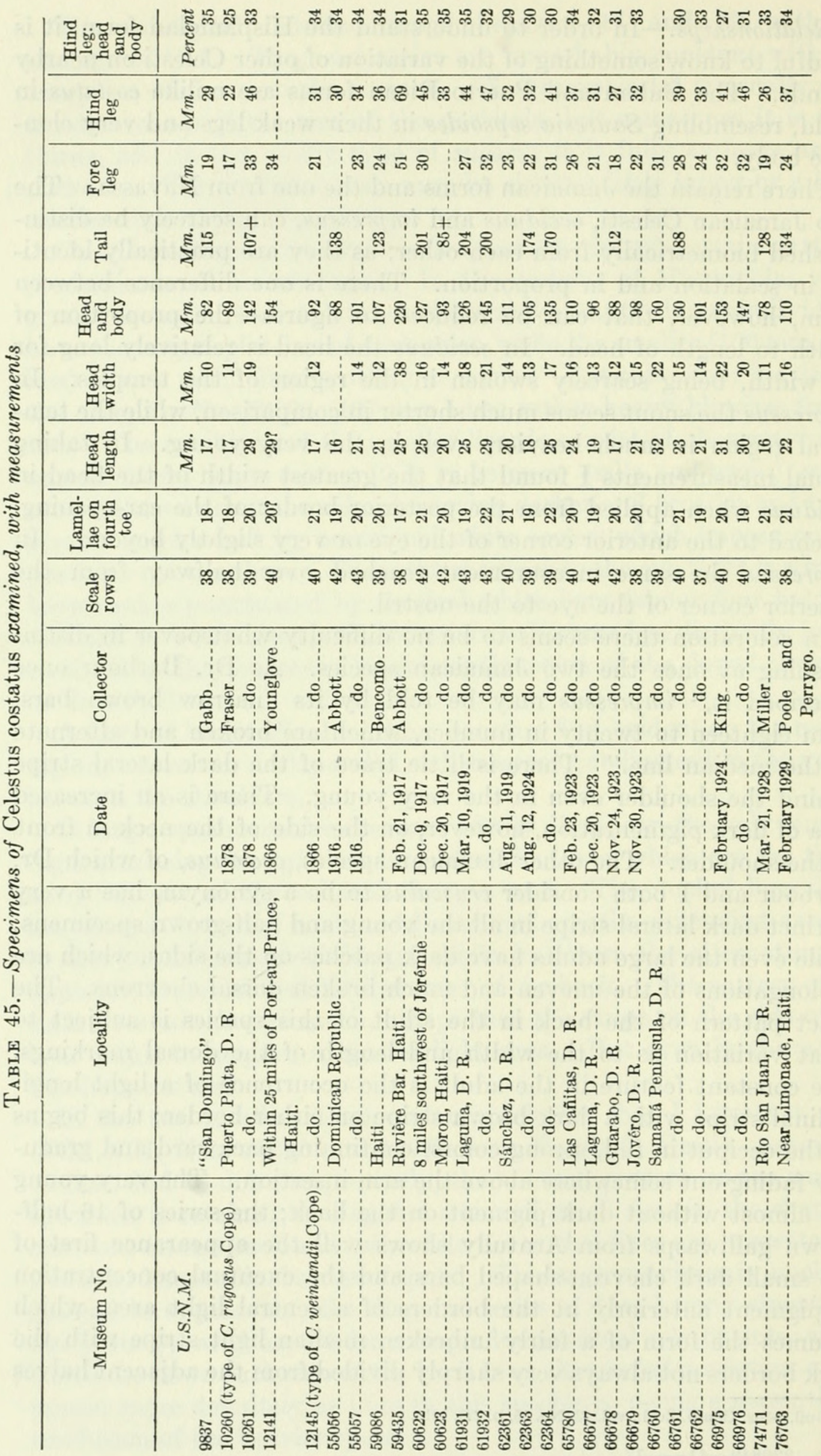


THE HERPETOLOGY OF HISPANIOLA

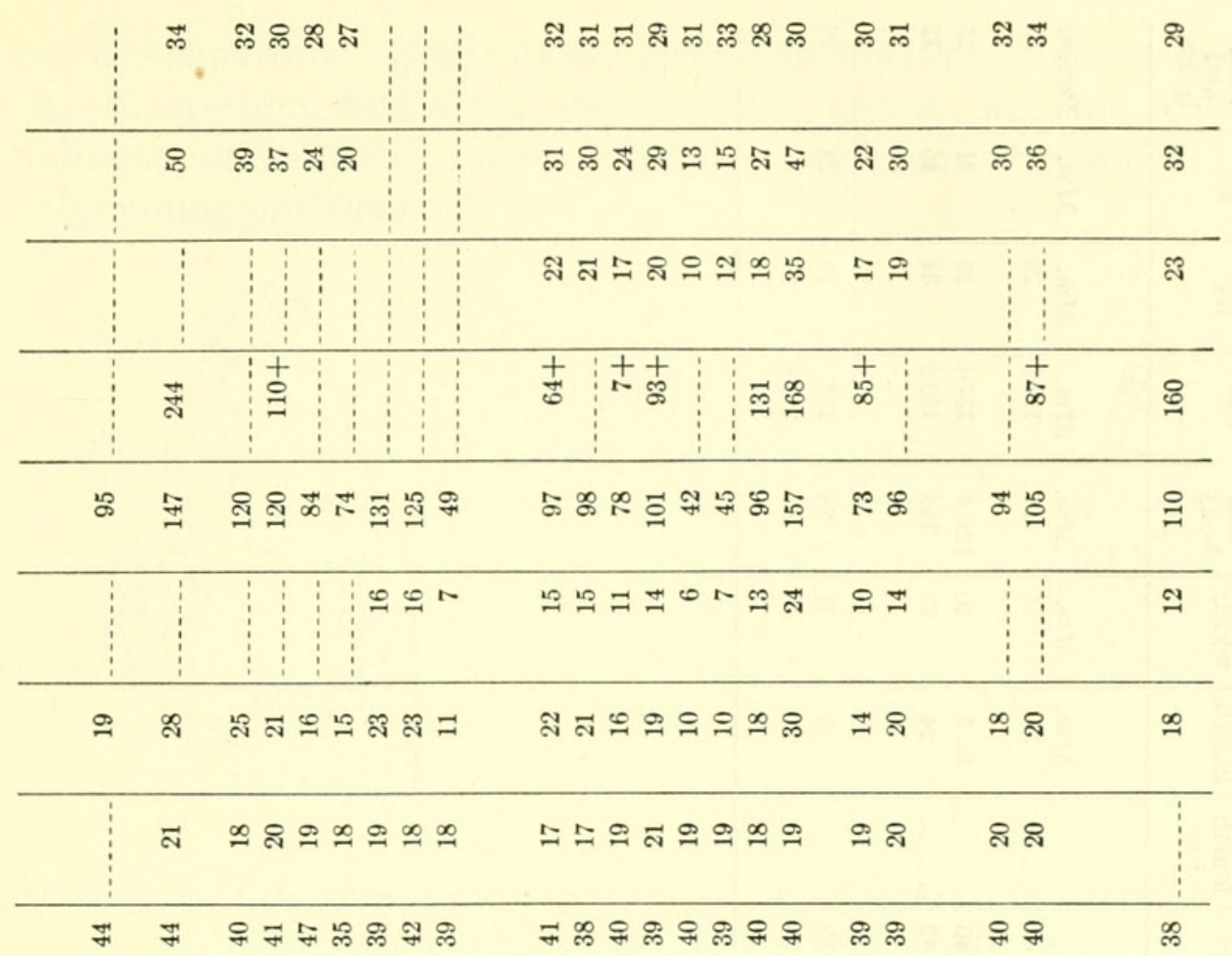

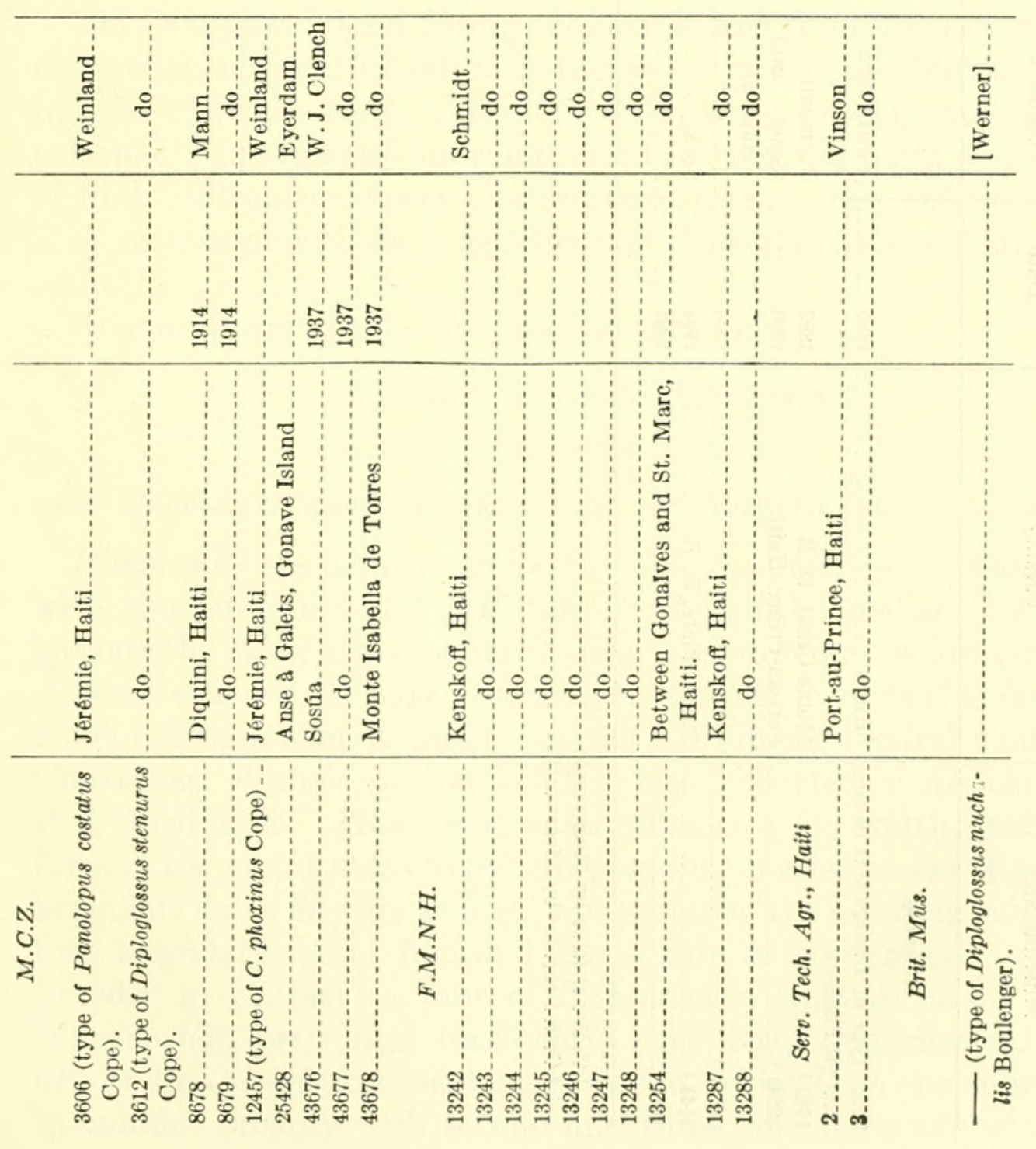




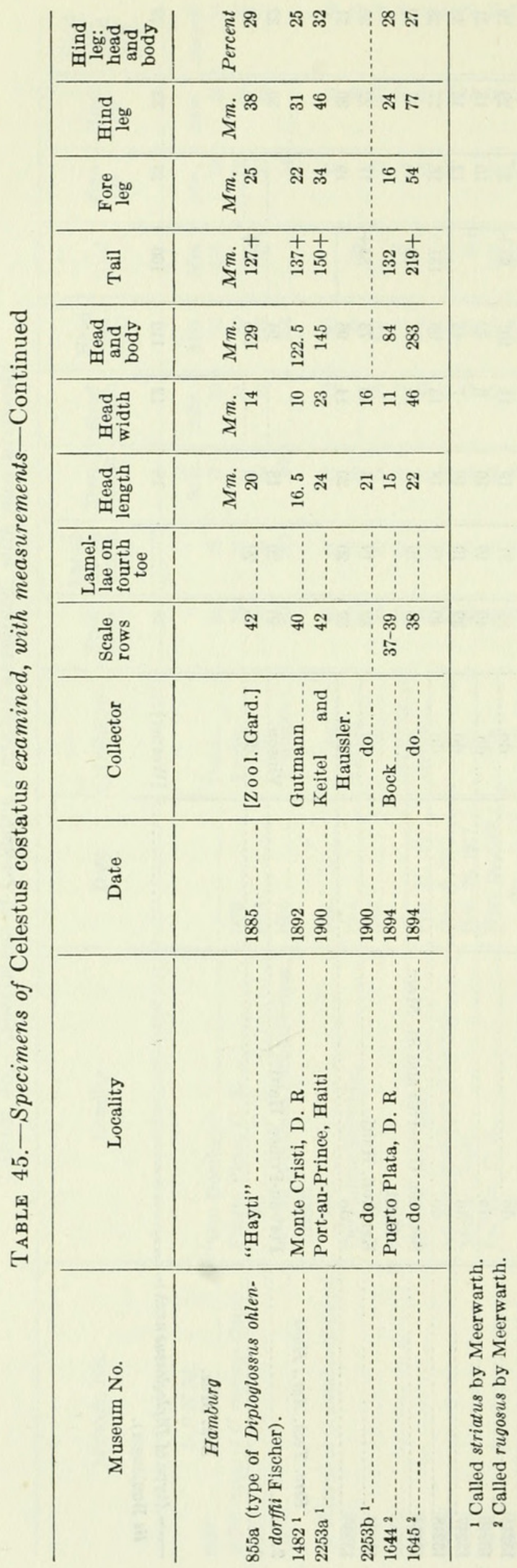


of the chevrons. Some of the largest in the series have not yet developed anything but a few spots in that region, keeping the pale and almost immaculate dorsal coloration which is evidently so typical the young occiduus.

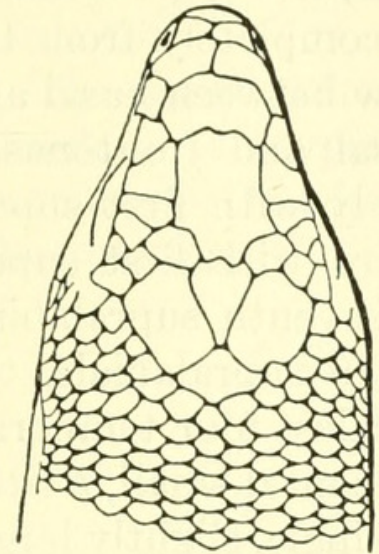

$a$

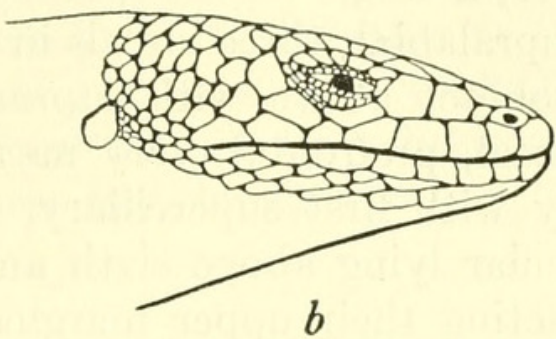

$b$

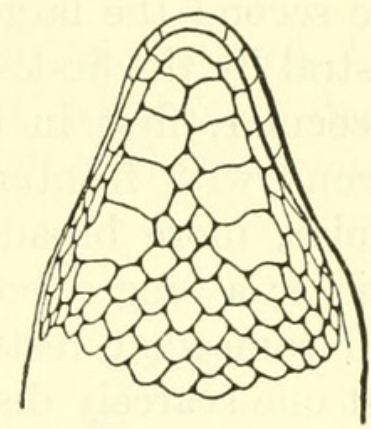

$c$

Figure 68.-Celestus badius: $a$, Top of head; $b$, side of head; $c$, chin. U.S.N.M. No. 25818, type, from Navassa Island. Twice natural size.

The Navassa Island form, Celestus badius, I prefer to regard as a distinct species until fresh material can give a better idea of its range in color and scalation. The old and faded type specimens suggest the coloring of impressus somewhat, and their general build and shortness of limb still more convey the impression that their relationships are here, instead of with the long-legged and heavily patterned Hispaniolan form.

Specimens examined.-As listed in table 45.

\section{CELESTUS DARLINGTONI Cochran}

Figure 69

1939. Celestus darlingtoni Cochran, Proc. New England Zool. Club, vol. 18, p. 2.

Diagnosis.-Generally similar to Celestus costatus in scalation but with shorter limbs and tail, fewer subdigital lamellae, fewer scales around the body, smaller adult size, and different coloration.

Description of the type.-An adult, M.C.Z. No. 44374, from Valle Nuevo, Dominican Republic, in the Cordillera Central southeast of Constanza, elevation 6,000 to 8,000 feet, collected in August 1938 by P.J. Darlington. Head moderately elongate, its width nearly threefourths its length measured from posterior border of ear. Rostral rectangular, twice as wide as high, not touching the nasal, in contact with first supralabial and followed by a pair of supranasals, which are broadly in contact; a pair of frontonasals slightly larger than the supranasals; prefrontal undivided, irregularly quadrilateral; frontal one and one-half times as long as broad, wider than the supraoculars, in contact broadly with second and third, and narrowly with first; a 
pair of frontoparietals separated from each other by the posterior prolongation of the frontal; parietals moderate, only slightly larger than the interparietal, separated from the supraoculars by one scale in addition to a small frontoparietal, and from each other by the shieldshaped interparietal and a small 5-sided occipital; five supraoculars, the second the largest; a single nasal separated completely from the rostral by the first supralabial; three loreals in row between nasal and preocular, first in contact above with supranasal and frontonasal, second with frontonasal, prefrontal, very narrowly with first supraocular, more broadly with first superciliary, third with first superciliary; a long subocular lying above sixth and seventh supralabials and somewhat restricting their upper margins; 10 supralabials, the last one scarcely distinguishable from the neck scales; four temporals in the first row, forming a semicircle behind eye; mental small, a little larger than the anterior infralabials, followed by a single, slightly larger postmental; four pairs of large chin shields and a fifth small pair, the two anterior pairs in contact with each other and with the infralabials; ear opening round, very small, less than one-half the eye opening; body very elongate, the tips of the fore limbs and hind limbs lying against the body separated by an interval equal to length of forelimb; 37 scale rows around the middle of the body; 86 dorsal scales between the occipital and a point directly above the vent; 59 ventrals from the anal plates to the center of the breast level with the axillae; dorsal scales with a median keel and 12 to 14 distinct striae, laterals more faintly striated, ventrals practically smooth; six preanal scales, the outermost not enlarged; limbs short, only moderately developed, the foreleg equal to distance from tip of snout to posterior border of ear, the hindleg 25 percent of the length of head and body; five rather short fingers, third slightly longer than fourth, these having, respectively, 10 and 9 subdigital lamellae; toes five, all relatively short, fourth only slightly longer than third, these having, respectively, 12 and 14 lamellae; scales on sole of foot rounded and almost tubercular in appearance, not spinose; tail nearly cylindric, tapering to a point, shorter than head and body and covered with scales like those of body, the two median scale rows underneath the tail considerably wider than the others.

Dimensions: Head to posterior border of ear, $13.5 \mathrm{~mm}$.; head and body, $67 \mathrm{~mm}$.; tail, $57 \mathrm{~mm}$.; foreleg, $14 \mathrm{~mm}$.; hindleg, $17 \mathrm{~mm}$.; width of head, $10 \mathrm{~mm}$.

Color (in alcohol): Body color vandyke brown above, with about 10 narrow dark brown dorsal stripes of which the central ones are more or less broken up; lateral region deep clove brown, with a pearl-gray dot on each scale; ventral region pearl gray with coarse mottlings of dull brown; head plates with dark brown margins; a heavier aggregation of brown behind eye and along dorsolateral region suggesting a 
dark stripe; ventral surface pale with dark spots, more distinct on the throat; tail colored like the body but lighter.

Paratypes.-M.C.Z. Nos. 44375 and 44376 and U.S.N.M. Nos. 107563 and 107564 , all with the same data as the type.

Variations.-The measurements of the paratypes are shown in table 46.

The dorsal coloration in all is the same as that of the type. The smallest paratypes are glaucous blue ventrally, with faint darker mottlings. The length of the hindleg is between 25 and 28 percent of the total length in these individuals.

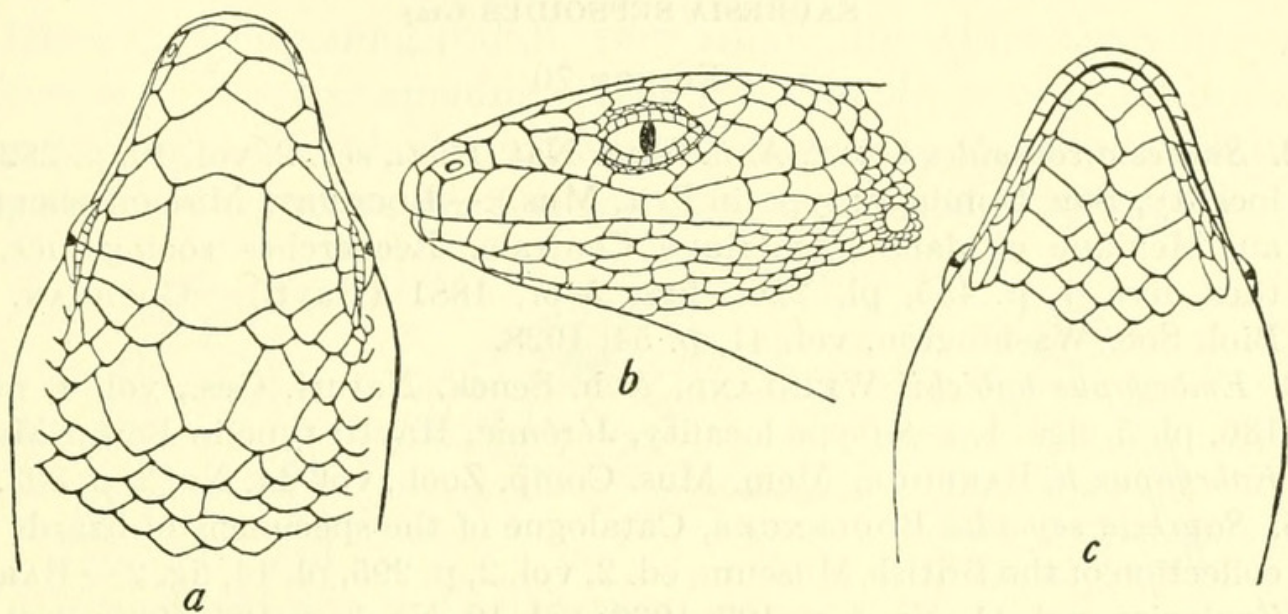

Figure 69.-Celestus darlingtoni: $a$, Top of head; $b$, profile of head; $c$, chin. U.S.N.M. No. 107563, paratype, from Valle Nuevo, southeast of Constanza, Dominican Republic. Three times natural size.

TABLE 46.-Variations in four paratypes of Celestus darlingtoni (measurements in millimeters)

\begin{tabular}{|c|c|c|c|c|}
\hline Measurement & $\begin{array}{l}\text { M.C.Z. } \\
\text { No. } 44375\end{array}$ & $\begin{array}{c}\text { M.C.Z. } \\
\text { No. } 44376\end{array}$ & $\begin{array}{l}\text { U.S.N.M. } \\
\text { No. } 107563 \\
\left(\sigma^{7}\right)\end{array}$ & $\begin{array}{l}\text { U.S.N.M. } \\
\text { No. 107564 } \\
\text { (juv.) }\end{array}$ \\
\hline Head length..... & 10 & 10.5 & 13 & \\
\hline Head width ....... & 8 & 7.5 & 10 & 7 \\
\hline Head and body... & 50 & 52 & 63 & 42 \\
\hline Tail & 54 & 57 & 44 (repr.) & 45 \\
\hline Foreleg & 10 & 10 & 13.5 & 8 \\
\hline Hindleg........... & 14 & 14.5 & 18 & 11 \\
\hline Dorsal scales......... & 86 & 80 & 81 & 81 \\
\hline Ventral scales . . . . . . . & 57 & 53 & 54 & 58 \\
\hline Scale rows around body & 38 & 37 & 38 & 37 \\
\hline Supraoculars. & 5 & 5 & 5 & 5 \\
\hline Subdigital lamellae, fourth toe..... & $14-15$ & $14-14$ & $16-15$ & $13-13$ \\
\hline
\end{tabular}

\section{Genus SAURESIA Gray}

1852. Sauresia GRAY, Ann. Mag. Nat. Hist., ser. 2, vol. 10, p. 281 (type, S. sepsoides).

1863. Embryopus Weinland, Abh. Senck. Naturf. Ges., vol. 4, pt. 2, p. 135 (type, E. habichii). 
The genus Sauresia deserves to be kept strictly apart from Celestus in spite of its apparent resemblance to the exceedingly attenuate and weaklimbed Celestus sagrae of Cuba and $C$. pleei in Puerto Rico.

The gap that exists between Wetmorena and Celestus is bridged by Sauresia, which resembles each genus in certain characters. Like Wetmorena, Sauresia has but four toes and fingers, and the relationships of toe length are similar in both. It differs from Wetmorena in possessing an ear opening and in having a relatively longer and narrower head. In these very respects it resembles the Cuban and Puerto Rican Celesti, although differing from these markedly in foot structure.

\section{SAURESIA SEPSOIDES Gray}

Figure 70

1852. Sauresia sepsoides Gray, Ann. Mag. Nat. Hist., ser. 2, vol. 10, p. 282 (type locality, San Domingo; type in Brit. Mus.).-Bocourt, Mission scientifique au Mexique et dans l'Amérique Centrale, Recherches zoologiques, Reptiles, livr. 7, p. 455, pl. 22G, figs. 5-5f, 1881 (Hayti)-Cochran, Proc. Biol. Soc. Washington, vol. 41, p. 54, 1928.

1863. Embryopus habichii Weinland, Abh. Senck. Naturf. Ges., vol. 4, pt. 2, p. 136, pl. 5, figs. 1, a-e (type locality, Jérémie, Hayti; type in Berlin Mus.).Enbryopus h. Barbour, Mem. Mus. Comp. Zool., vol. 44, No. 2, p. 303, 1914. 1885. Sauresia sepoides Boulenger, Catalogue of the specimens of lizards in the collection of the British Museum, ed. 2, vol. 2, p. 295, pl. 14, fig. 2.-BARBoUR, Zoologica, vol. 11, No. 4, p. 100, 1930; vol. 19, No. 3, p. 123, 1935; Bull. Mus. Comp. Zool., vol. 82, No. 2, p. 139, 1937.

1914. Celestus sepoides Barbour, Mem. Mus. Comp. Zool., vol. 44, No. 2, p. 303; Proc. New England Zool. Club, vol. 7, p. 13, 1919, p. 13.-C. sepsoides Schmidt, Bull. Amer. Mus. Nat. Hist., vol. 44, art. 2, p. 16, 1921.-Cochran, Proc. U. S. Nat. Mus., vol. 66, art. 6, p. 10, 1924; Proc. Biol. Soc. Washington, vol. 41, p. 54, 1928.

Description.-U.S.N.M. No. 65785, from Samaná and Laguna, Dominican Republic, collected in March 1923 by Dr. W. L. Abbott. Head moderately elongate, its width about two-thirds of its length measured from the posterior border of the ear. Rostral low, rhomboidal, much wider than high, not touching the nasal, in contact with the first supralabial and followed by a pair of supranasals broadly in contact; a pair of frontonasals twice as long as the supranasals; prefrontal undivided, broader than long, roughly pentagonal in outline but with the posterior border indented in the center where it meets a slight anterior prolongation of the frontal; frontal almost twice as long as broad, wider than the supraoculars, in contact broadly with the second and third and very narrowly with the first supraocular; parietals large, separated from each other by the occipital, separated from the supraoculars by three small scales on each side; interparietal triangular, about equal to a parietal in area, and about twice as large as the fan-shaped occipital that follows it; five supraoculars, the second the largest; a single nasal plate, its lower border in contact with the 
first two upper labials; three loreals in a row between nasal and preocular, first in contact with the supranasal and frontonasal; second with frontonasal, prefrontal, first supraocular, and first superciliary; third with first superciliary; a large subocular lying above and partly between the fifth and sixth supralabials; eight supralabials, the last ones diminishing slowly in size; three temporals forming a semicircle behind the eye, which continues on top of the head separating the supraoculars from parietal and interparietal; mental very small, not differentiated except by position from the neighboring infralabials, followed by a large unpaired postmental; four pairs of chin shields, the first three of which are in contact with the infralabials and with their fellows; ear opening round, very small, not wider than one-sixth the diømeter of the eye opening on the left side of the head and smaller still on the right side; body exceedingly elongate, the adpressed limbs failing to meet by more than twice their combined lengths; 35 scales

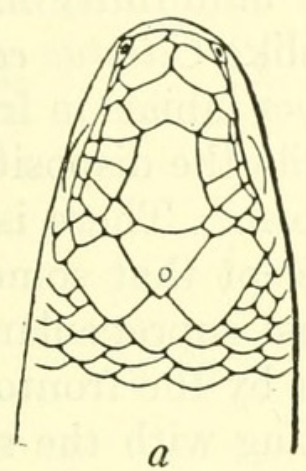

$a$
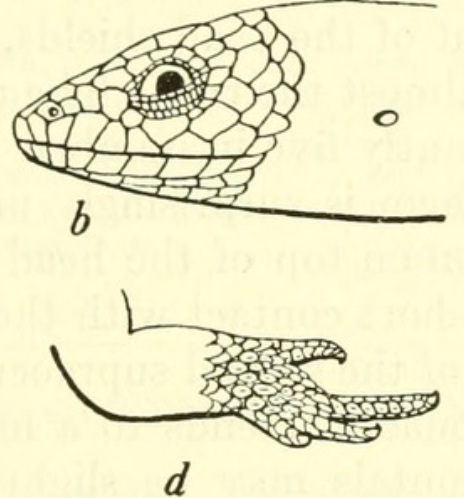

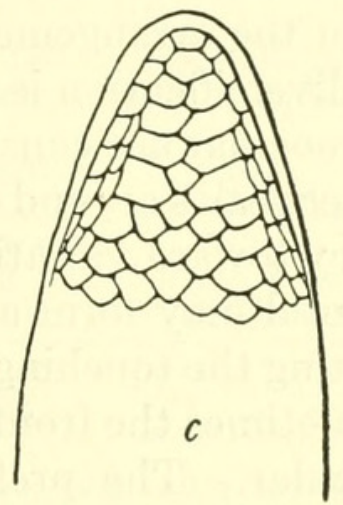

Figure 70.-Sauresia sepsoides: $a$, Top of head; $b$, side of head; $c$, chin; $d$, underside of hindfoot. U.S.N.M. No. 65785, from Samaná and Laguna, Dominican Republic. Four times natural size.

around the middle of the body; 110 dorsal scales in a straight line between the occipital and a point directly above the vent; 85 ventrals from the anal plate to the center of the breast level with the axillae; dorsal scales each with seven or eight striae, not forming keels, however; laterals and ventrals with much weaker striae; preanal scales not enlarged; limbs very weakly developed; the foreleg equaling two-thirds the distance between end of snout and posterior border of ear; four very short fingers, the third having five subdigital lamellae, the third and fourth subequal in length; toes longer, the third much the longest and having 10 subdigital lamellae each with a median ridge; the lamellae of the other toes not ridged; scales on sole of foot not spinose but rounded; tail (reproduced) nearly cylindric, ending in a point, covered with scales like those of the body, about two-thirds as long as the head and body; the two median scale rows underneath the tail very slightly larger than the others. 
Dimensions: Head to posterior border of ear, $7.5 \mathrm{~mm}$.; head and body, $46 \mathrm{~mm}$.; tail (reproduced), $32 \mathrm{~mm}$.; hindleg, $8 \mathrm{~mm}$.; foreleg, 5 $\mathrm{mm}$; axilla to groin, $32 \mathrm{~mm}$.; head width, $5 \mathrm{~mm}$.

Color (in alcohol): Body color sepia above, light wood brown below. A wide seal-brown lateral stripe beginning behind the eye and continuing backward without interruption to the tip of the tail, separated from its fellow dorsally by nine scale rows; the upper border of this stripe sharply and evenly cut off in a straight line from the dorsal tone; the lower border of the stripe merging and fading very gradually into the ventral hue. A few scattered slightly darker spots on the nuchal region and some lighter ones on the sides of the neck within the limits of the dark stripe. Upper head scales with dark posterior margins. Labials dark, with conspicuous light anterior borders. Sides of the throat with a few longitudinal rows of dark dots; reproduced portion of tail dusky; remainder of under surface immaculate.

Variations.-In Sauresia sepsoides the greatest uniformity may be noted in the arrangement of the head shields, unlike Celestus costatus where diversification is almost the rule. The upper labials in front of the infraocular are constantly five in number, while the disposition of the other scales around them is surprisingly uniform. There is little tendency toward variation on top of the head except that sometimes the frontal may form a short contact with the first supraocular, thus preventing the touching of the second supraocular by the frontonasal, and sometimes the frontonasal extends to a meeting with the second supraocular. The prefrontals may be slightly better developed in some specimens, while in others they are not distinguishable from the postocular scales except by position.

In No. 66977 the first and second pairs of chin shields are in contact with the lower labials. This same individual has only two consecutive scales between nasal and preocular, the third apparently having been fused with the preocular, which is quite large.

In the 27 specimens in the National collection, the number of scales around the body shows a surprising constancy compared to that of the West Indian Celesti. There are 35-37 scales at midbody, with only two occurrences of 37 , so that 35 and 36 appear to be the rule. The subdigital lamellae of the longest toe are 9 to 11 . There seems to be no variation in color, save that some individuals are more heavily spotted on the neck, with a slight tendency toward the formation of short, longitudinal marks that anastomose and make a sort of dark network pattern, which fades out between the axillae. The uninterrupted dark-brown lateral band with its clearly cut upper edges separated by the nine dorsal rows of sepia scales gives a very uniform appearance to the specimens when they are placed side by side. 
All the reproduced parts of the tails are dusky brown beneath, while the original portion of the tail is light below. Thus the tails are dark in irregular proportions, depending on where the severance came.

The specimen with the longest tail, No. 76705, has this member one and two-fifths the length of head and body. It is probable that the tail is not much more than this even in a perfect state.

Specimens examined.-As listed in table 47.

TABLE 47.-Specimens of Sauresia sepsoides examined

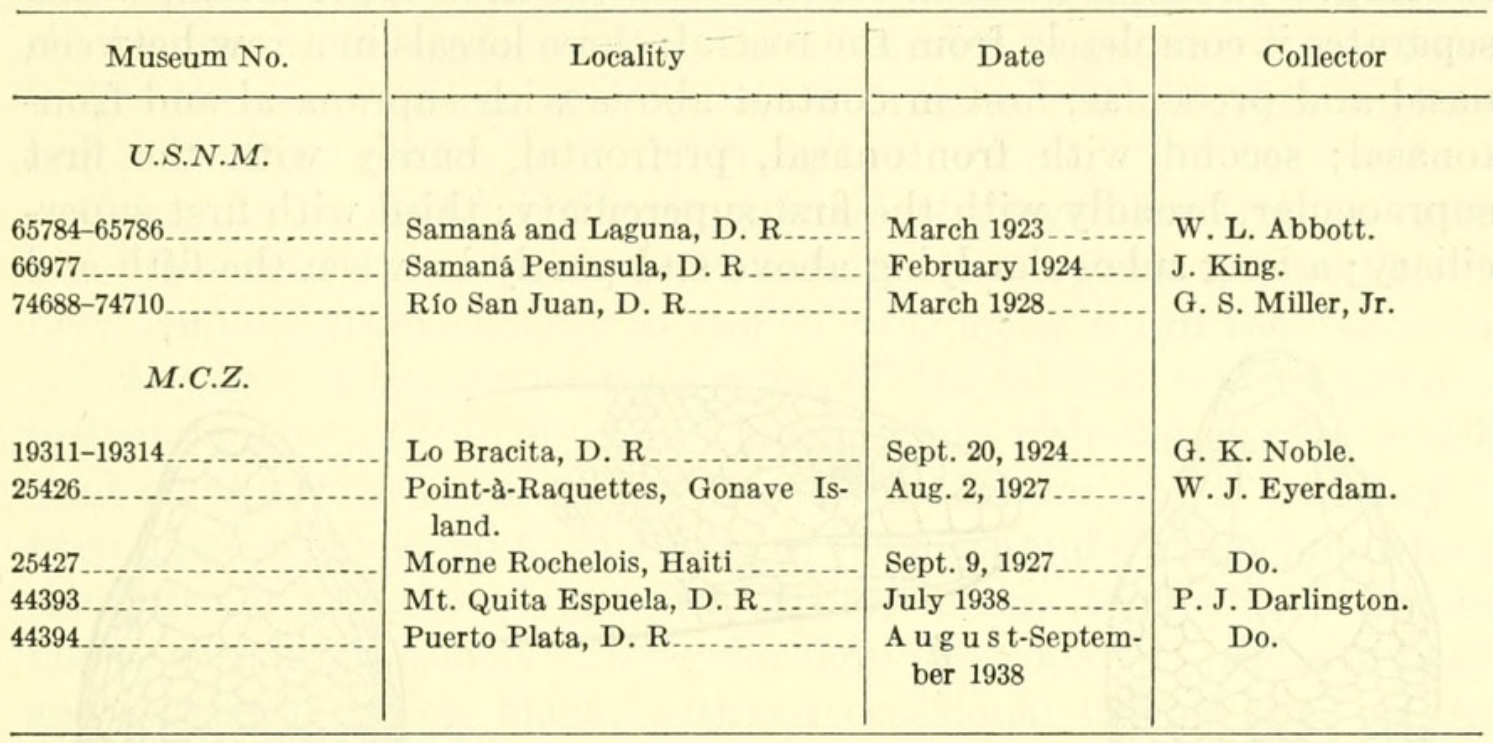

\section{Genus WETMORENA Cochran}

1927. Wetmorena Cochran, Proc. Biol. Soc. Washington, vol. 40, p. 91 (type, $W$. haetiana Cochran).

The relationship of this genus to Sauresia has already been discussed under the latter genus.

\section{WETMORENA HAETIANA Cochran}

FIGURE 71

1927. Wetmorena haetiana Cochran, Proc. Biol. Soc. Washington, vol. 40, p. 91 (type locality, Morne Cabaio, Massif de la Selle, Haiti); Occ. Pap. Boston Soc. Nat. Hist., vol. 8, p. 179, 1934.-Barbour and Loveridge, Bull. Mus. Comp. Zool., vol. 69, No. 10, p. 359, 1929.-BArвour, Zoologica, vol. 11, No. 4, p. 100, 1930; vol. 19, No. 3, p. 123, 1935; Bull Mus. Comp. Zool., vol. 82, No. 2, p. 140, 1937.

Description of the type.-U.S.N.M. No. 72600, collected on Morne Cabaio, Massif de la Selle, Haiti, on April 10, 1927, by Dr. A. Wetmore, at an altitude of 7,500 feet above sea level. Head not distinct from neck, short, its width equaling the distance from the end of the snout to the posterior border of the interparietal; rostral rhomboidal, much wider than high, not touching the nasal, in contact with the first supralabial and followed by a pair of supranasals broadly in contact; a pair of frontonasals a little larger than the supranasals; prefrontal undivided, pentagonal in shape but much wider than long, very 
slightly concave posteriorly; frontal once and one-fourth as long as broad, twice as broad as the supraoculars, in contact broadly with the first three; a pair of frontoparietals separated widely from each other by the posterior prolongation of the frontal; parietals large, almost twice the size of the interparietal, separated from the supraoculars by two small scales and the frontoparietals, and from each other by the shield-shaped interparietal and the fan-shaped occipital, which is about two-thirds the size of the interparietal; five supraoculars, the second the largest; a single nasal in contact with the first upper labial, which separates it completely from the rostral; three loreals in a row between nasal and preocular, first in contact above with supranasal and frontonasal; second with frontonasal, prefrontal, barely with the first supraocular, broadly with the first superciliary; third with first superciliary; a long subocular lying above and partly between the fifth and

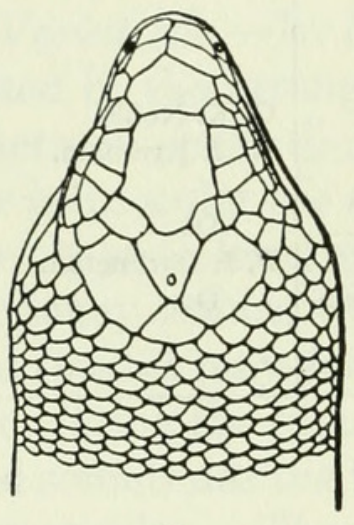

$a$
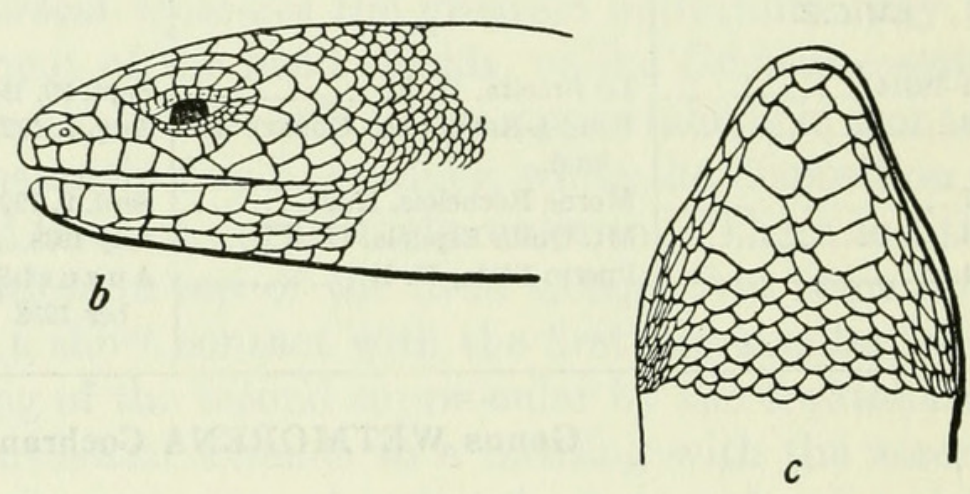

$c$

FIgURE 71.-Wetmorena haetiana: $a$, Top of head; $b$, side of head; $c$, chin. U.S.N.M. No. 72600, type, from Morne Cabaio, Massif de la Selle, Haiti. Twice natural size.

sixth supralabials; 10 supralabials, the last one scarcely distinguishable from surrounding scales; five temporals in the first row, forming a semicircle behind the eye; mental very small, scarcely differentiated except by position from the neighboring infralabials, followed by a somewhat larger, unpaired postmental; four pairs of chin shields, the first two pairs of which are in contact with the infralabials and with each other; no external ear opening, but where it might have been the region is indented to a slight extent and is covered by very small scales; body elongate, the adpressed limbs failing to meet by a distance equal to two-thirds their combined lengths; 40 to 42 scales around the body anteriorly lessening to 35 at midbody; dorsals with about 10 heavy striae (almost amounting to fine keels) to a scale; laterals less heavily striated; 110 dorsal scales in a straight line between the occipital and a point directly above the vent; 70 ventral scales from the anal plates to the center of the breast level with the axillae; laterals very faintly striated; ventrals perfectly smooth; the body scales sometimes uneven in size and irregular in shape so that rows do not run perfectly parallel; preanal scales very slightly enlarged; limbs short and poorly 
developed, the foreleg equal to the distance from the snout to the posterior border of the parietal; four short and stout fingers, the second and third subequal, the third with eight subdigital lamellae; four toes, the third much the longest, having 11 subdigital lamellae beneath it on the left foot, 12 on the right foot, the proximal ones prominently ridged in the middle; claws retractile into the last lamella which has a median distal suture; scales on soles of foot not spinose, but very much rounded, with a group of about half a dozen enlarged ones on the heel; tail (tip reproduced) nearly cylindric, ending in a point, two-thirds the length of the head and body, covered with scales like those of the body; the four median scale rows underneath the tail very slightly larger than the others.

Color (in alcohol): Dark grayish olive above; head scales with black posterior borders; about 10 more or less regular, narrow, black lines running from occiput to end of tail, made up of the darkened lateral edges of the dorsal scale rows; all lateral and ventral surfaces lustrous black with many small bluish-white irregular marks, which tend on the sides to form short vertical rows and which tendency is even more pronounced on the sides of the neck and on the chin, where the anterior portions of the chin shields become blue-white. Limbs black, with a few scattered irregular light spots above. Sides of head and temporal region black, with an occasional lighter area on the labials.

Dimensions: Head and body, $87 \mathrm{~mm}$; tail, $60 \mathrm{~mm}$; head width, $13 \mathrm{~mm}$.; foreleg, $11.5 \mathrm{~mm}$.; hindleg, $19 \mathrm{~mm}$.

Variations.-As I remarked in my original description, the paratypes though of all ages vary but little in color pattern or scalation. The subdigital lamellae are either 10 or 11 in number. The number of scale rows around the body vary in the type from 42 near the axil to 35 in the posterior part of the body, though the fact that the scales are somewhat uneven and not always arranged in uniform rows makes it impossible to give an exact figure. The three paratypes now in this collection have $42-35,42-34$, and 38-34, respectively.

Relationships.-Following my original description of this species I appended some remarks on its relationship to Sauresia sepsoides, which may be quoted in full: "The Haitian Sauresia sepsoides is most similar to Wetmorena haetiana. The head scalation in the two species is very much alike, the absence of an external ear-opening in haetiana being the only striking feature of the head structure itself by which they may be told apart.

"But in bodily proportions a considerable difference may be noted at once; Sauresia sepsoides, while a much smaller lizard, is much more elongate in body and has more delicate legs than the larger and stockier species which I am just describing. The number of scale-rows 
around the body, and the degree of striation in the dorsal scales, are likewise other differences which can not be overlooked.

"In coloration a vast difference is apparent at once. In sepsoides, the ventral surface is immaculate yellowish, while in haetiana this surface is black, spotted with irregularly shaped blue-white markings. In sepsoides, the slight amounts of dark pigment appearing in the dorsal scales are found in the central region of each scale, but in haetiana all the dark pigment is concentrated at the lateral regions of each scale, leaving the central portion conspicuously paler."

Specimens examined.-As listed in table 48.

TABLE 48.- Specimens of Wetmorena haetiana examined

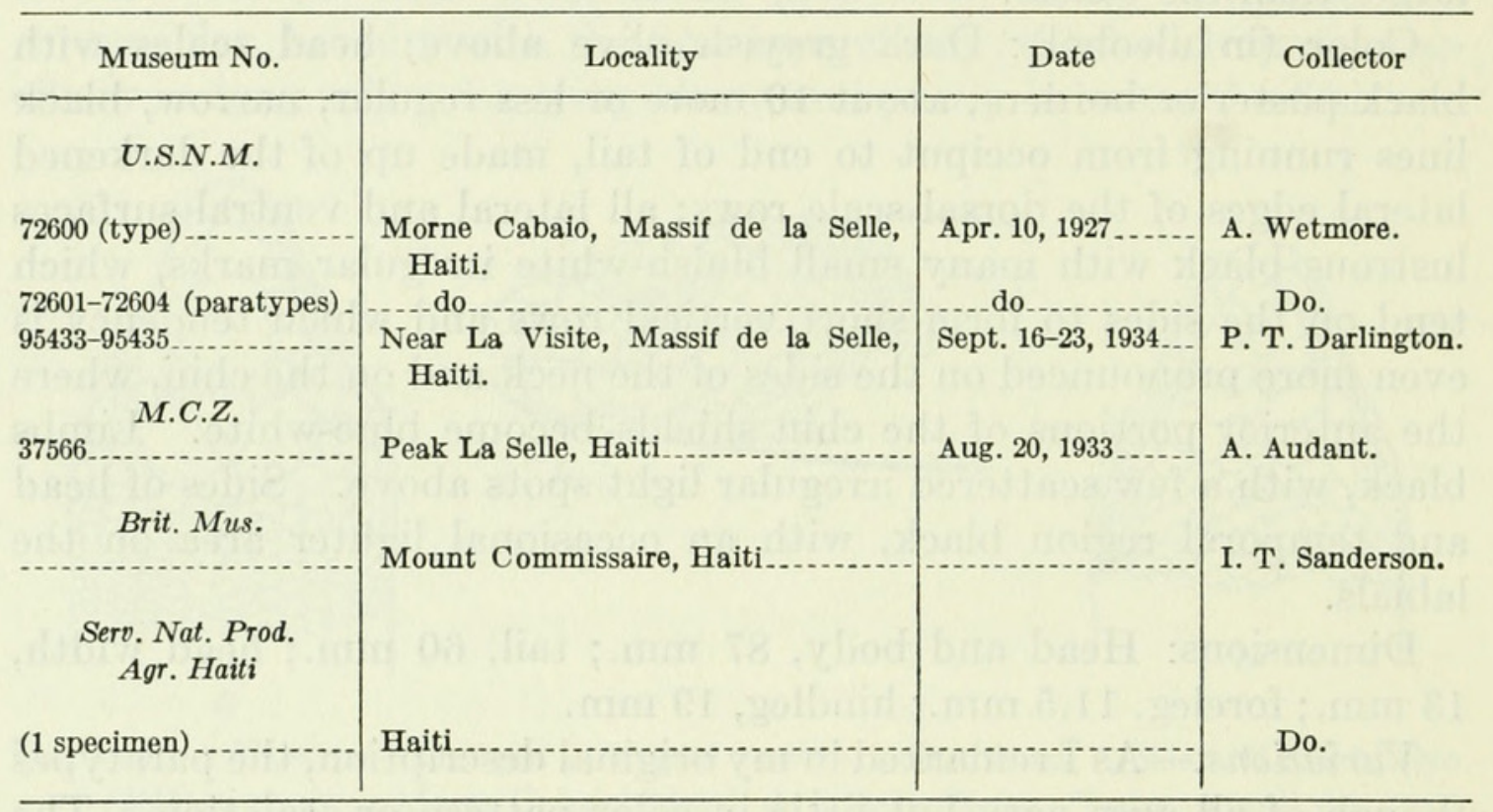

\section{Family TEIIDAE}

\section{Genus AMEIVA Meyer}

1795. Ameiva Meyer, Synopsis reptilium, p. 27 (type, A. americana=Lacerta ameiva).

\section{A KEY TO THE FORMS OF AMEIVA IN HISPANIOLA AND ADJOINING ISLANDS}

$a^{1}$. Less than 12 longitudinal rows of subequal ventral plates.

$b^{1}$. Upper caudal scales perfectly smooth; 8 rows of ventral plates;

first supraocular in contact with loreal.

$c^{1}$. Three medial preanals subequal_._._. _. lineolata lineolata (p. 263)

$c^{2}$. Anterior preanal much larger than the 2 posterior ones

(Beata Island) _... lineolata beatensis (p. 267)

$b^{2}$. Upper caudal scales keeled.

$c^{1}$. Ventrals in 10 longitudinal rows of subequal plates; first supraocular separated from loreal; third supraocular partially separated from frontoparietal by granules.

$d^{1}$. Caudal scales oblique; wide dark dorsolateral stripe usually immaculate (except in old individuals, in which the invading lighter spots are not arranged vertically) 
$d^{2}$. Caudal scales straight; wide dark dorsolateral stripe invaded by lighter spots which tend to form vertical bars

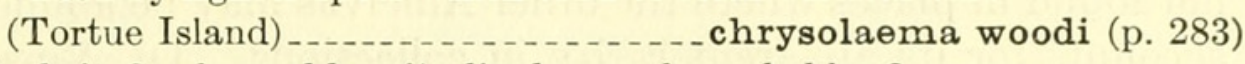

$c^{2}$. Ventrals in 8 subequal longitudinal rows, bounded by 2 very small external series; third supraocular fully in contact with frontoparietal.

$d^{1}$. Dorsolateral black band relatively narrow; no light lines or spots; 37 lamellae under fourth toe; 22 scales in fifteenth verticil of tail (Gonave Island) _... . . . _... barbouri (p. 292)

$d^{2}$. Dorsolateral black band relatively wide, edged below by a narrow light line; 40 lamellae under fourth toe; 25 scales in fifteenth verticil (Saona Island) _ _ _ _ rosamondae (p. 295) $a^{2}$. Twelve longitudinal rows of subequal ventral plates.

$b^{1}$. Enlarged brachials usually wider than long; postbrachials rather conspicuously enlarged; numerous rows of spots distributed uniformly over sides and back; interparietal smaller than adjacent scales.

$c^{1}$. Pattern usually of spots and stripes _ chrysolaema chrysolaema (p. 275)

$c^{2}$. Pattern entirely of spots (Beata Island) __ chrysolaema abbotti (p. 285)

$b^{2}$. Brachials, if enlarged at all, not wider than long; postbrachials usually not very conspicuously enlarged; a black lateral band not or scarcely invaded by white spots; interparietal larger than adjoining scales................ chrysolaema affinis (p. 289)

In order to express the greater or less degree of difference between the Hispaniolan Ameivas, it seems best to recognize taeniura, rosamondae, and barbouri as full and distinct species, to make beatensis a subspecies of lineolata, and abbottii, affinis, and woodi subspecies of chrysolaema.

\section{AMEIVA LINEOLATA LINEOLATA Duméril and Bibron}

\section{Figures 72,73}

1839. Ameiva lineolata Duméril and Bibron, Erpétologie générale, vol. 5, p. 119 (type locality, Saint-Domingue; collector, Dr. Bally; type in Brit. Mus.). - Gray, Catalogue of the specimens of lizards in the collection of the British Museum, p. 20, 1845.-Duméril, Catalogue méthodique de la collection des reptiles (Paris Museum), p. 116, 1851.-Bocourt, Mission scientifique au Mexique et dans l'Amérique Centrale, Recherches zoologiques, Reptiles, pl. 20A, fig. 5-5D (figures of the type specimen), text, p. 253, 1874.-BodLENGER, Catalogue of the specimens of lizards in the collection of the British Museum, ed. 2, vol. 2, p. 349, 1885.-Garman, Bull. Essex Inst., vol. 19, p. 11, 1887 (Hayti and San Domingo).-Barbour, Mem. Mus. Comp. Zool., vol. 44, No. 2, p. 311, 1914; Zoologica, vol. 11, No. 4, p. 103, 1930; vol. 19, No. 3, p. 126, 1935.-Barbour and Noble, Bull. Amer. Mus. Nat. Hist., vol. 44, art. 2, p. 17, 1921.-Mertens, Senckenbergiana, vol. 20, No. 5, p. 341, 1938; Publ. Inst. Cient. Domínico-Alemán, vol. 1, p. 94, 1939.-BöкеR, Publ. Inst. Cient. Domínico-Alemán, vol. 1, p. 18, 1939.

This beautiful lizard belongs to one of the dwarf species of the genus. Its longitudinal black-and-white striping is paralleled in a most interesting way by the wholly unrelated iguanid lizard Hispaniolus pratensis. Where most of the larger Ameivas can travel and disperse themselves over a relatively large territory, this small lizard 
seems to be restricted to certain limited ranges in Hispaniola and is not found in places where the other Ameivas may be abundant. This accounts for its apparent rarity in collections. Dr. Vinson has told me that this lizard is exceedingly abundant in the spot where he collected two specimens for us - the sisal plantation on the Cul-deSac Plain of Haiti-but that he knew of it in no other place in western Haiti.

Description.-U.S.N.M. No. 59208, an adult male from Thomazeau, Haiti, collected on April 3, 1917, by J. B. Henderson and Paul Bartsch. Rostral forming an obtuse angle behind; nostril in the lower part of the anterior nasal plate, which is broadly in contact with its fellow behind the rostral; frontonasal wider than long, in contact with both

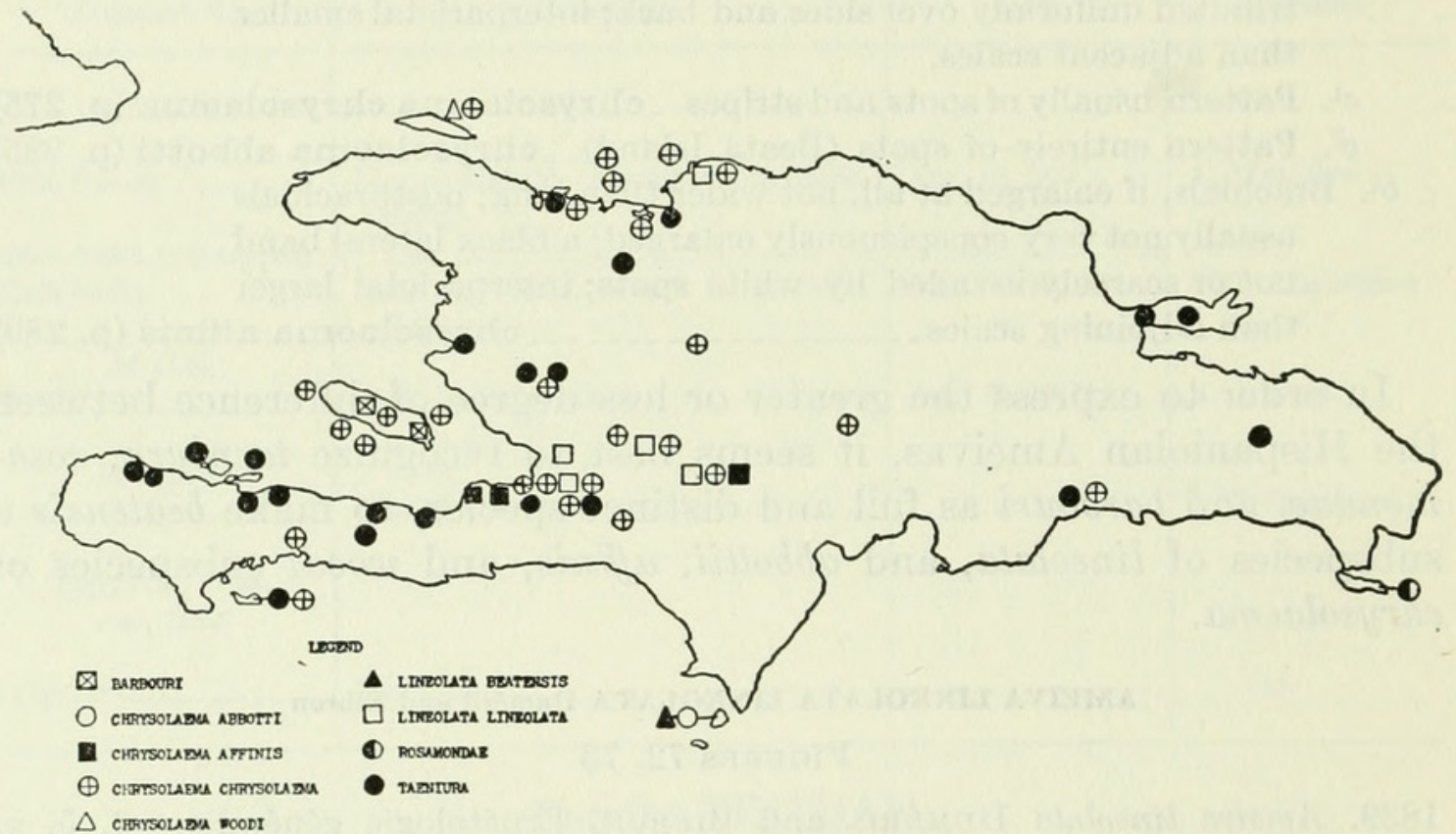

Figure 72.-Distribution of Ameiva in Hispaniola.

the nasals, loreal, and prefrontal; prefrontals broadly in contact; frontal elongate, pentagonal, in contact with the first three supraoculars; a pair of frontoparietals in contact with the third and fourth supraoculars; five occipitals in a transverse row, the median the largest and almost rectangular in shape; seven or eight superciliaries; four supraoculars, the first in contact with the loreal and with the first two superciliaries; a pair of small frontoparietals broadly in contact with the third supraocular; the three posterior supraoculars separated from the superciliaries by a single row of granular scales; the fourth supraocular partly in contact with the occipital shield which borders the median one; loreal undivided; about eight supralabials, the last very small, the third largest, the sixth coming directly below the center of the eye, the second in contact with posterior nasal and loreal; temples with small granular scales like those of body, surrounded by larger ones; mental followed by an unpaired postmental; 


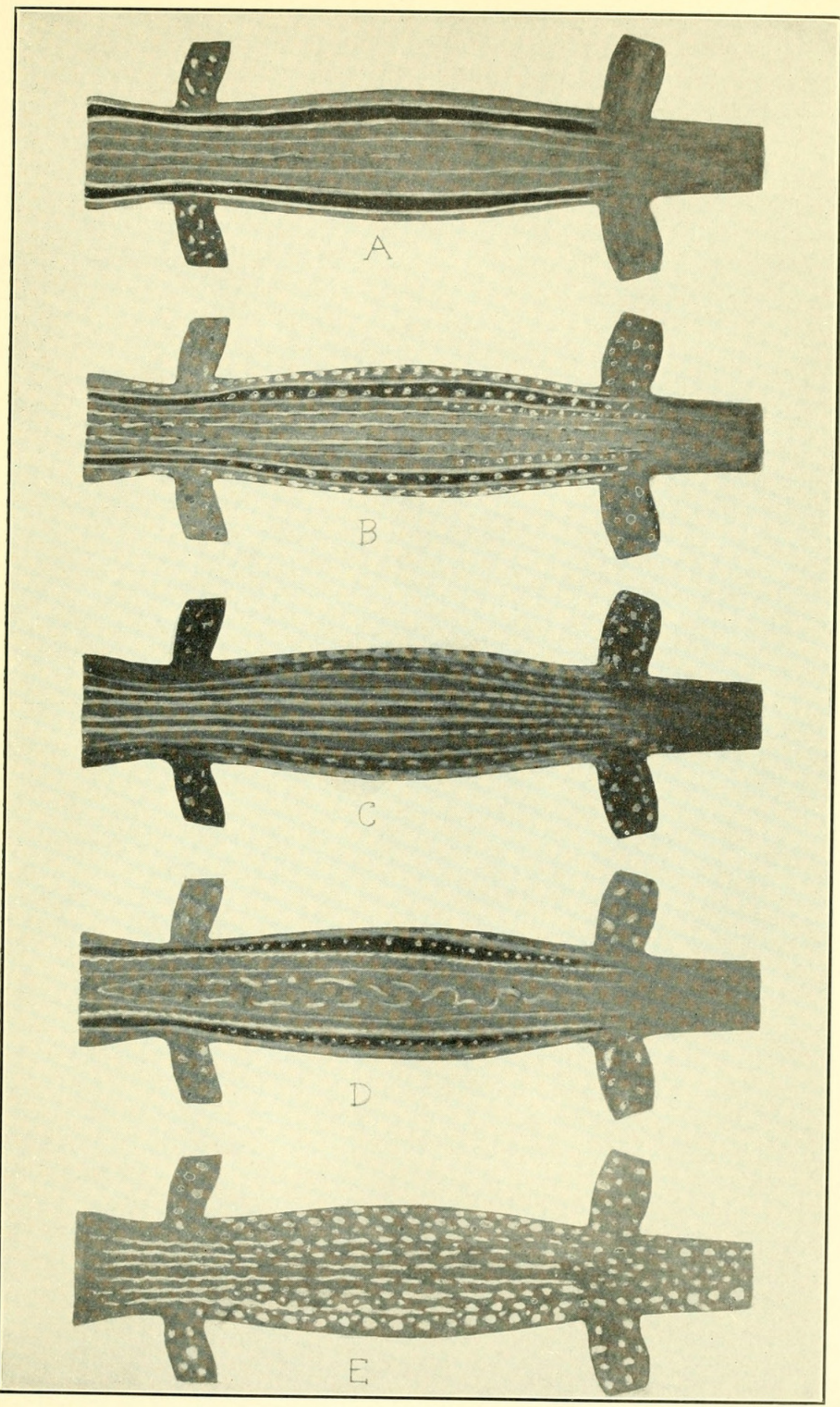

(See next page for explanation.) 


\section{Plate 8}

Color pattern of Ameiva chrysolaema affinis and A. c. chrysolaema.

A, Ameiva chrysolaema affinis from Momance, Haiti, U.S.N.M. No. 67111.

B, Ameiva chrysolaema chrysolaema from Cap-Haitien, Haiti, U.S.N.M. No. 74086.

C, Ameiva chrysolaema chrysolaema from Damien, Port-au-Prince, Haiti, U.S.N.M. No. 75888 .

D, Ameiva chrysolaema chrysolaema from Cap-Haïtien, Haiti, U.S.N.M. No. 74077.

E, Ameiva chrysolaema chrysolaema, type, from within 25 miles of Port-au-Prince, Haiti, U.S.N.M. No. 12140. 
five infralabials, the first small, the last four large and subequal; first pair of chin shields completely in contact; between infralabials and chin shields a wedge composed of a single series of small scales extending anteriorly to the middle of the third infralabial; chin and throat covered with granules of fairly regular size, becoming somewhat larger, however, on the jaws below the ears; on the portion between the throat folds (the mesoptychium) several rows of larger hexagonal scales, which attain their maximum development in the center, where a group of about a dozen enlarged scales are prominent; back, sides, and upper part of limbs covered with fine, uniform granules, except the upper arm, which is covered above by large imbricate scales; about 28 dorsal granules in the standard distance from center of eye to tip of snout; under side of body with 8 longitudinal and 33 transverse rows of rectangular plates; three large preanal shields forming a triangle; on the lower arm two series of very wide antebrachial plates, the outer one of which continues along the upper arm, becoming rather narrow at the elbow; in addition to this antebrachial row on the upper arm there are four other rows behind it, the last (the post-antebrachial) having increasingly wider scales as it nears the elbow joint; underside of thigh covered with about six rows of hexagonal plates, one row of which is considerably larger than the others; 16 femoral pores; on the under side of tibia two rows of plates of which one in the outer row is enormously enlarged; upper side of wrist with regular series of transverse plates corresponding to the metacarpals; 34 subdigital lamellae on the fourth toe; tail covered with smooth diagonal scales set in regular transverse rows, 18 scales in the fifteenth verticil from the base.

Dimensions: Head and body, $51 \mathrm{~mm}$; head to posterior ear, 13.5 $\mathrm{mm}$.; tail incomplete; foreleg, $18 \mathrm{~mm}$.; hindleg, $32 \mathrm{~mm}$; axilla to groin, $26 \mathrm{~mm}$.

Color (in alcohol): Body French gray above, immaculate pearl gray below, tail and hindlegs plumbeous. A series of narrow longitudinal black dorsal and lateral stripes running from the region of the eyes onto the tail, these stripes equal in width except for the next to the lowest on each side, which is slightly the widest, noticeably so on the upper temporal region near its origin at the posterior corner of the eye; loreal region with a faint dark stripe, which is the anterior continuation of this widest dark stripe; the lowest stripe begins above the corner of the mouth, passes through the ear and continues along the side and onto the tail; the two pairs of dorsal stripes originate on the supraocular plates, leaving the anterior part of the snout without any pattern at all, and pass backward to the scapular region where they narrow somewhat to allow the insertion of another pair of black stripes, which in turn allows a single black stripe to be interpolated in the center of the back about halfway between axilla and groin. 
Thus there are 8 fairly wide black stripes on the neck, 10 just behind the arm insertion, and 11 in front of the hindleg, the central (dorsal) ones the narrowest. Arms with three fairly distinct black stripes on upper surface; legs with black vermiculations on upper surface, the posterior aspect of the femur with a pair of narrow black lines separated by the pearl-gray body color. On the base of the tail the stripes of black become the same width as the interspaces of plumbeous-gray, and rapidly become less and less distinct. Throat, chin, and upper and lower labials all immaculate pale olive-buff.

Variations.-The characters of this species seem to be subject to only a small degree of variation. Even the number of dorsal granules in the standard distance from center of eye to tip of snout is far less
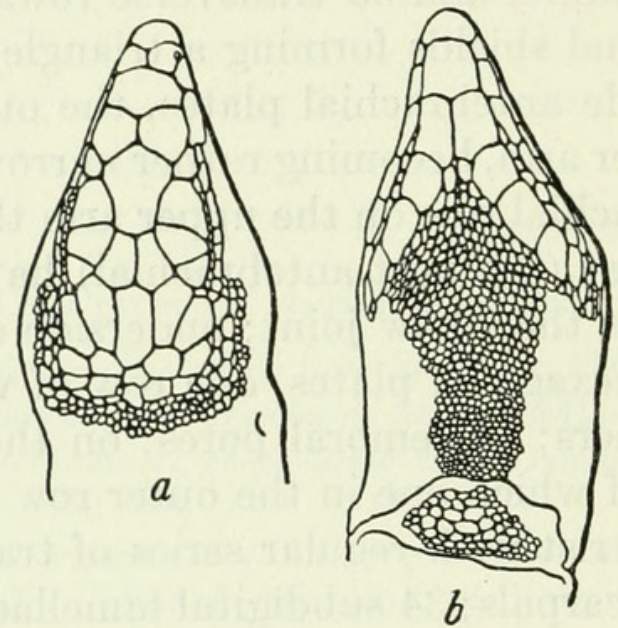
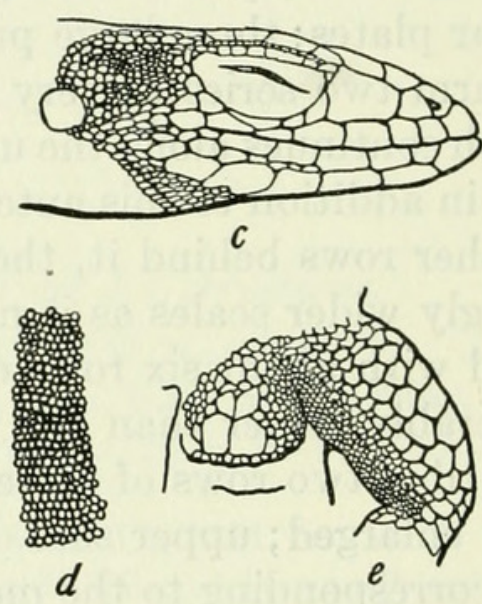

Figure 73.-Ameiva lineolata lineolata: $a$, Top of head; $b$, chin and throat; $c$, side of head; $d$, dorsal granules; $e$, preanal and femoral region. U.S.N.M. No. 59208, from Thomazeau, Haiti. Two and one-half times natural size.

variable than is usually the case among Ameivas. The scalation of the head is practically the same in all the specimens, except in U.S.N.M. No. 77953, where the excessive enlargement of the first superciliary has prevented the contact of the first preocular and the loreal that takes place in the other examples. The fourth supraocular is sometimes completely separated by granular scales from the occipital bordering the median one. This is not, however, a character of much significance. Body scalation is quite constant, there being 8 transverse rows in every case, while the longitudinal rows are 32 to 34. The tail has 17 to 19 plates in the fifteenth verticil. Coloration is as constant as scale arrangement; there are 8 black stripes on the neck and 11 on the sacrum in all specimens. The two examples from Cul-de-Sac Plain have tails dark below and above; in the two from Thomazeau the tails are light below.

Relationships.-Ameiva lineolata, as well as A. beatensis, appears to be related to $A$. wetmorei of Puerto Rico. All three species have the first supraocular in contact with the loreal, a character not met with in other Ameivas with oblique supracaudal scales. 
In comparing the type of Ameiva wetmorei with my specimens of lineolata, however, certain differences are at once apparent. A. wetmorei has but 3 supraoculars; the frontoparietal is undivided; the middle occipital shield is very small, being bordered on each side by a single large shield. A. lineolata, on the other hand, has 4 supraoculars; the frontoparietal is divided; the middle occipital is larger than the others, having a smaller shield on each side, which in turn is bordered by another shield of approximately equal size. In coloration, the unequal width of dark and light stripes in wetmorei is in great contrast to the uniform fine striping of lineolata. The former species has light round spots against a black background on the upper limb surfaces; the latter has striped arms and vermiculated legs. The similarities of the two species are much more striking than their differences, however, and their obvious affinity affords one more link in the zoogeographic chain of evidence for the connection of Puerto Rico and Hispaniola in ages past.

The Beata Island form described by Dr. Noble under the name of Ameiva beatensis in 1923 is of course the closest to its probable parent lineolata, although it too shows a resemblance to wetmorei in having the pattern continued onto the end of the snout, which is not the case in true lineolata, as Dr. Noble has pointed out.

Specimens examined.-As listed in table 49.

TABLE 49.-Specimens of Ameiva lineolata lineolata examined

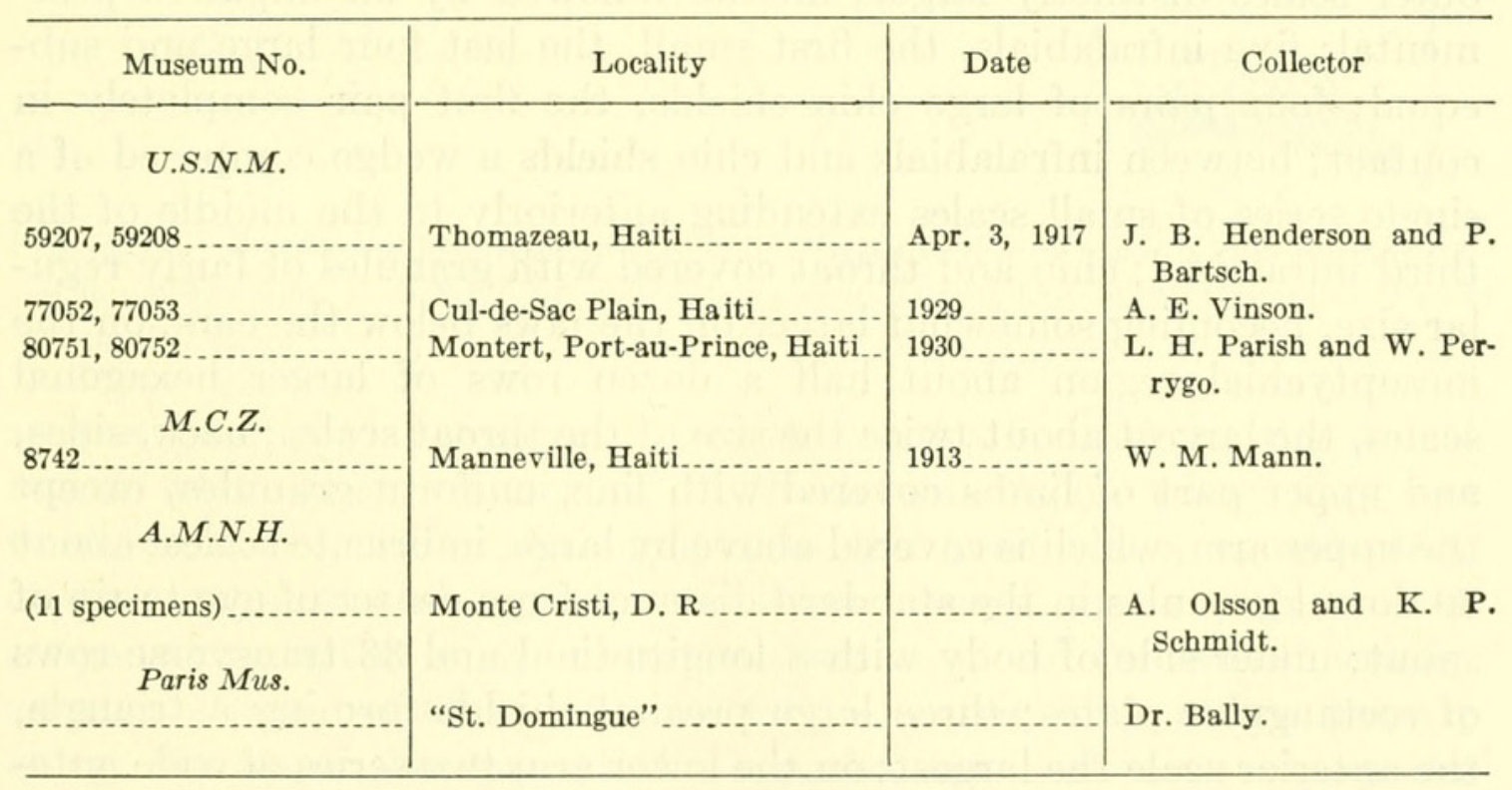

AMEIVA LINEOLATA BEATENSIS Noble

Figures 72,74

1923. Ameiva beatensis Noble, Amer. Mus. Nov., No. 64, p. 2 (type locality, Beata Island, Dominican Republic; collector, G. K. Noble).-BARBour, Zoologica, vol. 11, No. 4, pp. 69, 103, 1930; vol.19, No. 3, p. 127, 1935; Bull. Mus. Comp. Zool., vol. 82, No. 2, p. 145, 1937. 
Description.-U.S.N.M. No. 83882, an adult from Beata Island, Dominican Republic, collected on May 11, 1931, by Dr. A. Wetmore and F. C. Lincoln. Rostral forming an obtuse angle behind; nostril in the lower part of the anterior nasal plate, which is broadly in contact with its fellow behind the rostral; frontonasal wider than long, in contact with both the nasals, loreal, and prefrontal; prefrontals broadly in contact; frontal elongate, pentagonal, in contact with the first three supraoculars; five occipitals in a transverse row, the median rectangular, slightly smaller than the adjacent scales; seven superciliaries, the first in contact with the loreal, the third the longest; four supraoculars, the first in contact with (on one side barely separated from) the loreal and with the first two superciliaries; a pair of small frontoparietals broadly in contact with the third supraocular; the three posterior supraoculars separated from the superciliaries by a single row of granular scales; five occipitals, the median one the smallest, those adjacent to it the largest; the fourth supraocular on one side completely separated by granular scales from the occipital bordering the median one, on the other side partially in contact with it; loreal undivided; about seven supralabials, the last very small, the third and fourth largest, the intersection between the fifth and sixth coming directly below the center of the eye, the first in contact with the rostral and nasals, the second in contact with posterior nasal and loreal; temples with small scales a little larger than those on the back, the outer scales distinctly larger; mental followed by an unpaired postmental; five infralabials, the first small, the last four large and subequal; four pairs of large chin shields, the first pair completely in contact; between infralabials and chin shields a wedge composed of a single series of small scales extending anteriorly to the middle of the third infralabial; chin and throat covered with granules of fairly regular size, becoming somewhat larger on the jaws below the ears; on the mesoptychial region about half a dozen rows of larger hexagonal scales, the largest about twice the size of the throat scales; back, sides, and upper part of limbs covered with fine, uniform granules, except the upper arm, which is covered above by large, imbricate scales; about 30 dorsal granules in the standard distance from center of eye to tip of snout; under side of body with 8 longitudinal and 33 transverse rows of rectangular plates; three large preanal shields forming a triangle, the anterior scale the largest; on the lower arm two series of wide antebrachial plates, the outer one of which continues along the upper arm, becoming narrower at the elbow; in addition to this antebrachial row on the upper arm there are five other rows behind it, the fourth (post-antebrachial) having increasingly wider scales as it nears the elbow joint; under side of thighs covered with several rows of hexagonal plates; femoral pores 14 and 16 ; under side of tibia with two rows of plates of which one in the outer row is enormously enlarged; upper 
side of wrist with regular series of transverse plates corresponding in position to the metacarpals; 35 subdigital lamellae on the fourth toe; tail covered with smooth, diagonal scales set in regular transverse rows, about 16 scales in the fifteenth verticil from the base.

Dimensions: Head and body, $55 \mathrm{~mm}$.; head to posterior ear, $20 \mathrm{~mm}$.; tail (reproduced), about $105 \mathrm{~mm}$.; foreleg, $19 \mathrm{~mm}$; hindleg mutilated; axilla to groin, $28 \mathrm{~mm}$.

Color (in alcohol): Body color above pale gray to china blue, immaculate pale blue below; tail and legs pale blue; a series of longitudinal black dorsal and lateral stripes running from the tip of the snout, dividing on the body and continuing on to the tail, these
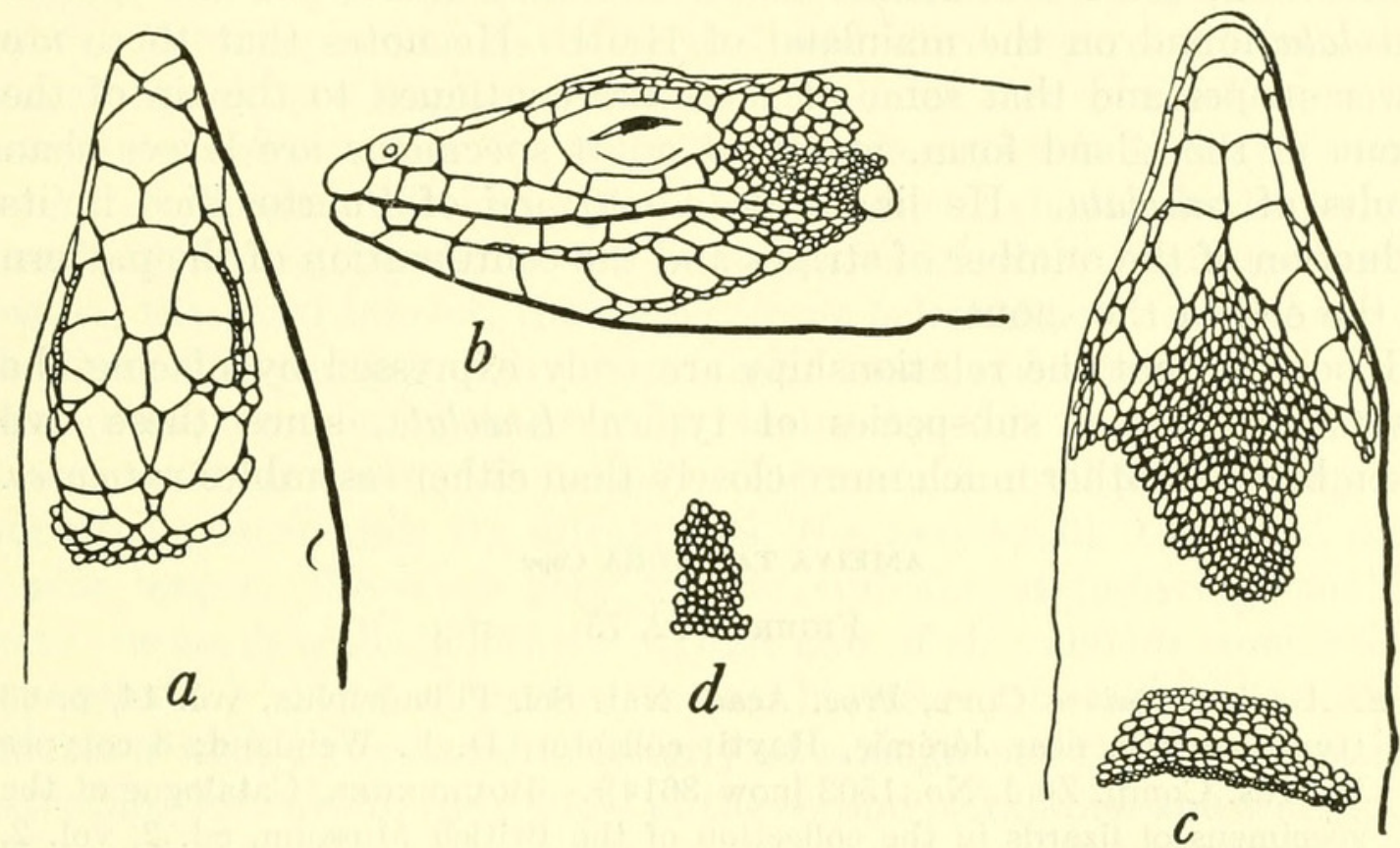

Figure 74.-Ameiva lineolata beatensis: $a$, Top of head; $b$, side of head; $c$, chin and throat; $d$, dorsal granules. U.S.N.M. No. 83882, from Beata Island, Dominican Republic. Twice natural size.

stripes gradually increasing in width on the body from the dorsal region where they are narrow to the lateral region where they are twice as wide; those continuing onto the head widen considerably on the temporal and supraocular regions; loreal region with a black stripe, which is the anterior continuation of one of the lateral stripes; another stripe begins on the rostral as a pale gray stripe passing along the upper borders of the supralabials, darkening above the corner of the mouth, passing through the ear and continuing along the side and on to the tail; the black stripes passing through the supraocular plates and joining on the frontonasal do not divide on the body; the dorsal stripes originate as a single black stripe ending on the frontal, but forking once on the neck, and allowing the interpolation of another black stripe just behind the scapular region; this interpolated stripe forks at the middle of the back, forming the 
narrowest of the black stripes. There are consequently 7 black and 6 white stripes on the head, 8 black and 7 white on the neck, 9 black and 8 white behind the arm insertion and 10 black and 9 white in front of the hindleg (not counting the white flanks). Arms with three distinct black stripes on upper surface; legs with black vermiculations on upper surface; the posterior aspect of the femur with a pair of narrow black lines separated by the pale blue body color. On the base of the tail the black stripes narrow and rapidly lose their distinctness. Throat, chin, infralabials, and lower borders of supralabials immaculate olive-buff.

Relationships.-As Dr. Noble himself pointed out in the original description, the Beata Island lizard is closely related to the typical lineolata found on the mainland of Haiti. He notes that there are fewer stripes and that some of these are continued to the tip of the snout in the island form, and that adult specimens are larger than adults of lineolata. He likens it to wetmorei of Puerto Rico in its reduction of the number of stripes and the continuation of the pattern to the end of the snout.

I believe that the relationships are truly expressed by placing the Beata form as a subspecies of typical lineolata, since these two resemble each other much more closely than either resembles wetmorei.

\section{AMEIVA TAENIURA Cope}

Figures 72,75

1862. Ameiva taeniura Cope, Proc. Acad. Nat. Sci. Philadelphia, vol. 14, p. 63 (type locality, near Jérémie, Hayti; collector, D. F. Weinland; 3 cotypes in Mus. Comp. Zool. No. 1503 [now 3614]).-Boulenger, Catalogue of the specimens of lizards in the collection of the British Museum, ed. 2, vol. 2, p. 350, 1885; Proc. Zool. Soc. London, 1890, p. 78 (Hayti; Brit. Mus.).Garman, Bull. Essex Inst., vol. 19, p. 11, 1887 (Jérémie, Hayti; Mus. Comp. Zool. specimens).-Müller, Verh. Naturf. Ges. Basel, vol. 10, pt. 1, p. 212, 1892 (specimen from Miragoane, Hayti; Basel Mus.).-Meerwarth, Mitth. Nat. Mus. Hamburg, vol. 18, p. 29, 1901.-Barbour, Mem. Mus. Comp. Zool., vol. 44, No. 2, p. 310, 1914; Zoologica, vol. 11, No. 4, p. 102, 1930; vol. 19, No. 3, p. 126, 1935; Bull. Mus. Comp. Zool., vol. 82, No. 2, p. 143, 1937.-Sснмidt, Bull. Amer. Mus. Nat. Hist., vol. 44, art. 2, p. 17, 1921.-Cochran, Proc. U. S. Nat. Mus., vol. 66, art. 6, p. 10, 1924; Proc. Biol. Soc. Washington, vol. 41, p. 54, 1928; Occ. Pap. Boston Soc. Nat. Hist., vol. 8, p. 183, 1934. Barbour and Loveridge, Bull. Mus. Comp. Zool., vol. 69 , No. 10, p. 214, 1929.-Böker, Publ. Inst. Cient. DomínicoAlemán, vol. 1, p. 18, 1939.

1915. Ameiva lineolata Barbour and Noble, Bull. Mus. Comp. Zool., vol. 59, No. 6, p. 433 (part) (not of Duméril and Bibron).

1938. Ameiva chrysolaema boekeri Mertens, Senckenbergiana, vol. 20, p. 338, fig. 6; Publ. Inst. Cient. Domínico-Alemán, vol. 1, p. 90, 1939.

1939. Ameiva chrysolaema bökeri Böker, Publ. Inst. Cient. Domínico-Alemán, vol. 1 , p. 18, 1939. 
Description.-U.S.N.M. No. 59240 from Jérémie, Haiti, collected by J. B. Henderson and Dr. Paul Bartsch on April 10, 1917. Rostral forming a right angle behind; nostril in the lower part of the anterior nasal plate, which is rather narrowly in contact with its fellow behind the rostral; frontonasal nearly as wide as long, in contact with both nasals, loreal, and prefrontal; prefrontals rather narrowly in contact; frontal elongate, pentagonal, in contact broadly with the first two supraoculars and very narrowly with the third; a pair of frontoparietals in contact with the third supraoculars; five occipitals in a transverse row, the central and the outermost ones a little smaller than the remaining two; seven or eight superciliaries, the fourth much the longest; three supraoculars, the first well separated from the loreal by the first superciliary, the second and third separated from the superciliaries by a single row of granular scales, the third followed by a group of three or four small scales, which separate it from the outer occipitals; loreal undivided; about seven upper labials, the last very small and barely distinguishable from the scales of the lower temporal region, the third largest, the sixth coming below the center of the eye, the second in contact with the posterior nasal and very slightly with the loreal; temples with granular scales smaller than the dorsals, about equal to those of the sides of the neck; mental followed by an unpaired postmental; six infralabials, the first small, the third and fourth largest, the sixth very minute and almost indistinguishable from the small scales following it; first pair of chin shields completely separated by a row of narrow scales; between infralabials and chin shields a wedge composed anteriorly of a single series of small scales extending forward to the middle of the second infralabial and widening posteriorly to three scales; chin and throat covered with granules of fairly regular size becoming gradually larger and then suddenly very small just before the mesoptychial region is reached; on this region about three rows of larger hexagonal scales which attain their maximum development in the center; back, sides, and upper part of limbs covered with fine uniform granules; those on the sides smaller; about 43 dorsal granules in the standard distance from center of eye to tip of snout; under side of body with 34 transverse and 8 longitudinal rows of rectangular plates, with some additional scales bordering the latter, which are less than one-fourth their area; a pair of enlarged preanals, preceded by a single large shield, which is in turn preceded by a smaller one; on the lower arm a wide (outer) and a narrow (inner) series of antebrachial plates, the wider series being continuous with a similar series on the upper arm, although greatly reduced in size at the elbow; no additional enlarged series of antebrachials on the upper arm; a patch of half a dozen slightly enlarged and imbricate scales on the back of the arm above the elbow; under side of thigh covered with about four rows of hexagonal plates, decreasing gradually 
in size toward the femoral pores; 14 femoral pores; under side of tibia with three rows of plates, of which two in the outer row are considerably enlarged; upper side of hand with five regular series of transverse plates corresponding to the metacarpals; fifth (outer) toe extending a little farther than the first (inner); 36 subdigital lamellae on the fourth toe; tail covered with diagonal scales set in transverse rows, the dorsal ones keeled, the ventral ones smooth, 28 scales in the fifteenth verticil from the base.
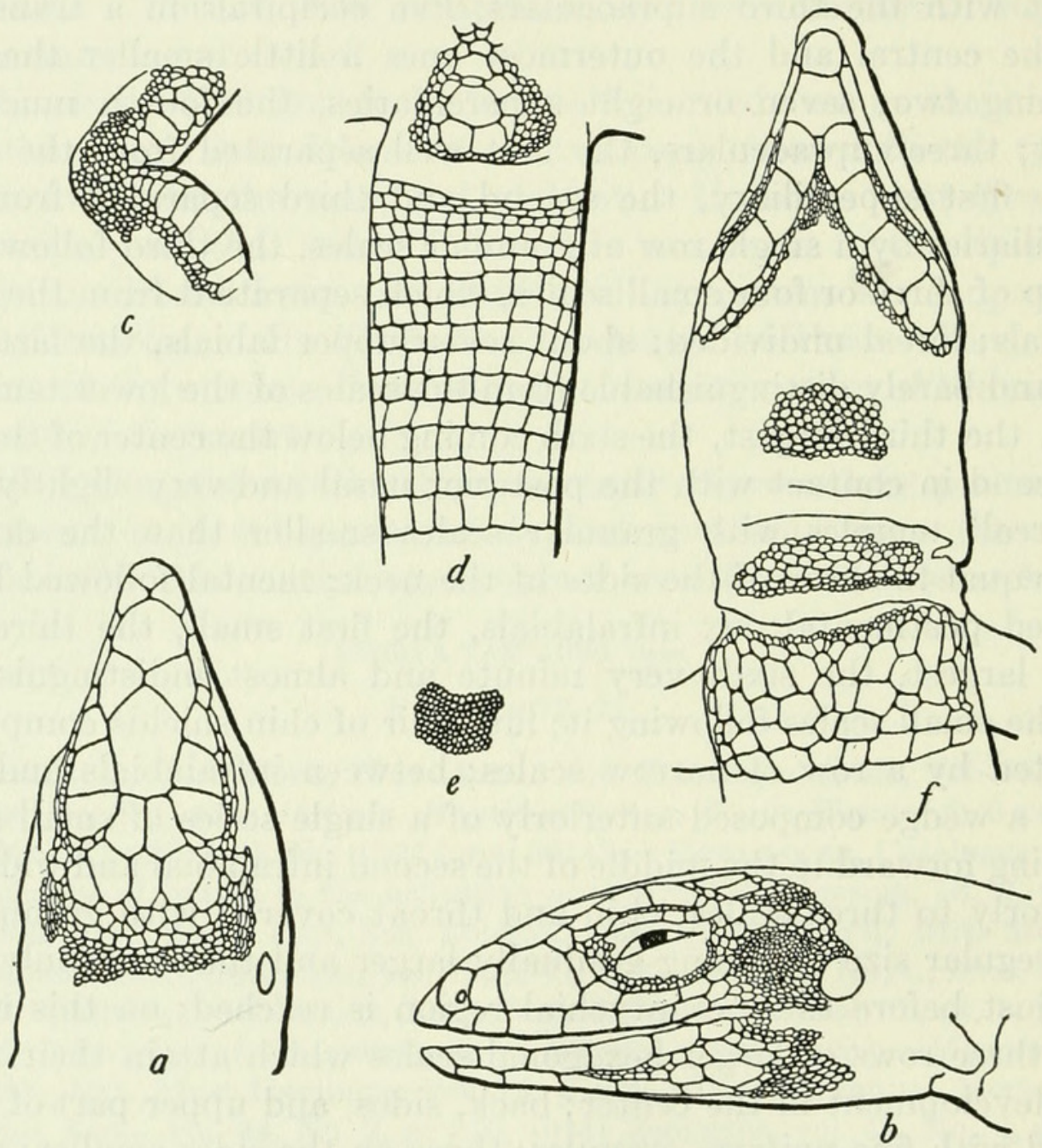

Figure 75.-Ameiva taeniura: $a$, Top of head; $b$, side of head; $c$, forearm showing antebrachials; $d$, anal region; $e$, dorsal granules; $f$, chin and chest. U.S.N.M. No. 59240, from Jérémie, Haiti. Twice natural size.

Dimensions: Head and body, $77 \mathrm{~mm}$.; head to posterior border of ear, $20 \mathrm{~mm}$.; tail, $188 \mathrm{~mm}$.; fore limb, $28 \mathrm{~mm}$.; hind limb, $51 \mathrm{~mm}$.

Color (in alcohol): Body color light indigo above, fading to immaculate pea green on the head; a wide black lateral stripe running from behind the eye over the ear, along the body and onto the tail, with a narrow white line bordering it above and below; another much narrower black stripe above and parallel to this wide lateral stripe and another very indistinct narrow dark stripe below it that becomes very evident on the tail; posterior part of back with traces of another pair 
of dark dorsal stripes; lower surfaces immaculate pale Nile blue lightening to olive-buff on the throat; limbs pale indigo blue like the body; tail turquoise blue fading to heliotrope toward the tip, with the three black lateral lines of the body continued very heavily on its proximal half, the central one being the most pronounced, as on the body.

Variations.-This species, like Ameiva lineolata lineolata, is quite constant in its characters. There are always three large supraoculars, the first one of which is constantly separated from the loreal by the first superciliary. The occipitals are always arranged in a transverse series of five subequal ones, or else the three middle ones are large and the two outermost are much smaller. In a few specimens, one could almost say that 10 longitudinal ventral rows of plates are present when the outer row is larger than usual, but in most cases there are eight rows and a few enlarged scales which are not equal to more than a fourth or a third the area of the neighboring row. There are 33 to 36 transverse rows of ventral scales. The femoral pores may vary from 13 to 18 in number. While in nearly all cases there are two enlarged preanal plates preceded by a single one, yet in some cases there are four subequal marginal plates (U.S.N.M. No. 59220, M.C.Z. No. 3614 [2 specimens]) and in one case there are three (M.C.Z. No. 3614 [1 specimen]). The tail at the fifteenth verticil bears 24 to 32 scales, and the subdigital lamellae number 34 to 42 . The brachials and antebrachials are usually continuous, although very much reduced in the specimens from Grande Cayemite Island (M.C.Z. Nos. 25535 and 25536) and actually discontinuous in one of the four type specimens of taeniura from Jérémie (M.C.Z. No. 3614). Postbrachials are always present, often rather large, but sometimes medium or small in size. The dorsal granules of lizards from the mainland of Hispaniola number 36 to 46 in the standard distance from center of eye to tip of snout; in the two specimens from Grande Cayemite Island (M.C.Z. Nos. 25535 and 25536) we find 52 and 48 granules, respectively, showing a tendency toward differentiation in the isolated region.

The wide dark lateral stripe is frequently invaded by light spots in old individuals. Sometimes there are no additional stripes above or below the lateral stripe, but the usual coloration is like that of the described specimen.

Relationships.-The nearest relative to Ameiva taeniura is Ameiva polops of St. Croix. Their similarity is apparent at a casual glance, and the first impression is deepened after careful comparison. Not only is the color pattern essentially the same, but the head and body proportions are also alike, and, were they known to occur together, it would be extremely difficult to separate the two by scalation. The dorsal granules in the type of Ameiva polops (U.S.N.M. No. 30693) are small, like the two Grande Cayemite examples of taeniura already 
referred to. The femoral pores of polops are 19 or 20 in the type, but a taeniura from L'Atalaye (U.S.N.M. No. 76654) approaches it by having as many as 17 and 18 pores. The tail scales of polops are large, 24 around the fifteenth verticil; this number is duplicated in a taeniura from Miragoane (U.S.N.M. No. 77071). Were it not for the two equally heavy stripes on each side of the body in polops, where taeniura has but one heavy stripe and several narrower ones, it would be extremely difficult to make a valid separation on the material at hand.

TABLE 50.-Specimens of Ameiva taeniura examined

\begin{tabular}{|c|c|c|c|}
\hline Museum No. & Locality & Date & Collector \\
\hline U.S.N.M. & $\begin{array}{l}\text { San Francisco Mountains, D. } \\
\text { R. }\end{array}$ & September $1905 \ldots$ & A. Busck. \\
\hline $55052-55055$ & Samaná Peninsula?, D. R & 1916 & W. L. Abbott. \\
\hline 59220 & Pétionville, Haiti. . . & Mar. 23, 1917. & $\begin{array}{l}\text { J. B. Henderson and P. } \\
\text { Bartsch. }\end{array}$ \\
\hline $59240-59242$ & Jérémie, Haiti . ........ & Apr. $10-14,1917$. & Do. \\
\hline $59244 \ldots \ldots$ & Petit Gonave, Haiti & Apr. $9,1917 \ldots \ldots$ & Do. \\
\hline $59245,59246 \ldots$ & Trou des Roseaux, Haiti & Apr. 13,1917 & Do. \\
\hline 65018 & Laguna, D. R & May $1922 \ldots$ & W. L. Abbott. \\
\hline 66765 & Samaná Peninsula, D. R & 1923 & Do. \\
\hline 66974 & do & February 1924 & J. King. \\
\hline $72623 \ldots \ldots$ & Fonds-des-Nègres, Haiti_. ..... & Apr. $12,1927 \ldots \ldots$ & A. Wetmore. \\
\hline 72635 & Miragoane, Haiti_ . . & Apr. $11,1927 \ldots$ & Do. \\
\hline 74133,74134 & San Michel du Nord, Haiti & $\begin{array}{l}\text { Dec. } 20,1927-\text { Mar. } \\
15,1928 .\end{array}$ & A. J. Poole. \\
\hline 75922 & Artibonite Valley, Haiti_..... & 1928 & J. S. C. Boswell. \\
\hline $76654-76655$ & L'Atalaye, Haiti & January 1929 & $\begin{array}{l}\text { A. J. Poole and W. } \\
\text { Perrygo. }\end{array}$ \\
\hline $77070,77071 \ldots$ & Miragoane, Haiti.................. & July $1927 \ldots \ldots$ & W. J. Eyerdam. \\
\hline $80767,80770 \ldots$ & $\begin{array}{l}10 \text { miles east of Baradères, } \\
\text { Haiti. }\end{array}$ & Apr. $6-7,1930$ & $\begin{array}{l}\text { L. H. Parish and W. } \\
\text { Perrygo. }\end{array}$ \\
\hline $80799,80800 \ldots$ & Petit Trou de Nippes, Haiti... & Apr. $8,1930 \ldots$ & Do. \\
\hline $80819-80823 \ldots$ & Petite Cayemite Island, Haiti & Apr. $16,1930 \ldots$ & Do. \\
\hline $80838,80839 \ldots \ldots$ & Île a Vache, Haiti............... & Apr. $30,1930 \ldots$ & Do. \\
\hline M.C.Z. & do & Apr. $29,1931 \ldots$ & $\begin{array}{l}\text { A. Wetmore and F. C. } \\
\text { Lincoln. }\end{array}$ \\
\hline 3614 (3 cotypes) & Jérêmie, Haiti........ & & D. F. Weinland. \\
\hline $8691 \ldots$ & Diquini, Haiti ........ & 1913 & W. M. Mann. \\
\hline $25530-25532$ & Miragoane, Haiti & July $1927 \ldots$ & W. J. Eyerdam. \\
\hline $25535,25536 \ldots \ldots$ & $\begin{array}{l}\text { Grande Cayemite Island, } \\
\text { Haiti. }\end{array}$ & & Do. \\
\hline $37593,37594 \ldots \ldots$ & Cap-HaItien, Haiti & Mar. 31,1934 & Utowana Expedition. \\
\hline Hamburg Mus. & $\begin{array}{l}\text { Santa Barbara do Samaná, } \\
\text { D. R. }\end{array}$ & 1937 & W. J. Clench. \\
\hline F.M.N.H. & “Haiti”...- & & Linnaea. \\
\hline $132,134,135,154,161,165 \ldots$ & Santo Domingo City, D. R ... & $1895 \ldots \ldots$ & G. K. Cherrie. \\
\hline 5983 (5 specimens) . . . . . & Sánchez, D. R & $1924 \ldots \ldots$ & E. Kaempfer. \\
\hline
\end{tabular}


The original description of Ameiva chrysolaema boekeri Mertens agrees completely with the characters of taeniura-10 longitudinal rows of enlarged ventrals, upper caudal scales keeled, first supraocular separated from loreal and third supraocular partially separated from frontoparietal by granules, as well as in coloration.

Specimens examined.-As listed in table 50.

\section{AMEIVA CHRYSOLAEMA CHRYSOLAEMA Cope}

Figures 72, 76, 77; Plate 8, B-E.

1839. Ameiva plei Duméril and Bibron, Erpétologie générale, vol. 5, p. 5, p. 114 (part) (cotypes from Porto Rico [Martinique!] collected by M. Plée; 1 cotype from Sainte-Domingue; collector, M. Alexandre Ricord).

1863. Ameiva pleei Reinhardt and Lütken, Vid. Medd. Nat. Foren. (Copenhagen), 1862, pp. 239, 244; extr. pp. 87, 92 (San Domingo).

1869. Ameiva chrysolaema Cope, Proc. Acad. Nat. Sci. Philadelphia, vol. 20, p. 127 (type locality [said to be Gonave Island], within 25 miles of Port-auPrince, Haiti; collector, A. C. Younglove; cotypes, U.S.N.M. Nos. 12140, 12142).-Bocourt, Mission scientifique au Mexique et dans l'Amérique Centrale, Recherches zoologiques, Reptiles, pt. 3, pl. 20B, figs. 5, 5a-d; texte, pp. 252, 253, 1874.-Bodlenger, Catalogue of the specimens of lizards in the collection of the British Museum, ed. 2, vol. 2, p. 355, 1885; Proc. Zool. Soc. London, 1890, p. 79 (Hayti; Brit. Mus.).-Fischer, Jahrb. Hamburg Wiss. Anst., vol. 5, p. 24, 1888.-Müller, Verh. Naturf. Ges. Basel, vol. 10, pt. 1, p. 212, 1892.-Barbour, Mem. Mus. Comp. Zool., vol. 44, No. 2, p. 309, 1914; Zoologica, vol. 9, No. 4, p. 103, 1930.-Barbour and Noble, Bull. Mus. Comp. Zool., vol. 59, No. 6, p. 432, 1915.-Sснмidт, Bull. Amer. Mus. Nat. Hist., vol. 44, art. 2, p. 16, 1921.-Cochran, Proc. U. S. Nat. Mus., vol. 66, art. 6, p. 10, 1924; Proc. Biol. Soc. Washington, vol. 41, p. 54, 1928.-Ameiva chrysolaema chrysolaema Cochran, Occ. Pap. Boston Soc. Nat. Hist., vol. 8, p. 181, 1934.-BARBour, Zoologica, vol. 19, No. 3, p. 126, 1935; Bull. Mus. Comp. Zool., vol. 82, No. 2, p. 143, 1937.-MerTens, Senckenbergiana, vol. 20, No. 5, p. 338, 1938; Publ. Inst. Cient. Domínico-Alemán, vol. 1, p. 88, 1939.-Böker, Publ. Inst. Cient. DomínicoAlemán, vol. 1, p. 18, 1939.

1871. Amiva vittipunctata Cope, Proc. Acad. Nat. Sci. Philadelphia, vol. 22, p. 220 (type locality said to be near City of Santo Domingo; type in Acad. Nat. Sci. Philadelphia, No. 12140).

1885. Ameiva vittipunctata Boulenger, Catalogue of the specimens of lizards in the collection of the British Museum, vol. 2, p. 355.-Meerwarth, Mitth. Nat. Mus. Hamburg, vol. 18, p. 34, 1901.-Sснміdт, Bull. Amer. Mus. Nat. Hist., vol. 44, art. 2, p. 17, 1921.-Mertens, Publ. Inst. Cient. DomínicoAlemán, vol. 1, p. 92, 1939.-Böker, Publ. Inst. Cient. Domínico-Alemán, vol. 1 , p. 18, 1939.

The type of Amiva vittipunctata Cope is now in the museum of the Academy of Natural Sciences of Philadelphia, bearing the number 12140. The type of Ameiva chrysolaema Cope is in the United States National Museum with the same number 12140. The two specimens are identical as to the occipital plates and most other characters, and it is extremely probable that they are both from the same shipment from the same source and that they were both National Museum 
specimens cataloged under the same number before they were lent to Cope, who apparently separated them and described them three years apart as types of separate species and with different data.

TABLE 51.-Variations according to locality in Ameiva chrysolaema chrysolaema and A. c. affinis.

A MEIVA CHRYSOLAEMA CHRYSOLAEMA

\begin{tabular}{|c|c|c|c|c|c|c|c|c|}
\hline Locality & $\begin{array}{l}\text { Num- } \\
\text { ber of } \\
\text { speci- } \\
\text { mens }\end{array}$ & $\begin{array}{l}\text { Interpa- } \\
\text { rietals }\end{array}$ & $\begin{array}{l}\text { Longi- } \\
\text { tudinal } \\
\text { ventrals }\end{array}$ & $\begin{array}{c}\text { Femoral } \\
\text { pores }\end{array}$ & $\begin{array}{l}\text { Pre- } \\
\text { anals }\end{array}$ & $\begin{array}{l}\text { Tail at } \\
\text { 15th ver- } \\
\text { ticil }\end{array}$ & $\begin{array}{l}\text { Lamellae } \\
\text { under } \\
\text { 4th toe }\end{array}$ & Postbrachials \\
\hline Gonave Island - & 20 & $\left\{\begin{array}{l}18 \text { large } \\
2 \text { medium }\end{array}\right.$ & $35-39$ & $17-21$ & $4-8$ & $34-46$ & $39-50$ & $\left\{\begin{array}{l}2 \text { large. } \\
15 \text { medium. } \\
3 \text { small. }\end{array}\right.$ \\
\hline Mon Repos & 5 & 5 small.. & $37-40$ & $19-25$ & $4-8$ & $39-42$ & $42-47$ & $\left\{\begin{array}{l}1 \text { medium. } \\
4 \text { small. }\end{array}\right.$ \\
\hline Thomazeau.... & 10 & $\left\{\begin{array}{l}9 \text { small } \\
1 \text { medium }\end{array}\right.$ & $37-40$ & $16-20$ & $6-8$ & $38-47$ & $40-52$ & $\left\{\begin{array}{l}5 \text { large. } \\
2 \text { medium. } \\
3 \text { small. }\end{array}\right.$ \\
\hline Manneville,..... & 10 & 10 small. . & $37-40$ & $16-20$ & $4-9$ & $40-45$ & $39-50$ & $\left\{\begin{array}{l}8 \text { medium. } \\
2 \text { small }\end{array}\right.$ \\
\hline Tubano...... & 3 & 3 small & $36-38$ & $17-19$ & 4 & $35-39$ & $39-42$ & 3 small. \\
\hline
\end{tabular}

AMEIVA CHRYSOLAEMA AFFINIS

\begin{tabular}{|c|c|c|c|c|c|c|c|c|}
\hline Momance........ & 9 & 9 large $\ldots . . .$. & $37-40$ & $19-23$ & $6-9$ & $42-48$ & $44-49$ & 9 small. \\
\hline Pére................ & 4 & 4 large & $38-40$ & $19-22$ & $7-9$ & $44-46$ & $44-48$ & 4 small. \\
\hline Manneville...... & 2 & $\left\{\begin{array}{l}1 \text { large } \\
1 \text { medium }\end{array}\right.$ & $38-39$ & $19-21$ & $6-10$ & $42-44$ & $45-46$ & 2 small. \\
\hline
\end{tabular}

Then Boulenger, who had no specimens of either vittipunctata or chrysolaema, and hence no way of guessing the great variability of the form, placed vittipunctata in that part of his key based on the presence of a small central group of enlarged gulars and three supraoculars, with chrysolaema apparently easily separable into that section having all the gular scales minutely granular and possessing four supraoculars. Later Meerwarth applied Cope's name vittipunctata to the type of Fischer's affinis.

In 1915, Barbour and Noble suspected that there were two closely related forms (i. e., chrysolaema and their so-called vittipunctata) on Hispaniola, separable by the greater or lesser development of the brachials, but unfortunately they also applied Cope's name vittipunctata to the one with the small brachials, which should properly be called affinis. Therefore, the published records of specimens of vittipunctata seen by Barbour and Noble should go into the synonymy of affinis, while Boulenger's, and probably Schmidt's, belong under chrysolaema.

The proper differentiation of this form and Ameiva chrysolaema affinis required considerable search for even a single stable character. The characters formerly used to distinguish them are exceedingly variable or entirely untrustworthy. The best distinction, which can 
almost invariably be relied upon, I found to be in the size relation of the interparietal to the scales adjacent to it on either side; in chrysolaema, the interparietal scale is smaller, never larger, than the adjacent scales, while in affinis the interparietal scale is larger, never smaller. Rarely a specimen of either species may have the interparietal and its adjacent scales approximately equal in area; this is due to a little more splitting than usual at the border of a scale. The difference in ratio is due to the amount of splitting up of these large scales, indeed in the case of chrysolaema, the prominent area for splitting up seems
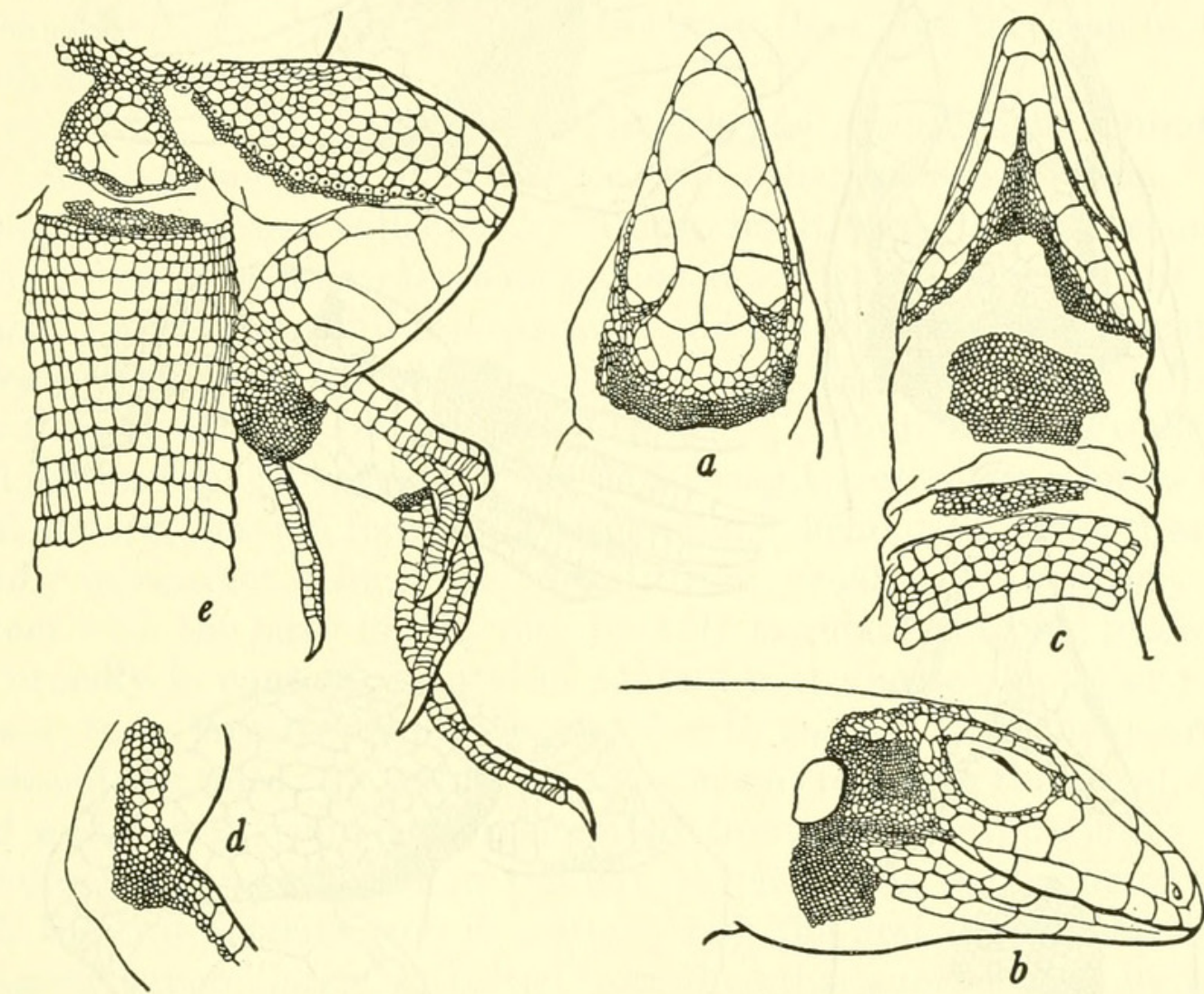

Figure 76.-Ameiva chrysolaema chrysolaema: $a$, Top of head; $b$, side of head; $c$, chin and throat; $d$, forearm showing antebrachials; $e$, anal and femoral regions. U.S.N.M. No. 12140, cotype, from near Port-au-Prince, Haiti. One and one-fourth times natural size.

to be that of the median occipital region, while in affinis the splitting has avoided the central region and displays its activity chiefly at the sides of the occiput.

The other differentiating characters are more or less unstable, as I have found through studying carefully a large series of examples. Coloration is usually of some importance, the intensely spotted style being that of chrysolaema, while a wide, black, lateral band practically uninvaded by light dots ordinarily marks a specimen of affinis. In addition, the brachials are usually quite conspicuously enlarged in chrysolaema, but very small and scarcely differentiated from the surrounding granules in affinis. Sometimes, however, an example of chrysolaema will be found without the considerably enlarged scales. 
The black throat supposed to be constantly present in chrysolaema is belied by the actual white or pale blue-gray color found there occasionally; in affinis, so far as I have observed, the throat is light in color. The presence of enlarged postbrachials is a varying condition in both species; chrysolaema has rather large postbrachials as a

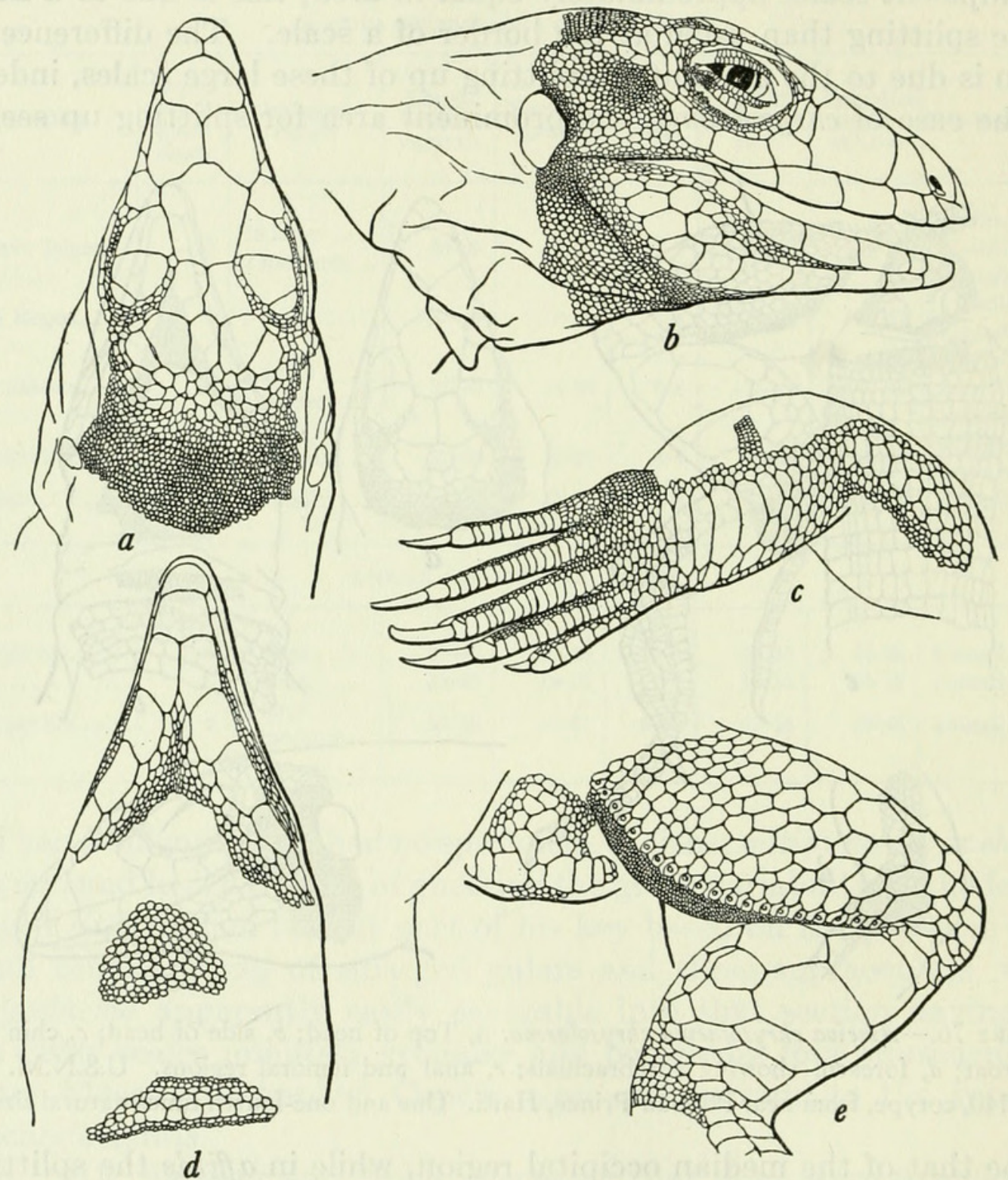

FigURE 77.-Ameiva chrysolaema chrysolaema: $a$, Top of head; $b$, side of head; $c$, forearm showing antebrachials; $d$, chin and throat; $e$, hindleg and anal region. U.S.N.M. No.66730, from Tubano, Azua Province, Dominican Republic. One and one-half times natural size.

rule, but some examples were found that had the postbrachials scarcely enlarged beyond the size of the surrounding granules; in affinis most specimens do not have enlarged postbrachials, but several examples were found that had postbrachials larger than those of the exceptional chrysolaema having very small postbrachials. Essentially the same thing is true in regard to the enlarged brachials also.

As to the scales of the median gular region, they are of absolutely no value diagnostically, as a series of specimens from either species 
may readily be secured that will show a perfect gradation through all the degrees of variation to which this region is subject. Schmidt ${ }^{12}$ believed that he could tell the species apart by noting the frontonasal scale-supposedly chrysolaema always had it truncate or rounded anteriorly, and affinis had it with an anterior angle. I find, however, that both conditions occur in any series from a single locality. Likewise, in a number of individuals of both species, I find that the fourth supraocular may be small, medium-sized, or fairly large, the variation being purely individual on the Haitian mainland. In the extensive material from Gonave Island, I did find a tendency in the fourth supraocular to be constantly a little larger than was the case in the mainland chrysolaema.

Two of the three specimens of Ameiva plei described by Duméril and Bibron came from Puerto Rico; the other one came from "St. Domingue" and was collected by Alexandre Ricord. This specimen I believe to be a true chrysolaema, inasmuch as the figure of it by Bocourt shows the small interparietal and the larger adjacent scales.

Description of a cotype.-U.S.N.M. No. 12140, an adult from near Port-au-Prince, Haiti, collected by A. C. Younglove. Profile of head flat on top, curved at the end of the snout; nostril anterior to the nasal suture; rostral forming a right angle behind; anterior nasals broadly in contact behind the rostral; frontonasal as wide as long, in contact with the large loreal, very broadly angulate in front; prefrontals broadly in contact; frontal in contact with the two anterior preoculars; three large preoculars, with a fourth one less than one-quarter the size of the third; the anterior preocular not touching the loreal, the third and fourth completely separated from the frontoparietals by granules; six superciliaries on the left, seven on the right side of the head, the two anterior ones in contact with the first supraocular, the remaining superciliaries separated from the other supraoculars by two rows of granules; two frontoparietals, followed by a transverse row of five occipitals, the median one smaller than the two adjoining it, these in turn followed by about three rows of unequal postoccipitals; ear opening large; five upper labials to a point directly beneath the center of the eye, the third and fourth the longest; six lower labials to the same point, the second and third the longest; the wedge of granular scales on the chin extending for about one-third of the distance between the first pair of chin shields, which are partially in contact; chin and throat covered with granular scales, those of the central gular region enlarged, but gradually merging into the small ones; mesoptychium covered with two irregular rows of enlarged scales, bordered by one or two successively smaller rows. Dorsal scales granular, uniform, about 62 in the standard distance from tip of snout to center of eye; laterals similar but smaller. Ventral plates in 12 longitudinal series

12 Bull. Amer. Mus. Nat. Hist., vol. 44, art. 2, p. 17, 1921. 
bounded by two exceedingly small external series, and in 37 transverse series; brachial scales conspicuously enlarged, in three or four fairly regular rows, the largest of these rows having about six scales, each of them being wider than long; postbrachials appearing as about a dozen scales considerably larger than the surrounding granules; antebrachials in four rows of enlarged scales, the widest having four or five large straplike scales across the wrist; brachials and antebrachials well separated by numbers of small scales; femoral pores 20 and 21 ; anterior face of thigh covered with (5 to 10) rows of enlarged flat scales; four tibial rows, the external row composed of six scales of which the second and third (proximal) are much larger than the others; no enlarged postanals; seven enlarged plates at the anterior border of the anus, the median and the outermost the smallest, with a pair of enlarged scales in front of these, and a single large scale in front of the pair; 46 scales in the fifteenth verticil of the tail. The hindleg being adpressed, the fourth toe reaches to halfway between the eye and the tympanum. Hands and feet long and slender; the small combs very evident on the toes; fourth toe with 44 lamellae beneath it; fifth toe slightly longer than first. Tail slightly over twice the length of the head and body, not noticeably depressed in its proximal portion, the scales straight, strongly keeled above, faintly on the sides and beneath on the distal portion.

Dimensions: Head and body, $136 \mathrm{~mm}$.; tail, $290 \mathrm{~mm}$.

Color (in alcohol): Ground color of body and limbs dull indigo, with 17 longitudinal series of round white dots running onto the tail, the median rows beginning as anastomosing light lines behind the shoulder, those of the dorsolateral region the largest, the very outermost reaching to the edges of the ventral plates; upper surface of legs heavily spotted with white, the arms less so; nuchal region becoming gradually light and immaculate; head and throat very light; ventral plates slate with their posterior borders whitish; breast and mesoptychial region black, with a few light dots on the lateral portions, and a very definite boundary anteriorly.

Variations.-The amount of variation, as I have already indicated (see table 51), is considerable. In the many specimens I have had the privilege of examining closely, the number of longitudinal ventrals varies between 35 and 40 ; of femoral pores between 16 and 25 ; of preanal plates between 4 and 9 ; of tail scales at the fifteenth verticil between 34 and 47 ; of lamellae under the fourth toe between 39 and 52 ; and finally of dorsal granules between 61 and 73 . A comparatively stable feature of scalation is the number of transverse ventral rows, which in all cases is 12 , although very frequently a row of small plates borders the outer series but never reaches significant proportions. 
Postbrachials are almost always present, although they may vary in size from small to medium and very large.

The dark lateral band almost invariably possesses a row of large or small light spots down its center. This is seldom the case in the closely allied affinis, which gives the impression of being a striped but not a spotted animal. In chrysolaema the spots predominate in the pattern as a rule, although there are plenty of adults, especially on the mainland of Hispaniola, which retain the juvenile pattern of partly stripes and partly spots. Occasionally a melanistic individual is found, for instance U.S.N.M. No. 49935, in which no traces of spots or stripes appear.

The pattern of our smallest specimen, No. 75888, from Damien, measuring $47 \mathrm{~mm}$. in head and body length, consists of six equidistant, narrow, light dorsal stripes beginning on the nuchal region and continuing to the end of the body. Below the outermost of these stripes is a fairly wide, dark, lateral stripe with a row of round light dots down its center. Below this the sides have two fairly regular rows of light dots on a dark ground. Another young lizard from Damien, No. 75889 , measuring $55 \mathrm{~mm}$., is similar in pattern, except that the dorsal stripes are wavy and already show a tendency to break up, while the sides are more heavily spotted. In both specimens the lower surfaces are all more or less suffused with dark. The adult from Damien, No. 75887, measuring $94 \mathrm{~mm}$., is like No. 75889, with the dorsal stripes as distinct as in the much smaller animal.

Sometimes in striped adults one may count five dorsal light stripes; oftener there are traces of six. Almost always the posterior parts of these stripes are extremely irregular, or are broken up into spots, and often there are additional rows of spots between them posteriorly. It is true that most of the adults from Gonave Island are more heavily spotted than those of similar size from the mainland of Hispaniola, but on the mainland every sort of intergradation of pattern may still be found.

The largest individual in the National Museum, No. 80367, comes from Anse à Galets, Gonave Island. Its head and body length is $147 \mathrm{~mm}$.

Relationships.-It cannot be doubted that chrysolaema and affinis are very closely related. As I have already pointed out, they differ usually in coloration, since chrysolaema tends to a more spotted appearance, while affinis shows less invasion of the lateral dark stripe by spots. Furthermore the interoccipital plate in chrysolaema is usually smaller than, though occasionally equal to, the scales bordering it laterally, while in affinis the interoccipital is larger than the juxtaposed lateral scales although sometimes the three occipitals are of equal size. 
Both Hispaniolan species are probably related to the Puerto Rican exul, which has the occipital pattern of chrysolaema in most of our 72 examples of it. In addition, the brachials and antebrachials are separated in most of the specimens of exul as they always are in chrysolaema and affinis. This character, although not very stable at the best, differentiates them from the Cuban auberi, which ordinarily possesses a continuous series of brachials. This species also has the occipital pattern of chrysolaema, as does alboguttata from Mona Island.

Specimens examined.-As listed in table 52.

TABLE 52.-Specimens of Ameiva chrysolaema chrysolaema examined

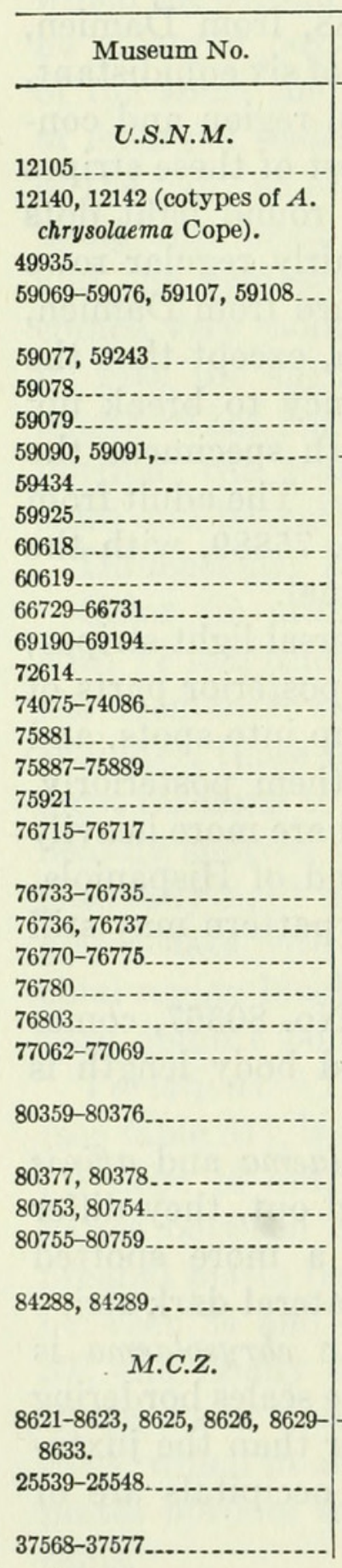

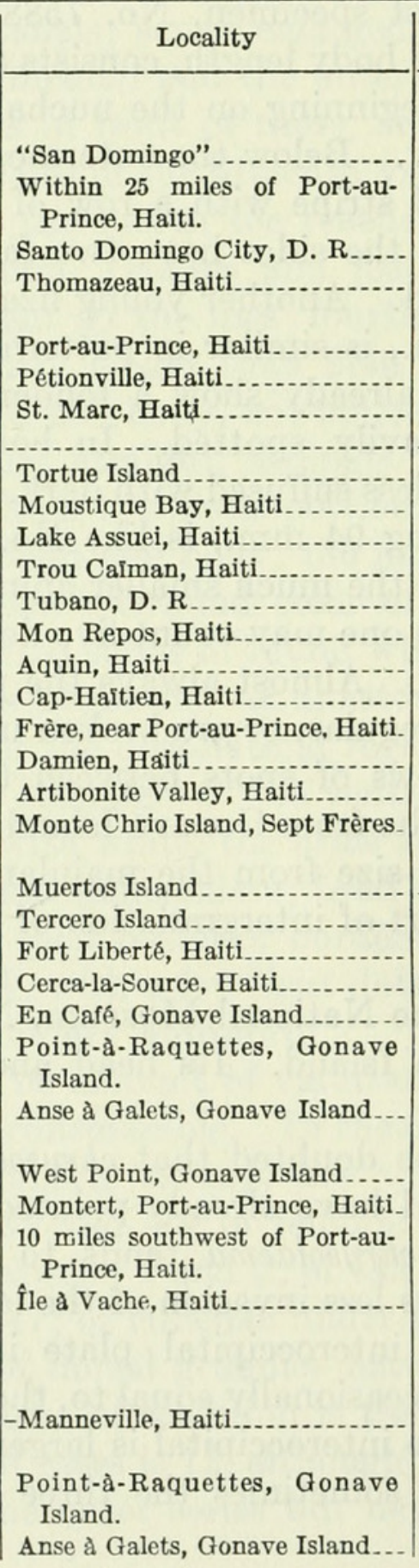

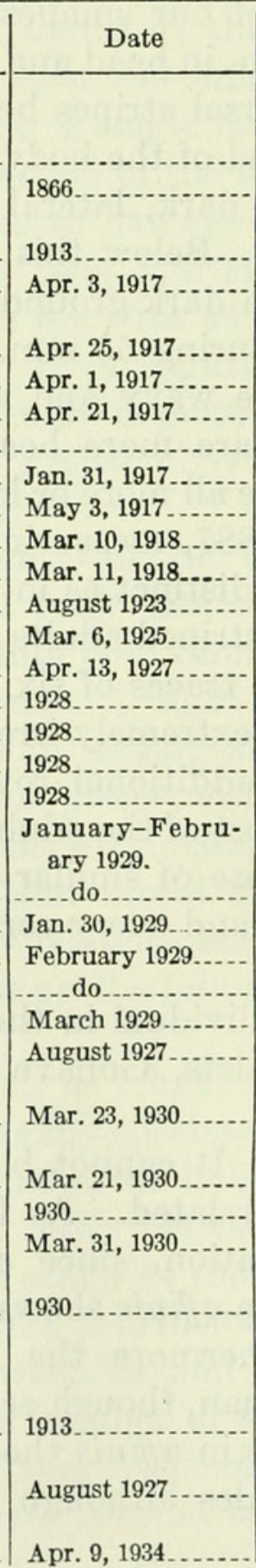

Collector

C. A. Fraser.

A. C. Younglove.

J. N. Rose.

J. B. Henderson and P. Bartsch.

Do.

Do.

Do.

C. Bencomo.

W. L. Abbott.

Do.

Do.

Do.

E. Kaempfer.

G. S. Miller, Jr.

A. Wetmore.

A. J. Poole.

J. S. C. Boswell.

Do.

Do.

A. J. Poole and W. Perrygo.

Do.

Do.

Do.

Do.

Do.

W. J. Eyerdam.

L. H. Parish and W. Perrygo.

Do.

Do.

Do.

Do.

W. M. Mann.

W. J. Eyerdam.

Ctowana Expedition. 
TABLE 52.-Specimens of Ameiva chrysolaema chrysolaema examined-Continued

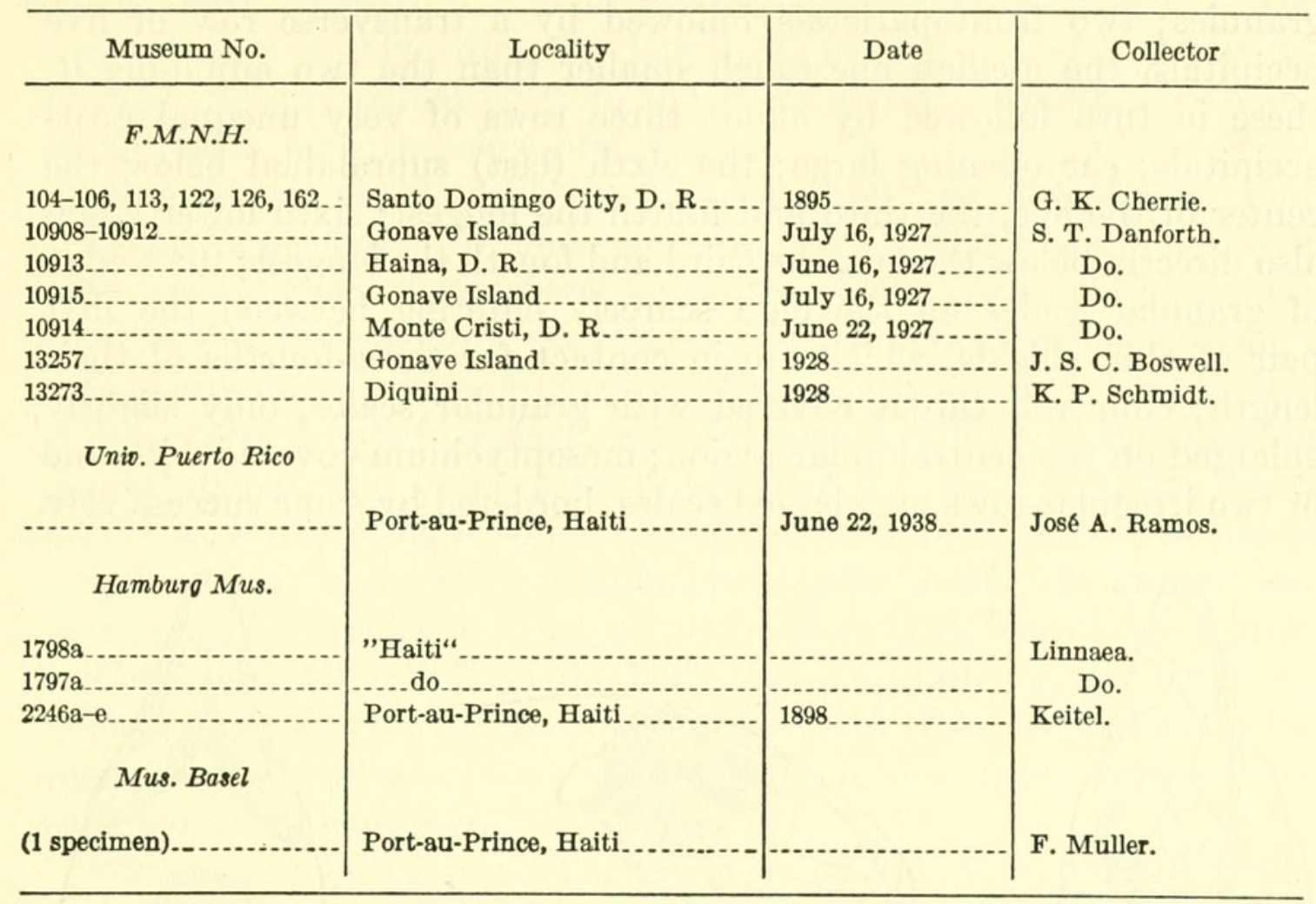

\section{AMEIVA CHRYSOLAEMA WOODI Cochran}

Figures 72, 78

1934. Ameiva chrysolaema woodi Cochran, Occ. Pap. Boston Soc. Nat. Hist., vol. 8, p. 181.

1937. Ameiva chrysolaema juliae Cochran, in Barbour, Bull. Mus. Comp. Zool, vol. 82, No. 2, p. 144 (in synonymy).

Diagnosis. - Scalation similar to that of Ameiva chrysolaema chrysolaema, but with usually 10 subequal longitudinal ventral rows and with a row of small scales as the only traces of the two additional rows, which are well developed in the typical form; a wide black dorsolateral band invaded by spots of the ground color, these spots tending to form vertical bars by running together, making a rather prominent series of irregular vertical bands when this pattern is fully carried out.

Type.-An adult male, M.C.Z. No. 37583, from Île Tortue, Haiti, collected on April 3, 1934, by the Utowana Expedition.

Description of the type.- Profile of head flat on top, curved at the end of the snout; nostril anterior to the nasal suture; rostral forming a right angle behind; anterior nasals broadly in contact behind the rostral; frontonasal as wide as long, narrowly in contact with the large loreal, very broadly angulate in front; prefrontals broadly in contact; frontal in contact with the two anterior preoculars; three large preoculars, the anterior one not touching the loreal, the third partly separated from the frontoparietal by granules; seven superciliaries, the first two in contact with the first supraocular, the remaining 
superciliaries separated from the other supraoculars by two rows of granules; two frontoparietals followed by a transverse row of five occipitals, the median one much smaller than the two adjoining it, these in turn followed by about three rows of very unequal postoccipitals; ear opening large; the sixth (last) supralabial below the center of the eye, the third and fourth the longest; sixth lower labial also directly below the eye, the third and fourth the longest; the wedge of granular scales on the chin scarcely entering between the first pair of chin shields, which are in contact for three-fourths of their length; chin and throat covered with granular scales, only slightly enlarged on the central gular region; mesoptychium covered with one or two irregular rows of enlarged scales, bordered by some successively
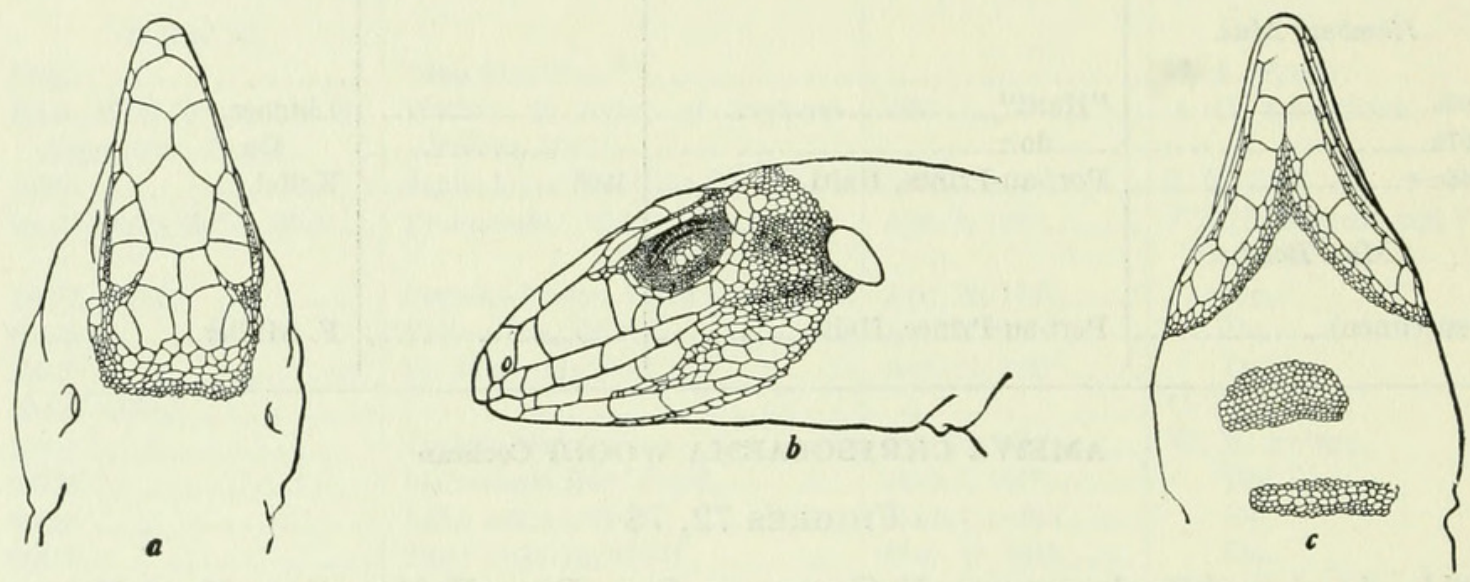

Figure 78.-Ameiva chrysolaema woodi: $a$, Top of head; $b$, side of head; $c$, chin and throat. M.C.Z. No. 37583 , from Ile Tortue, Haiti. Natural size.

smaller ones. Dorsal scales granular, uniform, about 60 in the standard distance from tip of snout to center of eye; laterals similar but smaller. Ventral plates in 10 longitudinal series bounded by two exceedingly small external ones, and in 38 transverse series; brachial scales conspicuously enlarged, in three or four fairly regular rows, the longest of these rows having about a dozen scales, each about as wide as long; three or four conspicuously widened postbrachial scales surrounded by smaller scales soon merging with the surrounding granules; antebrachials in about three rows of enlarged scales, the median the widest, having four or five large straplike scales across the wrist; brachials and antebrachials separated by numerous small scales; femoral pores 21 (left) and 22 (right); anterior face of thigh covered with eight or nine rows of enlarged flat scales; four tibial rows, the external row composed of six scales of which the second and third (proximal) are much larger than the others; no enlarged postanals; four enlarged plates at the anterior border of the anus, the median pair the largest, with a single large scale in front of these and a smaller single scale preceding it; 40 scales in the fifteenth verticil of the tail. The hind leg being adpressed, the fourth toe reaches to the posterior edge of the tympanum. Hands and feet long and 
slender; the small combs very evident on the toes; fourth toe with 42 lamellae beneath it; fifth toe slightly longer than first. Tail (reproduced) nearly twice the length of head and body, rather depressed in its proximal portion, the scales straight, keeled above and on the sides, smooth below proximally.

Dimensions: Head and body, $125 \mathrm{~mm}$; tail (reproduced), $233 \mathrm{~mm}$.

Color (in alcohol): Ground color pea green to dull china blue above, with a wide black dorsolateral band invaded by spots of the ground color, which tend to form vertical bars by running together, making a rather prominent series of irregular vertical stripes when this pattern is fully carried out; four dark dorsal stripes, much narrower than the lateral stripes, the inner pair quite indistinct anteriorly, the outer pair with a row of light spots appearing posteriorly; upper surface of tail china blue with rather regular black spots; lower lips immaculate pale china blue; sides of head, chin and ventral surfaces French gray, suffused with olive buff on the belly, legs and tail. A few light turquoise blue spots on the anterior forearm and tibia, as well as on the edges of the ventral plates; posterior thigh and upper part of tibia with a dark reticulation.

Paratypes.-There are 34 paratypes of all ages, M.C.Z. Nos. 37584-37592 and U.S.N.M. Nos. 95127-95132, taken on April 2-3, 1934 , at the same place as the type. In addition, a rather mutilated specimen taken by Dr. W. L. Abbott on Isle Tortue on January 31, 1917, represents this subspecies, although its pattern is not fully developed, while the outer ventral row is composed of scales larger than those of most of the paratypes taken by the Utowana party.

Relationships.- The color pattern of more or less vertical bars on the black dorsolateral band distinguishes the new species both from $c$. abbotti, an entirely spotted form, and from c. chrysolaema, in which the spots have not taken so regular an arrangement across the dark stripes. It appears to be very close to $c$. chrysolaema, however, in most other characteristics.

\section{AMEIVA CHRYSOLAEMA ABBOTTI Noble}

Figures 72,79

1923. Ameiva abbotti Noble, Amer. Mus. Nov., No. 64, p. 1.-Barbour, Zoologica, vol. 11, No. 4, p. 103, 1930.-Barbour and Loveridge, Bull. Mus. Comp. Zool., vol. 69, No. 10, p. 210, 1929.

1934. Ameiva chrysolaema abbotti Cochran, Occ. Pap. Boston Soc. Nat. Hist., vol. 8, p. 181.-Barbour, Zoologica, vol. 19, No. 3, p. 126, 1935; Bull. Mus. Comp. Zool., vol. 82, No. 2, p. 144, 1937.

It is very evident in studying typical Ameiva chrysolaema chrysolaema that the form is in process of breaking up. A series of specimens from one locality will all have a fairly similar pattern, which may differ in some slight detail from that of a series of lizards from another locality, but intergrading forms are always to be found on the His- 
paniolan mainland. As I have mentioned elsewhere, the Gonave Island lizards tend to a maximum of spotting and a minimum of striping. On the mainland occurs the highly striped affinis, in which spots are seldom found; this form has not yet been found on the neighboring islets, although the spotted chrysolaema occurs indiscriminately all over the mainland and the nearer islets as well as on Gonave. The effects of isolation in defining a color phase are shown in the Beata Island lizard, which seems to be separable on color alone, as no tendency toward striping is to be found, even in the very young, although the spots are disposed in longitudinal rows. I am retaining abbotti as a subspecific name, since it belongs to a race now entirely separated geographically from its ancestral stock, where further differentiation may well continue to take place.

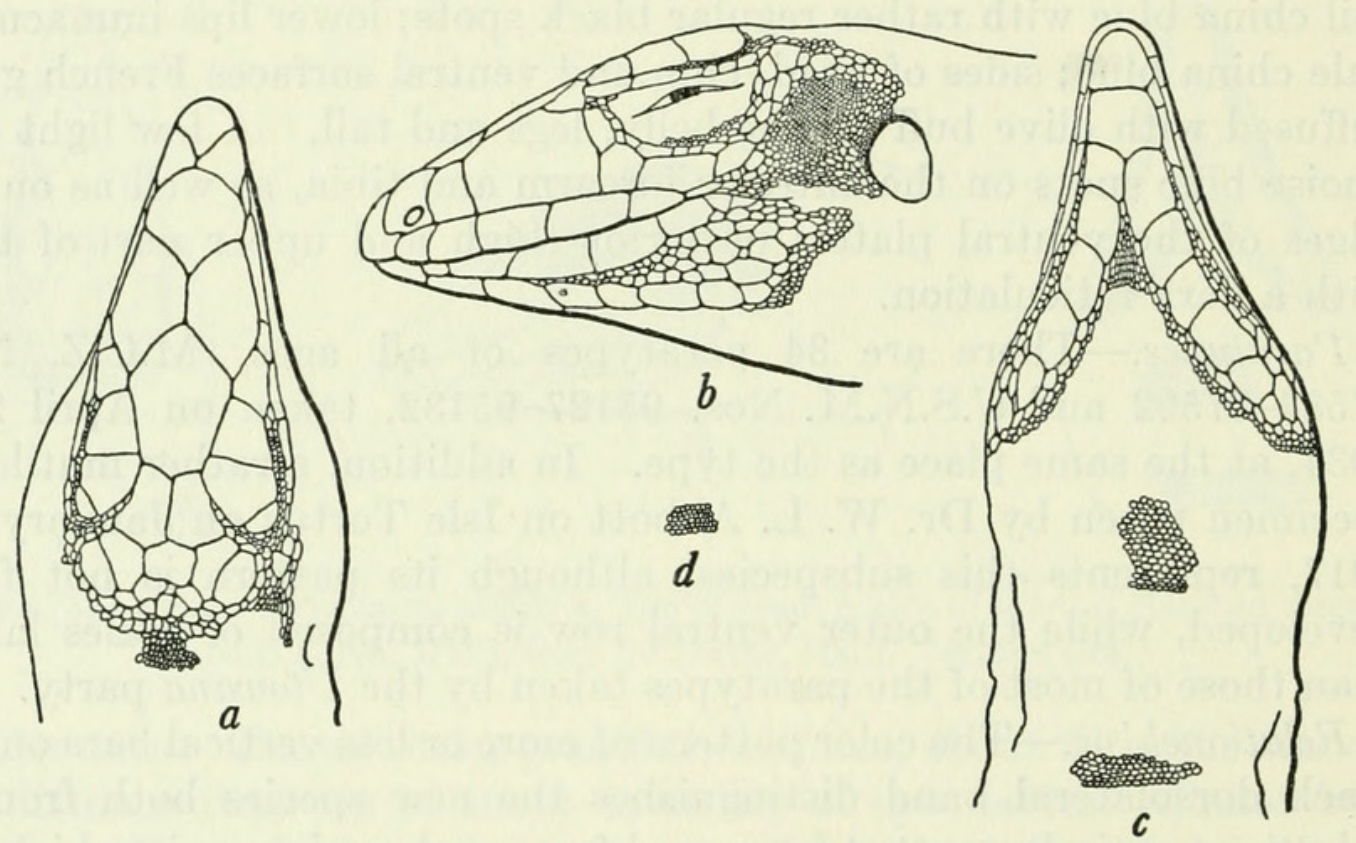

FigURE 79.-Ameiva chrysolaema abbotti: $a$, Top of head; $b$, side of head; $c$, chin and throat; $d$, middorsal granules. U.S.N.M. No. 83885, from Beata Island, Dominican Republic. One and one-half natural size.

Noble's distinction of abbotti from chrysolaema by the frontal being in contact with the third supraocular or separated from it by a row of small scales does not hold absolutely. The amount of contact between the prefrontals also is an extremely variable feature in large series of specimens.

Description.-U.S.N.M. No. 83885, an adult from Beata Island, Dominican Republic, taken May 11, 1931, by Dr. A. Wetmore and F. C. Lincoln. Profile of head flat on top, curved at the snout; nostril anterior to the nasal suture; rostral forming an acute angle behind; anterior nasals broadly in contact behind to rostral; frontonasal as wide as long, in contact with the large loreal, very broadly angulate in front; prefrontals broadly in contact; frontal in contact with the three anterior preoculars; three large preoculars and a fourth one less than one-quarter the size of the third; anterior preocular not 
touching the loreal, the third only partly separated from the frontoparietals by granules; six or seven superciliaries, the two anterior ones in contact with the first supraocular, the remaining superciliaries separated from the other supraoculars by two rows of granules; two frontoparietals, followed by a row of five occipitals, the median shorter but wider than the two adjoining it, these in turn followed by about three rows of very unequal postoccipitals; ear opening large; five upper labials to a point directly beneath the center of the eye, the third and fourth the longest; five lower labials to the same point, the third and fourth the longest; the wedge of granular scales on the chin scarcely extending between first pair of chin shields which are broadly in contact; chin and throat covered with granular scales, those of the central gular region enlarged, but gradually merging into the small ones; mesoptychium covered with about four irregular rows of enlarged scales which are not larger than those on the central gular region. Dorsal scales granular, uniform, about 79 in the standard distance from tip of snout to center of eye; laterals similar but smaller. Ventral plates in 12 longitudinal series, the outer row less than half the area of the inner adjacent one and bounded on its outer border by large granular scales; 37 transverse series. Brachial scales conspicuously enlarged, arranged in three regular rows each composed of about six scales, which are as wide as long; postbrachials appearing as a patch of about a dozen scales considerably larger than the surrounding granules; antebrachials in three rows of enlarged scales, the widest row having four or five large straplike scales across the wrist; brachials and antebrachials well separated by numbers of small scales; femoral pores 19 and 21; anterior face of thigh covered with (five to nine) rows of enlarged flat scales; four tibial rows, the external row composed of six scales of which the second and third are much larger than the others; no enlarged postanals; a row of about 10 very unequally enlarged scales in front of the anus, the median pair and the outer ones the smallest; a single very large scale in front of the small median pair, surrounded by several smaller scales; 39 scales in the fifteenth verticil of the tail. The hindleg being adpressed, the fourth toe reaches to halfway between ear and tympanum. Hands and feet long and slender; the small combs very evident on the toes; fourth toe with 43 lamellae beneath it; fifth toe slightly larger than first. Tail nearly two and one-half times the length of the head and body, not noticeably depressed in its proximal portion; the scales straight, strongly keeled above, faintly on the sides and beneath on the distal portion.

Dimensions: Head and body, $112 \mathrm{~mm}$; tail, $275 \mathrm{~mm}$.

Color (in alcohol): Ground color of body and limbs slate-black above to dull Nile blue on the belly, turning to olive-buff on lower surfaces of hindlegs and tail; upper surfaces of body and limbs with 
numerous large white dots, which do not align themselves very definitely into longitudinal rows; nuchal region becoming gradually light and immaculate china blue, turning toward sage green on top of head; chin and throat very light, faintly clouded with olive-gray; breast and mesoptychial region black; outermost ventral plates with occasional dark areas; tail spotted like the body but with the dark area less intense and with the spots conforming to the rectangular shape of the tail scales.

Variations.-In the eight specimens in the National collection, variability in scale count is not great. The scales in the fifteenth verticil of the tail number between 36 and 41; the lamellae of the fourth toe are 39 to 45 ; the femoral pores are 19 to 24 ; the dorsal granules are 71 to 79 per standard distance in adult specimens. The dorsal granules are thus found to be somewhat finer than is the case in typical chrysolaema.

In the occipital plates the three median ones tend to be about the same in area, or else the central one is slightly smaller than the adjacent ones, in this respect agreeing with typical chrysolaema.

The preanal plates usually number six to eight, and the one or two median scales are usually smaller than those on either side.

In coloration the three half-grown specimens are similar to the adults, and there is no trace of definite striping on the body, although the light dots may seem to lie in parallel rows for short distances. In two lizards a reproduced tail has been grown, and the pattern of the reproduced part is in symmetrical light and dark stripes, in decided contrast to the original portion of the member which is spotted with rather irregular areas of light and dark. This bit of evidence shows that the ancestral pattern was probably of stripes, like those of the typical chrysolaema as well as of the subspecies affinis.

Some living examples of abbotti were brought back to the National Zoological Park by Dr. Wetmore and Mr. Lincoln. Their exquisite hues are suggested in the following color notes obtained from the living creature:

Top of head brick red turning to olive-green on nuchal region; dorsal spots olive; ground color black; lateral spots and those on anterior femur and on upper arm pale blue; tail clay color with diminishing black spots; loreal and labial regions coral red; some pale spots below eye; olive to salmon in front of ear, with the upper surfaces of hands and feet salmon; throat and belly coral to brick red; under parts of forearm and throat black; under parts of hindleg rufous to orangevermilion.

Specimens examined.-U.S.N.M. Nos. 83883-83889, 84293, 8506285064, Beata Island, May 11-13, 1931, Dr. A. Wetmore and F. C. Lincoln; M.C.Z. Nos. 37578-37582, Beata Island, April 11, 1934, Utowana Expedition. 


\section{AMEIVA CHRYSOLAEMA AFFINIS (Fischer)}

Figures 72,80

1883. Cnemidophorus affinis Fischer, Beschreibungen neuer Reptilien, SeparatAbdruck aus dem Osterprogramm des akademischen Gymnasiums, Hamburg, p. 1 (type locality, Haiti; collector, Dr. J. G. Fischer; type, Mus. Hamburg No. 790).

1914. Ameiva vittipunctata Barbour, Mem. Mus. Comp. Zool., vol. 44, No. 2, p. 310 (not of Cope); Zoologica, vol. 11, No. 4, p. 102, 1930; vol. 19, No. 3, p. 126, 1935; Bull. Mus. Comp. Zool., vol. 82, No. 2, p. 143, 1937.-Barbour and Noble, Bull. Mus. Comp. Zool., vol. 59, No. 6, p. 436, 1915.-Хснмidт, Bull. Amer. Mus. Nat. Hist., vol. 44, art. 2, p. 17, 1921.-Mertens, Senckenbergiana, vol. 20, No. 5, p. 341, 1938.

1888? Ameiva regularis Fischer, Jahrb. Wiss. Anst. Hamburg, vol. 5, p. 26 (type locality, Sanssouci, Hayti).

Description.-U.S.N.M. No. 67111 (formerly M.C.Z. No. 8642), an adult collected at Momance, Haiti, by Dr. W. M. Mann in 1913. Profile of head slightly convex on top, more curved toward the end of the snout; nostril anterior to the nasal suture; rostral forming an acute angle behind; anterior nasals narrowly in contact behind the rostral; frontonasal as wide as long, narrowly in contact with the large loreal, truncate in front; prefrontals broadly in contact, frontal in contact with the two anterior preoculars; three large preoculars, with a fourth one equal to about one-quarter of the area of the third; the anterior preocular not touching the loreal, the third and fourth completely separated from the frontoparietals by a row of granules; nine superciliaries on the left, eight on the right side of the head, the second (normally) the longest, the two anterior ones (normally) in contact with the first supraocular, the remaining superciliaries separated from the other supraoculars by two rows of granules; two frontoparietals, followed by a row of five occipitals, of which the central one is the largest; these in turn followed by four or five irregular rows of rather small and unequal postoccipitals; ear opening large; five upper and five lower labials to a point directly beneath the center of the eye, the third of each series the longest; the wedge of granular scales on the chin extending to about halfway between the first pair of chin shields, which are anteriorly in contact; chin and throat covered with granular scales, those of the central gular region very slightly enlarged and merging gradually into the smaller ones; mesoptychium covered with two irregular rows of slightly enlarged scales, bordered by one or two successively smaller ones. Dorsal scales granular, uniform, about 71 in the standard distance from tip of snout to center of eye; laterals similar but smaller. Ventral plates in 12 longitudinal series bounded by two very small external series, and in 38 transverse series; brachial scales very slightly enlarged, merging into the surrounding granules; antebrachial scales conspicuously enlarged, in one very wide series of four straplike scales bordered by two or three 
much smaller series merging rapidly into the surrounding granules; no enlarged postbrachials; femoral pores 22 and 23 ; anterior face of thigh covered with four to six rows of enlarged flat scales; four tibial rows, the external row composed of six scales, of which the second and third are much larger than the others; no enlarged postanals; seven enlarged plates at the anterior border of the anus, the median and the outer-

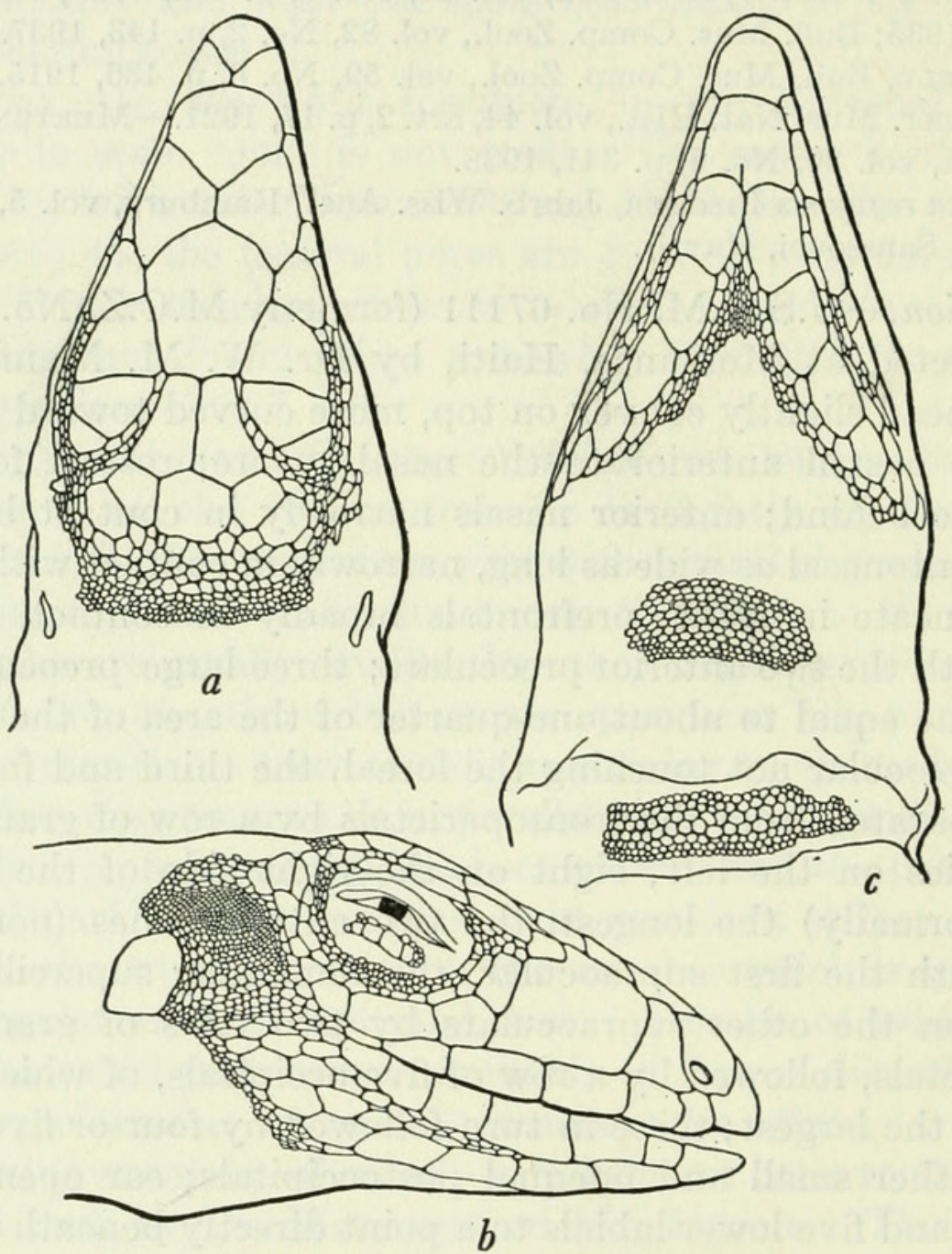

Figure 80.-Ameiva chrysolaema affinis: $a$, Top of head; $b$, side of head; $c$, throat and chin. U.S.N.M. No. 67111, from Momance, Haiti. Twice natural size.

most the smallest, with a pair of enlarged scales in front of these and a pair of smaller ones in front of them; 46 scales in the fifteenth verticil of the tail. The hindleg being adpressed, the fourth toe reaches to the anterior corner of the eye. Hands and feet long and slender; the small combs very evident on the toes; fourth toe with 48 lamellae beneath it; fifth toe slightly longer than first. Tail two and a half times the length of the head and body, not noticeably depressed in its proximal portion, the scales straight, strongly keeled above, faintly on the sides, and beneath on the distal portion. 
Dimensions: Head and body, $90 \mathrm{~mm}$.; tail, $224 \mathrm{~mm}$.; head to posterior ear, $26 \mathrm{~mm}$.; foreleg, $35 \mathrm{~mm}$; hindleg, $71 \mathrm{~mm}$.; axilla to groin, $43 \mathrm{~mm}$.

Color (in alcohol): Ground color of head and body dull indigo, with six longitudinal light lines running from neck to lumbar region, the two lower light lines on each side bordering a wide, dark, lateral stripe entirely uninvaded by spots; the two dorsal light lines less distinct and narrower, enclosing at their origin on the nuchal region traces of another (median dorsal) light line, which fades out between the shoulders; under parts pearl gray, the tail darker, the ventral scales with indigo mottling on their anterior portion, the throat light with a very slight darkening through the mesoptychium; lower part of sides with a slight suggestion of spotting; some large white spots on the loreal, labials and lower parts of jaw to the shoulder.

Variations.-In the specimens I have examined, the number of longitudinal ventrals ranges between 37 and 40; of femoral pores between 19 and 23 ; of preanal plates, between 6 and 10 ; of tail scales at the fifteenth verticil, between 42 and 48 ; of lamellae under the fourth toe, between 44 and 49 ; and of dorsal granules, between 59 and 79. Here, as in chrysolaema chrysolaema, the number of transverse ventral scales is 12 , sometimes with an additional very small outer series. All these characters come within the limits of the range of chrysolaema chrysolaema, and it is not possible to try to differentiate the subspecies on these features.

The greatly reduced brachials that characterize affinis do not appear to be enlarged in this species to the same extent as in typical chrysolaema. The broad dark lateral stripe is usually immaculate, though sometimes invaded by scattered white dots. It is decidedly different from the heavily spotted appearance of a typical chrysolaema, where the lateral bands, when present, have a row of large dots along the center and where the upper and lower light borders are likewise set with white dots. The median occipital plate is sometimes larger than, sometimes equal to, the plates bordering it laterally-it is never smaller than these plates, as is usually the case in chrysolaema chrysolaema. Postbrachials are usually absent, but when present they are very small.

Relationships.-I have already reviewed the relationships of chrysolaema affinis under the discussion of typical chrysolaema. I may add, however, that apparently chrysolaema chrysolaema is more clearly allied to the Cuban and Puerto Rican species than is affinis, since the Cuban and Puerto Rican lizards have well-developed brachials and a small median occipital, unlike affinis.

Specimens examined.-As listed in table 53. 
TABLE 53.- Specimens of Ameiva chrysolaema affinis examined

\begin{tabular}{|c|c|c|c|}
\hline Museum No. & Locality & Date & Collector \\
\hline U.S.N.M. & & & \\
\hline $\begin{array}{l}\text { 67111, } 67712 \text { (formerly M. C. Z. } \\
\text { Nos. } 8636 \text { and 8642). }\end{array}$ & Momance, Haiti. & 1913 & W. M. Mann. \\
\hline M.C.Z. & & & \\
\hline $\begin{array}{l}8614,8618 \\
8634,8635,8638-8641,8644\end{array}$ & $\begin{array}{l}\text { Manneville, Haiti... } \\
\text { Momance, Haiti }\end{array}$ & $\begin{array}{l}1913 \\
1913\end{array}$ & Do. \\
\hline $13271-13274$ & Pére, Haiti & 1919 & G. M. Allen. \\
\hline Hamburg Mus. & & & \\
\hline 760a (type of $C$. affinis) & "Haiti"..... & 1883 & J. G. Fischer. \\
\hline
\end{tabular}

\section{AMEIVA BARBOURI Cochran}

Figures 72,81

1928. Ameiva barbouri Cochran, Proc. Biol. Soc. Washington, vol. 41, p. 56.Barbour and Loveridge, Bull. Mus. Comp. Zool., vol. 69, No. 10, p. 211, 1929.-BARBoUr, Zoologica, vol. 11, No. 4, p. 103, 1930; vol. 19, No. 3, p. 127, 1935; Bull. Mus. Comp. Zool., vol. 82, No. 2, p. 144, 1937.

Original description.- "Type.-Mus. Comp. Zool. No. 25537 (collector's no. 288, lot 53) adult from La Source, Gonave Island, collected on August 7, 1927, by Walter J. Eyerdam.

"Description of the type.--Profile of head flat on top, not curved except at the very end of the snout; nostril anterior to the nasal suture; rostral forming a right angle behind; anterior nasals broadly in contact behind the rostral; frontonasal longer than wide, [broadly angulate in front,] in contact with the large loreal; prefrontals broadly in contact; frontal in contact with three supraoculars on each side; three large supraoculars, the anterior one not touching the loreal; behind the third supraocular three small scales occupying the position of a fourth supraocular; fronto-parietals in close contact with the third supraocular; seven superciliaries on the right and six on the left, the two anterior ones on each side in contact with the first supraocular, the remaining superciliaries separated from the posterior supraocular by a row of granules; two fronto-parietals, followed by a transverse row of five subequal occipitals, these in turn being followed by about three rows of irregular post-occipitals; ear-opening large; five upper labials to a point directly beneath the center of the eye, the third and fourth the longest; six lower labials to the same point, the third the longest; the wedge of granular scales on the chin extending to the first pair of chin shields, which are partially in contact; chin and throat covered with granular scales, a distinct wide band of enlarged scales across the middle; mesoptychium covered with one or two irregular rows of enlarged scales, bordered by two or three successively smaller rows. Dorsal scales granular, uniform, 34 in the standard distance (from tip 
of snout to center of eye); laterals similar but smaller. Ventral plates in eight longitudinal series bounded by two very small external series, and in thirty-five transverse series; brachials and ante-brachials well separated, four wide strap-like scales across the fore-arm; postbrachials present as about four pairs of somewhat enlarged scales at the elbow, only slightly larger than the granular scales on the back; femoral pores 16 and 18; anterior face of thigh covered with six or seven rows of flat scales; two tibial rows, the external row composed of four scales, of which the second and third are much larger than the
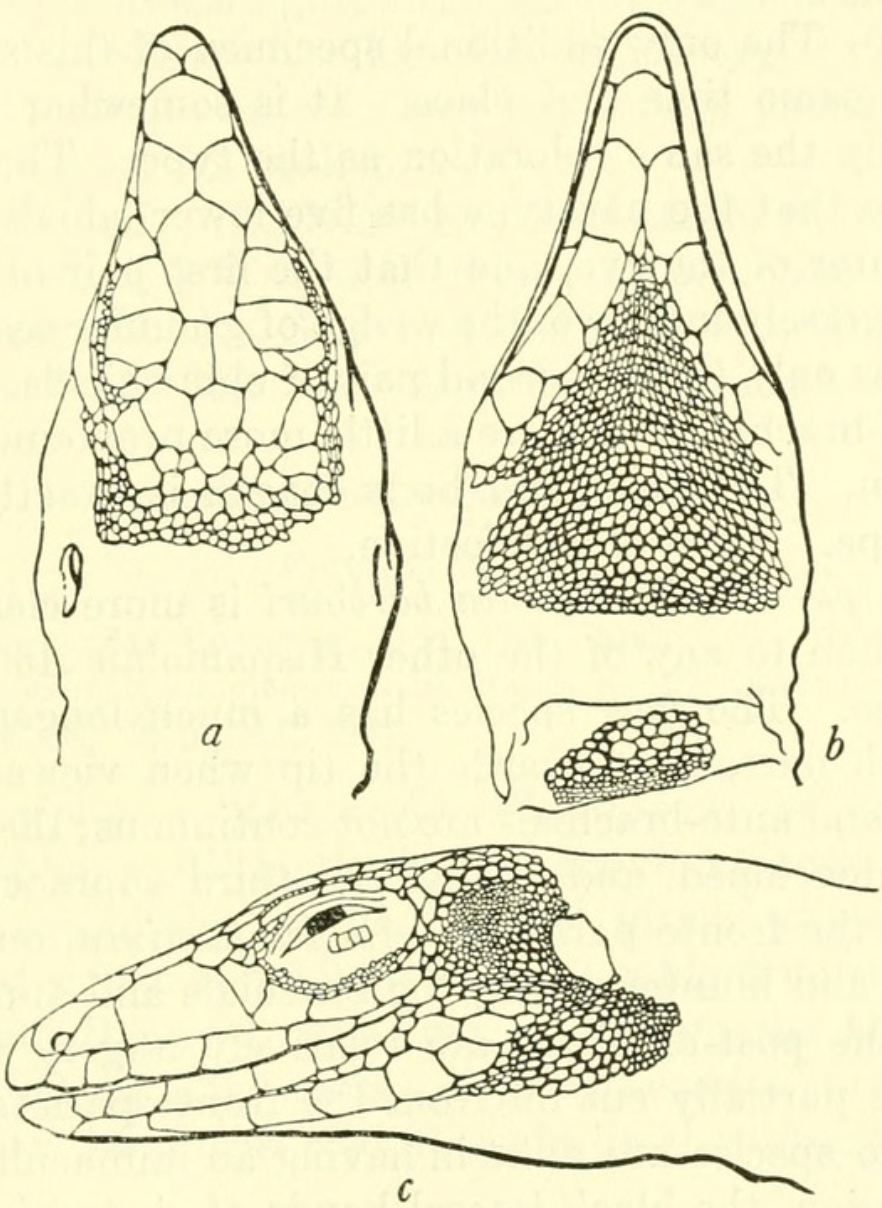

Figure 81.-Ameiva barbouri: $a$, Top of head; $b$, chin and throat; $c$, side of head. M.C.Z. No. 25537, type, from La Source, Gonave Island, Haiti. Twice natural size.

others; no enlarged postanals; a pair of enlarged plates at the anterior border of the anus and two single median scales in front of them, the anterior the smaller; twenty-two scales in the fifteenth verticil of the tail. The hind leg being adpressed, the fourth toe reaches to the anterior edge of the tympanum. Hands and feet long and slender; the small "combs" very evident on the toes; fourth toe with thirty-seven lamellae beneath it, fifth toe longer than first. Tail exceedingly long, almost three times the length of the head and body together, and somewhat noticeably depressed in its proximal third; the scales obliquely set, very weakly keeled above, quite smooth on the side and bottom. 
"Dimensions.-Head and body, $84 \mathrm{~mm}$.; tail, $230 \mathrm{~mm}$.

"Coloration (in alcohol).-Tail, ventral plates and under side of limbs brilliant cerulean blue; throat, chin, labials and point of snout rosy pink; dorsal surfaces uniform dull bluish-gray, without any light spots or lines whatever, but showing a bronze iridescence on shoulders and on base of tail; a dusky band beginning indistinctly on the canthus, passing over the ear and above the shoulder, broadening and becoming black on the sides, narrowing above the insertion of the hind leg and fading out on the sides of the tail; the outer two rows of ventral plates black anteriorly.

"Variation.- The only additional specimen of this species was collected at the same time and place. It is somewhat mutilated, but shows precisely the same coloration as the type. The only essential differences are that the paratype has five lower labials to a point beneath the center of the eye, and that the first pair of chin-shields is divided transversely into two, the wedge of granular scales on the chin extending thus only to this second pair of chin-shields. On the paratype the post-brachial plates are a little more pronounced than in the type specimen. The head and body length is exactly the same as that of the type. The tail is defective.

"Relationships.-While Ameiva barbouri is more clearly related to A. taeniura than to any of the other Hispaniolan Ameivas, they are not very close. The new species has a much longer snout, which becomes much narrower towards the tip when viewed from above; the brachials and ante-brachials are not continuous; the post-brachials are less well developed, and finally, the third supraocular is fully in contact with the fronto-parietal. Ameiva taeniura, on the contrary, has a shorter and blunter snout; the brachials and ante-brachials are continuous; the post-brachials are relatively larger, while the third supraocular is partially cut off from the fronto-parietal by granules. While the two species are alike in having an immaculate bluish-gray mid-dorsal region, the black lateral bands of $A$. taeniura are sharply marked off by a narrow light line above and below, and the central portion of the black band contains numerous light spots.

"In $A$. barbouri, the black band merges gradually into the dorsal and lateral ground-color, and is itself without any spots or vermiculations whatever."

A third example of this interesting teiid was taken by the Smithsonian-Parish Expedition on Gonave Island. It is like the type in all essentials. There are 18 femoral pores on each leg; the preanals are arranged precisely as in the type specimen; and there are likewise 22 scales in the fifteenth verticil of the tail, which is reproduced beyond this point. There are four lower labials to a point below the center of the eye. The head and body together measure $73 \mathrm{~mm}$.; arm, 24 $\mathrm{mm}$.; leg, $50 \mathrm{~mm}$.; snout to posterior border of tympanum, $19 \mathrm{~mm}$. 
The same coloration prevails in this specimen, with a similar absence of any tendency toward white stripes bordering the dark lateral stripes.

One additional specimen of this species, F.M.N.H. No. 10916, taken on Gonave Island by S. T. Danforth on July 16, 1927, has 17 and 18 femoral pores, 5 lower labials to a point below the center of the eye, and the preanal plates as in the type. The third supraocular is in close contact with the prefrontal, without any intervening granules. The brachials and antebrachials are practically continuous on the left side, but not continuous on the right, although the scales between them are fairly large. The coloration is like that of the type. The head and body measure $72 \mathrm{~mm}$; arm, $24 \mathrm{~mm}$.; leg, $49 \mathrm{~mm}$.; snout to posterior border of ear, $19 \mathrm{~mm}$; tail broken.

Specimens examined.-U.S.N.M. No. 80827, Gonave Island, May 14, 1930, L. H. Parish and Watson Perrygo; M.C.Z. Nos. 25537 (type), and 25538 (paratype), La Source, Gonave Island, August 7, 1927, W. J. Eyerdam; F.M.N.H. No. 10916, Gonave Island, July 16, 1927. S. T. Danforth.

\section{AMEIVA ROSAMONDAE Cochran}

Figures 72,82

1934. Ameiva rosamondae Cochran, Occ. Pap. Boston Soc. Nat. Hist., vol. 8, p. 179.-Barbour, Zoologica, vol. 19, No. 3, p. 127, 1935; Bull. Mus. Comp. Zool., vol. 82, No. 2, p. 144, 1937.

Original description.- "Diagnosis.-Eight rows of ventral plates; caudal scales oblique, distinctly keeled above, smooth on sides and bottom of tail; nostril anterior to the nasal suture; three large supraoculars, the first not in contact with loreal; a black dorso-lateral band beginning behind the eyes, widening greatly on the body and continuing on the tail; no light spots except on anterior surface of femur; 40 lamellæ under the fourth toe; 25 scales in the fifteenth verticil of the tail.

"Type--An adult, M.C.Z. 37567, from Saona Island, Dominican Republic, collected on April 8, 1934, by the Utowana Expedition.

"Description of the type.-Profile of head flat on top, curved only at the very end of the snout; nostril anterior to the nasal suture; rostral forming a right angle behind; anterior nasals broadly in contact behind the rostral; frontonasal as long as wide, narrowly in contact with the large loreal; prefrontals broadly in contact; frontal in contact with three supraoculars on each side; three large supraoculars, the anterior one not touching the loreal; a very minute scale behind the third supraocular; frontoparietals in close contact with the third supraocular; seven superciliaries, the three anterior ones on the left side in contact with the first supraocular, the two anterior on the right; the remaining superciliaries separated from the posterior supraoculars 
by a row of granules; two frontoparietals, followed by a transverse row of five subequal occipitals; these in turn being followed by three rows of irregular post-occipitals; ear-opening large; five upper labials to a point directly beneath the center of the eye, the third and fourth the longest; the keeled subocular nearly reaching to the lip between the fifth and sixth supralabials; first infralabial very minute; sixth infralabial under center of eye; the wedge of granular scales on the chin extending to the posterior border of the first pair of chin shields,
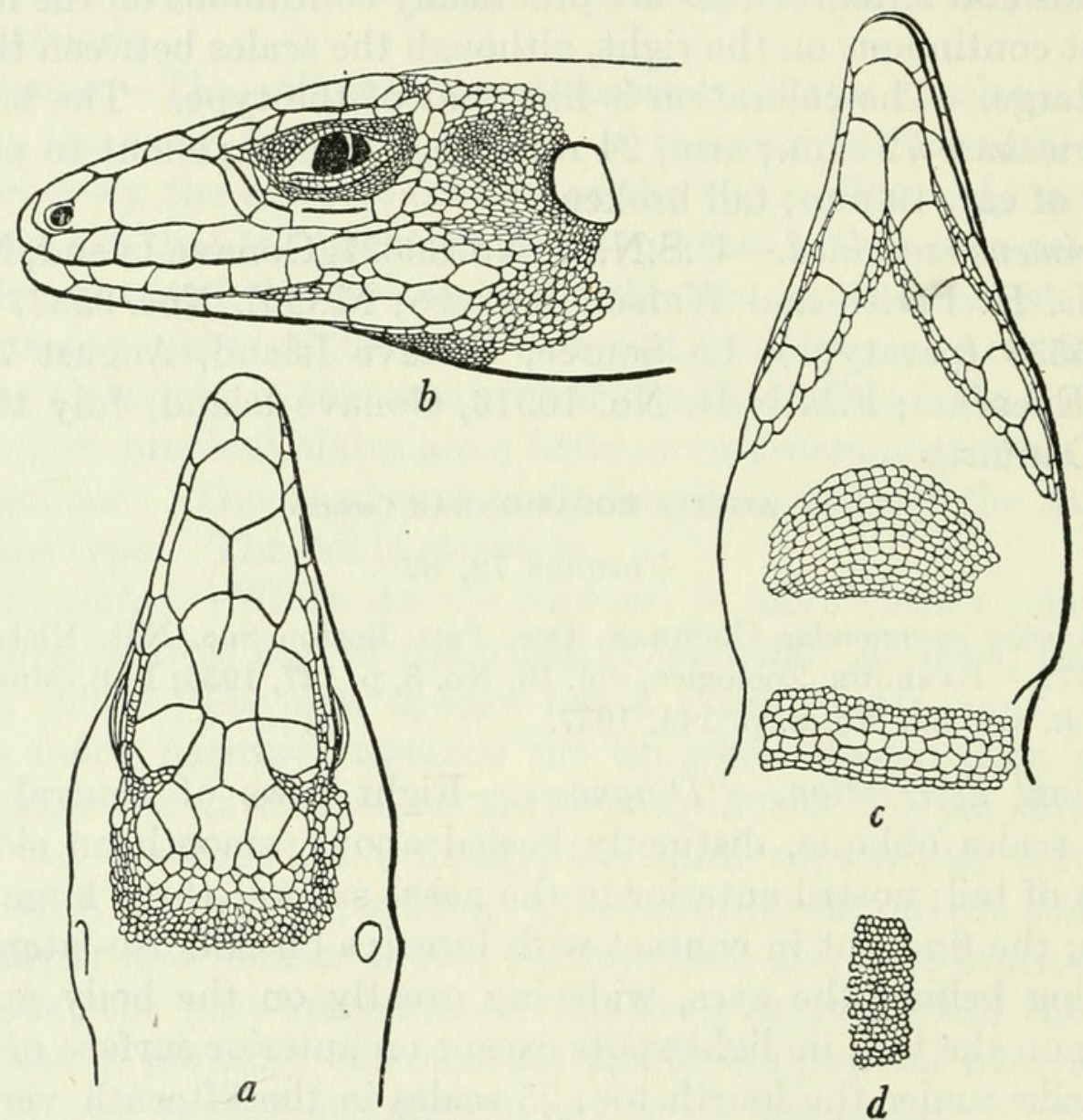

Figure 82.-Ameiva rosamondae: $a$, Top of head; $b$, side of head; $c$, chin and throat; $d$, dorsal granules. M.C.Z. No. 37567, type, from Saona Island, Dominican Republic. Twice natural size.

which are nearly completely in contact; chin and throat covered with granular scales, with a patch of enlarged scales in the middle; mesoptychium covered with two rows of rather regular, enlarged scales bordered by one or two smaller rows. Dorsal scales granular, uniform, 37 in the standard distance (from tip of snout to center of eye); laterals similar but smaller. Ventral plates in eight longitudinal series bounded by two very small external series, and in 35 transverse series; brachials and antebrachials well separated; six wide straplike scales across the forearm; post-brachials present as a group of three or four larger and several smaller scales at the elbow, all the post-brachials considerably larger than the dorsal granules; femoral pores 18; anterior 
face of thigh covered with five or six rows of flat scales; two tibial rows, the external row composed of four scales, the second and third very large; no enlarged postanals; a pair of enlarged plates at the anterior border of the anus and two single median scales in front of them, the anterior the smaller; 25 scales in the fifteenth verticil of the tail. The hind leg being adpressed, the fourth toe reaches to the anterior edge of the tympanum. Hands and feet long and slender, the small "combs" very evident on the toes; fourth toe with 40 lamellae beneath it; fifth toe longer than first. Tail (reproduced) slender, long, almost square in section in its proximal half; the scales obliquely set, strongly keeled above, becoming keeled to smooth on the sides, smooth below.

"Dimensions.-Head and body, $100 \mathrm{~mm}$.; tail (reproduced), $199 \mathrm{~mm}$.

"Coloration in alcohol.-Ground color lilac-gray on the back, washed with fawn color on the head and turning to pale blue and glaucous-blue on the tail; a black dorso-lateral band beginning behind the eyes, widening greatly on the body and continuing on the tail; this black band edged below by a narrow light area which becomes a definite white stripe in the groin and breaks up on the anterior surface of the femur into a number of light spots but continues down the tail as a definite stripe; lower half of loreal, labials and throat orange-buff lightening to buff-yellow on the center of the throat; rest of under surfaces of body and limbs glaucous-blue suffused anteriorly with cream color; tail azure blue beneath, with a black stripe on each side beginning a short distance behind the anus and fading out before the middle of the tail is reached.

"Relationships.-The new species at once suggests Ameiva barbouri in its striking coloration, and this relationship is fully borne out by details of scalation. They both have eight longitudinal rows of ventral plates (in my original diagnosis of Ameiva barbouri, there were said to be ten rows, but the number is afterward correctly stated in the complete description), the caudal scales are oblique and keeled, and both have three large supraoculars. The new species differs from barbouri in having a longer fourth toe, a greater number of scales around the tail, a wider black dorso-lateral band, and in being somewhat larger in size."

\section{Family AMPHISBAENIDAE}

\section{Genus AMPHISBAENA Linnaeus}

1758. Amphisbaena Linnaeus, Systema naturae, ed. 10, vol. 1, p. 229 (type A. fuliginosa).

Like all secretive and burrowing creatures, the ground lizards of this group are not likely to come to the notice of any naturalist not specially intent upon searching for them. Turning over rocks and

$226849-41-20$ 
logs may yield a few, but undoubtedly the best way to get series of them would be to follow a plow over some field already somewhat cultivated, as Dr. Barbour did to secure the Puerto Rican forms. It may well be that they are lacking entirely in certain portions of Hispaniola, while common enough in other parts, where conditions of the soil may suit their special needs.

\section{KEY TO THE SPECIES OF AMPHISBAENA OF HISPANIOLA}

$a^{1}$. Rostral plate fused with nasals; body rings 208-234; tail rings

18-24 normally _... manni (p. 298)

$a^{2}$. Rostral plate perfectly distinct.

$b^{1}$. Body rings 203-216; tail rings 13-16_._.

$b^{2}$. Body rings 217; tail rings 20-21 (Grande Cayemite) .... caudalis (p. 302)

\section{AMPHISBAENA MANNI Barbour}

Figure 83

1914. Amphisbaena manni Barbour, Mem. Mus. Comp. Zool., vol. 44 No. 2, p. 318 (type locality, Cap-Haïtien, Haiti); Zoologica, vol. 11, No. 4, p. 104, 1930; vol. 19, No. 3, p. 128, 1935; Bull. Mus. Comp. Zool., vol. 82, No. 2, p. 146, 1937.-Sснмidт, Bull. Amer. Mus. Nat. Hist., vol. 44, art. 2, p. 18, 1921.-Barbour and Loveridge, Bull. Mus. Comp. Zool., vol. 69, No. 10, p. 214, 1929.

Description of a paratype.-U.S.N.M. No. 67113, a half-grown specimen from Cap-Haïtien, Haiti, collected in 1914 by W. M. Mann. Rostral completely fused with the nasals, which are partially separated on top of the snout by a median cleft less than one-half the length of the suture between the long prefrontals; a short suture leading from the lower border of the nostril backward to the first upper labial; ocular rather small, unequally 4-sided, smaller than the postocular or the third supralabial; a rather small temporal between the postocular and the third supralabial, not (on left side) or barely (on right) in contact with the ocular and somewhat smaller; eye plainly visible through the ocular; frontals a little shorter than prefrontals and not so broad; a pair of small, poorly differentiated occipitals in contact behind the frontals; three supralabials, the second as long as the other two together; three lower labials, the first very minute, the second exceedingly large, the third quite small; a moderate-sized malar shield behind the second lower labial; mental followed by a very large median postmental somewhat longer than broad; just behind the postmental and between the second infralabials are three scales (the postgeneials) lying in a transverse row, the central one much the smallest; 230 rings on the body and 20 on the tail; the dorsal segments of each ring longer than broad; the 10 median ventral segments broader than long, the inner two conspicuously so; 14 segments above the lateral line and 16 below it; six anal shields; eight preanal pores.

Dimensions: Total length (body somewhat mutilated) about 120 
mm.; snout to posterior border of occipitals, $6 \mathrm{~mm}$.; tail, $11 \mathrm{~mm}$.; diameter at midbody, $4 \mathrm{~mm}$.

Color (in alcohol): Above dark fawn color, lightening to wood brown below, all the scales and plates quite uniformly colored.

Relationships.-While Amphisbaena manni is the Hispaniolan representative of the Puerto Rican caeca, as Dr. Barbour rightfully stated in his original description of manni, it can nevertheless be told at a glance from all other West Indian amphisbaenians by its fused nasal and rostral plates. None of the specimens of caeca show any approach to such a condition. The Hispaniolan species seems a little smaller also, our largest specimen, No. 74679, measuring only $195 \mathrm{~mm}$. in length, as against $242 \mathrm{~mm}$. for No. 27320 from Bayamon, Puerto Rico.

Variations.-There seems to be more variation in the number of preanal pores in A. manni than is the rule in other West Indian Amphisbaena, which are quite constant in this respect. There is certainly a
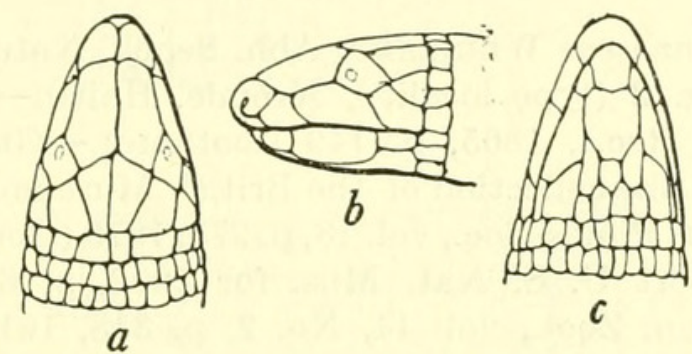

FigURE 83.-Amphisbaena manni: $a$, Top of head; $b$, side of head; $c$, chin. U.S.N.M. No. 67113, paratype, from Cap-Haïtien, Haiti. Three times natural size.

marked tendency for the occurrence of six pores in ground lizards from Río San Juan, since in our series of nine specimens from that region, but one specimen varies by having seven pores. Two of Schmidt's specimens from the Dominican Republic had six pores, and one of Dr. Barbour's type series from Cap-Haïtien had seven. Considerable variability is likewise shown in the number of segments above and below the lateral line. The specimens that have come under my observation may have $12,13,14$, or 16 dorsal segments and 14,16 , or 18 ventral segments. The range in the number of body rings is a matter of local distribution to some extent, as my series from Río San Juan, just mentioned in connection with a low count of preanal pores, have a fairly high and homogeneous count in the number of body rings, ranging nicely from 225 to 234 . But the two specimens from Boca del Infierno both possess eight preanal pores and have a very low number of body rings, 219 and 208, which are the lowest recorded counts for this species.

Specimens examined.-As listed in table 54. 
TABLE 54.-Specimens of Amphisbaena manni examined

\begin{tabular}{|c|c|c|c|}
\hline Museum No. & Locality & Date & Collector \\
\hline U.S.N.M. & & & \\
\hline 67113 (paratype) & Cap-HaItien, Haiti & 1913 & W. M. Mann. \\
\hline 69175 & San Francisque, Haiti & Mar. $18,1925 \ldots \ldots$ & G. S. Miller, Jr. \\
\hline $74679-74687$ & Río San Juan, D. R & March 1928 & Do. \\
\hline 74978,74979 & Boca del Infierno, D. R & Mar. $14,1928 \ldots . .$. & Do. \\
\hline $\begin{array}{c}\text { 76656, } 76657 \text { M.C.Z. } \\
\text { M. }\end{array}$ & $\begin{array}{l}\text { L'Atalaye, near San Michel du } \\
\text { Nord, Haiti. }\end{array}$ & January $1929 \ldots$ & $\begin{array}{l}\text { A. J. Poole and W. } \\
\text { Perrygo. }\end{array}$ \\
\hline $\begin{array}{l}8645 \text { (type), } 8646,8647 \\
\text { (paratypes). }\end{array}$ & Cap-Haitien, Haiti & 1913 & W. M. Mann. \\
\hline 44389 & Constanza, D. R & August 1938_....... & P. J. Darlington. \\
\hline 44390 & Villa Altagracia, D. R & July $1938 \ldots \ldots$ & Do. \\
\hline 44399 & Sánchez, D. R...... & - do & Do. \\
\hline
\end{tabular}

\section{AMPHISBAENA INNOCENS Weinland}

FigURE 84

1863. Amphisbaena innocens Weinland, Abh. Senck. Naturf. Ges., vol. 4, pt. 2, p. 137 , pl. 5, fig. 2 (type locality, Jérémie, Haiti).-GüNther, Zoological literature (Zool. Rec.), 1865, p. 149 (footnote).-GraY, Catalogue of the Shield reptiles in the collection of the British Museum, vol. 2, p. 37, 1872.Cope, Proc. Amer. Philos. Soc., vol. 18, p. 273, 1879 (Gonave Island, Haiti).Stejneger, Report U. S. Nat. Mus. for 1902, p. 677, 1904.-Barbour, Mem. Mus. Comp. Zool., vol. 44, No. 2, p. 318, 1914; Zoologica, vol. 11, No. 4, p. 104, 1930; vol. 19, No. 3, p. 128, 1935; Bull. Mus. Comp. Zool., vol. 82, No. 2, p. 146, 1937.-Cochran, Proc. U. S. Nat. Mus., vol. 66, art. 6, p. 11, 1924; Proc. Biol. Soc. Washington, vol. 41, p. 54, 1928; Occ. Pap. Boston Soc. Nat. Hist., vol. 8, p. 184, 1934.-BARBour and Loveridge, Bull. Mus. Comp. Zool., vol. 69, No. 10, p. 214, 1929.

1901. Amphisbaena caeca Meerwarth, Mitth. Naturh. Mus. Hamburg, vol. 18, p. 37 (Haiti) (not of Cuvier).

Description.-U.S.N.M. No. 60620, from Moron, southwestern Haiti, collected on December 25, 1917, by Dr. W. L. Abbott. Rostral small, triangular, scarcely visible from above; prefrontals long, the suture between them somewhat longer than the frontal suture and twice as long as the nasal suture; ocular moderate, quadrangular, smaller than the postocular and the third supralabial, which meet in a point behind it; a well-developed temporal between the postocular and the third supralabial, just failing to touch the ocular; eye plainly visible through ocular; one pair of occipitals, slightly longer than broad, in contact behind the frontals; three supralabials, the second about once and a half as long as the first or the third; mental followed by a large median postmental which is once and a half as long as broad; three lower labials, the second longer than the other two together; behind the second lower labial a large malar shield; just behind the postmental and 
below the second supralabials lies a transverse row of two scales (the postgeneials) ; no median dorsal groove; 211 rings on the body and 15 on the tail; the segments of each ring longer than broad, except the two median ventral ones, which are slightly broader than long and between which the sutures are less deep than elsewhere; 15 segments above the lateral line and 22 below it; 10 anal shields; four preanal pores.

Dimensions: Head and body, $199 \mathrm{~mm}$.; tail, $16 \mathrm{~mm}$.; greatest diameter of body, $8 \mathrm{~mm}$.; snout to posterior border of occipital shield, $8 \mathrm{~mm}$.

Color (in alcohol): Light clay color above; below buff; anus white; each segment with a darker center.

Variations.-The number of body and tail rings varies little in this species, the limit being 203 to 216 body rings, and 13 to 16 tail rings. The scales above the lateral line may be in $14,15,16$, or 18 rows;
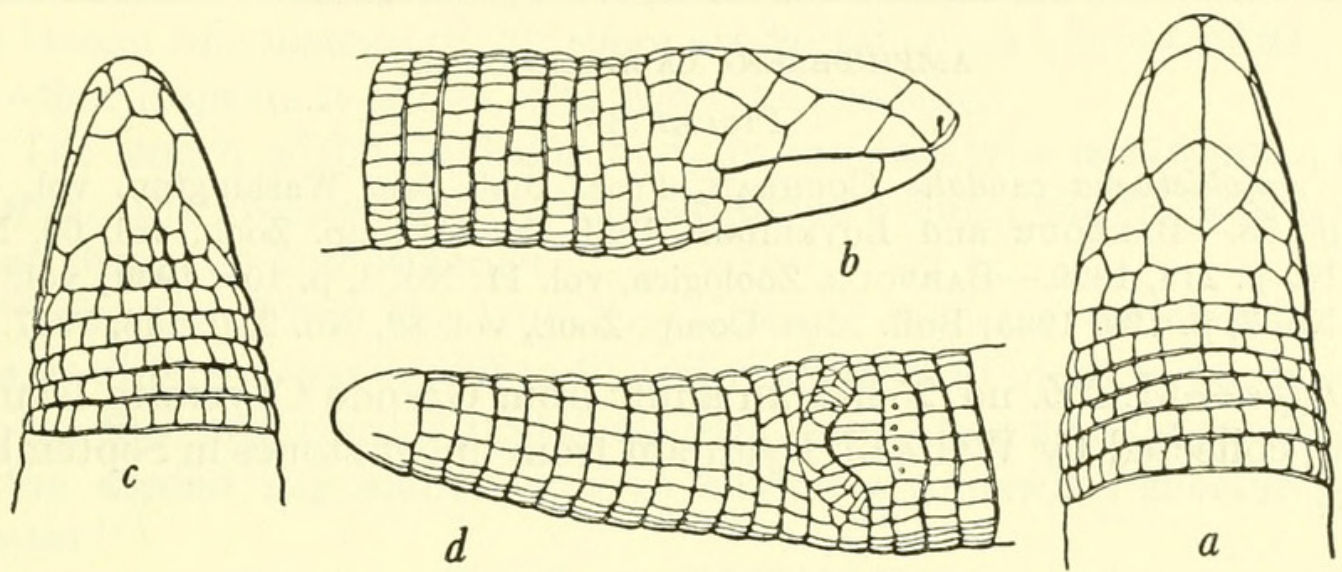

Figure 84.-Amphisbaena innocens: $a$, Top of head; $b$, side of head; $c$, chin; $d$, tail. U.S.N.M. No. 60620, from Moron, Haiti. Twice natural size.

below it in $18,19,20,21,22$, or 24 rows. The anal plates are subject to some variation; in one example, No. 59212, the scales are wide and there are but six; in the described specimen, No. 60620, there are 10 straplike scales; in yet another the scale on each side of the median pair has divided across and the posterior portion has again divided lengthwise, so that there are eight scales counting across the posterior portion and but six anteriorly. In one of my examples there are three postgeneials touching the mental, the central one being only narrowly in contact however. In No. 69440 this same condition is approached, although the median scale does not enter quite far enough into the wedge to touch the mental.

Relationships.-The distinctions between this species and A. caeca of Puerto Rico have been so adequately defined by Dr. Stejneger that no repetition of them is needed here.

Specimens examined.-As listed in table 55. 
TABLE 55.-Specimens of Amphisbaena innocens examined

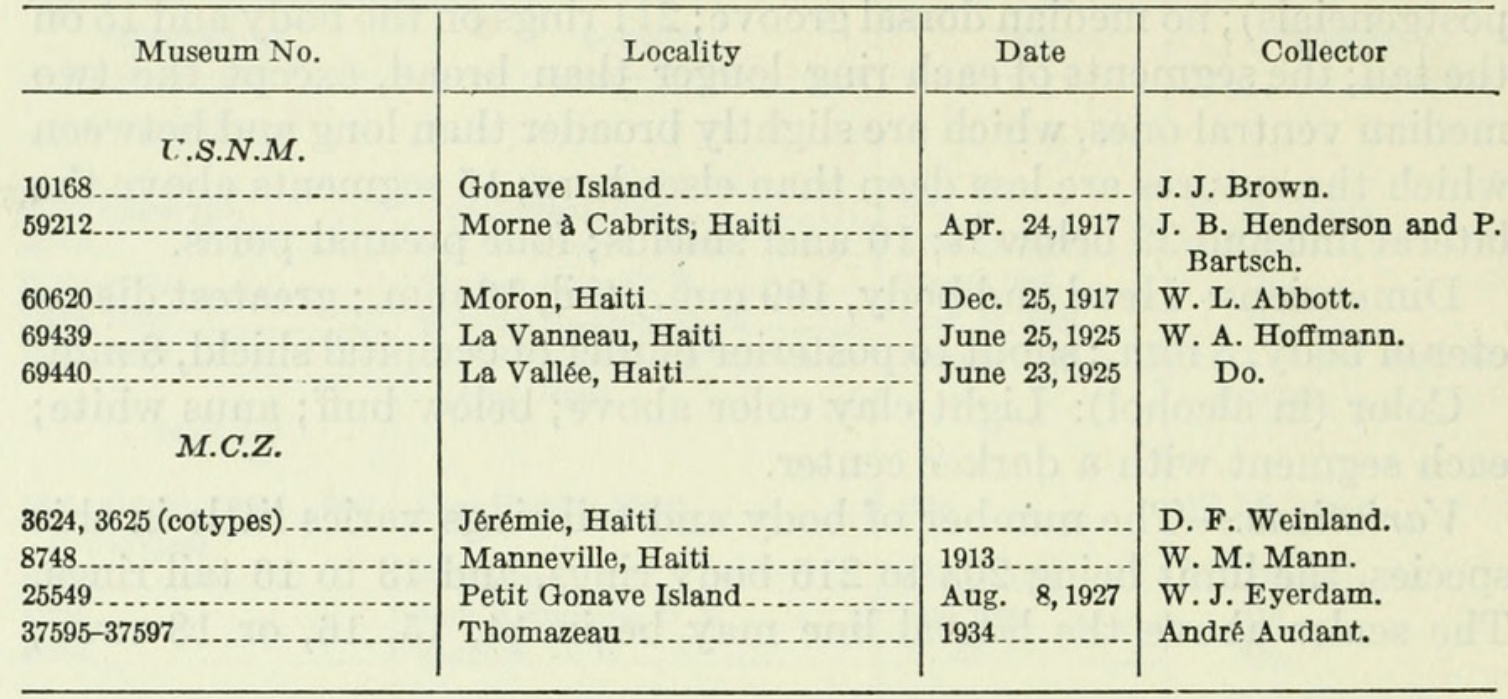

\section{AMPHISBAENA CAUDALIS Cochran}

FIGURE 85

1928. Amphisbaena caudalis Cochran, Proc. Biol. Soc. Washington, vol. 41, p. 58.-Barbour and Loveridge, Bull. Mus. Comp. Zool., vol. 69, No. 10, p. 214, 1929.-BARBour, Zoologica, vol. 11, No. 4, p. 105, 1930; vol. 19, No. 3, p. 129, 1935; Bull. Mus. Comp. Zool., vol. 82, No. 2, p. 146, 1937.

"Type.-M.C.Z. no. 25550, an adult from Grande Cayemite Island, Haiti, collected by Walter J. Eyerdam from under stones in September 1927.
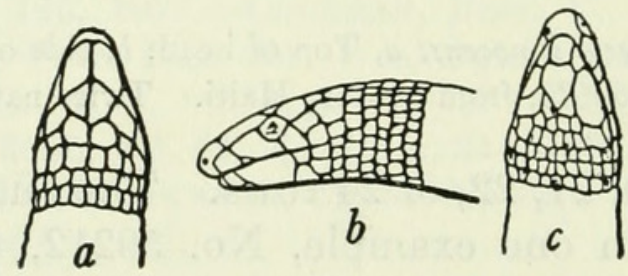

Figure 85.-Amphisbaena caudalis: $a$, Top of head; $b$, side of head; $c$, chin. M.C.Z. No. 25550, type, from Grande Cayemite Island, Haiti. Twice natural size.

"Description of the type.-Rostral small, triangular, scarcely any of it visible from above; prefrontals long, the suture between them a little longer than that between the frontals and slightly over twice the length of the nasal suture; ocular moderate, quadrangular, smaller than the postocular and about equal to the third supralabial; a well developed temporal between the postocular and third supralabial, just touching the ocular and about equal to it in size; eye plainly visible through the ocular; two pairs of occipitals in contact behind the frontals, the anterior pair longer than broad, the posterior pair squarish; three supralabials, the second as long as the other two together; three lower labials, the second much longer than the other two together; behind the second lower labial a large malar shield; mental followed by a large median postmental somewhat longer than broad; just behind the postmental and between the second supra- 
labials are two scales (post-geneials) lying in a transverse row; 217 rings on the body and 21 on the tail; the segments of each ring longer than broad, excepting the two median ventral ones which are slightly broader than long and between which the suture is less deep than elsewhere; 14 segments above the lateral line and 20 below it; six anal. shields; four preanal pores.

"Color (in alcohol).-Drab above, the center of each segment darker; lighter below anteriorly, turning to yellowish-white posteriorly.

"Dimensions.-Head and body length, $137 \mathrm{~mm}$; tail, $12 \mathrm{~mm}$; greatest diameter of body, $5 \mathrm{~mm}$.

"Variations.-A single paratype, taken at the same time and place as the type, besides being somewhat larger, varies from it in the following slight characteristics: The temporal scale is relatively somewhat smaller than in the type specimen; there are 18 segments below the lateral line instead of 20 ; there are 20 tail-rings instead of 21 . In all other respects it agrees with the type specimen.

"The length of the head and body in the paratype is $170 \mathrm{~mm}$.; tail, $17 \mathrm{~mm}$.; the greatest body diameter about $6 \mathrm{~mm}$.; the body is somewhat shrunken and stiffened.

"Remarks.-From the true Amphisbaena innocens, its closest relative, it differs in having 20 to 21 tail rings instead of 13 to 16 ; in having the first and third supralabials proportionately smaller in relation to the second supralabial, and in having a somewhat shorter postmental."

\section{Family SCINCIDAE}

\section{Genus MABUYA Fitzinger}

1826. Mabuya Fitzinger, Neue Classification der Reptilien ..., p. 23 (type, M. carinata).

\section{KEY TO MABUYA FROM HISPANIOLA}

Limbs widely separated when laid along sides; 26 scale rows; dorsum with 10 dark stripes lineolata (p. 303)

Limbs overlapping when laid along sides; 30 to 32 scale rows; a pale dorsolateral band bordered above by a dark narrow stripe and below by a broad dark band lightening posteriorly_-_mabouya sloanii (p. 305)

\section{MABUYA LINEOLATA Noble and Hassler}

FigURE 86

1933. Mabuya lineolata Noble and Hassler, Amer. Mus. Nov., No. 652, p. 16.-Barbour, Zoologica, vol. 19, No. 3, p. 129, 1935; Bull. Mus. Comp. Zool., vol. 82, No. 2, p. 147, 1937.

Original description.- "Diagnostic Characters.-A slim, shortlegged species having ten stripes of dark brown extending the length of the body; supranasals in contact behind the rostral; two pairs of nuchals; when the limbs are pressed along the side of the body, the appendages fail to meet by a distance greater than or equal to the length of the hind limbs. 
“Detalled Description.-Type: A. M.N.H. No. 42145, female. Collected at Monte Cristy, D. R., January 8, 1930, by W. G. Hassler. "Snout short; a small postnasal present; anterior loreal making a narrow contact with the first labial; supranasal in contact behind the rostral; frontonasal broader than long, making contact with the anterior angle of the frontal; prefrontals barely separated by the frontonasal; frontal about one-fifth longer than the frontoparietals; about the same length as a parietal, in contact with the second supraocular only; four supraoculars, second one-half again as large as any of the others; four superciliaries, second as long as the third and fourth combined; a pair of frontoparietals, about the same length as an interparietal; parietals in contact behind the latter; one pair of nuchals; four supralabials anterior to the suboculars; one or two suboculars followed by a supralabial which is larger than the anterior supralabials and slightly higher than the suboculars. Ear opening
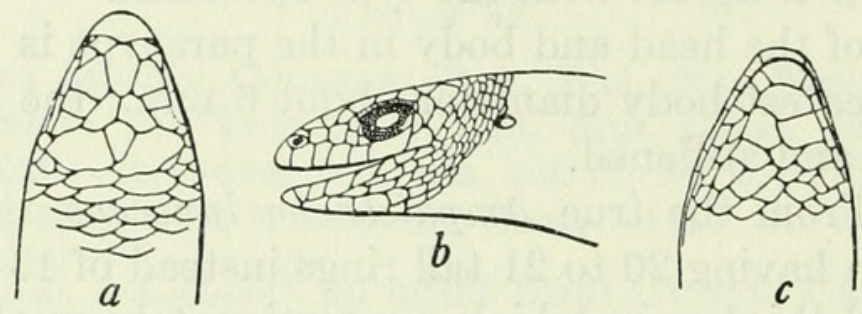

Figure 86.-Mabuya lineolata: $a$, Top of head; $b$, profile of head; $c$, chin.

No. 51766, paratype, from Monte Cristi, Dominican Republic. Twice natural size.

ovoid, a trifle smaller than the diameter of the transparent plate in the lower eyelid, its greatest diameter about equal to length of the scales covering the side of the body. Dorsal scales smooth; 26 scales around the middle of the body, laterals a little smaller than the others. When the legs are pressed against the body the hind leg fails to meet the anterior leg by a distance greater than the total length of the hind limb; subdigital lamellae smooth; tail regenerated, nevertheless slightly longer than the head and body length.

"Dorsal surface of the head, body and tail (in alcohol) striped, a ground tone of gray divided on the dorsal surface by ten conspicuous stripes of dark brown, the two most ventral stripes on each side about half the width of the two stripes immediately dorsal to them on either side; the latter extending from the region of the eyes the whole length of the body and well on to the tail; the dark stripes not co-equal in width to a scale but extending through the middle or the lateral portion of each scale. Ventral surface a uniform grayish tint except on the tail where the two most ventral stripes on the side of the body have converged to form two barely defined stripes on either side of the midline of the tail. 


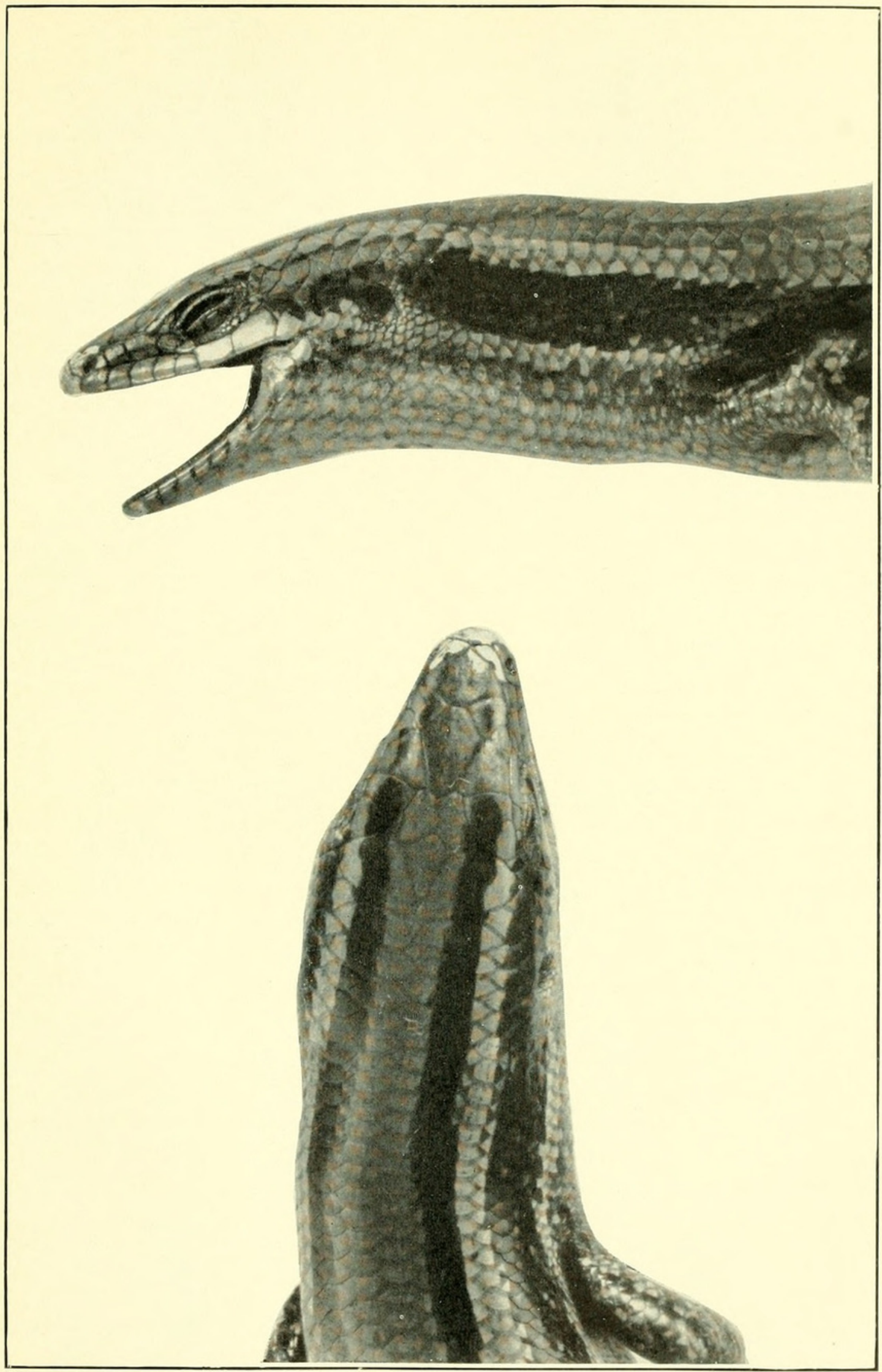

MABUYA MABOUYA SLOANII

Side and top of head of M.C.Z. No. 3617, the cotype of Mabuya nitida from "San Domingo." About twice natural size. 

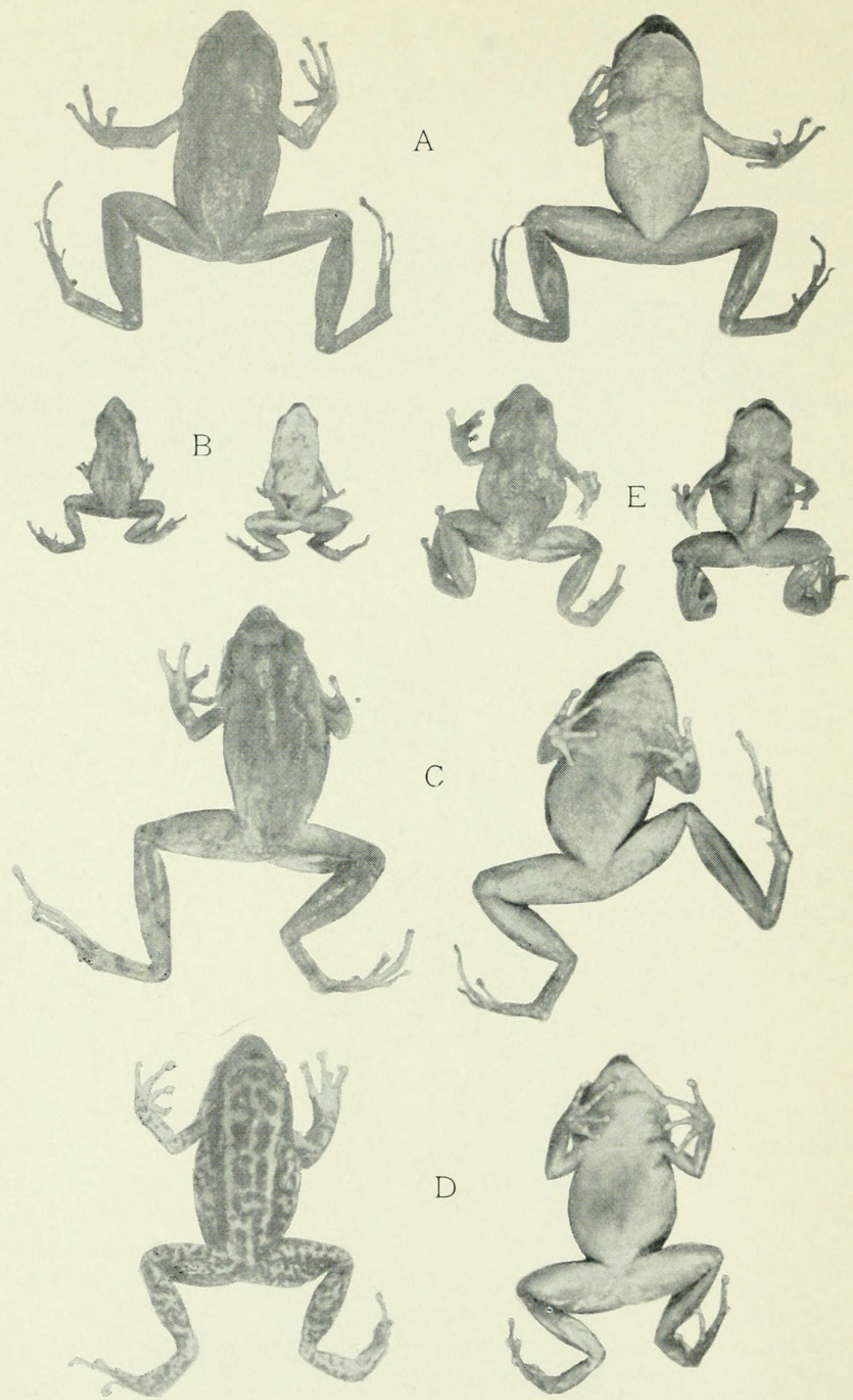

A, Eleutherodactylus glandulifer, type, M.C.Z. No. 19851, from Massif de la Hotte, Haiti; B, E. glanduliferoides, type, M.C.Z. No. 21597, from near La Visite, La Selle Range, Haiti; C, E. femur-levis, type, M.C.Z. No. 19836, from Desbarriere, Massif de la Hotte, Haiti; D, E. pictissimus, type, M.C.Z. No. 19846, from Tardieu, Massif de la Hotte, Haiti; E, E. semipalmatus, type, M.C.Z. No. 21561, from Massif de la Hotte, Haiti. 
"Dimensions.-Snout to vent, $59 \mathrm{~mm}$.; axilla to tip of longest finger, $10.5 \mathrm{~mm}$.; groin to tip of longest toe, $15 \mathrm{~mm}$.; tip of snout to ear opening, $8.5 \mathrm{~mm}$.; greatest breadth of head, $6 \mathrm{~mm}$.

"VARIATION.-Of the two paratypes, an adult male (A.M.N.H. No. 51766 ), measuring $56 \mathrm{~mm}$. from snout to vent, is almost identical to the type, having the same distinctive color pattern and short legs. When its hindleg is pressed forward and its foreleg backward, the distance between the appendages is approximately equal to the length of the hind leg. The head-scales are essentially like those of the type, but there is only one elongated subocular on each side. The other, a young specimen (A.M.N.H. No. 51765), $27 \mathrm{~mm}$. from snout to vent, differs from the two adults in the series by having a stripe on either side of the body in addition to the ten stripes of dark brown found in the adults. There is also some indication of five other longitudinal stripes of brown along the ventral surface of the belly.

"In life the dark stripes were nearly black while the light ones were lemon-yellow, changing into bluish at the tail-base. The tail was blue and the whole color pattern greatly resembled that of Ameiva lineolata Duméril and Bibron.

"НАвiтAт.-The species is known only from the region of Monte Cristy, Dominican Republic. The type was secured by a native who said he found it under rubbish near the bank of the Rio Yaque del Norte, not far from Monte Cristy. The other two specimens were brought in by natives from the same region. They were mistaken for Ameiva lineolata due to the remarkable resemblance in size and color. Despite the fact that over 300 of the Ameiva were brought in and the junior writer made a special search for them, no other specimens of Mabuya were secured."

A minor difference existing in the paratype, A.M.N.H. No. 51766, is that its frontal plate is one and a half times the length of a frontoparietal; these scales are more nearly the same in the type. The paratype likewise has two well-developed pairs of nuchals. Following the nuchals there are about 61 dorsal scales to a point above the vent. The fourth toe has 14 lamellae on its lower surface.

\section{MABUYA MABOUYA SLOANII (Daudin)}

\section{Plate 9}

1802. Scincus sloanii DAUdin, Histoire naturelle . . . des reptiles, vol. 4, p. 287, pl. 55 , fig. 2 .

1904. Mabuya sloanii Stejneger, Rep. U. S. Nat. Mus. for 1902, p. 608 (Vieques, Porto Rico, Mona, Virgin Islands, Haiti).-Barbour, Mem. Mus. Comp. Zool., vol. 44, No. 2, p. 320, 1914 (Vieques, Porto Rico, Mona, St. Thomas, St. John, Just van Dyke, St. Croix, Haiti); Zoologica, vol. 11, No. 4, p. 105, 1930.-Schmidt, Ann. New York Acad. Sci., vol. 28, p. 194, 1920; Publ. Field Mus. Nat. Hist., zool. ser., vol. 12, No. 12, p. 156, 1926; Scientific Survey of Porto Rico and the Virgin Islands, New York Acad. Sci., vol. 10, pt. 1, p. 121, 1928.-Fowler, Carnegie Inst. Washington Publ. 252, p. 7, 1918. 
1887. Mabuya nitida Garman, Bull. Essex Inst., vol. 19, p. 51 (type locality, Porto Rico and San Domingo).-Schmidt, Scientific Survey of Porto Rico and the Virgin Islands, New York Acad. Sci., vol. 10, pt. 1, p. 122, 1928.Barbour and Loveridge, Bull. Mus. Comp. Zool., vol. 69, No. 10, p. 302, 1929 .

1935. Mabuya mabouia Barbour, Zoologica, vol. 19, No. 3, p. 129; Bull. Mus. Comp. Zool., vol. 82, No. 2, p. 147, 1937.

1936. Mabuya mabouya sloanii DunN, Proc. Acad. Nat. Sci. Philadelphia, vol. 87 , p. 546.

The only Hispaniolan specimen of a skink that came to the attention of zoologists in more than a century was M.C.Z. No. 3617, one of the four cotypes of Mabuya nitida Garman, the other three of which came from Puerto Rico. With seven good specimens of Puerto Rican skinks at hand, Schmidt in 1928 took pains to restrict the name nitida to the Puerto Rican form if any separation were ever proved valid.

Redescription of the cotype of Mabuya nitida.-M.C.Z. No. 3617, an adult female from "Santo Domingo," collected in 1859 by D. F. Weinland. Head depressed, snout moderate; supranasals narrowly in contact behind the rostral, separating the latter from the frontonasal, which is broader than long and in contact with the frontal; nasal irregularly trapezoidal, with the large nostril in the posterior half; a small postnasal; two loreals, the posterior about one and onehalf times as large as the anterior; prefrontals separated, in contact with both loreals and with the second supraocular; frontal a little shorter than its distance from posterior end of interparietal, in contact with a second supraocular only; four supraoculars, the first small, separated from the frontal, the second largest, narrowly in contact with the prefrontal; four superciliaries, second very long; two frontoparietals in contact with second, third, and fourth supraoculars; an interparietal, behind which the parietals are in contact; two pairs of enlarged nuchals; a transparent disk on lower eyelid; temporals large; five subequal supralabials preceding the sixth (subocular) which is followed by a seventh supralabial both longer and higher than the sixth; mental followed by an unpaired postmental and three chin shields on each side, the first pair being in contact on the middle line, the posterior two separated by a median scale; ear opening round, small, slightly larger than the disk of the lower eyelid, without projecting scales in front; dorsal scales perfectly smooth; 32 scales around the middle of the body, about 70 on the middle line from chin to vent; limbs overlapping when adpressed along the body; vent bordered anteriorly by six scales, the two middle pairs somewhat enlarged.

Color (in alcohol): Above bronze green, with a pale dorsolateral band extending from the supranasals over the superciliaries to the middle of the body, where it gradually disappears; this band is bordered above by a narrow dark stripe and below by a broader dark 
brown band from nostrils over ear and shoulder, gradually becoming lighter and disappearing on the groin; labials dark edged; a short light stripe beginning on the upper lip, passing beneath the ear, reaching the shoulder and fading out on the sides; lower parts pale bluish gray.

Dimensions: Snout to vent, $87 \mathrm{~mm}$; tip of snout to posterior border of ear, $15 \mathrm{~mm}$.; axilla to groin, $54 \mathrm{~mm}$.; fore limb, $19 \mathrm{~mm}$.; hind limb, $25 \mathrm{~mm}$.; tail reproduced.

Variations.-The Museum of Zoology of the University of Michigan has recently acquired three fine specimens of this rare skink from Ciudad Frujillo in the Dominican Republic through the efforts of C. C. Roys, one of their student collectors. These specimens, a female and two males, agree well with the only other known Hispaniolan example, M.C.Z. No. 3617, in almost every way. Their similarities and differences may be easily grasped from table 56 , based on a table given by Dr. Dunn (1936) in his "Notes on American Mabuyas."

The pattern is very similar in all the specimens, varying only in distinctness but very little in position or width of stripes.

Specimens examined.-M.C.Z. No. 3617 (type of M. nitida), Santo Domingo, 1859, F. Weinland; 3 specimens (M.Z.U.M.), Ciudad Frujillo, Dominican Republic, 1937, C. C. Roys.

TABLE 56.-Variations in four specimens of Mabuya mabouya sloanii (measurements in millimeters)

\begin{tabular}{|c|c|c|c|c|}
\hline Characteristic & $\underset{3617}{\text { M.C.Z. No. }}$ & $\begin{array}{c}\text { M.Z.U.M. } \\
\text { O }\end{array}$ & M.Z.U.M. & M.Z.U.M. \\
\hline Supranasals in contact... & Barely & No & No & No \\
\hline Prefrontals in contact.... & No & No & No & No \\
\hline Parietals in contact...... & Yes & Yes & Slightly & Slightly \\
\hline Nuchal pairs................. & 2 & 1 & 1 & \\
\hline Supraoculars & 3 & 3 & 3 & \\
\hline Suboculars & $6(+1)$ & $5(+1)$ & 5 & \\
\hline Scales around body .......... & 32 & 30 & 30 & 30 \\
\hline Scales from chin to vent & 70 & 64 & 61 & 62 \\
\hline Anals............. & $1+4+1$ & 8 & $3+2+3$ & $3+2+3$ \\
\hline Limbs overlapping & Yes & No & Yes & Yes \\
\hline Length of head and body .......... & 87 & 93 & 87 & 82 \\
\hline Length of tail..................... & Reproduced & 196 & 278 & 128 \\
\hline
\end{tabular}

1 Tip reproduced.

${ }^{2}$ Most of tail reproduced.

\section{Suborder SERPENTES}

Nine genera of snakes belonging to three families are known to occur in Hispaniola. None of the dangerously poisonous kinds are found there, although the genus Ialtris has grooved fanglike posterior maxillary teeth. 


\section{KEY TO THE GENERA OF HISPANIOLAN SNAKES}

$a^{1}$. Under side of body covered with small scales like those on back

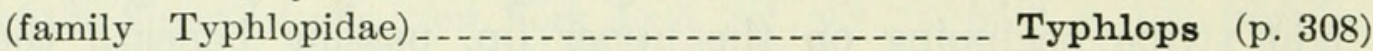

$a^{2}$. Under side of body covered with transverse plates.

$b^{1}$. Plates on under side of tail undivided (family Boidae).

$c^{1}$. Anterior teeth on both jaws very strongly enlarged; scale rows around body 33 or more................ Epicrates (p. 313)

$c^{2}$. Anterior teeth gradually decreasing in size; scale rows 27 to 29

$b^{2}$. Plates on under side of tail in pairs (family Colubridae).

$c^{1}$. Body slender and elongate; scales narrow, lanceolate, in 17 or 19 rows diminishing to 11 or 13 at base of tail _._ Uromacer (p. 329)

$c^{2}$. Body not unusually slender; scales normally wide.

$d^{1}$. Snout acuminate, slightly turned up in profile_ Hypsirhynchus (p. 344)

$d^{2}$. Snout normally rounded in profile.

$e^{1}$. One or two apical pits near tip of each dorsal scale.

$f^{1}$. Posterior maxillary teeth enlarged but not grooved

Alsophis (p. 347)

$f^{2}$. Posterior maxillary teeth enlarged and grooved_ Ialtris (p. 373) $e^{2}$. No apical pits present.

$f^{1}$. A loreal present; anal divided ........... Leimadophis (p. 353)

$f^{2}$. No loreal; anal single _................ Darlingtonia (p. 372)

\section{Family TYPHLOPIDAE}

\section{Genus TYPHLOPS Oppel}

1811. Typhlops Oppes, Die Ordnungen, Familien und Gattungen der Reptilien ..., p. 54 (type, T. lumbricalis).

1844. Ophthalmidion Duméril and Bibron, Erpétologie générale, vol. 6, p. 262

(type, O. longissimum).

1845. Anilios Gray, Catalogue of the specimens of lizards in the collection of the

British Museum, p. 135 (type, A. australis; not Anilius Oken, 1816).

1845. Meditoria Gray, ibid., p. 130 (type, T. nasutus).

The species of blindsnakes occurring in the territory under consideration may be distinguished as follows:

A single preocular; anterior border of ocular convex _..... lumbricalis (p. 308)

Two preoculars; anterior border of ocular concave

pusillus (p. 311)

\section{TYPHLOPS LUMBRICALIS (Linnaeus)}

\section{FigURE 87}

1758. Anguis lumbricalis Linnaeus, Systema naturae, ed. 10, vol. 1, p. 228 (type locality, America); ed. 12, vol. 1, p. 391, 1766.

1830. Typhlops cubae Bibron, in de la Sagra's Historia fisica, politica y natural de la isla de Cuba, vol. 4, Reptiles, p. 122, pl. 22 (French ed. p. 204) (type locality, Cuba).

1844. Typhlops lumbricalis Duméril and Bibron, Erpétologie générale, vol. 6, p. 287 (part).-Duméril, Catalogue méthodique de la collection des reptiles (Mus. Paris), p. 205, 1851 (part).-Bodlenger, Catalogue of the snakes in the British Museum, vol. 1, p. 31, 1893 (part).-Meerwarth, Mitth. Naturh. Mus. Hamburg, vol. 18, p. 5, 1901 (part).-Barbour, Proc. Biol. Soc. Washington, vol. 28, p. 77, 1915; Mem. Mus. Comp. Zool., vol. 47, No. 2, p. 185, 
1919; Zoologica, vol. 11, No. 4, p. 107, 1930; vol. 19, No. 3, p. 130, 1935; Bull. Mus. Comp. Zool., vol. 82, No. 2, p. 149, 1937.-Sснміdт, Bull. Amer. Mus. Nat. Hist., vol. 44, art. 2, p. 18, 1921.-Cochran, Journ. Washington Acad. Sci., vol. 14, pp. 174-179, 1924; Proc. U. S. Nat. Mus., vol. 66, art. 6, p. 11, 1924; Proc. Biol. Soc. Washington, vol. 41, p. 54, 1928.-Amaral, Mem. Inst. Butantan, vol. 4, p. 137, 1929.

Description.-U.S.N.M. No. 55298, from Sánchez, Santo Domingo, collected in October 1916 by Dr. W. L. Abbott. Head rather depressed, snout strongly projecting, somewhat rounded when viewed from above; diameter of body varying from $7 \mathrm{~mm}$. on the neck to 10 $\mathrm{mm}$. at midbody and near the tail, contained in total length 30 times. Rostral broader than the first median scale behind it (the "prefrontal") about two-sevenths the width of the head, extending well behind a line drawn between the anterior edges of the eyes; nostril on the lateral horizontal edge, on a suture that extends from the middle of the upper edge of the second supralabial to the rostral suture at the lateral horizontal edge, the lower anterior nasal thus being in contact with
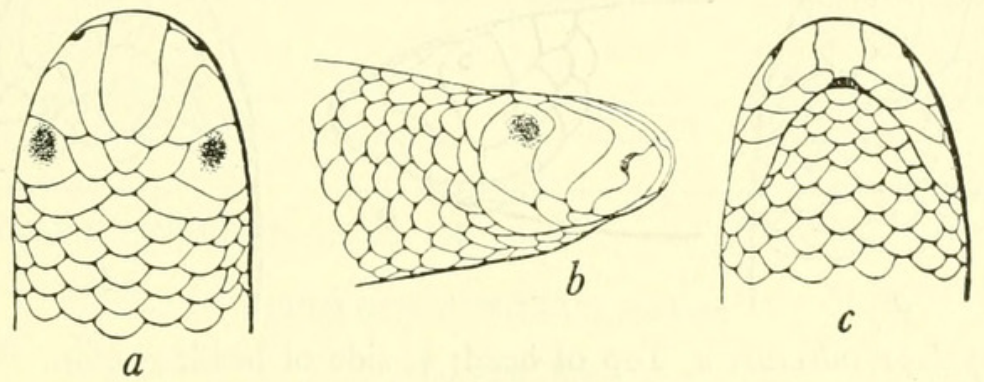

FIGURE 87.-Typhlops lumbricalis: $a$, Top of head; $b$, side of head; $c$, chin. U.S.N.M. No. 55298, from Sánchez, Dominican Republic. Three times natural size.

the first and second supralabials and the upper posterior one with the second and third; nasals not in contact behind the rostral; preocular as wide and as high as the ocular, in contact with the third supralabial; eye very distinct; ocular with its anterior edge forming a compound curve like an inverted S, in contact with the third and fourth supralabials. An enlarged elongate "parietal" scale bordering the upper half of the posterior edge of the ocular plate; parietals separated from each other by a frontal and an interparietal; the three median scales behind the rostral (prefrontal, frontal, and interparietal) subequal and all much smaller than the parietals, not quite so large as the true body scales on the back; one postocular situated between the parietal and the last supralabial; four upper labials, the last largest. Scale rows 20 , posteriorly 18 ; ventrals 257 ; subcaudals 11 ; tail ending in a spine.

Dimensions: Total length, $300 \mathrm{~mm}$; tail, $8 \mathrm{~mm}$.

Color: Above reddish brown, the color deepening to chestnut on the frontal region, each scale being light-edged; a dark-brown stripe along the center of the rostral shield and a brown spot on the third 
and fourth labials; nasals, remainder of labials, and posterior half of ocular pale yellow; ocular above eye dark brown; each dark body scale with an abruptly light base; under side pale yellow, the coloration of upper and lower surfaces blending very gradually together, with no abrupt transition anywhere.

Variations.-A specimen labeled simply Santo Domingo, No. 66887, agrees with the described specimen in possessing the very conspicuously enlarged parietals. On the right side of the head are two postoculars; the left side is normal, possessing but one. This snake is smaller in size, darker in coloration, and has dark centers through the nasals and preocular, as well as on the rostral plate. Another large but bleached snake, No. 10276, from Puerto Plata, has enlarged parietals and a single postocular, just as in No. 55298. A recently collected specimen, No. 75893, has enlarged parietals but possesses two postoculars, the upper one of which, however, is quite
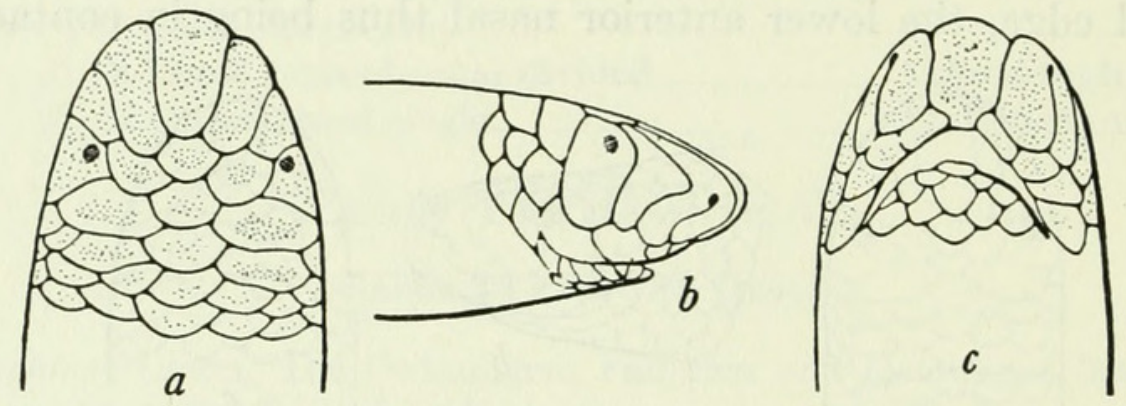

Figure 88.-Typhlops sulcatus: $a$, Top of head; $b$, side of head; $c$, chin. U.S.N.M. No. 12371, type, from Navassa Island. Three times natural size.

small. It is more purplish than the preceding specimens, and the high lights falling on the smooth scales give it a metallic appearance.

As I stated in a former paper on the species, the variation in the Hispaniolan form is not sufficiently known to justify separation as a distinct species. Much more material ought to be secured from the Bahamas and Navassa, as well as from Hispaniola itself.

On this page is a drawing made from a photograph of the actual type of Cope's Typhlops sulcatus (U.S.N.M. No. 12371, Navassa Island. $^{14}$ More topotypic material from Navassa is urgently needed before the validity of this species can be settled. The main difference that is instantly apparent upon comparing the type of $T$. sulcatus with T. lumbricalis from Hispaniola is that in the former the nasal suture does not reach the rostral, but stops short at the nostril, while in the latter a perfectly distinct suture from the rostral to the upper labial divides the nasals into two separate scales. But the value of this character will be known only by the regularity with which it occurs in a series of blindsnakes from the respective type localities. The number of ventrals is about 385 in sulcatus, a much higher count 
than is found in lumbricalis. It is to be regretted that only one specimen-the type - has ever been collected on Navassa.

Specimens examined.-As listed in table 57.

TABLE 57.-Hispaniolan specimens of Typhlops lumbricalis examined

\begin{tabular}{|c|c|c|c|c|c|c|}
\hline Museum No. & Locality & Date & Collector & 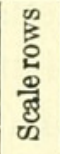 & 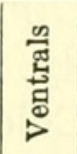 & 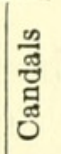 \\
\hline U.S.N.M. & & & & & & \\
\hline 10276 & Puerto Plata, D. R & 1878 & C. A. Fraser..... & 20 & 258 & 12 \\
\hline 55298 & Sánchez, D. R & October, 1916 & W. L. Abbott..... & 20 & 257 & 11 \\
\hline 66887 & Santo Domingo . . & (n) & P. Bartsch & 20 & 295 & 12 \\
\hline 75893 & Port-au-Prince, Haiti.......... & 1928 & J. S. C. Boswell... & 20 & 278 & 11 \\
\hline A.M.N.H. & $\begin{array}{l}\text { Grand Cayemite Island, } \\
\text { Haiti. }\end{array}$ & $1927 \ldots$ & W. J. Eyerdam... & & & \\
\hline Sero. Tech. Dept. Agr. & San Fedro de Macoris, Hait1_ & & G. K. Noble........ & .... & 245 & \\
\hline (n) & Damien, Haiti & December, 1927 & A. E. Vinson....... & 20 & 273 & 13 \\
\hline Brit. Mus. & Hinche, Haiti.......... & & I. T. Sanderson... & & & \\
\hline (n) & Port Bendet, Haiti.............. & (n) & -...do do & & & \\
\hline
\end{tabular}

14 Proc. Acad. Nat. Sci. Philadelphia, 1868, p. 128.

\section{TYPHLOPS PUSILLUS Barbour}

\section{FiguRe 89}

1914. Typhlops pusillus Barbour, Mem. Mus. Comp. Zool., vol. 44, No. 2, p. 323; Zoologica, vol. 11, No. 4, p. 106, 1930; vol. 19, No. 3, p. 130, 1935; Bull. Mus. Comp. Zool., vol. 82, No. 2, p. 148, 1937.-Sснмidt, Bull. Amer. Mus. Nat. Hist., vol. 44, art. 2, p. 18, 1921.-Cochran, Proc. U. S. Nat. Mus., vol. 66, art. 6, p. 11, 1924.-BARbour and Loveridge, Bull. Mus. Comp. Zool., vol. 69, No. 10, p. 357, 1929.-Böker, Publ. Inst. Cient. Domínico-Alemán, vol. 1, p. 18, 1939.

Description.-Adult, U.S.N.M. No. 9803, from Santo Domingo; 1897; Charles A. Fraser, collector. Snout depressed and somewhat projecting, rounded laterally; nostrils slightly below the lateral horizontal edge; rostral one-fifth the width of the head, not extending backward to line of the eyes; nostril on a suture starting from the middle of the upper edge of the second supralabial and joining the rostral suture just above the lateral horizontal edge, the lower (anterior) nasal thus being in contact with the first and second supralabials and the upper (posterior) one in contact with the second and third; supralabials four, the fourth largest; two preoculars, the lower roughly square in shape, in contact with the third supralabial, the upper longer and less deep; ocular with concave anterior edge in contact with third and fourth supralabials; supraoculars, prefrontal, and frontal subequal, scarcely differentiated in shape from the body 
scales; an enlarged straplike plate on each side of the frontal and in contact with the posterior border of the ocular shield for half its length; eye distinctly visible; 20 scale rows around the body; about 285 scales on the middle line of the body underneath from chin to vent and 15 under the tail, which ends in a spine.

Dimensions: Head and body, $140 \mathrm{~mm}$; t tail, $5 \mathrm{~mm}$.; diameter of body, $4 \mathrm{~mm}$.

Color (in alcohol): Light brown above; edges of scales darker than their centers; the head plates in front of the eye buff, without markings, the remainder of the head scales like those of the body; throat buff; the rest of the ventral surface grayish white, merging evenly into the darker dorsal color.

Variations.-To judge by the drawing of the type specimen in Dr. Thomas Barbour's original description, the type has a wider rostral than do those of the National Museum collection. The second supralabial seems a little lower in the figure of the type than in any of
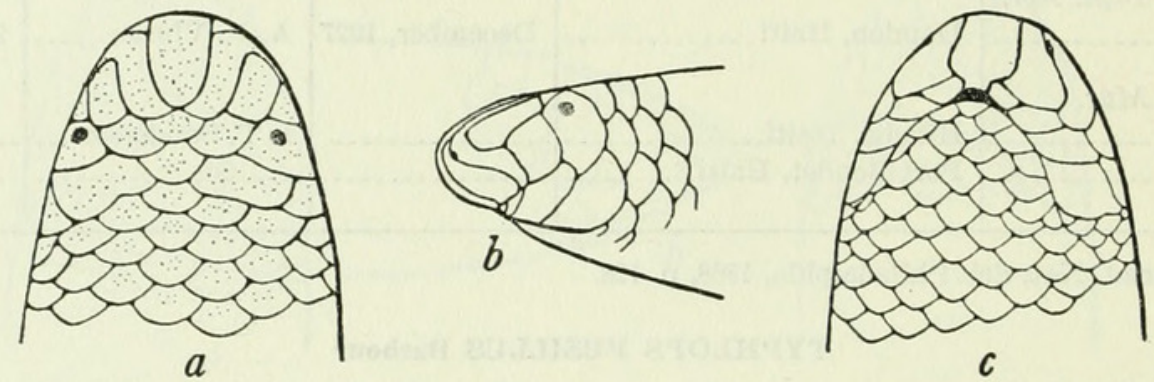

Figure 89.-Typhlops pusillus: $a$, Top of head; $b$, side of head; $c$, chin. U.S.N.M. No.9803, from "Santo Domingo." Six times natural size.

the other specimens and of a somewhat different shape, but this slight difference is probably due to the angle at which the specimen was held in making the drawing. The straplike plates behind the ocular do not seem to be at all evident in the drawing of the type specimen. The midventral scale count of the type of pusillus was wrongly given as 370 . It is really about 275 , Dr. Barbour writes me. The variation in the number of ventral plates in the National Museum series is between 272 and 304; the caudals number between 10 and 19 .

Remarks.-Nothing is known regarding the habits of this tiny snake, but its mode of living cannot be far different from that of the better known Typhlops lumbricalis. Other snakes must occasionally dine upon them, for No. 64271 was taken from the stomach of a Leimadophis parvifrons protenus taken in the Mao-Yaqui Valley.

Specimens examined.-As listed in table 58. 
TABLE 58.-Specimens of Typhlops pusillus examined

\begin{tabular}{|c|c|c|c|c|c|c|}
\hline Museum No. & Locality & Date & Collector & 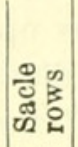 & 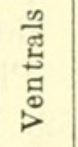 & 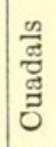 \\
\hline U.S.N.M. & "Santo Domingo" & $1877 \ldots \ldots \ldots$ & C. A. Fraser & & & \\
\hline $64271 \ldots \ldots \ldots \ldots$ & Mao-Yaqui Valley, D. R & Feb. 24,1921 & W. L. Abbott & 20 & 280 & 19 \\
\hline $69441 \ldots$ & La Vallèe, Haiti & June $23,1925 \ldots$ & W. A. Hoffman... & 20 & & 13 \\
\hline $70640 \ldots$ & San Michel du Nord, Haiti_ & November, 1925 & E. C. Leonard... & 20 & 285 & 13 \\
\hline $74496 \ldots$ & do & & A. J. Poole & 20 & 272 & 10 \\
\hline $74944 \ldots$ & Río San Juan, D. R & March, $1928 \ldots$ & G. S. Miller, Jr & 20 & 272 & 13 \\
\hline $74980 \ldots$ & Boco del Infierno, D. R. & Mar. 14, 1928_. & .... do & 22 & 282 & 12 \\
\hline $76649 \ldots$ & L'Atalaye, Haiti ........... & January $1929 \ldots$ & A. J. Poole and & 20 & 304 & 17 \\
\hline M.C.Z. & & & & & & \\
\hline 8719 (type) $\ldots$ & Cap-HaItien, Haiti. & $1913 \ldots$ & W. M. Mann.. & - & 275 & $\cdots$ \\
\hline $8773 \ldots \ldots \ldots . . . .$. & Ennery, Haiti & $1913 \ldots$ & do & .... & & ... \\
\hline $8755-8758$ & Cap-Haïtien, Haiti .... & $1913 \ldots$ & .....do do... & 18 & & ... \\
\hline $8774-8775 \ldots$ & Grande Rivière, Haiti .. & $1913 \ldots$. & .....do_... & & & \\
\hline $9367-9369$ & Cap-Haîtien, Haiti & $1913 \ldots$ & ....... do .... & & & $\cdots$ \\
\hline A.M.N.H. & Caimito, Cara River. & & K. P. Schmidt.. & & & \\
\hline & Sánchez & & C. R. Halter ....... & & & \\
\hline
\end{tabular}

\section{Family BOIDAE}

\section{Genus EPICRATES Wagler}

1830. Epicrates Wagler, Natürliches System der Amphibien . . . p. 168 (type, B. cenchria).

[Since a complete synonymy to this genus is given by Dr. Stejneger in the Puerto Rican herpetology, it is not necessary to repeat it here.]

Hispaniola harbors a subspecies of each of three very distinct species of this genus, while the other West Indian islands have but one variety apiece where any occurs. Thus we find its own form peculiar to Cuba, Jamaica, Turks Islend, Mona Island, and Puerto Rico.

\section{KEY TO THE SPECIES OF EPICRATES OF HISPANIOLA}

$a^{1}$. Scale rows 48 or more striatus striatus (p. 313)

$a^{2}$. Scale rows not more than 40 .

$b^{1}$. Ventrals 244-261, caudals 70-81 inornatus fordii (p. 318)

$b^{2}$. Ventrals $274-297$, caudals $93-110$ gracilis gracilis (p. 321)

\section{EPICRATES STRIATUS STRIATUS (Fischer)}

FigURe 90

1849. Epicrates angulifer Gray, Catalogue of the specimens of snakes in the collection of the British Museum, p. 94 (Haiti; Brit. Mus., R. Twining, coll.) (not of Bibron 1840).-Amaral, Mem. Inst. Butantan, vol. 4, p. 140, 1929. 
1856. Homalochilus striatus Fischer, Abh. Nat. Ver. Hamburg, vol. 3, p. 102, pl. 2, fig. 2a-2b (St. Domingo and St. Thomas).-JAN, Iconographie générale des ophidiens, livr. 6, pl. 4, 1864; text, p. 86, 1865.-Garman, Proc. Amer. Philos. Soc., vol. 24, p. 279, 1887 (Haiti).

1862. ?Homalochilus multisectus Cope, Proc. Acad. Nat. Sci. Philadelphia, 1862, p. 70 (type locality unknown; type in Mus. Philadelphia Acad.; Smith and Stewardson, coll.).

1862. ?Homalochilus strigilatus Cope, Proc. Acad. Nat. Sci. Philadelphia, 1862, p. 71 (type locality, New Providence Island, Bahamas); Proc. U. S. Nat. Mus., vol. 10, p. 439, 1887 (New Providence).-Garman, Proc. Amer. Philos. Soc., vol. 24, p. 279, 1887 (Andros).-Epicrates strigilatus BARBour, Bull. Mus. Comp. Zool., vol. 46, No. 3, p. 59, 1904 (Nassau, Bahamas).

1863. Epicrates striatus Steindachner, Denkschr. Akad. Wien, vol. 22, pt. 2, p. 93, pl. -, figs. 5, 6.-Bodlenger, Catalogue of the snakes in the British Museum, vol. 1, p. 96, 1893 (San Domingo).-ZEnNeck, Zeitschr. Wiss. Zool., vol. 64, pp. 57, 62, 347, 1898.-STEJNEGER, The batrachians and land reptiles of the Bahama Islands, p. 336, 1905.-Barbour, Amer. Nat., 1906, p. 325; Bull. Mus. Comp. Zool., vol. 44, p. 325, 1914; Zoologica, vol. 11, No. 4, p. 107, 1930.-Rosén, Contributions to the fauna of the Bahamas, vol. 2, p. 38, 1911.-Sснмidt, Bull. Amer. Mus. Nat. Hist., vol. 44, p. 18, 1921.-Cochran, Proc. U. S. Nat. Mus., vol. 66, art. 6, p. 11, 1924; Occ. Pap. Boston Soc. Nat. Hist., vol. 8, p. 184, 1934.-STull, Bull. Antivenin Inst., vol. 5, No. 2, p. 39, 1931.

1863. Epicrates versicolor Steindachner, Denkschr. Akad. Wien, vol. 22, pt. 2, p. 89, pl. - , figs. 1-4 ("Columbia"; type in Zool. Mus. Vienna).

1901. Epicrates angulifer striatus Meerwarth, Mitth. Naturh. Mus. Hamburg, vol. 18 , p. 5 .

1935. Epicrates striatus striatus Stull, Proc. Boston Soc. Nat. Hist., vol. 40, No. 8, p. 397.-Barbour, Zoologica, vol. 19, No. 3, p. 131, 1935; Bull. Mus. Comp. Zool., vol. 82, No. 2, p. 149, 1937.

Description.-Adult male, U.S.N.M. No. 60604; Les Basses, southwestern Haiti; January 9, 1918; Dr. W. L. Abbott, collector. Rostral a little broader than high, visible from above; nasals divided, broader than long, narrowly in contact; anterior prefrontals broadly in contact, the outer posterior corners prolonged backward; posterior prefrontals broken up into numerous small plates; two supraoculars, the posterior the larger; frontal region covered with irregular shields; parietals not distinguishable in size from the other scales on the occiput; first two supralabials in contact with nasal on the left, first three on the right side; loreal nearly twice as long as high, in contact with the second to fifth on left and third to seventh labials on right; two preoculars, the upper much the larger; 14 upper labials on left side, 15 on right, the eighth reaching the eye on both sides; 5 postoculars; temporals small, not distinguishable except by position from the surrounding scales; scales in 48 rows around the body; ventrals 278 ; anal entire; caudals 89.

Color (in alcohol): Top of head drab, becoming lighter on the upper lip; two indistinct dark parallel bands from the posterior border of each eye continuing backward onto the neck; body color buff, obscured by a series of seal-brown rhombs beginning at the occiput, 
separated by cross bands of the body color one scale in width, and having a central group of buff-colored scales; on the sides a very irregular series of darker spots; tail and posterior part of body dull clove brown with occasional scattered groups of light or dark scales; ventral surface pale olive-buff, the posterior borders white.

Remarks.-Steindachner's excellent figure of Epicrates versicolor is almost identical with some Haitian specimens. The length of the frontal, which Steindachner mentions as a possible distinguishing feature, is an exceedingly variable character in the genus. Steindachner himself was doubtful of the distinctness of his species and felt that intermediates might possibly be found between Epicrates

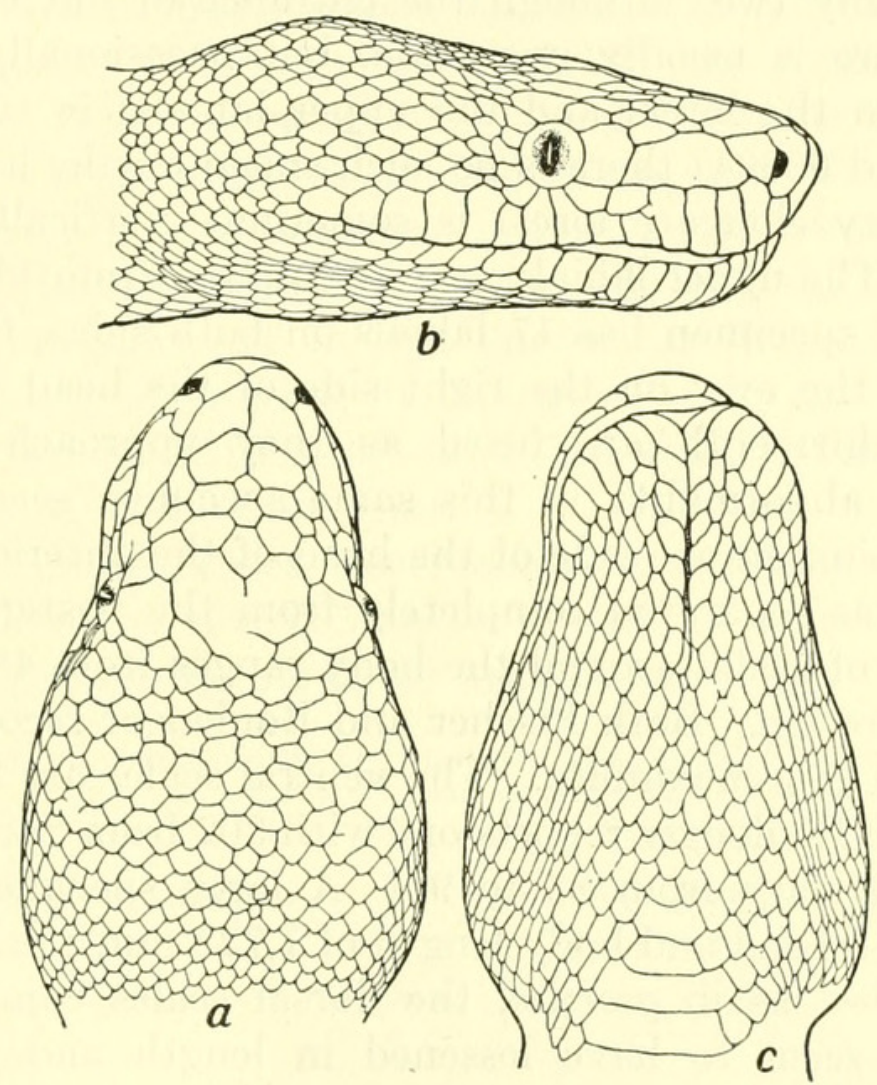

Figure 90.-Epicrates striatus striatus: $a$, Top of head; $b$, side of head; $c$, chin. U.S.N.M. No. 55044, from Samaná Peninsula, Dominican Republic. Natural size.

versicolor from "Columbia" and Epicrates striatus from the Antilles that would make it necessary to unite the two species. It is probable that his specimen did not come from Colombia at all, but might have been caught in New Providence or Haiti where it must have once been fairly abundant.

Variations. - Some of the head shields are rather variable in size and shape. The posterior prefrontals, for example, are large and relatively few in number in some of the specimens, while in others they are broken up into many scales, small and irregular in shape, but arranged rather symmetrically across the snout. The frontal plate assumes a great variety of shapes. Sometimes its outline is 
very irregular, owing to the dividing of small portions from it; again there may be a suture lengthwise down the middle, dividing the frontal into two even halves. The only scales that seem to have some permanence in shape and size in this series of specimens are the anterior prefrontals and the supraoculars; the anterior prefrontals are constant in the prolongation backward of their outer posterior borders, and the supraoculars are fairly constant in having a small anterior and a large posterior shield, although occasionally there is a single large supraocular or three small ones. The ring of ocular scales is incomplete in every specimen except No. 60604, where it is complete on the right side only. The number of upper labials entering the eye is usually two, although the entrance of but one is not infrequent. There is usually one scale, but occasionally two, intercalated between the loreal and the upper labials; in two specimens (Nos. 60603 and 60604) there is no such shield on the left side of the head. The very elongate loreal is sometimes vertically divided or semidivided. The upper labials vary in number from 14 to 16 . The Tortuga Island specimen has 17 labials on both sides, the ninth and tenth entering the eye; on the right side of the head the eleventh, twelfth, and thirteenth are fused as they approach the mouth. Another slight abnormality in this same specimen seems to be the horizontal division on one side of the head of the anterior part of the loreal, which has separated completely from the posterior part.

The number of scales around the body ranges from 48 to 60 in the specimens before me. Both Fischer and Boulenger record specimens having 63 rows as a maximum. The ventral scales are 272 to 295 in my series, while Boulenger reports one with 302 from Santo Domingo. The subcaudals vary from 85 to 90 . A large specimen, U.S.N.M. No. 84260 , has a head and body length of $1,723 \mathrm{~mm}$.; tail, $230 \mathrm{~mm}$.

In this species, as in gracilis, the dorsal scales compared to the ventral plates seem to have lessened in length and consequently increased in number, although not to so great an extent as in gracilis. In No. 55044, for example, at the center of the body I find 25 ventrals occupying the same amount of space as 35 to 40 dorsals, while in gracilis the proportion of ventrals to dorsals is quite regularly 1 to 2 . The increase takes place in the fourth to the eighth dorsal row in striatus.

The variation in color is not great, the pattern on the whole series remaining nearly as I have described it, with slight differences in intensities on different individuals.

Relationships.-Epicrates striatus seems to be readily distinguishable from others of the genus by the large numbers of scale rows around the body. The Cuban species, E. angulifer, is the only other known form approximating it in this respect. The presence of a complete ocular 
ring of scales, separating the eye from the upper labials, distinguishes angulifer from striatus readily enough.

Whether the New Providence snake is really identical with the Haitian one is a question that has been discussed by several authors. Cope described Homalochilus strigilatus from New Providence in 1862, partly on features of the head scalation, which have since proved to be entirely inconstant, and partly on coloration, the Haitian serpents supposedly not possessing the fairly continuous dark lateral band anteriorly, as did the New Providence ones. In a very young boa from New Providence (U.S.N.M. No. 36596) the lateral band is exceedingly conspicuous and distinct for over half the body length; in four young Haitian boas of about the same size (U.S.N.M. Nos. 9802, 66714,66715 , and 69432 ) the breaking up into spots begins on the neck - the first spot, somewhat more elongate than the rest, being the only reminder of the origin of the lateral stripe so relatively unbroken in the New Providence specimens. All the adults from both islands in the National Museum series at least coincide with the coloration of the respective young, except in one specimen, U.S.N.M. No. 12671, supposedly collected in Haiti by Younglove. In this specimen there is certainly a more distinct lateral stripe than appears in the other specimens known to be from Haiti.

Under the circumstances, nevertheless, it seems advisable to retain the subspecific name of strigilatus for the snakes from the Bahamas.

Specimens examined.-As listed in table 59.

TABLE 59.-Specimens of Epicrates striatus striatus examined

\begin{tabular}{|c|c|c|c|c|c|c|c|}
\hline Museum No. & Locality & Date & Collector & 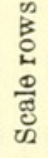 & 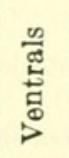 & 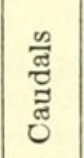 & 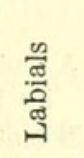 \\
\hline \multicolumn{8}{|l|}{ U.S.N.M. } \\
\hline 9801 . & Santo Domingo ...... & $1877 \ldots \ldots$. & C. A. Fraser ..... & 52 & 285 & 85 & $14-15$ \\
\hline $9802 \ldots$ & do do & $1877 \ldots$ & _. & 57 & 284 & $36+$ & $15-15$ \\
\hline $12405 \ldots$ & $\begin{array}{l}\text { Within } 25 \text { miles of Port- } \\
\text { au-Prince, Haiti. }\end{array}$ & 1866 & A. C. Younglove & 53 & 282 & 80 & $15-15$ \\
\hline $12470 \ldots$ & . . do do & $1866 \ldots$ & ......do.... & 59 & 285 & 89 & $15-15$ \\
\hline $12471 \ldots$ & do_nd & $1866 \ldots$ & ..... do_...... & 53 & 288 & 85 & $14-15$ \\
\hline $12472 \ldots$ & _. & $1866 \ldots$ & ..... do & 56 & 288 & 90 & $15-15$ \\
\hline $55044 \ldots$ & Samaná Peninsula, D. R. & $1916 \ldots$ & W. L. Abbott & 52 & 288 & $\ldots$. & $15-15$ \\
\hline $55045 \ldots$ & - do do & $1916 \ldots$ & do & 53 & 295 & $\ldots$ & $14-?$ \\
\hline $59080 \ldots$ & Haiti & (n) & C. Bencomo & $\cdots$ & $\ldots-$ & $\ldots$ & $15-15$ \\
\hline $59436 \ldots$ & Bombardopolis, Haiti_... & Mar. 28, 1917. & W. L. Abbott..... & 60 & -.... & 85 & $15-16$ \\
\hline $59437 \ldots$ & Tortue Island & Feb. 1, 1917_. & _... do_......... & 55 & 286 & $\cdots$ & $17-17$ \\
\hline $59918 \ldots$ & Port-au-Paix, Haiti...... & $\begin{array}{l}\text { Apr. } 16-17 \text {, } \\
\text { 1917. }\end{array}$ & ...................... & 57 & 285 & 88 & $14-14$ \\
\hline $59919 \ldots$ & ...... do & . do do........... & _.....do do......... & 55 & 282 & 87 & $14-15$ \\
\hline $60603 \ldots$ & Molène, Haiti....... & Jan. 28, 1918.. & _.... do & 51 & 279 & -... & $15-16$ \\
\hline $60604 \ldots$ & Les Basses, Haiti...... & Jan. $9,1918 \ldots$ & $\ldots$............ & 48 & 278 & 89 & $14-15$ \\
\hline $66714 \ldots$ & Guarabo, D. R & Nov. 22, 1923 & _... do do & 55 & 290 & 90 & $15-15$ \\
\hline 66715 & do & .....do do & _... do__.......... & 55 & 279 & 87 & $15-13$ \\
\hline $69432 \ldots$ & Thor, Haiti & Apr. 28,1925 . & W. A. Hoffman ... & 58 & 290 & 89 & $16-16$ \\
\hline
\end{tabular}


TABLE 59.-Specimens of Epicrates striatus striatus examined-Continued

\begin{tabular}{|c|c|c|c|c|c|c|c|}
\hline Museum No. & Locality & Date & Collector & 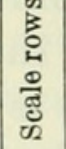 & 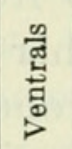 & 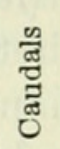 & 尝 \\
\hline 80864 & Íle à Vache, Haiti & 1930 & L. H. Parish and & 56 & 272 & 83 & $14-14$ \\
\hline M.C.Z. & Damien, Port-au-Prince & 1930 & do & 58 & 281 & 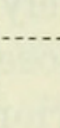 & $16-16$ \\
\hline $3601 \mathrm{a} \ldots$ & Jérémie, Haiti............. & & D. F. Weinland... & 53 & 284 & 91 & $15-15$ \\
\hline $3601 \mathrm{~b}$ & - do do & -... & do & 58 & 280 & 86 & $15-16$ \\
\hline $3601 c$ & do & n.t.n. & _. do & 54 & 287 & 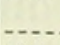 & $13-14$ \\
\hline 3609 & do & 1886 & do & 51 & 278 & 84 & $15-15$ \\
\hline $5643 \ldots \ldots . .$. & do & $1886 \ldots$ & 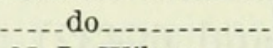 & 53 & 283 & $\ldots$ & $13-15$ \\
\hline $6289 \ldots \ldots$ & S. Domingo & June $2,1889 \ldots$ & N. L. Wilson & 54 & 293 & 74 & $15-14$ \\
\hline 8612 & Diquini, Haiti. & 1913 & W. M. Mann..... & 53 & 291 & ... & $16-15$ \\
\hline 8613 & Jacmel, Haiti. . . & 1913 & do do & 55 & 282 & 81 & $15-16$ \\
\hline $37598 \ldots$ & Cul-de-Sac, Haiti. ........ & (n) & A. Audant ......... & 55 & 284 & $\cdots$ & $15-16$ \\
\hline 43676 & Sosúa, D. R & 1937 & W. J. Clench & $\ldots$ & ..... & $\ldots$ & $\ldots$ \\
\hline $\begin{array}{c}\text { F.M.N.H. } \\
\text { F. }\end{array}$ & $\begin{array}{l}\text { Santa Barbara do Sam- } \\
\text { aná, D. R. }\end{array}$ & 1937 & do.................. & $\cdots$ & . & $\ldots$ & $-\ldots$. \\
\hline $6000(q) \ldots$ & Sánchez, D. R . & 1924 & E. Kaempfer...... & 51 & 294 & 83 & $15-15$ \\
\hline Brit. Mus. & Port-au-Prince, Haiti.... & Dec. $6,1928 \ldots$ & K. P. Schmidt .... & 59 & 289 & $\ldots$ & $14-13$ \\
\hline a & Santo Domingo . - & & Zool. Soc....... & 63 & 302 & 82 & \\
\hline b & - . do & -... & _..... do & 55 & 290 & 81 & -.... \\
\hline 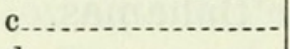 & - do & - n & do & 57 & 281 & 82 & - n \\
\hline d & ? & $\ldots . .$. & do & 61 & 288 & 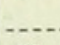 & -..... \\
\hline e.................... & ? & $\ldots$ & do_........ & 55 & 283 & 88 & $\ldots$ \\
\hline Hamburg Mus. & $?$ & & Hasler Hosp..... & 51 & 271 & 79 & - \\
\hline $\begin{array}{l}\text { A (cotype recorded } \\
\text { by Fischer). }\end{array}$ & St. Thomas... & & Slebohm & 57 & 290 & 66 & $\ldots . .$. \\
\hline $\begin{array}{l}\text { B (cotype recorded } \\
\text { by Fischer). }\end{array}$ & St. Domingo .. & & & 63 & 285 & 87 & ...... \\
\hline Wien Mus. & & & & & & & \\
\hline $\begin{array}{l}\text { Cotypes of } E \text {. versi- } \\
\text { color Steindachner. }\end{array}$ & "Columbia". . & & & 58 & 288 & & 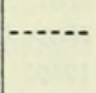 \\
\hline
\end{tabular}

EPICRATES INORNATUS FORDII (Günther)

Figure 91

1851. ?Chilabothrus inornatus DumérIL, Catalogue méthodique de la collection des reptiles (Mus. Paris), p. 220 (part) (young from Hatii) (not of Reinhardt).

1861. Pelophilus fordii GüNther, Proc. Zool. Soc. London, 1861, p. 142, pl. 23 (type locality "Western Africa," type in Brit. Mus.).-Chilabothrus f., JAN, Iconographie général des ophidiens, text, p. 87, 1865.-Epicrates fordii Boulenger, Catalogue of the snakes in the British Museum, vol. 1, p. 98, 1893 (San Domingo).-Z Zenneck, Zeitschr. Wiss. Zool., vol. 64, pp. 65, 152, 292, 348, pl. 3, figs. 55-57, pl. 7, figs. 212-213, 1898.-Stejneger, Rep. 
U. S. Nat. Mus. for 1902, pp. 691, 693, 1904; The batrachians and land reptiles of the Bahama Islands, Geogr. Soc. Baltimore, p. 335, 1905.-BARBour, Mem. Mus. Comp. Zool., vol. 44, p. 325, 1914; Zoologica, vol. 11, No. 4, p. 108, 1930.-Sснмidt, Field Mus. Nat. Hist., Zool. Ser., vol. 12, No. 12 , pp. 153-159, 1926.-Amaral, Mem. Inst. Butantan, vol. 4, p. 140, 1929 (part).-Stull, Bull. Antivenin Inst., vol. 5, No. 2, p. 40, 1931.Cochran, Occ. Pap. Boston Soc. Nat. Hist., vol. 8, p. 184, 1934.

1888. Chilabothrus maculatus Fischer, Jahrb. Hamburg Wiss. Anst., vol. 5, p. 33, pl. 3, fig. 7 (type localities, Cape Haytien and Gonaives, Hayti; collector, H. Rolle).

1935. Epicrates inornatus fordii Stull, Proc. Boston Soc. Nat. Hist., vol. 40, No. 8, p. 397.

1935. Epicrates fordii fordii Barbour, Zoologica, vol. 19, No. 3, p. 132; Bull. Mus. Comp. Zool., vol. 82, No. 2, p. 150, 1937.

Description.-U.S.N.M. No. 59085; Haiti; Celestino Bencomo, collector. Rostral a little broader than deep, tip visible from above; internasals as broad as long; three pairs of prefrontals, the first two pairs about equal, the third pair slightly larger and separated by a smaller interpolated scale; frontal as broad as long, twice as broad as the supraocular, showing a tendency to divide longitudinally, very uneven in its posterior margin; parietals exceedingly small, separated by the prolonged posterior border of the frontal; first supralabial in contact with anterior nasal, second with the two nasals and loreal; loreal divided into two on each side, on the right by a diagonal suture, on the left by a perpendicular suture; 13 supralabials; a large preocular with a subpreocular consisting of the detached upper third of the sixth supralabial; the upper part of the fifth supralabial also detached on the right side of the head; sixth and seventh labials (eighth also on left side of head) entering the eye; five and six postoculars on left and right sides respectively; temporal scales small, not so large as those on the side of the body; 33 scale rows; 246 ventrals; anal entire; 78 subcaudals, entire.

Color (in alcohol): Head and body fawn color; a dark russet streak along the top of the upper labials to corner of mouth; above this a light streak beginning at the nostril passing through the eye and extending diagonally downward; labials white; occipital region russet, indistinctly marked with gray; a double dorsal series of squarish brown spots edged with black, usually confluent across the back, extending from the neck to the tip of the tail where they become much smaller, their number 63 and 65 on the left and right sides, respectively; a single series of much smaller and more numerous spots on each side of the body extending from the fourth to the seventh or eighth scale-row, disappearing on the tail; ventrals a little lighter in color than dorsals; the anterior part of each scale darker.

Dimensions.-Total length, $740 \mathrm{~mm}$; tail, $130 \mathrm{~mm}$.

Relationships.-The pattern on the top of the head in No. 59085 is 
very similar to Zenneck's plate 3 , figure $57 .{ }^{13}$ Zenneck's three specimens of fordii had the interpolated scale between the posterior prefrontals, Fischer's Chilabothrus maculatus had it, and my specimen and that in the Museum of Comparative Zoology have it also; therefore it seems to be a constant character of this very rare species.

Epicrates fordii belongs to that group of the genus having the fewest number of scale rows around the body. The reduced size of the supraocular plate in relation to the frontal sets apart the two Hispaniolan species fordii and gracilis from the Puerto Rican inornatus. A direct comparison of the two species fordii and gracilis brings the conviction that they are related closely but that they are now entirely distinct species. The snout of gracilis is much broader and the rostral shield is correspondingly considerably wider in proportion to its
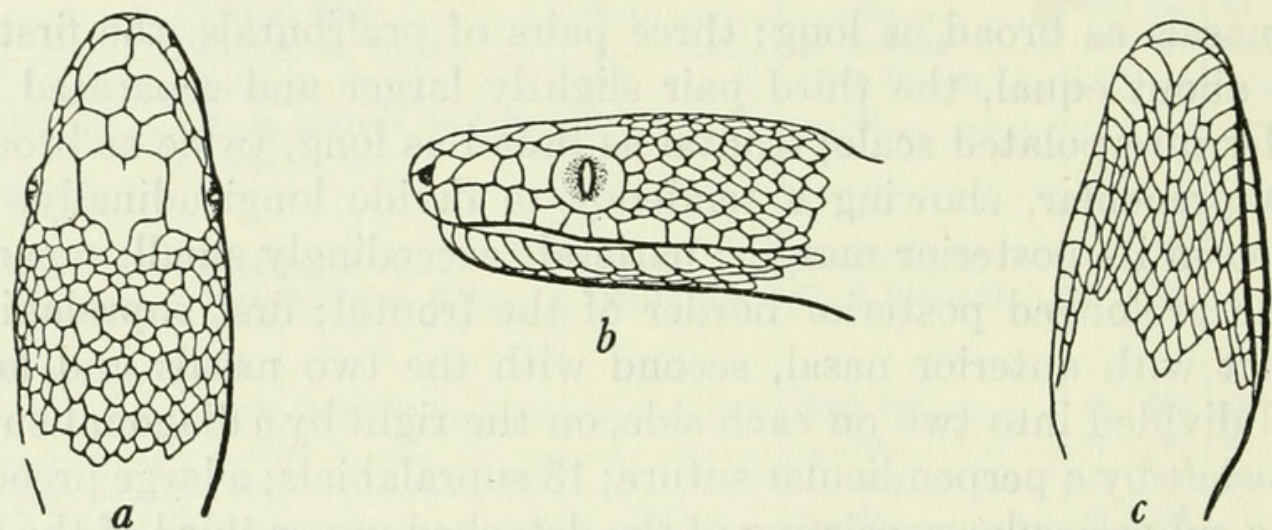

FIGURE 91.-Epicrates inornatus fordii: $a$, Top of head; $b$, side of head; $c$, chin. U.S.N.M. No. 59085, from Haiti. Twice natural size.

height than in fordii. Furthermore, gracilis has but one large plate in the loreal region, while fordii has 2 to 4 small ones. The occipital region in gracilis is covered with larger and more irregularly shaped scales than in fordii, where they are smaller and more evenly broken up. Additional specimens may, of course, bring exceptions to these last two points, but, even so, the shape of the rostral and the generally lower scale count in fordii should easily distinguish the two species.

Variations.-Aside from the three specimens in the U. S. National Museum, only nine other specimens are known-the three in the British Museum, the three cotypes of Chilabothrus maculatus in Hamburg, and three in the Museum of Comparative Zoology. These 12 specimens show a variation of 33 to 37 in number of scale rows around the body, 244 to 261 in ventrals, and 70 to 81 in caudals. The number of upper labials is 12 to 14 , and the dorsal spots are between 61 and 76 , the count usually varying by several points on the right or the left side, owing to unequal fusion of the spots.

Specimens examined.-As listed in table 60.

${ }^{13}$ Zeitschr. Wiss. Zool., vol. 64, 1898. 
TABLE 60.-Specimens of Epicrates inornatus fordii examined

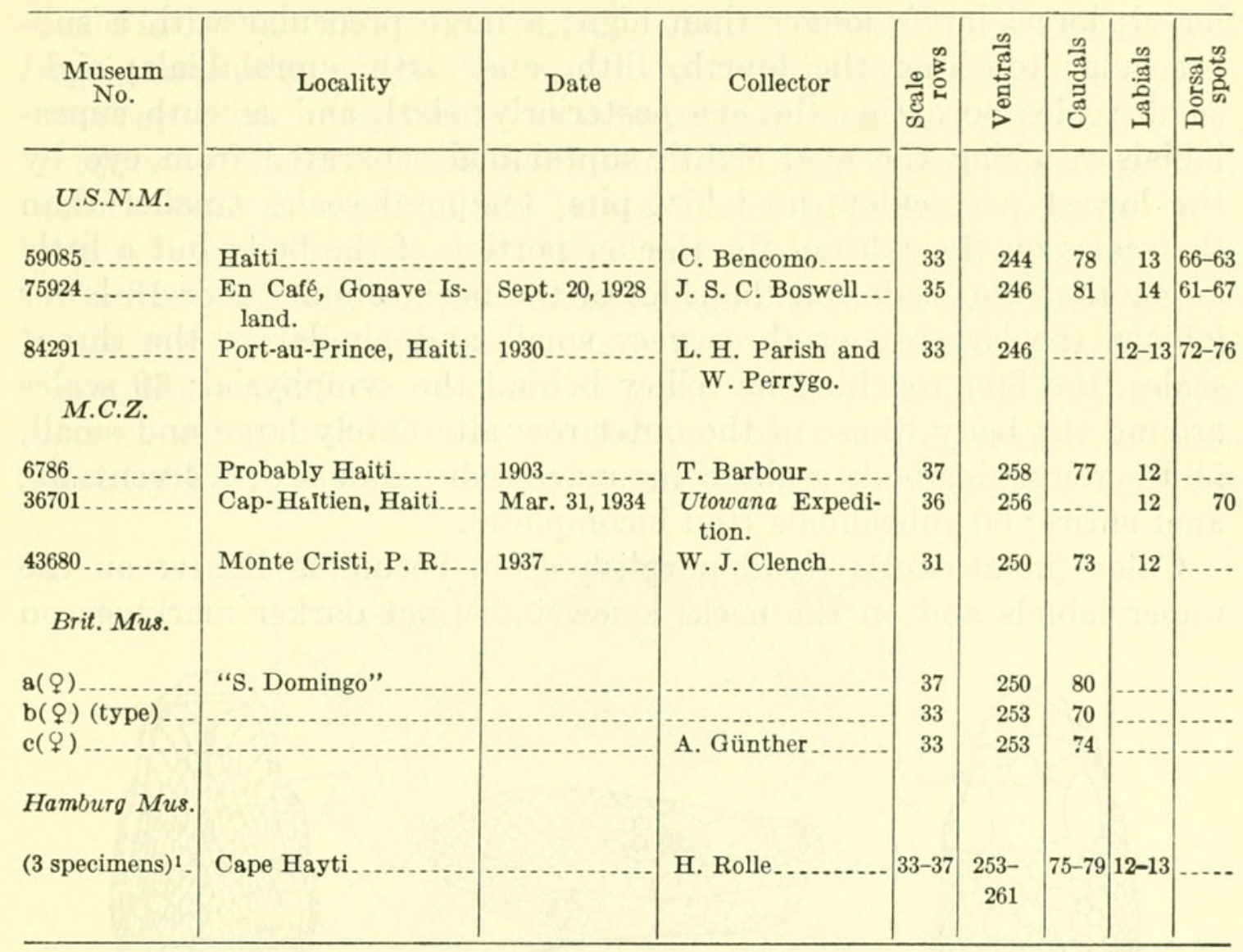

1 Types of Chilabothrus maculatus; largest, $780 \mathrm{~mm}$. in total length; tail, $130 \mathrm{~mm}$.

\section{EPICRATES GRACILIS GRACILIS (Fischer)}

Figure 92,93

1888. Chilabothrus gracilis Fischer, Jahrb. Hamburg Wiss. Anst., vol. 5 (for 1887), p. 35, pl. 3, fig. 8 (type locality, Cape Haytien, Hayti; collector, H. Rolle).-Epicrates g. Boulenger, Catalogue of the snakes in the British Museum, vol. 1, p. 98, 1893.-ZENNECK, Zeitschr. Wiss. Zool., vol. 64, pp. 64, 348, 1898.-BArbour, Mem. Mus. Comp. Zool., vol. 44, No. 2, p. 326, 1914; Zoologica, vol. 11, No. 4, p. 108, 1930; vol. 19, No. 3, p. 132, 1935; Bull. Mus. Comp. Zool., vol. 82, No. 2, p. 132, 1937.-Cochran, Proc. U. S. Nat. Mus., vol. 66, art. 6, p. 12, 1924.-Amaral, Mem. Inst. Butantan, vol. 4, p. 140, 1929.

1935. Epicrates gracilis gracilis Stull, Proc. Boston Soc. Nat. Hist., vol. 40, No. 8, p. 397.

Description.-U.S.N.M. No. 55025; Rojo Cabo, Samaná Peninsula, Santo Domingo; August 29, 1916; Dr. W. L. Abbott, collector. Rostral a little broader than high, tip just visible from above; internasals about two-thirds as long as first pair of prefrontals; anterior pair of prefrontals large; the next pair much shorter, with a very small scale between them; a transverse series of five irregular polygonal scales between the frontal and the second pair of prefrontals; frontal nearly as broad as long, twice as broad as the supraoculars; parietals narrowly in contact, small and uneven in outline; 13 supralabials, the last 
very small, the first in contact with nasal, the second with nasal and loreal; loreal large, longer than high; a large preocular with a subpreocular touching the fourth, fifth, and sixth supralabials; eight small scales bordering the eye posteriorly; sixth and seventh supralabials reaching the eye; eighth supralabial separated from eye by the lowest postocular; no labial pits; temporal scales smaller than the scales on the sides of the thicker portion of the body but a little larger than the scales on the sides of the neck; about 12 or 13 lower labials, the last two or three very small and similar to the throat scales, the first touching its fellow behind the symphysial; 39 scales around the body, those of the outer row alternately large and small, all the remaining body scales being much reduced in size; 274 ventrals; anal entire; 60 subcaudals (tail incomplete).

Color (in alcohol): Head purplish drab, becoming lighter on the upper labials and on the neck; a few indistinct darker markings on
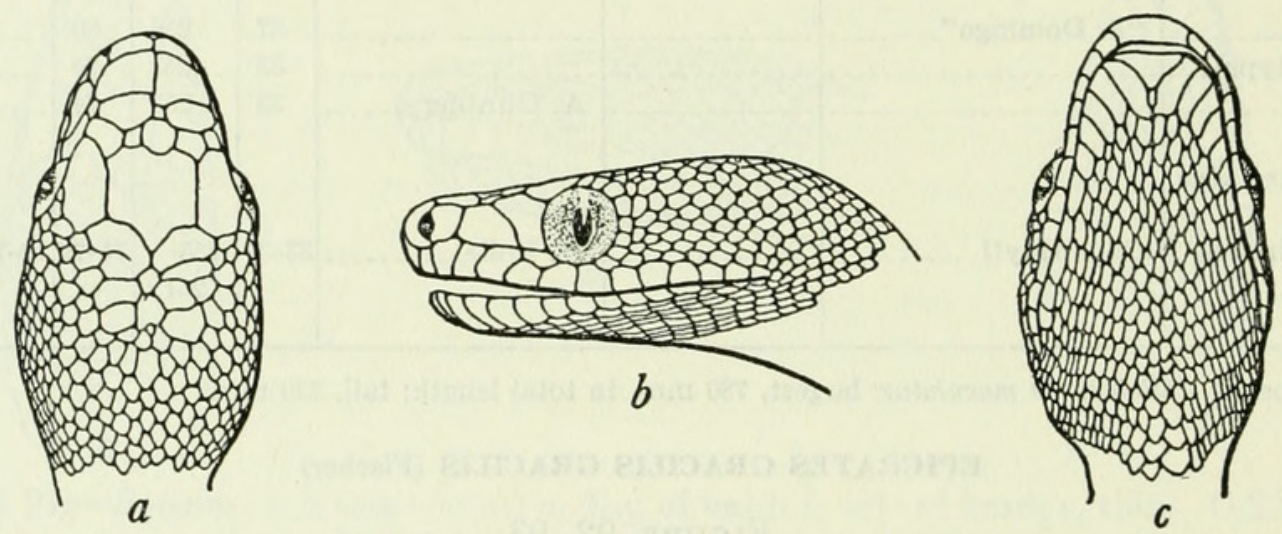

Figure 92.-Epicrates gracilis gracilis: $a$, Top of head; $b$, side of head; $c$, chin. U.S.N.M.

No. 55025, from Rojo Cabo, Samaná, Dominican Republic. Twice natural size.

the temporal region and on the occiput; body fawn color, with a series of about 70 roundish black spots about five scales long on each side of the middorsal line. Each spot separated from the preceding one by a light interspace about three scales in length; saddlelike blotches often formed across the back by confluent spots of the two series; on each side of the body two lateral series of smaller black spots, the smaller series which is fairly regular in shape occupying the first and second scale rows; the inner and larger series very irregular, but usually on the fourth to the eleventh rows and sometimes anastomosing with the outer series; tail much like the body in color pattern, except that the median series of spots are much smaller and closer together, and the lateral series of spots are scarcely distinct; throat pale buff beneath; ventral surface light anteriorly, becoming more and more suffused with pale gray mottlings posteriorly until only the edge of each ventral and caudal scale remains light; a few dark spots scattered irregularly near the ends of the ventrals and on the caudals. 
A second specimen in our collection (No. 66713) has a very similar scale formula. In coloration, however, this snake is markedly different, as shedding of the skin was about to take place when the serpent was captured. The whole body (in alcohol) is a beautiful pale bluish gray, with the saddlelike blotches a very little darker than the body color. Only a trace of the lateral series of spots is visible. The ventral surface is very pale bluish, the chin and throat cream-colored. In both specimens the alternating large and small scales in the first scale row are very noticeable (see the accompanying figure), while from the second row onward a great diminution in length with a corresponding increase in number of body scales seems to have taken place. Though in most nonconstricting snakes and boas the

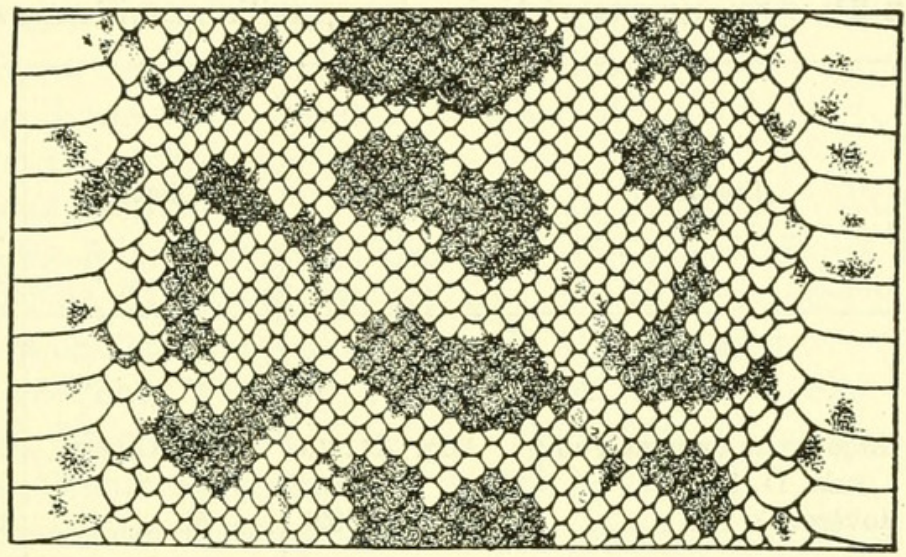

Figure 93.-Dorsal pattern of Epicrates gracilis gracilis, same specimen as shown in fig. 92.

dorsal scales are equal in length and therefore equal numerically to the ventral plates, in this species there are twice as many dorsals in a given length as there are ventrals. A similar but much less frequent diminution of dorsal scales may be noted in $E$. striatus although the scalation in that species is not so symmetrical and there are no alternating small scales in the first scale row. In the drawing of the type of E. gracilis this unusual scalation was indicated.

Dimensions: Total length of No. 55025, $700 \mathrm{~mm}$.; tail (defective), $100 \mathrm{~mm}$. Total length of No. 66713, $890 \mathrm{~mm}$; tail, $150 \mathrm{~mm}$.

Variations.-The only other known specimens of this exceedingly rare snake are the types described by Fischer, one of which was figured in his original description, and three in the Museum of Comparative Zoology. The specimens in the National Museum agree very well with Fischer's figure, although some small differences may be noted.

In the figure of the type, and also in No. 66713, three scales in a transverse row separate the frontal from the second pair of prefrontals, while in No. 55025 there are five scales making the separation. The second pair of prefrontals is separated from the loreal and preocular 
by a small scale in the original figure; in No. 55025 this small scale is absent on one side of the head, and the loreal and preocular touch the second prefrontal; in No. 66713 the small scale is absent on both sides of the head. In the figure, a number of large irregular scales are shown behind the parietals. These large plates, in No. 55025, seem more regularly arranged as a series of three pairs following the parietals and separated by a median row of scales, while No. 66713 resembles the type in that there are no regularly arranged scales on the occipital region.

Relationships.-Its affinity to Epicrates fordii has been discussed under relationships of that species.

Specimens examined.-As listed in table 61.

TABLE 61.-Specimens of Epicrates gracilis gracilis examined

\begin{tabular}{|c|c|c|c|c|c|c|c|}
\hline Museum No. & Locality & Date & Collector & 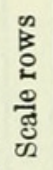 & 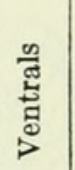 & 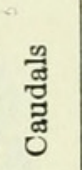 & 超 \\
\hline U.S.N.M. & \multirow{3}{*}{$\begin{array}{l}\text { Rojo Cabo, Samaná Penin- } \\
\text { sula, D. R. } \\
\text { Jovéro, D. R. }\end{array}$} & \multirow{3}{*}{$\begin{array}{l}\text { Aug. } 29,1916 \\
\text { Nov. } 29,1923\end{array}$} & \multirow{3}{*}{$\begin{array}{l}\text { W. L. Abbott... } \\
\text { do }\end{array}$} & \multirow{3}{*}{$\begin{array}{l}39 \\
39\end{array}$} & \multirow{3}{*}{$\begin{array}{l}274 \\
279\end{array}$} & \multirow{3}{*}{$\begin{array}{l}60+ \\
93\end{array}$} & \multirow{3}{*}{$\begin{array}{l}13 \\
13\end{array}$} \\
\hline $\begin{array}{l}55025 \ldots \\
66713 \ldots\end{array}$ & & & & & & & \\
\hline $\begin{array}{r}\text { M.C.Z. } \\
5135\end{array}$ & & & & & & & \\
\hline $\begin{array}{l}43655 \\
43687\end{array}$ & $\begin{array}{l}\text { Sosúa, D. R } \\
\text { Santa Barbara do Samaná, }\end{array}$ & $\begin{array}{l}1937 \\
1937 \ldots \ldots\end{array}$ & $\begin{array}{l}\text { W. J. Clench... } \\
\text { do }\end{array}$ & $\begin{array}{l}38 \\
42\end{array}$ & $\begin{array}{l}285 \\
274\end{array}$ & $\begin{array}{c}75+ \\
102\end{array}$ & $\begin{array}{r}12-13 \\
13\end{array}$ \\
\hline & & & & & & & \\
\hline a (cotype) & "Cape Hayti"- - & & H. Rolle & 40 & 282 & 100 & 11 \\
\hline b (cotype) . - & do & & -_do & 40 & 289 & 103 & 12 \\
\hline
\end{tabular}

\section{Genus TROPIDOPHIS Bibron}

1840. Tropidophis Bibron, in de la Sagra's Historia fisica, politica y natural de la isla de Cuba, vol. 4, Reptiles, p. 124; French ed., p. 208 (type, Boa melanura).

1841. Leionotus Bibron, ibid., p. 127; French ed., p. 212 (type, L. maculatus) (not of Kirby, 1837).

1842. Ungalia Gray, Zool. Misc., 1842, p. 46 (type, Boa melanura).

1843. Erycopsis Fitzinger, Systema reptilium, p. 27 (type, Boa melanura).

1856. Notophis Hallowell, Proc. Acad. Nat. Sci. Philadelphia, 1856, p. 156 (type, $N$. bicarinatus $=$ Boa melanura).

1864. Lionotus Peters, Monatsb. Berlin Akad. Wiss., 1864, p. 388 (emend.).

1868. Ungualia Cope, Proc. Acad. Nat. Sci. Philadelphia, 1868, p. 101 (emend.).

Although the neighboring island of Cuba harbors five living representatives belonging to both of the larger groups of this genus, a single species of Tropidophis is recognized on the island of Hispaniola. 


\section{TROPIDOPHIS MACULATUS HAETIANUS (Cope)}

Figures 94-96

1864. Tropidophis maculatus JAN, Iconographie générale des ophidiens, livr. 5, pl. 2, fig. 1, text p. 75 (San Domingo, Mus. Hamburg).-Barbour and Ramsden, Mem. Mus. Comp. Zool., vol. 47, No. 2, p. 91, 1919 (part) (Cuba, also Jamaica, Haiti, Navassa).-T. maculata Barbour, Mem. Mus. Comp. Zool., vol. 44, No. 2, p. 328, 1914 (part) (Cuba, Jamaica, Haiti, Navassa).-Schmidt, Bull. Amer. Mus. Nat. Hist., vol. 44, p. 19, 1921 (Sanchez, Santo Domingo).-Ungalia maculata Bodlenger, Catalogue of the snakes in the British Museum, vol. 1, p. 112, 1893 (part) (Cuba, San Domingo, Jamaica).-Meerwarth, Mitth. Mus. Hamburg, vol. 18, pt. 2, p. 8, 1901 (San Domingo).-Amaral, Mem. Inst. Butantan, vol. 4, p. 143, 1929.

1879. Ungualia haetiana Cope, Proc. Amer. Philos. Soc., vol. 18, p. 273 (type locality, Puerto Plata, Haiti); Proc. Acad. Nat. Sci. Philadelphia, 1894, p. 436.-Garman, Proc. Amer. Philos. Soc., vol. 24, p. 279, 1887 (Haiti).-Tropidophis haetiana Stejneger, in Shattuck, The Bahama Islands, p. 336, 1905.T. haetianus Stejneger, Proc. U. S. Nat. Mus., vol. 53, p. 280, 1917 (Santo Domingo and Haiti).

1888. Tropidophis conjunctus Fischer, Jahrb. Hamburg Wiss. Anst., vol. 5, p. 31, pl. 3, fig. 5 (type locality, Cape Haytien, Hayti; Rolle, coll.)-Cochran, Proc. U. S. Nat. Mus., vol. 66, art. 6, p. 12, 1924.-Ungalia conjuncta BoulENGER, Catalogue of the snakes in the British Museum, vol. 1, p. 113, 1893.Zenneck, Zeitschr. Wiss. Zool., vol. 64, pp. 96, 357, 1898.-Werner, Arch. Naturg., vol. 87, sect. A, pt. 7, p. 250, 1921.-Tropidophis conjuncta BARBOUR, Mem. Mus. Comp. Zool., vol. 44, p. 329, 1914.

1921. Ungalia maculata Werner, Arch. Naturg., vol. 87, sect. A, pt. 7, p. 249 (part).

1924. Tropidophis maculata haetiana Cochran, Proc. U. S. Nat. Mus., vol. 66, art. 6, p. 12 (Santo Domingo).

1928. Tropidophis maculatus haetianus Strul, Occ. Pap. Mus. Zool. Univ. Mich., No. 195, p. 14; Bull. Antivenin Inst., vol. 5, No. 2, p. 40, 1931; Proc. Boston Soc. Nat. Hist., vol. 40, No. 8, p. 401, 1935.-BARBour, Zoologica, vol. 11, No. 4, p. 109, 1930; vol. 19, No. 3, p. 133, 1935; Bull. Mus. Comp. Zool., vol. 82, No. 2, p. 152, 1937.-Cochran, Occ. Pap. Boston Soc. Nat. Hist., vol. 8, p. 184, 1934.-Böker, Publ. Inst. Cient. Domínico-Alemán, vol. 1, p. 18, 1939.

Description of the type.-Adult, U.S.N.M. No. 10164, collected at Port-au-Prince, Haiti, by Dr. J. J. Brown. Head not very distinct from neck; rostral broader than deep, well visible from above; internasals longer than broad; two pairs of prefrontals, the first much the larger; frontal a little longer than its distance from the rostral, one and one-half times the width of the supraocular; parietals large, prominent, regular in outline, a little shorter than the frontal; no interparietal; one preocular and three postoculars; 10 upper labials, the tenth small, the fourth and fifth entering the eye on the right side of the head, the fifth excluded by a postocular on the left side; only the labials in front of the orbit higher than long; 12 lower labials, the first separated from its fellow by the symphysial, which is divided; first pair of chin shields longer than the second; about five pairs of 
scales following these before the gastrosteges; scale rows 29 , smooth, some of the vertebrals enlarged just anterior to the tail; ventrals 189 ; anal entire; subcaudals 34 , single.

Dimensions: Head and body, $620 \mathrm{~mm}$.; tail, $74 \mathrm{~mm}$.

Color in (alcohol): Head markings much faded in this specimen; ground color of head and body ochraceous-buff, the under surface slightly paler; a very distinct dark blotch on the edge of the mouth extending from the second to the fourth upper labial; four rows of maroon spots on each side of the body, the inner series the largest and darkest; down each side of the ventral plates a row of dark blotches two or three scales long usually confluent with the first series of lateral spots, extending nearly to the middle of the belly, sometimes alternating and sometimes opposite, with the interspaces

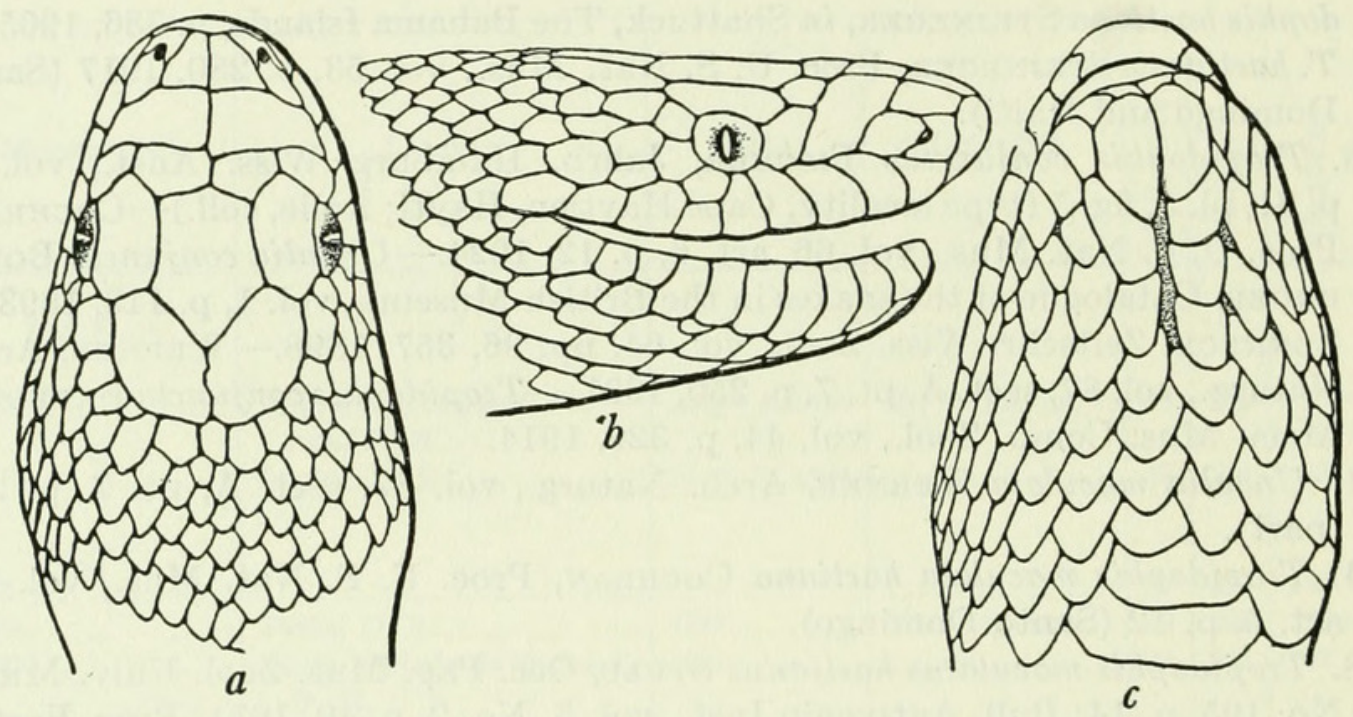

Figure 94.-Tropidophis maculatus haetianus: $a$, Top of head; $b$, side of head; $c$, chin.

U.S.N.M. No. 10164, type, from Port-au-Prince, Haiti. Two-thirds natural size.

of light ground color between the blotches giving the whole ventral surface a checkerboard appearance. Toward the tail only the middle pair of dorsal blotches and the ventral blotches persist.

In a less faded specimen (No. 64910) the head shows the following pattern: Top of snout uniform dark slate color, bordered by a narrow black line from in front of the eye to the internasals; rostral, nasals, and upper labials abruptly pale; an elongate dark spot on the edge of the mouth extending from the second to the fourth upper labial; a dark postocular streak fading to gray above and ending just behind the corner of the mouth; a light crescentic mark on the upper temporal region; the occipital region dark slate color. In this specimen, as in some of the others, the dark ventral blotches extend over one and a half to two ventral plates, so that there is a little less of the dark color in proportion to the light interspace. This diminution of dark pigment is in no way comparable to the occurrence of small 
patches of black dots, which characterizes the melanura group. In all my specimens the eight rows of spots on the body are present, as is also the case with two Cuban snakes (Nos. 56328 and 27455).

Variations.-The type specimen is so far exceptional in having 29 rows of scales at midbody. As in so many other instances, the lack of sufficient material limits our knowledge as to the true extremes of variation. In Barbour and Ramsden's Herpetology of Cuba, they say concerning the validity of the form haetiana of Cope that "its peculiar character was supposed to be due to the presence of an interparietal ..." This is a slip, for the absence of an interparietal was one of the characters selected by Cope as a means of distinguishing his

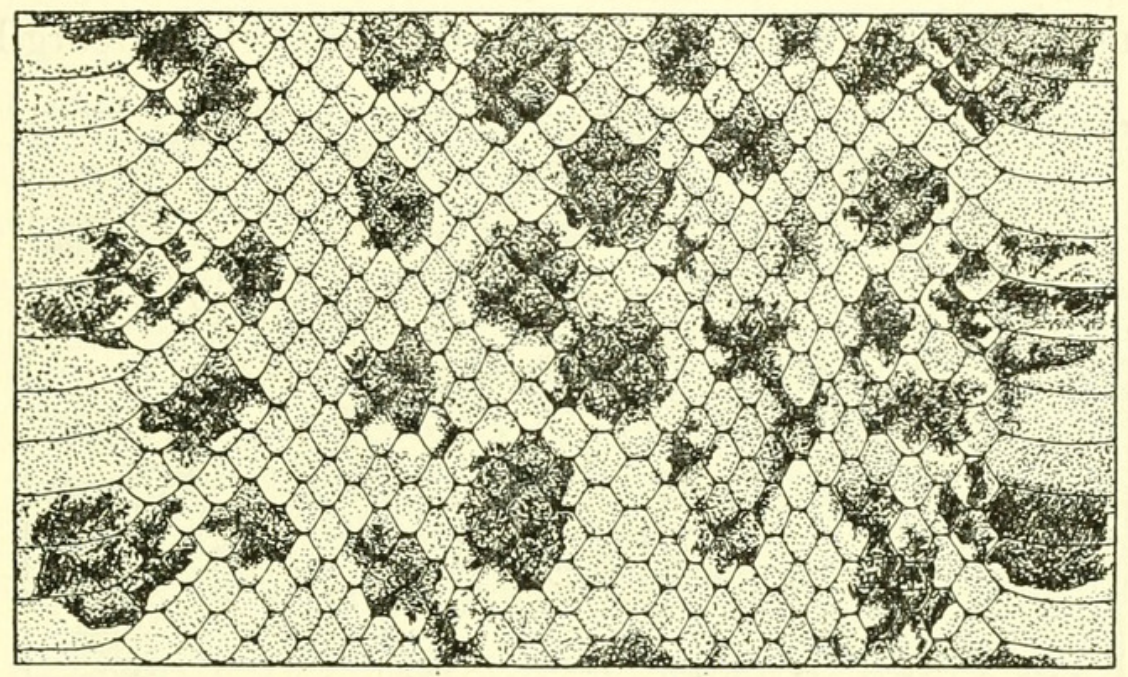

Figure 95.-Dorsal pattern of Tropidophis maculatus haetianus, same specimen as shown in fig. 94.

species haetiana, as the original description reads "parietals in contact medially," and no mention of an interparietal is made. A few of the Hispaniolan specimens (U.S.N.M. Nos. 35980, 64910, 70459, and M.C.Z. No. 8739a) have an interparietal, in all cases a very small one, which does not prevent the parietals from being in contact medially in their anterior portion. Jan's figure ${ }^{14}$ shows a specimen with two small interparietals completely separating the parietals, the specimen, he states, having been collected in Santo Domingo. The Cuban and Jamaican specimens, on the other hand, have one or two interparietals, usually large and separating the parietals entirely. In one snake from Habana, No. 56328, the parietals are in contact anteriorly.

The enlargement of the vertebral scales occurs very irregularly in the species under consideration. In most of the specimens I have seen there is a series of a dozen or more conspicuously enlarged scales on the back a short distance anterior to the vent. Some of the

14 Iconographie générale des ophidiens, livr. 5, pl. 2, fig. 1, 1864. 
snakes have only a few such scales that may truly be called enlarged. One snake (U.S.N.M. No. 55046) has the scales greatly enlarged from the tail to the neck region, and for years this single specimen was here regarded as an example of Tropidophis conjunctus Fischer. The figure of the type of Tropidophis conjunctus is similar to No. 55046 in all essentials, except that there is a single pair of large prefrontals in the type, while in No. 55046 there are two pairs, the posterior being about the size of the internasals. The same indefinite merging of the last few upper labials with the scales of the neck is to be noted in both. The type has 25 scale rows, 188 ventrals, 40 subcaudals, and $10-11$ supralabials.

My inquiry as to this specimen addressed to the museum in Hamburg brought forth the following information from Herr Georg Dunker,

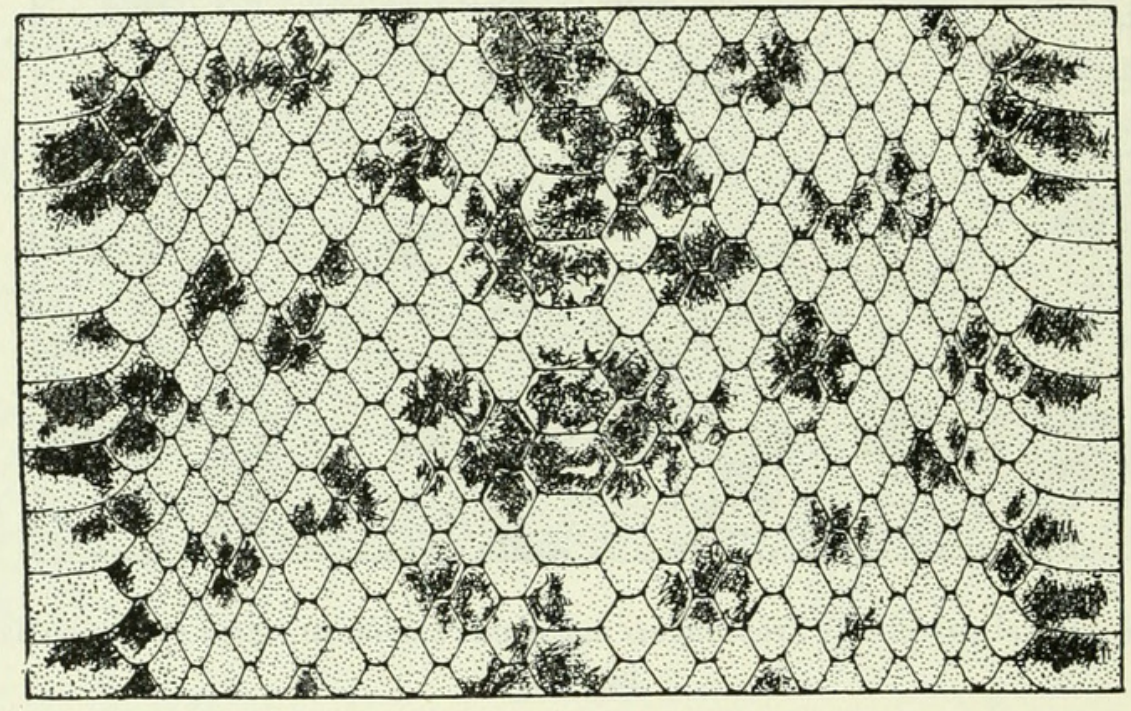

FIGURE 96.-Dorsal pattern and extreme enlargement of posterior vertebral scales of

Tropidophis maculatus haetianus. U.S.N.M. No. 55046, from Cape Samaná, Dominican Republic.

curator of reptiles and amphibians, under date of June 26, 1929: "For his paper of 1887, Dr. Fischer has used a collection of reptiles from Haiti, which belonged to a firm of dealers in natural-history objects, Linnaea-Berlin, and has returned the collection to this firm after having worked it through. It is not known to whom the Linnaea has sold this collection, but I am sure that it has not been sold to our Museum. Therefore Tropidophis conjuncta is not represented in our collection." In Dresden I saw a record of an Ungalia maculata (D. 928, 1507) bought from Linnaea in 1890 and identified as maculata by Dr. O. Boettger. Can this specimen possibly be the lost type of conjuncta?

Specimens examined.-As listed in table 62. 
TABLE 62.-Specimens of Tropidophis maculatus haetianus examined

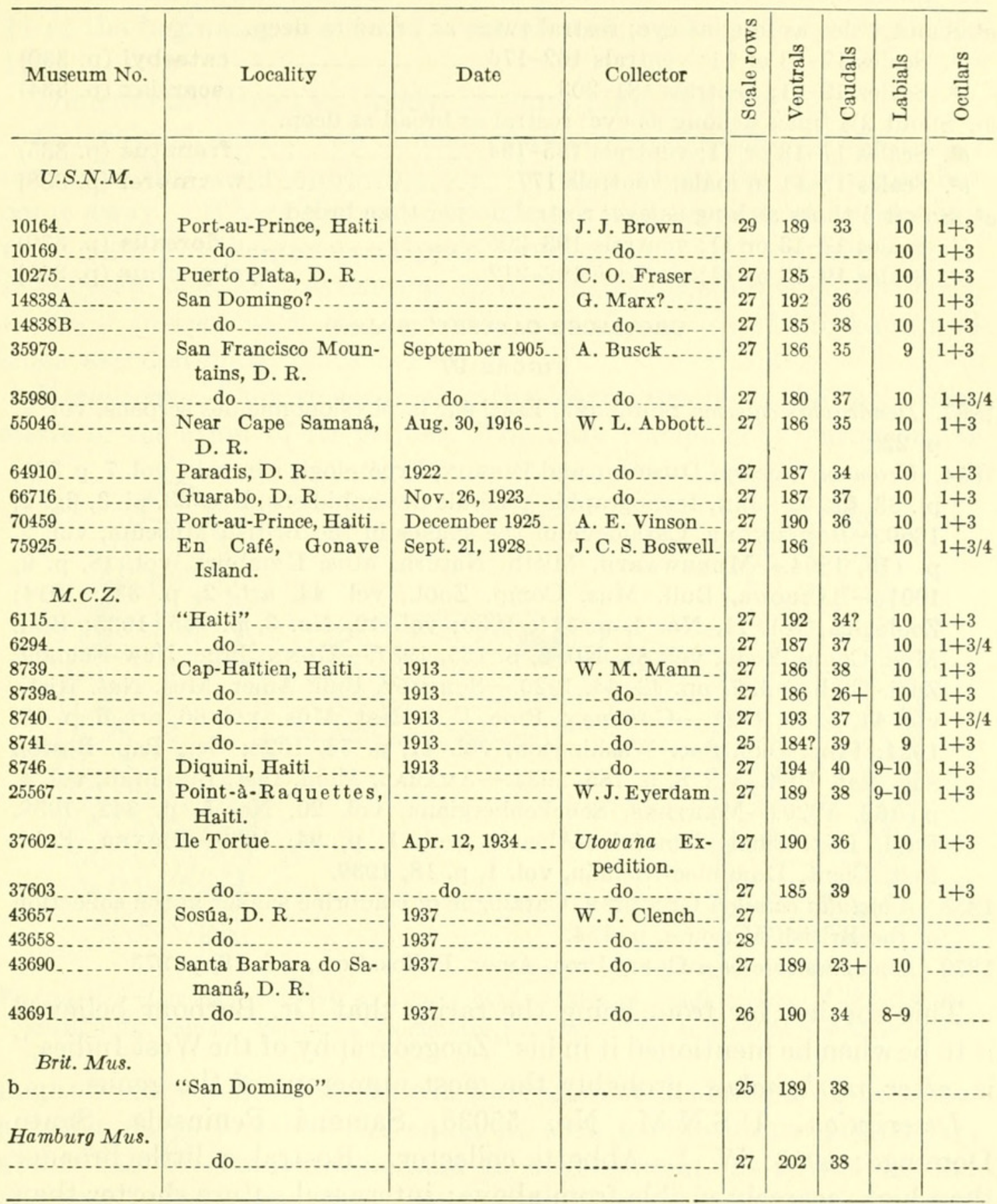

Family COLUBRIDAE

\section{Genus UROMACER Duméril and Bibron}

1837. Dendrophis Schlegel, Essai sur la physionomie des serpens, vol. 2, p. 220. 1853. Uromacer Duméril and Bibron, Mém. Acad. Sci. France, vol. 23, p. 478; Erpétologie générale, vol. 7, p. 719, 1854.-J JN, Elenco sistematico degli Ofidi . . ., p. 87, 1863.-Barbour, Mem. Mus. Comp. Zool., vol. 44, art. 2, p. 331, 1914.-DunN, Proc. New England Zool. Club, vol. 7, p. 42, 1920.

1858. Ahaetulla GüNther, Catalogue of colubrine snakes in the collection of the British Museum, p. 151 (part).

1869. Megalocercus Dumé Ril, Arch. Mus. Hist. Nat. Paris, vol. 10, p. 202 (type, U. catesbyi).

1900. Neomacer Cope, Rep. U. S. Nat. Mus. for 1898, p. 734 (misprint). $226849-41-22$ 


\section{KEY TO THE SPECIES OF UROMACER}

$a^{1}$ Snout twice as long as eye; rostral twice as broad as deep.

$b^{1}$. Scales $17-13$ or 11 ; ventrals $162-176 \ldots \ldots$.

$b^{2}$. Scales 19-11; ventrals 181-203_................ scandax (p. 334)

$a^{2}$. Snout $2 \frac{1}{2}$ times as long as eye; rostral as broad as deep.

$b^{1}$. Scales $17-13$ or 11 ; ventrals $185-194 \ldots \ldots$ frenatus (p. 335)

$b^{2}$. Scales $17-11$ in male; ventrals $177 \ldots \ldots$. 338 )

$a^{3}$. Snout 3 times as long as eye; rostral deeper than broad.

$b^{1}$. Scales 17-13 or 11; ventrals 193-205_._._.

$b^{2}$. Scales $19-13$ or 11 ; ventrals 192-212_.......... oxyrhynchus (p. 341)

\section{UROMACER CATESBYI (Schlegel)}

\section{FIGURE 97}

1837. Dendrophis catesbyi Schlegel, Essai sur la physionomie des serpens, vol. 2, p. 226.

1854. Uromacer catesbyi Duméril and Bibron, Erpétologie générale, vol. 7, p. 721, pl. 83, fig. 2.-J -JN, Iconographie générale des ophidiens, livr. 33, pl. 3, fig. 2, 1869.-Boulenger, Catalogue of the snakes in the British Museum, vol. 2, p. 115, 1894.-Meerwarth, Mitth. Naturh. Mus. Hamburg, vol. 18, p. 9, 1901.-Barbour, Bull. Mus. Comp. Zoöl., vol. 44, art. 2, p. 331, 1914; Zoologica, vol. 11, No. 4, p. 111, 1930; vol. 19, No. 3, p. 135, 1935; Bull. Mus. Comp. Zool., vol. 82, No. 2, p. 155, 1937.-Duns, Proc. New England Zool. Club, vol. 7, pp. 42, 44, 1920.-Sснмidт, Bull. Amer. Mus. Nat. Hist., vol. 44, p. 19, 1921.-Cochran, Proc. U. S. Nat. Mus., vol. 66, art. 6, p. 13, 1924; Proc. Biol. Soc. Washington, vol. 41, p. 54, 1928; Occ. Pap. Boston Soc. Nat. Hist., vol. 8, p. 185, 1934.-Amaral, Mem. Inst. Butantan, vol. 4, p. 162, 1929.-Mertens, Senckenbergiana, vol. 20, No. 5, p. 342, 1938. Publ. Inst. Cient. Domínico-Alemán, vol. 1, p. 94, 1939.-Böker, Publ. Inst. Cient. Domínico-Alemán, vol. 1, p. 18, 1939.

1858. Ahaetulla catesbyi GüNTher, Catalogue of colubrine snakes in the collection of the British Museum, p. 154.

1879. Leptophis catesbeyi Cope, Proc. Amer. Philos. Soc., vol. 18, p. 273.

This species, far from being the rarity that Dr. Barbour believed it to be when he mentioned it in his "Zoogeography of the West Indies," is, after oxyrhynchus, probably the most numerous of the genus.

Description.-U.S.N.M. No. 55036, Samaná Peninsula, Santo Domingo; 1916; W. L. Abbott, collector. Rostral a little broader than high, scarcely visible from above; internasal suture shorter than the prefrontal suture; frontal as long as its distance from the rostral, shorter than the parietals, widely separated from the preocular; supraocular about as wide as frontal; diameter of eye one-half the length of the snout; nasal semidivided, longer than its distance from the eye; loreal small, a little broader than high; one large preocular; two postoculars, the upper much the larger; temporals $1+1$ on the right side, $1+2$ on the left; eight supralabials, second in contact with nasal, prefrontal and loreal; third, fourth, and fifth supralabials entering the eye; 10 lower labials, the first in contact with its fellow behind the symphysial; the anterior chin shields in contact with five lower labials, and the posterior pair, which are the longer, with two 
lower labials; scales smooth, without pores, in 17 rows, decreasing to 11 at the beginning of the tail; ventrals 166 ; anal divided; subcaudals 170.

Dimensions: Head and body, $810 \mathrm{~mm}$.; tail, $590 \mathrm{~mm}$.

Color (in alcohol): Top of head and body indigo blue, lightening to cerulean, this color appearing very intense where the epidermis has come away. Where the outer covering is still present, the scales are more nearly olive-green. Upper labials, chin, and ventral surface Nile green, this color extending up to the third scale row on the sides, where it merges with the darker blue. The scales of the back and sides are distinctly black-edged.

Variations.-This species being the least extreme is the most constant in scalation of its genus. The only conspicuous variation, as
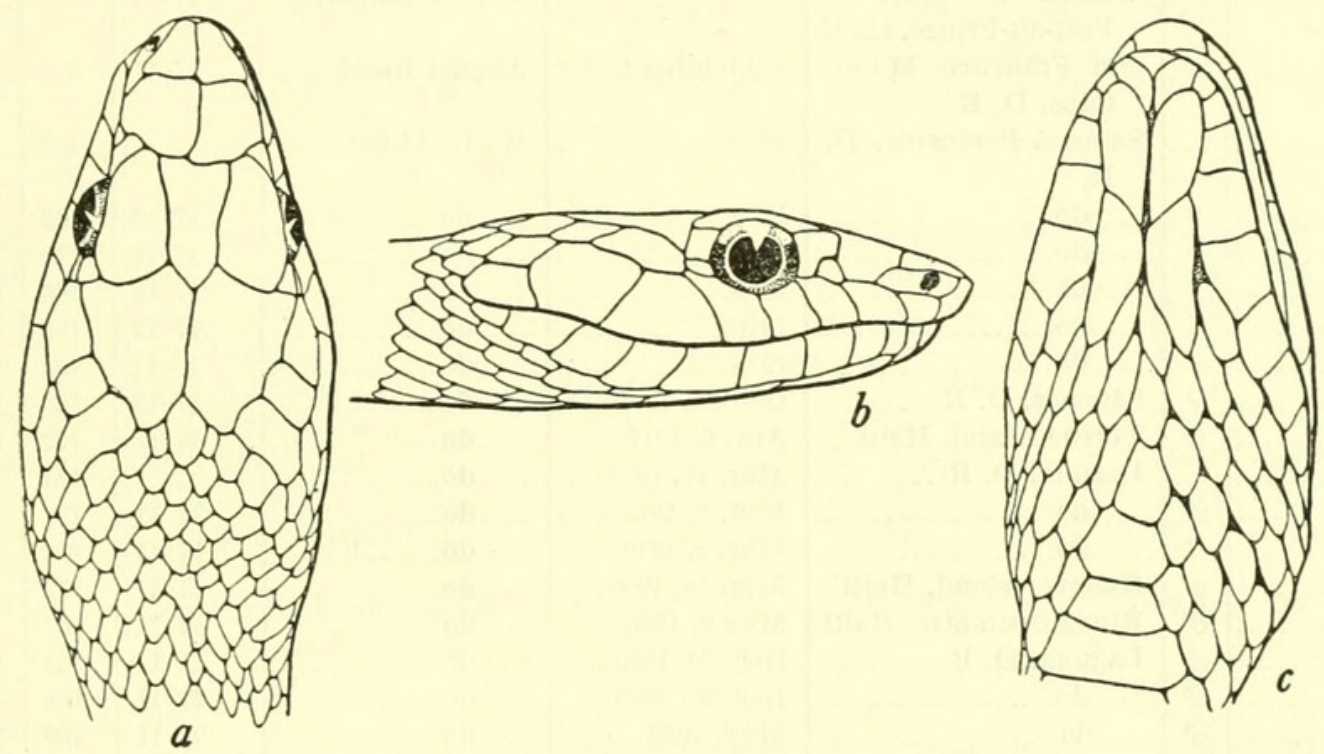

Figure 97.-Uromacer catesbyi: $a$, Top of head; $b$, side of head; $c$, chin. U.S.N.M. No. 55036, from Samaná Peninsula, Dominican Republic. One and one-half natural size.

might be expected, takes place in the region of the loreal. Some show a rather large loreal about equal in area to the upper postocular; about half of them are medium in development, as in the figured specimen; some others have very small, almost granular loreals, and in one specimen the loreals are absent on both sides of the head. The nasal is semidivided in most cases, although in a few individuals it is wholly divided.

The figured specimen has a single posterior temporal, instead of two, the usual number. This condition is repeated in two other specimens in the National collection, while another has three posterior temporals. There is not much variation in the ocular plates; in an occasional specimen there are one or three postoculars. The coloration is unvarying in nearly all the animals, although two (Nos. 61926 and 69435) are almost black above and beneath, while the latter specimen has black upper labials below the white streak. 
This species is widespread throughout the main island. The same species occurs on Tortue, Vache, and Gonave Islands, as well as on Petite Cayemite. No. 63115 has the remains of a frog, evidently Hyla dominicensis, in its stomach.

Specimens examined.-As listed in table 63.

TABLE 63.-Specimens of Uromacer catesbyi examined

\begin{tabular}{|c|c|c|c|c|c|c|c|}
\hline $\begin{array}{l}\text { Museum } \\
\text { No. }\end{array}$ & Sex & Locality & Date & Collector & $\begin{array}{l}\text { Scale } \\
\text { rows }\end{array}$ & $\begin{array}{l}\text { Ven- } \\
\text { trals }\end{array}$ & $\begin{array}{l}\text { Cau- } \\
\text { dals }\end{array}$ \\
\hline U.S.N & & & & & & & \\
\hline $9832 \ldots$ & $\sigma^{\pi}$ & “Santo Domingo"-... & & Wm. Gabb..... & $17-11$ & 171 & \\
\hline 10277 & $\sigma^{7}$ & Puerto Plata, D. R & 1878 & C. A. Fraser .. & $17-11$ & 166 & 173 \\
\hline $12100 \ldots$ & ㅇ & "Santo Domingo" & & Wm. Gabb....... & $17-13$ & 167 & \\
\hline 12139 & $\sigma^{7}$ & $\begin{array}{l}\text { Within } 25 \text { miles of } \\
\text { Port-au-Prince, Haiti. }\end{array}$ & $1866 \ldots$ & A. C. Younglove.. & $17-11$ & 167 & \\
\hline 35981 & $\sigma^{x}$ & $\begin{array}{l}\text { San Francisco Moun- } \\
\text { tains, D. R. }\end{array}$ & September 1905 & August Busck.... & $17-11$ & 171 & $\cdots$ \\
\hline 55033 & & $\begin{array}{l}\text { Samaná Peninsula, D. } \\
\text { R. }\end{array}$ & 1916 & W. L. Abbott. & & 167 & \\
\hline 5034 & ㅇ & . do & $1916 \ldots$ & .... do & $17-12$ & 169 & \\
\hline 55035 & 우 & do & $1916 \ldots$ & ............. & $17-13$ & 170 & 172 \\
\hline 55036 & ㅇ & do & 1916 & ........... & $17-13$ & 166 & 170 \\
\hline 55037. & q & do & 1916 & ..... do & $17-12$ & 165 & 168 \\
\hline 55038 & $\sigma^{7}$ & do & 1916 & ..... do & $17-11$ & 162 & 176 \\
\hline 55299 & 운 & Sánchez, D. R & Oct. 26,1916 & _...do do......... & $17-13$ & 165 & 167 \\
\hline 59920 & $\sigma^{\top}$ & Tortue Island, Haiti... & Apr. $6,1917 \ldots$ & ............. & $17-11$ & 172 & 193 \\
\hline 61925 & ... & Laguna, D. R.......... & Mar. 10, 1919 & $\ldots$ do_........ & (n...... & 164 & 169 \\
\hline 61926 .- & $\sigma^{7}$ & do & Mar. 6,1919 & ..... do & $17-11$ & 171 & \\
\hline 1927 & $\sigma^{7}$ & do & Mar. 8,1919 & ..... do & $17-11$ & 171 & \\
\hline 3115 & $\sigma^{7}$ & Gonave Island, Haiti & Mar. 16,1920 & do do & $17-11$ & 172 & $\ldots$ \\
\hline $63116 \ldots$ & $\sigma^{7}$ & Êtang Saumatre, Haiti. & May $6,1920 \ldots$ & ..... do & $17-11$ & 167 & 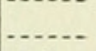 \\
\hline $63598 \ldots$ & $\sigma^{7}$ & Laguna, D. R & Dec. $20,1920 \ldots$ & .... do & $17-11$ & 165 & 168 \\
\hline 63599 & $0^{x}$ & do & Dec. $20,1920 \ldots$ & .... do & $17-11$ & 168 & 170 \\
\hline 65019 & $\sigma^{7}$ & do & May, $1922 \ldots$ & ..... do ..... & $17-11$ & 169 & 166 \\
\hline 65020 & ᄋ & do & May $8,1922 \ldots$ & . . do & $17-13$ & 165 & 165 \\
\hline 66727 & $\sigma^{7}$ & Jovéro, D. R & Dec. $7,1923 \ldots$ & do & $17-11$ & 165 & 165 \\
\hline $66728 \ldots$ & $\sigma^{2}$ & Laguna, D. R. & Dec. $12,1923 \ldots$ & . do & $17-11$ & 171 & 175 \\
\hline $66773 \ldots$ & $\sigma^{7}$ & $\begin{array}{l}\text { Samaná Peninsula, } \\
\text { D. R. }\end{array}$ & 1923 & W. L. Abbott..... & $17-11$ & 166 & 170 \\
\hline 66971 - & $\sigma^{7}$ & Laguna, D. R........... & February 1924 & John King ....... & $17-11$ & 171 & \\
\hline $69435 \ldots$ & $\sigma^{7}$ & Mariani, Haiti........ & Sept. $5,1924 \ldots$ & W. A. Hoffman. & $17-11$ & 167 & 189 \\
\hline $72640 \ldots$ & $\sigma^{7}$ & Sánchez, D. R........ & May $13,1927 \ldots$ & A. Wetmore... & $17-11$ & 171 & 173 \\
\hline 74099 & $\sigma^{7}$ & Cap Hartien, Haiti & Mar. 3-6, 1928 & A. J. Poole & $18-11$ & 175 & 197 \\
\hline 74945 & $\sigma^{7}$ & Río San Juan, D. R & March 1928.... & G. S. Miller, Jr & $17-11$ & 172 & 169 \\
\hline $\begin{array}{l}74946 \text { (head } \\
\text { only). }\end{array}$ & $\ldots$ & do & do . . . . . & . do . . . . . & & & 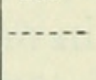 \\
\hline 74947 & $\sigma^{7}$ & .... do .... & do . . . . & do & $17-11$ & 163 & 175 \\
\hline 74948 & 웅 & do & do _ _ n & ..... do . . . & $17-13$ & 172 & -... \\
\hline $74949 \ldots$ & $\sigma^{7}$ & do & _._. do & .... do . . . . & $17-11$ & 164 & 170 \\
\hline 75014 & $\sigma^{x}$ & Samaná, D. R & Mar. 14, 1928_... & do. & $17-11$ & 162 & 179 \\
\hline 75926 & $\sigma^{7}$ & $\begin{array}{l}\text { Anse a Galets, Gonave } \\
\text { Island. }\end{array}$ & Sept. 21,1928 & J. S. C. Boswell... & $17-11$ & 165 & 184 \\
\hline 76644 & $\sigma^{x}$ & $\begin{array}{l}\text { San Michel du Nord, } \\
\text { Haitı. }\end{array}$ & Dec. $21-31,1928$ & $\begin{array}{l}\text { A. J. Poole and } \\
\text { W. Perrygo. }\end{array}$ & $17-11$ & 176 & $171+$ \\
\hline $76645 \ldots$ & $\sigma^{7}$ & do & do & do & $17-11$ & 176 & 173 \\
\hline $76776 \ldots$ & $\sigma^{7}$ & Cerca-la-Source, Haíti_. & February 1929 & do & $17-11$ & 174 & 189 \\
\hline 80812 & 우 & $\begin{array}{l}\text { Petit Trou de Nippes, } \\
\text { Haiti. }\end{array}$ & 1930 & $\begin{array}{l}\text { L. H. Parish and } \\
\text { W. Perrygo. }\end{array}$ & $17-12$ & 166 & $\cdots$ \\
\hline 80825 & $\sigma^{x}$ & $\begin{array}{l}\text { Petite Cayemite Island, } \\
\text { Haiti. }\end{array}$ & 1930 & do & $17-11$ & 169 & \\
\hline
\end{tabular}


TABLE 63.-Specimens of Uromacer catesbyi examined-Continued

\begin{tabular}{|c|c|c|c|c|c|c|c|}
\hline $\begin{array}{l}\text { Museum } \\
\text { No. }\end{array}$ & Sex & Locality & Date & Collector & $\begin{array}{l}\text { Scale } \\
\text { rows }\end{array}$ & $\begin{array}{l}\text { Ven- } \\
\text { trals }\end{array}$ & $\begin{array}{l}\text { Cau- } \\
\text { dals }\end{array}$ \\
\hline $\begin{array}{r}\text { U.S.N.I } \\
\text { Contin }\end{array}$ & & & & & & & \\
\hline 80875 & $\sigma^{7}$ & Île à Vache, Haiti...... & $1930 \ldots \ldots$ & $\begin{array}{l}\text { L. H. Parish and } \\
\text { W. Perrygo. }\end{array}$ & $17-11$ & 169 & \\
\hline 80876 & $\sigma^{7}$ & ..... do ... & $1930 \ldots$ & _. do & $17-11$ & 165 & \\
\hline 80877 -. & $\sigma^{7}$ & .....do . . . & $1930 \ldots$ & _. do . . . . & $17-11-12$ & 168 & 169 \\
\hline $80878 \ldots$ & $\sigma^{7}$ & .... do . . . . & $1930 \ldots$ & _. do _ _. & $17-11$ & 166 & 169 \\
\hline $80879 \ldots$ & $\sigma^{7}$ & _. do $\ldots$. & $1930 \ldots$ & _... do & $17-11$ & 172 & $\cdots$ \\
\hline $80880 \ldots$ & $\sigma^{x}$ & do & $1930 \ldots$ & _. do & $17-11$ & 165 & \\
\hline 80881 & $\sigma^{7}$ & - do $d 0_{2}$ & $1930 \ldots$ & - do & $17-11$ & 170 & 197 \\
\hline 80882 & $\sigma^{7}$ & -.... do . . . & $1930 \ldots$ & - do . . . & $17-11$ & 167 & \\
\hline 80883 & $\sigma^{7}$ & -.... do . . . & $1930 \ldots$ & _.... do & $17-11$ & 163 & 180 \\
\hline 80884 & $\sigma^{7}$ & ...... do _ _. & 1930 & -.... do _. . & $17-11$ & 166 & 185 \\
\hline $83866 \ldots$ & $\sigma^{7}$ & Derocher, Haiti...... & Apr. 18, 1931.. & $\begin{array}{l}\text { A. Wetmore and } \\
\text { F. C. Lincoln. }\end{array}$ & $17-11$ & 166 & 172 \\
\hline $83870_{--}$ & $0^{7}$ & Île à Vache, Haiti. & Apr. $28,1931$. & .... do . . . & $17-11$ & 169 & 186 \\
\hline 603A. & $\sigma^{x}$ & Jérémie. . & & D. F. Weinland & $17-11$ & 164 & \\
\hline 3603B - - & $\sigma^{7}$ & ...... do .... & & do & $17-11$ & 164 & 179 \\
\hline 3603C.. & $\sigma^{7}$ & do & 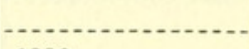 & do do & $17-11$ & 163 & $\ldots$ \\
\hline $5617 \ldots$ & $\sigma^{7}$ & Haiti & 1886 & .... do - n & $17-10$ & 164 & $\ldots$ \\
\hline $8670 \ldots$ & $0^{7}$ & Momance.... & $1913 \ldots$ & W. M. Mann ..... & $17-11$ & 167 & 181 \\
\hline $8747 \ldots$ & $0^{7}$ & Manneville..... & 1913 & .... do & $17-11$ & 169 & 201 \\
\hline $12864 \ldots$ & $\sigma^{7}$ & Thomazeau..... & 1919 & G. M. Allen...... & $17-11$ & 169 & 190 \\
\hline $12865 \ldots \ldots$ & 웅 & 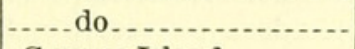 & 1919 & .... do _. & $17-13$ & 167 & 172 \\
\hline $\begin{array}{l}12869 \text { (muti- } \\
\text { lated). }\end{array}$ & $\cdots$ & Gonave Island . . . . & 1918 & -...do do - n & 17 & $\ldots$. & $\ldots$ \\
\hline $13676 \ldots$ & $\sigma^{7}$ & $\begin{array}{l}\text { Choco, } 6 \text { miles south of } \\
\text { Sosúa. }\end{array}$ & Mar. 26, 1916 & J. L. Peters....... & $17-11$ & 168 & 169 \\
\hline 16323 & $\sigma^{7}$ & La Romana........... & $1922 \ldots \ldots$ & E. Lieder... & $17-11$ & 166 & \\
\hline 16324 & $\sigma^{x}$ & d... do - . & 1922 & do & $17-11$ & 172 & 171 \\
\hline 25533 & \% & Hinche & June $25-28,1927$ & W. J. Eyerdam... & $17-13$ & 170 & 166 \\
\hline $25534 \ldots$ & $\sigma^{\pi}$ & do & _. do & do do & $17-11$ & 173 & 183 \\
\hline $25535 \ldots$ & $\sigma^{7}$ & $\begin{array}{l}6 \text { miles from Mira- } \\
\text { goane. }\end{array}$ & July $16,1927 \ldots$ & -.... do & $17-10$ & 162 & 189 \\
\hline 25536 & $\sigma^{7}$ & Near Lake Miragoane.. & $1927 \ldots$ & .....do do . . & $17-11$ & 164 & 183 \\
\hline 37599 & $\sigma^{7}$ & $\begin{array}{l}\text { Cul-de-Sac, Port-au- } \\
\text { Prince, Haiti. }\end{array}$ & (n....... & A. Audant... & $17-11$ & 173 & 177 \\
\hline 37604 & $\sigma^{7}$ & Cap-Haïtien, Haiti..... & Mar. 31, 1934_.. & $\begin{array}{l}\text { Utowana expedi- } \\
\text { tion. }\end{array}$ & $17-11$ & 175 & \\
\hline 37605 & $\sigma^{x}$ & a...ut & - & ..... do . . . & $17-11$ & 166 & $\ldots$ \\
\hline 37606 & $\sigma^{7}$ & -_._do do _ _ & .... do _ _ n & .... do . . . . & $17-11$ & 172 & 183 \\
\hline $37607 \ldots$ & $\sigma^{7}$ & La Tortue Island.... & Apr. $2,1934 \ldots$ & .... do . . . . & $17-11$ & 175 & 188 \\
\hline $37608 \ldots$ & $0^{7}$ & Île à Vache & Apr. $12,1934 \ldots$ & ..... do . . . & $17-11$ & 165 & 180 \\
\hline $37609 \ldots$ & $\sigma^{\pi}$ & ..... do ..... & .... do . . . & .... do . . . & $17-11$ & 171 & $\cdots$ \\
\hline $37610 \ldots$ & $0^{x}$ & ... do . . . & ..... do & ..... do . . . & $17-11$ & 164 & $\cdots$ \\
\hline $37611 \ldots$ & $\sigma^{7}$ & do & Apr. 2, 1934 $\ldots$ & . . do . . . . & $17-11$ & 168 & 175 \\
\hline $37612 \ldots$ & $\sigma^{7}$ & do & . do do & ... do & $17-11$ & 169 & \\
\hline $37613 \ldots$ & $\sigma^{7}$ & ... do & .... do & . do do & $17-11$ & 170 & 181 \\
\hline $37614 \ldots$ & $\sigma^{7}$ & . . do do & do & do & $17-11$ & 173 & 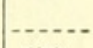 \\
\hline $37615 \ldots$ & $\sigma^{7}$ & do & ..... do & do & $17-11$ & 164 & 170 \\
\hline $37616 \ldots$ & $\sigma^{7}$ & _. . do do..... & .... do & do & $17-11$ & 163 & 184 \\
\hline $37617 \ldots$ & $\sigma^{7}$ & .....do do..... & ............... & ..... do & $17-11$ & 163 & 180 \\
\hline $37618 \ldots$ & juv. & ..... do....... & ............... & . . do do....... & $17-11$ & 164 & 186 \\
\hline 37619 & juv. & $\ldots$ do_..... & ............ & . . do & $17-11$ & 164 & 176 \\
\hline $37620 \ldots$ & juv. & ..... do do..... & ...... do & do & $17-11$ & 177 & 179 \\
\hline $37621 \ldots$ & juv. & ..... do do...... & .... do & do & $17-11$ & 167 & $\ldots$ \\
\hline $37622 \ldots \ldots$. & juv. & . ....do_....... & .... do........ & . . & $17-11$ & 163 & 187 \\
\hline
\end{tabular}


TABLE 63.-Specimens of Uromacer catesbyi examined-Continued

\begin{tabular}{|c|c|c|c|c|c|c|c|}
\hline $\begin{array}{l}\text { Museum } \\
\text { No. }\end{array}$ & Sex & Locality & Date & Collector & $\begin{array}{l}\text { Scale } \\
\text { rows }\end{array}$ & $\begin{array}{l}\text { Ven- } \\
\text { trals }\end{array}$ & $\begin{array}{l}\text { Cau- } \\
\text { dals }\end{array}$ \\
\hline $\begin{array}{l}\text { M.C.Z.- } \\
\text { Continued }\end{array}$ & & & & & & & \\
\hline 37623 & juv. & Île à Vache.... & April $2,1934 \ldots$ & $\begin{array}{l}\text { Utowana expedi- } \\
\text { tion. }\end{array}$ & $17-11$ & 170 & 193 \\
\hline 43662 & $\ldots$ & Sosúa, D. R & $1937 \ldots$ & W. J. Clench....... & 17 & 166 & 173 \\
\hline F.M.N.H. & & & & & & & \\
\hline $102 \ldots$ & $\sigma^{7}$ & $\begin{array}{l}\text { Santo Domingo City, } \\
\text { D. R. }\end{array}$ & $1895 \ldots$ & G. K. Cherrie & $17-11$ & 169 & 177 \\
\hline $103 \ldots$ & $\sigma^{7}$ & do & $1895 \ldots$ & ... do & $17-11$ & 162 & 176 \\
\hline $5962 \ldots \ldots$ & $\sigma^{7}$ & Sánchez, D. R & $1924 \ldots \ldots$ & E. Kaempfer...... & $17-11$ & 162 & 177 \\
\hline 5987 & $\sigma^{7}$ & do..... do & $1924 \ldots \ldots$ & . do do............. & $17-11$ & 166 & 172 \\
\hline 10906 & $\sigma^{7}$ & Seybo, D. R ............ & $1924 \ldots \ldots$ & S. T. Danforth & $17-11$ & 167 & 176 \\
\hline $10907 \ldots \ldots$ & 우 & do & 1924 & _...do_._. & $17(19)-13$ & 176 & 169 \\
\hline $13295 \ldots \ldots$ & $\sigma^{7}$ & $\begin{array}{l}\text { Marianna Spring, west } \\
\text { of Port-au-Prince, } \\
\text { Haiti. }\end{array}$ & Dec. $1,1928 \ldots$ & F. C. Wonder & $17-11$ & & -.... \\
\hline $\begin{array}{l}18357 \text { (head } \\
\text { only). }\end{array}$ & $\cdots$ & Sánchez, D. R.......... & 1924 & E. Kaempfer.... & $17-$ & & \\
\hline 18358 & $\sigma^{7}$ & .............. & $1924 \ldots \ldots$ & ......do do...... & $17-11$ & 169 & 177 \\
\hline $\begin{array}{l}18359 \text { (head } \\
\text { only). }\end{array}$ & -... & ............... & $1924 \ldots \ldots$ & - do & $17-$ & - & -.... \\
\hline $\begin{array}{l}18360 \text { (head } \\
\text { only). }\end{array}$ & & do & 1924 & .....do.. & $17-$ & 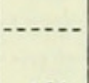 & \\
\hline $18361 \ldots$ & $\sigma^{7}$ & .....do do & $1924 \ldots$ & do & $17-11$ & 166 & 167 \\
\hline $18362 \ldots$ & $\sigma^{7}$ & _. do & $1924 \ldots$ & do do............... & $17-11$ & 162 & 174 \\
\hline $18363 \ldots$ & $\sigma^{7}$ & . do do.............. & 1924 & do & $17-11$ & 168 & 163 \\
\hline $18364 \ldots$ & $\sigma^{x}$ & do................... & 1924 & do & $17-11$ & 163 & 178 \\
\hline 18365 & $\sigma^{7}$ & . do do & $1924 \ldots$ & do & $17-11$ & 169 & 171 \\
\hline $18366 \ldots$ & $\sigma^{7}$ & ..... do & $1924 \ldots$ & do & $17-11$ & 169 & 178 \\
\hline $18367 \ldots$ & $\sigma^{7}$ & _._. do & $1924 \ldots$ & 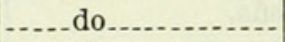 & $17-11$ & 168 & 173 \\
\hline $18368 \ldots$ & $\sigma^{7}$ & . & $1924 \ldots$ & _._. do & $17-11$ & 168 & - n \\
\hline 18369 & $\sigma^{7}$ & do & $1924 \ldots$ & _.._do_._...... & $17-11$ & 171 & 172 \\
\hline 18370 & $\sigma^{7}$ & do do............... & $1924 \ldots$ & do & $17-11$ & 166 & 179 \\
\hline
\end{tabular}

\section{UROMACER SCANDAX Dunn}

Figure 98

1920. Uromacer scandax DunN, Proc. New England Zool. Club, vol. 7, p. 43 (type locality, Tortuga Island).-Amaral, Mem. Inst. Butantan, vol. 4, p. 163, 1929.-BARBodr, Zoologica, vol. 11, No. 4, p. 11, 1930; vol. 19, No. 3, p. 135, 1935; Bull. Mus. Comp. Zool., vol. 82, No. 2, p. 155, 1937.

The type specimen is thus far the only recorded example of this species. The following description of it is taken directly from Dunn's paper cited above:

"Diagnosis.-Like Uromacer catesbyi, but with 19-11 scale rows and 181 ventrals.

"Type, adult female. U.S.N.M., no. 59,438, Tortuga [Tortue] Island, West Indies, May, $1917,{ }^{15}$ collected by W. L. Abbott.

"Description.-Scales, 19-11; ventrals 181; caudals $162+$; oculars,

18 The date of collecting is really January 31,1917 , according to the label placed upon this specimen by Dr. Abbott. 
1-2; temporals, 1-2; eye contained twice in its distance from tip of snout; rostral twice as broad as high; labials eight above, 4 and 5 entering eye; lower labials ten, five in contact with anterior chin shields, which are shorter than the posterior; nasal separated from loreal by prefrontal, which is broadly in contact with second labial. Dark bluish, lighter on sides. A black line through eye; upper labials white. Belly light gray anteriorly to dark bluish grey posteriorly.

"Only the type has been seen. It is evidently allied to catesbyi."

Dimensions: Head and body, $704 \mathrm{~mm}$.; tail, $486 \mathrm{~mm}$.

The head of this specimen has been twisted and bent, but the proportions and relationships of the various scales are perfectly distinct.
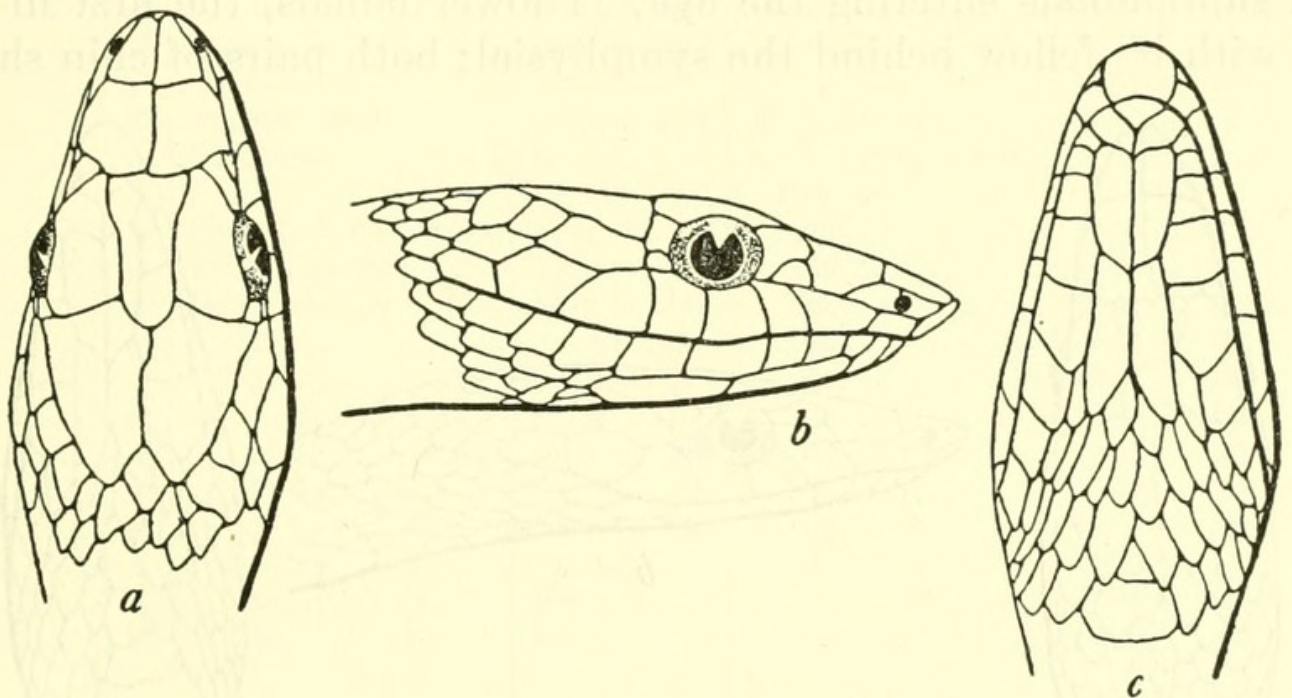

Figure 98.-Uromacer scandax: $a$, Top of head; $b$, side of head; $c$, chin. U.S.N.M. No. 59438, type, from Ile Tortue, Haiti. Twice natural size.

\section{UROMACER FRENATUS (Günther)}

Figure 99

1865. Ahaetulla frenata GüNthen, Ann. Mag. Nat. Hist., ser. 3, vol. 15, p. 94, pl. 2, fig. B (type locality ?).

1887. Uromacer inornatus Garman, Proc. Amer. Philos. Soc., vol. 24, p. 284.Barbour and Loveridge, Bull. Mus. Comp. Zool., vol. 69, No. 10, p. 358, 1929 .

1894. Uromacer frenatus Bodlenger, Catalogue of the snakes in the British Museum, vol. 2, p. 116.-BArBour, Bull. Mus. Comp. Zool., vol. 44, art. 2, p. 331, 1914; Zoologica, vol. 11, No. 4, p. 111, 1930; vol. 19, No. 3, p. 135, 1935; Bull. Mus. Comp. Zool., vol. 82, No. 2, p. 156, 1937.-Dunn, Proc. New England Zool. Club, vol. 7, pp. 42, 44, 1920.-Sснміdт, Bull. Amer. Mus. Nat. Hist., vol. 44, p. 19, 1921.-Cochran, Proc. U. S. Nat. Mus., vol. 66, art. 6, p. 13, 1924; Proc. Biol. Soc. Washington, vol. 41, p. 54, 1928; Occ. Pap. Boston Soc. Nat. Hist., vol. 8, p. 185, 1934.-Amaral, Mem. Inst. Butantan, vol. 4, p. 163, 1929.

This species seems to be the rarest in point of numbers of the three occupying the mainland of Hispaniola. Its range is likewise limited, for it is definitely recorded only from Haiti itself. 
Description.-Adult male, U.S.N.M. No. 60614; Jérémie, Haiti; December 3, 1917; Dr. W. L. Abbott, collector. Rostral as deep as broad, scarcely visible from above; internasal suture shorter than the prefrontal suture; frontal shorter than its distance from the rostral, much shorter than the parietals, and widely separated from the preocular; supraocular about as wide as frontal; diameter of eye twofifths the length of the snout; nasal undivided, two-thirds as long as its distance from the eye; loreal small, a little broader than high; one preocular on the right side, two on the left; two postoculars, the upper the larger; temporals $1+2 ; 8$ supralabials, the second in contact with the nasal, prefrontal and loreal; the third, fourth and fifth supralabials entering the eye; 11 lower labials, the first in contact with its fellow behind the symphysial; both pairs of chin shields
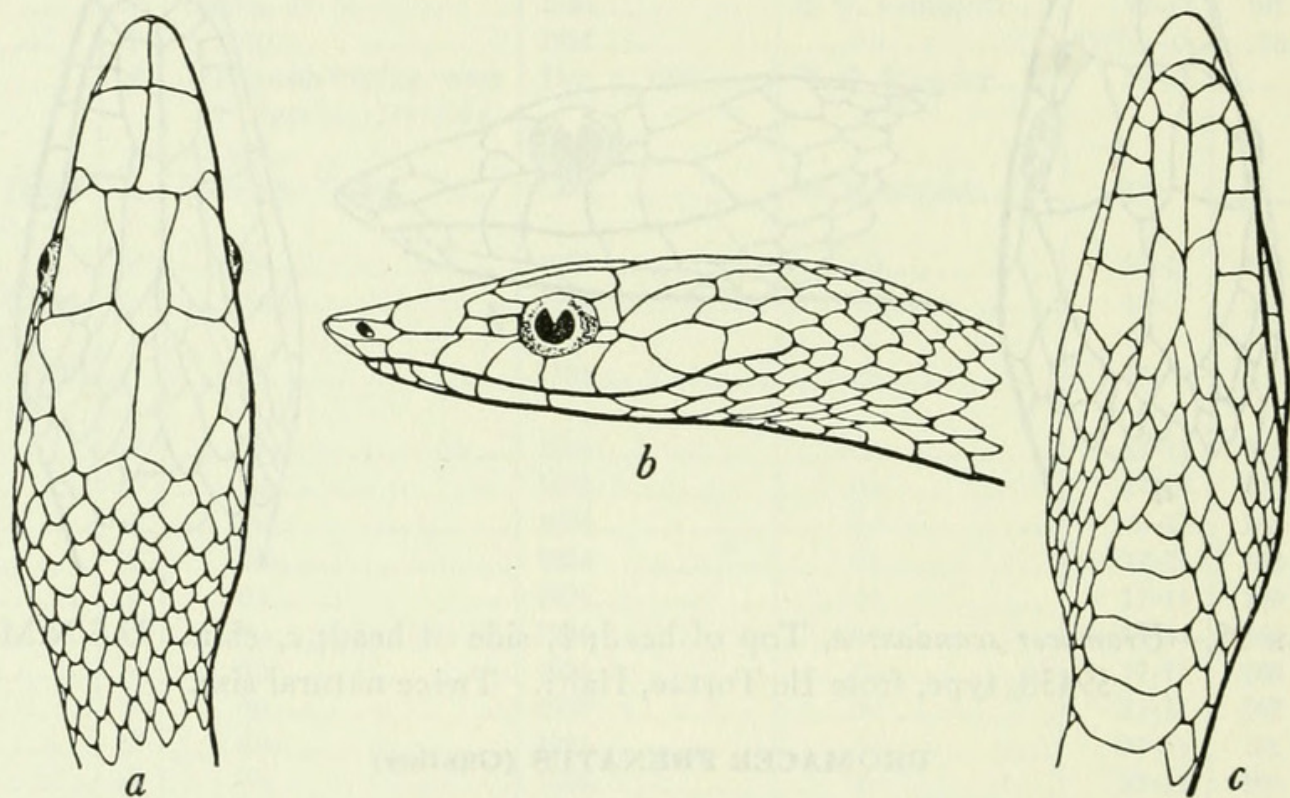

Figure 99.-Uromacer frenatus: $a$, Top of head; $b$, side of head; $c$, chin. U.S.N.M. No. 60614 , from Jérémie, Haiti. Twice natural size.

the same in length; the first pair in contact with five and the second pair with two lower labials; scales smooth, without pores, in 17 rows decreasing to 11 at the beginning of the tail; ventrals 192, anal divided; subcaudals 205 . Head and body, $678 \mathrm{~mm}$.; tail, $548 \mathrm{~mm}$.

Color (in alcohol): Dull turquoise blue on top of the head, becoming brighter on the neck; body color drab-gray above, somewhat paler beneath; a sharp white line extending from the tip of the snout along the upper labials and gradually becoming indistinct on the side of the neck; throat and chin pale turquoise blue.

Variations.-The tendency toward variation on the head shields seems to be quite marked in the region in front of the eye. In nearly all cases where a single large preocular is found, this scale has a deep horizontal crease through the middle, and in a few cases a partial division has actually taken place along this groove. The loreal itself may be present or absent, or reduced to the size of a mere granule. 
In M.C.Z. No. 25557 there is a single postocular, instead of two, the usual number. There are nine upper labials in M.C.Z. No. 3610B, one of the cotypes of $U$. inornatus Garman.

TABLE 64.-Specimens of Uromacer frenatus examined

\begin{tabular}{|c|c|c|c|c|c|c|c|}
\hline Museum No. & $\operatorname{Sex}$ & Locality & Date & Collector & Scales & $\begin{array}{l}\text { Ven- } \\
\text { trals }\end{array}$ & $\begin{array}{l}\text { Cau- } \\
\text { dals }\end{array}$ \\
\hline \multicolumn{8}{|l|}{ U.S.N.M. } \\
\hline $60611 \ldots$ & $\sigma^{7}$ & Jérémie, Haiti... & Dec. 29,1917 & W. L. Abbott .... & $17-11$ & 189 & 191 \\
\hline $60612 \ldots$ & $\sigma^{7}$ & 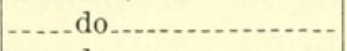 & Jan. 16, 1918 & .... do do & $17-11$ & 191 & 171 \\
\hline $60613 \ldots$ & $\sigma^{7}$ & - do do & Jan. 21, 1918 & .... do & $17-11$ & 186 & \\
\hline $60614 \ldots$ & $\sigma^{7}$ & .... do & Dec. 3,1917 & do do & $17-11$ & 194 & 205 \\
\hline $60615 \ldots$ & $\sigma^{7}$ & Moron, Haiti. ... & Dec. 24,1917 & do do & $17-11$ & 194 & 199 \\
\hline $60616 \ldots$ & $\sigma^{7}$ & 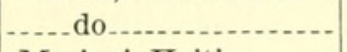 & .... do & _. do do & $17-11$ & 192 & (n..... \\
\hline $69436 \ldots$ & $\sigma^{7}$ & Mariani, Haiti.. & Oct., 201924 & W. A. Hoffman ........ & $17-11$ & & 173 \\
\hline $80772 \ldots$ & $-\cdots$ & Baradères........ & 1930 & $\begin{array}{l}\text { L. H. Parish and W. } \\
\text { Perrygo. }\end{array}$ & $17-11$ & & ......... \\
\hline $80813_{\ldots} \ldots$ & १ & Petit Trou de Nippes. & Apr. 8,1930 & - do do & $17-13$ & & 197 \\
\hline $80824 \ldots$ & $\sigma^{7}$ & Petite Cayemite...... & Apr. 16,1930 & _... do do........... & $17-11$ & $\cdots-1$ & -...... \\
\hline $80865 \ldots$ & 운 & Île à Vache & May 3,1930 & . do do............... & $17-13$ & 189 & \\
\hline $80866 \ldots$ & $\sigma^{7}$ & -.... do & .....do do & do & $17-11$ & 194 & 206 \\
\hline $80867 \ldots$ & $\sigma^{7}$ & . . . do do...... & _... do do & . do do & $17-11$ & 185 & . \\
\hline $80868 \ldots$ & $\sigma^{7}$ & ..... do & ..... do & . do do & $17-11$ & 195 & 212 \\
\hline 80869 & q & ...... do ...... & May 5,1930 & do & $17-13$ & 188 & (n..... \\
\hline $80870 \ldots$ & $\sigma^{7}$ & $\ldots$. & .....do do & . & $17-11$ & 193 & 208 \\
\hline $80871 \ldots$ & $\sigma^{7}$ & . do do & May 7,1930 & ..... do & $17-11$ & 193 & 209 \\
\hline $80872 \ldots \ldots$. & \% & .... do do & .....do do & _...do do........... & $17-13$ & 186 & - \\
\hline $80873 \ldots \ldots$. & \& & . $d o$ & $1930 \ldots \ldots$ & . & $17-13$ & 189 & (-...... \\
\hline $80874 \ldots . . .$. & $\sigma^{7}$ & . do do & $1930 \ldots$ & ..... do ................. & $17-11$ & 188 & 199 \\
\hline \multicolumn{8}{|l|}{ M.C.Z. } \\
\hline $3345 \mathrm{~A} \ldots$ & $\sigma^{7}$ & Haiti & $1865 \ldots \ldots$ & D. F. Weinland & $17-11$ & 185 & \\
\hline $3345 \mathrm{~B} \ldots \ldots$ & १ & ..... do & $1865 \ldots \ldots$ & Uhler and Weinland. & $17-13$ & 188 & 198 \\
\hline $3610 \mathrm{~A} \ldots \ldots$ & 운 & Jérémie, Haiti..... & 1865 & - do do... & $17-13$ & 185 & (n.... \\
\hline $3610 \mathrm{~B} \ldots$ & $\sigma^{7}$ & . do & 1865 & - do do & $17-11$ & 190 & $174+$ \\
\hline $8683 \ldots$ & ㅇ & Diquini, Haiti..... & 1913 & W. M. Mann & $17-13$ & 188 & (n...... \\
\hline $12866 \ldots$ & $\sigma^{7}$ & Père, Haiti......... & August, 1919 & G. M. Allen & $17-11$ & $\ldots$ & (n...... \\
\hline $25557 \ldots \ldots$ & ? & Miragoane, Haiti & July 27,1927 & W. J. Eyerdam...... & $17-13$ & $\ldots$ & 200 \\
\hline $37627 \ldots \ldots$ & 우 & Île à Vache, Haiti..... & Apr. 12,1934 & Utowana Expedition & $17-13$ & 190 & 205 \\
\hline $37628 \ldots$ & 우 & - do & -... do do....... & - do do & $17-13$ & 188 & 214 \\
\hline $37629 \ldots$ & ㅇ & _... do_....... & ..... do & - do do.... & $17-13$ & 186 & 201 \\
\hline $37630 \ldots .$. & ㅇ & .....do_.... & -.... do & - . do do & $17-13$ & 184 & n \\
\hline $37631 \ldots$ & $\sigma^{7}$ & ..... do & -.... do & ..... do & $17-11$ & 192 & $\ldots$ \\
\hline $37632 \ldots$ & 우 & .....do do .... & .....do do & .....do...... & $17-13$ & 184 & 182 \\
\hline $37633 \ldots \ldots$ & $\sigma^{7}$ & ...... do & $\ldots$. . do & . . . do do..... & $17-11$ & 189 & 187 \\
\hline $37634 \ldots \ldots$ & $\sigma^{7}$ & .... do ....... & ......do do..... & ......do_....... & $17-11$ & 189 & 195 \\
\hline 37635 & $\sigma^{7}$ & ..... do & .... do & . do do & $17-11$ & 189 & 209 \\
\hline $37636 \ldots$ & $\sigma^{7}$ & .....do do..... & ..... do ..... & ....do do & $17-11$ & 191 & \\
\hline $37637 \ldots$ & $\sigma^{7}$ & .............. & ..... do do...... & _....do do & $17-11$ & 188 & 190 \\
\hline $37638 \ldots$ & ㅇ & ............ & ..... do ..... & _... do do....... & $17-13$ & 192 & 197 \\
\hline $37639 \ldots$ & ㅇ & ............... & .....do...... & _... do do....... & $17-13$ & 187 & 196 \\
\hline $37640 \ldots \ldots$ & 우 & ....do_.... & .....do do....... & _.... do_........ & $17-13$ & 189 & 210 \\
\hline $37641 \ldots \ldots$ & 웅 & _... do ...... & ..... do ........ & $\ldots$ do & $17-13$ & 188 & 206 \\
\hline $37642 \ldots \ldots$ & $\sigma^{7}$ & .... do & ...... do & - do & $17-11$ & $\ldots$ & 197 \\
\hline \multicolumn{8}{|l|}{ Brit. Mus. } \\
\hline a (type)... & & & & & 17 & 191 & \\
\hline b & $\ldots$ & Jérémie, Haiti.......... & & J. G. Fischer & 17 & 190 & (n..... \\
\hline c.......... & $\ldots$ & S. Domingo & & - & 17 & 193 & 205 \\
\hline
\end{tabular}


Our Tortue Island snake was considered by Dunn ${ }^{16}$ to be an example of frenatus. I regard it as catesbyi, since the eye diameter goes exactly twice into the length of the snout, while its scale formula and color pattern are matched by undoubted catesbyi from the mainland of Hispaniola and its rostral plate is identical in proportion with these. Schmidt ${ }^{17}$ has recorded as frenatus a snake collected by him at Los Quemados, Dominican Republic, having 171 ventrals and 177 caudals. He considers this one and our Tortue Island specimen as somewhat aberrant $U$. frenatus. I believe that the Los Quemados snake is more probably catesbyi with a slightly elongate snout.

Specimens examined.-As listed in table 64.

\section{UROMACER WETMOREI Cochran}

FigURe 100

1931. Uromacer wetmorei Cochran, Proc. Biol. Soc. Washington, vol. 44, p. 91.Barbour, Zoologica, vol. 19, No. 3, p. 135, 1935; Bull. Mus. Comp. Zool., vol. 82 , No. 2, p. 155, 1937.

This island species is related to Uromacer frenatus but differs from it in scale count as well as in the exceedingly narrow frontal. No new
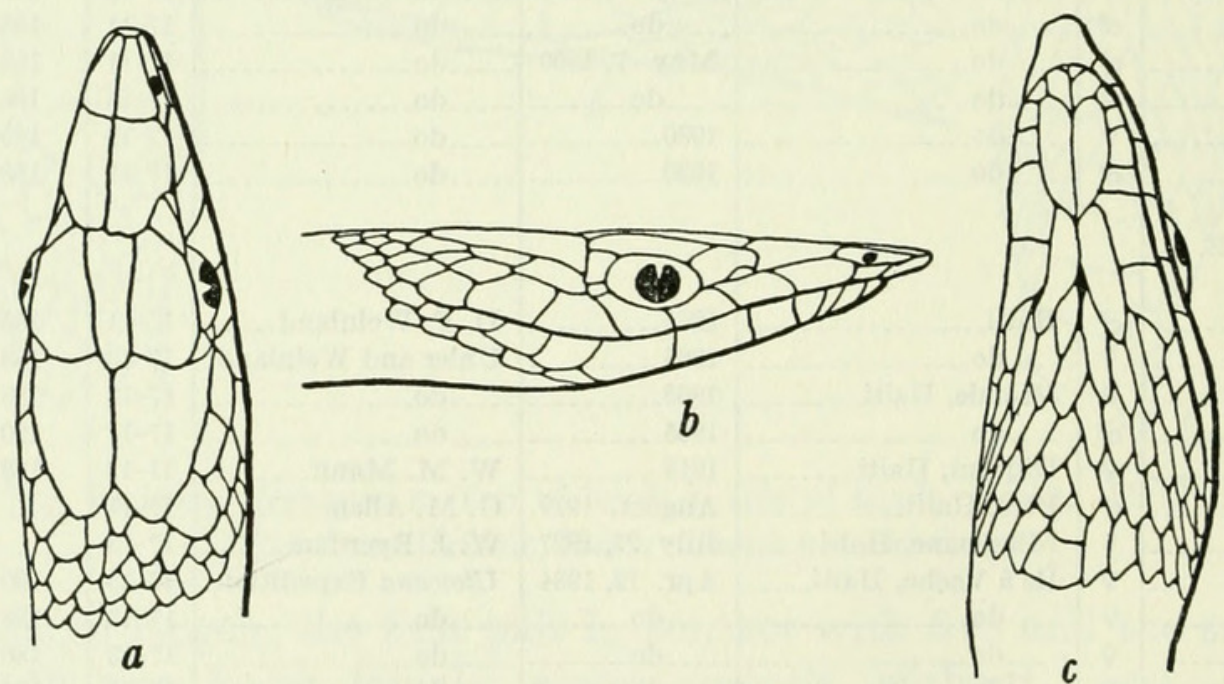

FIGURE 100.-Uromacer wetmorei: $a$, Top of head; $b$, side of head; $c$, chin. U.S.N.M. No. 83891, type, from Beata Island, Haiti. Twice natural size.

material has been forthcoming since the original description appeared:

"Type.-U.S.N.M. No. 83891, an adult male collected on Beata Island, Dominican Republic, on May 13, 1931, by Dr. A. Wetmore and Mr. F. C. Lincoln. Rostral as broad as deep, scarcely visible from above; internasal suture shorter than the prefrontal suture; frontal much shorter than its distance from the rostral, somewhat shorter than the parietals, and widely separated from the preocular; supraocular wider than the frontal; diameter of eye three-eighths the

16 Proc. New England Zool. Club, vol. 7, p. 44, 1920.

17 Bull. Amer. Mus. Nat. Hist., vol. 44, art. 21, p. 19, 1921. 
length of the snout; nasal undivided, two-thirds as long as its distance from the eye; loreal small, a little wider than high; one preocular; two postoculars, the lower one very small; temporals $1+2 ; 8$ supralabials, the second in contact with the nasal and prefrontal, barely with the loreal; the third, fourth and fifth supralabials entering the eye; 11 lower labials, the first in contact with its fellow behind the symphysial; both pairs of chin-shields the same in length, the first pair in contact with five and the second with two lower labials; scales smooth, without pores, in 17 rows decreasing to 11 at the beginning of the tail; ventrals 177; anal divided; caudals 179.

"Dimensions.-Head and body, $620 \mathrm{~mm}$.; tail, $420 \mathrm{~mm}$.; eye diameter, $3.8 \mathrm{~mm}$.; eye to tip of snout, $9.2 \mathrm{~mm}$.

"Coloration (in alcohol).- Top of head dark Nile blue, merging on the neck with the light drab of the body color; traces of narrow sepia cross-bars separated by the width of one scale on the anterior portion of the body, posteriorly becoming much less obvious, and appearing as sepia patches on the skin and sometimes on the edge of a scale, with a general darkening of the mid-dorsal area with suffusions of light sepia; upper and lower labials and chin pale glaucous green; a narrow black line beginning on the rostral and continuing backwards along the top of the upper labials, sharply separating the dark hue of the top of the head from the pale color of the lips, this line fading out quickly on the neck; ventral surface pinkish buff with a fine uneven powdering of sienna; a sepia spot rarely occurring on the edge or middle of a ventral plate; tail with similar spots occurring more frequently but just as irregularly.

"The finding of a representative of the Hispaniolan Uromacer frenatus on an outlying island was to be expected, since catesbyi had given rise to scandax on Tortuga Island, and oxyrhynchus to dorsalis on Gonave Island."

\section{UROMACER DORSALIS DUnn}

FIGURE 101

1920. Uromacer dorsalis Dunn, Proc. New England Zool. Club, vol. 7, p. 43 (type locality, Gonave Island).-Cochran, Proc. Biol. Soc. Washington, vol. 41, p. 54, 1928; Occ. Pap. Boston Soc. Nat. Hist., vol. 8, p. 185, 1934.Barbour and Loveridge, Bull. Mus. Comp. Zool., vol. 69, No. 10, p. 358, 1929.-Barbour, Zoologica, vol. 11, No. 4, p. 111, 1930; vol. 19, No. 3, p. 135, 1935; Bull. Mus. Comp. Zool., vol. 82, No. 2, p. 155, 1937.-Amaral, Mem. Inst. Butantan, vol. 4, p. 163, 1929.

This species, as well as Uromacer scandax Dunn, was described from a single specimen. I append Dunn's original description:

"Diagnosis.-A Uromacer with 17-13 scale rows, 205 ventrals, eye three times in snout, and a dark dorsal band.

"Type, adult female, M.C.Z., no. 12,867, Gonaives [Gonave] Island, West Indies, August, 1919, collected by G. M. Allen. 
"Description.-Scales, 17-13; ventrals, 205; anal, divided; caudals,?; oculars, 1-2; temporals, 1-2; eye contained three times in its distance from tip of snout, rostral higher than wide; labials, eight above, 4 and 5 entering eye; lower labials ten, five in contact with anterior chin shields, which are as long as the posterior; nasal separated from loreal by prefrontal, which reaches labials 2 and 3 . The scales of the fourth dorsal row bordered with black on upper posterior edge; scales of first, second and third rows, white anteriorly, darker on posterior part of body; dorsum above scale row four, brown; head and throat blue (green in life?); upper labials white, edged above with dark, which is continuous with the stripe along the fourth scale row; belly light gray

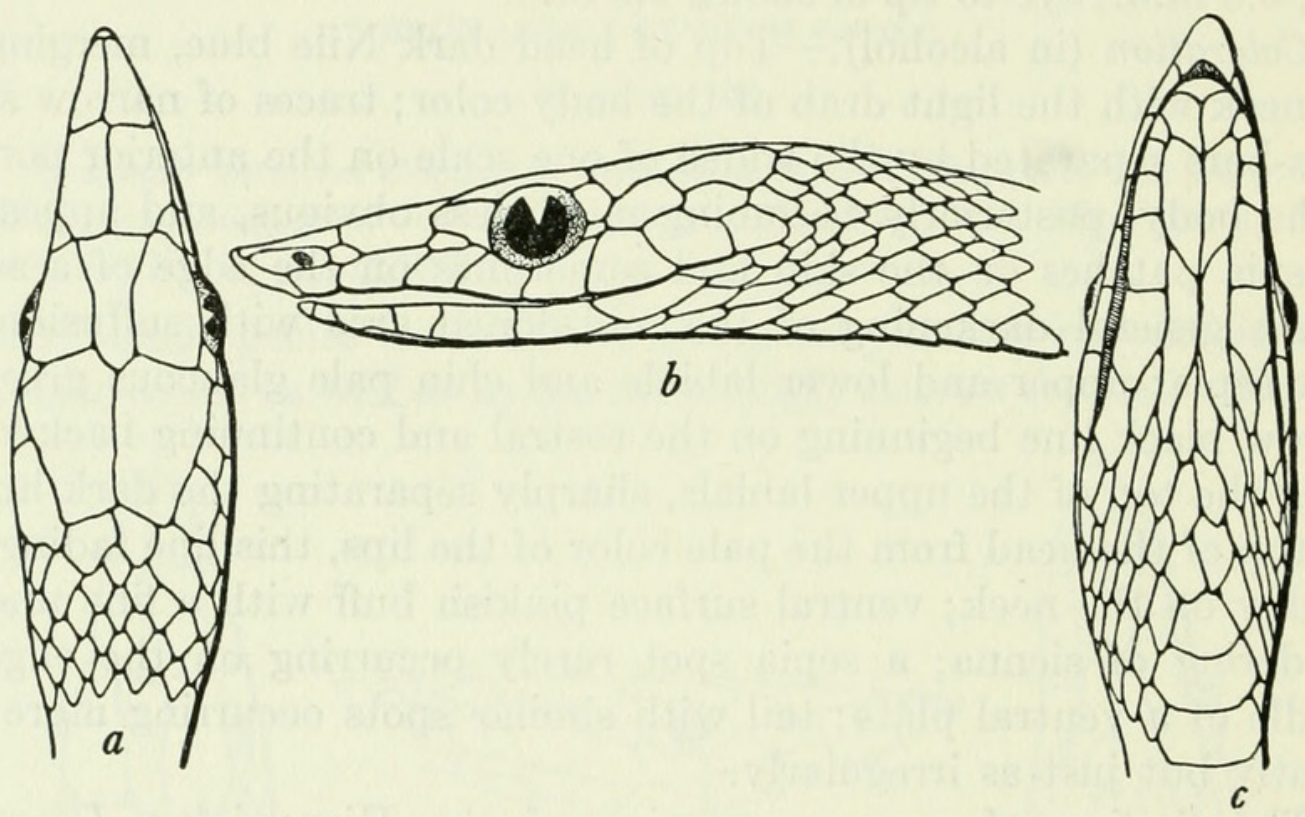

Figure 101.-Uromacer dorsalis: $a$, Top of head; $b$, side of head; $c$, chin. U. S. N. M. No. 77083, from La Grande Source, Gonave Island. Twice natural size.

anteriorly to dark gray posteriorly, a dark dot on ends of ventrals anteriorly.

"The type is the only specimen of this form, but its peculiarities are such that there is no doubt of its specific distinctness. Apparently it is derived from $U$. frenatus."

Additional specimens were collected by Walter Eyerdam at La Grande Source, Gonave Island. Two are adult males, having 17 scale rows around the body, narrowing to 11 at the base of the tail. One has a mutilated body so that a ventral count cannot be made; this specimen, M.C.Z. No. 25559, has 212 caudals and head plates as in the type. The other male has 205 ventrals and 206 caudals and normal head plates also.

The light lateral stripe appearing on the first four longitudinal scale rows of the type is not apparent in these two specimens, the whole body being a drab-gray above, slightly darker middorsally and on the belly; the light labial stripe is continued however for about two head 
lengths beyond the mouth before it fades out. In No. 25559 some of the scales on the back are conspicuously black-edged. In No. 25560 (now U.S.N.M. No. 77083) the posterior half of every second or third scale in the seventh longitudinal series is black, and the scales between are somewhat darkened at the tips and lighter at their bases; this arrangement persists on the anterior third of the body with fair regularity. The ventral coloration of No. 25559 is like that of the type. In the other example, however, the dark blotches occur usually on the bases of the scales of the first longitudinal series and only rarely on the ends of the ventrals.

TABLE 65.-Specimens of Uromacer dorsalis examined

\begin{tabular}{|c|c|c|c|c|c|c|c|}
\hline $\begin{array}{l}\text { Museum } \\
\text { No. }\end{array}$ & Sex & Locality & Date & Collector & Scales & $\begin{array}{l}\text { Ven- } \\
\text { trals }\end{array}$ & $\begin{array}{l}\text { Cau- } \\
\text { dals }\end{array}$ \\
\hline U.S.N.M. & & & & & & & \\
\hline $\begin{array}{l}77083 \text { (former- } \\
\text { ly) M.C.Z. } \\
\text { No. 25560). }\end{array}$ & $\sigma^{7}$ & $\begin{array}{l}\text { La Grande Source, Go- } \\
\text { nave Island. }\end{array}$ & $1927 \ldots \ldots$ & W.J. Eyerdam ..... & $17-11$ & 205 & 206 \\
\hline $80828 \ldots \ldots . . . .$. & q & Gonave Isiand. ......... & $1930 \ldots$ & $\begin{array}{l}\text { L. H. Parish and } \\
\text { W. Perrygo. }\end{array}$ & $17-13$ & 193 & 208 \\
\hline M.C.Z. & q & Palma, Gonave Island... & $1930 \ldots$ & _.... do & $17-13$ & 197 & (n) \\
\hline 12867 (type) .. & 우 & Gonave Island . . . . & August,1919 & G. M. Allen....... & $17-13$ & 205 & .... \\
\hline $25559 \ldots \ldots$ & $\sigma^{7}$ & $\begin{array}{l}\text { La Grande Source, Go- } \\
\text { nave Island. }\end{array}$ & 1927 & W. J. Eyerdam.... & $17-11$ & - n..... & 212 \\
\hline 37624 & ㅇ & $\begin{array}{l}\text { Anse à Galets, Gonave } \\
\text { Island. }\end{array}$ & April 1934_.. & $\begin{array}{l}\text { Utowana Expedi- } \\
\text { tion. }\end{array}$ & $17-13$ & 197 & 208 \\
\hline $37625 \ldots \ldots$ & \% & - do & ..... do ........ & .... do & $17-13$ & 194 & 208 \\
\hline $37626 \ldots \ldots$ & q & do & ....do . ..... & . . do . . . . & $17-13$ & ....... & -...... \\
\hline
\end{tabular}

In U.S.N.M. No. 80829, from Palma, the light lateral stripe is exceedingly conspicuous on the four outer scale rows, while on the fifth scale row a diagonal black spot across the upper posterior border of each scale emphasizes the separation of the lateral and dorsal colors. U.S.N.M. No. 80828 from La Grande Source has the lateral light stripe apparent on the anterior part of the body, but posteriorly it becomes indistinct, since the black borders of the fifth row of scales are much less accentuated. Three others from Anse à Galets do not enlarge the known scale counts of this species. U.S.N.M. No. 80829 has a head and body length of $797 \mathrm{~mm}$.; tail, $544 \mathrm{~mm}$. +tip.

Specimens examined.-As listed in table 65.

\section{UROMACER OXYRHYNCHUS Duméril and Bibron}

Figure 102

1854. Uromacer oxyrhynchus Duméril and Bibron, Erpétologie générale, vol. 7, p. 722 , pl. 83, fig. 1.-Garman, Proc. Amer. Philos. Soc., vol. 24, p. 284, 1887.-Fischer, Jahrb. Hamburg Wiss. Anst., vol. 5, p. 41, pl. 3, fig. 6, 1888.-Boulenger, Catalogue of the snakes in the British Museum, vol. 2, 
p. 116, 1894.-Meerwarth, Mitth. Naturh. Mus. Hamburg, vol. 18, pt. 2, p. 10, 1901.-Barbour, Mem. Mus. Comp. Zool., vol. 44, art. 2, p. 332, 1914; Zoologica, vol. 11, No. 4, p. 110, 1930; vol. 19, No. 3, p. 134, 1935; Bull. Mus. Comp. Zool., vol. 82, No. 2, p. 155, 1937.-Dunn, Proc. New England Zool. Club, vol. 7, pp. 42, 44, 1920.-Sснмidr, Bull. Amer. Mus. Nat. Hist., vol. 44, p. 19, 1921.-Noble, Nat. Hist., vol. 23, No. 2, p. 111, 1923.-Cochran, Proc. U. S. Nat. Mus., vol. 66, art. 6, p. 13, 1924; Proc. Biol. Soc. Washington, vol. 41, p. 54, 1928; Occ. Pap. Boston Soc. Nat. Hist., vol. 8, p. 185, 1934.-Amaral, Mem. Inst. Butantan, vol. 4, p. 163, 1929.

1858. Ahaetulla oxyrhyncha GÜNTHER, Catalogue of colubrine snakes in the collection of the British Museum, p. 154.

1879. Leptophis oxyrhynchus Cope, Proc. Amer. Philos. Soc., vol. 18, p. 273.

This beautiful snake is now the most abundant on Hispaniola. It is a tree dweller and therefore escapes oftener from the voracious mongoose than do the other serpents that spend their lives on the ground.

Description.-U.S.N.M. No. 63596; adult female; Laguna, Dominican Republic; December 21, 1920; W. L. Abbott, collector. Rostral
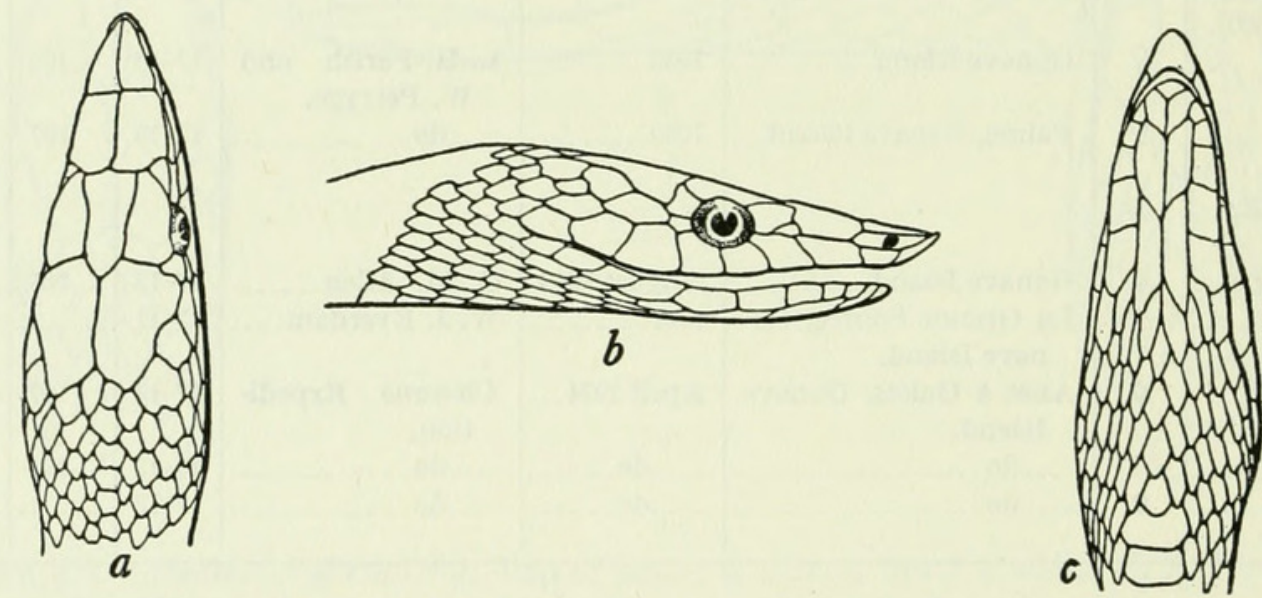

FIGURE 102.-Uromacer oxyrhynchus: $a$, Top of head; $b$, side of head; $c$, chin. U.S.N.M. No. 63596, from Laguna, Dominican Republic. Twice natural size.

considerably higher than broad, scarcely visible from above because of the sharp projection of the snout; internasal suture shorter than the prefrontal suture; frontal three-fourths as long as its distance from the rostral, shorter than the parietals, separated from the preocular; supraocular about as wide as the frontal; diameter of eye one-third the length of the snout; loreal small, broader than high; one large preocular; two postoculars, the upper larger; temporals $1+2 ; 8$ supralabials, the second very long and in contact with the nasal, prefrontal, and loreal; the third, fourth, and fifth supralabials entering the eye; 11 lower labials, the first in contact with its fellow behind the symphysial; the first pair of chin shields shorter than the second pair; scales smooth, without pits, in 19 rows decreasing to 13 at the beginning of the tail; ventrals 198, anal divided; subcaudals 192 . Head and body, $690 \mathrm{~mm}$.; tail, $530 \mathrm{~mm}$. 
Color (in alcohol): Upper surface of head, body, and tail deep cobalt blue; a very definite white line beginning at the snout, passing along the upper labials and continuing on the body on the upper half of the first and the lower half of the second scale rows; chin and throat pale turquoise blue; the remainder of the ventral surface pale drab-gray.

Variations.-In this series it may be seen that the variation of ventral plates is between 192 and 212, and caudals between 184 and 214. The variation of the head shields of this species is remarkably small. Few specimens have any variation in the number of supralabials-U.S.N.M. Nos. 55300 and 66972 have nine upper labials on both sides of the head, and No. 69198 has nine on one side only. One other specimen has two anterior temporals on one side of the head. Two snakes have a single postocular, and these same individuals are further distinguished by lacking loreal plates; in No. 10167 there is a very minute loreal on the left side only.

The diameter of the eye in relation to the length of the snout is a constant ration of 1 to 3 in all these specimens.

Specimens examined.-As listed in table 66.

TABLE 66.-Specimens of Uromacer oxyrhynchus examined

\begin{tabular}{|c|c|c|c|c|c|c|c|}
\hline $\begin{array}{l}\text { Museum } \\
\text { No. }\end{array}$ & Sex & Locality & Date & Collector & $\begin{array}{l}\text { Scale } \\
\text { rows }\end{array}$ & $\begin{array}{l}\text { Ven- } \\
\text { trals }\end{array}$ & $\begin{array}{l}\text { Cau- } \\
\text { dals }\end{array}$ \\
\hline \multicolumn{8}{|l|}{ U.S.N.M. } \\
\hline $10163 \ldots$ & ad. $\uparrow$ & Port-au-Prince, Haiti... & & J. J. Brown. ........ & $19-13$ & 198 & 195 \\
\hline $10167 \ldots$ & ad. $\%$ & do & & do & $19-13$ & 194 & ...... \\
\hline $12101 \mathrm{a}$ & q & Puerto Plata, D. R..... & & W. Gabb_....... & $19-13$ & 204 & 202 \\
\hline $12101 \mathrm{~b}$ & $\sigma^{7}$ & do & & _... do & $19-11$ & 192 & 198 \\
\hline $12143 \ldots$ & ad. $\sigma^{7}$ & Port-au-Prince, Haiti & - & A. C. Younglove... & $19-11$ & 200 & $202+$ \\
\hline $49943 \ldots$ & ad. $\%$ & $\begin{array}{l}\text { San Pedro de Macoris, } \\
\text { D. R. }\end{array}$ & Mar. 28, 1913_. & J. N. Rose $\ldots . . . .$. & $19-13$ & 196 & 191 \\
\hline 55039 & ad. $\sigma^{7}$ & $\begin{array}{l}\text { Samaná Peninsula, } \\
\text { D. R. }\end{array}$ & $1916 \ldots$ & W. L. Abbott & $19-11$ & 200 & 204 \\
\hline $55040 \ldots$ & ad. $\sigma^{7}$ & . do & 1916 & ......do_.... & $19-11$ & 206 & 200 \\
\hline $55041 \ldots$ & ad. $\sigma^{x}$ & ....do do._. & 1916 & .....do ........ & $19-11$ & 208 & 202 \\
\hline $55042 \ldots$ & ad. $\sigma^{7}$ & _....do do & 1916 & .....do do......... & $19-11$ & 199 & \\
\hline $55043 \ldots$ & ad. $\sigma^{7}$ & ..._do_._._._. & 1916 & .....do do... & $19-11$ & 204 & 205 \\
\hline $55300 \ldots$ & ad. $\sigma^{7}$ & Jarabacoa, D. R.... & Oct. $16,1916 \ldots$ & .... do . . & $19-11$ & 200 & 199 \\
\hline $56459 \ldots$ & ad. 우 & Hispaniola & 1896 & J. Hurter & $19-13$ & 195 & 194 \\
\hline $59456 \ldots \ldots$ & ad. $\%$ & Tortue Island & Feb. 3, 1917 ... & W. L. Abbott & $19-13$ & 203 & 199 \\
\hline $59457 \ldots \ldots$ & $\mathrm{ad} \cdot \sigma^{7}$ & do do & Feb. $7,1917 \ldots$ & ..... do & $19-11$ & 206 & 214 \\
\hline $59458 \ldots \ldots$ & ad. $\sigma^{7}$ & . do do & Feb. 8, 1917... & ............ & $19-11$ & 210 & -.... \\
\hline $59459 \ldots \ldots$ & ad. + ? & . & Feb. $7,1917 \ldots$ & .....do_.... & $19-13$ & 196 & 199 \\
\hline $59460 \ldots \ldots$ & ad. + & do & Feb. 1, 1917 ... & ...... do & $19-13$ & 198 & 202 \\
\hline $59461 \ldots \ldots$ & ad. $\sigma^{7}$ & Port-de-Paix, Haiti...... & Feb. 27, 1917 _. & .... do do.......... & $19-11$ & 201 & 185 \\
\hline $59462 \ldots . .$. & ad. + ? & Tortue Island & Feb. 30, 1917_. & . & $19-13$ & 203 & 207 \\
\hline $59463 \ldots \ldots$ & ad. $\sigma^{7}$ & do & Feb. 3, 1917 ... & ..... do .............. & $19-11$ & 196 & 203 \\
\hline $59923 \ldots \ldots . . .$. & ad. $\sigma^{7}$ & do & May 23,1917 & do do & $19-11$ & 207 & 200 \\
\hline $59924 \ldots \ldots$ & ad. ? & do & May $22,1917 \ldots$ & -....do_..... & $19-13$ & 201 & 204 \\
\hline $63596 \ldots$ & ad. $+?$ & Laguna, D. R & Dec. 21,1920 & _..._do_..... & $19-13$ & 198 & 192 \\
\hline $63597 \ldots \ldots$ & ad. + ? & _. do & . _. do & ..... do & $19-13$ & 202 & 192 \\
\hline $65021 \ldots$ & ad. $\%$ & do & May $1922 \ldots$ & do do & $19-13$ & 202 & 184 \\
\hline $65790 \ldots$ & ad. + & Samaná, D. R . . . & Mar. $4,1923 \ldots$ & ..... do & $19-13$ & ...... & 187 \\
\hline $65791 \ldots$ & juv. $\sigma^{x}$ & $\begin{array}{l}\text { Samaná and Laguna, } \\
\text { D. R. }\end{array}$ & March 1923_... & _...do do & $19-11$ & 202 & 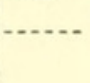 \\
\hline
\end{tabular}


TABLE 66.-Specimens of Uromacer oxyrhynchus examined-Continued

\begin{tabular}{|c|c|c|c|c|c|c|c|}
\hline $\begin{array}{l}\text { Museum } \\
\text { No. }\end{array}$ & Sex & Locality & Date & Collector & $\begin{array}{l}\text { Scale } \\
\text { rows }\end{array}$ & $\begin{array}{l}\text { Ven- } \\
\text { trals }\end{array}$ & $\begin{array}{l}\text { Cau- } \\
\text { dals }\end{array}$ \\
\hline \multicolumn{8}{|l|}{$\begin{array}{l}\text { U.S.N.M.- } \\
\text { Continued }\end{array}$} \\
\hline $66726 \ldots$ & ad. $\sigma^{7}$ & Guarabo, D. R & Nov. 22,1923 & W. L. Abbott ..... & $19-11$ & 192 & 187 \\
\hline $66770 \ldots$ & ad. $\%$ & $\begin{array}{l}\text { Samaná Peninsula, } \\
\text { D. R. }\end{array}$ & 1923 & do & $19-13$ & 198 & 190 \\
\hline $66771 \ldots$ & ad. $\%$ & do & $1923 \ldots$ & ..... do . . & $19-13$ & 197 & ....... \\
\hline 66772 & ad. $\%$ & do & 1923 & _... do & $19-13$ & 200 & 197 \\
\hline 66972 & ad. $\sigma^{7}$ & do & February 1924. & J. King ......... & $19-11$ & 201 & 188 \\
\hline $69198 \ldots$ & ad. + & $\begin{array}{l}\text { San Michel du Nord, } \\
\text { Haiti. }\end{array}$ & Apr. 6, 1925 ... & G. S. Miller, Jr. & $19-13$ & 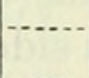 & 199 \\
\hline 74098 & $\sigma^{7}$ & Cap-HaItien, Haiti..... & Mar. 3-6, 1928 . & A. J. Poole & $19-11$ & 203 & 204 \\
\hline 74950 & 우 & Río San Juan, Haiti.... & March $1928 \ldots$ & G. S. Miller, Jr... & $19-13$ & 198 & 192 \\
\hline $74951 \ldots$ & $\sigma^{7}$ & do & . do . . . . . & _. do . . . & $19-11$ & 212 & 205 \\
\hline $74952 \ldots$ & $\sigma^{7}$ & do & .... do & do & $19-11$ & 195 & 198 \\
\hline 74953 & $\sigma^{7}$ & do & do & do & $19-11$ & 208 & (n) \\
\hline $75927 .-$ & 우 & $\begin{array}{l}\text { Anse à Galets, Gonave } \\
\text { Island. }\end{array}$ & Sept. $21,1928 \ldots$ & J. S. C. Boswell & $19-13$ & 202 & 194 \\
\hline $76643 \ldots$ & ㅇ & $\begin{array}{l}\text { San Michel du Nord, } \\
\text { Haiti. }\end{array}$ & $\begin{array}{l}\text { Dec. 21-31, } \\
1928\end{array}$ & Poole and Perrygo & $19-13$ & 194 & \\
\hline M.C.Z. & & & & & & & \\
\hline 3005 & & "Haiti"'......... & $1873 \ldots \ldots$ & N. Attwood & & $\ldots$ & \\
\hline 5452 & & Samaná, D. R ...... & $1885 \ldots \ldots$ & M. A. Frazar . & & -.... & $\ldots$ \\
\hline 8668 & & Momance, Haiti........ & $1913 \ldots \ldots$ & W. M. Mann. & & $\ldots$ & $\ldots$ \\
\hline 8669 & 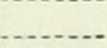 & do & 1913 & .... do . . . . & & $\ldots$ & $\ldots$ \\
\hline $8684 \ldots$ & 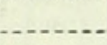 & Diquini, Haiti. .......... & $1913 \ldots \ldots$ & . do do _....... & & 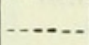 & $\ldots$ \\
\hline $7832 \ldots$ & $\ldots$ & Santiago de la Vega, D. R - & 1910 & A. H. Verrill ....... & 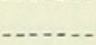 & ...... & $\ldots$ \\
\hline $12868 \ldots$ & & Père, Haiti & August 1919... & G. M. Allen & $\ldots$ & ...... & (n) \\
\hline 13678 & & Sosúa, D. R & (2) & J. L. Peters ..... & & $\ldots$ & $\cdots$ \\
\hline $25558 \ldots$ & & Miragoane, Haiti........ & July $13,1927 \ldots$ & W. J. Eyerdam .... & -.... & $\ldots$ & $\cdots$ \\
\hline $37600 \ldots$ & & $\begin{array}{l}\text { Cul-de-Sac, Port-au- } \\
\text { Prince, Haiti. }\end{array}$ & - & A. Audant & & & \\
\hline $37643 \ldots$ & ㅇ & Tortue Island & Apr. 2, 1934... & $\begin{array}{l}\text { Utowana Expedi- } \\
\text { tion. }\end{array}$ & $19-13$ & 200 & \\
\hline 37644 & 우 & .... do no . & .... do & ..... do & $19-13$ & 203 & 191 \\
\hline $37645 \ldots \ldots$ & & do & do do & .... do & - & (n..... & -..... \\
\hline $37645-37663$ & & Cap-Haïtien, Haiti...... & Mar. 31,1934 & .... do & & (n.... & $\ldots$ \\
\hline $43663 \ldots \ldots$ & & Sosúa, D. R & $1937 \ldots \ldots$ & W. J. Clench.. & $19-11$ & 191 & $\cdots$ \\
\hline $43679 \ldots$ & & $\begin{array}{l}\text { Monte Isabella de Tor- } \\
\text { res, D. R. }\end{array}$ & & ....do do . . . . & $19-11$ & 202 & \\
\hline $43696 \ldots$ & & $\begin{array}{l}\text { Santa Barbara do Sa- } \\
\text { maná, D. R. }\end{array}$ & & do & $19-13$ & 196 & 191 \\
\hline F.M.N.H. & & & & & & & \\
\hline 101. & ᄋ & $\begin{array}{l}\text { Santa Domingo City, } \\
\text { D. R. }\end{array}$ & & & $19-13$ & 195 & 187 \\
\hline $\begin{array}{l}5986 \text { (head } \\
\text { only). }\end{array}$ & & Sánchez, D. R & $1924 \ldots$ & E. Kaempfer & $19 \ldots$ & $\cdots$ & \\
\hline
\end{tabular}

\section{Genus HYPSIRHYNCHUS Günther}

1858. Hypsirhynchus GÜNTHer, Catalogue of colubrine snakes in the collection of the British Museum, p. 48 (type, H. ferox).

\section{HYPSIRHYNCHUS FEROX Günther}

\section{Figure 103}

1858. Hypsirhynchus ferox GüNTHER, Catalogue of colubrine snakes in the collection of the British Museum, p. 49 (type locality, "Barbadoes" = San Domingo).-Cope, Proc. Acad. Nat. Sci. Philadelphia, 1871, p. 218; Proc. 
Amer. Philos. Soc., vol. 18, p. 273, 1879.-Fischer, Jahrb. Hamburg Wiss. Anst., vol. 5, p. 41, 1888.-Bodlenger, Catalogue of the snakes in the British Museum, vol. 2, p. 117, pl. 6, fig. 1, 1894-Menrwarth, Mitth. Nat. Mus. Hamburg, vol. 18, p. 10, 1901.-BARBour, Mem. Mus. Comp. Zool., vol. 44, No. 2, p. 332, 1914; Zoologica, vol. 11, No. 4, p. 111, 1930; vol. 19, No. 3, p. 139, 1935; Bull. Mus. Comp. Zool., vol. 82, No. 2, p. 162, 1937.Schmidt, Bull. Amer. Mus. Nat. Hist., vol. 44, art. 2, p. 19, 1921.-Amaral, Mem. Inst. Butantan, vol. 4, p. 163, 1929.-Cochran, Occ. Pap. Boston Soc. Nat. Hist., vol. 8, p. 185, 1934.

1862. Hypsirhynchus scalaris Cope, Proc. Acad. Nat. Sci. Philadelphia, 1862, p. 72 (type locality, Hayti near Jérémie).-Garman, Proc. Amer. Philos. Soc., vol. 24, p. 284, 1887.-Barbour and Loveridge, Bull. Mus. Comp. Zool., vol. 69 , No. 10 , p. $283,1929$.

Description.-U.S.N.M. No. 10162, from Port-au-Prince, collected by J. J. Brown. Snout rather elongate, the rostral forming an
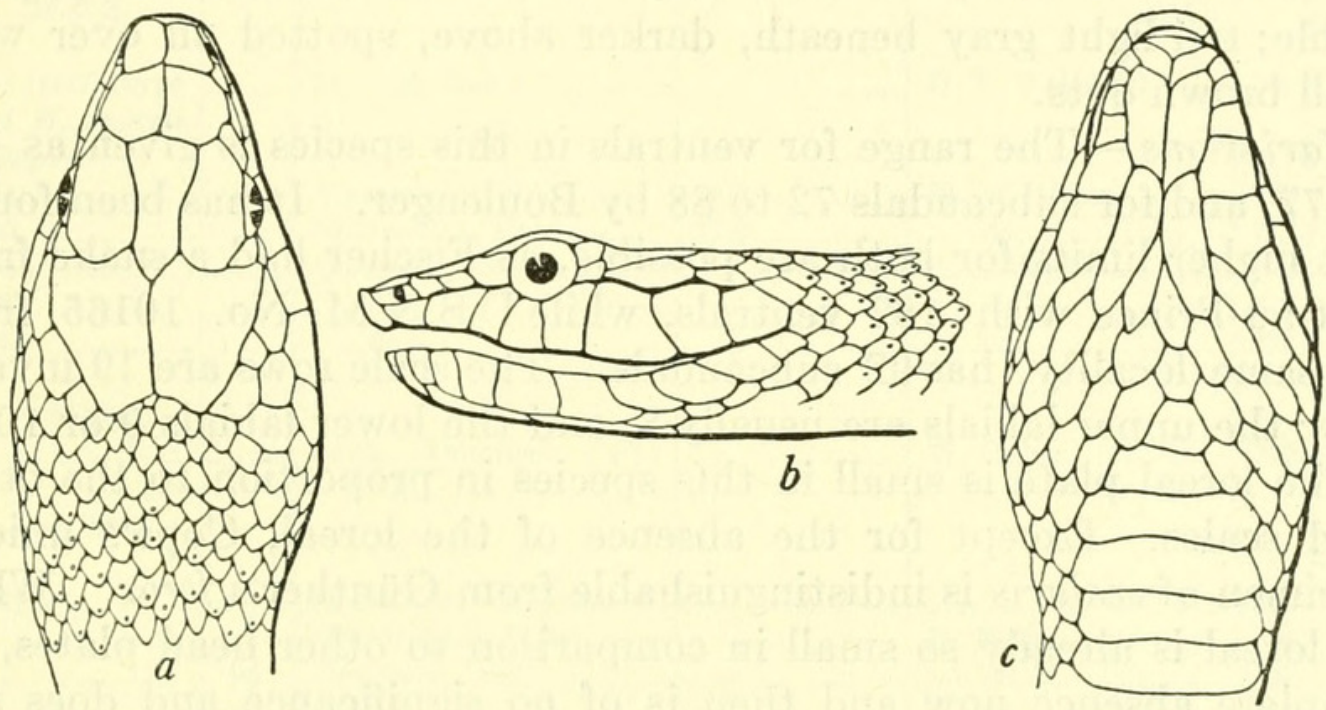

FIGURE 103.-Hypsirhynchus ferox: $a$, Top of head; $b$, side of head; $c$, chin. U.S.N.M. No. 10162, from Port-au-Prince, Haiti. One and one-half times natural size.

acute angle with the top of the snout, the upper portion projecting strongly and slightly turning up. Rostral much broader than deep, only its upper border visible from above; internasals as long as broad, shorter than the prefrontals; frontal as broad as supraocular, its length twice its breadth, a little longer than its distance from the end of the snout, a little shorter than the parietals; loreal longer than deep, rather small; one preocular and two postoculars, the lower the smaller; temporals 1 plus 2 ; eight supralabials, the third, fourth, and fifth entering the eye; a distinct depression on the side of the head along the upper borders of the supralabials; 10 lower labials, five in contact with the anterior chin shields, which are a little shorter than the posterior. Scales in 19 rows, each scale with a single large pore situated in the dorsal half of the scale near the tip. Ventrals 178; anal divided; subcaudals 86 . Head and body, $563 \mathrm{~mm}$.; tail, $173 \mathrm{~mm}$. 
Color: Above pale gray-brown, each scale powdered with many minute brown dots; a dorsal series of arrow-shaped brown markings distinct on the anterior portion of the body, but becoming indistinct posteriorly; head with an elongate brown median stripe; numerous other brown spots on the snout, supraorbital region and parietals; a white stripe commencing on the loreal region and continuing backwards upon the upper portion of the supralabials, widening on the neck and continuing for a very short distance on the body on the second and third scale rows before it becomes indistinct. Entire chin and lower portion of supralabials dark brown, with a few large white spots on the infralabials and on the chin shields. Ventral surface graybrown, with numerous small brown dots on each ventral plate, particularly congregated at its posterior border as well as at the sides and on the lowest scale row, so that a more or less distinct lateral stripe is visible; tail light gray beneath, darker above, spotted all over with small brown dots.

Variations.-The range for ventrals in this species is given as 166 to 177 , and for subcaudals 72 to 88 by Boulenger. It has been found that higher limits for both are possible, as Fischer had a snake from Port-au-Prince with 182 ventrals, while U.S.N.M. No. 10165, from the same locality, has 92 subcaudals. The scale rows are 19 invariably; the upper labials are usually 8 , and the lower labials 9 or 10 .

The Joreal plate is small in this species in proportion to the other head scales. Except for the absence of the loreal, Cope's unique specimen of scalaris is indistinguishable from Günther's ferox. When the loreal is already so small in comparison to other head plates, its complete absence now and then is of no significance and does not warrant any specific separation. The frontal is usually equal to its distance from the end of the snout, though occasionally a little longer.

The variation in intensity of color must be rather great, as No. 69433 is a very dark purplish brown, on which no markings show except the light streak on the sides of the head and neck. The young specimen No. 10166, on the contrary, has every marking very distinct, while anteriorly on the sides additional rectangular blotches are visible above the light stripe, and below it on every second or third scale of the first scale row is a dark brown irregular spot.

Specimens examined.-As listed in table 67. 
TABLE 67.-Specimens of Hypsirhynchus ferox examined

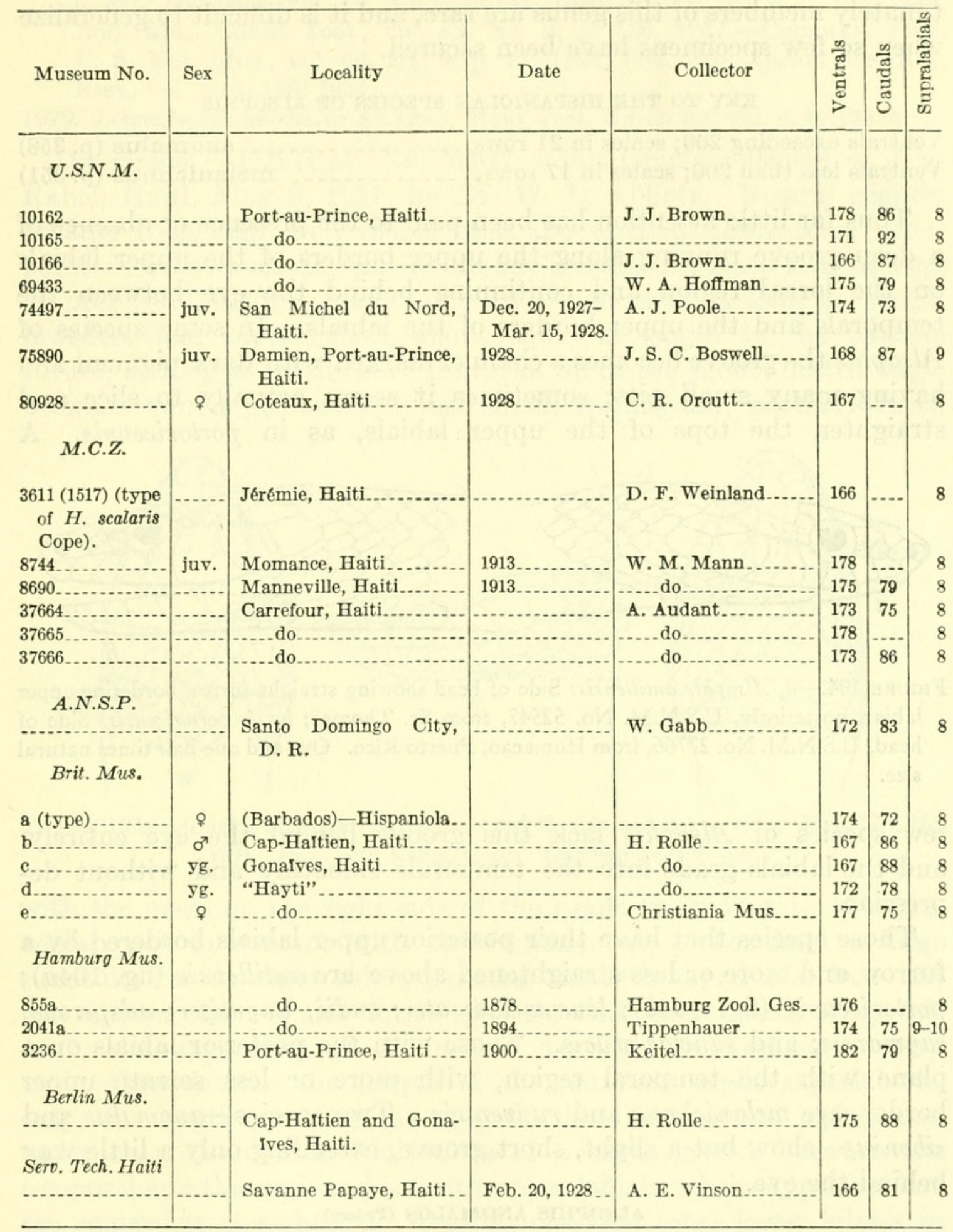

\section{Genus ALSOPHIS Fitzinger}

1843. Alsophis Fitzinger, Systema reptilium, p. 26 (type, Psammophis antillensis Schlegel).

1862. Haliophis Cope, Proc. Acad. Nat. Sci. Philadelphia, 1862, p. 77 (emend.). 1882. Alophis StahL, Fauna of Puerto-Rico, p. 70 (error).

1884. Ocyophis Cope, Proc. Amer. Philos. Soc., vol. 23, p. 491 (type, O. ater).

1887. Halsophis Cope, Proc. U. S. Nat. Mus., vol. 10, p. 439 (emend.).

1894. Dromicus Boulenger, Catalogue of the snakes in the British Museum, vol. 2, p. 118 (type, D. angulifer) (not of Bibron, 1842). 
Possibly more than two species occur on Hispaniola, but unfortunately members of this genus are rare, and it is difficult to generalize when so few specimens have been secured.

\section{KEY TO THE HISPANIOLAN SPECIES OF ALSOPHIS}

Ventrals exceeding 200 ; scales in 21 rows Ventrals less than 200; scales in 17 rows_............ melanichnus (p. 351)

Thus far little attention has been paid to the presence or absence of a deep groove running along the upper borders of the upper labials on the loreal region and continuing behind the eye between the temporals and the upper borders of the labials. In some species of Alsophis the groove becomes a channel marked with dark pigment and having many small pits; sometimes it seems actually to slice and straighten the tops of the upper labials, as in portoricensis. A
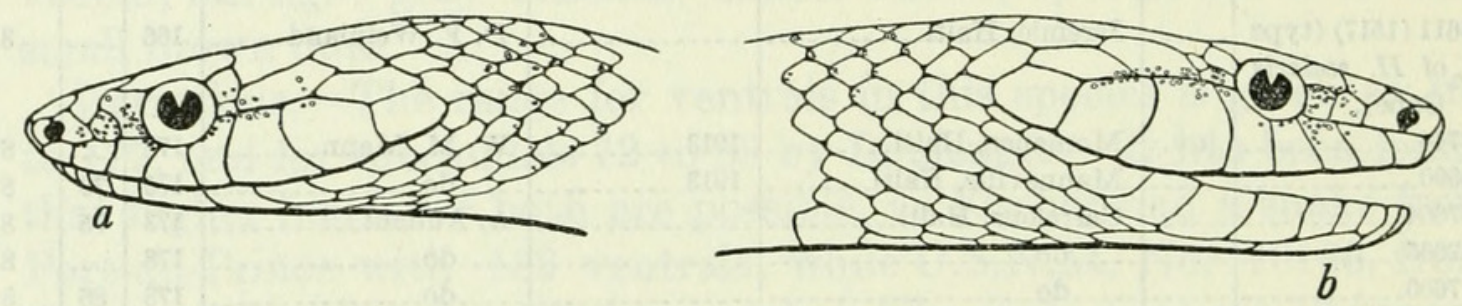

FIGURE 104.- a, Alsophis antillensis: Side of head showing straight furrow bordering upper labials posteriorly, U.S.N.M. No. 52547, from St. Thomas; $b, A$. portoricensis: Side of head, U.S.N.M. No. 27766, from Humacao, Puerto Rico. One and one-half times natural size.

few species of Alsophis lack this groove behind the eye entirely, and the labials grade into the temporals smoothly and without depression.

Those species that have their posterior upper labials bordered by a furrow and more or less straightened above are antillensis (fig. 104a); portoricensis (fig. 104b); leucomelas; ater; vudii; angulijer; adspersus; caymanus; and sanctae-crucis. Those with the posterior labials on a plane with the temporal region, with more or less serrate upper border, are melanichnus and rufiventris. Two species-anomalus and sibonius - show but a slight, short groove, extending only a little way behind the eye.

\section{ALSOPHIS ANOMALUS (Peters)}

Figure 105

1863. Zamenis anomalus Peters, Monatsb. Akad. Wiss. Berlin, 1863, p. 282 (type locality unknown).

1888. Dromicus (Alsophis) anomalus Fischer, Jahrb. Hamburg Wiss. Anst., vol. 5, p. 37 (Cape Haytien; Grand Rivière, Hayti; collector, H. Rolle).Müller, Verh. Naturf. Ges. Basel, vol. 10, No. 1, p. 203, 1892 ("Pet. Gonaives a. Haiti"”).-Boulenger, Catalogue of the snakes in the British Museum, vol. 2, p. 125, 1894 (Hayti).-Meerwarth, Mitth. Nat. Mus. Hamburg, vol. 18, p. 13, 1901. 
1914. Alsophis anomalus Barbodr, Mem. Mus. Comp. Zool., vol. 44, art. 2, p. 336; Zoologica, vol. 11, No. 4, p. 111, 1930; vol. 19, No. 3, p. 135, 1935; Bull. Mus. Comp. Zool., vol. 82, No. 2, p. 156, 1937.-Cochran, Proc. U. S. Nat. Mus., vol. 66, art. 6, p. 13, 1924; Occ. Pap. Boston Soc. Nat. Hist., vol. 8, p. 186, 1934.

1929. Leimadophis anomalus Amaral, Mem. Inst. Butantan, vol. 4, p. 164.

Description.-U.S.N.M. No. 59917, adult female collected at Jean Rabel, Haiti, May 8, 1917, by Dr. W. L. Abbott. Rostral slightly broader than high, well visible from above; snout projecting, rather pointed; internasals as long as broad; internasal suture half as long as prefrontal suture; frontal one and one-fourth as long as broad, broader than supraoculars, about equal in length to the parietal suture, as long as its distance from the tip of the snout; nostril large, between two large nasals; loreal small, rectangular, partially fused
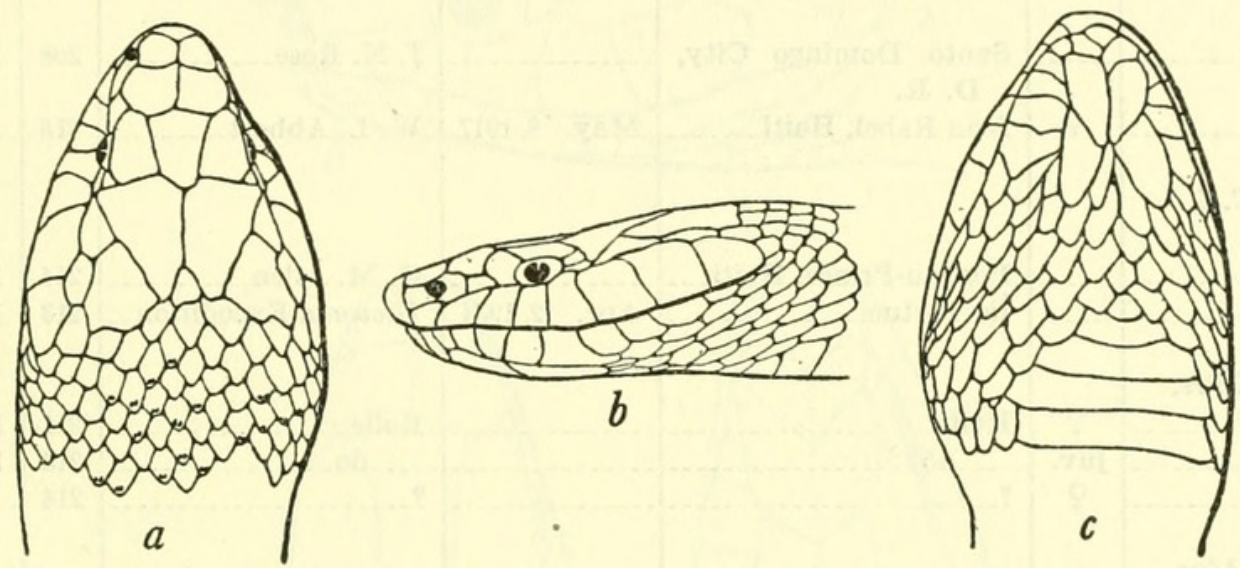

Figure 105.-Alsophis anomalus: $a$, Top of head; $b$, side of head; $c$, chin. U.S.N.M. No. 59917, from Jean Rabel, Haiti. One-half natural size.

with the nasal on the right side of the head; eye moderate; one preocular, not in contact with the frontal; two postoculars; a large subocular on the right side separating the fifth supralabial from the eye and on the left side fused with the fifth supralabial; temporals $1+2$, the uppermost of the second vertical temporal series very large, three-fourths the length of the parietals; eight supralabials, only the fourth entering the eye, the last three much higher and wider than the others; indications of a slight groove between the temporal and the sixth and seventh upper labials, whose upper borders are somewhat straightened; five (on one side four) lower labials in contact with the anterior chin shields which are as long as the posterior; 21 rows of smooth scales around the body, each scale with two conspicuous pores near the tip; 215 ventrals obtusely angulate laterally; anal divided; tail defective in this specimen.

Color (in alcohol): Above uniform russet brown, each scale becoming slightly darker toward the tip; ventrals uniform buff. The upper labials become lighter in the center; the lower labials and the chin shields are yellow, with their posterior margins dark brown. 
This specimen was measured by Dr. Abbott, who records that the head and body equaled $1,770 \mathrm{~mm}$. and the defective tail $130 \mathrm{~mm}$.; the ovaries contained 22 eggs.

Variations.-One other specimen in the U. S. National Museum, No. 49934, is much smaller and is albinistic, although traces of the russet brown body color are still apparent on top of the tail and toward the end of the body.

TABLE 68.-Specimens of Alsophis anomalus examined

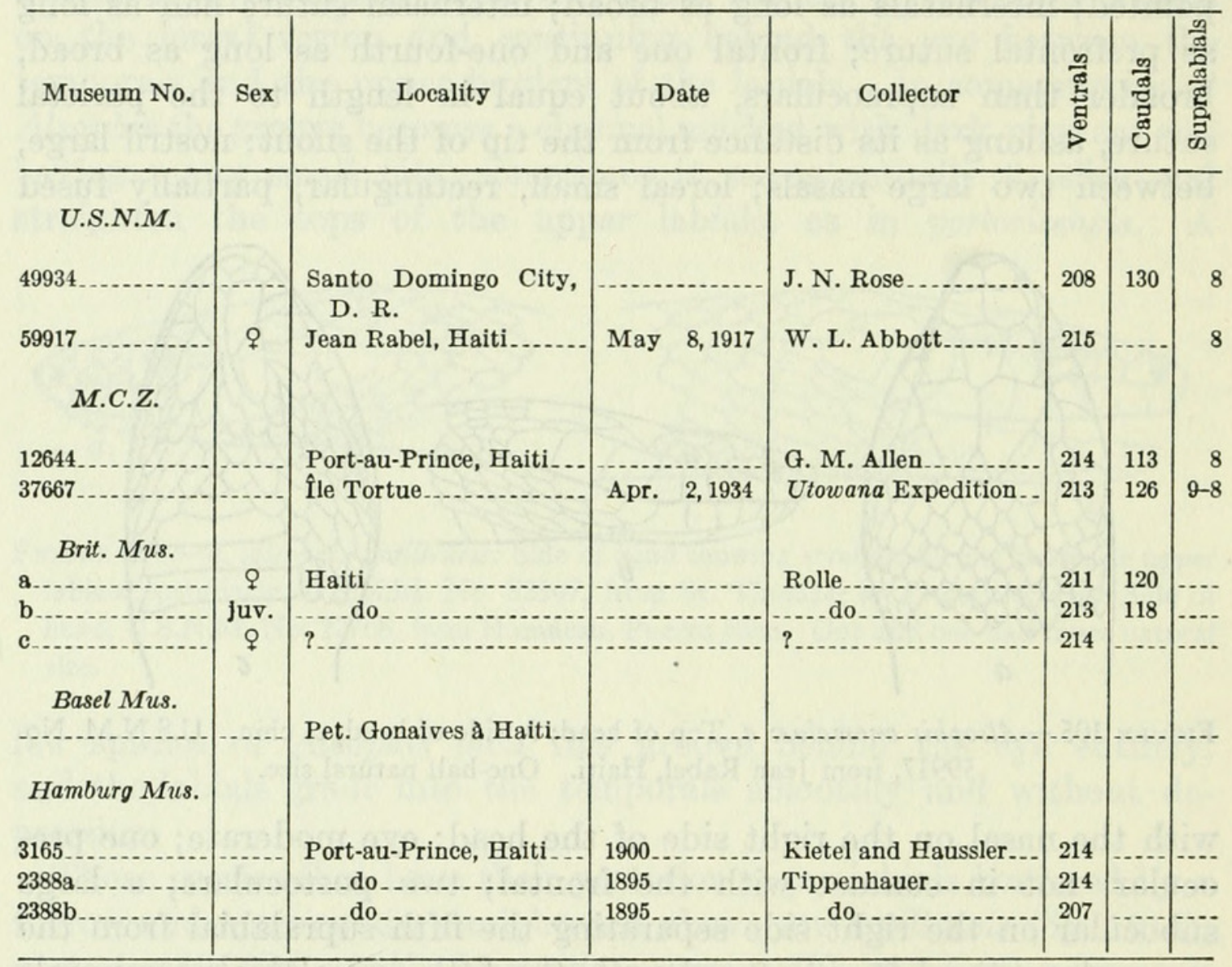

Regarding the Tortue specimen, M.C.Z. No. 37667, I made the following notes: Its head scales are similar in every respect to those of U.S.N.M. No. 49934 from Santo Domingo City, the latter slightly larger. In the M.C.Z. specimen, faint dark narrow cross bars are visible posteriorly, with even fainter suggestions of chevronshaped blotches on the neck and anterior part of the body. The head shields have very narrow dark margins. The entire under surface is pale, with a powdering of gray dots across the posterior border of each ventral.

Specimens examined.-As listed in table 68. 


\section{ALSOPHIS MELANICHNUS Cope}

FIGURE 106

1862. Alsophis melanichnus Cope, Proc. Acad. Nat. Sci. Philadelphia, 1862, p. 76.-Boulenger, Catalogue of the snakes in the British Museum, vol. 2, p. 122, 1894 (part under Dromicus sanctae-crucis).-BARBour, Bull. Mus. Comp. Zool., vol. 44, art. 2, p. 335, 1914 (not of Cope); Zoologica, vol. 11, No. 4, p. 112, 1930; vol. 19, No. 3, p. 136, 1935; Bull. Mus. Comp. Zool., vol. 82 , No. 2, p. $156,1937$.

1929. Leimadophis antillensis sancticrucis Amaral, Mem. Inst. Butantan, vol. 4, p. 164 (not of Cope).

Description.-Adult male; M.C.Z. No. 7836; Santiago de la Vega, Dominican Republic, 1910; A. H. Verrill, collector. Rostral broader
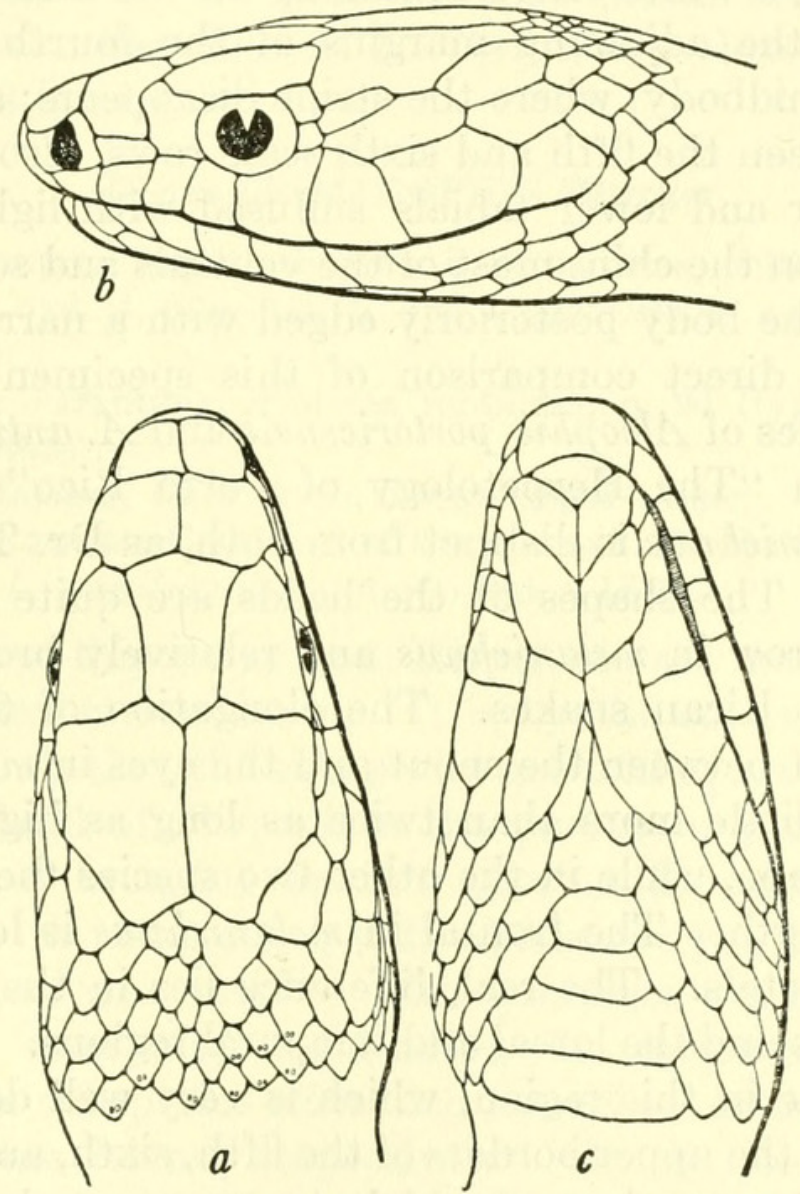

Figure 106.-Alsophis melanichnus: $a$, Top of head; $b$, side of head; $c$, chin. M.C.Z. No. 7836, from La Vega, Dominican Republic. One and one-half natural size.

than high,narrowly visible from above; internasal suture slightly shorter than prefrontal suture; frontal much broader than supraoculars, a little longer than its distance from the end of the snout, somewhat longer than the parietal suture; nostril large, between two large nasals; loreal very elongate, almost wedge-shaped, two-thirds as long as diameter of eye; one preocular, not in contact with frontal; two postoculars, the lower very small; temporals $2+2$, the upper anterior temporal on each side of the head very narrow and appearing to be abnormally divided off from the lower anterior temporal; supralabials eight on 
left side, nine (the third divided into two) on right side, the fourth and fifth normally entering the eye, the third almost entering; the fifth, sixth, and seventh upper labials highest, with no groove along their upper edges; five lower labials on each side in contact with anterior chin shields, which are shorter than the posterior; 17 rows of smooth scales around the body, with two pores near the tip of each dorsal scale; 189 ventrals; anal divided; 108 pairs of subcaudals.

Dimensions: Head and body, $830 \mathrm{~mm}$; t tail, $340 \mathrm{~mm}$. The dimensions of the type, M.C.Z. No. 1522, as given by Cope, are: Head and body, $630 \mathrm{~mm}$; tail, $260 \mathrm{~mm}$.

Color (in alcohol): Above uniform deep olive-green, not much lighter beneath; a white stripe beginning on the side of the neck, and continuing on the adjoining margins of the fourth and fifth scale rows as far as midbody, where the stripe disappears; a very indistinct black line between the fifth and sixth scale rows, also disappearing at midbody; upper and lower labials suffused with lighter color; some white blotches on the chin; most of the ventrals and some of the scales on the side of the body posteriorly edged with a narrow light border.

Remarks.-A direct comparison of this specimen of melanichnus with the examples of Alsophis portoricensis and A. antillensis described by Stejneger in "The Herpetology of Porto Rico" is sufficient to prove that melanichnus is distinct from both, as Dr. Thomas Barbour has indicated. The shapes of the heads are quite different, being elongate to narrow in melanichnus and relatively broad and short in the two Puerto Rican snakes. The elongation of the head is particularly evident between the snout and the eyes in melanichnus; thus the loreal is a little more than twice as long as high and is nearly triangular in shape, while in the other two species the height is about equal to the length. The frontal in melanichnus is longer in proportion to the parietals. The real difference lies in the region between the upper labials and the loreal and temporal regions. In portoricensis there is a groove in this region, which is very well developed behind the eye between the upper borders of the fifth, sixth, and seventh upper labials and the temporals, and which deepens to a channel filled with brown pigment and with little pits in the scales. Thus the upper edges of these labials are straightened, and a sharp, straight furrow runs backward from the eye to the beginning of the last labial in portoricensis. The allied antillensis also has this furrow, which is filled with dark pigment and is pitted similarly, although not quite so prominently. In melanichnus, however, there is no indication of such a channel, the posterior labials and temporals being fitted one to another in the customary mosaic style, and the whole region from the lip to the parietal being graduated and smooth, without any furrow or little pits. 
It is probable that the two specimens from San Domingo listed by Meerwarth as Dromicus sanctae-crucis portoricensis are either Alsophis melanichnus or an entirely new species. If they are true melanichnus then the range of ventral scales for that species would be from 174 to 189 , quite overlapping that of portoricensis, so that in future the presence or absence of a groove on the side of the head would have to be used to differentiate the two species, instead of the scale formula.

Garman ${ }^{18}$ lists Alsophis melanichnus from Bayamon, Puerto Rico, but the specimens he had were probably portoricensis, certainly not true melanichnus.

Specimens examined.-M.C.Z. No. 7836 (adult male), Santiago de la Vega, Dominican Republic, A. H. Verrill, 17 scale rows, 189 ventrals, 108 caudals, $8-9$ labials.

\section{Genus LEIMADOPHIS Fitzinger}

1842. Dromicus Bibron, in de la Sagra's Historia fisica, politica y natural de la isla de Cuba, vol. 4, Reptiles, p. 133 (type Coluber cursor) (not Dromica Dejean, 1826).

1843. Leimadophis Fitzinger, Systema reptilium, p. 26 (type, Coronella almadensis $=$ L. reginae).

1843. Calophis Fitzinger, idem (type, Herpetodryas cursor).

1894. Liophis Bodlenger, Catalogue of the snakes in the British Museum, vol. 2, p. 126 (type, L. poecilogyrus) (not of Wagler, 1830).

The members of this genus from Hispaniola are much alike as far as the head scalation is concerned. It is by the coloration and by the number of ventrals that the subspecies are told apart.

On the mainland of Hispaniola the parvifrons group seems to be still in process of breaking up into three subspecies geographically separated but with integrading individuals not yet eliminated. The same small differences coupled with complete separation from the mainland have eventually resulted in the formation of the more readily separable subspecies alleni and tortuganus known from Gonave Island and Tortue Island, respectively. On the mainland the least depauperate form, L. parvifrons protenus, shows the greatest variation in scale count and in color pattern, occupies the central position, and has the widest range, occurring over most of the island. In the northeastern part of the Dominican Republic on the Samana Peninsula and inland over the low area to La Vega, its type locality, occurs the melanistic form described by Dunn as Leimadophis p. niger. Numerous partly melanistic specimens with a fairly low ventral count may be found that cannot be definitely assigned to either protenus or niger. At the extreme tip of the southwestern peninsula, around Jérémie, Haiti, is found L. p. parvifrons. The difference between

${ }_{18}$ Proc. Amer. Philos. Soc., vol. 24, p. 283, 1887. 
protenus and parvifrons is very arbitrarily fixed, since specimens from near Jérémie with 142 to 149 ventrals are called parvifrons, while others from Miragoane and eastward with 149 or more are designated as protenus. It seems best to keep these subspecific names, as a difference does appear to exist between the three forms in spite of the integrading specimens.

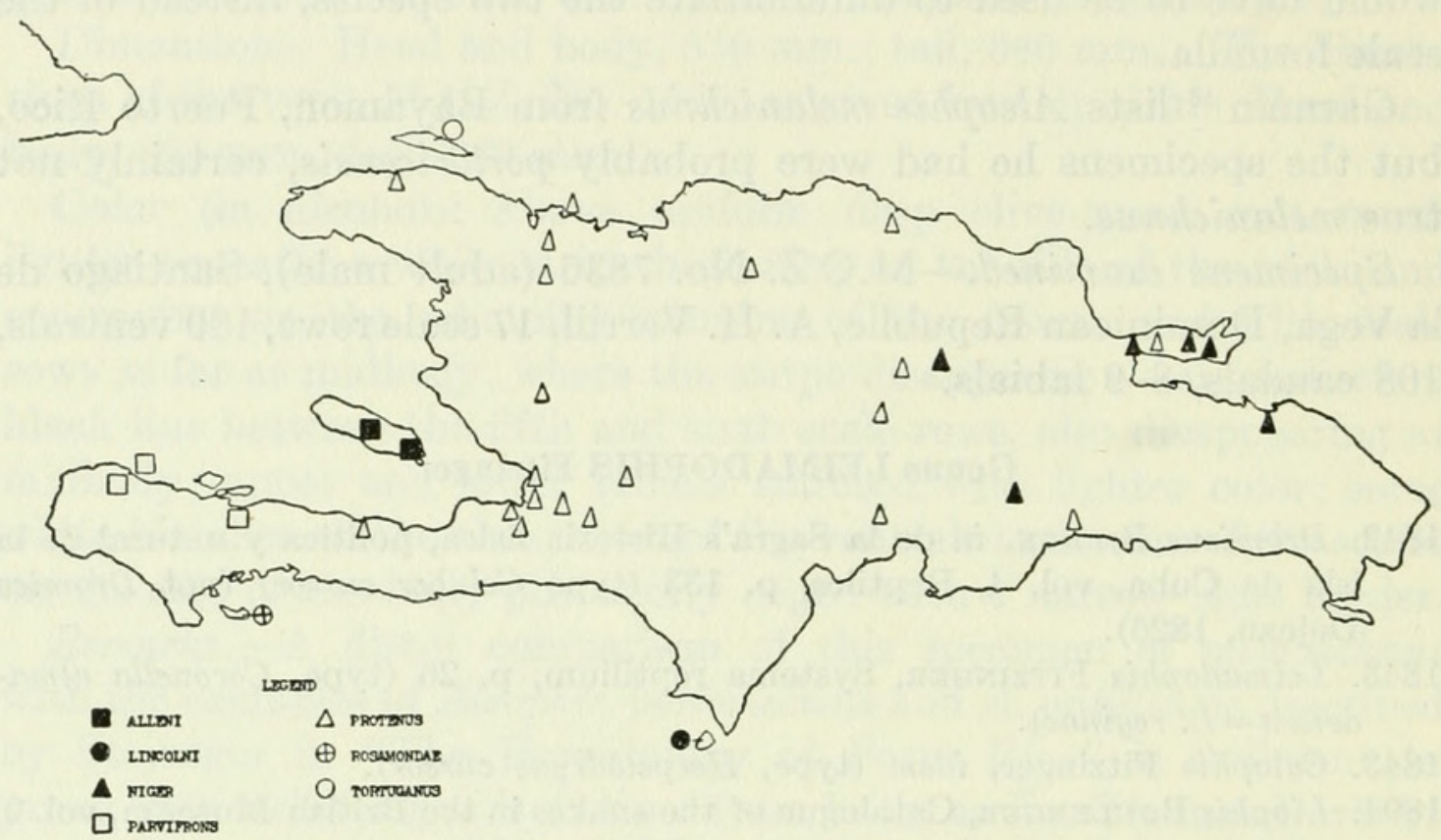

Figure 107.-Distribution of subspecies of Leimadophis parvifrons in Hispaniola.

KEY TO THE HISPANIOLAN SUBSPECIES OF LEIMADOPHIS PARVIFRONS

$a^{1}$. Frontal and supraoculars equal in width at their midlines (Beata

Island) . . . .

$a^{2}$. Frontal wider than supraoculars.

$b^{1}$. Color blackish, no distinct stripes

$b^{2}$. Distinct light lateral stripes on a dark ground color.

$c^{1}$. Light lateral stripe confined mostly to fifth and sixth scale rows anteriorly.

$d^{1}$. Ventral count low; ventrals $142-149 \ldots \ldots \ldots$..... parvifrons (p. 354 )

$d^{2}$. Ventral count higher; ventrals $149-167 \ldots \ldots \ldots$ protenus (p. 362 )

$c^{2}$. Light lateral stripe invading seventh scale row anteriorly.

$d^{1}$. Light lateral strip distinct on body and tail.

$e^{1}$. Ventrals 157-165 (Gonave Island) _.............. alleni (p. 365)

$e^{2}$. Ventrals 168-169 (Tortue Island) _..._.....- tortuganus (p. 367)

$d^{2}$. Light lateral stripe becoming reduced to small light spots down middle of sixth scale row, disappearing at midbody, ventrals 148-153 (Île à Vache) .....- rosam ondae (p. 368)

\section{LEIMADOPHIS PARVIFRONS PARVIFRONS (Cope)}

\section{Figures 107, 108, $115 f$}

1862. Dromicus parvifrons Cope, Proc. Acad. Nat. Sci. Philadelphia, 1862, p. 79 (type locality, Haiti near Jérémie; type in Mus. Comp. Zool.; collector, Dr. Weinland).-Garman, Proc. Amer. Philos. Soc., vol. 14, p. 282, 1887 (Jérémie, Hayti).-Müller, Verh. Naturf. Ges. Basel, vol. 10, pt. 1, p. 203, 1892 
(Cape Hayti).-Barbour and Loveridge, Bull. Mus. Comp. Zool., vol. 69, No. 10 , p. 254, 1929.-Leimadophis parvifrons BarBour, Mem. Mus. Comp. Zool., vol. 44, art. 2, p. 339, 1914 (part).-AMaral, Mem. Inst. Butantan, vol. 4 , p. $167,1929$.

1920. Leimadophis parvifrons parvifrons DunN, Proc. New England Zool. Club, vol. 7, p. 38.-Cochran, Proc. U. S. Nat. Mus., vol. 66, art. 6, p. 14, 1924. 1930. Dromicus parvifrons parvifrons Barbour, Zoologica, vol. 11, No. 4, p. 115; vol. 19, No. 3, p. 139, 1935; Bull. Mus. Comp. Zool., vol. 82, No. 2, p. 161, 1937.

Description.-Adult female; U.S.N.M. No. 60607; Moline, southwest Haiti; January 31, 1918; W. L. Abbott, collector. Rostral much broader than high, well visible from above; internasal suture shorter than prefrontal suture; frontal slightly longer than its distance from end of snout, shorter than parietals, widely separated from preocular; supraocular as wide as frontal; nasal divided, longer than its distance from eye; loreal small, as high as broad; one large preocular, two

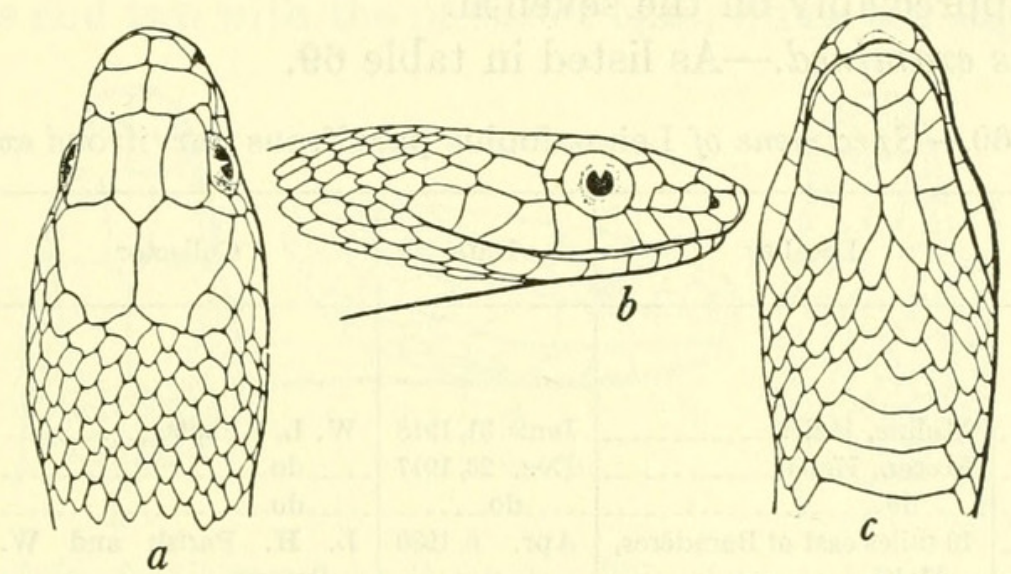

Figure 108.-Leimadophis parvifrons parvifrons: $a$, Top of head; $b$, side of head; $c$, chin. U.S.N.M. No. 60607, from Moline, Haiti. One and one-half times natural size.

postoculars; one large anterior temporal followed by two smaller ones; eight supralabials, the second in contact with posterior nasal and loreal, barely reaching the preocular; third, fourth, and fifth entering the eye; lower labials ten on right and nine on left side of mouth, four on each side in contact with the anterior chin shields and two with the posterior ones, which are the longer; scales smooth, without pores, in 19 rows; ventrals 148; anal divided; caudals 76 (tail defective). Head and body, $420 \mathrm{~mm}$.; tail, $192 \mathrm{~mm}$. +tip.

Color (in alcohol): Top of head and body dark olive-brown; a light ochraceous streak beginning at the nostrils, running back through the supraoculars and temporals, and continuing down the sides of the body on the sixth scale row and the upper half of the fifth; a dark brown streak from the nostril passing through the loreal and postoculars and continuing on the fourth scale row and the extreme lower edge of the fifth; a black stripe starting on the snout and continuing down the median dorsal row on back and tail; upper and lower 
labials and throat white; the ventral scales light anteriorly, darkening as midbody is approached; a black spot on the outer ends of the first 30 ventral plates.

Remarks.-This subspecies seems to be the rarest of the forms on the island itself. The five cotypes now in the Museum of Comparative Zoology and the four specimens in the National Museum are all that I have seen. Schmidt does not mention that the American Museum of Natural History had an example of the species in 1921. Boulenger's specimens were either protenus or niger, none being typical parvifrons.

Variations.-With so small a series, it is not possible to judge what the limits of variation in the ventral and caudal count for this race would be. At present all that can be said is that the ventral plates number around 142 to 149 , and the subcaudals 110 to 129 . The position of the lateral light stripe seems to be constant, for it extends over the upper half of the fifth and all of the sixth scale-rows, not infringing appreciably on the seventh.

Specimens examined.-As listed in table 69.

TABLE 69.-Specimens of Leimadophis parvifrons parvifrons examined

\begin{tabular}{|c|c|c|c|c|c|}
\hline Museum No. & Locality & Date & Collector & $\begin{array}{l}\text { Ven- } \\
\text { trals }\end{array}$ & $\begin{array}{l}\text { Cau- } \\
\text { dals }\end{array}$ \\
\hline \multicolumn{6}{|l|}{ U.S.N.M. } \\
\hline $60607(q) \ldots$ & Moline, Haiti . . . & Jan. 31,1918 & W. L. Abbott... & 148 & \\
\hline 60609 & Moron, Haiti & Dec. 23,1917 & . do & 146 & 118 \\
\hline $60610 \ldots$ & do & ................. & do & 146 & 117 \\
\hline 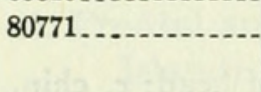 & $\begin{array}{l}10 \text { miles east of Baradères, } \\
\text { Haiti. }\end{array}$ & Apr. 6,1930 & $\begin{array}{l}\text { L. H. Parish and W. } \\
\text { Perrygo. }\end{array}$ & 149 & 129 \\
\hline M.C.Z. & & & & & \\
\hline 3344 (2 females) ... & Jérémie, Haiti.. & & D. F. Weinland...... & $\begin{array}{l}143 \\
142\end{array}$ & $\begin{array}{l}110 \\
112\end{array}$ \\
\hline & & 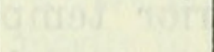 & & 142 & 111 \\
\hline 3602 (3 females) ... & ....do_. & & .......... & 142 & 116 \\
\hline & & & & 143 & 118 \\
\hline
\end{tabular}

\section{LEIMADOPHIS PARVIFRONS LINCOLNI Cochran}

Figdres 107, 109, $115 c$

1931. Leimadophis parvifrons lincolni Cochran, Proc. Biol. Soc. Washington, vol. 44, p. 91.-BArвodr, Zoologica, vol. 19, No. 3, p. 139, 1935; Bull. Mus. Comp. Zool., vol. 82, No. 2, p. 161, 1937.

1930. Dromicus parvifrons niger BARBoUR, Zoologica, vol. 11, No. 4, p. 114 (from Beata Island) (not of Dunn).

Original description.- "Diagnosis.-Frontal and supraocular plates equal in width measured across the center; internasals as long as the prefrontals; snout relatively long and narrow in front of eyes; dorsal black stripe only 3 scales in width; light lateral stripe on side of neck appearing broken into spots by the invasion of the sinuous black lateral stripe. 
"Type.-U.S.N.M. No. 83890, an adult from Beata Island, Dominican Republic, collected on May 15, 1931, by Dr. A. Wetmore and Mr. F. C. Lincoln. Rostral broader than deep; internasals as long as prefrontals; length of frontal one and one-fifth times its distance from the end of the snout, a little shorter than the parietals, separated from the preocular; supraocular only slightly narrower than the anterior portion of the frontal and equal to its width taken through the middle; nasal divided, a little longer than its distance from the eye; loreal moderate in size, squarish, a little broader than deep; one preocular; 2 postoculars, the upper slightly the larger; one anterior temporal followed by three smaller ones on the right (apparently normal) side of the head; the left side with $2+2$ rather irregular temporal series; eight upper labials, the second in contact with the posterior nasal and loreal but not reaching the preocular, the third, fourth, and fifth entering the eye; ten lower labials, five in contact with the anterior chin-shields and two with the posterior ones, which are slightly longer
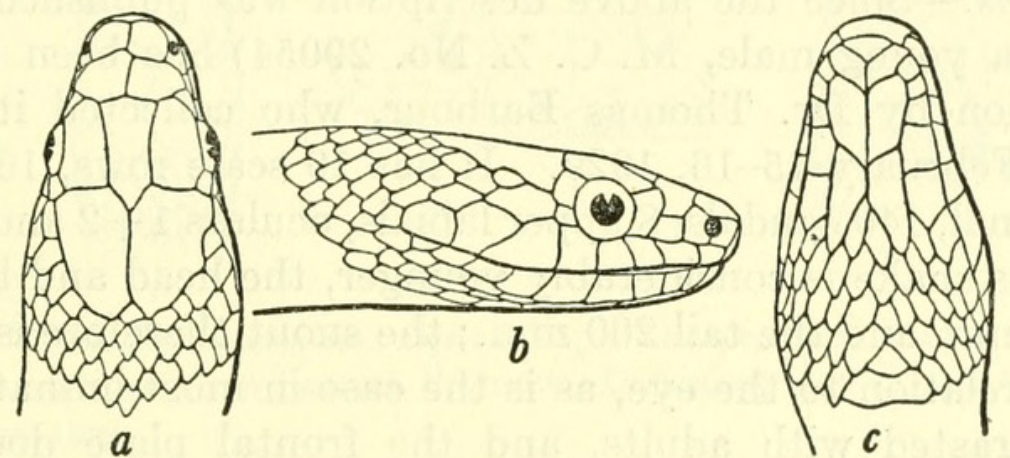

Figure 109.-Leimadophis parvifrons lincolni: $a$, Top of head; $b$, side of head; $c$, chin. U.S.N.M. No. 83890, type, from Beata Island, Haiti. One and one-half times natural size.

than the anterior; scales in 19 rows, without pores; ventrals 163 ; anal divided; caudals 128 with a considerable portion of the tail-tip missing.

"Color (in alcohol).- Top of head olive, this tone shading gradually into a wide black dorsal stripe; a light area beginning on the canthus, widening on the supraocular and continuing for about three headlengths along the body on the seventh and eighth scale-rows before it merges with the black uniform color of the body; a distinct black band beginning at the tip of the snout and continuing backwards as a sharp defining border to the light area as far as the occipital region; posterior to this region the black band undulates so that the light area is alternately narrow and wide, giving the appearance of light spots indistinctly fused; upper labials and chin vinaceous-buff, sharply contrasted to the dark lateral stripe on the head but becoming darker on the throat and finally turning to dull china blue mottled with dark plumbeous gray on the belly; the light tone extends on the side of the neck up to the middle of the fourth scale-row, but very shortly the 
dark plumbeous hue obscures its limits entirely, so that the ventral coloration seems to merge gradually with the uniform black of the dorsal tone; the anal plates and some of the preanal gastrosteges are largely vinaceous-buff, and the subcaudals show more of this color towards the tip, as the plumbeous clouding ceases.

"Dimensions.-Head and body, $507 \mathrm{~mm}$.; tail (defective), $350 \mathrm{~mm}$.

"This subspecies is recognizable at a glance, for it is the only one that shows any indication of spots taking the place of stripes. Its snout is relatively longer than in any other subspecies of Leimadophis parvifrons as evidenced by the nearly equal internasal and prefrontal lengths and the very narrow frontal. In the narrowness of the black dorsal stripe the new subspecies is closest to tortuganus from Tortuga Island, which has a width of four scales on the neck widening to five further back. The new subspecies is one in which differentiation has proceeded furthest from the original stock exemplified by Leimadophis parvifrons parvifrons from western Haiti."

Variations.-Since the above description was published, a second specimen (a young male, M. C. Z. No. 29054) has been brought to my attention by Dr. Thomas Barbour, who collected it on Beata Island on February 15-16, 1929. It has 19 scale rows, 165 ventrals, a divided anal, 140 caudals, 8 upper labials, oculars $1+2$ and temporals $1+2$. This snake is considerably younger, the head and body measuring $283 \mathrm{~mm}$. and the tail $200 \mathrm{~mm}$.; the snout therefore is somewhat shorter in relation to the eye, as is the case in most immature snakes when contrasted with adults, and the frontal plate does not yet display the narrowed proportions so obvious in the fully adult type specimen.

The two snakes are almost identical in pattern, except that in the younger the tones are much more definite. From the neck to three or four head lengths behind the head a lateral series of black, confluent, diamond-shaped spots are apparent, giving to the narrow light line directly above a very zigzag appearance. In both snakes small scattered black dots occur on the anterior part of the belly, although posteriorly the young snake is not suffused with dark, which is again a juvenile characteristic.

\section{LEIMADOPHIS PARVIFRONS NIGER DUnn}

Figures $107,110,115 e$

1920. Leimadophis parvifrons niger Dunn, Proc. New England Zool. Club., vol. 7, p. 39.-Schmidt, Bull. Amer. Mus. Nat. Hist., vol. 44, art. 2, p. 20, 1921.Cochran, Proc. U. S. Nat. Mus., vol. 66, art. 6, p. 14, 1924.-Barbour and Loveridge, Bull. Mus. Comp. Zool., vol. 69, No. 10, p. 288, 1929.

1894. Liophis parvifrons Boulenger, Catalogue of the snakes in the British Museum, vol. 2, p. 141 (specimen $h$ ) (part).

1930. Dromicus parvifrons niger Barbour, Zoologica, vol. 11, No. 4, p. 114; vol. 19, No. 3, p. 139, 1935; Bull. Mus. Comp. Zool., vol. 82, No. 2, p. 161, 1937. 
Description of a paratype.-Adult male; U.S.N.M. No. 55031; Samaná Peninsula, Dominican Republic; 1916; W. L. Abbott, collector. Rostral broader than deep; internasal suture not quite so long as prefrontal suture; frontal longer than its distance from end of snout, shorter than the parietals, not in contact with the preocular; supraocular narrower than frontal; nasal divided, longer than its distance from eye; loreal small, 4-sided, slightly longer than deep; one preocular; two postoculars nearly equal in size on theleft side, the lower postocular divided horizontally on right; one large anterior temporal followed by two smaller ones; eight upper labials, the second in contact with posterior nasal and loreal but rather widely separated from the preocular; fourth and fifth supralabials broadly and third narrowly in contact with eye; ten lower labials, five in contact with anterior chin shields and two with the posterior ones; the anterior and posterior
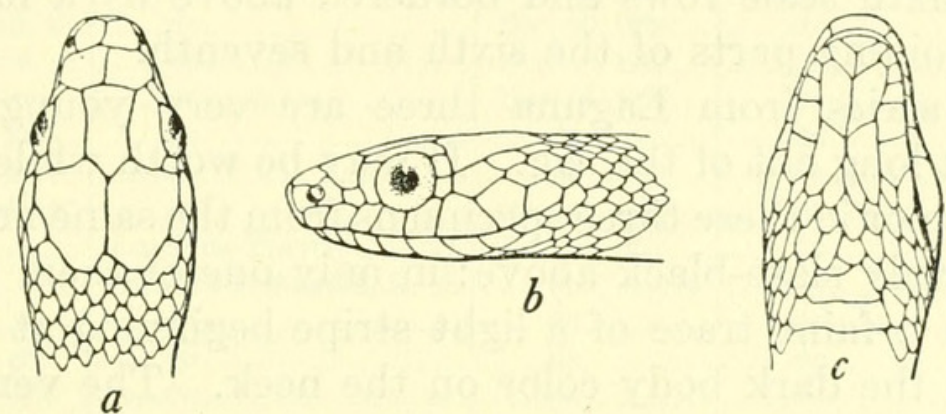

FigURE 110.-Leimadophis parvifrons niger: $a$, Top of head; $b$, side of head; $c$, chin. U.S.N.M.

No. 55031, paratype, from Samaná Peninsula, Dominican Republic. One and one-half times natural size.

chin shields equal in length; scales in 19 rows, without pores; ventrals 151; anal divided; caudals 132 . Head and body, $369 \mathrm{~mm}$.; tail, 273 $\mathrm{mm}$.

Color (in alcohol): Body black above and below; head black above, the lower border of rostral and labials white; throat white, spotted with black; the first few ventral plates white in the center; a few white scales just behind the corner of the mouth, indistinctly continued as light-edged scales occasionally found on the first three scale rows; the anal plates and a few ventrals preceding it marked with white; under side of tail posteriorly white.

Variations.-While all the adult specimens in the National Museum show a uniformly black dorsal surface, the variation in color on the ventral surface is noticeable. In some specimens the white spots on the scales of the anal region are entirely absent and only the extreme tip of the tail is white; in quite a number these spots are as in the described specimen, while on a few snakes (one of which is No. 55026, also a paratype) the light color is found on nearly every ventral scale from midbody to tail tip. 
There is a young snake (No. 55032, one of the paratypes) that is uniformly white on the whole ventral surface, with the exception of a few black spots near the ends of the first 30 ventrals. This snake, instead of being an intense lustrous black above, is more nearly olivebrown, with the first two scale rows lightening to grayish blue, which color also appears at the extreme outer ends of the ventrals. There is a trace of a light stripe leading from the eye through the outer border of the parietals, but this stripe quickly merges with the dark body color. Another snake nearly fully grown (No. 65787) is light beneath, although some of the ventrals are suffused with dark on their anterior edges. This specimen, which is also olive-brown, shows a very distinct narrow black middorsal stripe leading from the neck almost to the beginning of the tail. On this specimen anteriorly there are indications of a dark lateral stripe occurring on the fourth, fifth, and part of the sixth scale rows and bordered above by a narrow white stripe on adjoining parts of the sixth and seventh.

Out of a series from Laguna three are very young specimens, evidently not long out of the egg. It may be worth while to note the variation in color in these three specimens from the same brood. They are all uniformly slate-black above; in only one of them (No. 66723) is there even a faint trace of a light stripe beginning at the eye and merging into the dark body color on the neck. The ventral surface is dark bluish gray in two of them (Nos. 66721 and 66722), while in the third the belly is nearly white. In No. 66722 the throat and chin are heavily speckled with black, a black spot appearing even on the first, fifth, and sixth upper labials on both sides; in the other two snakes the chin and throat are nearly immaculate. In all these specimens there is a more or less regular series of dots along the outer ends of the anterior ventral scales, while a row of black spots on the side of the neck occupying parts of the first and second scale rows can be readily discerned in two of the specimens. A nearly adult snake from Jovéro (No. 65787) and another from Liali (No. 65788) show lateral stripes, though the dorsal surface is much darker in hue than the average protenus. The ventral coloration is also light, and I regard these specimens as approaching protenus, though still bearing much of the melanism characteristic of niger.

Specimens examined.-As listed in table 70. 
TABLE 70.-Specimens of Leimadophis parvifrons niger examined

\begin{tabular}{|c|c|c|c|c|c|c|}
\hline Museum No. & Sex & Locality & Date & Collector & $\begin{array}{l}\text { 胥 } \\
\text { 点 } \\
\stackrel{0}{0}\end{array}$ & 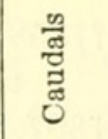 \\
\hline \multicolumn{7}{|l|}{ U.S.N.M. } \\
\hline 55026 (paratype).- & $\sigma^{7}$ & Samaná Peninsula, D. R. & 1916 & W. L. Abbott... & 152 & 126 \\
\hline 55027 (paratype) .. & $\sigma^{7}$ & 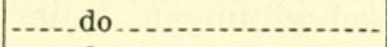 & 1916. & ....... do & 150 & -...... \\
\hline 55028 (paratype) .. & व & - do & 1916 & $\ldots$ do $\ldots$ & 155 & (n...... \\
\hline 55029 (paratype) -- & 우 & -.... do & 1916 & ..... do ..... & 151 & $\ldots$ \\
\hline 55030 (paratype) -- & 우 & 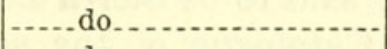 & $1016 \ldots$ & .....do..... & 147 & 125 \\
\hline 55031 (paratype) -- & $\sigma^{7}$ & -... do & $1916 \ldots$ & ..... do ..... & 153 & 132 \\
\hline 55032 (paratype) -- & 우 & ..... do $\ldots . . . .$. & 1916 & $\ldots$ do ....... & 155 & ........ \\
\hline 63600 & - n. & Laguna, D. R & Dec. $23,1920 \ldots$ & ..... do...... & 153 & 124 \\
\hline $63601 \ldots \ldots$ & .......... & - . do do & Dec. $26,1920 \ldots$ & ......do..... & 154 & 124 \\
\hline $65787 \ldots \ldots$ & & Jovéro, D. R.... & Feb. $18,1923 \ldots$ & $\ldots$ do $\ldots . . .$. & 150 & 126 \\
\hline $65788 \ldots$ & - n & Liali, D. R..... & Feb. $12,1923 \ldots$ & .....do... & 151 & 125 \\
\hline 66717 & ad. वౌ & Laguna, D. R.. & Dec. $12,1923 \ldots$ & ....... do .... & 151 & -......... \\
\hline $66718 \ldots$ & ad. $\%$ & ....... do & Dec. $16,1923 \ldots$ & ...... do . . & 152 & 125 \\
\hline $66719 \ldots \ldots$ & ad. $\sigma^{7}$ & - do . . . . & Dec. $20,1923 \ldots$ & -.... do . . . & 155 & -......... \\
\hline 66720 & juv. ఠ & .....do do $\ldots . . . .$. & Dec. $15,1923 \ldots$ & ..... do ..... & 148 & -....... \\
\hline $66721 \ldots$ & juv. & ...... do & Dec. 16, 1923... & -..... do ..... & 156 & 128 \\
\hline $66722 \ldots$ & juv. & - . do $\ldots . . . . .$. & ..... do . . . . & ..... do..... & 151 & 129 \\
\hline $66723 \ldots$ & juv. & -.... do . . . . & ...... do $\ldots$ & ..... do .... & 152 & 135 \\
\hline $66724 \ldots \ldots$ & ad. o’? & .....do do & Dec. $12,1923 \ldots$ & ......do do.... & 154 & (.......... \\
\hline 66725 & -........ & Loma de Traverso, D. R- & Dec. $14,1923 \ldots$ & ......do do... & 154 & (n....... \\
\hline $66774 \ldots . . . . . . .6$ & - n........ & Samaná Peninsula, D. R. & 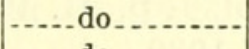 & ......do.... & 154 & (n........ \\
\hline $66775 \ldots$ & -........ & - do do n & -..... do & -..... do.... & 156 & -....... \\
\hline 66776 & $\sigma^{\top} ?$ & .....do do . . . . & -..... do ... & .... do do.... & 152 & -....... \\
\hline $66777 \ldots$ & व’? & -.... do . . .... & ...... do... & -....do... & 148 & $120+$ \\
\hline $66778 \ldots \ldots$ & (n......... & -....do........ & -.....do... & -.....do...... & 151 & (n....... \\
\hline $66779 \ldots$ & o’? & ..... do & ......do do... & ......do........ & 152 & 127 \\
\hline $66780 \ldots$ & $\sigma^{7}$ & ...... do.. & -....... do & -.... do & 157 & 135 \\
\hline (n) & juv. & -........ do & -....do... & ......do....... & 148 & 121 \\
\hline $\begin{array}{l}66782 \\
66783\end{array}$ & (n......... & -......... & -............... & ..... do....... & 149 & 131 \\
\hline 66783 & (n) & -....... & -...... do & ....... do & $\cdots-$ & (n) \\
\hline 66784 & juv. & - do & ....dondo....... & ............... & 151 & 126 \\
\hline $66970_{--}$ & $\ldots \ldots$ & $\begin{array}{l}6 \text { miles northeast of Sa- } \\
\text { maná, D. R. }\end{array}$ & February 1924.- & J. King ..... & 151 & -........ \\
\hline 69434 & - n. & Rivière Froide, Haiti.... & Aug. 20, 1925 ... & W. A. Hoffman. & 153 & $111+$ \\
\hline $72638 \ldots \ldots$ & - & Sánchez, D. R.............. & May $13,1927 \ldots$ & A. Wetmore...- & 149 & 123 \\
\hline 72639 & juv. & - do do & ....do........... & .....do do . . & 153 & 121 \\
\hline 74954 & -........ & Río San Juan, D. R...... & March 1928_... & G. S. Miller, Jr - & 155 & 121 \\
\hline 74955 & & -... do & .....do........... & ..... do . . . & 153 & -...... \\
\hline $74956 \ldots$ & & -.... do ..... & ...... do ... & ....... do . . & 155 & 120 \\
\hline $74957 \ldots \ldots$ & $\cdots$ & ...... do .... & ..... do. . & ..... do . . . & 155 & 134 \\
\hline $74958 \ldots$ & & ...... do & -.... do ..... & -... do.............. & 148 & 123 \\
\hline \multicolumn{7}{|l|}{ F.M.N.H. } \\
\hline 5988 & ㅇ & Sánchez, D. R... & $-\ldots$ & E. Kaempfer.... & 155 & 115 \\
\hline $5989 \ldots$ & ఠ’ & $\ldots$ do $\ldots . . . . . . .$. & $\ldots$ & ..... do . . . ....... & 154 & 126 \\
\hline $5999 \ldots \ldots$ & $\sigma^{7}$ & -... do do . . & - & -.... do & 155 & 134 \\
\hline \multicolumn{7}{|l|}{ M.C.Z. } \\
\hline 7833 (type) & \& & La Vega, D. R & - n........... & & 149 & $111+$ \\
\hline 7833 & ㅇ & - do do $_{-}$ & 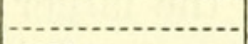 & - & 156 & -....... \\
\hline $43692 \ldots \ldots$ & & $\begin{array}{l}\text { Santa Barbara do Sa- } \\
\text { mana, D. R. }\end{array}$ & $1937 \ldots \ldots \ldots$ & W. J. Clench...- & 156 & 138 \\
\hline $43693 \ldots$ & & - do & $1937 \ldots \ldots$ & ..... do .... & 150 & -........ \\
\hline 43694 & - n...... & - do do & $1937 \ldots \ldots$ & -....do do & 151 & 135 \\
\hline 43695 & & - ... do do & $1937 \ldots \ldots$ & -.... do............... & $\ldots$ & 131 \\
\hline
\end{tabular}




\section{LEIMADOPHIS PARVIFRONS PROTENUS (Jan)}

Figdres $107,111,115 g$

?1858. Dromicus lineatus GüNTHER, Catalogue of colubrine snakes in the collection of the British museum, p. 132 (part?).

1867. Dromicus protenus $\mathrm{J}_{\mathrm{AN}}$, Iconographie générale des ophidiens, livr. 25, pl. 3, fig. 2 (type locality, Port-au-Prince, Hayti; type in Hamburg Mus.).

1869. Dromicus parvifrons Cope, Proc. Amer. Philos. Soc., vol. 11, p. 164 (eastern San Domingo); vol. 18, p. 273, 1879.

1883. Leptophis frenatus Fischer, Beschreibungen neuer Reptilien, SeparatAbdruck aus dem Osterprogramm des akademischen Gymnasiums, Hamburg p. 8, pl. - , figs. 9-11 (type locality said to be Sierra Leone).

1894. Liophis parvifrons Bodlenger, Catalogue of the snakes in the British Museum, vol. 2, p. 141 (part).

1914. Leimadophis parvifrons Barbour, Mem. Mus. Comp. Zool., vol. 44, pt. 2, p. 339 (part).

1920. Leimadophis parvifrons protenus Dunn, Proc. New England Zool. Club, vol. 7, p. 38.-Schmidt, Bull. Amer. Mus. Nat. Hist., vol. 44, p. 19, 1921.Cochran, Proc. U. S. Nat. Mus., vol. 66, art. 6, p. 14, 1924; Proc. Biol. Soc. Washington, vol. 41, p. 54, 1928.

1930. Dromicus parvifrons protenus Barbour, Zoologica, vol. 11, No. 4, p. 114; vol. 19, No. 3, p. 139, 1935; Bull. Mus. Comp. Zool., vol. 82, No. 2, p. 161, 1937.-Cochran, Occ. Pap. Boston Soc. Nat. Hist., vol. 8, p. 188, 1934Mertens, Senckenbergiana, vol. 20, No. 5, p. 342, 1938; Publ. Inst. Cient. Domínico-Alemán, vol. 1, p. 94, 1939.-Böker, Publ. Inst. Cient. DomínicoAlemán, vol. 1, p. 18, 1939.
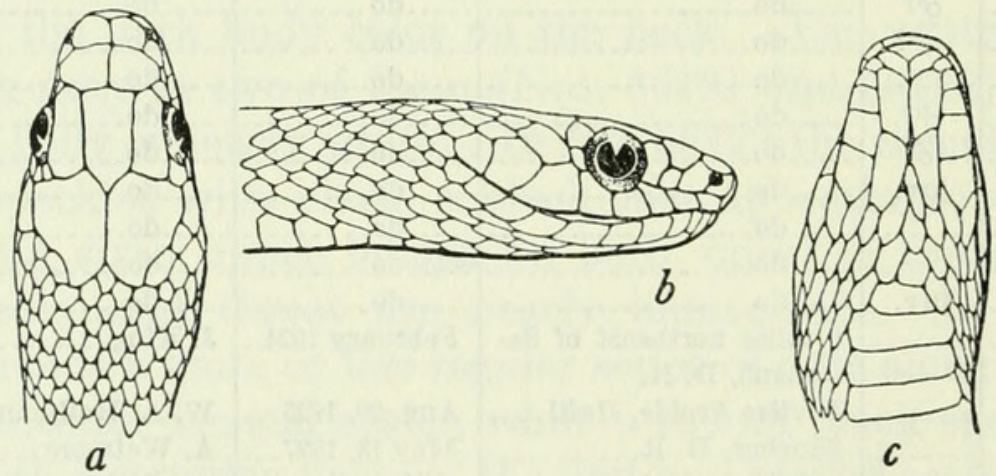

FIGURE 111.-Leimadophis parvifrons protenus: $a$, Top of head; $b$, side of head; $c$, chin. U.S.N.M. No. 65789, from Las Cañitas, Dominican Republic. One and one-half times natural size.

Description.-Adult male, U.S.N.M. No. 65789; Las Cañitas, Dominican Republic; February 25, 1923; W. L. Abbott, collector. Rostral broader than deep; internasal suture much shorter than the prefrontal suture; frontal longer than its distance from end of snout, shorter than parietals, separated from preocular; supraocular considerably narrower than frontal; nasal divided, longer than its distance from eye; loreal small, a little deeper than broad; one preocular; two postoculars, the upper the larger; one anterior temporal followed by two smaller ones; eight upper labials, the second in contact with the posterior nasal and loreal but not reaching the preocular, the third, fourth, and fifth entering the eye; 10 lower labials, five in contact with the anterior chinshields and two with the posterior ones, which are equal in length to the anterior; scales in 19 rows, without pores; 
ventrals 157; anal divided; caudals 128 . Head and body, $371 \mathrm{~mm}$; tail, $259 \mathrm{~mm}$.

Color (in alcohol): Top of head and back olive-brown; a white line beginning on the snout and continuing on the canthus rostralis, passing through the upper portion of the eye and backward ihrough the upper postocular and parietal and onto the adjoining halves of the fifth and sixth scale rows down the body; on the tail the light stripe occupies the middle of the second row for half the distance, where it merges with the olive-brown color to the tip; a dark olive stripe beginning at the tip of the snout, continuing on the side of the head and on the fourth and lower half of the fifth scale rows; the first three scale rows bluish gray, the edges occasionally olive; upper labials white; chin and throat cream-white, with a few dark spots on the lower labials and others scattered on the anterior ventrals; lower surface of body creamcolor; the outer edges of the ventrals, and posteriorly their anterior borders also suffused with bluish gray; subcaudals cream color with bluish-gray marks on the outer and inner borders; posterior third of the tail immaculate.

Variation.-Color variation is very marked in this species, especially middorsally. The lower dark lateral stripe is quite constant, as is the light stripe bordering it above, always on part of the fifth, all the sixth, and usually also on the lower part of the seventh scale rows. The dark lateral stripe just described originates at the nostril and passes through the eye; the light bordering stripe is first seen on the canthus rostralis, broadening on the supraocular region and continuing backward on neck and body. The middorsal stripe originates on the snout and continues over the parietal region; on the neck it is four and two half-scales wide, but increases until by midbody it covers seven and two half-scales. This stripe may remain uniformly dark throughout its entire length. It usually disintegrates behind the head into a series of black-spotted olive scales with the median dorsal row sometimes prominent and black and sometimes not at all differentiated by color. To make this row seem more clear-cut when it is differentiated, the scales on either side of it are frequently flecked with white at the tips, while the outer ones of the stripe are uniformly dark, so that it appears that this middorsal stripe is made up of five little stripes altogether-three dark ones and two lighter. The ventral surface may be a more or less uniform light olive, with only a little invasion of the lateral dark pigment on the ends of the gastrosteges, or there may be (and usually is) a plentiful scattering of round black dots more or less in regular pairs on the throat, and a black dot on the end of every ventral. These gradually disappear near midbody.

Habits. - The stomach of No. 74498 contained the remains of a fullgrown Anolis chloro-cyarus.

Specrmens examined.-As listed in table 71. 
TABLE 71.-Specimens of Leimadophis parvifrons protenus examined

\begin{tabular}{|c|c|c|c|c|c|c|}
\hline Museum No. & Sex & Locality & Date & Collector & 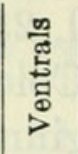 & 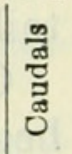 \\
\hline \multicolumn{7}{|l|}{ U.S.N.M. } \\
\hline $30 \ldots$ & & Dominican Republic.. & & W. Gabb... & 159 & 122 \\
\hline 31 -. & $\sigma^{7}$ & -...do do & & .....do do & 154 & 120 \\
\hline $33 \ldots$ & $\sigma^{7}$ & do & $\ldots$ & -................. & 152 & 113 \\
\hline 278 & \& & Puerto Plata, D. R............ & & C. A. Fraser... & 157 & 111 \\
\hline 44 & $\sigma^{7}$ & Port-au-Prince, Haiti... & & A. C. Younglo & 153 & 118 \\
\hline 46.-. & ㅇ & do & & _.....do do & 157 & 115 \\
\hline $45 \ldots$ & \& & Azua, D. R........ & March 20, 1913... & J. N. Rose.... & 160 & \\
\hline 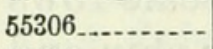 & q & Jarabacoa, D. R. & Oct. 12,1916 & W. L. Abbott & 156 & \\
\hline$n^{2}$ & ... & - do do $^{-2}$ & - do & -... do & 157 & 111 \\
\hline 08 & q & El Río, D. R & October $1916 \ldots$ & -... do & 156 & $\ldots$ \\
\hline $09 \ldots$ & \% & -... do do & -.....do do & ....... do & 153 & $\ldots$ \\
\hline $310 \ldots$ & ㅇ & - do do & - do do & - do & 152 & $\ldots$ \\
\hline 311 & & - do do & -............. & -.... do & 158 & -... \\
\hline $55312 \ldots$ & $\sigma^{7} ?$ & 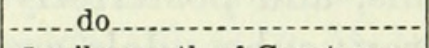 & ..... do do...... & ..... do & 156 & 111 \\
\hline 55313 & 운 & $\begin{array}{l}5 \text { miles north of Constanza, } \\
\text { D. } \mathrm{R} \text {. }\end{array}$ & -..... do & ...... do & 153 & 116 \\
\hline 314 & $\sigma^{7}$ & 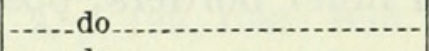 & do do & -................ & 158 & $\ldots$ \\
\hline 5 & ᄋ & -....do do & -.....do do & - do do & 161 & 114 \\
\hline 59171 & $\sigma^{x}$ & $\begin{array}{l}\text { Between Port-an-Prince and } \\
\text { San Croix Mission, Haiti. }\end{array}$ & Apr. $24,1917 \ldots$ & $\begin{array}{l}\text { J. B. Henderson and } \\
\text { P. Bartsch. }\end{array}$ & 163 & 121 \\
\hline 59441 & \% & Moustique, Haiti. ............ & Mar. 4, 1917...... & W. L. Abbott & 160 & 111 \\
\hline & & Mao-Yaqui Valley, D. R & 1921 & -... do & 163 & 117 \\
\hline & & Las Cañitas, D. R & Feb. 25, 1923... & $\ldots d$ & 157 & 128 \\
\hline & & Repos, Haiti.............. & Mar. 3, 1925 ... & G. S. Miller, Jr .... & 153 & -... \\
\hline & $-\cdots$ & San Michel du Nord, Haiti. & Apr. 6,19 & -...do do & 165 & 127 \\
\hline & & do & Mar. 27,1 & .................... & 159 & 119 \\
\hline & & Miragoane, I & Sept. 26,1 & W. J. Eyerda & 154 & -... \\
\hline & & ti.......... & Mar. 3-6, 1928_... & A. J. Poole.... & 155 & $\ldots$ \\
\hline 74498 & & San Michel du Nord, Haiti. & $\begin{array}{l}\text { Dec. } 20, \quad 1927- \\
\text { Mar. } 15,1928\end{array}$ & ..... do & 157 & .... \\
\hline & & ............... & _... do do............ & 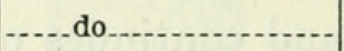 & 160 & \\
\hline & & - do do & - do do & $\ldots d$ & 159 & 112 \\
\hline & & - do do & ....do do & - do & 160 & 124 \\
\hline 75891 & & $\begin{array}{l}\text { Damien, Port-au-Prince, } \\
\text { Haiti. }\end{array}$ & 1928 & J. S. C. Boswell. & 160 & $\ldots$ \\
\hline 75892 & & do & & -...... do & 149 & 109 \\
\hline 601. & & Pétionville, Haiti. & $1928 \ldots \ldots$ & $\ldots d$ & 158 & 116 \\
\hline 902 & . & Diquini, Haiti. . . & 1928 & do & 156 & 115 \\
\hline 76646 & & San Michel du Nord, Haiti. & Dec. $21-31,1928$ & $\begin{array}{l}\text { A. J. Poole and W. } \\
\text { Perrygo. }\end{array}$ & 158 & 112 \\
\hline & & & ....do do & -...do do & 159 & 114 \\
\hline $650 \ldots$ & & lore & January $1929 \ldots$ & .............. & 165 & 117 \\
\hline $76659 \ldots$ & & Dondon, Haiti. & Jan. 10-20, 1929_.. & 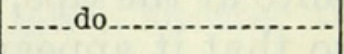 & 154 & $-\cdots$ \\
\hline & & & & & & \\
\hline & & & $1927 \ldots$ & W. J. Eyerdam. . & & $\cdots$ \\
\hline $25565 \ldots$ & & .............. & 1927 & ......do do & $\ldots$ & $-\cdots$ \\
\hline $25566 \ldots$ & & Cap-Haitien, Haiti.. & Oct. 4, 1927....... & -...do do & $\ldots$ & $-\cdots$ \\
\hline $37673 \ldots$ & & do & Mar. 31, 1934 & Utowana Expedition.. & 157 & 111 \\
\hline 37674 & & $\ldots$ do & -.... do & do & 159 & 120 \\
\hline 37675 & & Thomazeau, Haiti............. & 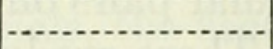 & A. Audant & 158 & 120 \\
\hline $37676 \ldots$ & & $\begin{array}{l}\text { Cul-de-Sac, near Port-au- } \\
\text { Prince, Haiti. }\end{array}$ & & ..... do & 157 & \\
\hline & & Sosúa, D. R & 1937 & W. J. Clench.............. & 155 & 112 \\
\hline & & do & 1937 & 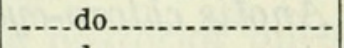 & 153 & 102 \\
\hline 43561.... & & | & | $1937 \ldots \ldots \ldots . . . .$. & - do & 152 & \\
\hline
\end{tabular}


TABLE 71.-Specimens of Leimadophis parvifrons protenus examined-Continued

\begin{tabular}{|c|c|c|c|c|c|c|}
\hline Museum No. & Sex & Locality & Date & Collector & 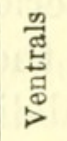 & 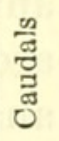 \\
\hline F.M.N.H. & \multirow{7}{*}{$\begin{array}{c}\sigma^{\top} \\
\text { juv. } \\
\text { juv. } \\
\wp \\
\text { juv. } \\
\wp\end{array}$} & & & & \multirow{7}{*}{$\begin{array}{l}149 \\
160 \\
158 \\
159 \\
157 \\
153\end{array}$} & \multirow[b]{2}{*}{118} \\
\hline $100 \ldots . .$. & & Santo Domingo City, D. R & $1895_{\ldots} .$. & G. K. Cherrie.. & & \\
\hline $13250 \ldots$ & & Kenskoff, Haiti.............. & Dec. 2,1928 . & K. P. Schmidt_ & & \\
\hline $13264 \ldots$ & & Citadel, Haiti..... & Dec. 5,1928 . & ...... do & & 122 \\
\hline $13265 \ldots$ & & ...._do do_._._._. & ......do_....... & ...... do _..... & & \\
\hline $13267 \ldots$ & & Diquini, Haiti....... & Dec. 7,1928 . & ......do........ & & 111 \\
\hline $13269 \ldots$ & & ...... do & ...... do & ......do_...... & & 125 \\
\hline
\end{tabular}

\section{LEIMADOPHIS PARVIFRONS ALLENI Dunn}

Figures 107, 112, 115a

1920. Leimadophis alleni Dunn, Proc. New England Zool. Club, vol. 7, p. 40.Cochran, Proc. U. S. Nat. Mus., vol. 66, art. 6, p. 15, 1924; Proc. Biol. Soc. Washington, vol. 41, p. 54, 1928.-BARBour and Loveridge, Bull. Mus. Comp. Zool., vol. 69, No. 10. p. 287, 1929.

1879. Dromicus parvifrons Cope, Proc. Amer. Philos. Soc., vol. 18, p. 273 (a variety from Gonave Island discussed but not named).-Amaral, Mem. Inst. Butantan, vol. 4, p. 167, 1929.

1930. Dromicus alleni Barbour, Zoologica, vol. 11, No. 4, p. 114; vol. 19, No. 3, p. 139, 1935; Bull. Mus. Comp. Zool., vol. 82, No. 2, p. 161, 1937.
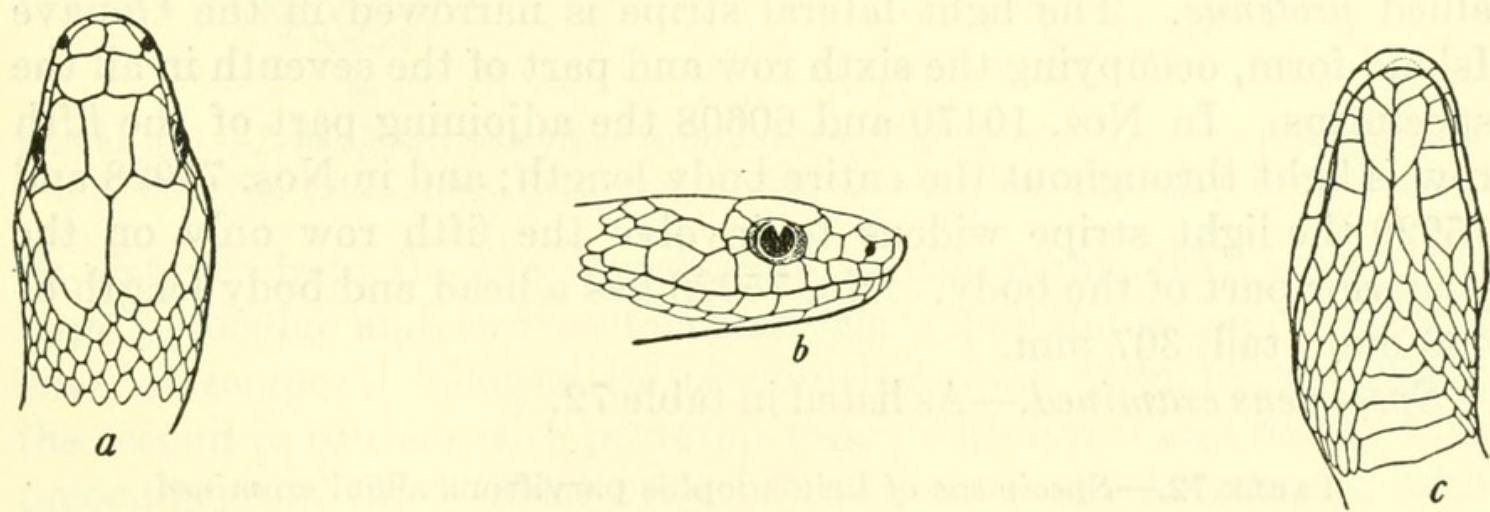

Figure 112.-Leimadophis parvifrons alleni: $a$, Top of head; $b$, side of head; $c$, chin. U.S.N.M. No. 10170, type, from Gonave Island, Haiti. One and one-half times natural size.

Description of the paratype.-Adult female, U.S.N.M. No. 10170; Gonave Island; J. J. Brown, collector. Rostral much broader than high, visible from above; internasal suture shorter than prefrontal suture; frontal longer than its distance from end of snout, shorter than parietals, separated from preocular; supraocular a little narrower than the frontal; nasal divided, longer than its distance from the eye; loreal moderate, a little deeper than broad; one large preocular and two postoculars, the upper the larger; eight upper labials, the second in contact with posterior nasal and loreal, but separated from the preocular; the third labial barely touching eye, the fourth and fifth 
broadly in contact with it; 10 lower labials, 5 in contact with the anterior chin shields and two with the posterior chin shields, which are the longer; scales smooth, without pores, in 19 rows; ventrals 164 ; anal divided; tail defective.

Color (in alcohol): Top of head olive-brown, lighter toward the snout, darkening toward the occiput; a yellowish-white line running from the snout over the eye and continuing on the sixth scale row including the adjoining portion of the fifth and almost all the seventh; the area between these lateral lines black, with occasionally a light line at the edge of a scale; a dark lateral stripe beginning at the snout, becoming black behind the eye and continuing along the body on the fourth row including the adjoining halves of the third and fifth; below this black stripe the body is bluish gray, with slightly darker edges on the scales; upper and lower labials cream-white, their posterior edges flecked with black; throat and ventral surface cream-white with a few black dots on the neck but otherwise immaculate.

Variations.-The snake from Gonave Island varies only slightly according to the specimens at hand. Head scalation is fairly uniform in all the examples. The ventral plates range in number from 157 to 164 and the caudals from 130 to 138 .

The brilliant pattern of clear-cut light and dark stripes is more marked in this subspecies than is the less intense coloration of the allied protenus. The light lateral stripe is narrowed in the Gonave Island form, occupying the sixth row and part of the seventh in all the specimens. In Nos. 10170 and 60608 the adjoining part of the fifth row is light throughout the entire body length; and in Nos. 75928 and 75929 the light stripe widens to involve the fifth row only on the posterior part of the body. No. 75928 has a head and body length of $436 \mathrm{~mm}$., tail, $307 \mathrm{~mm}$.

Specimens examined.-As listed in table 72.

TABLE 72.-Specimens of Leimadophis parvifrons alleni examined

\begin{tabular}{|c|c|c|c|c|c|}
\hline $\begin{array}{l}\text { Museum } \\
\text { No. }\end{array}$ & Locality & Date & Collector & $\begin{array}{l}\text { Ven- } \\
\text { trals }\end{array}$ & $\begin{array}{l}\text { Cau- } \\
\text { dals }\end{array}$ \\
\hline U.S.N.M. & & & & & \\
\hline $\begin{array}{l}10170 \text { (para- } \\
\text { type). }\end{array}$ & Gonave Island. & & J. J. Brown ... & 164 & \\
\hline $10171 \ldots \ldots$ & . do do............. & & ..... do do & 164 & 132 \\
\hline $60608 \ldots \ldots$ & do & Feb. 25, 1918_... & W. L. Abbott $\ldots$ & 161 & $\cdots$ \\
\hline $75928 \ldots \ldots$ & $\begin{array}{l}\text { Anse a Galets, Gonave } \\
\text { Island. }\end{array}$ & Sept. $21,1928 \ldots$ & $\begin{array}{l}\text { J. S. C. Boswell } \\
\text { do }\end{array}$ & 157 & 138 \\
\hline 76802 & En Café, Gonave Island..... & March 1929..... & $\begin{array}{l}\text { A. J. Poole and W. } \\
\text { Perrygo. }\end{array}$ & 159 & 130 \\
\hline $80830 \ldots . . . .$. & Gonave Island. & May $14,1930 \ldots$ & L. H. Parish and W. & 165 & 141 \\
\hline M.C.Z. & & & & & \\
\hline $12860 \ldots . . .$. & .... do & August 1919 & G. M. Allen & 164 & \\
\hline $12861 \ldots$ & ............. & ....................... & 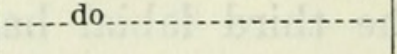 & 159 & 132 \\
\hline
\end{tabular}




\section{LEIMADOPHIS PARVIFRONS TORTUGANUS Dunn}

Figures $107,113,115 b$

1920. Leimadophis tortuganus Dunn, Proc. New England Zool. Club, vol. 7, p. 4U.Cochran, Proc. U. S. Nat. Mus., vol. 66, art. 6, p. 15, 1924.

1929. Leimadophis parvifrons Amaral, Mem. Inst. Butantan, vol. 4, p. 167.

1930. Dromicus tortuganus Barbodr, Zoologica, vol. 11, No. 4, p. 114; vol. 19, No. 3, p. 139, 1935; Bull. Mus. Comp. Zool., vol. 82, No. 2, p. 161, 1937.

1934. Dromicus parvifrons tortuganus Cochran, Occ. Pap. Boston Soc. Nat. Hist., vol. 8, p. 188.

Description.-Adult female; U.S.N.M. No. 59921; Tortue Island; June 21, 1917; W. L. Abbott, collector. Rostral broader than high, visible from above; internasal suture a little shorter than prefrontal suture; frontal considerably longer than its distance from end of snout, a little shorter than the parietals, separated from the preocular; supraocular slightly narrower than frontal; nasal divided, longer than
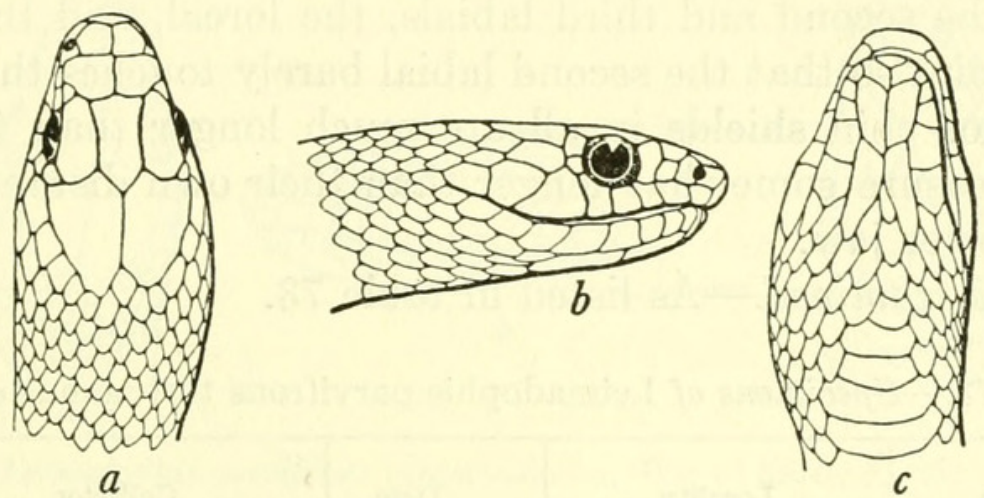

Figure 113.-Leimadophis parvifrons tortuganus: $a$, Top of head; $b$, side of head; $c$, chin.

U.S.N.M. No. 59921, from Île Tortue, Haiti. One and one-half times natural size.

its distance from the eye; loreal small, a little higher than broad; one large preocular and two postoculars, the upper the larger; one large anterior temporal followed by two smaller ones; eight upper labials, the second in contact with posterior nasal, with loreal and barely with preocular; the third labial very narrowly and the fourth and fifth labials broadly in contact with the eye; ten lower labials, five in contact with the anterior chin shields and two in contact with the posterior chin shields, which are much longer than the anterior ones; scales smooth, without pores, in 19 rows; ventrals 168; anal divided; caudals 122 (tail defective). Head and body, $433 \mathrm{~mm}$.; tail, $268 \mathrm{~mm}$. + tip.

Color (in alcohol): Top of head and back dark olive-brown, becoming lighter and bluish on the sides; a light streak beginning at the nostrils and leading back on the supraoculars and through the temporals and continuing along the body on the upper half of the sixth and lower half of the seventh scale rows; a black streak from the end of the snout through the eye and continuing on lower half of scale row 6 the entire length of the body; the anterior ends of the scales in rows 3,4 , and 5 also black on neck and anterior third of 
body; the first two scale rows white-edged on the neck and anterior part of the body; upper labials, chin, and throat white, with a decided pinkish tinge, very sparsely dotted with black; ventrals pale cream, their outer ends tinged with bluish and with an occasional black spot.

Variations.-In the paratype (No. 59439) the loreal is slightly broader than high, and the second labial just misses contact with the preocular. The pinkish color on the throat is very evident, and there are a number of black spots scattered on the upper and lower labials, continuing backward on the sides of the throat and on the ends of the first 30 or 40 ventrals. In the type, No. 59440, the loreal is very nearly square; otherwise the head scalation is exactly similar to that of the described specimen. The light edges of the first two scale rows are more prominent in the type and continue for a greater distance along the body than in No. 59921. In the ventral count of the 10 known specimens very little variation is shown. In all these specimens the second and third labials, the loreal, and the preocular meet in a point so that the second labial barely touches the preocular. The posterior chin shields in all are much longer than the anterior ones and measure somewhat longer than their own distance from the tip of the lower jaw.

Specimens examined.-As listed in table 73.

TABLE 73.-Specimens of Leimadophis parvifrons tortuganus examined

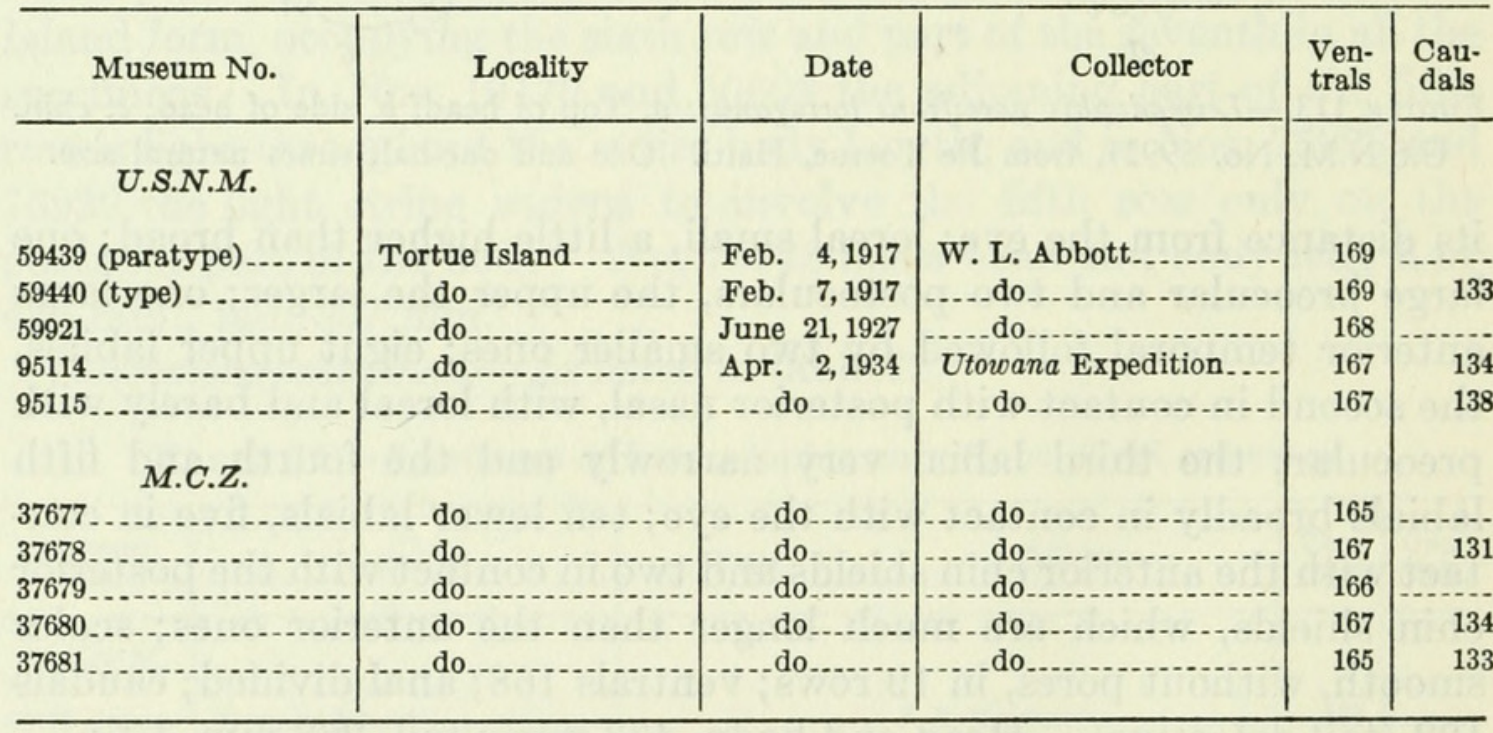

\section{LEIMADOPHIS PARVIFRONS ROSAMONDAE (Cochran)}

Figures $107,114,115 d$

1934. Dromicus parvifrons rosamondae Cochran, Occ. Pap. Boston Soc. Nat. Hist., vol. 8, p. 186.-BArbour, Bull. Mus. Comp. Zool., vol. 82, No. 2, p. 161, 1937.

Original description.-

"Diagnosis.-Melanistic in coloration, the dorso-lateral line being reduced to a pale straight stripe through the middle of the sixth 
scale row on the body, widening slightly on the neck to embrace the lower part of the seventh scale row; each scale of the outer row of dorsals with a large black spot; a similar spot on the outer ends of the ventrals; ventrals 148-153; caudals 115-131.

"Type.-An adult male, M.C.Z. 37668, from Isle Vache, Haiti, collected April 12, 1934, by the Utowana Expedition.

"Description.-Rostral broader than deep; internasals slightly shorter than prefrontals; length of frontal slightly exceeds its distance from the end of the snout, a little shorter than the parietals, separated from the preocular; supraocular about two-thirds as wide as the frontal; nasal divided, a little longer than its distance from the eye; loreal moderate in size, rectangular, a little broader than deep; one preocular; two postoculars, the upper the larger; temporals $1+1$ on the right side, $1+2$ on the left; 8 upper labials, the second in contact
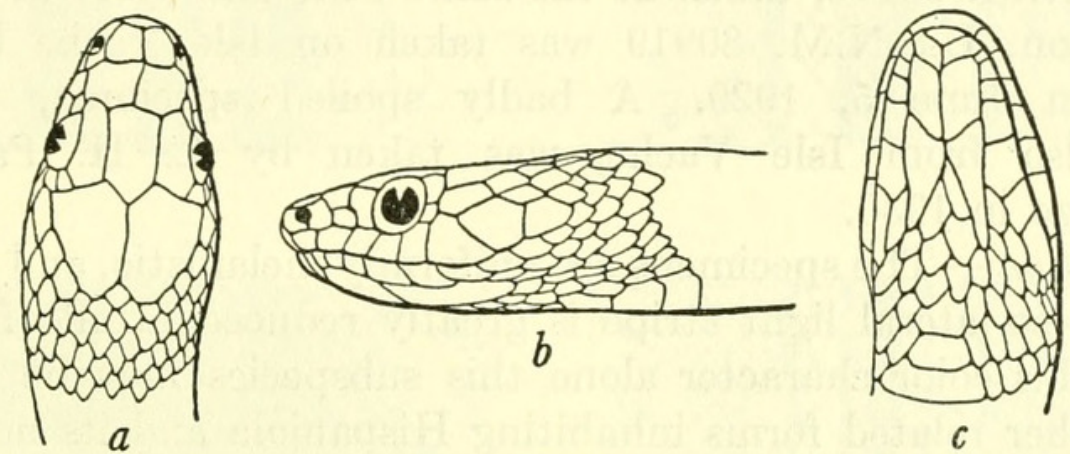

Figure 114.-Leimadophis parvifrons rosamondae: $a$, Top of head; $b$, side of head; $c$, chin. M.C.Z. No. 37668, type, from Île à Vache, Haiti. One and one-half times natural size.

with the posterior nasal and loreal but not reaching the preocular, the third, fourth and fifth entering the eye; 10 lower labials, five in contact with the anterior chin shields and two with the posterior ones which are slightly larger than the anterior; scales in 19 rows, without pores; ventrals 149; anal divided; caudals 131.

"Color (in alcohol).-Top and sides of head and body black; a pale blue dorso-lateral stripe beginning rather indistinctly on the canthus rostralis, continuing above the eye and through the temporal scales, and becoming much more distinct on the sides of the neck, where it occupies the upper part of the sixth and the lower part of the seventh scale rows, and narrowing on the body to some elongate white spots down the middle of the sixth scale row, with some fainter pale marks on the upper margins of the fifth scale row; the black dorsal area, which is $1 / 2+7+1 / 2$ scales wide, showing traces of a pair of very narrow broken white lines composed of the white margins between the eighth and ninth scale rows (in the type specimen), these broken lines very faint on the neck, more pronounced on the anterior part of the body but disappearing completely at mid-body; labials pale china blue, 
lightening on chin, this color darkening on belly where it becomes heavily suffused with indigo; a remnant of a pale lateral stripe from the labials along the sides of the neck on the second and third scale rows, and another on the lower half of the first scale row, both these fading out on the first third of the body; a large black spot at the outer border of each ventral plate, also continued on the tail nearly to its end; a median series of indistinct black spots on the third to the seventeenth ventrals, thereafter appearing as a pair of black spots gradually diverging from the center posteriorly and becoming quite small and indistinct just anterior to the vent; tail black above, with a faint continuation of the light dorsolateral stripe; lower part of tail pearl-gray with a mottling of small indigo spots.

"Dimensions.-Head and body, $406 \mathrm{~mm}$., tail, $301 \mathrm{~mm}$.

"Paratypes.-There are five additional specimens, M.C.Z. 37669-72, and U.S.N.M. 95116, taken at the same time and place as the type. In addition, U.S.N.M. 80919 was taken on Isle Vache by C. R. Orcutt on June 5, 1929. A badly spoiled specimen, U.S.N.M. 84292, also from Isle Vache, was taken by L. H. Parish and W. Perrygo in 1930.

"Variation.-The specimens are uniformly melanistic, and the width of the dorso-lateral light stripe is greatly reduced in all of them, so that by this color character alone this subspecies may be told from all the other related forms inhabiting Hispaniola and its neighboring islets. The traces of a pair of narrow intermediate white lines are almost lacking in two of the paratypes, and are less distinct in the three others than in the type. In two of the paratypes the dorsolateral light stripe occurs only on the sixth scale row on the neck.

"The ventrals vary between 148 and 153, the caudals between 115 and 131. A decided tendency towards having a single scale in the second temporal series is noticeable, since two of the paratypes resemble the type in having a single scale on one side of the head, one paratype has a single scale on both sides of the head, while only two specimens have the normal temporal count of $1+2$ scales on both sides."

Relationships.-The amount of melanism in L. p. rosamondae from Ile à Vache places it between $L$. p. lincolni, which has the light stripes more undulating, and $L . p$. niger, in which the stripes are almost entirely lacking. In position the stripes on the sixth, or sixth and seventh, scale rows, correspond to L. p. tortuganus. In its low scale-count, rosamondae seems to agree with some of the snakes in the subspecies protenus having the lowest scale-counts. Its tendency towards having a single scale in the second temporal series is a character peculiar to this subspecies. It is on the whole an easily recognizable form. 

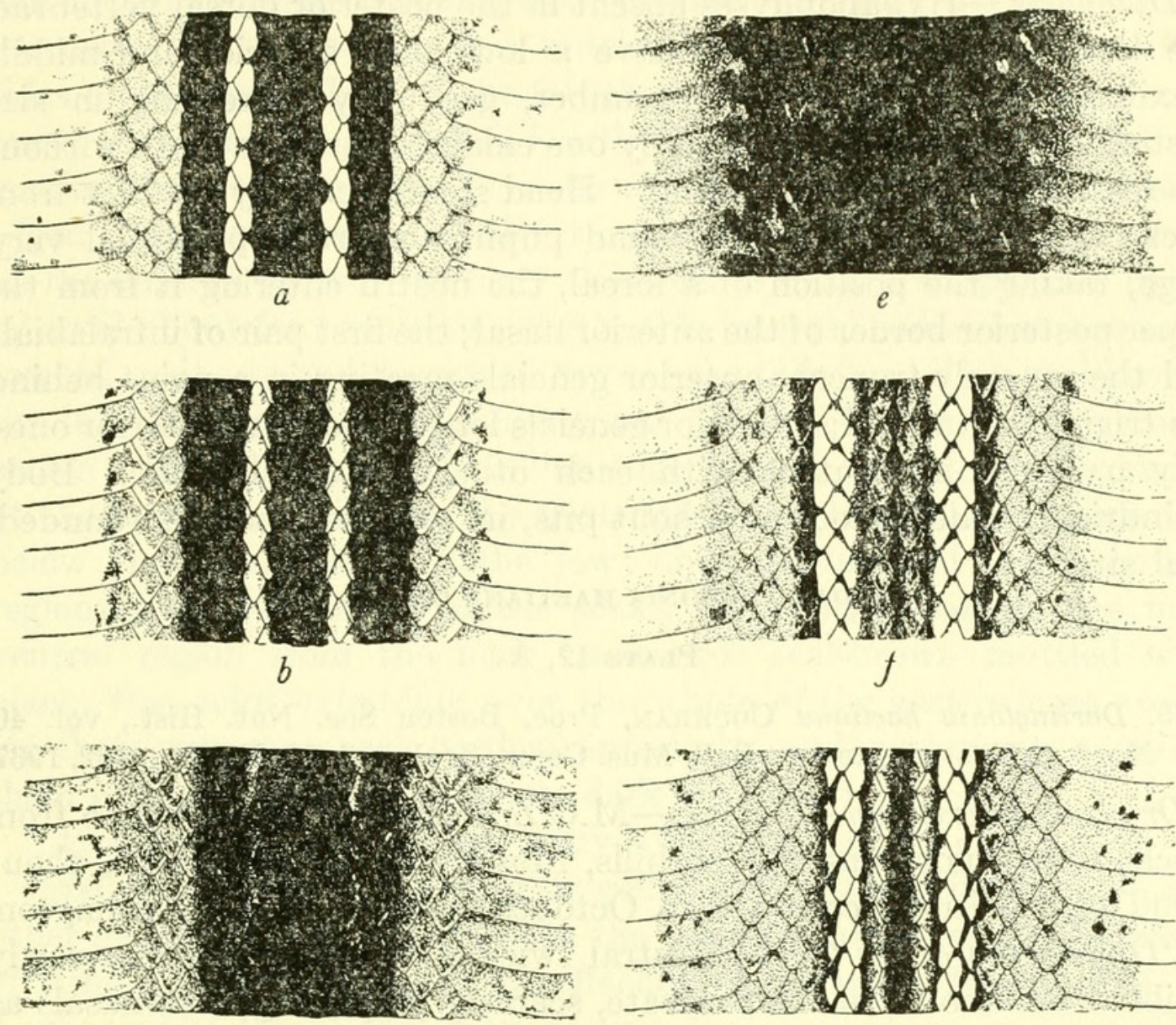

c

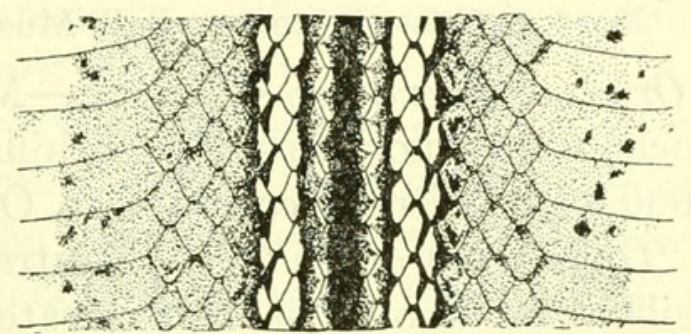

$g$

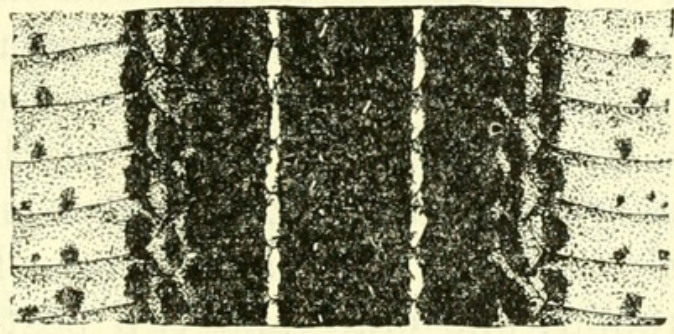

$d$

Figure 115.-Patterns of subspecies of Leimadophis parvifrons: a, alleni, U.S.N.M. No. 75929, from Gonave Island; b, tortuganus, U.S.N.M. No. 59440, type, from Île Tortue; c, lincolni, U.S.N.M. No. 83890, type, from Beata Island; d, rosamondae, M.C.Z. No. 37668, type, from Île à Vache; e, niger, U.S.N.M. No. 55031, paratype, from Samaná Peninsula; $f$, parvifrons, U.S.N.M. No. 60607 , from Moline, Haiti; $g$, protenus, U.S.N.M. No. 55307, from Jarabacoa, Dominican Republic. 


\section{Genus DARLINGTONIA Cochran}

1935. Darlingtonia Cochran. Proc. Boston Soc. Nat. Hist., vol. 40, No. 6, p. 374 (type, D. haetiana).

Diagnosis.-Hypapophyses absent in the posterior dorsal vertebrae, the lower surfaces of which have a low keel; anterior and middle maxillary teeth 12 or 13 in number, gradually increasing in size posteriorly, with a gap followed by one enlarged fanglike tooth without grooves; mandibular teeth equal. Head small, scarcely distinct from neck; eye rather large, with round pupil; no loreal; postnasal very large, taking the position of a loreal, the nostril entering it from the upper posterior border of the anterior nasal; the first pair of infralabials and the squarely truncate anterior geneials meeting in a point behind the triangular mental; posterior geneials longer than the anterior ones, only partially in contact with each other on the midline. Body cylindrical; scales smooth, without pits, in 19 rows; ventrals rounded; anal single.

\section{DARLINGTONIA HAETIANA Cochran}

Plate 12, A

1935. Darlingtonia haetiana Cochran, Proc. Boston Soc. Nat. Hist., vol. 40, No. 6, p. 375.-BARBour, Bull. Mus. Comp. Zool., vol. 82, No. 2, p. 162, 1937.

Original description.- "Type.-M.C.Z. 38,252, an adult female from Roche Croix, northeastern foothills, Massif de la Hotte, Haiti, about 5,000 feet altitude, collected in October, 1934, by P. J. Darlington.

"Description of the type.-Rostral twice as broad as deep, narrowly visible from above; snout truncate, scarcely projecting; internasals as long as broad, slightly shorter than the prefrontals; internasal suture three-fourths as long as prefrontal suture; frontal once and two-thirds as long as broad, much broader than the supraoculars, longer than its distance from the end of the snout, shorter than the parietals; nostril large, placed in the upper posterior border of the anterior nasal; postnasal large, broadly in contact with the preocular and bordering the prefrontals widely and the internasals narrowly; no loreal; eye rather large, pupil round; one prae- and two post-oculars; no suboculars; one large anterior temporal, on the right two small scales in front of it, on the left a small scale above it; two subequal posterior temporals; 7 supralabials, the third and fourth entering the eye, the fifth highest, the sixth widest; three lower labials on each side in contact with the anterior chinshields which are squarely truncate in front; posterior chinshields in contact with third and fourth infralabials, longer than the anterior, nearly separated from each other by a third pair of chinshields which are like the second but smaller; two additional series of paired scales before the first gastrostege more like the surrounding scales; mental shield triangular, its posterior angle meeting the inner ends of the first infralabials and the anterior chinshields; 8 infralabials; 19 rows of smooth scales around the body; no apical pits ; 
138 ventrals; anal single; 50 paired subcaudals, with a pointed scale at the tip. The type is unique.

"Color in alcohol.-Body color ecru-drab, with a decided seal-brown dorsal stripe 3 scales in width from the occiput to the end of the body, narrowing on the tail; another much narrower brown stripe down the sides on the upper half of the fourth and lower half of the fifth scale rows; each scale of the third, fourth and fifth rows with a very dark median line down its center; a series of very conspicuous small blackedged white spots covering about one scale on the seventh scale-row; on the anterior part of the body these white spots are separated by an interval about four scales in length, this interval somewhat increased toward midbody and decreased toward the tail; head dark seal-brown, the lateral parietal regions lightening to wood-brown; labials woodbrown with a black irregular line edged below with white beginning at the eye, continuing on the posterior upper labials and fading out below the commissure of the jaw; chin, throat and latero-ventral regions pale-drab, most of the scales edged with darker; the midventral region from the neck backwards seal-brown mottled with black, this color extending over the whole of the gastrosteges except for their extreme outer borders anteriorly, and posteriorly covering them entirely; urosteges uniform dark seal-brown.

"Measurements.-Head and body, $195 \mathrm{~mm}$.; tail, $88 \mathrm{~mm}$.

"Relationships.-While the new genus does not closely resemble any other genus of snake known from the West Indies or on the mainland of America, it is probably an offshoot of ancestral Dromicus [i. e., Leimadophis] stock, and may occupy the same niche in Haiti that Arrhyton does in Cuba."

\section{Genus IALTRIS Cope}

1862. Ialtris Cope, Proc. Acad. Nat. Sci. Philadelphia, 1862, p. 73 (type, Ialtris vultuosa $[=$ dorsalis $])$.

1879. Jaltris Cope, Proc. Amer. Philos. Soc., vol. 18, p. 273 (emend.).

Although this genus is one of the opisthoglyphs, it has not been regarded as dangerously poisonous to man. No record of its ever having attempted to bite has come to my knowledge. The adult female Ialtris dorsalis from Damien was sent alive to the National Museum by Dr. Vinson, and during the several weeks that I had it in my possession it showed only a gentle, unexcitable disposition.

\section{KEY TO THE SPECIES OF IALTRIS}

Frontal longer than its distance from end of snout; ventrals

179-191_.

Frontal equal to its distance from end of snout; ventrals 163_._-parishi (p. 376) 


\section{IALTRIS DORSALIS (Günther)}

Figure 116

1858. Philodryas dorsalis GüNther, Catalogue of colubrine snakes in the collection of the British Museum, p. 126 (type locality, S. Domingo).

1862. Ialtris vultuosa Cope, Proc. Acad. Nat. Sci. Philadelphia, 1862, p. 73 (near Jérémie).-Barbour and Loveridge, Bull. Mus. Comp. Zool., vol. 69, No. 10, p. 283, 1929.

1862. Dromicus mentalis GüNther, Ann. Mag. Nat. Hist., ser. 3, vol. 9, p. 128, pl. 9 , fig. 9 (type locality unknown).

1879. Jaltris dorsalis Cope, Proc. Amer. Philos. Soc., vol. 18, p. 273.

1896. Ialtris dorsalis Bodlenger, Catalogue of the snakes in the British Museum, vol. 3, p. 137, pl. 7, fig. 2.-BArbour, Mem. Mus. Comp. Zool., vol. 44, No. 2, p. 342, 1914; Zoologica, vol. 11, No. 4, p. 115, 1930; vol. 19, No. 3, p. 140, 1935; Bull. Mus. Comp. Zool., vol. 82, No. 2, p. 163, 1937.-Cochran, Proc. U. S. Nat. Mus., vol. 66, art. 6, p. 15, 1924; Proc. Biol. Soc. Washington, vol. 41, pp. 54, 127, 1928; Occ. Pap. Boston Soc. Nat. Hist., vol. 8, p. 188, 1934.

1909. Dromicus w-nigrum Werner, Jahrb. Wiss. Anst. Hamburg, vol. 26, pt. 2, p. 222.
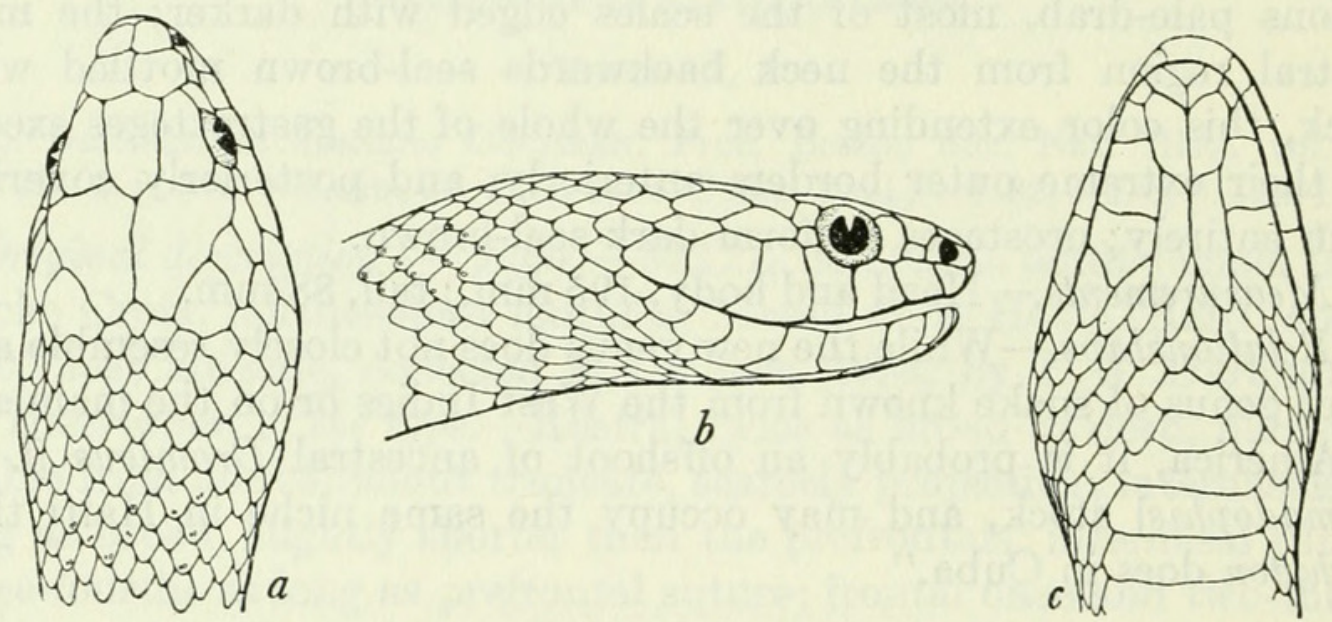

Figure 116.-Ialtris dorsalis: $a$, Top of head; $b$, side of head; $c$, chin. U.S.N.M. No. 60606, from Moron, Haiti. One and one-half times natural size.

Description.-Adult, U.S.N.M. No. 60606, from Moron, Haiti, collected by Dr. W. L. Abbott on December 23, 1917. Rostral much broader than deep, scarcely visible from above; internasals as long as broad, nearly as long as the prefontals; frontal nearly twice as long as broad, longer than its distance from the end of the snout, shorter than the parietals; loreal rectangular, small, a little longer than deep; one preocular not reaching the frontal; two postoculars, the lower the smaller, temporals $1+2$; the scales bordering the sides of the parietals enlarged; seven upper labials, the third and fourth entering the eye; nine lower labials, the fourth amd fifth the largest, the first four in contact with the anterior chin shields, which are much shorter than the posterior ones. Scales in 19 rows, with two pores sometimes only faintly visible near the tips; ventrals 185 ; anal divided; subcaudals $101+$, the extreme tail tip being gone. Head and body, $544 \mathrm{~mm}$.; tail, $225 \mathrm{~mm}$. +tip. 
Color: Olive above, tip of snout a little lighter; a black line from the nostril through the eye and continuing on the sides of the neck; a heavy black mark beginning on the frontal, continuing down the parietal suture, bifurcating and joining with the black line on the side of the head to form a large and conspicuous black W across the head; behind this a series of large irregular black spots, which very quickly become broken up into numerous smaller ones and finally lose their individuality completely, appearing only as black edges on some of the scales and forming short irregular bars occasionally. Posterior half of body and tail dark grayish brown, with dusky clouding on the edges of the scales. Throat and labials gray with black spots, which also occur on the anterior ventrals. Remainder of ventrals and subcaudals yellowish gray with a suffusion of dark pigment on the posterior borders of every scale.

TABLE 74.-Specimens of Ialtris dorsalis examined

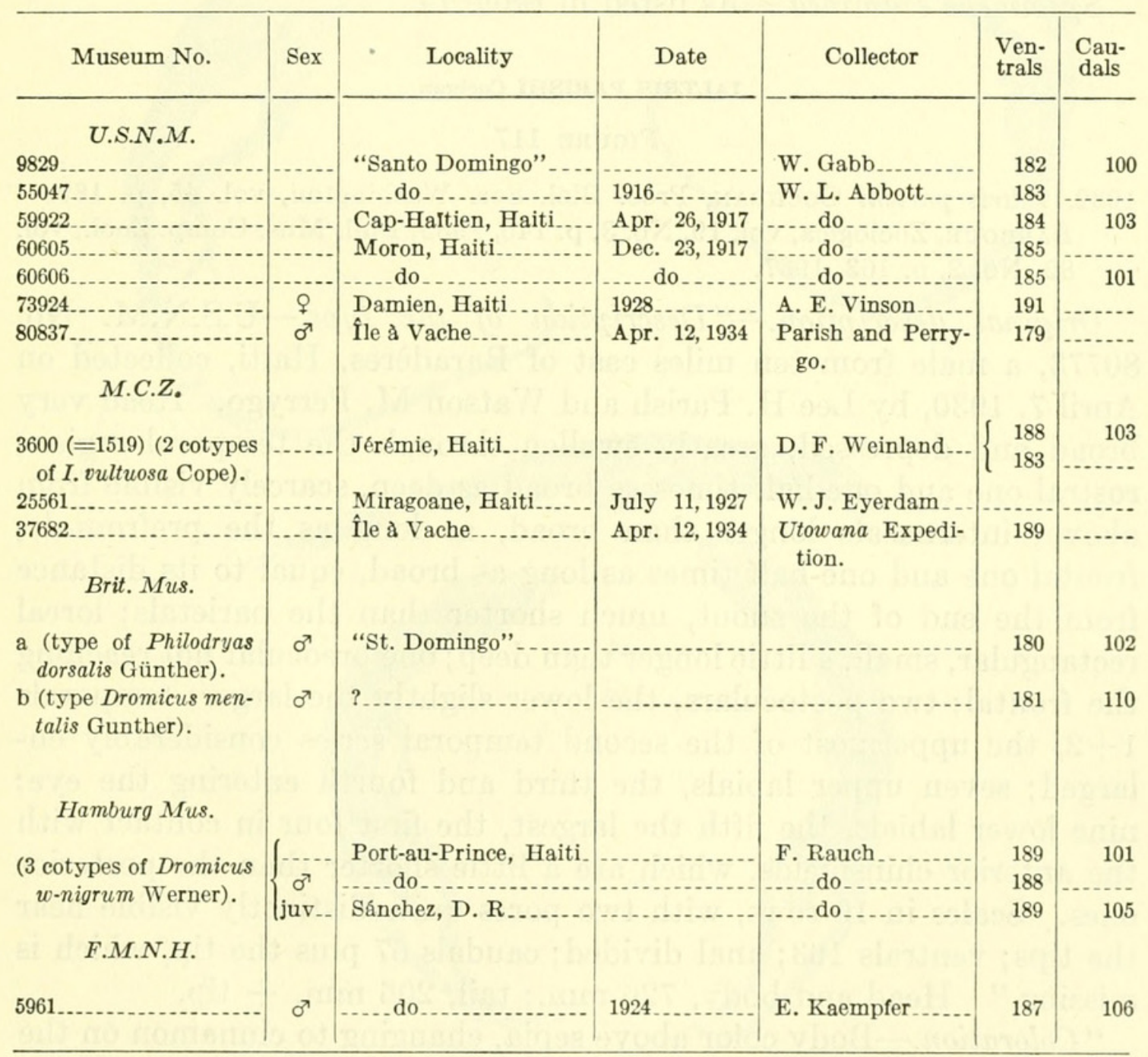

Variations.-In the number of ventral plates the range is not great, being from 180 to 191 ; the subcaudals are 100 to 110 . In one of the specimens in the U. S. National Museum, No. 60605, there are three postoculars on one side of the head, instead of the customary number, 
two, while in the second of Cope's cotypes of $I$. vultuosa there is a single postocular on one side of the head. In Werner's type of $D$. $w$ nigrum three postoculars are present. The number of labials is constant in this species, there being always seven supralabials and nine infralabials, of which only the first four touch the anterior chin shields. In some cases the lower postocular is very small; it is not surprising that there is some variation in this region, as in No. 60605 and in the type of Werner's w-nigrum.

The coloration seems to vary greatly in intensity irrespective of age. In No. 9829, which is an adult of good size, over a dozen regular black spots may be counted on the back before they begin to break up, while in No. 60606 only two spots approach a regular outline before breaking up. In Nos. 56047 and 9829 the throat, lips, and ventrals are immaculate, the three remaining snakes having these regions more or less heavily spotted with black dots.

Specimens examined.-As listed in table 74.

\section{IALTRIS PARISHI Cochran}

FIgURE 117

1932. Ialtris parishi Cochran, Proc. Biol. Soc. Washington, vol. 45, p. 189.Barbour, Zoologica, vol. 19, No. 3, p. 140, 1935; Bull. Mus. Comp. Zool., vol. 82, No. 2, p. 163, 1937.

Original description.- "Description of the type.-U.S.N.M. No. 80773, a male from ten miles east of Baradères, Haiti, collected on April 7, 1930, by Lee H. Parish and Watson M. Perrygo. Head very broad and depressed, greatly swollen through the temporal region; rostral one and one-half times as broad as deep, scarcely visible from above; internasals longer than broad, as long as the prefrontals; frontal one and one-half times as long as broad, equal to its distance from the end of the snout, much shorter than the parietals; loreal rectangular, small, a little longer than deep; one preocular not reaching the frontal; two postoculars, the lower slightly the larger; temporals $1+2$, the uppermost of the second temporal series considerably enlarged; seven upper labials, the third and fourth entering the eye; nine lower labials, the fifth the largest, the first four in contact with the anterior chinshields, which are a little shorter than the posterior ones. Scales in 19 rows, with two pores quite distinctly visible near the tips; ventrals 163; anal divided; caudals 67 plus the tip, which is missing." Head and body, $726 \mathrm{~mm}$.; tail, $206 \mathrm{~mm}$. + tip.

"Coloration.-Body color above sepia, changing to cinnamon on the snout and lips; head immaculate above; a very conspicuous white line narrowly edged above and below with black emanating from the lower posterior border of the eye and passing diagonally backwards to the commissure of the mouth, bisecting the two last upper labials; 


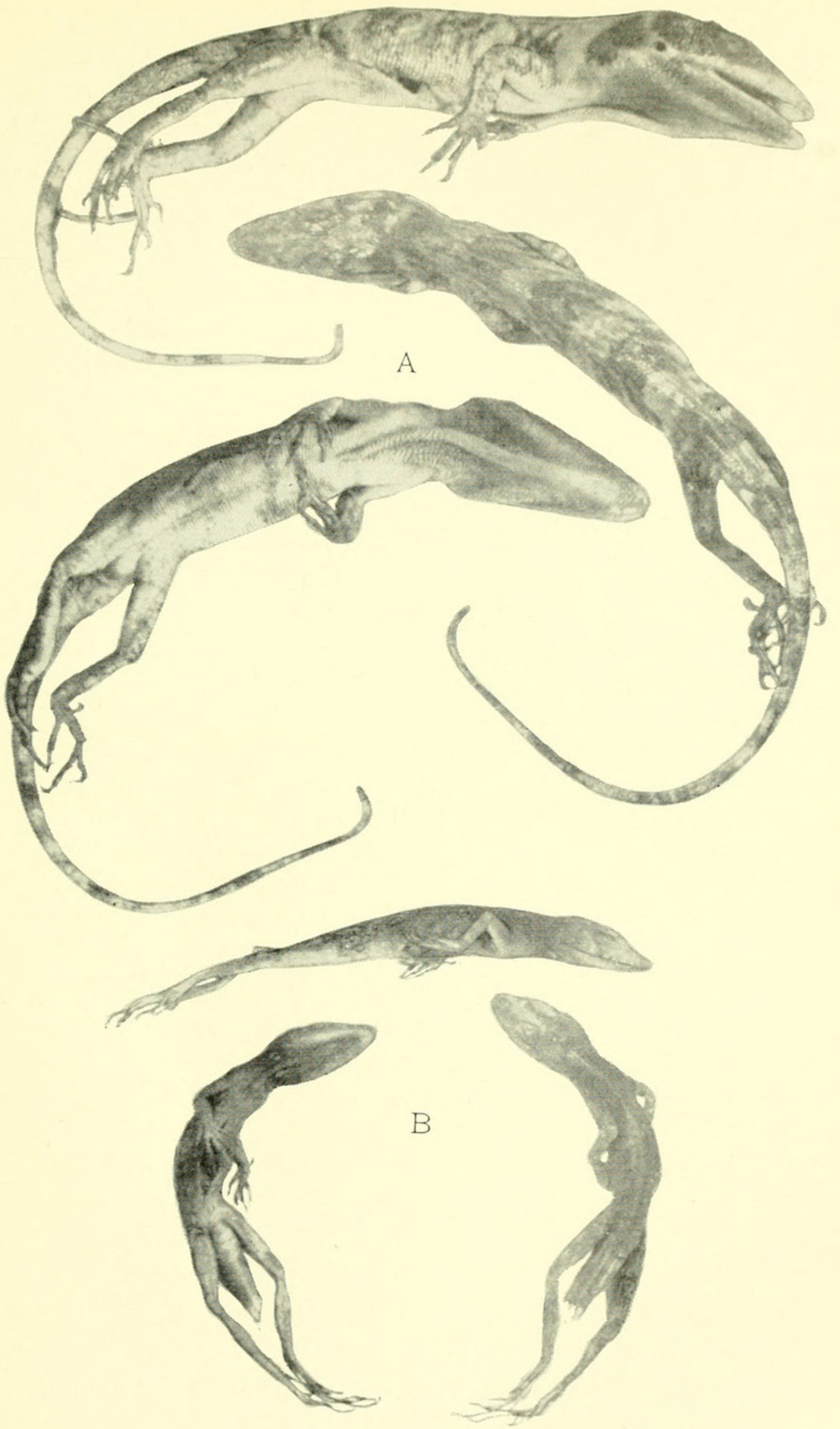

A, Xiphocercus darlingtoni, type, M.C.Z. No. 38251, from Roche Croix, Massif de la Hotte, Haiti; B, Anolis monticola, type, M.C.Z. No. 38296, from Massif de la Hotte, Haiti. 

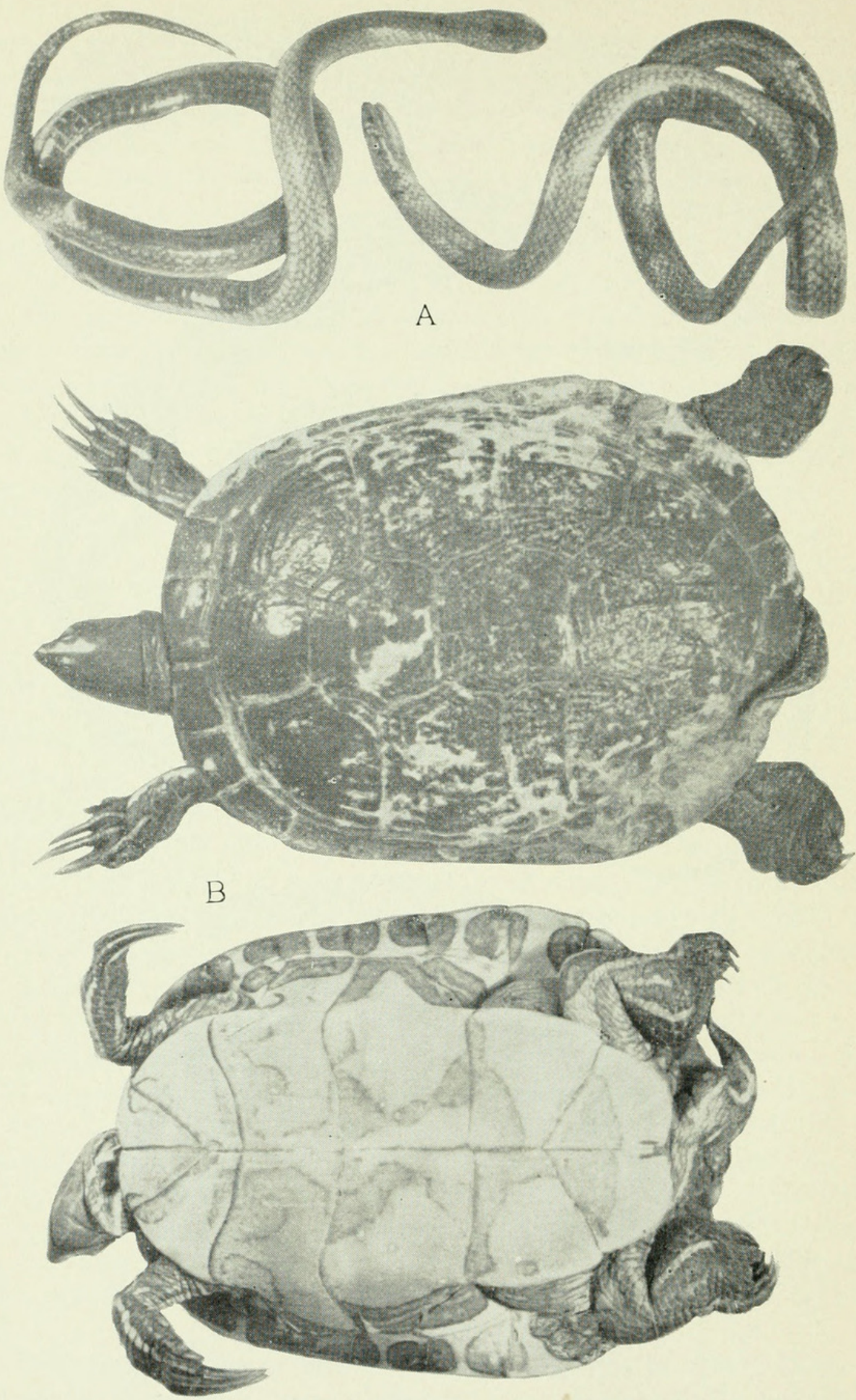

A, Darlingtonia haetiana, type, M.C.Z. No. 38252, from Roche Croix, Massif de la Hotte, Haiti; B, Pseudemys steinegeri vicina, paratype, M.C.Z. No. 43651, from Puerto Plata, Dominican Republic. 
on the body 45 cinnamon crossbars about 1 scale in length and edged posteriorly with a ragged dark border which is especially emphasized towards the outer ends of the bars, which do not extend below the fourth scale row; on the tail and posterior body the bars dorsally are definitely broken up, leaving alternating lateral spots of cinnamon irreglarly pervaded with black; ventral surface buif-pink, the outer ends of the scales heavily powdered with gray dots; two very irregular midventral series of squarish patches likewise composed of gray dots, and tending to run together into parallel stripes towards the end of the body; labials and chin with a heavy powdering of very pale gray dots which tend to become more numerous around the borders of the chin-shields.

"Remarks.-This second known species of the genus has a grooved fang exactly like that of Ialtris dorsalis. It cannot be said to resemble
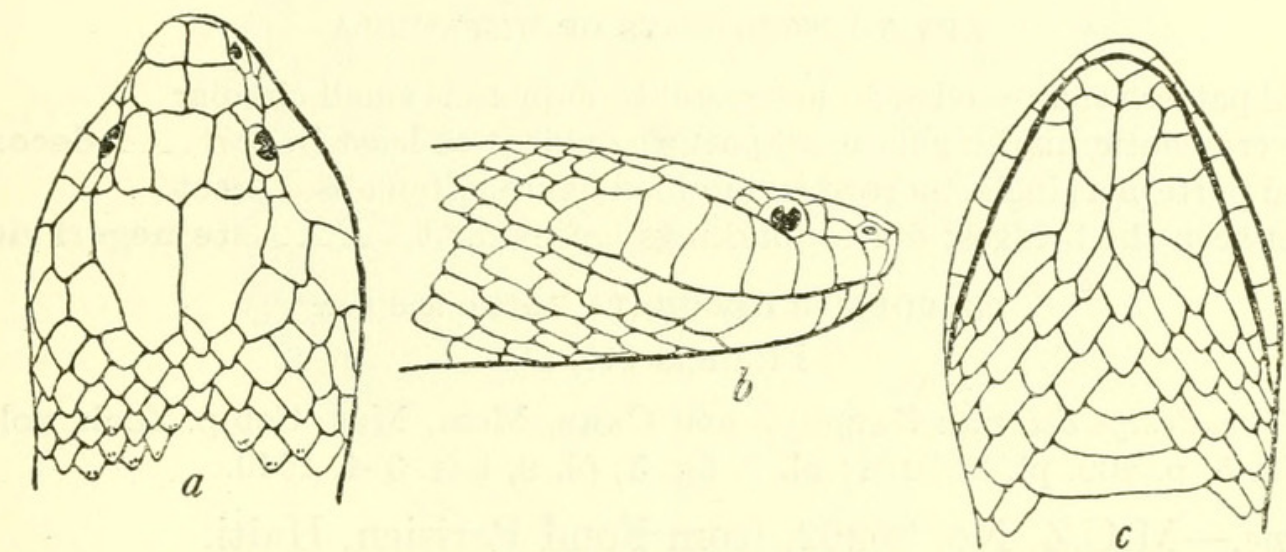

Figure 117.-Ialiris parishi: a, Top of head; $b$, side of head; $c$, chin. U.S.N.M. No. 80773 , type, from 10 miles east of Baradères, Haiti. Natural size.

dorsalis very closely, inasmuch as the coloration is very different and the number of ventrals is considerably less in the new species. The flatness and width of the head of the type suggested an adult Alsophis anomalus at first glance, but the teeth are utterly different.

"The headplates of the new species are quite similar to those of dorsalis, excepting that the frontal is shorter in proportion to its width in the former. The white diagonal line bordered with black above and below leading backwards from the eye in parishi is represented in dorsalis by the wide black streak that forms the outer stroke of the W-shaped head marking, but which in dorsalis does not drop to the commissure of the mouth."

The type is still the only known example in museum collections. 


\section{Order TESTUDINATA}

\section{Family TESTUDINIDAE}

\section{Genus PSEUDEMYS Gray}

1856. Pseudemys Gray, Proc. Zool. Soc. London, 1855, p. 195 (type, P. concinna).

The problem of differentiating the species of Antillean fresh-water turtles has been complicated by the lack of specimens from many crucial localities. The recent study by Barbour and Carr has included practically all the known Hispaniolan specimens, about three dozen in all. Even with this scanty material, two distinct forms have been recognized. The following key, synonymy, and diagnostic characters have been abstracted from the published work of Barbour and Carr. For detailed descriptions and discussions of the species, the original publication should be consulted.

\section{KEY TO PSEUDEMYS OF HISPANIOLA}

Plastral pattern composed of from several to numerous small circular or crescentic markings; dorsal pattern evident at least in part....._decorata Plastral pattern a single, more or less unified figure, often obsolescent between the bridges; dorsal markings not evident......... stejnegeri vicina

\section{PSEUDEMYS DECORATA Barbour and Carr}

Figures 118, 119

1940. Pseudemys decorata BArbour and $\mathrm{C}_{\mathrm{ARR}}$, Mem. Mus. Comp. Zool., vol. 54, No. 5, p. 409, pl. 2, fig. 1; pl. 7, fig. 3; pl. 9, figs. 3-4, 1940.

Type.-M.C.Z. No. 36862, from Fond Parisien, Haiti.

Diagnosis.-Readily distinguished by the plastral pattern, which consists of small, circular or elliptical markings scattered about over the plastron; snout of adult relatively sharp and nearly conical, that of mature male upturned and very long. Supratemporal stripe white in preserved specimens. Markings on carapace, at least on lower marginals, distinct in most specimens.

Recorded specimens.-M.C.Z. Nos. 36851-36860, from Thomazeau, Haiti; M.C.Z. Nos. 36861-36866, from Fond Parisien, Haiti; U.S.N.M. Nos. 59093-59096, from Thomazeau, Haiti, April 2, 1917, P. Bartsch and J. B. Henderson; U.S.N.M. No. 63096, from Fond Parisien, May 4, 1920, W. L. Abbott; U.S.N.M. No. 81091, from 10 miles north of Port-au-Prince, Haiti (originally recorded as being from Île à Vache), 1930, W. M. Perrygo.

\section{PSEUDEMYS STEJNEGERI VICINA Barbour and Carr}

Plate 12, B

1835. Emys decussata Duméril and Bibron, Erpétologie générale, p. 279.Duméril, Catalogue méthodique de la collection des reptiles, Muséum Paris, vol. 1, p. 11, 1851 (part).-Reinhardt and Lütken, Vid. Medd. Naturh. Foren., Copenhagen, 1862, p. 290, 1863; author's separate, p. 138. 1862. Clemmys decussata Strauch, Chelonologische Studien, p. 127 (part);

Mem. Acad. Sci. St. Petersbourg, ser. 7, vol. 38, No. 2, p. 78, 1890. 
1889. Chrysemys scripta, var. rugosa Boulenger, Catalogue of the chelonians, rhynchocephalians, and crocodiles in the British Museum, p. 79 (part).

1921. Pseudemys palustris Schmidt, Bull. Amer. Mus. Nat. Hist., vol. 44, p. 20. 1940. Pseudemys stejnegeri vicina BArbour and $\mathrm{C}_{\Lambda \mathrm{R}}$, Mem. Mus. Comp. Zool., vol. 54, No. 5, p. 408.
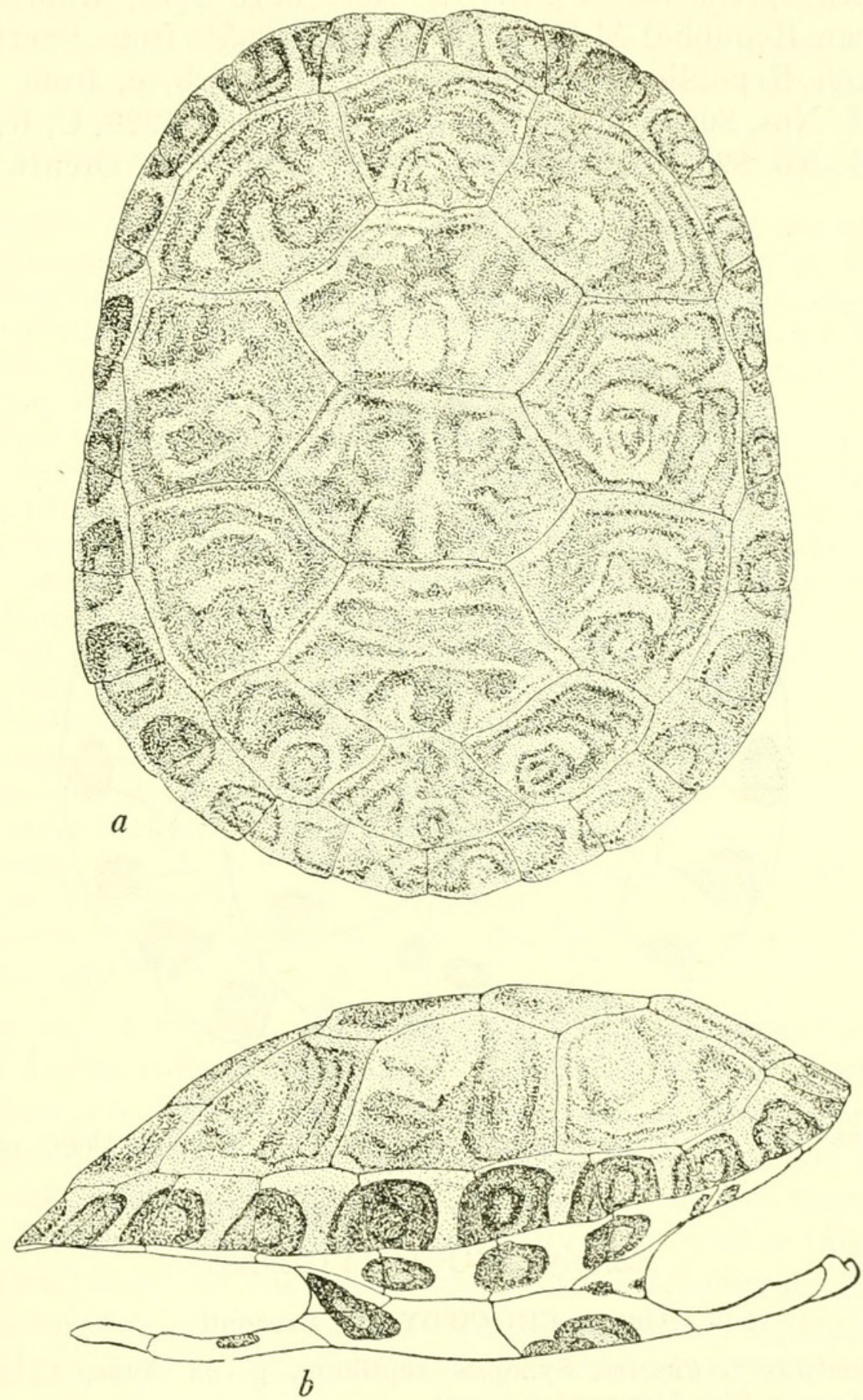

Figure 118.-P Peudemys decorata: $a$, Dorsum; $b$, side view. U.S.N.M. No. 59093, from Thomazeau, Haiti. Natural size.

Type.-F.M.N.H. No. 5977, from Sánchez, Dominican Republic. Diagnosis.-Very closely related to $P$. s. stejnegeri, from which it is distinguished by the broad head (width of head at anterior edge of tympanum contained in body length 7.0-7.2 times in vicina, 7.8-8.0 times in stejnegeri) and deep snout (depth of snout, including mandible, 
at anterior edge of orbit contained in body length 10.3-10.6 times in vicina, 12.0-14.4 times in stejnegeri), and by the plastral pattern. Distinguished from decorata by the absence of markings on the carapace and by the nature of the plastral pattern.

Recorded specimens.-F.M.N.H. Nos. 5976-5978, from Sánchez, Dominican Republic; M.C.Z. Nos. 43651-43654, from Puerto Plata, Dominican Republic; M.C.Z. Nos. 1891-2, a, b, c, from "Haiti"; U.S.N.M. Nos. 80932-80933, from Torbec, Haiti, 1929, C. R. Orcutt; U.S.N.M. No. 82565, from Cayes, Haiti, 1929, C. R. Orcutt.

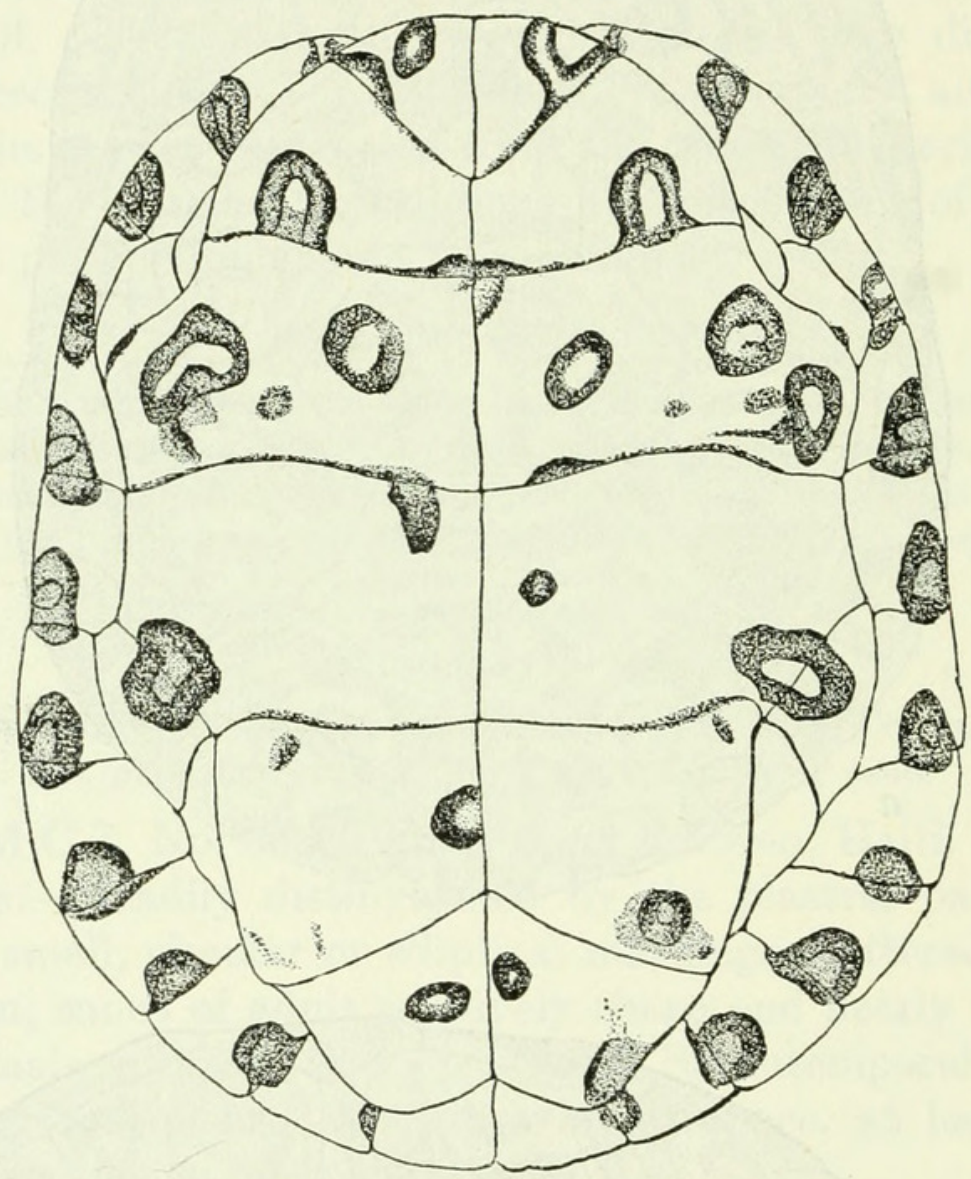

Figure 119.-Pseudemys decorata: Venter. Same specimen as shown in fig. 118.

\section{Order LORICATA \\ Family CROCODYLIDAE \\ Genus CROCODYLUS Laurenti}

1768. Crocodylus Laurenti, Synopsis reptilium, p. 53 (type, C. niloticus= Lacerta crocodilus Linnaeus, in part).

\section{CROCODYLUS ACUTUS Cuvier}

Figure 120

1807. Crocodylus acutus Cuvier, Ann. Mus. Hist. Nat., vol. 10, p. 55, pl. 1, figs. 3, 14; pl. 2, fig. 5.-Geoffroy, Ann. Mus. Hist. Nat., vol. 10, p. 70, 1807.-Duméril and Bibron, Erpétologie générale, vol. 3, p. 119, 1836.Coctead, in de la Sagra's Historia fisica, politica y natural de la isla de Cuba, vol. 4, Reptiles, p. 62, pl. 5, 1843.-STrauch, Synopsis der gegenwärtig lebenden Crocodiliden ... pp. 56, 102, 1866.-Wyman, Amer. Journ. Sci. 
and Arts, ser. 2, vol. 49, p. 105, 1870.-BArbour and RAmsden, Mem. Mus. Comp. Zool., vol. 47, No. 2, p. 202, pl. 12, fig. 1, 1919.-Sснмidt, Field Mus. Nat. Hist. Publ., zool. ser., No. 6, pp. 83, 85-92, 1924; Scientific survey of Porto Rico and the Virgin Islands, New York Acad. Sci., vol. 10, pt. 1, pp. 16, 19, 1928.-Barbour, Zoologica, vol. 11, No. 4, p. 116, 1930; vol. 19, No. 3, p. 141, 1935; Bull. Mus. Comp. Zool., vol. 82, No. 2, p. 166, 1937.-Mertens, Senckenbergiana, vol. 20, No. 5, p. 333, 1938; Publ. Inst. Cient. Domínico-Alemán, vol. 1, p. 84, 1939.-Böker, Publ. Inst. Cient. Domínico-Alemán, vol. 1, p. 16, 1939.

1807. Crocodilus biscutatus Cuvier, Ann. Mus. Hist. Nat., vol. 10, p. 53, pl. 2, fig. 6.

1844. Crocodilus americanus Gray, Catalogue of the tortoises, crocodiles, and amphisbaenians in the collection of the British Museum, p. 60.-HuxLEY, Journ. Linn. Soc. London, vol. 4, p. 11, 1860.-Bocourt, Mission scientifique au Mexique et dans l'Amérique Centrale, Reptiles, p. 30, pl. 8, figs. 1, la; pl. 9, fig. 1, 1870.-Cope, Proc. Amer. Philos. Soc., vol. 18, pl. 273, 1879.Garman, Proc. Amer. Philos. Soc., vol. 24, p. 286, 1887.-Boulenger, Catalogue of the chelonians, rhynchocephalians, and crocodiles in the British Museum, p. 281, 1889.-Meerwarth, Mitth. Nat. Mus. Hamburg, vol. 18, p. 38, 1901.-Barbour, Bull. Mus. Comp. Zool., vol. 52, No. 15, p. 301, 1910; Mem. Mus. Comp. Zool., vol. 44 No. 2, p. 346, 1914; Ann. Carnegie Mus., vol. 10, Nos. 1, 2, p. 299, 1916.-Моок, Bull. Amer. Mus. Nat. Hist., vol. 44, art. 7, p. 51 et seq.; art. 8, p. 67 et seq.; art 13, p. 151 et seq., 1921.

1862. Molinia americana GraY, Ann. Mag. Nat. Hist., ser. 3, vol. 10. p. 272; Trans. Zool. Soc. London, vol. 6, p. 150, 1867; Catalogue of the Shield reptiles in the collection of the British Museum, p. 106, 1873.

1870. Crocodilus lewyanus Bocourt, Mission scientifique au Mexique et dans l'Amérique Centrale, Reptiles, p. 33, pl. 8, figs. 2, 2a.

1870. Crocodilus mexicanus Bocourt, ibid., p. 34, pl. 8, figs. 3, 3a.

1870. Crocodilus pacificus Bocourt, ibid., p. 31, pl. 9, figs. 5, 5a, 5b.-Sumichrast, Bull. Soc. Zool. France, vol. 5, p. 171, 1880.

1885. Crocodilus americanus acutus GüNther, Biologia Centrali-Americana, Reptiles and Batrachians, p. 20.

Description.-U.S.N.M. No. 80893, a young individual from Île à Vache, Haiti, collected on May 7, 1930, by Lee H. Parish and Watson Perrygo. Nineteen upper teeth. Snout about one-half as long as broad at the base; a median ridge or longitudinal swelling along the snout; interorbital width contained about five times in the width of the flat cranial table; two large nuchals, with a smaller one posteriorly situated on each side; two pairs of smaller nuchals in a transverse row behind the occiput. Dorsal scutes well separated from the nuchals, in four longitudinal rows and about 15 transverse rows; the scutes of the two median rows regularly arranged, the others more or less irregular and more strongly keeled; sides with scattered keeled scutes. A slight web between the fingers; outer toes extensively webbed. A serrated fringe on the outer edge of the leg; scales on the limbs obtusely keeled.

Dimensions: Snout to anterior orbit, $64 \mathrm{~mm}$; snout to articular, $126 \mathrm{~mm}$; width of snout at level of anterior orbits, $34 \mathrm{~mm}$.; head and body, $340 \mathrm{~mm}$.; tail, $310 \mathrm{~mm}$.; foreleg, $97 \mathrm{~mm}$. ; hindleg, $137 \mathrm{~mm}$. 
Color: Above dull olive; numerous small sepia spots on head and neck, which enlarge on the back and merge to form irregular transverse cross bars, about four of these between the axilla and groin;

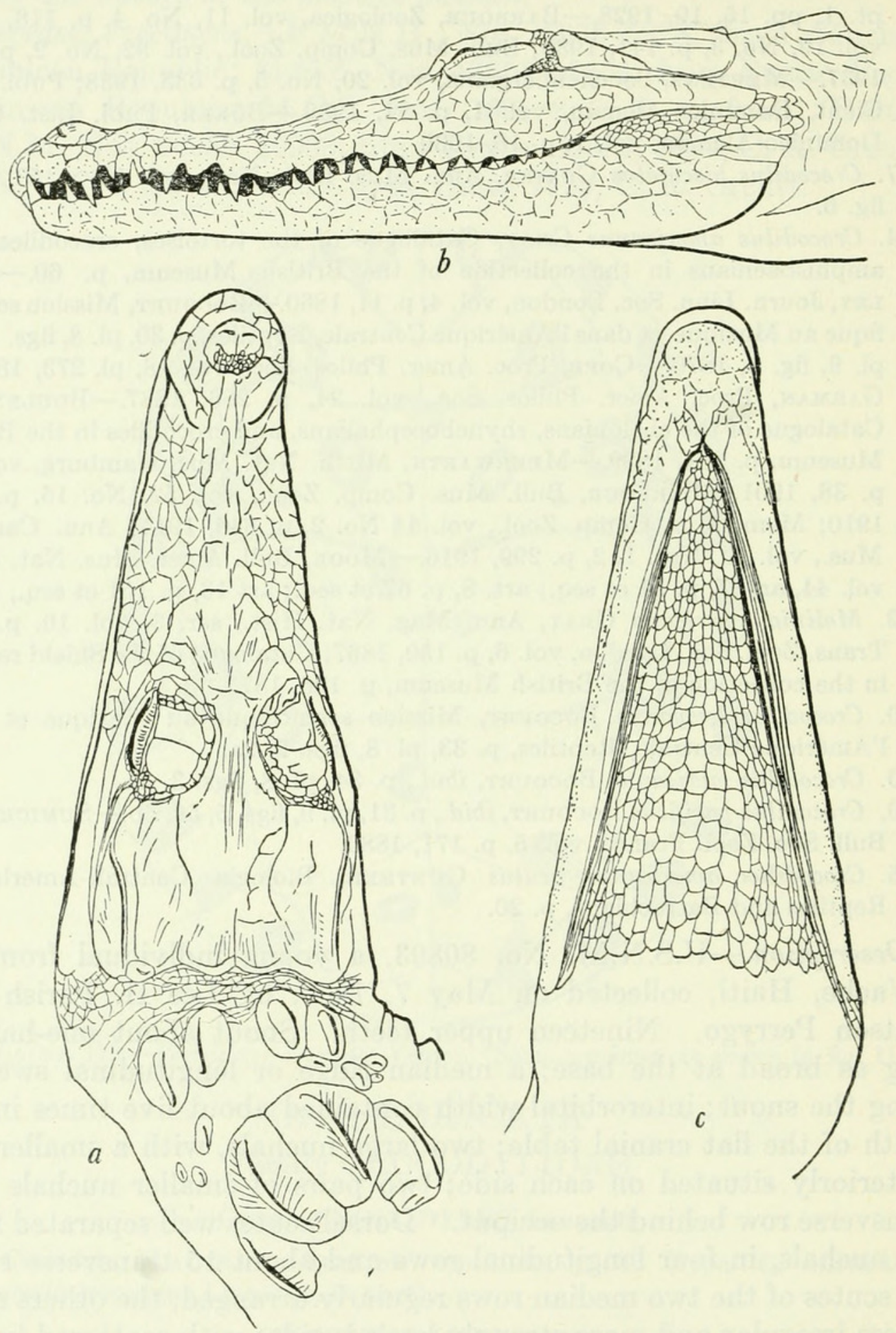

Figure 120.-Crocodylus acutus: $a$, Top of head; $b$, side of head; $c$, chin. U.S.N.M. No. 80893, from Île á Vache, Haiti. Two-thirds natural size.

tail with similar sepia markings, which are also arranged in fairly symmetrical bars; upper parts of limbs also splotched with sepia; lower parts immaculate buff, turning to dark olive-buff beneath the tail and limbs. 
Variations.-The four young Hispaniolan crocodiles are very similar in tooth structure as well as in head proportions. Their nuchal shields, however, are not entirely identical. While there are two pairs of large anterior nuchals in all four specimens, the posterior nuchals are absent in one case, single in one case, and paired in two cases.

A fifth specimen, from Lake Assuei, has a total length of 1,640 mm., the head and body measuring $840 \mathrm{~mm}$. together. This animal is like the others in every essential. It has two pairs of anterior nuchals, the inner ones much the larger and separated from the outer ones. No posterior nuchals occur in this individual.

Relationships.-On the basis of the material at hand, no separation seems to be possible between the West Indian acutus and those on the mainland. Mook has carefully compared the skull characters of various examples and finds that there is considerable age variation; most of his specimens lacked locality data, however, so that conclusions as to regional differentiation were not possible.

Distribution.-While this species occurs in southern Florida, the Greater Antilles (except Puerto Rico), and on both coasts of Central America from Mexico to Ecuador and Colombia, its distribution on the island of Hispaniola is not yet very well mapped out. Fraser's specimen from Puerto Plata is practically the only record from the Dominican Republic. Parish and Perrygo collected several young individuals on Ile à Vache, where it is common. At Aux Cayes, opposite Ille à Vache, Mr. Perrygo heard a report, from a native whose reliability he did not doubt, that a crocodile 12 feet in length had been killed some time before his visit, on the road bordering the coast near a bridge about 8 miles northeast of Aux Cayes. He saw a skin on Gonave Island that was over 6 feet long, and he encountered many smaller crocodiles at Anse à Galet. He heard reports that crocodiles were to be found in most of the lakes of Haiti and that they had been taken in the Artibonite River. Dr. Abbott's single specimen is from Lake Assuei. The difficulty of preserving and transporting so large and heavy a reptile as a crocodile no doubt explains why we have few preserved examples from a region where travel has hitherto been exceedingly difficult.

Specimens examined.-As listed in table 75.

TABLE 75.-Specimens of Crocodylus acutus examined

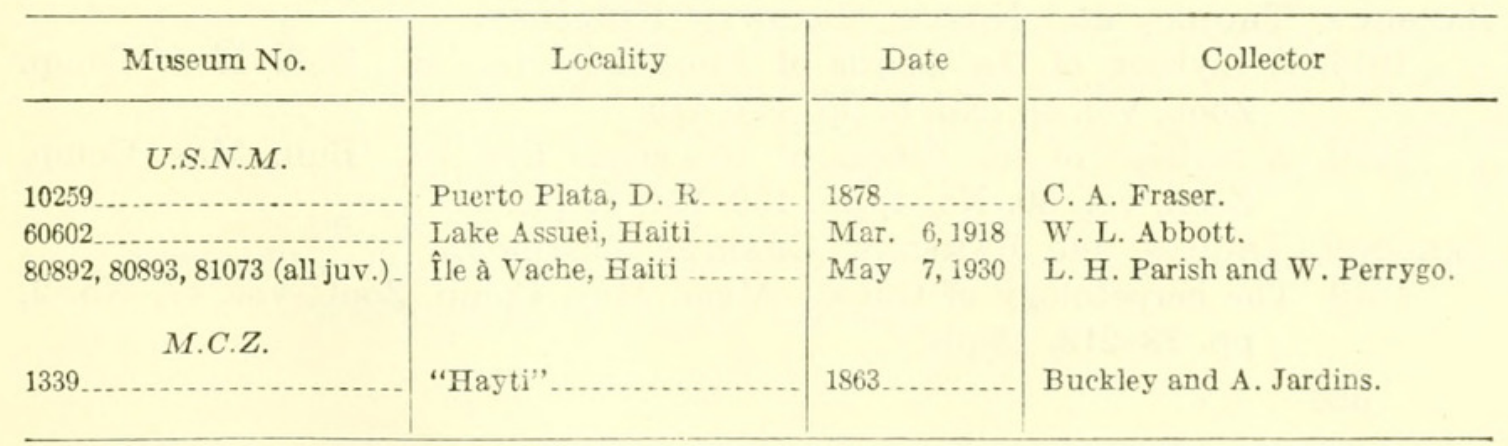




\section{BIBLIOGRAPHY}

Amaral, Afranio do.

1929. Estudos sobre ophidios neotropicos. XVIII. Lista remissiva dos ophidios de região neotropica. Mem. Inst. Butantan, vol. 4, pp. 192-271.

Barbour, Thomas.

1904. Batrachia and Reptilia from the Bahamas. Bull. Mus. Comp. Zool., vol. 46 , No. 3 , pp. 55-61.

1910. Notes on the herpetology of Jamaica. Bull. Mus. Comp. Zool, vol. 52 , No. 15 , pp. $273-301,2$ pls.

1914. A contribution to the zoögeography of the West Indies, with especial reference to amphibians and reptiles. Mem. Mus. Comp. Zool., vol. 44, No. 2, pp. 209-359, 1 pl.

1915. Recent notes regarding West Indian reptiles and amphibians. Proc. Biol. Soc. Washington, vol. 28, pp. 71-78.

1916. Additional notes on West Indian reptiles and amphibians. Proc. Biol. Soc. Washington, vol. 29, pp. 215-220.

1919. Herpetological notes: Notes on Celestus. Proc. New England Zool. Club, vol. 7, pp. 11-13.

1920. A note on Xiphocercus. Proc. New England Zool. Club, vol. 7, pp. 61-63.

1921. Sphaerodactylus. Mem. Mus. Comp. Zool., vol. 47, No. 3, pp. 217278 , pls. 1-26.

1925. New neotropical lizards. Proc. Biol. Soc. Washington, vol. 38, pp. 101-102.

1930a. The Anoles. I. The forms known to occur on the neotropical islands. Bull. Mus. Comp. Zool., vol. 70, No. 3, pp. 105-144.

1930b. A list of Antillean reptiles and amphibians. Zoologica, vol. 11, No. 4, pp. 61-116.

1935. A second list of Antillean reptiles and amphibians. Zoologica, vol. 19 , No. 3 , pp. 77-141.

1937. Third list of Antillean reptiles and amphibians. Bull. Mus. Comp. Zool., vol. 82, No. 2, pp. 77-166.

Barbour, Thomas, and Carr, Archie F., Jr.

1940. Antillean terrapins. Mem. Mus. Comp. Zool., vol. 54, No. 5, pp. $381-415,9$ pls.

Barbour, Thomas, and Loveridge, Arthur.

1929. Typical reptiles and amphibians in the Museum of Comparative Zoology. Bull. Mus. Comp. Zool., vol. 69, No. 10, pp. 205-360.

Barbour, Thomas, and Noble, Gladwyn Kingsley.

1915. A revision of the lizards of the genus Ameiva. Bull. Mus. Comp. Zool., vol. 59, No. 6, pp. 417-479.

1916. A revision of the lizards of the genus Cyclura. Bull. Mus. Comp. Zool., vol. 60 , No. 4, pp. $139-164,15$ pls.

Barbour, Thomas, and Ramsden, Charles Theodore.

1919. The herpetology of Cuba. Mem. Mus. Comp. Zool., vol. 47, No. 2, pp. $73-213,15$ pls. 


\section{$2 \mathrm{BHL}$ Biodiversity Heritage Library}

Cochran, Doris M. 1941. "The herpetology of Hispaniola." Bulletin 177, 1-398. https://doi.org/10.5962/bhl.part.14437.

View This Item Online: $\underline{\text { https://www.biodiversitylibrary.org/item/33190 }}$

DOI: https://doi.org/10.5962/bhl.part.14437

Permalink: https://www.biodiversitylibrary.org/partpdf/14437

\section{Holding Institution}

Smithsonian Libraries

\section{Sponsored by}

Smithsonian

\section{Copyright \& Reuse}

Copyright Status: NOT_IN_COPYRIGHT

This document was created from content at the Biodiversity Heritage Library, the world's largest open access digital library for biodiversity literature and archives. Visit BHL at https://www.biodiversitylibrary.org. 